\title{
Waves, Hydrodynamics and Sediment Transport Modeling at Grays Harbor, WA
}

Zeki Demirbilek, Lihwa Lin, Jarrell Smith, Earl Hayter,

December 2010

Ernest Smith, Joseph Gailani, Gregory Norwood, and David Michalsen

\section{US Army Corps of Engineers $S_{\circledast}$ Engineer Research and Development Center}

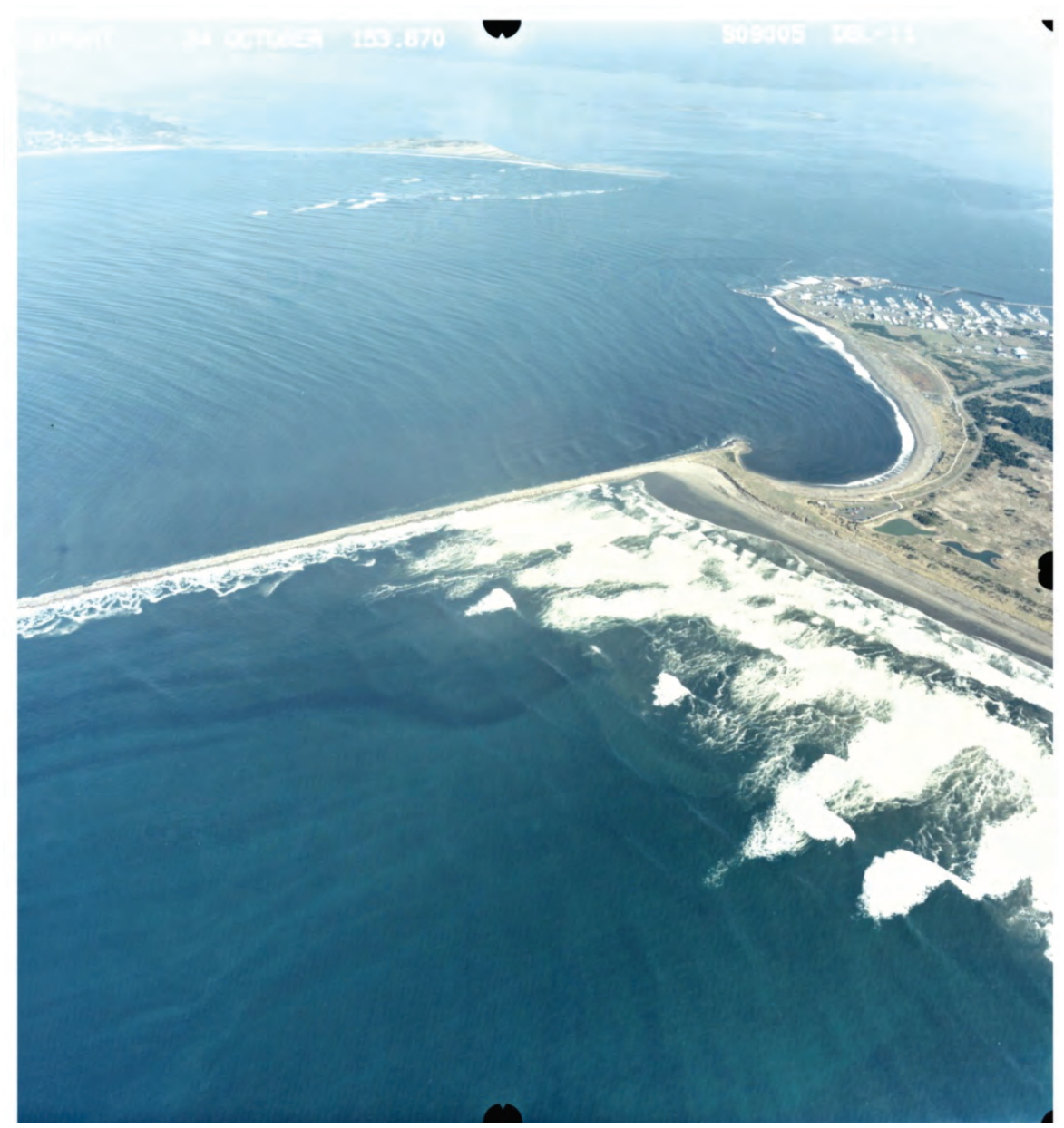




\section{Waves, Hydrodynamics and Sediment Transport Modeling at Grays Harbor, WA}

Zeki Demirbilek, Lihwa Lin, Jarrell Smith, Earl Hayter, Ernest Smith, Joseph Z. Gailani, and Gregory J. Norwood

Coastal and Hydraulics Laboratory

U.S. Army Engineer Research and Development Center

3909 Halls Ferry Road

Vicksburg, MS 39180-6199

David R. Michalsen

U.S. Army Corps of Engineers Seattle District

P.O. Box 3755

Seattle. WA 98124-3755

Final report

Approved for public release; distribution is unlimited.

Prepared for U.S. Army Corps of Engineers, Seattle District

P.O. Box 3755

Seattle, WA 98124-3755

4735 East Marginal Way South

Seattle, WA 98134-2385 


\begin{abstract}
This numerical modeling study was performed for the purpose of addressing short- and mid-term dredge material management issues for the Federal Navigation Project at Grays Harbor (GH), Washington. Seattle District (NWS) is also currently evaluating GH navigation channel realignment in the Point Chehalis/ Entrance reach because historic trends in survey data indicate this area is naturally scouring a new thalweg just north of the present channel. The realigned channel would take advantage of the thalweg, and a relocated channel is hypothesized to reduce annual dredging quantities. The impact of dredged material placement sites on channel maintenance is also examined. The three dredged disposal sites of interest considered in the present study are the Point Chehalis Disposal Site (PCDS), South J etty Disposal Site (SJ DS), and Half Moon Bay Beneficial Use Site (HMBBUS). The realignment of GH navigation channel is an attempt to establish optimal locations for the PCDS and SJ DS. The key issues of interest to the NWS investigated in this study were: a) changes in waves and hydrodynamics at GH navigation channel over time scales of 0.5 to 5 years, b) consequences of channel realignment on waves, hydrodynamics and sedimentation of GH navigation channel, c) sediment transport pathways in the lower GH and at three dredge material placement (DMP) sites, and d) channel infilling estimates from frequently occurring, low energy storms and less frequent, but more energetic storms. These issues were examined for two channel alternatives: "Existing" and "Realigned" channel configurations. The Realigned channel was modeled with and without the Existing channel filled.
\end{abstract}

Wave and hydrodynamic modeling results from CMS-Wave and ADCIRC models for the Existing and Realigned channels were used in the sediment modeling for the associated short- and long-term sediment transport at GH/HMB complex. Sediment transport modeling was performed using GTRAN, MPFATE, LTFATE and SEDZLJ models. Detailed description of wave, hydrodynamic and sediment transport modeling are provided in this report.

DISCLAIMER: The contents of this report are not to be used for advertising, publication, or promotional purposes. Citation of trade names does not constitute an official endorsement or approval of the use of such commercial products. All product names and trademarks cited are the property of their respective owners. The findings of this report are not to be construed as an official Department of the Army position unless so designated by other authorized documents. 


\section{Contents}

Figures and Tables....................................................................................................................

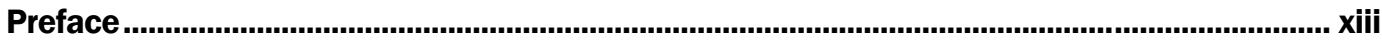

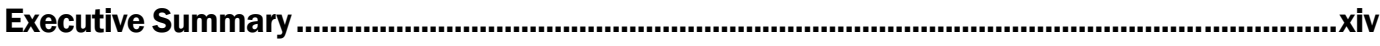

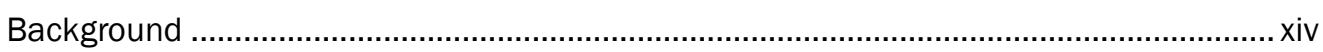

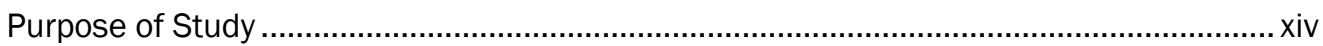

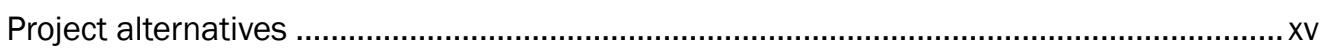

Wave and hydrodynamic modeling.......................................................................... Xvi

Sediment transport modeling.................................................................................. xvii

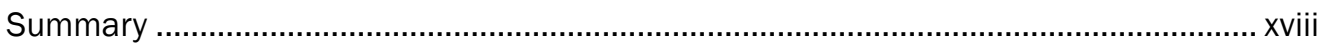

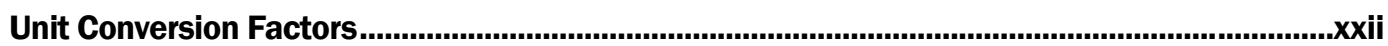

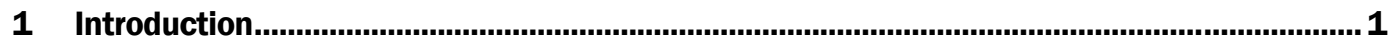

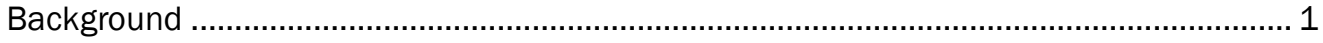

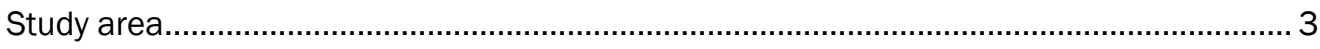

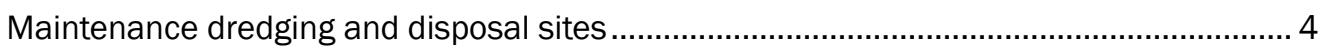

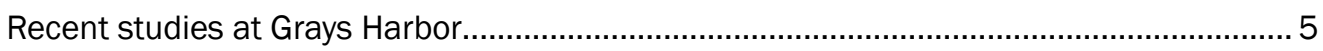

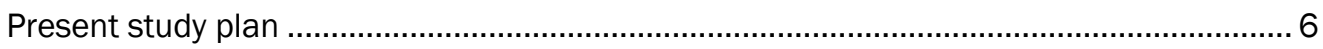

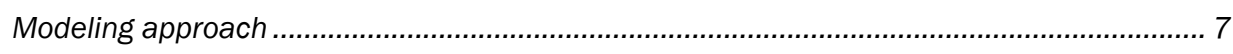

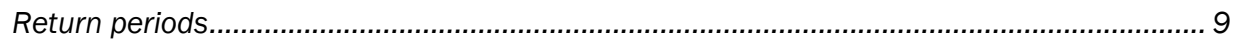

Development of boundary conditions ................................................................................ 10

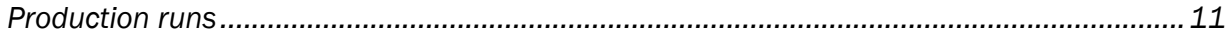

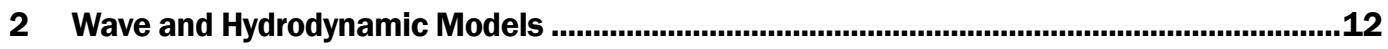

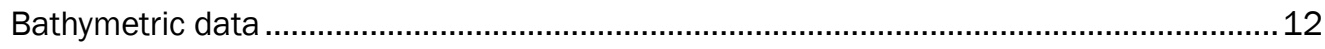

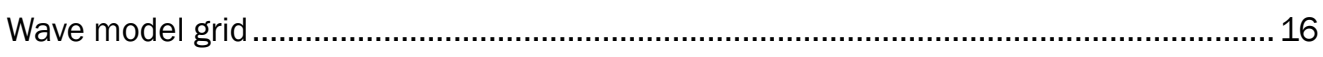

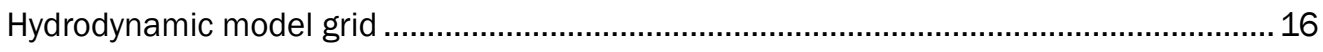

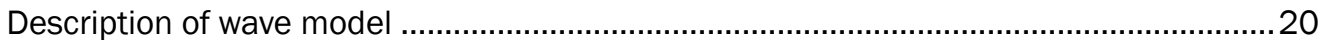

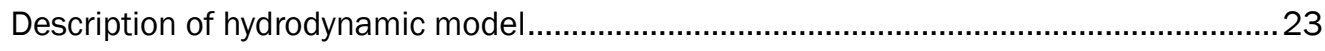

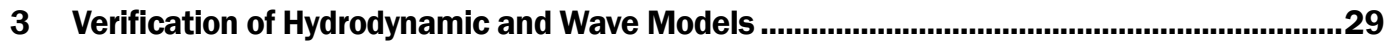

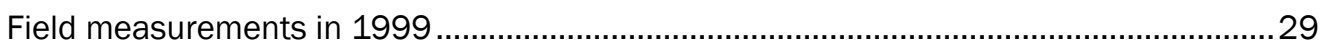

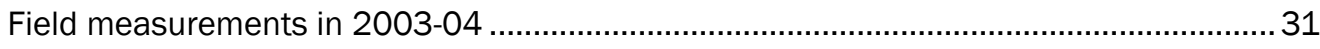

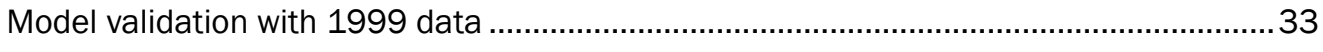

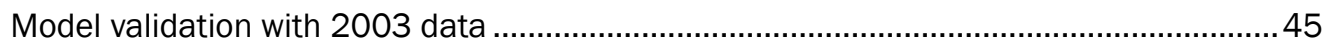

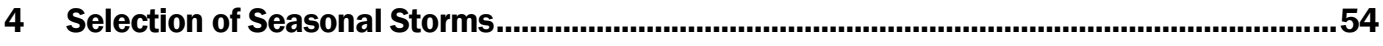

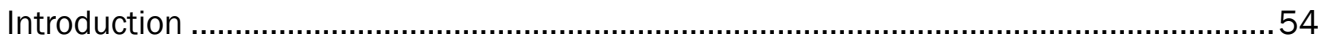

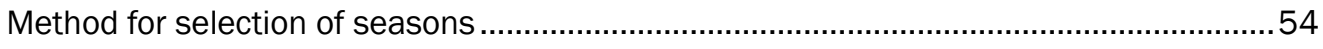

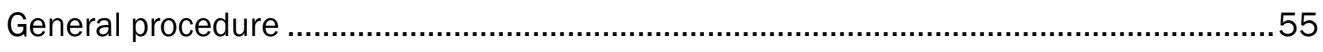

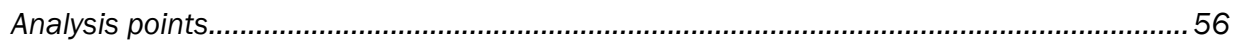




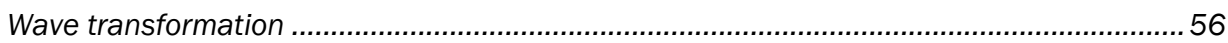

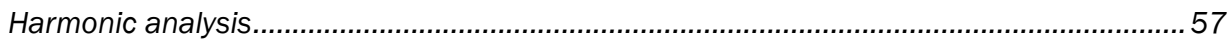

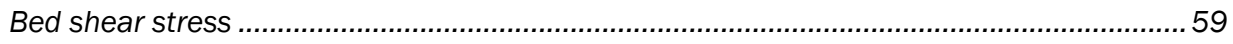

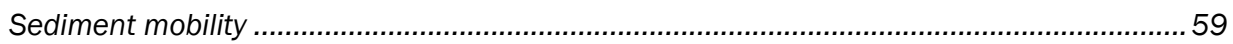

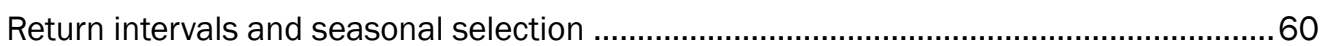

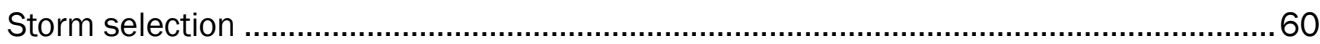

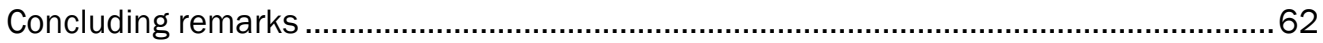

5 Hydrodynamic and Wave Modeling Results.......................................................................63

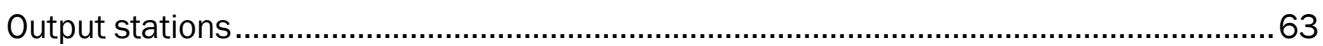

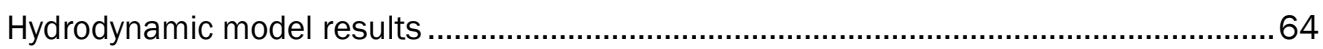

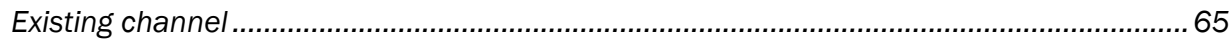

Realigned channel (with Existing channel unfilled) ........................................................... 71

Realigned channel (with Existing channel filled).................................................................. 72

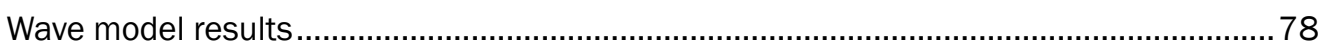

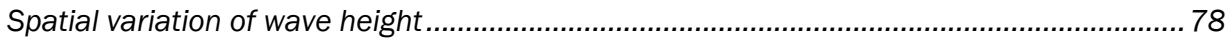

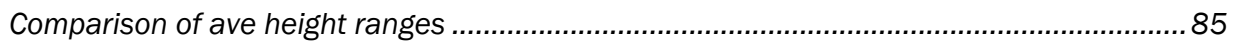

6 Description of Sediment Transport Models.............................................................................93

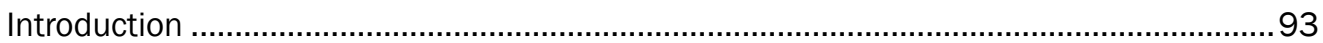

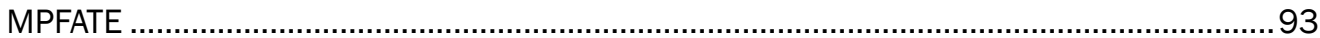

Sediment processes during dredged material placement operations..................................99 94

Model description............................................................................................................... 95

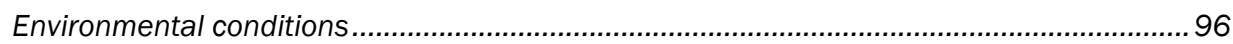

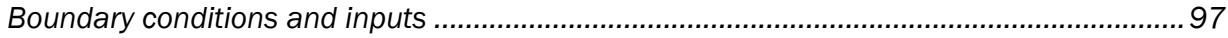

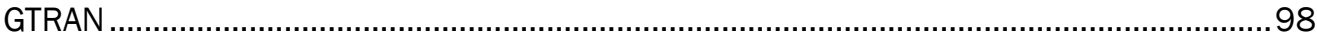

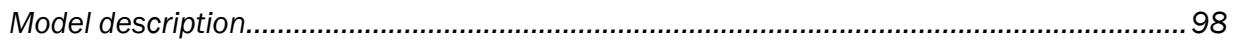

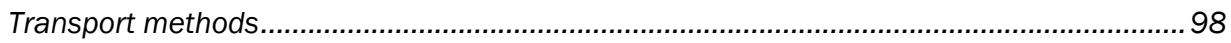

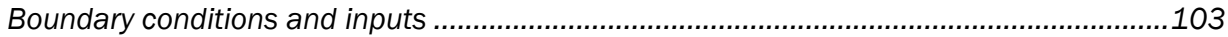

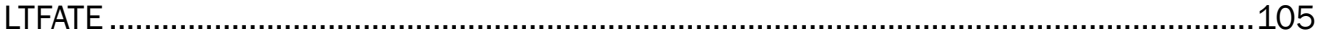

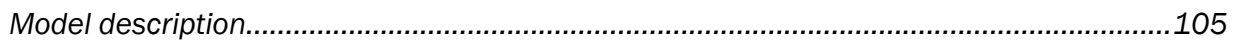

7 MPFATE and GTRAN Sediment Transport Model Results................................................ 116

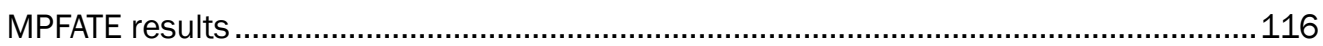

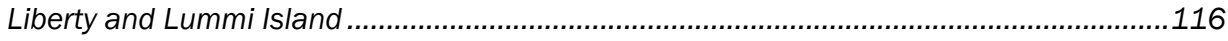

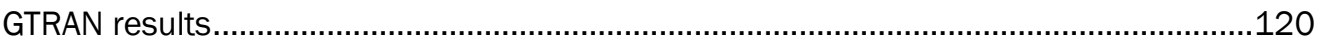

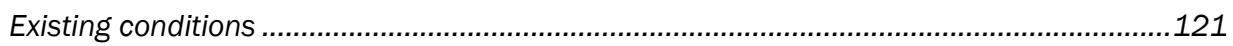

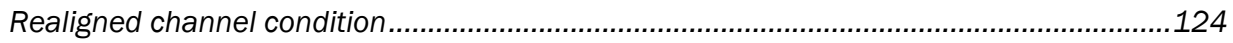

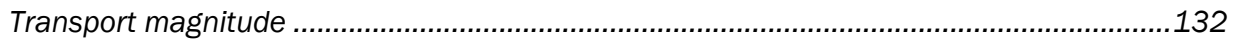

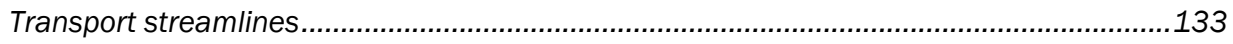

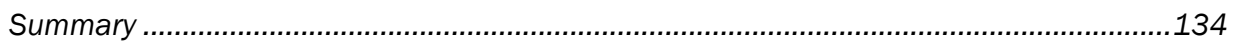

8 Cohesive Sediment Physical Processes ............................................................................ 135

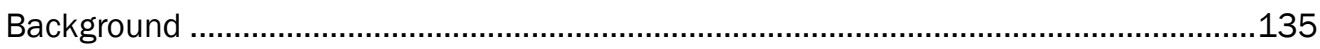

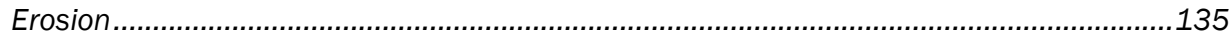

Settling velocity of eroded aggregates..........................................................................136

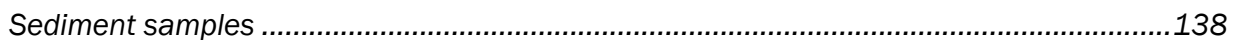




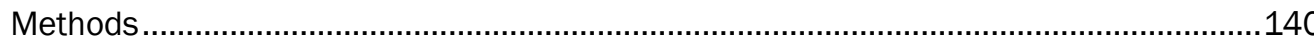

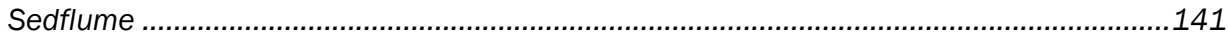

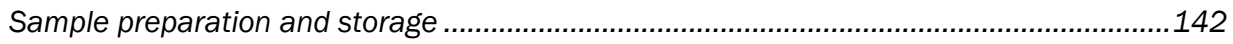

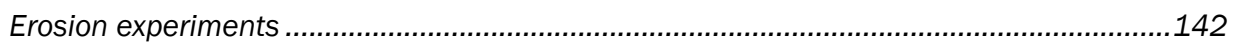

Measurements of sediment bulk properties ....................................................................143

Bulk density measurements............................................................................................ 144

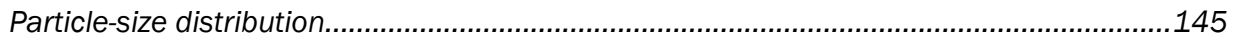

Multivariate erosion rate prediction ................................................................................ 146

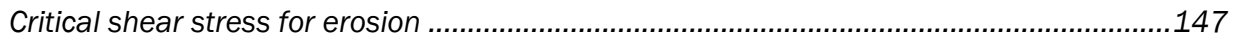

Settling velocity of eroded aggregates..........................................................................148

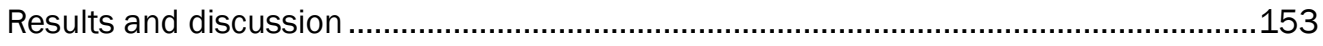

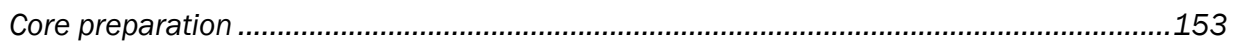

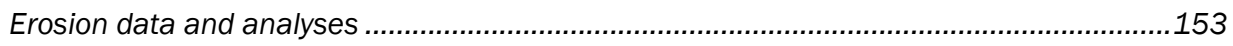

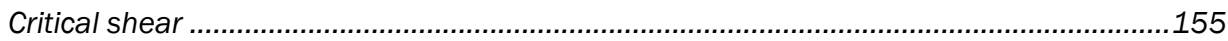

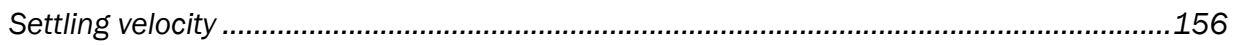

Summary and conclusions ................................................................................159

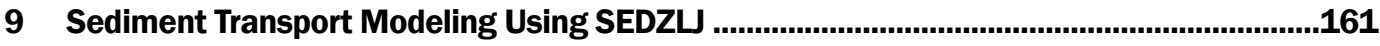

Introduction ............................................................................................................. 161

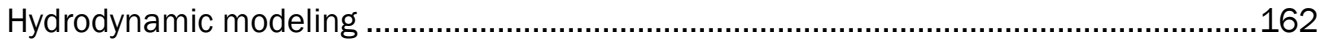

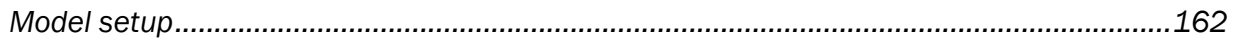

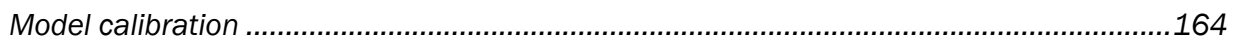

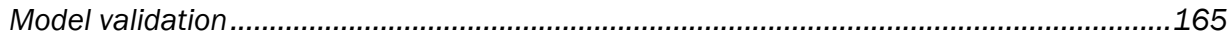

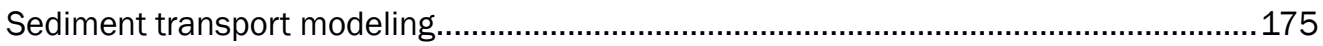

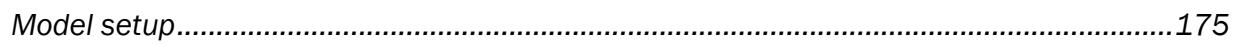

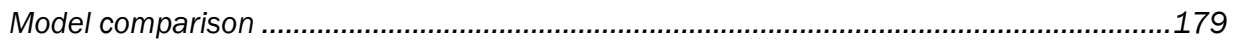

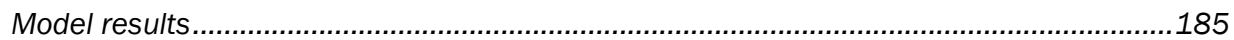

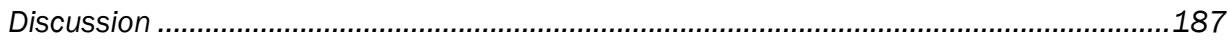

10 Conclusions.................................................................................................................. 198

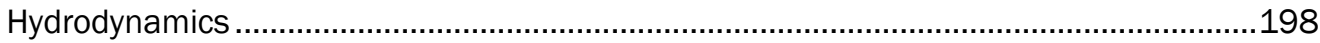

Sand transport pathways............................................................................................. 199

Cohesive and mixed sediment processes.................................................................200

Cohesive and mixed sediment transport ...............................................................200

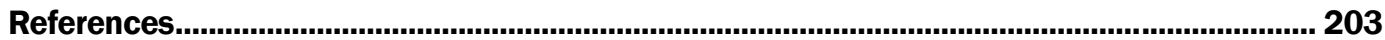

Appendix A. Results from GTRAN Simulations............................................................... 208

Report Documentation Page 


\section{Figures and Tables}

\section{Figures}

Figure 1-1. Grays Harbor project site.

Figure 1-2. Major land features around the Grays Harbor Navigation Project and channel reaches.

Figure 1-3. Grays Harbor Navigation Channel Project reaches.

Figure 2-1. Depth contours between offshore and entrance channel................................................ 12

Figure 2-2. Depth contours along navigation channel from offshore bar to Point Chehalis.............13

Figure 2-3. Depth contours in the east end of Grays Harbor estuary. ............................................ 13

Figure 2-4. Bathymetry of Existing Channel............................................................................ 15

Figure 2-5. Bathymetry of Realigned Channel with Existing Channel unfilled. ................................ 15

Figure 2-6. Bathymetry of Realigned channel with the Existing channel filled. ............................... 16

Figure 2-7. Bathymetric change in CMS-Wave grid domain. ........................................................ 17

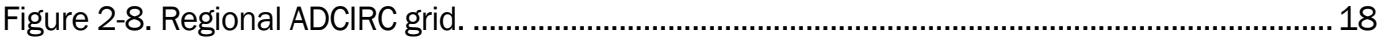

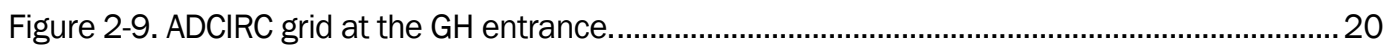

Figure 2-10. Input/Output files used in CMS-Wave simulation. .....................................................2 23

Figure 3-1. Location of wave and current stations in 1999 field measurements. ...........................30

Figure 3-2. Location of tide stations in 1999 field measurements..................................................30

Figure 3-3. Location of instrument deployment in Half Moon Bay................................................... 32

Figure 3-4. Buoy 46029 and 46211 wind and wave data for October and November 1999............34

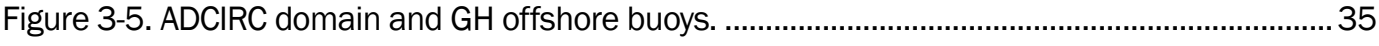

Figure 3-6. CMS-Wave domain and NDBC 46211.................................................................... 35

Figure 3-7. ADCIRC Calculated maximum flood current field for the 28 October 1999 storm event.

Figure 3-8. ADCIRC Calculated maximum ebb current field for the 28 October 1999 storm event.

Figure 3-9. Measured and calculated water levels for October and November 1999 at

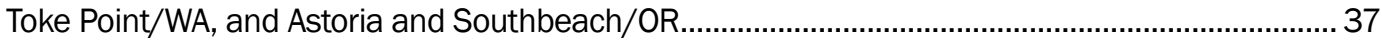

Figure 3-10. Measured and calculated water levels at GH Sta 1, 4 and 5....................................38

Figure 3-11. Measured and calculated water levels at GH Tide gauges 1, 2, 3 and 4....................39

Figure 3-12. Measured and calculated currents at GH Sta 1, 2 and 3........................................40

Figure 3-13. Measured and calculated currents at GH Sta 4, 5 and 6....................................... 41

Figure 3-14. CMS-Wave calculated wave field for the peak storm event on 28 October 1999........... 42

Figure 3-15. Measured and calculated waves at GH Sta 1. ............................................................... 42

Figure 3-16. Measured and calculated waves at GH Sta 2. .......................................................... 43

Figure 3-17. Measured and calculated waves at GH Sta 3........................................................... 43

Figure 3-18. Measured and calculated waves at GH Sta 4. ............................................................ 44

Figure 3-19. Measured and calculated waves at GH Sta 5 ............................................................... 44 


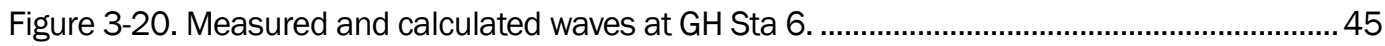

Figure 3-21. December 2003 wind and wave data at buoys 46029 and $46211 \ldots \ldots \ldots \ldots \ldots \ldots . . . . . . . . . . .46$

Figure 3-22. Measured and calculated water levels in December 2003 at Toke Point/WA,

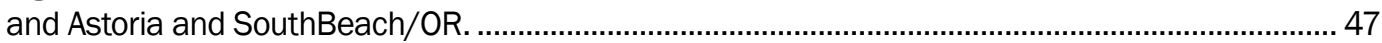

Figure 3-23. Measured and calculated water levels at HMB Stations 1 to 4 ..................................48

Figure 3-24. ADCIRC calculated maximum flood current field at HMB for the storm event of 25 December 2003

Figure 3-25. ADCIRC calculated maximum ebb current field at HMB for the storm event of 25 December 2003

Figure 3-26. Measured and calculated currents at HMB Stations 1 to 4.

Figure 3-27. CMS-Wave calculated wave field at HMB for the peak storm event of 25 December 2003. 51

Figure 3-28. Measured and calculated waves at Station HMB 1................................................... 51

Figure 3-29. Measured and calculated waves at Station HMB 2 ………………......................... 52

Figure 3-30. Measured and calculated waves at Station HMB 3................................................... 52

Figure 3-31. Measured and calculated waves at Station HMB 4.

Figure 4-1. Six simulation points selected within the three dredged material placement sites near the Grays Harbor entrance. Analysis stations are indicated by filled black circles with bold numbering.

Figure 4-2. Binned wave climate for GROW hindcast station 2041496 for the period 1970-2007. Grey indicates no wave records. N indicates number of populated bins (including water level bins). Total number of simulations is 2763. Direction of wave travel (towards which or oceanographic sense) is indicated in degrees relative to true north $(0=$ north, $90=$ east). Wave periods are given in seconds and significant wave height in $\mathrm{m}$. 58

Figure 4-3. Sediment mobility return periods for 38-year GROW hindcast record at calculation points 8 and 12 . Results are presented by season, with Q1 representing winter (Jan-Mar) and Q4 representing autumn (Oct-Dec). 61

Figure 5-1. Output stations along Existing and Realigned channels. 64

Figure 5-2. Spatial variation of average current speed at five stations along the Existing channel during the flood and ebb cycles.

Figure 5-3. Spatial variation of maximum current at five stations along the Existing channel speed during the flood and ebb cycles.

Figure 5-4. Percent occurrence of flood and ebb current at five stations along the Existing channel for 0.5-yr return period (Q2/1993).

Figure 5-5. Percent occurrence of flood and ebb current at five stations along the Existing channel for 2-yr return period (Q4/2006).

Figure 5-6. Percent occurrence of flood and ebb current at five stations along the Existing channel for 5-yr return period (Q4/1998).

Figure 5-7. Percent occurrence of flood and ebb current at five stations along the Existing channel for the extreme storm period (Jan-Feb/1990).

Figure 5-8. Spatial variation of average flood and ebb current speed at five stations along the Realigned channel with the Existing channel unfilled.

Figure 5-9. Spatial variation of maximum flood and ebb current speed at five stations along the Realigned channel with the Existing channel unfilled.

Figure 5-10. Percent occurrence of flood and ebb current at five stations along the Realigned channel for 0.5-yr return period (Q2/1993). 
Figure 5-11. Percent occurrence of flood and ebb current at five stations along the Realigned channel for 2-yr return period (Q4/2006).

Figure 5-12. Percent occurrence of flood and ebb current at five stations along the Realigned channel for 5-yr return period (Q4/1998).

Figure 5-13. Percent occurrence of flood and ebb current at five stations along the Realigned channel for an extreme storm event (Jan-Feb/1990).

Figure 5-14. Spatial variation of average flood and ebb current speed at five stations along the Realigned channel with the Existing channel filled.

Figure 5-15. Spatial variation of maximum flood and ebb current speed at five stations along the Realigned channel with the Existing channel filled.

Figure 5-16. Percent occurrence of flood and ebb current at five stations along the Realigned channel (w/ Existing channel filled) for a 0.5-yr return period (Q2/1993)

Figure 5-17. Percent occurrence of flood and ebb current at five stations along the Realigned channel (w/ Existing channel filled) for a 2-yr return period (Q4/2006).

Figure 5-18. Percent occurrence of flood and ebb current at five stations along the Realigned channel (w/ Existing channel filled) for a 5-yr return period (Q4/1998).

Figure 5-19. Percent occurrence of flood and ebb current at five stations along the Realigned channel (w/ Existing channel filled) for an extreme storm (Jan-Feb/1990).

Figure 5-20. Maximum and average significant wave heights for the Existing channel.

Figure 5-21. Maximum and average wave heights for the Realigned channel without the Existing channel filled.

Figure 5-22. Maximum and average wave heights for the Realigned channel with the Existing channel filled.

Figure 5-23. Percent occurrence comparison for three channels scenarios at Sta 8, 9 and 10 (Jan-Feb 1990, extreme storm period).

Figure 5-24. Percent occurrence comparison for three channels scenarios at Sta 8, 9 and 10 (Q2/1993, 0.5-yr return period).

Figure 5-25. Percent occurrence comparison for three channels scenarios at Sta 8, 9 and 10 (Q4/2006, 2-yr return period).

Figure 5-26. Percent occurrence comparison for three channels scenarios at Sta 8, 9 and 10 (Q4/1998, 5-yr return period).

Figure 5-27. Percent occurrence comparison for three channels scenarios at Sta 8, 11 and 12 (Jan-Feb 1990, extreme storm period).

Figure 5-28. Percent occurrence comparison for three channels scenarios at Sta 8, 11 and 12 (Q2/1993, 0.5-yr return period).

Figure 5-29. Percent occurrence comparison for three channels scenarios at Sta 8, 11 and 12 (Q4/2006, 2-yr return period). 89

Figure 5-30. Percent occurrence comparison for three channels scenarios at Sta 8, 11 and 12 (Q4/1998, 5-yr return period).

Figure 5-31. Percent occurrence comparison at Sta 13 and 14 for three channel scenarios (Jan-Feb 1990 extreme storm period).

Figure 5-32. Percent occurrence comparison at Sta 13 and 14for three channel scenarios (Q2/1993 of the 0.5-yr return period)..

Figure 5-33. Percent occurrence comparison at Sta 13 and 14 for three channel scenarios (Q4/2006 of the 2-yr return period). 
Figure 5-34. Percent occurrence comparison at Sta 13 and 14 for three channel scenarios

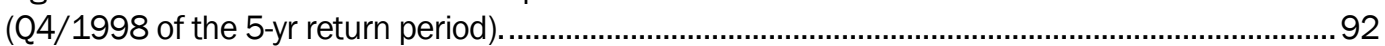

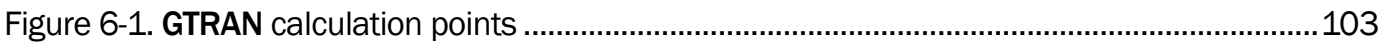

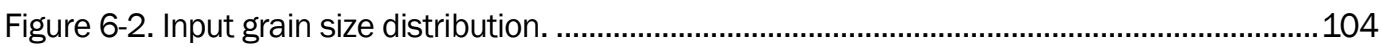

Figure 6-3. Sediment Mass Balance Achieved in SEDZレ..........................................................112

Figure 6-4. Multi-Bed Layer Model Used in SEDZD...................................................................113

Figure 6-5. Schematic of Active Layer Used in SEDZレ .............................................................114

Figure 7-1. Lift heights at Point Chehalis placement site..........................................................118

Figure 7-2. Lift heights at South Jetty placement site. ...............................................................119

Figure 7-3. Lift heights at Half Moon Bay placement site. ................................................................119

Figure 7-4. GTRAN results, existing conditions at Point Chehalis placement site. .........................122

Figure 7-5. GTRAN results of 5-yr simulated event with existing conditions at South Jetty placement site.

Figure 7-6. GTRAN results of 5-yr simulated event with existing conditions at Half Moon Bay placement site.

Figure 7-7 GTRAN results of 5-yr simulated event with realigned channel conditions at Point Chehalis placement site.

Figure 7-8. GTRAN results of 5-yr simulated event with realigned channel conditions at South Jetty placement site.

Figure 7-9. GTRAN results of 5-yr simulated event with realigned channel conditions at South Jetty placement site.

Figure 7-10. Transport ratio of realigned channel to existing conditions, 5-yr storm.

Figure 7-11. Increased transport with realigned channel at Point Chehalis placement site for 5-yr simulated event.

Figure 7-12. Decreased transport with realigned channel at Point Chehalis placement site for 5-yr simulated event.

Figure 7-13. Increased transport with realigned channel at South Jetty placement site for 5 -yr simulated event. 130

Figure 7-14. Decreased transport with realigned channel at South Jetty placement site for 5 -yr simulated event.

Figure 7-15 Increased transport with realigned channel at Half Moon Bay placement site for 5-yr simulated event.

Figure 7-16. Decreased transport with realigned channel at Half Moon Bay placement site for 5-yr simulated event.

Figure 7-17. Average transport rate for 5-yr simulated event, existing conditions.........................132

Figure 7-18. Average transport rate for 5-yr simulated event, realigned channel. .........................132

Figure 7-19. Transport streamlines for 5-yr simulated event, existing conditions.........................133

Figure 7-20. Transport streamlines for 5-yr simulated event, realigned channel...........................134

Figure 8-1. Cow Point Reach, Grays Harbor WA......................................................................139

Figure 8-2. Grains size distribution measurements for samples CP-1 through CP-4.....................140

Figure 8-3. Schematic illustrating operating principles of Sedflume. Pictured are Sedflume channel, flow development region, testing section and sediment core.

Figure 8-4. Sedflume erosion flume......................................................................................143

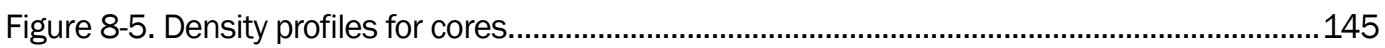


Figure 8-6. Size distributions (\% Volume and \% Finer) for slurried representative Grays Harbor dredged material.

Figure 8-7. A) Instrumentation frame indicating positioning of PICS, ADV, LISST, and CTD, B) Schematic of settling column indicating sample collection and image acquisition positions (in laboratory setting, column remains vertical with Sedflume effluent passing through settling column). C) Schematic of camera, settling column cross section, and LED lighting

Figure 8-8. Multivariate optimization of erosion function to Sedflume data for All core data. Points represent measured erosion rates at varying shear stress; lines represent optimized function values for each value of shear stress.

Figure 8-9. Estimated critical shear stress from base line erosion data.

Figure 8-10. A) Mass and count distributions of particle size (esd = equivalent spherical diameter), B) size and settling velocity for each tracked particle, C) size and estimated particle density, D) distributions of particle settling velocity, E) distributions of particle density.

Figure 8-11. A) Median settling velocity by particle class for all settling experiments, B) mass fraction by particle class for all settling experiments, C) settling velocity versus shear stress for all particle classes, D) mass fraction versus shear stress for all particle classes. 158

Figure 9-1. LTFATE Model Domain for Grays Harbor. 162

Figure 9-2. Chehalis River Discharge Time Series. Day 0 corresponds to 01 Jan 1990. 163

Figure 9-3. Humptulips River Discharge Time Series. Day 0 corresponds to 01 Jan 1990.

Figure 9-4. Comparison of measured and simulated tides at Tide Station \#1 during calibration period. Day 0 corresponds to 01 Jan 1990.

Figure 9-5. Comparison of measured and simulated tides at Tide Station \#2 during calibration period. Day 0 corresponds to 01 Jan 1990.

Figure 9-6. Comparison of measured and simulated tides at Tide Station \#3 during calibration period. Day 0 corresponds to 01 Jan 1990.

Figure 9-7. Comparison of measured and simulated tides at Tide Station \#4 during calibration period. Day 0 corresponds to 01 Jan 1990.

Figure 9-8. Comparison of measured and simulated tides at Tide Station \#5 during calibration period. Day 0 corresponds to 01 Jan 1990.

Figure 9-9. Comparison of measured and simulated currents at Current Station \#2 during calibration period. Day 0 corresponds to 01 Jan 1990.

Figure 9-10. Comparison of measured and simulated currents at Current Station \#3 during calibration period. Day 0 corresponds to 01 Jan 1990

Figure 9-11. Comparison of measured and simulated currents at Current Station \#4 during calibration period. Day 0 corresponds to 01 Jan 1990

Figure 9-12. Comparison of measured and simulated currents at Current Station \#5 during calibration period. Day 0 corresponds to 01 Jan 1990

Figure 9-13. Comparison of measured and simulated tides at Tide Station \#1 during validation period. Day 0 corresponds to 01 Jan 1990.

Figure 9-14. Comparison of measured and simulated tides at Tide Station \#2 during validation period. Day 0 corresponds to 01 Jan 1990.

Figure 9-15. Comparison of measured and simulated tides at Tide Station \#3 during validation period. Day 0 corresponds to 01 Jan 1990.

Figure 9-16. Comparison of measured and simulated tides at Tide Station \#4 during validation period. Day 0 corresponds to 01 Jan 1990. 
Figure 9-17. Comparison of measured and simulated tides at Tide Station \#5 during validation period. Day 0 corresponds to 01 Jan 1990.

Figure 9-18. Comparison of measured and simulated currents at Current Station \#2 during validation period. Day 0 corresponds to 01 Jan 1990.

Figure 9-19. Comparison of measured and simulated currents at Current Station \#3 during validation period. Day 0 corresponds to 01 Jan 1990.

Figure 9-20. Comparison of measured and simulated currents at Current Station \#4 during validation period. Day 0 corresponds to 01 Jan 1990.

Figure 9-21. Comparison of measured and simulated currents at Current Station \#5 during validation period. Day 0 corresponds to 01 Jan 1990

Figure 9-22. Comparison of measured and simulated SSC at Current Station \#1 during the calibration period. Day 0 corresponds to 01 Jan 1990.

Figure 9-23. Comparison of measured and simulated SSC at Current Station \#2 during the calibration period. Day 0 corresponds to 01 Jan 1990.

Figure 9-24. Comparison of measured and simulated SSC at Current Station \#3 during the calibration period. Day 0 corresponds to 01 Jan 1990.

Figure 9-25. Comparison of measured and simulated SSC at Current Station \#4 during the calibration period. Day 0 corresponds to 01 Jan 1990.

Figure 9-26. Comparison of measured and simulated SSC at Current Station \#5 during the calibration period. Day 0 corresponds to 01 Jan 1990.

Figure 9-27. Comparison of measured and simulated SSC at Current Station \#6 during the calibration period. Day 0 corresponds to 01 Jan 1990.

Figure 9-28. Comparison of measured and simulated SSC at Current Station \#7 during the calibration period. Day 0 corresponds to 01 Jan 1990.

Figure 9-29. Nautical Chart 18502-11-1996 of Grays Harbor (NOAA, 1996).

Figure 9-30. Percentage of sediment eroded from Pt Chehalis placement site with existing conditions that deposits in selected channel reaches for: a) 1993 event, b) 2006 event, c) 1998 event, and d) 1990 event.

Figure 9-31. Percentage of sediment eroded from Pt Chehalis placement site with realigned channel that deposits in selected channel reaches for: a) 1993 event, b) 2006 event, c) 1998 event, and d) 1990 event.

Figure 9-32. Percentage of sediment eroded from South Jetty placement site with existing conditions that deposits in selected channel reaches for: a) 1993 event, b) 2006 event, c) 1998 event, and d) 1990 event.

Figure 9-33. Percentage of sediment eroded from South Jetty placement site with realigned channel that deposits in selected channel reaches for: a) 1993 event, b) 2006 event, c) 1998 event, and d) 1990 event.

Figure 9-34. Percentage of sediment eroded from Half Moon Bay placement site with existing conditions that deposits in selected channel reaches for: a) 1993 event, b) 2006 event, c) 1998 event, and d) 1990 event.

Figure 9-35. Percentage of sediment eroded from Half Moon Bay placement site with realigned channel that deposits in selected channel reaches for: a) 1993 event, b) 2006 event, c) 1998 event, and d) 1990 event.

Figure A1. GTRAN results for the Existing Channel at Point Chehalis placement site. 208

Figure A2. GTRAN results for the Existing Channel at South Jetty placement site. ........................2210

Figure A3. GTRAN results for the Existing Channel at Half Moon placement site. 
Figure A4. GTRAN results for the Realigned Channel at Point Chehalis placement site.................214

Figure A5. GTRAN results for the Realigned Channel at South Jetty placement site. ..................... 216

Figure A6. GTRAN results for the Realigned Channel at Half Moon placement site. ......................218

Figure A7. Ratio of transport of Realigned Channel to Existing Channel. .......................................220

Figure A8. Areas of increased transport at Point Chehalis placement site with Realigned Channel.

Figure A9. Areas of decreased transport at Point Chehalis placement site with Realigned Channel. .224

Figure A10. Areas of increased transport at South Jetty placement site with Realigned Channel.

Figure A11. Areas of decreased transport at South Jetty placement site with Realigned Channel. 228

Figure A12. Areas of increased transport at Half Moon placement site with Realigned Channel.

Figure A13. Areas of decreased transport at Half Moon placement site with Realigned Channel. 232

Figure A14. Average transport rate for the Existing Channel. ...........................................................234

Figure A15. Average transport rate for the Realigned Channel....................................................236

Figure A16. Transport streamlines for the Existing Channel........................................................238

Figure A17. Transport streamlines for the Realigned Channel. .........................................................240

\section{Tables}

Table 2-1. Description of CMS-Wave I/O files..................................................................................... 24

Table 3-1. Water Level Station Locations and Elevation for 1999 field measurements................... 31

Table 3-2. Coordinates and deployment periods of wave/current stations for 1999 ...................... 31

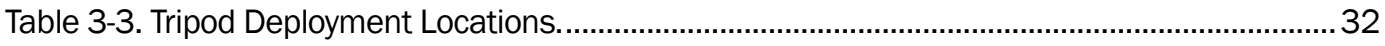

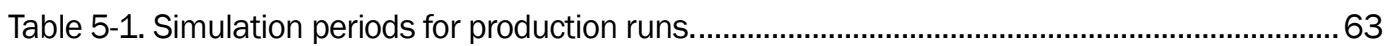

Table 5-2. Station coordinates for display of results from production runs...................................... 64

Table 7-1: Ratio of transport with realigned channel to transport with existing channel...............128

Table 9-1. Sediment Composition of the Eight Sedflume Cores....................................................... 177

Table 9-2. Percentage of Dredged Placement Sediment that Eroded from Placement

Sites.

Table 9-3. Times for $25 \%$ of the Dredged Placement Sediment to Erode from Placement

Sites. 194

Table 9-4. Times for 50\% of the Dredged Placement Sediment to Erode from Placement Sites. 


\section{Preface}

The modeling investigation presented in this report was authorized by the U.S. Army Corps of Engineers Seattle District (NWS) to address shortterm and mid-term dredge material management issues for the Federal Navigation Project at Grays Harbor, WA. David R. Michalsen was the NWS study manager and technical coordinator. The technical work was performed by Zeki Demirbilek, Lihwa Lin, J arrell Smith, Earl Hayter, Ernest Smith, J oseph Gailani, and David Michalsen. This work was performed at the Coastal and Hydraulics Laboratory (CHL) of the U.S. Army Engineer Research and Development Center (ERDC) during the period of J anuary 2009 to February 2010 under the direction of J ackie Pettway, Chief of the Entrances, Harbors and Structures Branch, Ty Wamsley, Chief of Coastal Processes Branch, Rose Kress, Chief of the Navigation Division, Bruce Ebersole, Chief of the Flood and Storm Protection Division, J ose Sanchez, Deputy Director and William D. Martin, Director of CHL.

Dr. J effery P. Holland was Director of ERDC. COL Kevin J. Wilson was Commander and Executive Director. 


\section{Executive Summary}

\section{Background}

The U.S. Army Engineer District, Seattle (NWS) requested that the U.S. Army Engineer Research and Development Center (ERDC), Coastal and Hydraulics Laboratory (CHL) perform a numerical modeling study for the purpose of addressing short-term and mid-term dredge material management issues for the Federal Navigation Project at Grays Harbor (GH), Washington. Seattle District is also currently evaluating Grays Harbor navigation channel realignment in the Point Chehalis/ Entrance reach. Historic trends in survey data indicate that this area is naturally scouring a new thalweg. The realigned channel would take advantage of this new thalweg developing just north of the present channel. Relocating the channel is hypothesized to reduce annual dredging quantities. The goal of this study is to assess the impact of dredged material placement sites (existing and alternative) on channel maintenance.

Previous studies at Grays Harbor have generated considerable information and predictive capability concerning the behavior of the navigation channel and adjacent coastal and inlet shorelines. The outcomes of previous studies have benefited the present modeling effort. This study was conducted as a multi-disciplinary approach, making full use of previous numerical modeling study grids, field measurements and surveying data of the hydrodynamics and dredge material management at GH. Additional numerical modeling studies were performed for waves, circulation and sediment transport processes using the most recent bathymetric conditions. These include modeling of the sediment pathways and fate of the dredge material for developing trend estimates of short- and long-term (several months) sediment patterns and their potential effects on the navigation project.

\section{Purpose of Study}

The NWS requested ERDC to provide Level 1 and Level 2 study options for an increased understanding and reduced uncertainties of the dredge management issues for the GH navigation project. The present study addressed the proposed Level 1 modeling effort in the Scope of Work (SOW) submitted to the NWS. The CHL modeling studies were conducted by a team consisting of Zeki Demirbilek, Lihwa Lin, J arrell Smith, Earl 
Hayter, Ernest Smith, Gregory Norwood, and J oseph Gailani. Zeki Demirbilek had the CHL overall project lead, whileJ arrell Smith led the laboratory SedFlume studies and sediment transport, fate, and pathways modeling activities. The NWS was responsible for fieldwork, and provided samples for SedFlume analyses conducted at ERDC. David R. Michalsen was the NWS technical point of contact. He provided oversight and guidance throughout this study, including background information and survey data used in this study, and oversight of the numerical modeling.

There are three dredged disposal sites of interest in the present study. These are the Point Chehalis, South J etty, and Half Moon Bay disposal sites. The Point Chehalis disposal site (PCDS) was established in 1976. The site is partitioned into three sections and the eastern section is presently the most actively utilized disposal area. The South J etty Disposal Site (SJ DS) was established to receive dredge material in 1988 to feed the scour area adjacent to the south jetty trunk. The nearshore Half Moon Bay Beneficial Use Site (HMBBUS) was established in 1992 to slow erosion of the Half Moon Bay (HMB) shoreline. Currently, the inner harbor sediments (silts/ clays) are placed exclusively at the PCDS and SJ DS, and the outer channel sediments ( $>95 \%$ marine sand) are placed at the three sites. The NWS is considering the realignment of the Point Chehalis/ Entrance reach of GH navigation channel in an attempt to establish optimal locations for the PCDS and SJ DS. Some of the key issues of interest to the NWS that were investigated in this study include:

- changes in waves and hydrodynamics at the GH navigation channel over time scales of 0.5 to 5 years

- consequences of channel realignment on waves, hydrodynamics and sedimentation of the GH navigation channel

- sediment transport pathways in the lower GH and at three dredge material placement (DMP) sites

- channel infilling estimates from frequently occurring, low energy torms and less frequent, but more energetic storms.

\section{Project alternatives}

Two channel alternatives were modeled in this study:

- "Existing" channel configuration at the GH/ HMB complex, which is also referred to as the "Base" plan. 
- "Realigned" channel configuration, which is being evaluated by the NWS.

The "Realigned" channel is modeled with and without the Existing channel filled. Two field data sets collected in 1999 and 2003 were used in calibration of numerical models. The final modeling of production runs for the above plans followed the verification. Wave and hydrodynamic modeling results for each plan were provided to the sediment modeling team for the associated short- and long-term sediment transport at the $\mathrm{GH} / \mathrm{HMB}$ complex.

\section{Wave and hydrodynamic modeling}

The height and direction of waves approaching the GH navigation channel change due to wave shoaling, refraction, diffraction, reflection, and breaking. Waves propagating through the channel interact with the bathymetry, surrounding land features, currents and coastal structures. A spectral wave model was necessary for this project, given the large extent of modeling domain over which wave estimates were required. The spectral wave model CMS-Wave, based on the wave-action balance equation, was used in this study to simulate steady-state spectral transformation of directional random waves in the GH/ HMB complex. The model operates on a halfplane for waves propagating only from the seaward boundary toward shore, with wave generation (wind input) included. The CMS-Wave model technical report describes its capabilities and provides validation examples to demonstrate the model's applicability to propagation of random waves over complicated nearshore bathymetry, where wave refraction, diffraction, reflection, shoaling, and breaking occurs simultaneously. Details of CMSWave modeling are provided in Chapters 2 through 5 of this report.

The hydrodynamic model used in this study is ADCIRC. It is a finite element model for solving two-dimensional horizontal shallow water equations to calculate the variation in the water surface elevation ( $\eta$ ) and velocities $(\mathrm{u}, \mathrm{v})$. Regional ADCIRC modeling provided regional and local scale water level and current fields required for wave and sediment transport modeling in the $\mathrm{GH}$ navigation channel. The length of the ADCIRC simulations varied from 2 weeks to 3 months for the three return periods $(0.5,2$ and 5 yrs $)$ considered in this study. The simulations were performed on high performance computing machines. Additional information on features of the ADCIRC model, including its governing equations, can be found in several references and from the model's home page, 
available at http://adcirc.org. Details of ADCIRC modeling are described in Chapters 2 through 5 of this report.

It is noted that both CMS-Wave and ADCIRC models were validated with 1999 and 2003 field data collected by USACE at GH that included wave, water level and velocity measurements. The bathymetry data for these years were provided by the NWS. The user specifies the tidal and wind forcings of model boundary conditions. Even though the emphasis of this study was on the outer channel region from the entrance to Point Chehalis, unknown, but thought to be secondary, effects of river inflows to Grays Harbor on channel sedimentation were represented in the sediment transport modeling using LTFATE, discussed below.

\section{Sediment transport modeling}

Three sediment transport models were used in this study: MPFATE, GTRAN and LTFATE. Background theory and formulation of these models are provided in Chapter 6.

MPFATE represents the accumulated sedimentation resulting from multiple placements from hoppers and scows. MPFATE is a Lagrangian model which represents dredged material descent from the placement vessel, collapse of the dredged material on the sediment bed, and passive transport of dredged material in suspension. MPFATE was applied to estimate initial conditions at the dredged material placement sites following a season of dredged material placement originating from the lower, middle, and inner harbor channels.

GTRAN estimates combined wave-current bed stresses and resulting sediment transport of noncohesive sediment at a point. The results from this model are used to infer sediment transport pathways near the GH entrance. The utility of GTRAN for this project is to rapidly assess sediment transport pathways for various candidate placement sites and channel alignment alternatives.

LTFATE is an Eulerian hydrodynamics and sediment transport model. The hydrodynamic and transport model in LTFATE is a finite difference model that solves the three-dimensional, vertically hydrostatic, free surface, turbulence averaged equations of motion. It contains dynamically linked hydrodynamic and constituent transport modules and can simulate barotropic and baroclinic flow in a water body due to astronomical tides, 
wind, density gradients, and river inflow. SEDZLJ is the sediment transport model in LTFATE and solves for wave- and current-induced bed shear stresses, cohesive and noncohesive sediment erosion and deposition, bedload transport of noncohesive sediment, bed armoring, consolidation of new deposits of fine-grain sediment, and morphologic changes resulting from erosion and deposition. The transport module in LTFATE is used to simulate the advective and dispersive transport of suspended sediment. LTFATE was applied to Grays Harbor to estimate residence times of dredged placed sediment at the three dredged material placement sites and channel infilling rates from sediment eroded from the placement sites for the existing and realigned channel configurations.

Sediment transport pathways and channel sedimentation were investigated for three return periods (0.5-, 2-, and 5-yr) and one extreme condition. These return intervals were determined from a statistical event selection method (based on a sediment mobility metric) applied to the Global Reanalysis of Ocean Waves (GROW) hindcast, a 38-yr hindcast record spanning the years 1970-2007 (Oceanweather, 2007). Full details of the statistical event selection method are presented in Chapter 4, and results of the sediment transport modeling are presented in Chapters 7 and 9.

\section{Summary}

The study results showed that hydrodynamics in and around the navigation channel were weakly affected by short-term bathymetric changes caused by dredging operations or natural sedimentation processes occurring in the GH entrance and back-bay area. These modeling results obtained with bathymetries from 1999 to 2008 showed no significant change in the calculated kinematics (water surface elevation and velocities) in the vicinity of the navigation channel. There was a comparatively larger difference in the velocity magnitudes between 1999 and 2003 field measured data and modeling during strong storm seasons. The term "strong" is defined here as a short lived event with flows and winds speeds of comparatively larger magnitudes than those occurring at other times. During storm events, the calculated increased transport depends on characteristics of sediments, wave conditions and flow speed and direction.

Sediment transport at the GH entrance is influenced by both waves and currents. Wave-current interactions act to increase bed stress and sediment mobility. The effects of waves diminished with deeper water depth and decreased wave height. Consequently, shallower areas near the 
entrance were more strongly influenced by waves than deeper areas within $\mathrm{GH}$. While waves act to enhance the bottom stress and mobilizing forces on bed sediments, currents dictated the rate and direction of transport.

GTRAN-estimated sand transport pathways (Chapter 7) indicated a general pattern of flood-dominated transport on the northern half of the GH entrance and ebb-dominated sediment transport on the southern half of the entrance. Transport at the dredged material placement sites was generally bimodal for both the existing and realigned channel. Transport at the Point Chehalis placement site was slightly ebb-dominant and transport at the South J etty placement site was strongly ebb-dominant. Less transport was calculated at the Half Moon Bay placement site, which showed a weak flood directed transport.

Transport magnitudes at the three existing placement sites generally showed a slight increase in transport with the realigned channel. Transport differences at the Point Chehalis placement site were small. Estimated transport at the South J etty placement site increased in the ebb direction, which would lead to increased erosion. Transport at the Half Moon Bay placement site showed a slight flood-directed increase in transport.

Transport streamlines indicate that circulation cells were present north of the Point Chehalis placement site and near the end of the north jetty. Based on plots of transport pathways, a more favorable location for dredge placement to transport sediment outside the entrance appears to be northwest of the South J etty site. However, this location has not been evaluated for practicality and safety.

The SEDZLJ modeling of Grays Harbor sediment transport at the three existing placement sites showed the following general results (specific details are provided in Chapter 9).

- During the simulation periods, up to 53 percent of the placed mass eroded from the Pt Chehalis site with the existing channel configuration, whereas less than 7 percent of the placed sediment eroded with the realigned channel. At the South J etty Site, 90 to 100 percent of the placed sediment eroded for both channel configurations. For the Half Moon Bay site, 80 to 100 percent eroded with the existing channel, whereas 60 to 97 percent eroded with the realigned channel. 
Significant variation in the eroded sediment mass with offshore wave conditions only occurred at the Pt Chehalis site for the existing channel configuration, and at the Half Moon Bay site for the realigned channel.

- Residence times for the placed sediment at each of the placement sites for all four modeled events were calculated. At the Pt Chehalis site, less than 7 percent of the placed sediment eroded during the four simulated events for the realigned channel configuration. More than 25 percent of the dredged placed sediment eroded from this site only during the 1998-Q4 simulated event with the existing channel configuration during which 53 percent of the sediment eroded. For the South J etty placement site both the 25 percent and 50 percent residence times for the realigned channel configuration was slightly to a lot greater than those for the existing channel configuration, whereas the residence times for the 1990-Q1 event were the same for the two channel configurations. For the Half Moon Bay placement site, the residence times were consistently greater for the realigned channel than for the existing channel.

- There are no significant differences in the fate of the eroded sediment between the existing conditions and realigned channel simulations. Of the mass eroded from the Pt Chehalis placement site, approximately 20 percent deposits within the navigation channel during the simulation period, with the Pt Chehalis reach receiving the vast majority of the sediment that erodes from this site. Mass eroded from the South J etty site does not vary significantly with offshore wave conditions, and the eroded fractions for the existing and realigned channel configurations are essentially identical. The largest fractions of dredged material eroded from the South J etty Site deposit at the Pt Chehalis and South Channel reaches, although the total amount deposited is very low (2-3 percent). Since the percentage of eroded sediment was essentially the same for the simulated events, the vast majority of the sediment that eroded during the simulations for both channel configurations deposited elsewhere, i.e., not in these four navigation channel reaches. Like the South J etty site, the Half Moon Bay site is mostly insensitive to incident wave climate, with the differences between existing and realigned channel configurations being insignificant at this site. Very little (less than 1.5 percent) of the sediment that erodes from the Half Moon Bay site deposits in any of these four navigation channel reaches. 
- Erosion rates of dredged material and the subsequent fate of this material within the federal navigation channel were not significantly changed between the existing and realigned channel configurations.

It should be recognized that dredged material deposited outside the navigation channel during these 3-month simulations may be subsequently resuspended and deposited in the channel. A longer term simulation would have to be performed to confirm this possibility and quantify the amount of additional deposition, if any, that occurs. The findings from these limited number of model simulations are that the realigned navigation channel does not appear to significantly alter 1) the residence times of the placed dredged material at the three dredged material sites, 2) the quantity of sediment eroded from the three dredged material sites, or 3) the mid-term (months) fate of the eroded material.

Other recommendations based on the present study are:

- Reduce the large uncertainty in the initial grain size distribution throughout the modeling domain by executing a spatially stratified surface grab sample program throughout the model domain and analyzing these samples for grain size distributions.

- Perform a Sedflume study of the sediment in the mounds at the three disposal sites.

- Quantify the flux and grain size distribution of the suspended sediment load transported by the two main rivers that flow into the harbor over a Spring, mean and neap tidal cycle.

- These actions would help greatly to reduce the uncertainty in the model results. The data gathered from these three tasks are essential for additional numerical modeling of sediment transport using LTFATE to accurately predict the resuspension rates of the mounded sediment at the disposal sites and the fate of the resuspended sediment during the four simulated events. 


\section{Unit Conversion Factors}

\begin{tabular}{|l|l|l|}
\hline Multiply & By & To Obtain \\
\hline Acres & $4,046.873$ & square meters \\
\hline acre-feet & $1,233.5$ & cubic meters \\
\hline cubic feet & 0.02831685 & cubic meters \\
\hline cubic inches & $1.6387064 \mathrm{E}-05$ & cubic meters \\
\hline cubic yards & 0.7645549 & cubic meters \\
\hline degrees (angle) & 0.01745329 & Radians \\
\hline degrees Fahrenheit & $(\mathrm{F}-32) / 1.8$ & degrees Celsius \\
\hline Fathoms & 1.8288 & Meters \\
\hline Feet & 0.3048 & Meters \\
\hline foot-pounds force & 1.355818 & Joules \\
\hline Inches & 0.0254 & Meters \\
\hline inch-pounds (force) & 0.1129848 & newton meters \\
\hline Knots & 0.5144444 & meters per second \\
\hline Microns & $1.0 \mathrm{E}-06$ & Meters \\
\hline miles (nautical) & 1,852 & Meters \\
\hline miles (U.S. statute) & $1,609.347$ & Meters \\
\hline Slugs & 14.59390 & Kilograms \\
\hline square feet & 0.09290304 & square meters \\
\hline square yards & 0.8361274 & square meters \\
\hline Yards & 0.9144 & Meters \\
\hline
\end{tabular}




\section{Introduction}

\section{Background}

The U. S. Army Corps of Engineers Seattle District (NWS) is interested in reducing annual maintenance dredging in the outer Federal Navigation channel at Grays Harbor (GH), Washington. The NWS deals with management decisions regarding the most effective use of maintenance dredged material. Through a number of previous physical, numerical modeling, and field data collection efforts, the NWS has developed a large body of knowledge and an information database about operations and maintenance of the navigation channel, its behavior, and impact of dredging operations on three Dredged Material Placement (DMP) sites adjacent to coastal and inlet shorelines. The project site is shown in Figure 1-1.

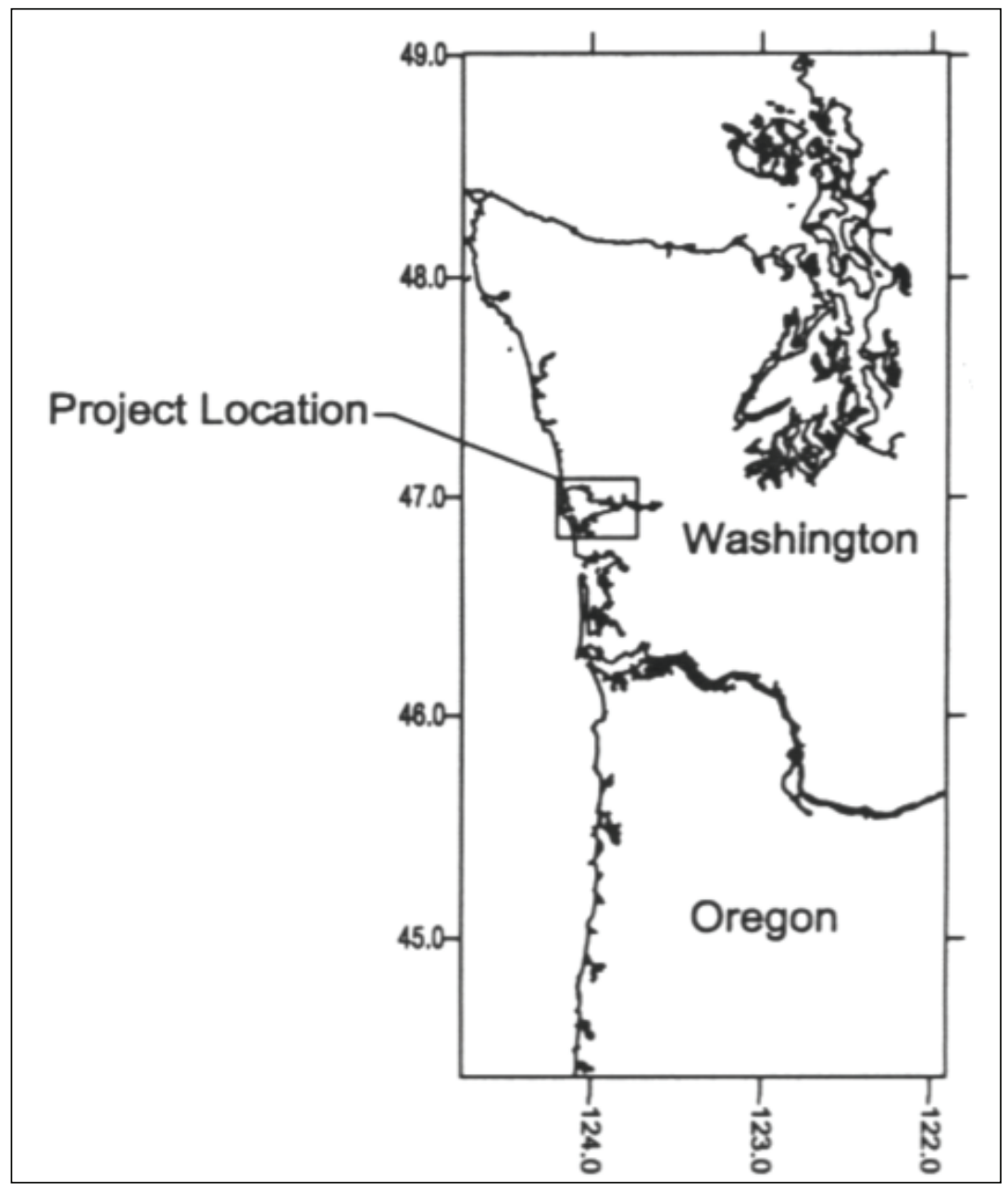

Figure 1-1. Grays Harbor project site. 
The navigation channel transitions from the Pacific Ocean into the Chehalis Point generally in a northeasterly direction, as shown in Figure 1-2. For more details, see Figure 1-3. It enters the inlet in a northeasterly direction, maintains an easterly direction in close proximity to the south jetty, and then turns abruptly northeast at Point Chehalis Reach. The South Reach and North Channel Reach are straighter and directed eastward, and these are joined by the Crossover Channel Reach, Hoquiam, Cow Point, and Aberdeen reaches in the back-bay area. Maintenance dredging requirements for the Point Chehalis and Cow Point reaches have been the most excessive. Consequently, past field measurements by the NWS were directed to collection of wave and current data, and evaluation of alternate channel orientations and depths to determine the optimal channel design for minimizing maintenance dredging requirements. For completeness, only an outline of recent field, laboratory and numerical modeling studies is provided here, since details of each previous study are available from their respective publications.

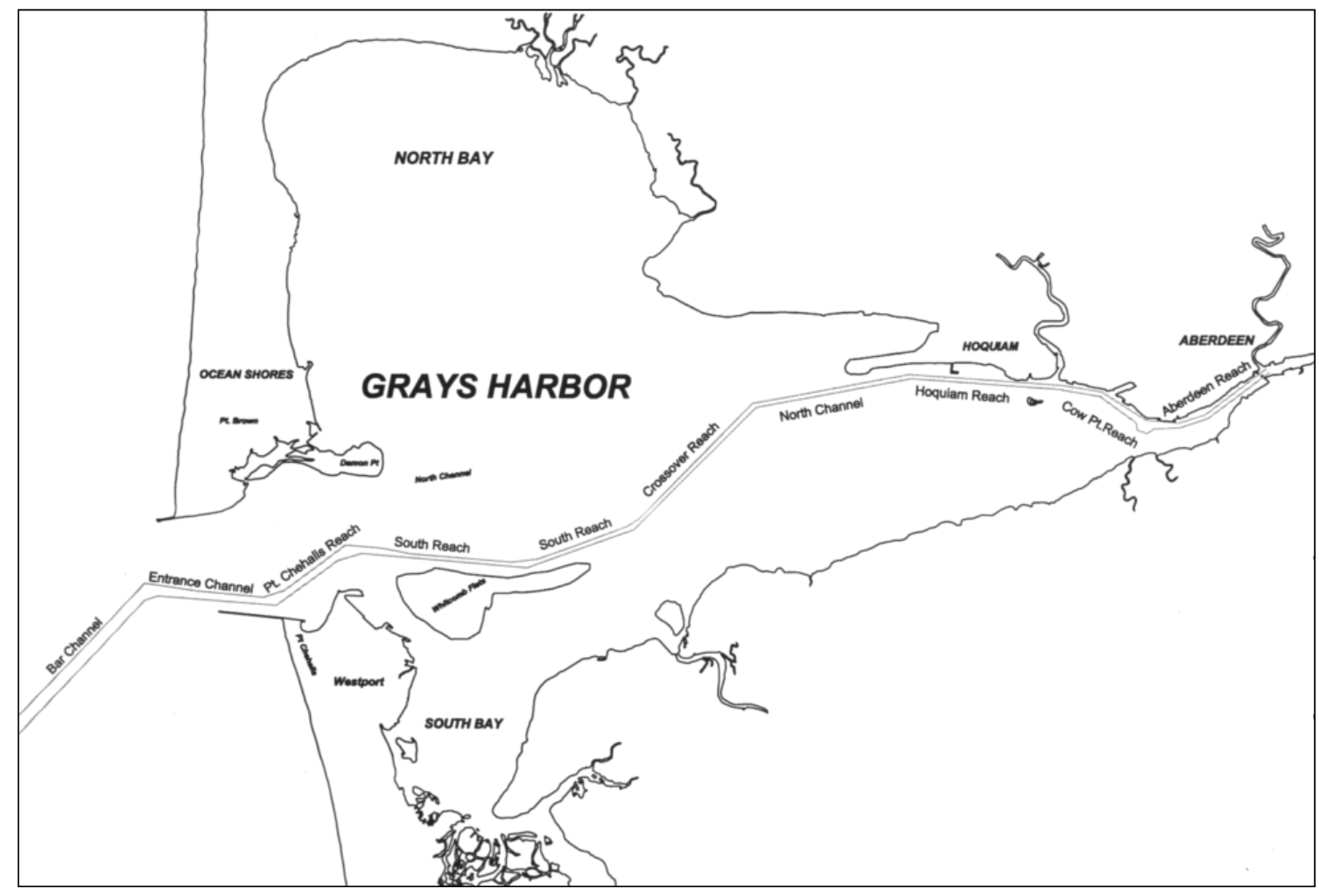

Figure 1-2. Major land features around the Grays Harbor Navigation Project and channel reaches. 


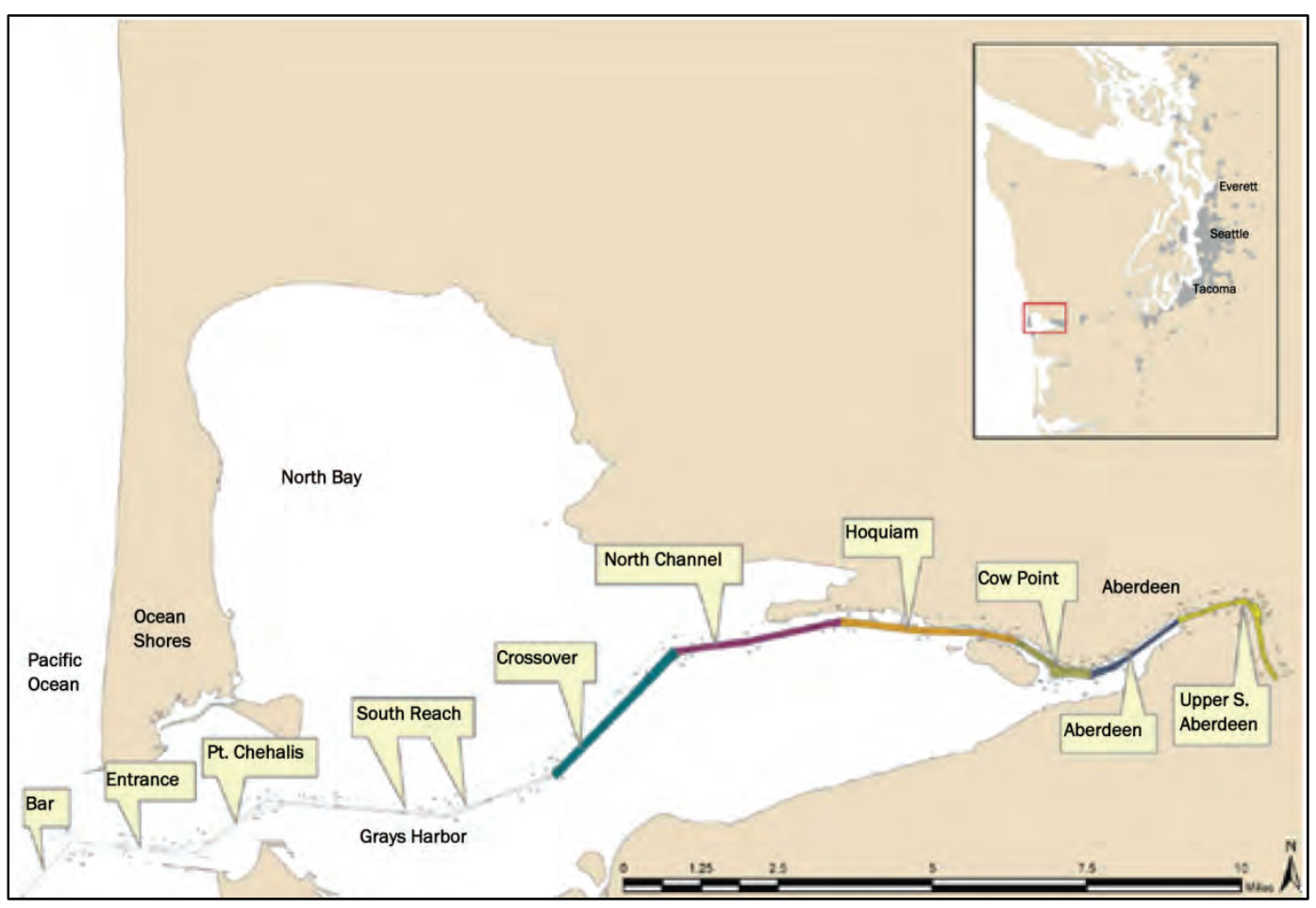

Figure 1-3. Grays Harbor Navigation Channel Project reaches.

\section{Study area}

The present project covers the GH area of approximately 75 square miles (200 square kilometers). The GH estuary is located in the southwest Pacific Ocean coast of the State of Washington about 50 miles north of the Columbia River mouth and approximately 150 miles south of the Strait of Juan de Fuca (Figure 1-1). The outer navigation channel starts seaward of the entrance and ends near the mouth of the Chehalis River. This estuary is long and elongated, and although it is mainly in a west-eastward direction, the navigation channel follows a zigzag pattern (Figure 1-2). The middle section of the estuary, where the channel passes through, is deeper than the water areas north and south of the channel. The GH estuary is nearly 15 miles wide at its broadest point.

The Federal navigation channel project is divided into "Outer" and "Inner" channel regions. Each region is divided into a number of "channel reaches" as shown in Figure 1-2. The Outer channel is 15 miles long from Aberdeen / WA to the entrance in the Pacific Ocean side (Figures 1-2 and 1-3). The $\mathrm{GH} / \mathrm{HMB}$ complex is one of the largest estuaries in the United States. It has a relatively large diurnal tidal range $(\sim 3 \mathrm{~m})$ and one of the greatest tidal prisms. Energetic incident waves of the Pacific Ocean and strong flood-ebb cyclic semi-diurnal tidally dominated flows are the main forces 
controlling the dynamic behavior of the GH navigation channel. The wide GH entrance is exposed directly to waves and tides of the Pacific Ocean. The east end of the GH estuary is narrower and depths are relatively shallower as compared to the open and relatively deep west side. The east end of the GH estuary is not the focus of the present study.

\section{Maintenance dredging and disposal sites}

Periodic annual dredging operations are conducted to maintain the authorized depth in navigation channel reaches for efficiency and safety of deep-draft water transportation in the GH estuary (Figure 1-3). Clamshell and hopper dredges are used in the annual maintenance dredging operations. The dredged material is disposed either at existing open-water disposal sites or nearshore placement and beach nourishment sites for beneficial uses. The beneficial usage of dredge material ensures that the Point Chehalis revetment extension remains buried and helps to maintain a stable, sandy beach profile of HMB. Beach nourishment is applied to the eastern shore of HMB. The rest of the dredged material is disposed of at the Point Chehalis, South J etty, or Southwest open-water disposal sites.

The NWS has established three disposal sites inside the GH/ HMB complex for management of the dredged material extracted from the navigation channel. On the basis of a series of movable-bed physical model studies conducted in the early 1970s at the Waterways Experiment Station (WES), NWS had established the Point Chehalis Disposal Site (PCDS) in 1976. This site was subsequently partitioned into three sections and the eastern section was, at the time, the most actively utilized disposal area until the 2009 dredging year.

The WES studies in the 1970s had also recommended establishing the South J etty Disposal Site (SJ DS) to feed the scour area adjacent to the south jetty trunk. The SJ DS began receiving dredge material in 1988. The third disposal site is the nearshore Half Moon Bay Beneficial Use Site (HMBBUS), and the NWS established this site in 1992 to slow erosion of the HMB shoreline. The inner harbor sediments (silts/ clays) are currently placed exclusively at the PCDS and SJ DS, while the outer harbor sediments (>95\% marine sand) are placed at three interior and other open-water disposal sites. The NWS is evaluating Grays Harbor navigation channel realignment in the Point Chehalis/ Entrance reach, expecting that the proposed realigned channel would take advantage of the thalweg 
developing just north of the Existing channel. Relocation of the channel is being considered because it could limit the annual dredging quantities.

\section{Recent studies at Grays Harbor}

Since the north and south jetties were constructed between 1894 and 1916, the shorelines both on the north and south sides of the entrance to GH have experienced significant changes. The jetties were constructed to minimize the dredging requirements for the federal deep-draft navigation channel by training the tidal current that carries material from the entrance area to offshore depths. By 1915, the offshore beach profile steepened sharply and the initially accreted new land seaward along the shoreline directly south of the South J etty had begun to recede. In December 1993, the South Beach shoreline breached at the South J etty root and the risk to navigation through the channel increased. The breach was filled in August 1994 with material dredged from the Federal navigation channel.

The NWS has since directed several studies to evaluate ongoing erosion problems occurring in and around $\mathrm{GH} / \mathrm{HMB}$ complex, including near Westport, to identify the most appropriate long-term solution to protect navigation in the Federal project. In 1999, the NWS completed a southward extension of the Point Chehalis Revetment and placement of maintenance dredged material within and directly on the shoreline of HMB.

The NWS has conducted a number of recent investigations between 1995 and 2007 that were focused on improvements to the navigation project. For reference and completeness, a partial list of documents related to most recent studies includes:

- Review of Long-Term Maintenance Plans for the South J etty, Grays Harbor Washington; report by subcommittee of the Committee on Tidal Hydraulics and Coastal Engineering Research Board, 1995.

- Long Term Maintenance of the South J etty at Grays Harbor, Washington; evaluation report, 1997.

- Grays Harbor Estuary Physical Dynamics Study, final data report, 1999.

- South J etty Sediment Processes Study, Grays Harbor, Washington: Evaluation of Engineering Structures and Maintenance Measures, ERDC/ CHL TR-03-4. 
- North J etty Performance and Entrance Navigation Channel Maintenance, Grays Harbor, Washington, ERDC/ CHL TR-03-12, Volumes I \& II, 2003-04.

- Analysis of Future Dredging Requirements: Entrance Channel, Point Chehalis Reach, South Reach and Crossover Channel, Stations 280+89 to $862+49$ evaluation report, 2005.

- Half Moon Bay, Grays Harbor, Washington: Moveable-Bed Physical Model Study, ERDC/CHL TR-06-15, 2006.

- Breach History and Susceptibility Study, South J etty and Navigation Project, Grays Harbor, Washington, ERDC/CHL TR-06-22, 2006.

Recent numerical modeling studies investigated effects of jetties on navigation, breaching of jetties, shoreline erosion and morphological changes in the navigation channel (Kraus and Arden, 2003; Osborne et al., 2003; Wamsley et al., 2006). Applicable information from these earlier studies was discussed with the NWS, including the revision and use of numerical model grids in the present study. The regional ADCIRC model grids developed in earlier studies were improved using the most recent bathymetric surveys, shorelines, and structures data obtained from the NWS. Additional depth modifications were made in the offshore bar area, outer entrance channel, near the south and north jetty structures, the HMB area, and in the reaches along the navigation channel at Point Chehalis and eastward. All information and findings from these and other past studies benefited the present study and were integrated into the Study Plan described next.

\section{Present study plan}

The dredged material at GH is disposed either at existing open-water disposal sites or nearshore placement and beach nourishment sites for beneficial uses. The work described in this report was performed to assist the NWS in the evaluation of the GH navigation project and three dredging disposal sites (PCDS, SJ DS and HMBBUS) inside the estuary.

The present study was conducted as multidisciplinary tasks including analysis of past studies and field data, laboratory analysis of core samples, and comprehensive numerical modeling tasks specific to waves, currents, and sediment transport. The study required performing a carefully selected set of numerical simulations of deepwater tides and waves obtained from evaluation of a 38-yr hindcast data set, GROW (Oceanweather, 2007), covering the years 1970-2007. Results were statistically analyzed to develop 
a reduced set of events corresponding to sediment mobility at the existing dredged material placement sites for three return periods ( $0.5,2$ and $5 \mathrm{yrs})$. These time scales were chosen for investigation of short- and long-term channel transport dynamics. Through an analysis described in Chapter 4, three-month-long seasons corresponding to each return period were selected for the hydrodynamic, wave and sediment transport modeling studies for the Existing and Realigned channel alternatives. The expected level of sedimentation and transport pathways over each return period was calculated. For both Existing and Realigned channel alternatives, modeling results provided an estimate of the impact of routine dredging maintenance operations on the three DMP sites presently utilized by the NWS.

The modeling tasks included a verification of ADCIRC and CMS-Wave in the area of interest. Two field data sets, collected by USACE in 1999 and 2003 , were used in verification of the models. The wave and hydrodynamic modeling tasks produced estimates of nearshore waves, water levels and current fields for conditions associated with each return period. A comparison between hydrodynamic and wave modeling results and field data was conducted for two project alternatives. Results were used to evaluate Federal navigation project alternatives. Information about the wave and hydrodynamics modeling study, including bathymetric data, meteorological and oceanographic data, boundary conditions and numerical model setup are presented in Chapter 2 of this report.

The methods used in modeling and analysis of sediment transport processes are described in Chapter 2. Wave and circulation modeling results are discussed in Chapter 3 and compared to field data. Chapter 4 provides a description of the statistical method used in event selection. Chapter 5 provides summary output of the hydrodynamic and wave modeling for the production runs. Chapters 7 and 8 are dedicated to sediment transport modeling, field data (core samples), and determination of sediment pathways to calculate predicted channel infilling at four DMP sites. Conclusions are provided in Chapter 6.

\section{Modeling approach}

Unless otherwise noted, all data and calculated quantities in this report are expressed in SI units. These include meteorological and oceanographic (metocean) data and calculated results for waves, water current, wind speed, and sediment transport quantities. Both the Geographic and State Plane coordinates were used in this modeling study. The length units for 
the horizontal plane are in meters, the State Plane NAD 83 is the horizontal system, with the Washington South Zone 4602. For the vertical plane, the length units are in meters, and vertical system is the mean lower low water (MLLW).

A set of specific tasks were performed by members of the project team after a careful analysis of deepwater and nearshore field data. The transformation of deepwater metocean data was necessary for characterization of shortand long-term coastal forcings affecting dredged and moveable sediments, and placement sites throughout the Grays Harbor study area.

The present study was comprised of six main tasks:

1. Review and analysis of 1999 and 2003 field data.

2. Analysis of a 38-yr GROW hindcast data set (Oceanweather, 2007).

3. Numerical modeling of regional and local scale waves and hydrodynamics due to winds and tides.

4. Analysis of sediment samples and numerical modeling of local scale sediment transport affecting the DMP sites.

5. Numerical modeling of local scale sediment transport in the GH navigation channel and three interior disposal sites.

6. Analysis and interpretation of the numerical modeling results.

Tides, winds, and waves influence this project site, and detailed modeling of these processes are required for predicting trends and pathways of dredged and forced sediments in the GH navigation project areas of interest. In addition to the dredging activities that contribute to evolution of the navigation channel, the bathymetry in the study area is highly dynamic and responds to tidal currents and wave processes (shoaling, refraction, reflection, diffraction, breaking and dissipation). The 1999 and 2003 bathymetry data collected by the NWS were used in this study to validate numerical wave and flow models. The reliability of the numerical models used in this study was assured by calibrating flow and wave models with wave and current data.

A 38-yr hindcast data set, called the Global Reanalysis of Ocean Waves (GROW) by Oceanweather (2007), was used in this study to develop shortand long-term statistical input conditions for numerical modeling (wave, hydrodynamic). The solutions of wave and hydrodynamics modeling were used in the sediment transport modeling to calculate trends and volumetric 
estimates. These statistics were defined in terms of "return periods" varying from 0.5 to 5 yrs in duration. In addition, the possible role of individual extreme storms on navigation channel was also simulated using the most severe condition encountered in the period 1970-2007.

Seasonal and inter-annual variability in storm conditions, caused by El Nino Southern Oscillation (ENSO) climatic patterns that influence sedimentation processes in the GH complex, were considered in the selection of return periods. The length of the time period for the navigation channel system to respond to environmental forcing was selected on a seasonal basis. Seasons are defined in this study as being four three-month-long quarterly intervals in a year, and defined as Q1 (J anuary - March), Q2 (April - J une), Q3 (J uly - September), and Q4 (October - December). A 38-year hindcast is used to define the statistical period of analysis for environmental forcing. The offshore wave conditions were obtained from the GROW hindcast data set, a 38-year record spanning the years 1970-2007. The offshore tidal constituents were obtained from the Le Provost tidal constituents (Le Provost et al. 1994). Offshore tidal and wave conditions were transformed to local conditions at the GH estuary that included the dredged material placement sites. This was accomplished using the numerical models ADCIRC and CMS-Wave, which are described in Chapters 2 and 3. These models were calibrated with field data and used to predict current speeds and wave heights for the quarterly events during each return period, as well as for the most severe storm event occurring within the 38-yr hindcast time.

The numerical models and data for modeling were selected in close consultation with the NWS. The ADCIRC flow model and CMS-Wave spectral wave model were chosen. Summary information about these models and details of the modeling tasks are described in Chapters 2 and 3. The MPFATE, GTRAN, and SEDZLJ models were selected for sediment transport modeling. Details of these models and sediment transport modeling are described in Chapters 6 through 10.

\section{Return periods}

Sediment mobility, defined as the ratio of shear stress to critical stress, was used in this study to determine sediment transport potential at the dredged material placement sites due to environmental forcing. Using simplified wave transformation and hydrodynamic estimates at the site of interest, four seasonal return intervals were determined based on sediment mobility at the existing dredged material placement sites. Given that the target 
return intervals for dredging quantities are relatively short, as compared to return periods for storm damage of structures (e.g., breakwaters, jetties, or levees), the target return periods for this study were selected as $0.5,2$, and 5 years. These return periods were considered characteristic of time scales for annual maintenance dredging. Because extreme events are also of interest to dredging operations, the most extreme event from the 38-year record was also considered in this study.

A statistical method is described in Chapter 4 for selection of the return periods. This method may also be used for sediment response parameters, integration periods, and determining appropriate record lengths for sediment transport analyses. The method is demonstrated for the GH navigation project using a 38-yr wave hindcast record. Return intervals for sediment mobility were determined by a statistical method of local sediment mobility calculated from the offshore and nearshore wind, water level, and wave conditions. The quarterly conditions selected for each return interval were simulated with the hydrodynamic and wave models to develop local waves, currents and water levels. Due to the existence of a large tidal range at $\mathrm{GH}$, nine stages of water levels ranging between $-2 \mathrm{~m}$ to $2 \mathrm{~m}$ were used (in increment of $0.5 \mathrm{~m}$ ) in the numerical simulations.

Co-existing waves and flows were used to calculate the bottom shear stresses over the entire modeling area. The mobility index was then calculated from these shear stresses as the ratio of the local shear stresses to a threshold (critical) shear stress value. In this study, a critical shear stress of 0.2 Pa was assumed, a value consistent with sandy sediment diameters of approximately $0.25 \mathrm{~mm}$ in the outer $\mathrm{GH}$ channel. A map of the mobility index was developed for nine water levels and three return periods. The four three-month-long time interval (seasons or quarters) that produced the largest value of the mobility index in each return period was determined. These quarterly periods became the simulation times for the wave and hydrodynamic models. Table 3-1 shows the quarters selected for three return periods.

\section{Development of boundary conditions}

The time period and conditions corresponding to two field data collections were used in the verification of numerical models to compare observed data to calculated waves and currents. Boundary conditions for wave and hydrodynamic models generated for two field data set measurement periods included wind and tidal inputs. The numerical modeling verification was 
conducted for 13 October-13 November 1999, and 10-30 December 2003. Model comparison to observed water surface elevation, current and wave data were performed. Wave and flow models were validated against field data using calculated water surface elevation, current, wave height, period, and direction. Flow and wave modeling were performed with the bathymetry data collected by the NWS in 1999 and 2003, and both waves and flow predictions were validated with field measurements. The two data sets greatly benefited this study and ensured that the models used were capable of accurately representing flow and waves in the areas of interest. Additional information about field data and verification is provided in Chapter 3.

\section{Production runs}

Following the initial verification of CMS-Wave and ADCIRC models with data, the base (Existing Channel) and one alternative (Realigned Channel) were simulated with wave and circulation models for the production runs. The simulation periods used in the production runs are listed in Table 3-1. The duration of simulation for each return period is different. The majority runs were 90-day long, covering the entire quarter, and a few were slightly shorter. The simulations for the extreme event were relatively short, about two-weeks long. The longer runs were split into monthly simulations to expedite computational demands on super-computers (e.g., minimize waiting time in queuing). Additional information about production runs is provided in Chapter 5. 


\section{Wave and Hydrodynamic Models}

\section{Bathymetric data}

Bathymetric data collected by the NWS in 1999, 2003, and 2008 were used in verification of flow and wave models to develop hydrodynamic and wave input conditions for sediment transport models. The production runs were performed for the Existing and Realigned Channel alternatives using 2008 bathymetry data. Depths on the numerical model grids were referenced to Mean Tide Level (MTL).

For purposes of highlighting depth changes, the modeling domain is divided into three parts: offshore, entrance channel, and inside bay. Figure 2-1 shows the variation of depth in the region from deepwater to offshore bar, and to the entrance channel and bay. Figures 2-2 and 2-3 provide 2008 bathymetric contours depicting depth change along the navigation channel and in the eastern end of the estuary. Depth change from the channel to surrounding coastal land areas is shown. The navigation channel is deeper than water areas that lie south and north of the channel.

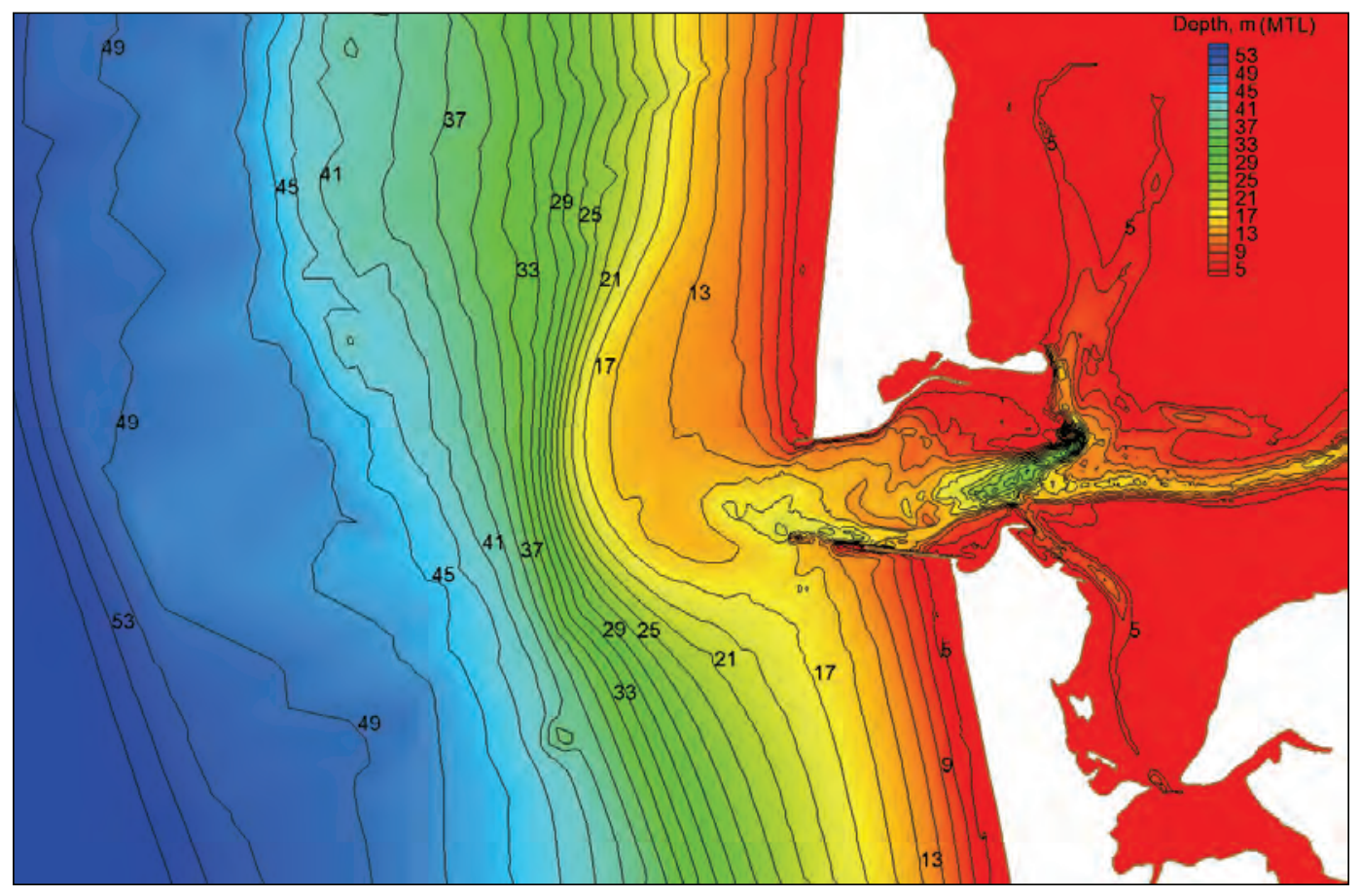

Figure 2-1. Depth contours between offshore and entrance channel. 


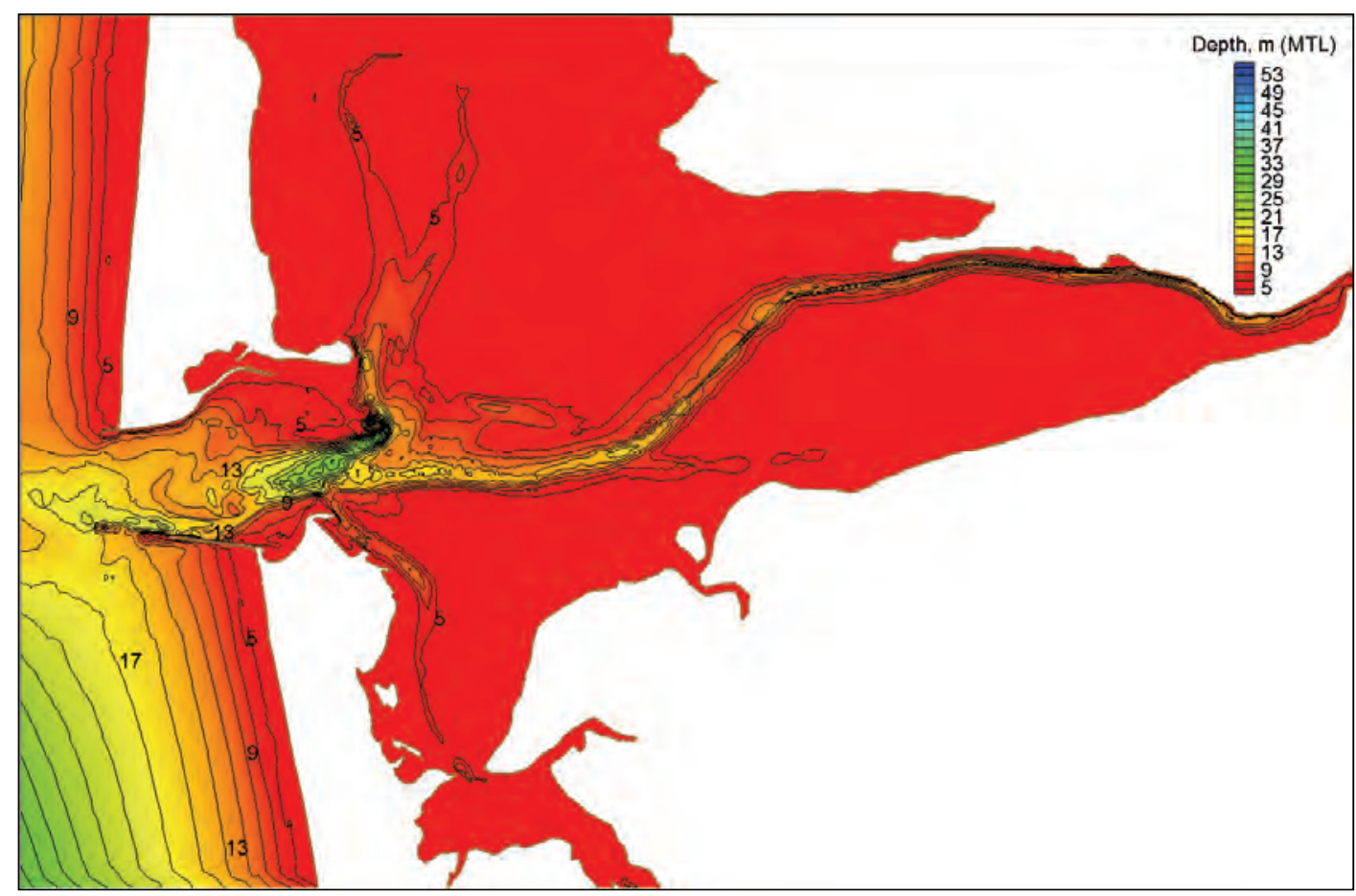

Figure 2-2. Depth contours along navigation channel from offshore bar to Point Chehalis.

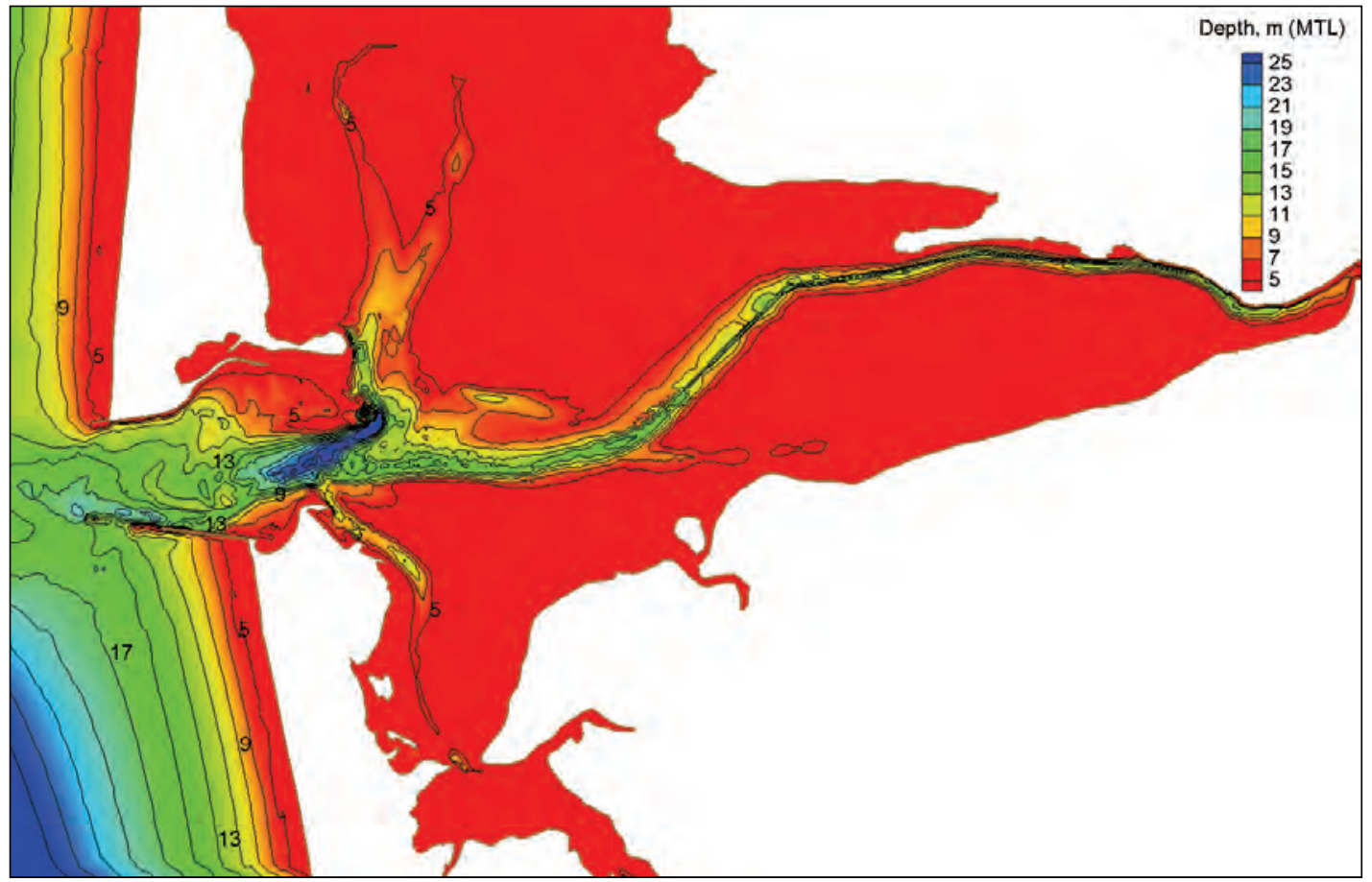

Figure 2-3. Depth contours in the east end of Grays Harbor estuary.

The depths for 1999, 2003 and 2008 are based on the NWS bathymetry surveys of the navigation channel and surrounding areas. Bathymetry for the remainder of the numerical model domain was obtained from the 
National Geophysical Data Center, Coastal Relief Bathymetry Database, for coastal regions of the Pacific Ocean and previous Grays Harbor studies. The authorized channel depth goes from $16 \mathrm{~m}$ Mean Lower Low Water (MLLW) at the entrance bar to $13 \mathrm{~m}$ MLLW at the Point Chehalis reach section. The difference between MLLW and MTL tidal datums at GH is $1.7 \mathrm{~m}$, as given by the National Oceanic and Atmospheric (NOAA) Tide Station 9441187 (Aberdeen, WA).

The quality of the bathymetric data in grid generation plays a significant role in the accuracy of the wave and hydrodynamic calculations. Because the bottom topography can change significantly over a relatively short time, bathymetric data collected closest to the simulation time were incorporated in grid generation for model verification runs (1999 and 2003 bathymetries) and production runs (2008 bathymetry). The change in topography over time is very critical in dynamic inlets such as GH that are characterized by high flows and strongly varying morphology. Bathymetric data was obtained from two sources. The Seattle District provided bathymetric data for the Grays Harbor region and part of the Washington-Oregon region. The bathymetric data for the area of the model domain not covered by the District's survey data were obtained from GEOphysical Data System (GEODAS), developed by the National Geophysical Data Center. The GEODAS data included bathymetric data from different time periods. Some data were collected as early as the 1970's and the most recent data were collected in 2008.

For the Grays Harbor estuary, each bathymetric file was positioned on the grid and checked for survey date and reference datums. For areas covered by more than one file, the most recent survey data was selected. A similar data decimation procedure was adopted for the rest of Grays Harbor as well. All depth data interpolated to the grid were in meters and referenced to MLLW and NAD83. Horizontal datum conversion from NAD27 to NAD83 was performed within the Surface Water Modeling System (SMS). Most of the District survey data were referenced to MLLW and to North American 1927 Datum (NAD27). The District provided bathymetric survey data for $\mathrm{GH}$, collected during the period 1999 - 2008. Use of these most recent data was maximized in the present study. The data were referenced to MLLW and to North American 1983 Datum (NAD83). The final bathymetries from the entrance of GH to the Point Chehalis area of the Existing and Realigned channel with and without the Existing Channel filled are shown in Figures 2-4, 2-5 and 2-6, respectively. 


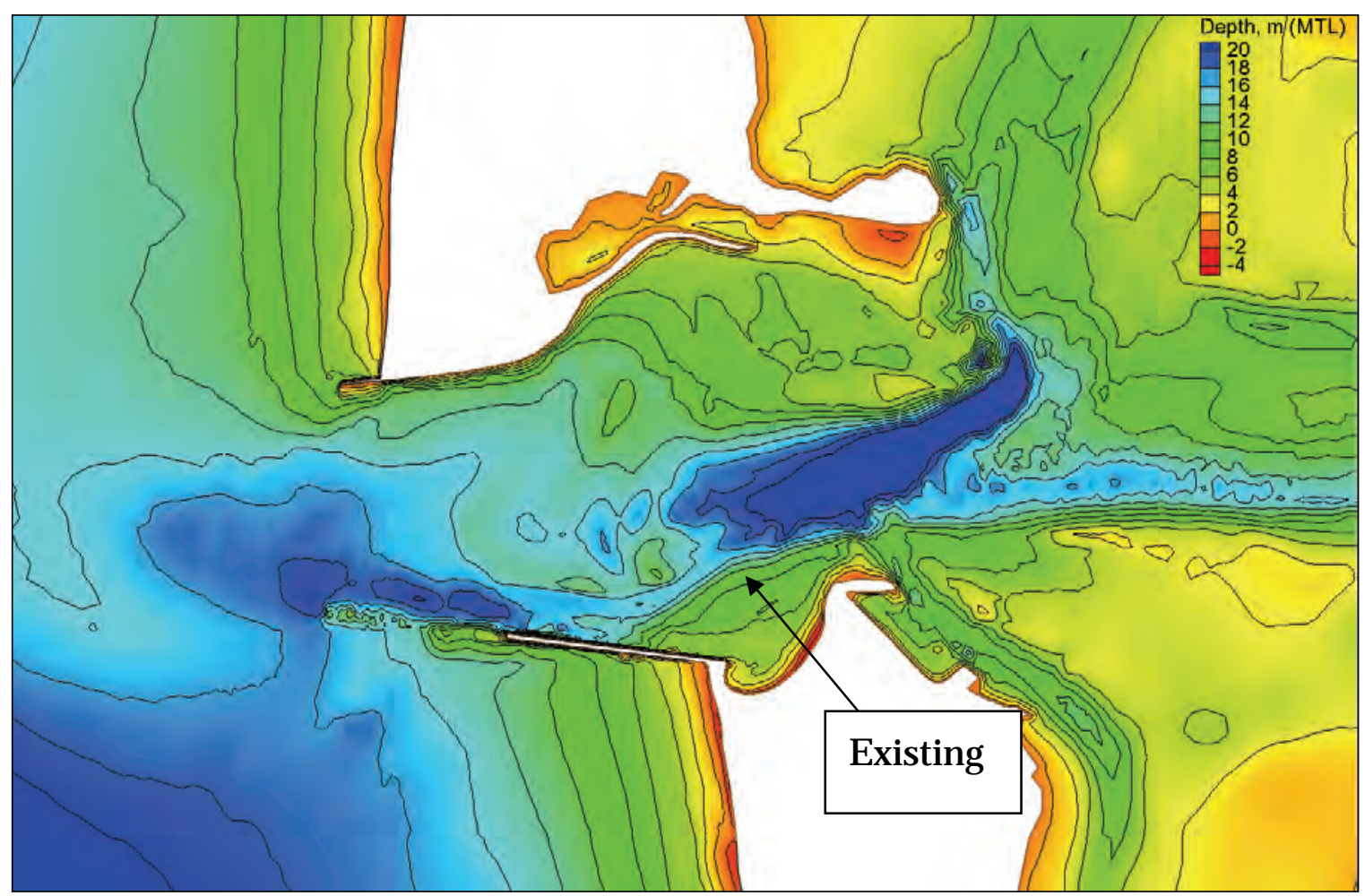

Figure 2-4. Bathymetry of Existing Channel.

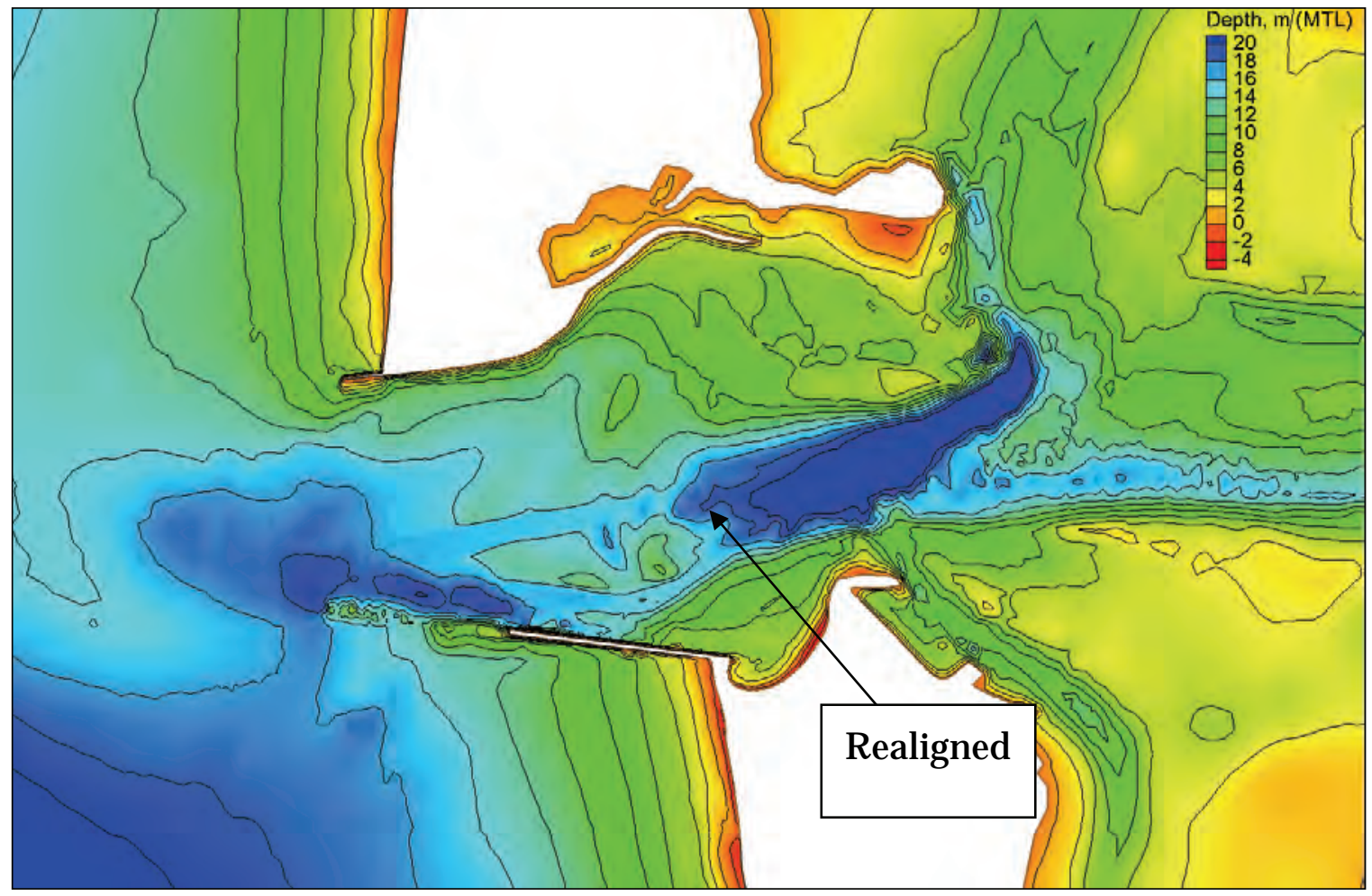

Figure 2-5. Bathymetry of Realigned Channel with Existing Channel unfilled. 


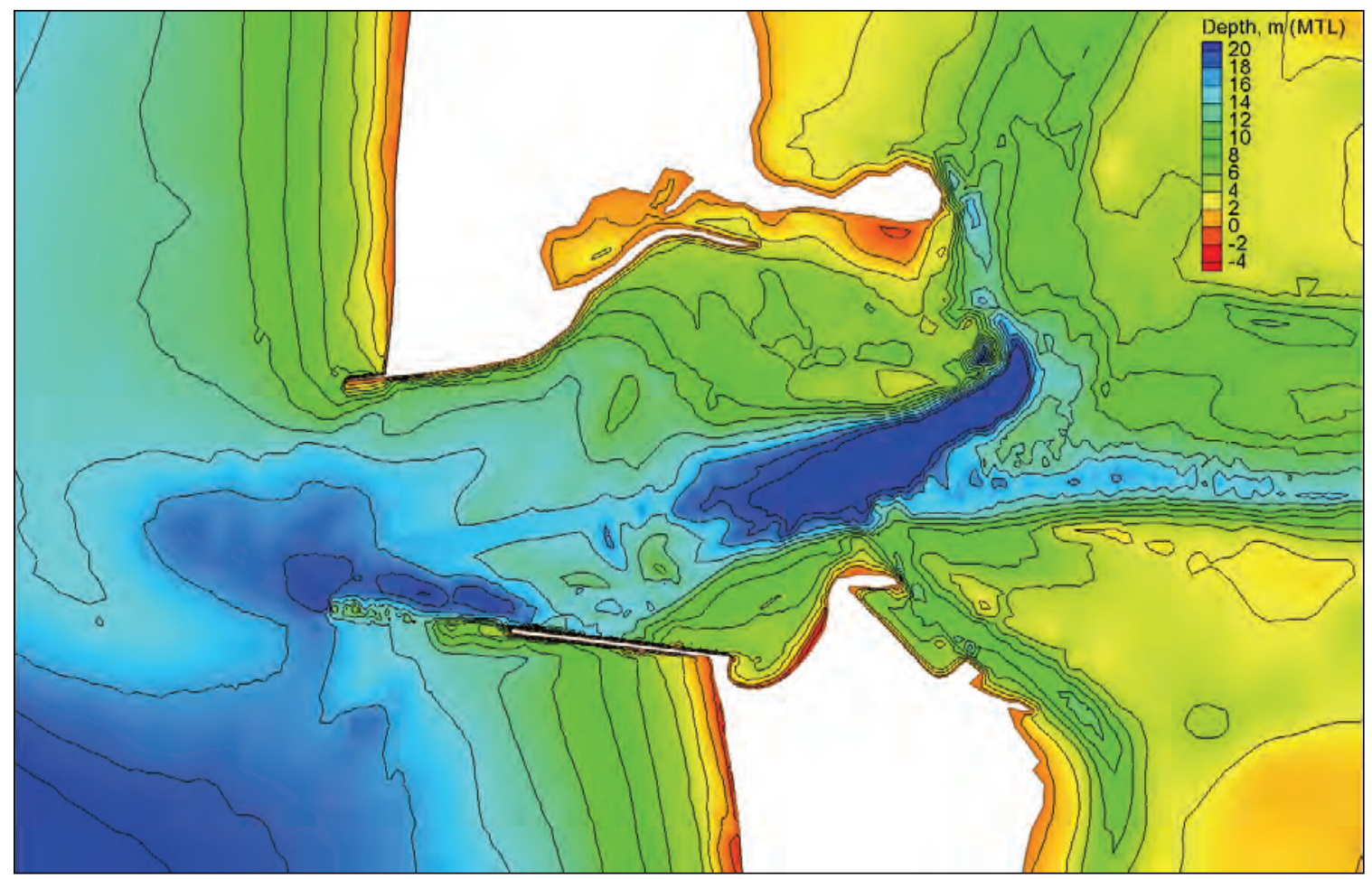

Figure 2-6. Bathymetry of Realigned channel with the Existing channel filled.

\section{Wave model grid}

The finite-difference grid domain of CMS-Wave and changes in depth contours are shown in Figure 2-7. The model computational domain covers approximately 330 square miles (860 square kilometers). The grid is oriented East-West, with the offshore boundary at the $40 \mathrm{~m}$ depth contour, and extends eastward to Aberdeen, WA. The CMS-Wave model has 94,000 cells (68,000 computational cells and 26,000 non-computational cells) with the largest and smallest cell sizes of 2,000 m and $30 \mathrm{~m}$, respectively. A variable grid was used in the areas from the entrance channel to Point Chehalis.

\section{Hydrodynamic model grid}

The ADCIRC domain and geometric/topographic description and resulting computational grid covers the shallow areas of GH surrounded by land, where water depths vary from $0 \mathrm{~m}$ to the $16 \mathrm{~m}$. The grid domain extends seaward to the deepwater to thousand of meters in the deep Pacific Ocean. For future reference, the study grid is called GH2010, and its boundaries were selected to ensure for the correct development, propagation, and attenuation of tides and storms without necessitating nested solutions or specifying ad hoc boundary conditions for tides or 


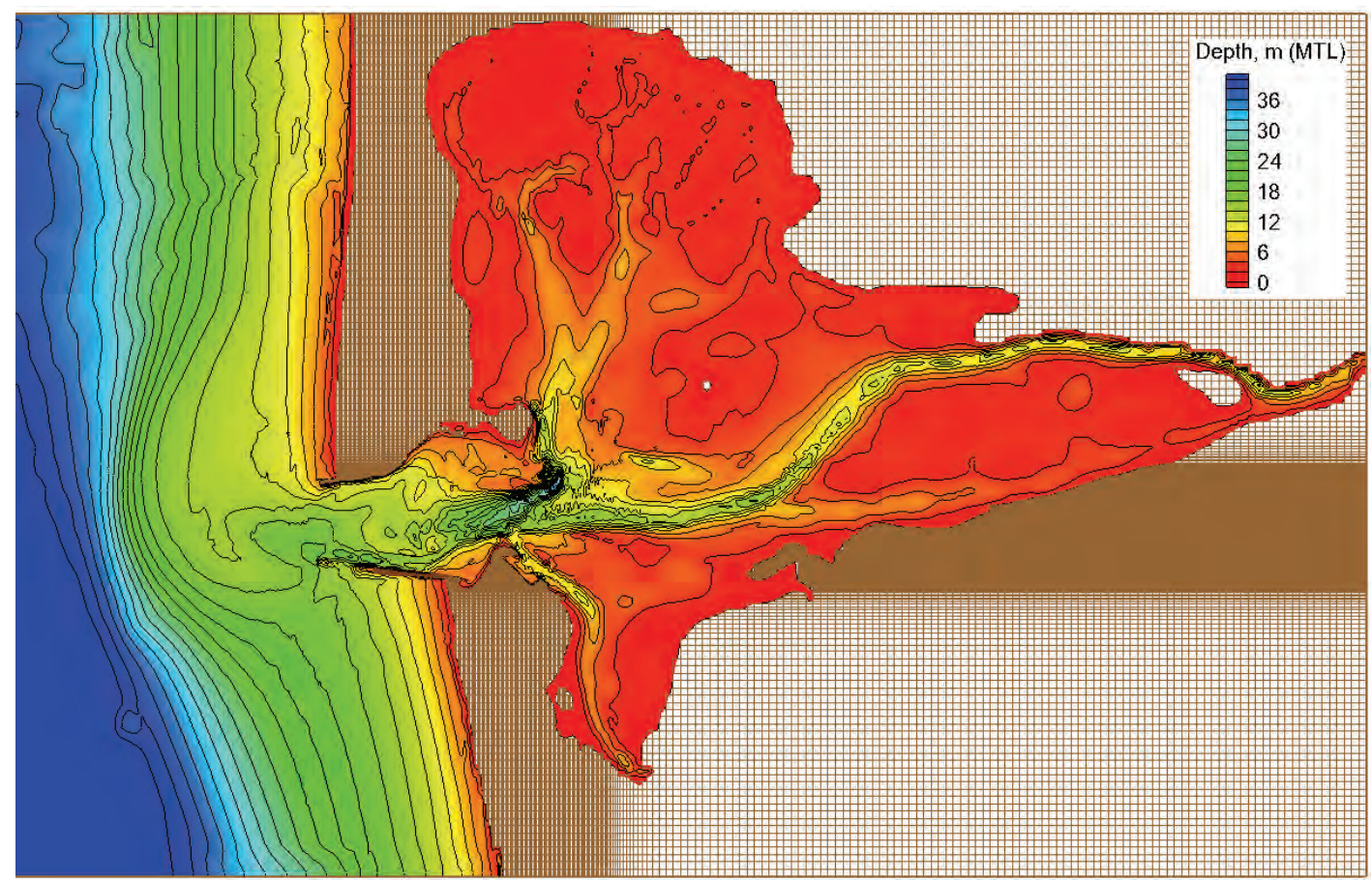

Figure 2-7. Bathymetric change in CMS-Wave grid domain.

storm surge. The GH2010 grid is used for all GH numerical modeling (e.g., Existing and Realigned channel) in this study to ensure consistency and matching solutions along the sub-region boundaries of wave and sediment transport models. Depths for the Existing and Realigned channel are appropriately specified.

The GH2010 has a 1,250 mile (2,000 km) open-water boundary (Figure 2-8). The extent of the domain was confined in a geographic range defined by longitude of $130.5^{\circ}$ to $122.7^{\circ} \mathrm{W}$ and latitude of $40.7^{\circ}$ to $51.2^{\circ} \mathrm{N}$. Its open ocean boundary was located in the deep ocean that lies outside the resonant basins, and was not located near the tidal amphidromes. Developing the ADCIRC grid involved a) defining the domain extent, b) preparing the bathymetric data, c) assigning depth values to the shoreline, d) referencing the bathymetric data to the model datum, and e) defining tidal flats within the GH estuary.

The project area of interest extends to approximately the $20 \mathrm{~m}$ depth contour to the West of the Entrance Channel, $13 \mathrm{~km}$ north of the North J etty and $9 \mathrm{~km}$ south of the South J etty. The varying resolution was added so that the entire navigation channel is at the smallest resolution. The development of an accurate unstructured grid for circulation modeling at GH requires appropriate selection of model domain and optimal resolution of features affecting propagation of tide and wind induced flow. 


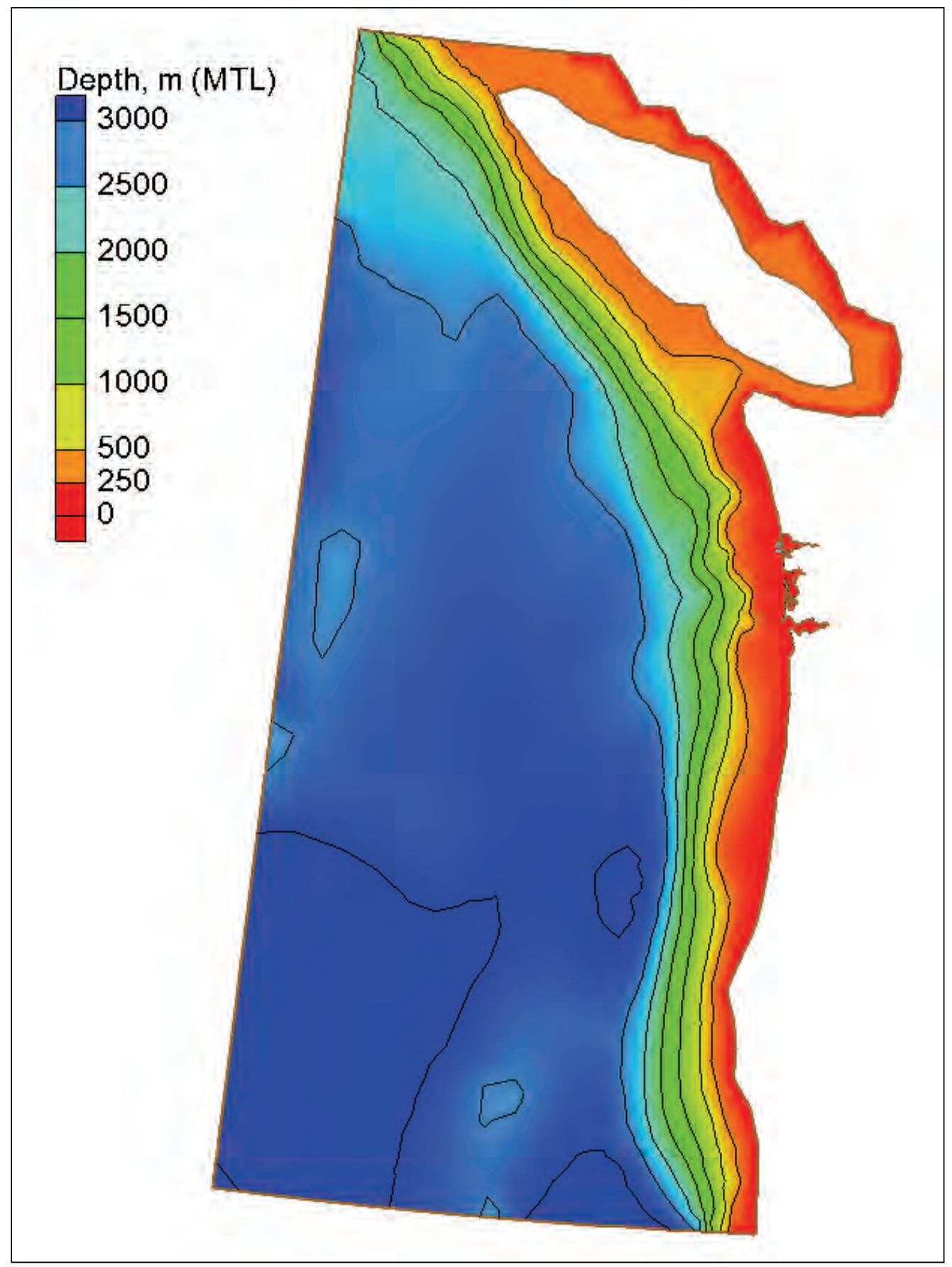

Figure 2-8. Regional ADCIRC grid.

The tidal response at the open boundary in this study is dominated by the astronomical constituents and nonlinear energy is limited due to the depth. The storm surge response along this boundary is essentially an inverted barometer pressure effect directly correlated to the atmospheric pressure deficit in the meteorological forcing; and it can therefore be easily specified. This boundary allows the model to accurately capture basin-to-shelf 
physics. The grid design provides localized refinement of the coastal areas of the Grays Harbor estuary and of the important hydraulic features. Attention was focused on the level of detail of the navigation channel, and areas near the South J etty, Half Moon Bay, Westport, and Point Chehalis, with nodal spacing reaching as low as $10 \mathrm{~m}$ in the most highly refined areas. This unstructured grid can resolve the critical features and the associated local flow processes with orders of magnitude fewer computational nodes because it provides resolution on a localized basis and fine resolution generally extends far outside the necessary area.

The GH2010 is refined locally to resolve navigation channel features and surrounding local topography/ bathymetry of structures and shorelines. In addition, wave breaking zones were identified based on local bathymetric gradients, and finer resolution was placed in these areas to ensure that the grid scale of the flow model is consistent with that for the CMS-Wave model. The wave modeling requirements are accommodated by adding a high level of resolution where significant gradients in the wave breaking were expected. The high resolution zones allow for the strong flow gradients to fully force the water body in these important regions and to ensure that the calculated water level and flow velocities are sufficiently accurate. Mesh resolution was not of concern in the shallow banks away from the navigation channel along the south and north coastlines of the GH estuary. This grid was calibrated and validated with data collected at GH in 1999 and 2003.

The GH2010 contains approximately 40,000 nodes and 77,000 elements. Grid resolution varies from $50 \mathrm{~km}$ in the deep Pacific Ocean to about $50 \mathrm{~m}$ in the GH estuary complex. The high grid resolution required for the study region leads to a final grid with more than 85 percent of the computational nodes placed within the estuary, starting at the outer bar of the Navigation channel outside the entrance. This enabled sufficient resolution while minimizing the computational run time for such an extensive domain. Geometry, topography and bathymetry in the GH2010 were all defined in coordination with the NWS. The bathymetry data provided by the NWS included the most recent surveys conducted following maintenance dredging of the navigation channel and replicated the prevailing conditions in 2008. The bathymetric and topographic data were interpolated to the GH2010 computational mesh by moving progressively from the coarsest and deepest to finest and shallowest areas of the computational domain. Bathymetric contours between the outer bar and entrance channel area 
were further revised based on recent data by the NWS, obtained from ongoing studies by NOAA, USGS, and tsunami research community works for the Northwest Pacific Ocean region.

Element areas vary greatly in GH2010, with the ratio of the offshore element to the smallest element in the navigation channel area being 1,000. Grid resolution can vary spatially, and grading between coarse and fine resolution was done with regard to transition between element areas. A general rule is that adjacent elements should not differ in size by more than 50 percent. More resolution was added to the study area, as shown in Figure 2-9, with finest node spacing of about $10 \mathrm{~m}$ near the South J etty, along the channel and at Point Chehalis.

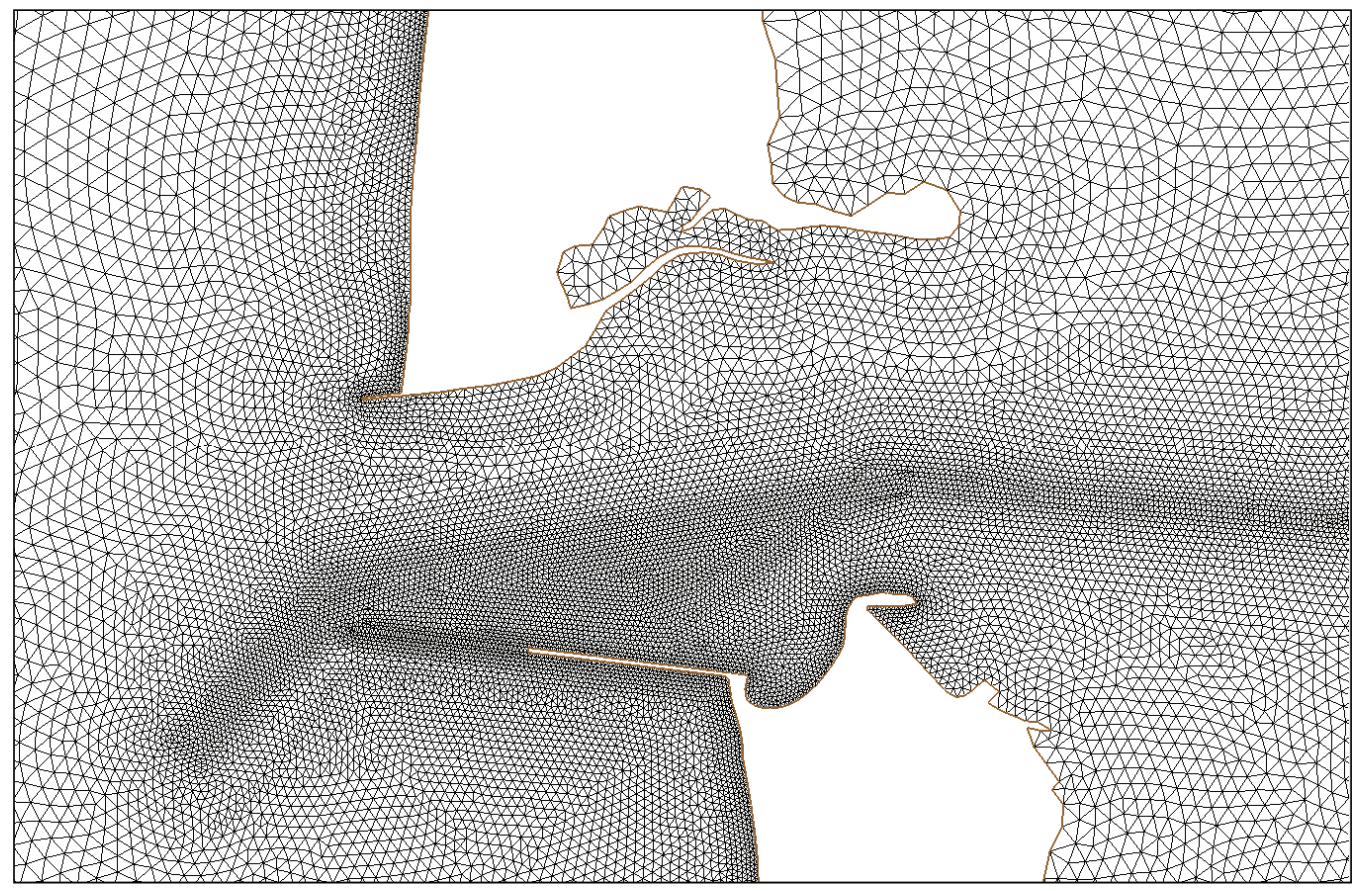

Figure 2-9. ADCIRC grid at the GH entrance.

\section{Description of wave model}

A spectral wave model CMS-Wave, based on a wave-action balance equation that includes wave refraction, shoaling, diffraction, reflection, breaking, and dissipation, is used in this study for wave modeling. It is a two-dimensional spectral wave model formulated from a parabolic approximation equation (Mase et al. 2005a) with energy dissipation and diffraction terms to simulate a steady-state spectral transformation of directional random waves co-existing with ambient currents in the coastal zone. The model operates on a coastal half-plane for waves propagating 
only from the seaward boundary toward shore. Wave generation (wind input), wave refraction, shoaling, diffraction and reflection, wave breaking, bottom friction, and wave dissipation are considered in this model. The model technical report ERDC/ CHL TR-08-13 (Lin et al. 2008) provides CMS-Wave validation and examples to demonstrate the model's applicability to propagation of random waves over complicated nearshore bathymetry where wave refraction, diffraction, reflection, shoaling, and breaking occur simultaneously. The report describes the model's general features, formulation, capabilities, input and output, and provides application guidelines.

The height and direction of waves approaching the GH Navigation channel change due to wave shoaling, refraction, diffraction, reflection, and breaking. Waves propagating through the $\mathrm{GH}$ channel interact with the bathymetry and are affected by surrounding land features, and currents and coastal structures. Advanced linear and nonlinear wave theories and solution methods may be used in wave transformation models for monochromatic and irregular or random waves moving from deep to shallow waters over varying bathymetry (Nwogu and Demirbilek 2001; Demirbilek and Panchang 1998). Each wave theory and associated numerical model has certain advantages and limitations, and the appropriateness of the models depends on the relative importance of various physical processes and the particular requirements of a project. A spectral wave model was necessary for this project given the large extent of modeling domain over which wave estimates were required.

By definition, the CMS-Wave spectral model transforms a wave spectrum of natural sea waves that is considered as the sum of a large number of harmonic waves, each with constant amplitude and phase, randomly chosen for each observance of a true record (Demirbilek and Vincent 2006). The CMS-Wave transformation model selected for the GH navigation project represents irregular wave forms and provides an estimate of wave parameters necessary for flow and sediment transport models.

CMS-Wave incorporates wind-wave generation, bottom friction, and spatially varied cell sizes that make the model suitable for more general use in the coastal region. Wave diffraction is included in the governing equations following the method of Mase et al. (2005a). Four different depth-limiting wave breaking formulas are provided including one for the wave-current interaction based on the dispersion relationship for wave 
blocking by an opposing current. Wave generation and whitecapping dissipation are parameterized as a source term and calibrated using field data (Lin and Lin 2004a and b, 2006b). Bottom friction loss is estimated based on the classical drag law formula (Collins 1972). Other features in CMS-Wave include grid nesting capability, variable rectangular cells, wave overtopping, wave runup on beach face, and wave-wave interaction.

The governing equation of CMS-Wave is the wave-action balance equation given by (Mase 2001)

$$
\frac{\partial\left(\mathrm{C}_{\mathrm{x}} \mathrm{N}\right)}{\partial \mathrm{x}}+\frac{\partial\left(\mathrm{C}_{\mathrm{y}} \mathrm{N}\right)}{\partial \mathrm{y}}+\frac{\partial\left(\mathrm{C}_{\theta} \mathrm{N}\right)}{\partial \theta}=\frac{\kappa}{2 \sigma}\left[\left(\mathrm{CC}_{\mathrm{g}} \cos ^{2} \theta \mathrm{N}_{\mathrm{y}}\right)_{\mathrm{y}}-\frac{\mathrm{CC}_{\mathrm{g}}}{2} \cos ^{2} \theta \mathrm{N}_{\mathrm{yy}}\right]-\boldsymbol{\varepsilon}_{\mathrm{b}} \mathrm{N}-\mathrm{S}
$$

where

$$
\mathrm{N}=\frac{\mathrm{E}(\sigma, \theta)}{\sigma}
$$

is the wave-action density to be solved and is a function of frequency $\sigma$ and direction $\theta . E(\sigma, \theta)$ is spectral wave density representing the wave energy per unit of water-surface area per frequency interval. We note that in the presence of an ambient current, the wave-action density is conserved, whereas the spectral wave density is not (Bretherton and Garrett 1968; Whitham 1974). Both wave diffraction and energy dissipation are included in the governing equation. The implementation of the numerical scheme is described elsewhere (Lin et al. 2008; Mase et al. 2005a; Mase 2001). C and $\mathrm{C}_{\mathrm{g}}$ are wave celerity and group velocity, respectively; $\mathrm{x}$ and $\mathrm{y}$ are the horizontal coordinates; $\mathrm{C}_{\mathrm{x}}, \mathrm{C}_{\mathrm{y}}$, and $\mathrm{C}_{\theta}$ are the characteristic velocity with respect to $\mathrm{x}, \mathrm{y}$, and, $\theta$ respectively; $\mathrm{N}_{\mathrm{y}}$ and $\mathrm{N}_{\mathrm{yy}}$ denote the first and second derivatives of $\mathrm{N}$ with respect to $\mathrm{y}$, respectively; $\kappa$ is an empirical parameter representing the intensity of diffraction effect; $\varepsilon_{b}$ is the parameterization of wave breaking energy dissipation; $S$ denotes additional source $S_{\text {in }}$ and sink $\mathrm{S}_{\mathrm{ds}}$ (e.g., wind forcing, bottom friction loss, etc.) and nonlinear wave-wave interaction terms. The treatment of wave diffraction, wave reflection, wave breaking, wave-current interaction, wind forcing, and whitecapping dissipation are described in the model's technical report (Lin et al. 2008).

CMS-Wave has been implemented in the Surface-water Modeling System, SMS (Zundel 2006). The SMS is a graphically interactive computer program designed to facilitate the operation of numerical models and creates input 
files and output visualization for CMS-Wave. Demirbilek et al. (2007) described the computer graphical interface of CMS-Wave model. The CMSWave interface in the SMS is similar to that of the half-plane model of STWAVE (Smith 2001b). The SMS can generate CMS-Wave grids with variable rectangle cells and half-plane STWAVE grids with constant square cells. Both wave models can use the same grid domain with identical grid orientation and layout, and the same file formats for their bathymetric and spectral energy files. This was done to facilitate the usage of CMS-Wave and allow users to utilize the same settings and files to run both models without modifications. Model input/ output files vary depending on user choices. The most common typical I/ O files are listed in Figure 2-10 and file descriptions are in Table 2-1.

\section{Description of hydrodynamic model}

The two-dimensional, depth-integrated implementation of the ADvanced CIRCulation (ADCIRC-2DDI) model is used in this study. The selection of wave and hydrodynamic models was closely coordinated with the NWS. The choice of models was based on their ability in previous studies to successfully and consistently reproduce recent field measurements. The objective of this study was to identify and examine hydrodynamic flow patterns in Grays Harbor estuary, with the primary focus on the navigation channel. The ADCIRC-2DDI was implemented to calculate water-surface and depthaveraged current in the study area. The study also involved acquiring an extensive set of measured water level and current data in 1999

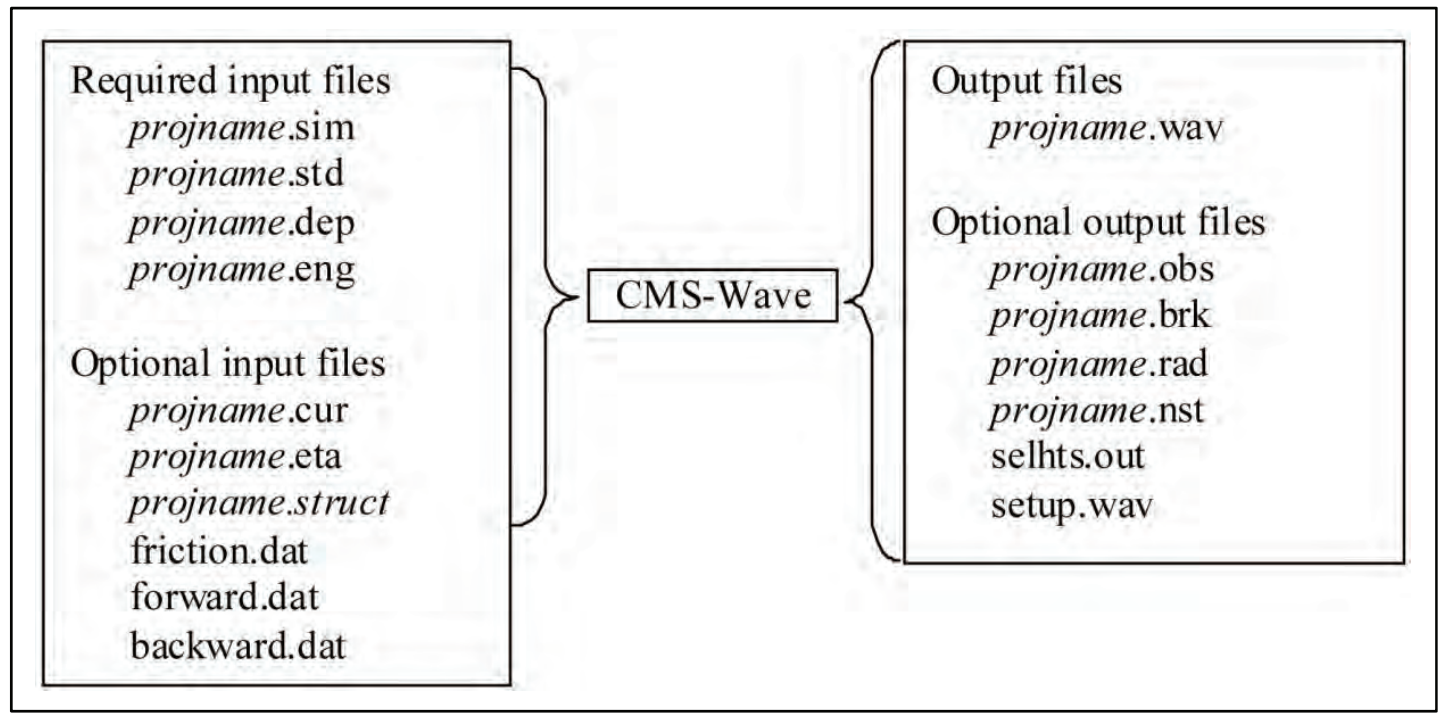

Figure 2-10. Input/Output files used in CMS-Wave simulation. 
Table 2-1. Description of CMS-Wave I/O files.

\begin{tabular}{|l|l|l|}
\hline File Name & Type & Description \\
\hline projname.sim & Input - required & Filenames for input/out of a simulation. \\
\hline projname.std & Input - required & Model parameters and output options. \\
\hline projname.dep & Input - required & Elevation value at each cell. \\
\hline projname.eng & Input - required & $\begin{array}{l}\text { Input energy spectra - this includes one spectra } \\
\text { for each open boundary for each wave case. } \\
\text { Wave spectra may be repeated. }\end{array}$ \\
\hline projname.cur & Input - optional & $\begin{array}{l}\text { Current value at each cell (components in u,v } \\
\text { directions). }\end{array}$ \\
\hline Projname.eta & Input - optional & Water level value at each cell. \\
\hline Projname.struct & Input - optional & $\begin{array}{l}\text { Selected structure or feature cells for special } \\
\text { calculations including wave transmission, } \\
\text { overtopping, and runup. }\end{array}$ \\
\hline projname.wav & Output - always & Wave height, period, and direction for each cell. \\
\hline projname.obs & Output - optional & Transformed energy spectra at selected cells. \\
\hline projname.brk & Output - optional & $\begin{array}{l}\text { Breaking flag or energy dissipated at each cell } \\
\text { due to breaking depending on breaking option. }\end{array}$ \\
\hline projname.rad & Output - optional & $\begin{array}{l}\text { Radiation stress gradients (in u,v directions) at } \\
\text { each cell. }\end{array}$ \\
\hline projname.nst & Output - optional & Transformed wave spectra at selected cells \\
\hline selhts.out & Output - optional & Wave parameters at selected cells. \\
\hline Setup.wav & Output - optional & $\begin{array}{l}\text { Wave setup and maximum water level field } \\
\text { including wave runup. }\end{array}$ \\
\hline
\end{tabular}

and 2003. An analysis of these data was undertaken to examine the water elevation fluctuations and magnitude and directional characteristics of the current. These data were used to evaluate the accuracy of model results.

$\mathrm{ADCIRC}$ is a system of computer programs for solving time dependent, varying free surface, circulation and transport problems in two horizontal dimensions. These programs utilize the finite element method in space and therefore can be run on highly flexible, irregularly spaced grids. Fine resolution can be specified in the area of interest and coarse resolution can be specified in areas distant from the region of interest. Model accuracy is directly related to the ability to resolve bathymetric features such as navigation channels, dredge mounds, structures (jetties and breakwaters), shorelines and topographic features, and ADCIRC's unstructured grid system allows this to be done well. Model simulations included forcing with tidal constituents and wind. 
Additional factors considered in the selection of flow model were: ADCIRC is a fully nonlinear finite element model that is capable of simulating twodimensional shallow water equations. It can be used in a serial or multiprocessor mode on personal computers, UNIX, Silicon Graphics, and CRAY operating systems. The model is used world-wide by industry, government and academic organizations. The uniqueness of ADCIRC is its ability to use depth-dependent mesh in areas where more resolution is needed due to changes in the flow conditions. ADCIRC is the Corps hydrodynamic model for regional scale circulation modeling to simulate hydrodynamics as well as sediment transport that is coupled to bed and hydrodynamic changes. The ability of ADCIRC to allow the domain to wet and dry as the tide changes is suitable for the shallow coastal environment.

A plethora of Corps publications, external reports, and journal papers provide in-depth information about theory, numerical features and performance of ADCIRC in numerous research studies and practical applications. Interested readers are referred to the homepage of the model for model features, peer-reviewed publications, and a list of practical applications. Thus, only a summary of the governing equations is provided here. More details of the two-dimensional shallow water equations and its computational philosophy and equations can be found at http://www.adcirc.org/.

The ADCIRC-2DDI is the two-dimensional, depth-integrated implementation of the ADCIRC coastal ocean model (Luettich et al. 1992, Westerink et al. 1992, Westerink et al. 1993, Luettich and Fulcher 2004, Luettich and Westerink 2004). It is used in this study to perform the hydrodynamic computations. Utilizing the wind and atmospheric pressure fields, the ADCIRC model can replicate tide induced and storm-surge water levels and currents. In two dimensions, the model is formulated with the depthaveraged shallow water equations for conservation of mass and momentum. Furthermore, the formulation assumes that the water is incompressible, hydrostatic pressure conditions exist, and that the Boussinesq approximation is valid. Using the standard quadratic parameterization for bottom stress and neglecting baroclinic terms and lateral diffusion / dispersion effects, the following set of conservation equations in primitive, nonconservative form, and expressed in a spherical coordinate system, are incorporated in the model (Flather 1988; Kolar et al. 1993): 


$$
\begin{gathered}
\frac{\partial \mathrm{U}}{\partial \mathrm{t}}+\frac{1}{\mathrm{r} \cos \varphi} \mathrm{U} \frac{\partial \mathrm{U}}{\partial \lambda}+\frac{1}{\mathrm{R}} \mathrm{V} \frac{\partial \mathrm{U}}{\partial \varphi}-\left[\frac{\tan \varphi}{\mathrm{R}} \mathrm{U}+\mathrm{f}\right] \mathrm{V}= \\
-\frac{1}{\mathrm{R} \cos \varphi} \frac{\partial}{\partial \lambda}\left[\frac{\mathrm{p}_{\mathrm{s}}}{\rho_{0}}+\mathrm{g}(\zeta-\eta)\right]+\frac{\tau_{\mathrm{s} \lambda}}{\rho_{0} \mathrm{H}}-\tau * \mathrm{U} \\
\frac{\partial \mathrm{V}}{\partial \mathrm{t}}+\frac{1}{\mathrm{r} \cos \varphi} \mathrm{U} \frac{\partial \mathrm{V}}{\partial \lambda}+\frac{1}{\mathrm{R}} \mathrm{V} \frac{\partial \mathrm{V}}{\partial \varphi}-\left[\frac{\tan \varphi}{\mathrm{R}} \mathrm{U}+\mathrm{f}\right] \mathrm{U}= \\
-\frac{1}{\mathrm{R}} \frac{\partial}{\partial \varphi}\left[\frac{\mathrm{p}_{\mathrm{s}}}{\rho_{0}}+\mathrm{g}(\zeta-\eta)\right]+\frac{\tau_{\mathrm{s} \lambda}}{\rho_{0} \mathrm{H}}-\tau * \mathrm{~V} \\
\frac{\partial \zeta}{\partial \mathrm{t}}+\frac{1}{\mathrm{R} \cos \varphi}\left[\frac{\partial \mathrm{UH}}{\partial \lambda}+\frac{\partial(\mathrm{UV} \cos \varphi}{\partial \varphi}\right]=0
\end{gathered}
$$

where

$$
\mathrm{t}=\text { time, }
$$

$\lambda$ and $\varphi=$ degrees longitude (east of Greenwich is taken positive) and degrees latitude (north of the equator is taken positive),

$\zeta=$ free surface elevation relative to the geoid,

$\mathrm{U}$ and $\mathrm{V}=$ depth-averaged horizontal velocities in the longitudinal and latitudinal directions, respectively,

$\mathrm{R}=$ the radius of the earth,

$\mathrm{H}=\zeta+\mathrm{h}=$ total water column depth,

$\mathrm{h}=$ bathymetric depth relative to the geoid,

$\mathrm{f}=2 \Omega \sin \varphi=$ Coriolis parameter,

$\Omega=$ angular speed of the earth,

$\mathrm{p}_{\mathrm{s}}=$ atmospheric pressure at free surface,

$\mathrm{g}=$ acceleration due to gravity,

$\eta=$ effective Newtonian equilibrium tide-generating potential parameter,

$\rho_{0}=$ reference density of water,

$\tau_{\mathrm{s} \lambda}$ and $\tau_{\mathrm{S \varphi}}=$ applied free surface stresses in the longitudinal and latitudinal directions, respectively, and

$\tau=$ bottom shear stress and is given by the expression $\mathrm{C}_{\mathrm{f}}\left(\mathrm{U}^{2}+\right.$ $\left.\mathrm{V}^{2}\right)^{1 / 2} / \mathrm{H}$ where $\mathrm{C}_{\mathrm{f}}$ is the bottom friction coefficient. 
The momentum equations (Equations 2-3 and 2-4) are differentiated with respect to $\lambda$ and $\tau$ and substituted into the time differentiated continuity equation (Equation 2-5) to develop the following Generalized Wave Continuity Equation (GWCE):

$$
\begin{gathered}
\frac{\partial^{2} \zeta}{\partial \mathrm{t}^{2}}+\tau_{0} \frac{\partial \zeta}{\partial \mathrm{t}}-\frac{1}{\mathrm{R} \cos \varphi} \frac{\partial}{\partial \lambda}\left[\frac{1}{\mathrm{R} \cos \varphi}\left(\frac{\partial \mathrm{HU} U}{\partial \lambda}+\frac{\partial(\mathrm{HUV} \cos \varphi}{\partial \varphi}\right)-\mathrm{UVH} \frac{\tan \varphi}{\mathrm{R}}\right] \\
{\left[-2 \omega \sin \varphi \mathrm{HV}+\frac{\mathrm{H}}{\mathrm{R} \cos \varphi} \frac{\partial}{\partial \lambda}\left(\mathrm{g}(\zeta-\alpha \eta)+\frac{\mathrm{p}_{\mathrm{s}}}{[} \mathrm{p}_{0}\right)+\tau_{*} \mathrm{HU}-\tau_{0} \mathrm{HU}-\tau_{\mathrm{s} \lambda}\right]} \\
-\frac{1}{\mathrm{R}} \frac{\partial}{\partial \varphi}\left[\frac{1}{\mathrm{R} \cos \varphi}\left(\frac{\partial \mathrm{HVV}}{\partial \lambda}+\frac{\partial \mathrm{HVV} \cos \varphi}{\partial \varphi}\right)+\mathrm{UUH} \frac{\tan \varphi}{\mathrm{R}}+2 \omega \sin \varphi \mathrm{HU}\right] \\
\left.+\frac{\mathrm{H}}{\mathrm{R}} \frac{\partial}{\partial \varphi}\left(\mathrm{g}(\zeta-\operatorname{alfa} \eta)+\frac{\mathrm{p}_{\mathrm{s}}}{\rho_{0}}\right)+\tau_{*}-\tau_{0} \mathrm{HV}-\frac{\tau_{\mathrm{s \lambda}}}{\rho_{0}}\right] \\
-\frac{\partial}{\partial \mathrm{t}}\left[\frac{\mathrm{VH}}{\mathrm{R}} \tan \varphi\right]-\tau_{0}\left[\frac{\mathrm{VH}}{\mathrm{R}} \tan \varphi\right]=0
\end{gathered}
$$

The ADCIRC model solves the GWCE in conjunction with the primitive momentum equations given in Equations 2-3 and 2-4. The GWCE-based solution scheme eliminates several problems associated with finite-element programs that solve the primitive forms of the continuity and momentum equations, including spurious modes of oscillation and artificial damping of the tidal signal. Forcing functions include time-varying water-surface elevations, wind shear stresses, and atmospheric pressure gradients.

The ADCIRC model uses a finite-element algorithm in solving the defined governing equations over complicated bathymetry encompassed by irregular sea/ shore boundaries. This algorithm allows for extremely flexible spatial discretizations over the entire computational domain and has demonstrated excellent stability characteristics. The advantage of this flexibility in developing a computational grid is that larger elements can be used in open-ocean regions where less resolution is needed, whereas smaller elements can be applied in the nearshore and estuary areas where finer resolution is required to resolve hydrodynamic details. 
Hydrodynamic forcing of the study area included forcing with a time series of water level forcing constructed from astronomical tidal constituents at the open ocean boundary. The model was run with the Le Provost tidal constituent database (Le Provost et al. 1994). This tidal constituent database was selected to force the model because it produced better agreement between the model water surface values and the measured values.

Meteorological forcing of surface wind and atmospheric pressure defined on a longitude, latitude grid, was interpolated in space onto the ADCIRC grid. Wind data at 10-m elevation and water surface pressure were read every 6 hours from NCEP/NCAR Reanalysis data sets by the Earth System Research Laboratory, NOAA (http://www.esrl.noaa.gov/psd/data/gridded/data.ncep.reanalysis.html). 


\section{Verification of Hydrodynamic and Wave Models}

Two major field data sets were collected at GH in 1999 and 2003-2004 by USACE to investigate coastal and inlet physical processes at the entrance and along the entrance channel. Both data sets include water levels, waves, currents, and suspended sediment concentration measurements from multiple stations. The 1999 data collection covers a large area encompassing the outer channel, the entrance, and inside GH from mid September to mid December. The 2003-2004 data were collected around Half Moon Bay from 9 December 2003 to 19 February 2004. These field data provided a groundtruth for numerical modeling used in the present study to investigate navigation channel design and maintenance issues for the Grays Harbor Federal navigation project. At the same time, offshore wind and wave data were available from NDBC Buoy 46029 and CDIP Buoy 036 / NDBC 46211, respectively. Local surface wind data was available from the nearby Hoquiam Airport. Two NOAA tide stations, Westport (9441102) and Aberdeen (9441187), are located at GH. However, they were not operational in 1993 and 2003-2004.

\section{Field measurements in 1999}

The 1999 data collection program measured water levels, waves, currents, and suspended sediment concentration around the entrance and inside GH from mid September to mid November 1999, spanning two lunar months. Waves, currents, and suspended sediment concentration from eight stations, Sta 0 to 7, (Figure 3-1) captured tidal current patterns and wave transformation from outside the entrance to the upper reaches of $\mathrm{GH}$, with minimum interference to navigation channel usage. Instruments for waves, currents, and suspended sediment concentration measurements were installed in two deployment periods: Sta 0 to 6 were installed in the $1^{\text {st }}$ deployment (11 September to 11 October), and Sta 1 to 7 were installed in the $2^{\text {nd }}$ deployment (12 October to 17 November). Water levels were also collected at these same stations. However, because of the pressure sensor malfunction on several stations, water level data are only available from three stations, Sta 1, 4, and 5. Additional water level data are available from five coastal tide stations, Tide 1 to 5 , along the shoreline inside $\mathrm{GH}$ and in the Chehalis River (Figure 3-2). 


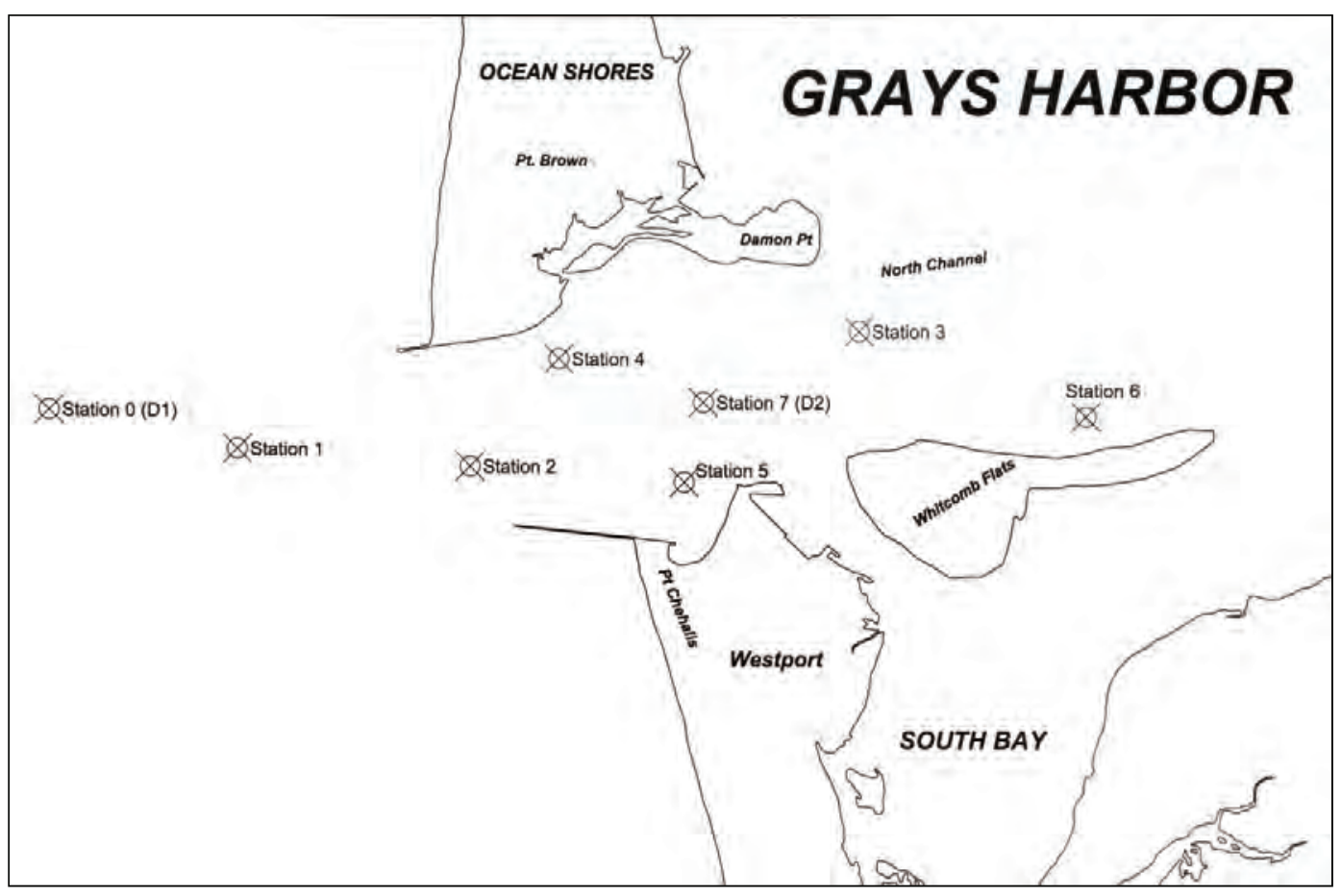

Figure 3-1. Location of wave and current stations in 1999 field measurements.

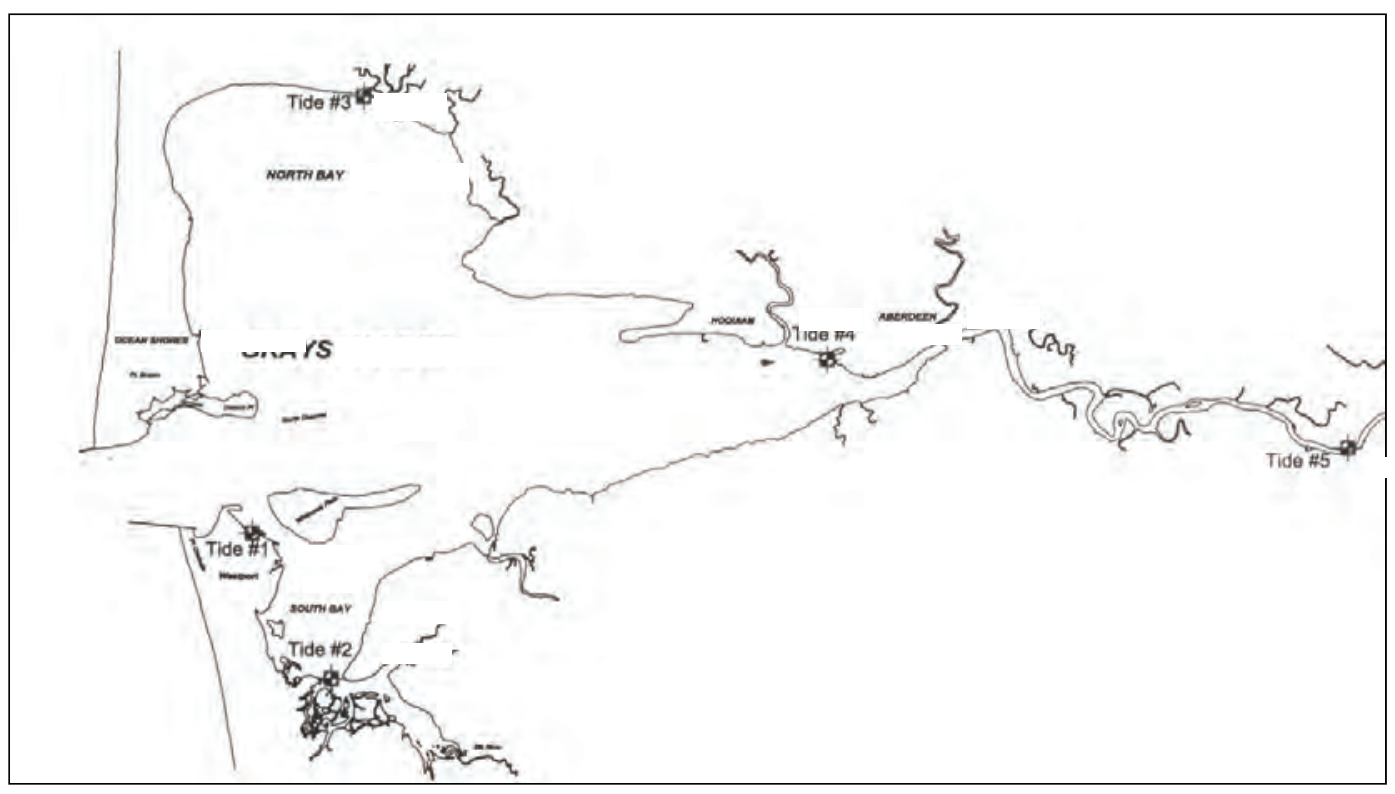

Figure 3-2. Location of tide stations in 1999 field measurements.

Water level data were adjusted to the tidal datum using the published geodetic and tidal elevations for a benchmark in Westport. Table 3-1 presents the approximate horizontal location and the measured elevations of the tide stations Tide 1 to 5. Table 3-2 presents the wave and current station coordinates, and deployment and recovery times. 
Table 3-1. Water Level Station Locations and Elevation for 1999 field measurements.

\begin{tabular}{|l|l|l|l|l|l|}
\hline \multirow{2}{*}{ Tide Station } & \multirow{2}{*}{} & \multicolumn{2}{|c|}{ Sensor Elevation* } & \multicolumn{2}{c|}{ Location NAD83 } \\
\cline { 3 - 6 } & Monument Surveyed to & $\begin{array}{l}\text { NAVD88 } \\
\text { (meters) }\end{array}$ & $\begin{array}{l}\text { MLLW } \\
\text { (meters) }\end{array}$ & Latitude & Longitude \\
\hline Tide 1 (USCG1) & "Tidal 2 1952" & -2.20 & -1.74 & 46.9047 & 124.1051 \\
\hline Tide 2 (Bay Bridge) & "Gunville2" & -2.29 & -1.83 & 46.8622 & 124.0695 \\
\hline Tide 3 (North Bay) & GH County digital Mon & -0.99 & -0.53 & 47.0415 & 124.0655 \\
\hline Tide 4 (Aberdeen) & "Tidal 5 1934" & -2.05 & -1.59 & 46.9659 & 123.8584 \\
\hline Tide 5 (Montesano) & $\begin{array}{l}\text { NW Corner Sect. 14 T17N R8W. } \\
\text { W.M. }\end{array}$ & -0.75 & -0.29 & 46.9453 & 123.6321 \\
\hline Tidal 2 1952 & & 4.65 & 5.11 & & \\
\hline
\end{tabular}

* Monument for NAVD88 to MLLW Conversion (Tidal 2 1952) Westport

Benchmark Disk "Tidal 2 1952" is reference for NOS Tidal Benchmark "9441102" and NGS Geodetic Benchmark PID "SD0042"

Table 3-2. Coordinates and deployment periods of wave/current stations for 1999.

\begin{tabular}{|c|c|c|c|c|c|c|}
\hline & \multirow[b]{2}{*}{ Sta } & \multicolumn{3}{|c|}{ WA State Plane S. Zone NAD83 } & \multirow{2}{*}{$\begin{array}{c}\text { Deployed } \\
\text { Date-Time (UTC) }\end{array}$} & \multirow{2}{*}{$\begin{array}{r}\text { Recovered } \\
\text { Date-Time (UTC) }\end{array}$} \\
\hline & & Easting & Northing & $\begin{array}{l}\text { Depth } \\
\text { (m, MLLW) }\end{array}$ & & \\
\hline \multirow{7}{*}{ 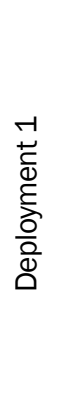 } & 0 & 705282.6 & 599924.4 & 16.8 & 1999/09/13 16:47 & 1999/10/11 16:50 \\
\hline & 1 & 713901.7 & 598213.5 & 13.7 & 1999/09/13 17:06 & 1999/10/11 17:00 \\
\hline & 2 & 724449.4 & 597435.9 & 12.7 & 1999/09/12 16:23 & 1999/10/11 17:35 \\
\hline & 3 & 741749.6 & 603377.0 & 13.4 & 1999/09/12 17:22 & 1999/10/12 18:08 \\
\hline & 4 & 728309.1 & 602282.8 & 9.8 & 1999/09/12 16:55 & 1999/10/13 18:02 \\
\hline & 5 & 733915.8 & 596621.2 & 8.6 & 1999/09/11 22:00 & 1999/10/13 18:16 \\
\hline & 6 & 752027.3 & 599613.2 & 8.6 & 1999/09/11 21:26 & $1999 / 10 / 1218: 24$ \\
\hline \multirow{7}{*}{$\begin{array}{l}\text { N } \\
\stackrel{2}{0} \\
\frac{0}{2} \\
\frac{0}{0} \\
\frac{0}{0}\end{array}$} & 1 & 713951.7 & 598203.9 & 13.0 & 1999/10/12 17:34 & 1999/11/17 22:20 \\
\hline & 2 & 724469.4 & 597434.3 & 12.3 & 1999/10/12 17:09 & 1999/11/17 22:00 \\
\hline & 3 & 741784.5 & 603393.6 & 11.5 & 1999/10/13 17:40 & 1999/11/17 16:33 \\
\hline & 4 & 728368.1 & 602232.0 & 10.3 & 1999/10/14 17:55 & 1999/11/17 16:11 \\
\hline & 5 & 733917.9 & 596576.0 & 7.0 & 1999/10/14 17:40 & 1999/11/17 15:53 \\
\hline & 6 & 752054.2 & 599609.0 & 8.3 & 1999/10/13 17:18 & 1999/11/17 16:53 \\
\hline & 7 & 734895.2 & 600291.5 & 15.3 & 1999/10/14 21:59 & 1999/11/17 22:55 \\
\hline
\end{tabular}

\section{Field measurements in 2003-04}

Waves, currents and suspended sediment concentrations were measured in and around Half Moon Bay during two months of the winter storm season from 9 December 2003 thru 19 February 2004. The stations were identified as HMB1 through HMB4. Table 3-3 indicates deployment and retrieval dates along with time, location and elevations. 
Table 3-3. Tripod Deployment Locations.

\begin{tabular}{|c|c|c|c|c|c|}
\hline \multirow[b]{2}{*}{ Station } & \multirow{2}{*}{$\begin{array}{l}\text { Deployment } \\
\text { Date }\end{array}$} & \multicolumn{2}{|c|}{ Position } & \multirow{2}{*}{$\begin{array}{l}\text { Elevation } \\
\text { (ft, MLLW) }\end{array}$} & \multirow[b]{2}{*}{ Retrieval Date } \\
\hline & & Easting* & Northing* & & \\
\hline HMB1 & $\begin{array}{l}12 / 9 / 03 \\
1 / 11 / 04\end{array}$ & \begin{tabular}{|l|l|} 
& 732658 \\
E 732680 \\
\end{tabular} & $\begin{array}{l}\text { N } 595744 \\
\text { N } 595695 \\
\end{array}$ & $\begin{array}{l}-21 \\
-21 \\
\end{array}$ & $\begin{array}{l}1 / 10 / 04 \\
2 / 19 / 04 \\
\end{array}$ \\
\hline HMB2 & $\begin{array}{l}12 / 9 / 03 \\
1 / 11 / 04\end{array}$ & $\begin{array}{l}\text { E } 735469 \\
\text { E } 735412\end{array}$ & \begin{tabular}{|l|} 
N 595018 \\
N 594913
\end{tabular} & $\begin{array}{l}-10 \\
-10\end{array}$ & \begin{tabular}{|l|}
$1 / 10 / 04$ \\
$2 / 19 / 04$
\end{tabular} \\
\hline HMB3 & $\begin{array}{l}12 / 9 / 03 \\
1 / 11 / 04\end{array}$ & $\begin{array}{l}\text { E } 734697 \\
\text { E } 734574\end{array}$ & \begin{tabular}{|l|} 
N 593563 \\
N 593744
\end{tabular} & $\begin{array}{l}+1 \\
-5\end{array}$ & \begin{tabular}{|l|}
$1 / 10 / 04$ \\
$2 / 19 / 04$
\end{tabular} \\
\hline HMB4 & $\begin{array}{l}12 / 9 / 03 \\
1 / 11 / 04\end{array}$ & $\begin{array}{l}\text { E } 733680 \\
\text { E } 733808\end{array}$ & $\begin{array}{l}\text { N } 593665 \\
\text { N } 593675\end{array}$ & $\begin{array}{l}-4 \\
-4\end{array}$ & \begin{tabular}{|l|}
$1 / 10 / 04$ \\
$2 / 19 / 04$
\end{tabular} \\
\hline
\end{tabular}

Station HMB1 was inside the entrance of Grays Harbor between the south jetty and the Point Chehalis Reach of the shipping channel at an elevation of approximately -6.4 m (-21 ft) mllw. Station HMB2 was near the USCG Point Chehalis Front Range Tower at an elevation of approximately -3 m (-10 ft) mllw. Station HM3 was near the beach at a bed elevation of approximately $1.6 \mathrm{~m}$ (-5 ft) mllw in the southeast portion of Half Moon Bay. Station HMB4 was in the southwest portion of Half Moon Bay, at an elevation of approximately - $1.3 \mathrm{~m}$ (-4 ft) mllw. The HMB4 location was chosen to situate the platform in the lee of the diffraction mound south of the eastern terminus of the south jetty. Figure 3-3 illustrates the location of each station.

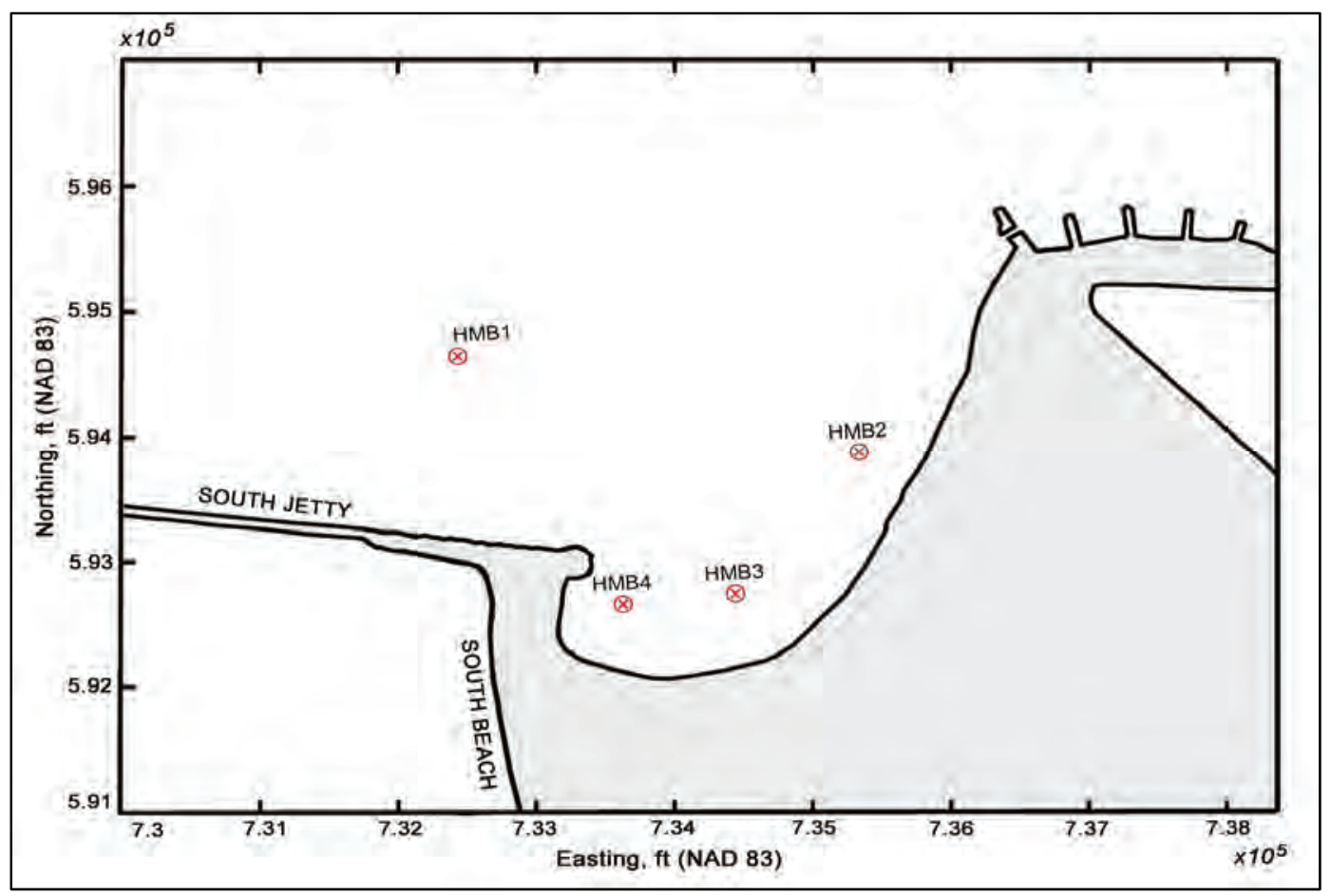

Figure 3-3. Location of instrument deployment in Half Moon Bay. 


\section{Model validation with 1999 data}

Model validation with the 1999 data was made for a 30-day period of 14 October to 12 November in the $2^{\text {nd }}$ instrument deployment that had greater offshore waves than in the $1^{\text {st }}$ deployment period. Figure $3-4$ shows the wind and wave time series data collected at Buoys 46029 and 46211 in October and November 1999. The ADCIRC run is forced by tides (Le provost tidal constituents) and surface wind field. Figure 3-5 shows the ADCIRC domain. River flow influxes are not considered since the emphasis in this study is on the sediment issues at the outer navigation channel caused by tides and waves.

Figure 3-6 shows the CMS-Wave domains. The CMS-Wave simulation is forced by the regional ADCIRC water levels and currents, surface wind field, and offshore waves based on the CDIP Buoy 036 (NDBC 46211).

Figures 3-7 and 3-8 show calculated storm current fields for flood and ebb conditions, respectively, at 28 October 1999. Figure 3-9 shows ADCIRC water levels and data at Stations at NOAA Tide Stations Toke Point, WA (9440910), Astoria, OR (9439040), and Southbeach, OR (9435380). Figure 3-10 shows ADCIRC water levels and data at GH Stations Sta 1, 4, and 5. Figure 3-11 shows ADCIRC water levels and data at GH Tide 1 to 4. The model simulation reproduced the pattern of the measured water surface elevation in the entrance area very well. The match is not perfect and there are some differences between the model and data. These differences are most likely related differences in model forcing (input winds and tides) as compared to actual conditions that occurred during these measurements. Overall, the model-data comparison at seven field Stations in 1999 is very good, with the model accurately representing the water surface elevation and capturing the tide range.

Figures 3-12 and 3-13 show ADCIRC currents and data at Sta 1-3 and 4-6, respectively. The model-data agreement for velocities is reasonable, but is not as good as that for water surface elevation. The difference between the calculated and measured currents is particularly large at Sta 1, where the largest difference in maximum calculated and measured velocities is about 20 percent. Flow velocities are also sensitive to differences in the inputs of model and actual field conditions at the time of measurements. 

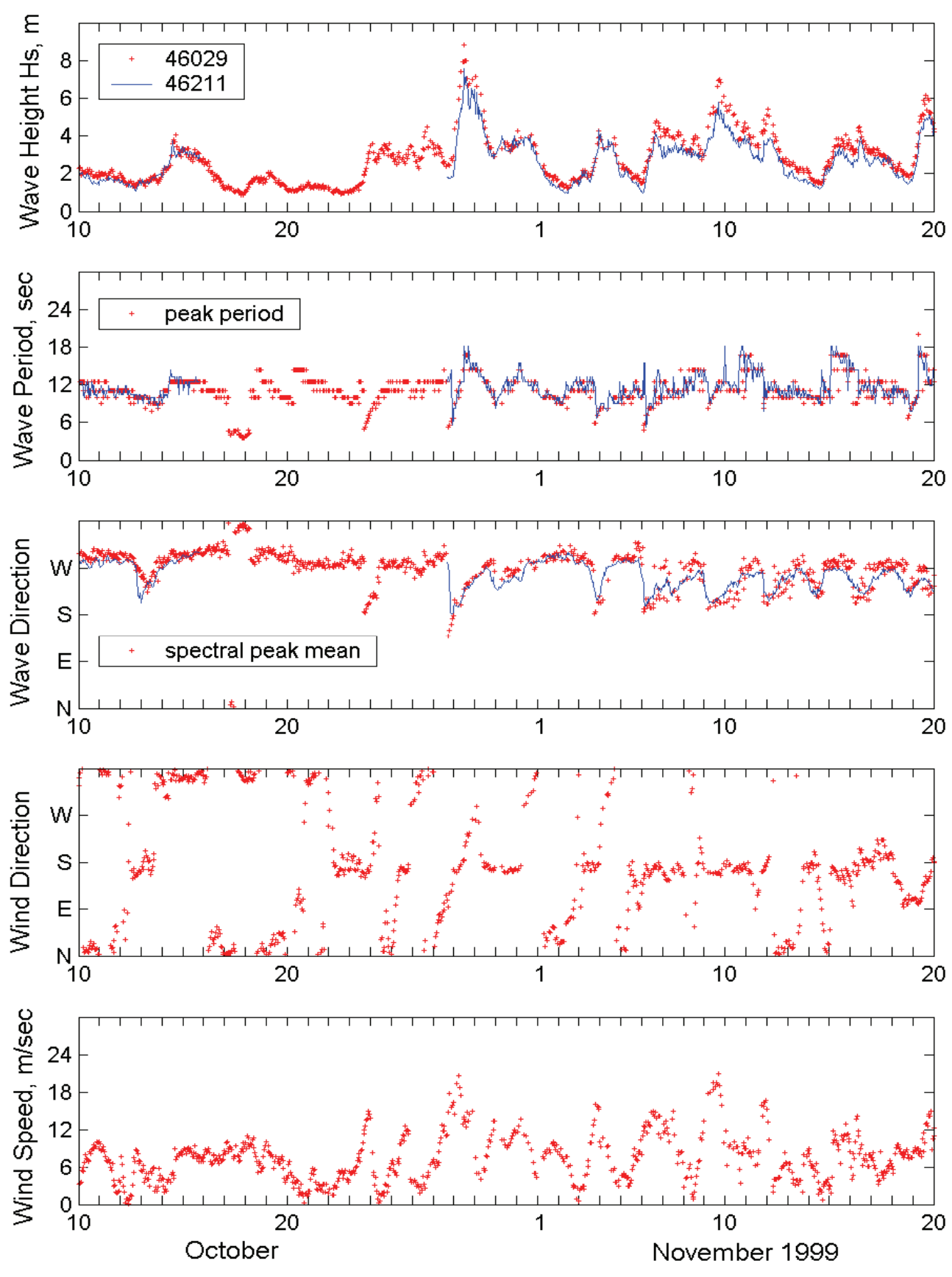

Figure 3-4. Buoy 46029 and 46211 wind and wave data for October and November 1999. 


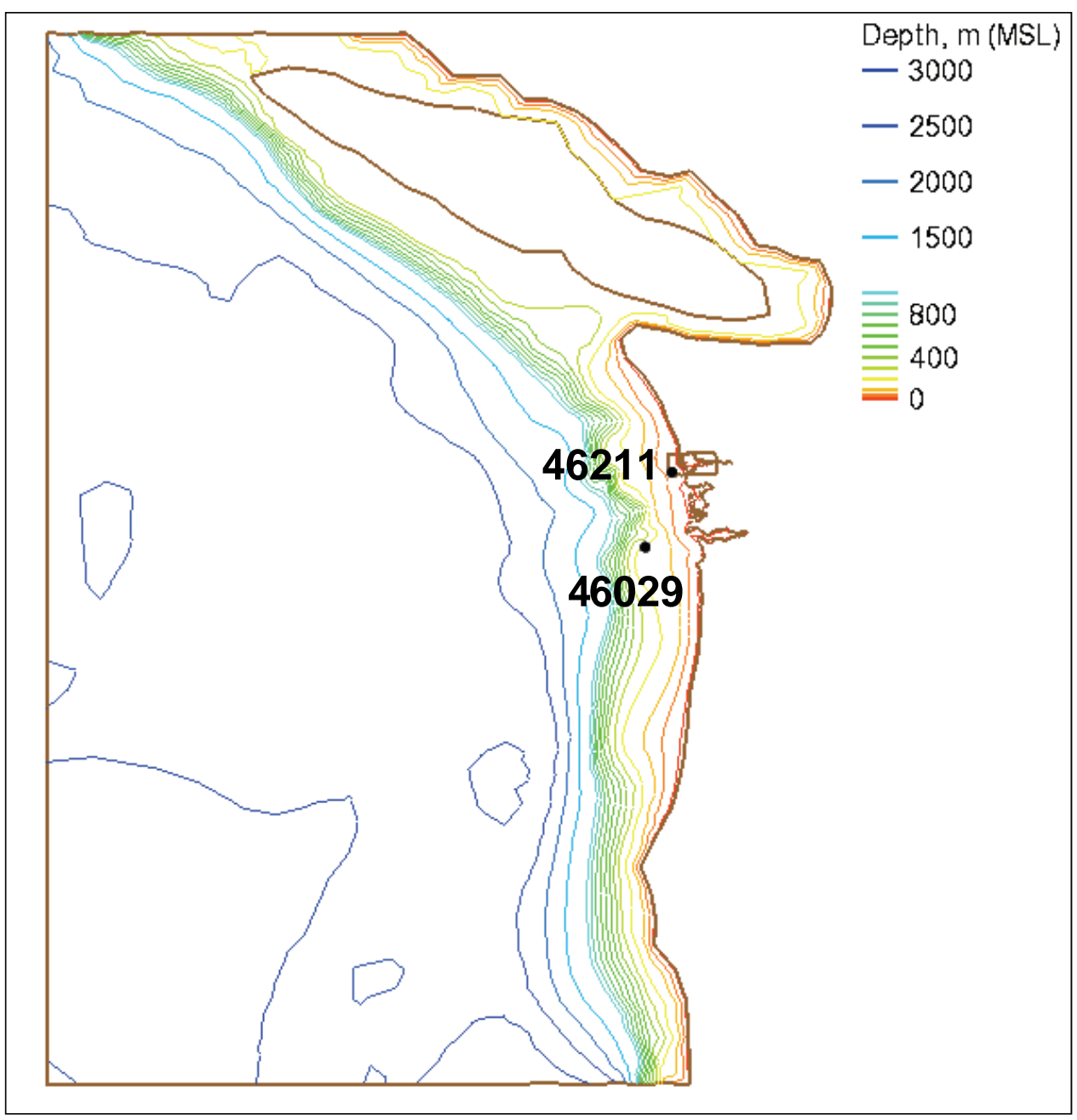

Figure 3-5. ADCIRC domain and GH offshore buoys.

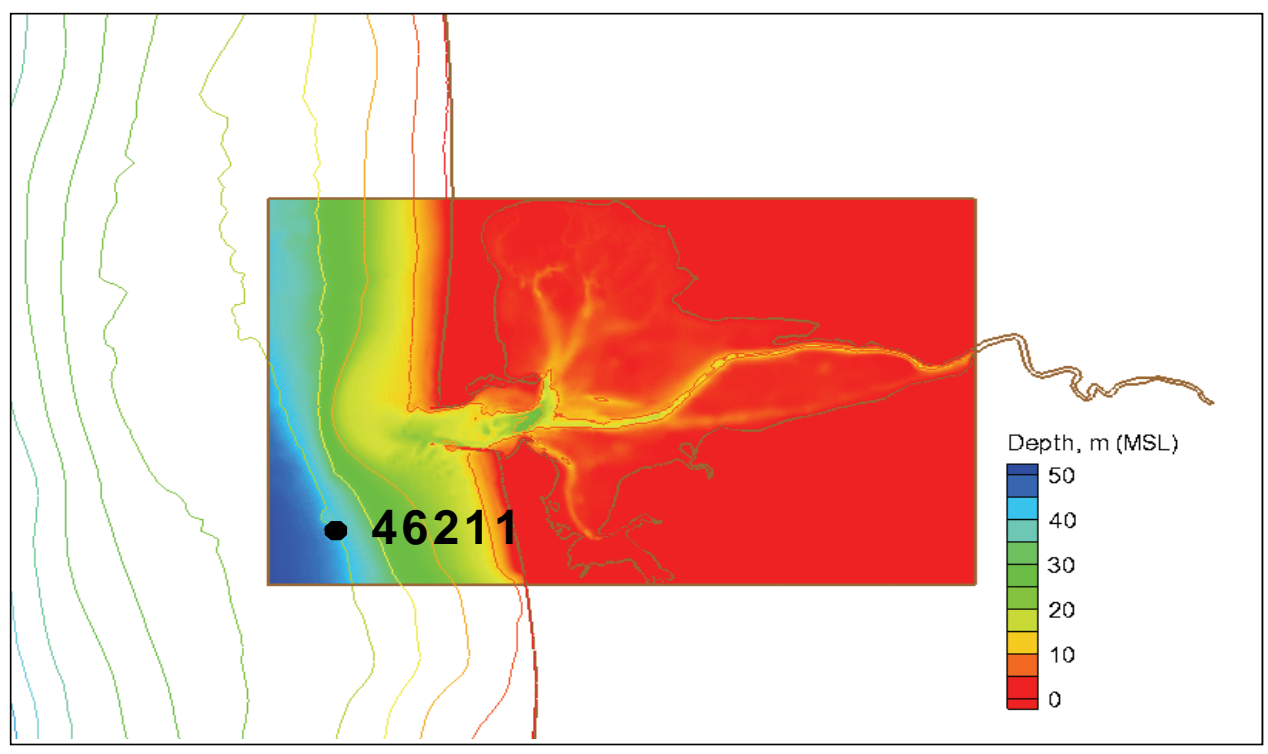

Figure 3-6. CMS-Wave domain and NDBC 46211. 


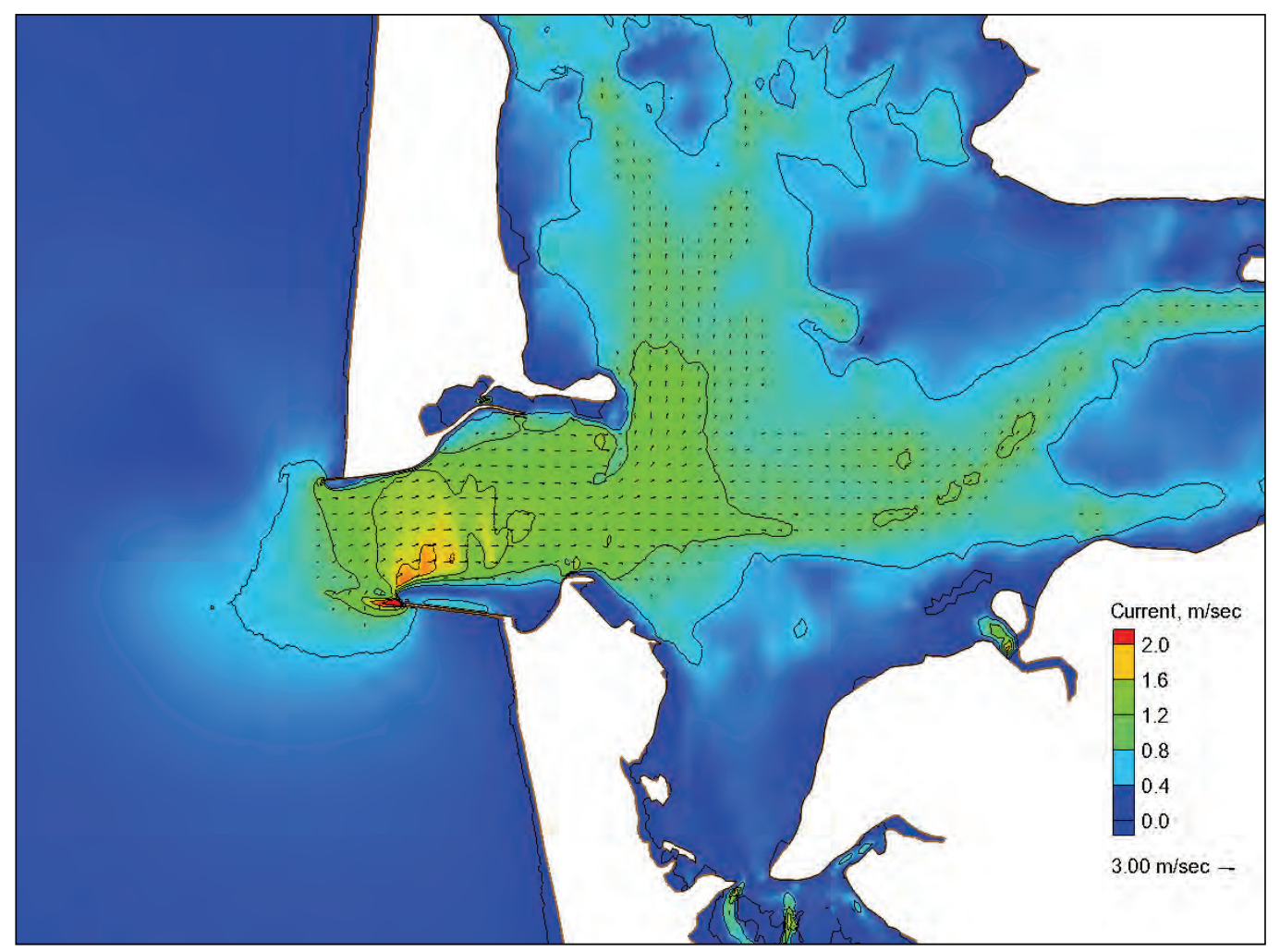

Figure 3-7. ADCIRC Calculated maximum flood current field for the 28 October 1999 storm event.

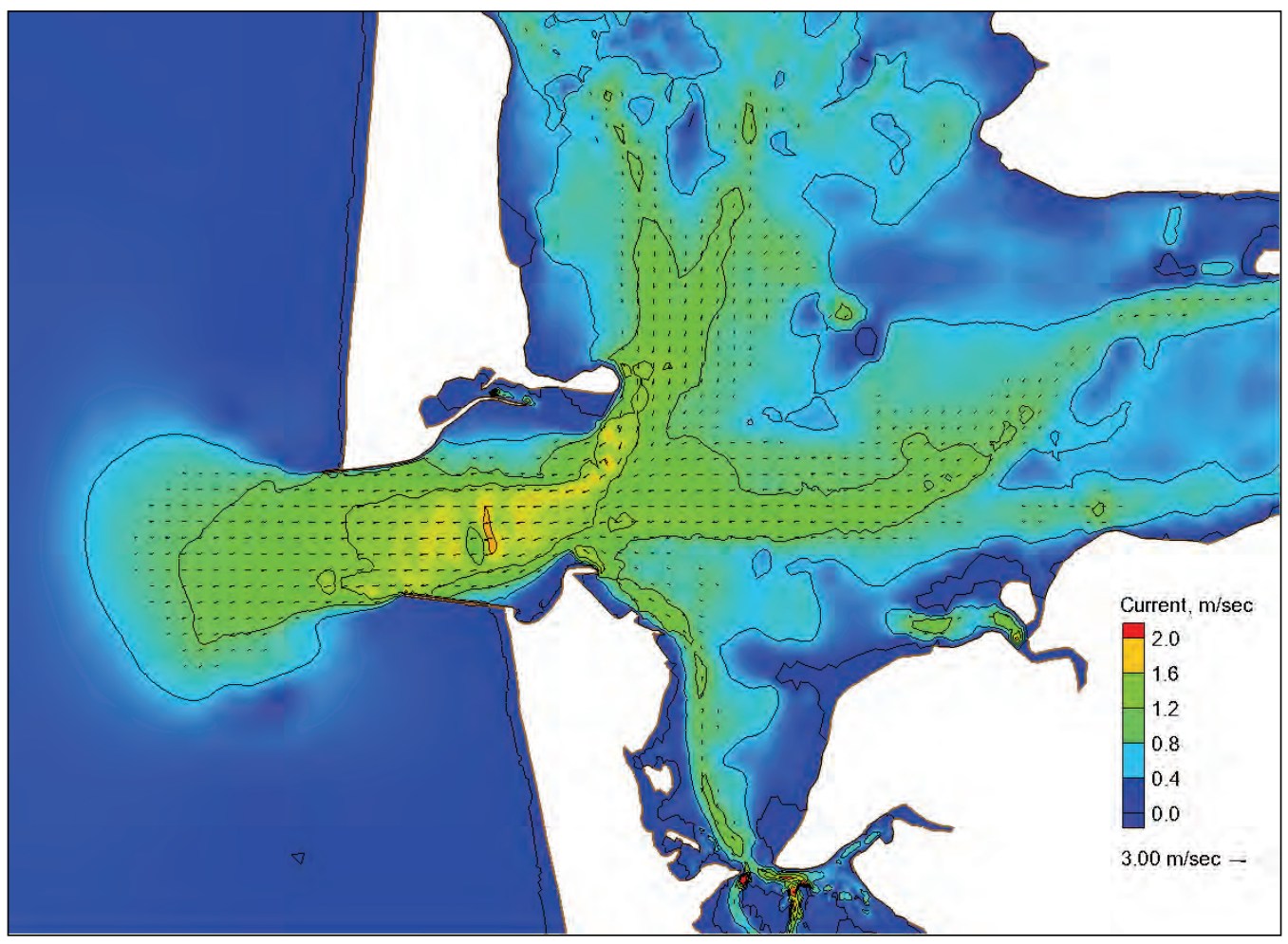

Figure 3-8. ADCIRC Calculated maximum ebb current field for the 28 October 1999 storm event. 


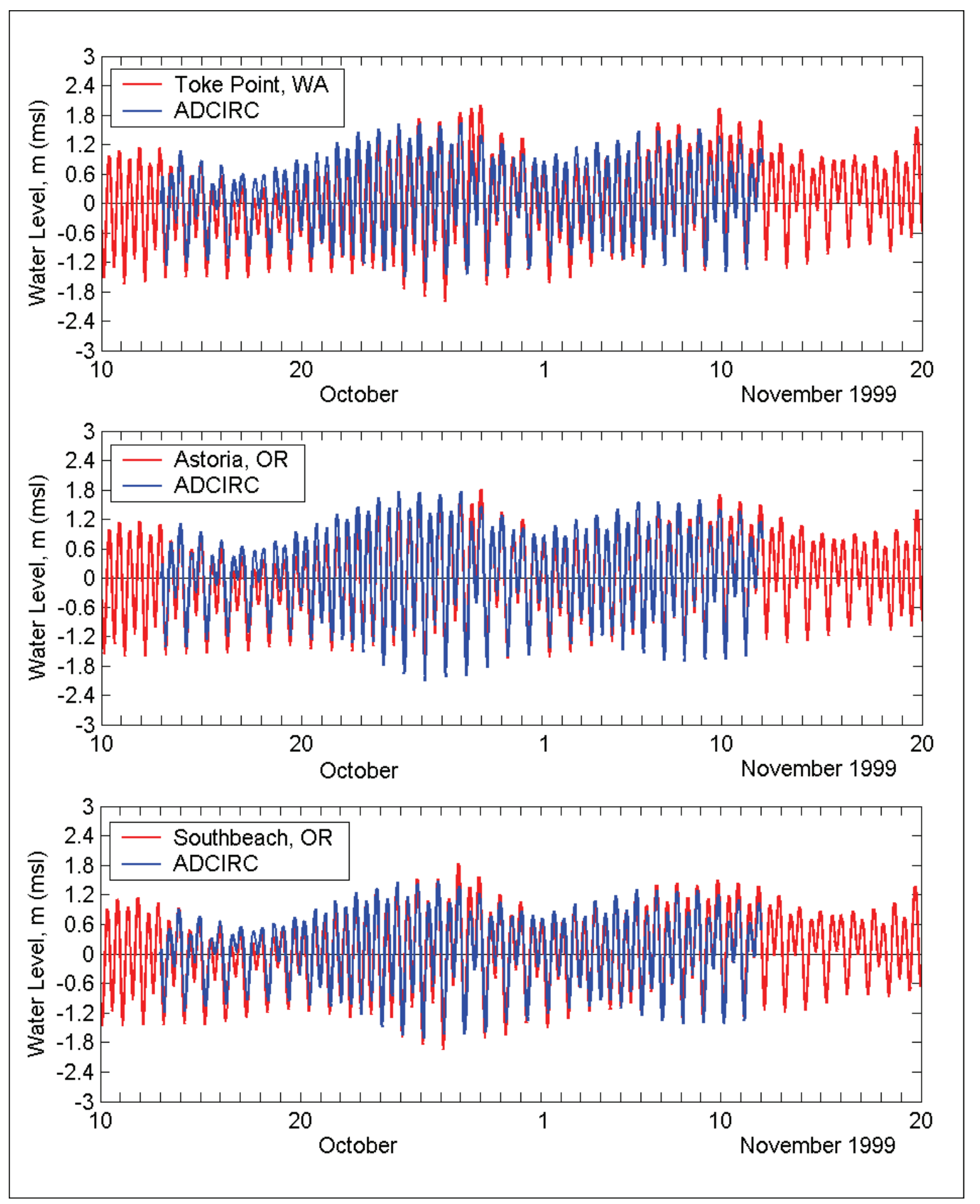

Figure 3-9. Measured and calculated water levels for October and November 1999 at Toke Point/WA, and Astoria and Southbeach/OR. 

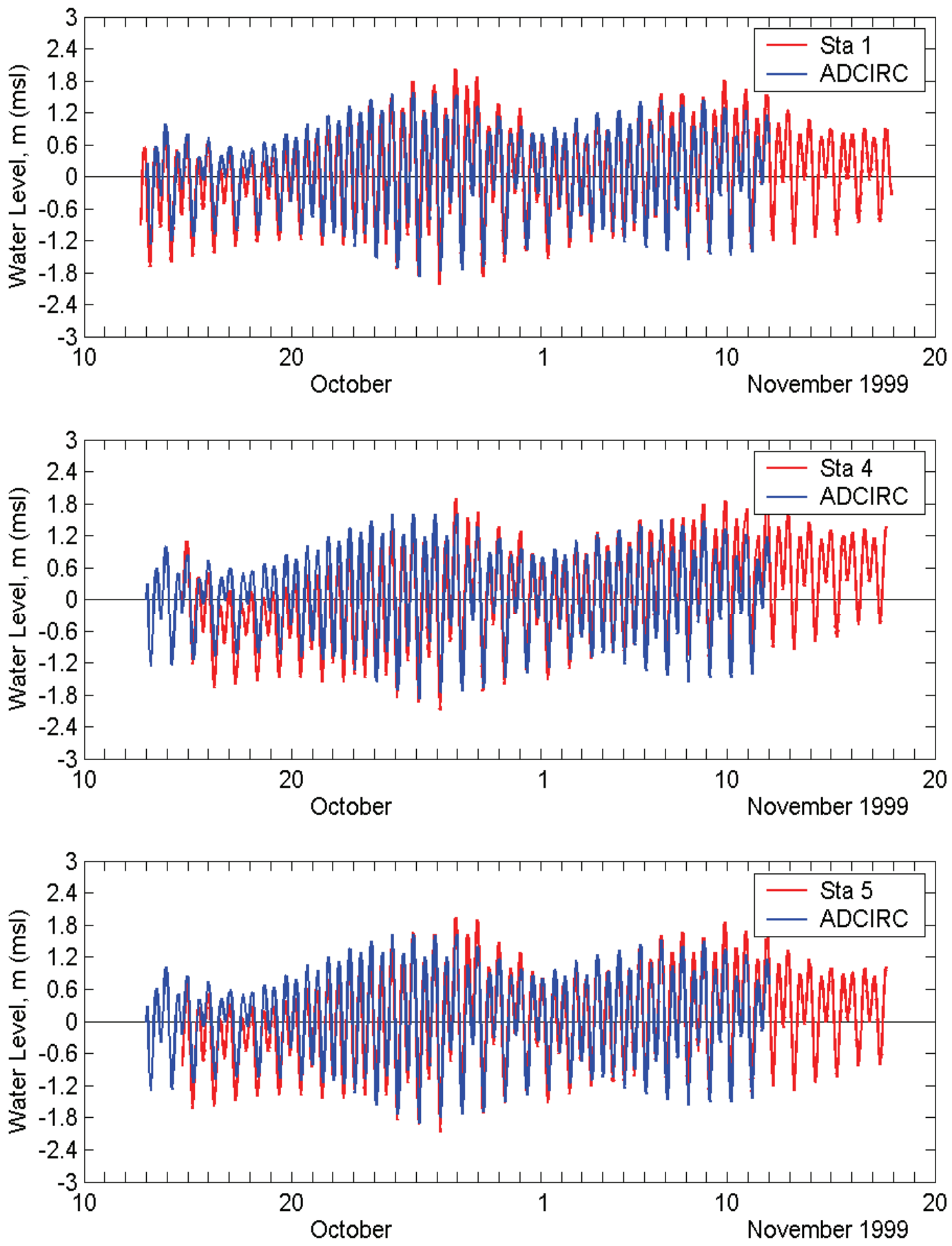

Figure 3-10. Measured and calculated water levels at GH Sta 1, 4 and 5. 

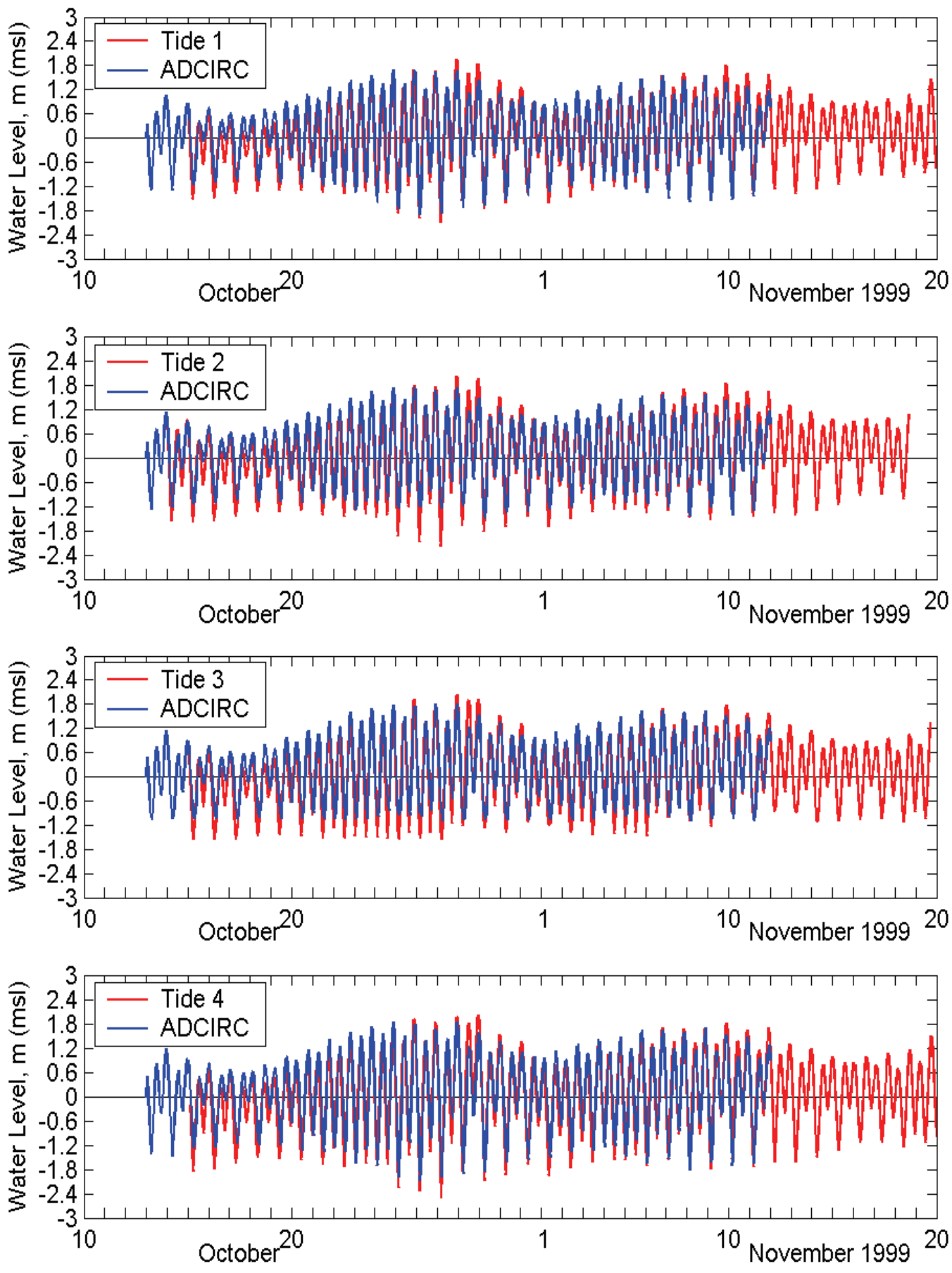

Figure 3-11. Measured and calculated water levels at GH Tide gauges 1, 2, 3 and 4. 

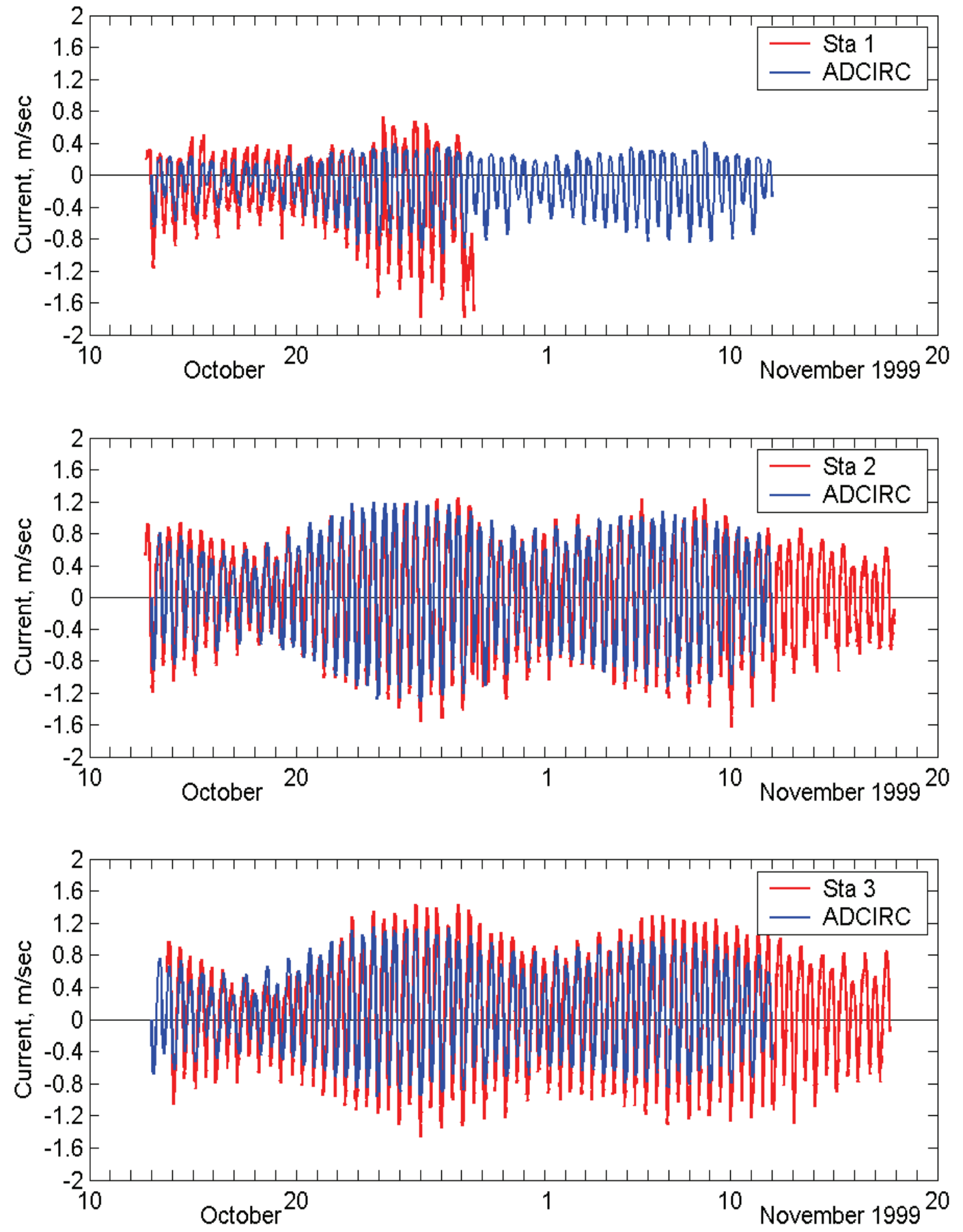

Figure 3-12. Measured and calculated currents at GH Sta 1, 2 and 3. 

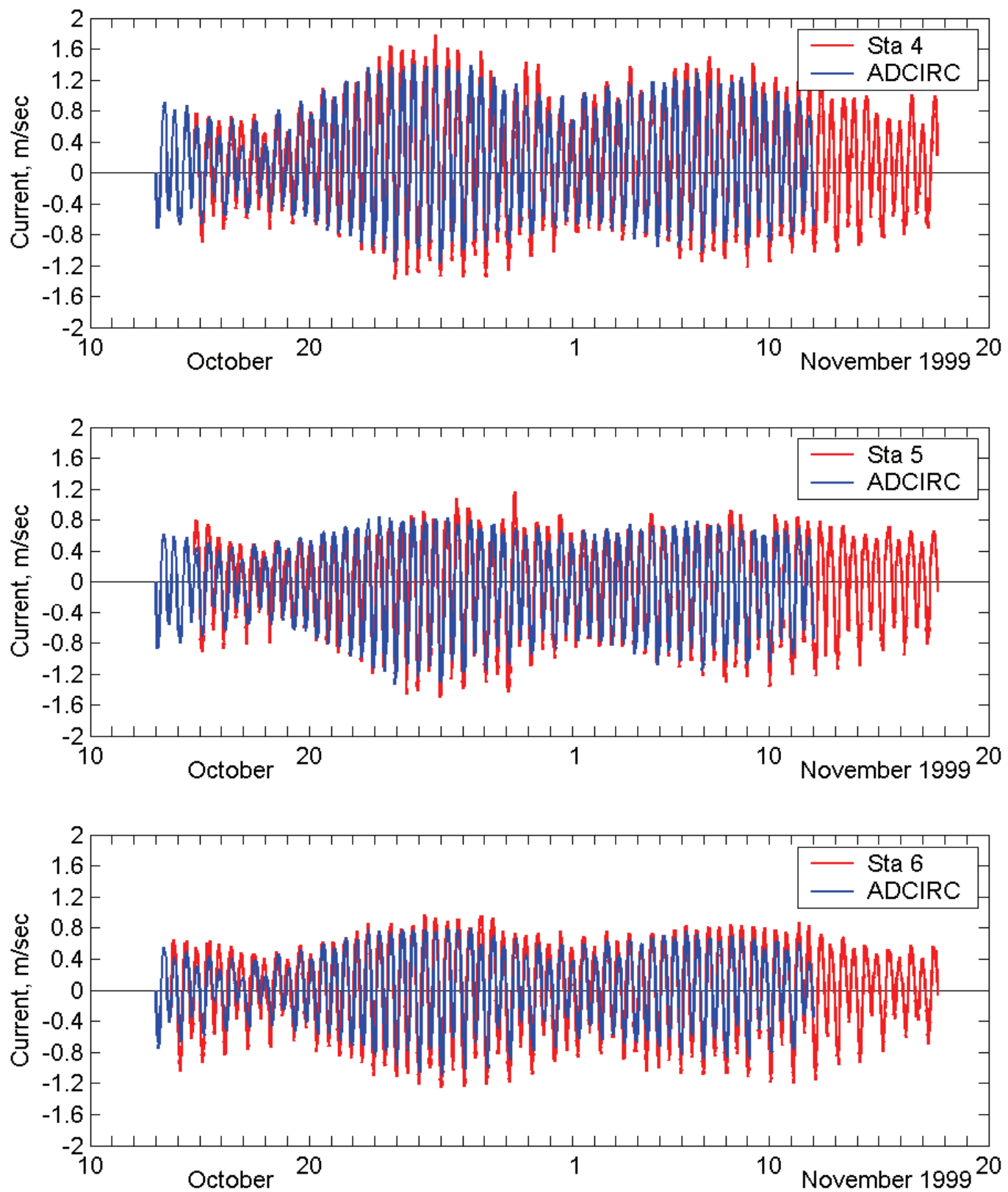

Figure 3-13. Measured and calculated currents at GH Sta 4, 5 and 6.

Figure 3-14 shows the calculated wave field corresponding to the peak storm event in 28 October 1999. Figures 3-15 to 3-20 show the calculated and measured waves for Sta 1 to 6. 


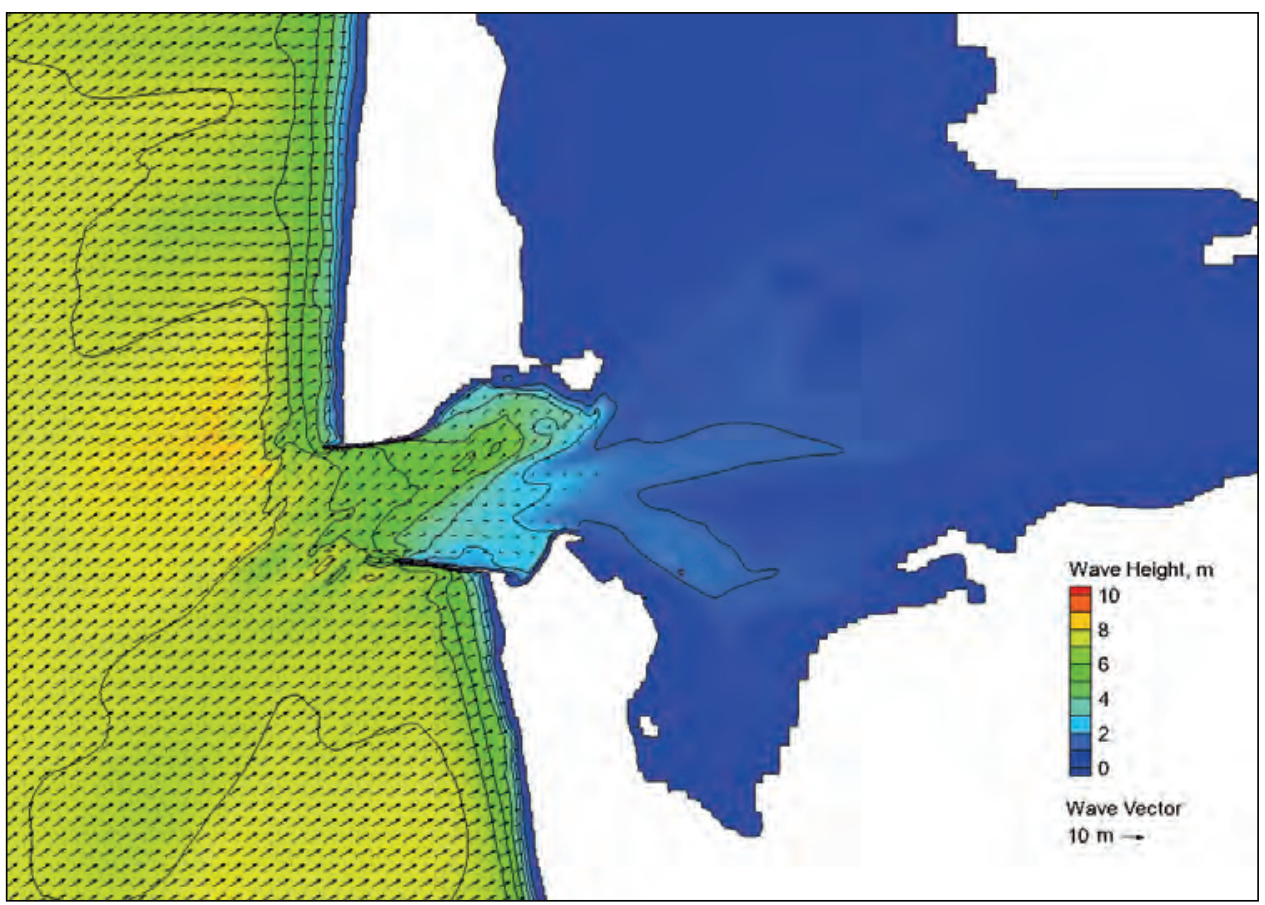

Figure 3-14. CMS-Wave calculated wave field for the peak storm event on 28 October 1999.

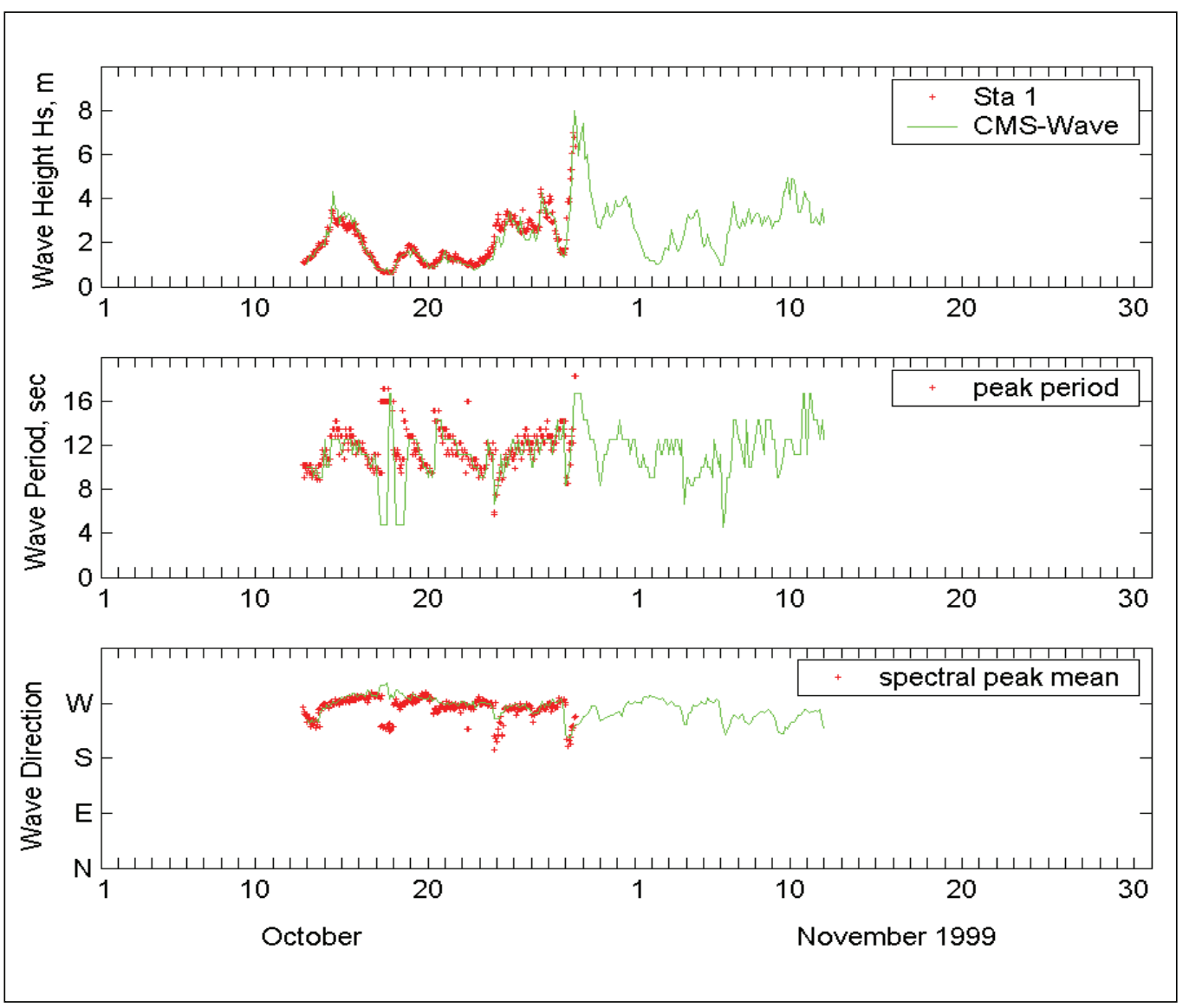

Figure 3-15. Measured and calculated waves at GH Sta 1. 


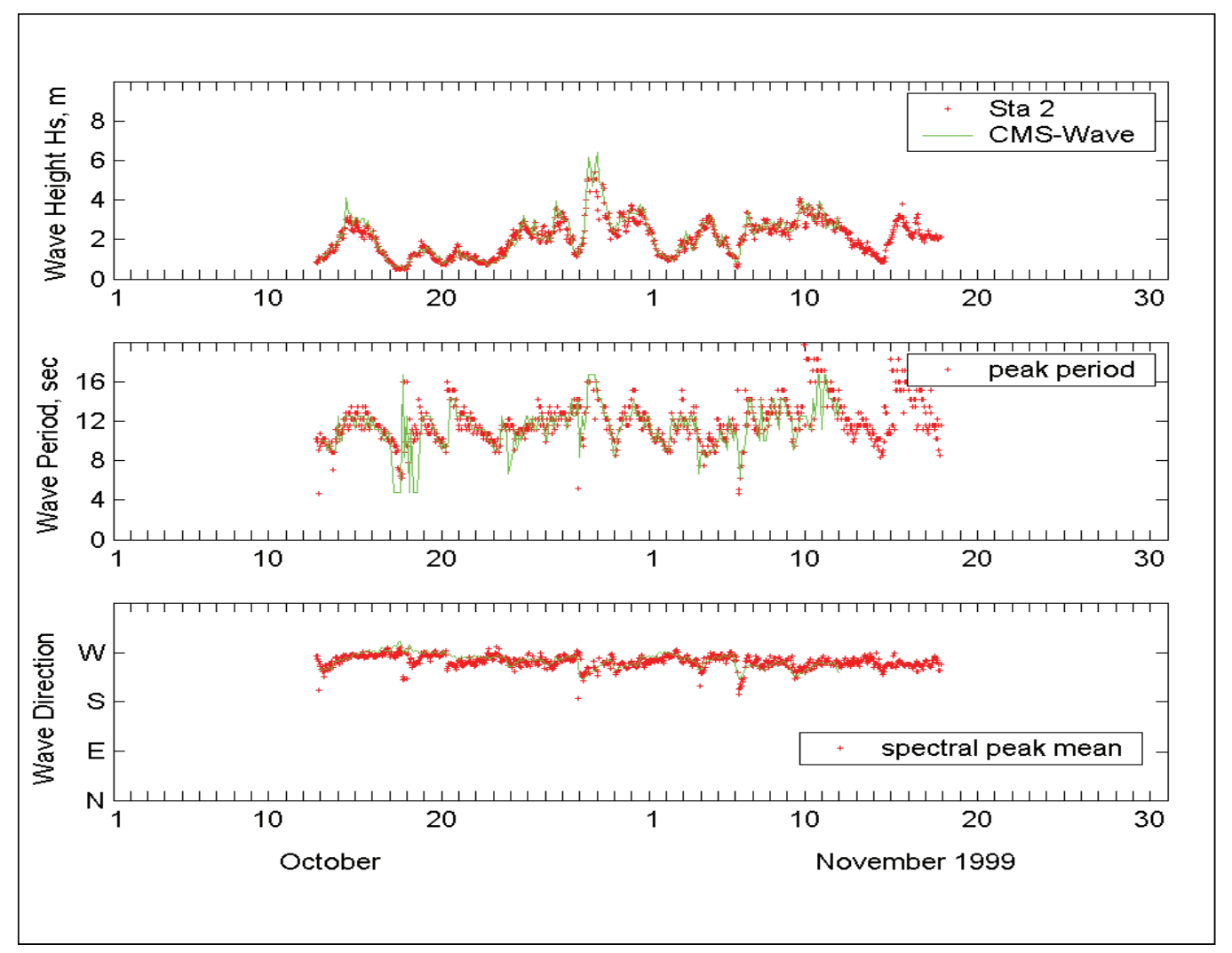

Figure 3-16. Measured and calculated waves at GH Sta 2.

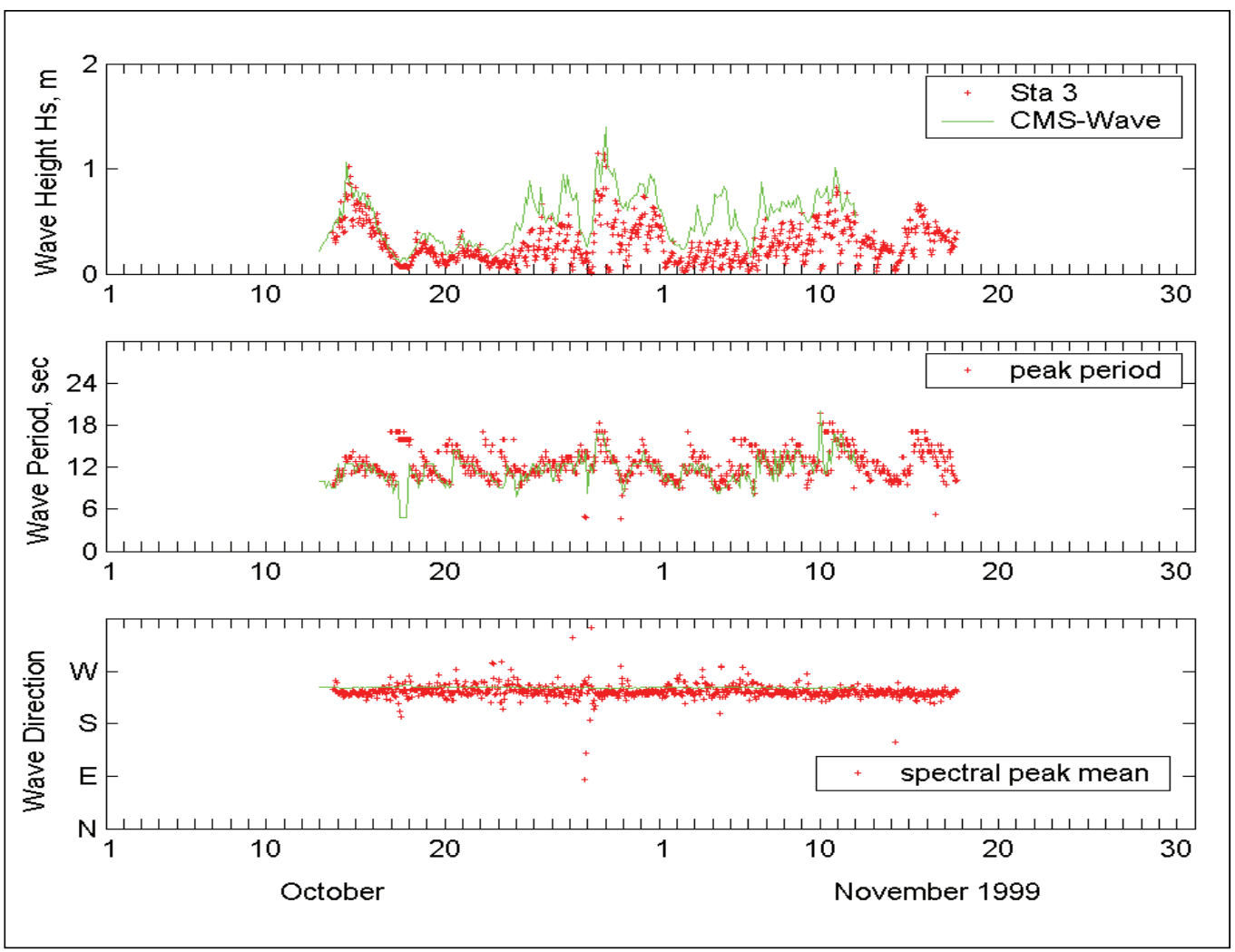

Figure 3-17. Measured and calculated waves at GH Sta 3. 


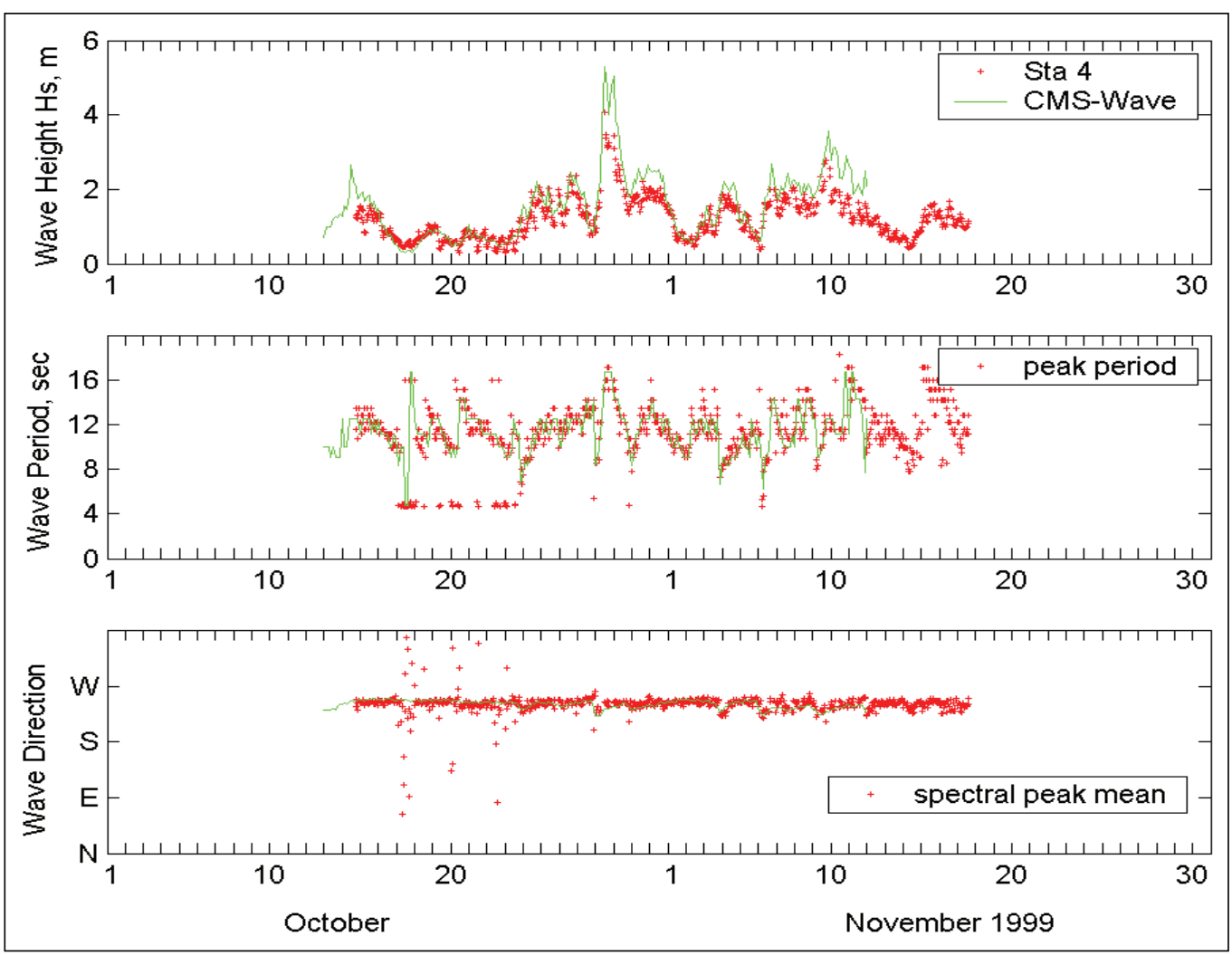

Figure 3-18. Measured and calculated waves at GH Sta 4.
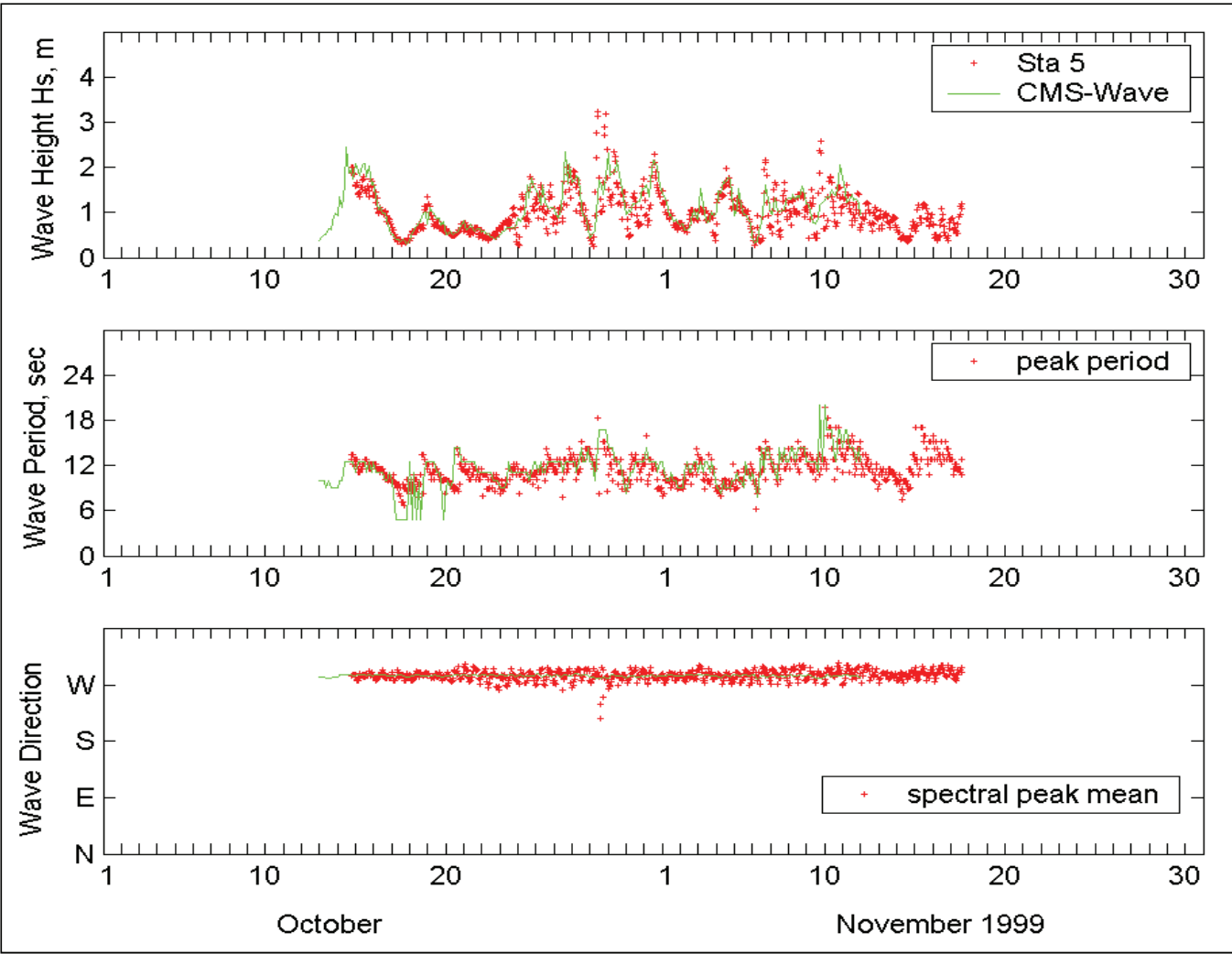

Figure 3-19. Measured and calculated waves at GH Sta 5. 


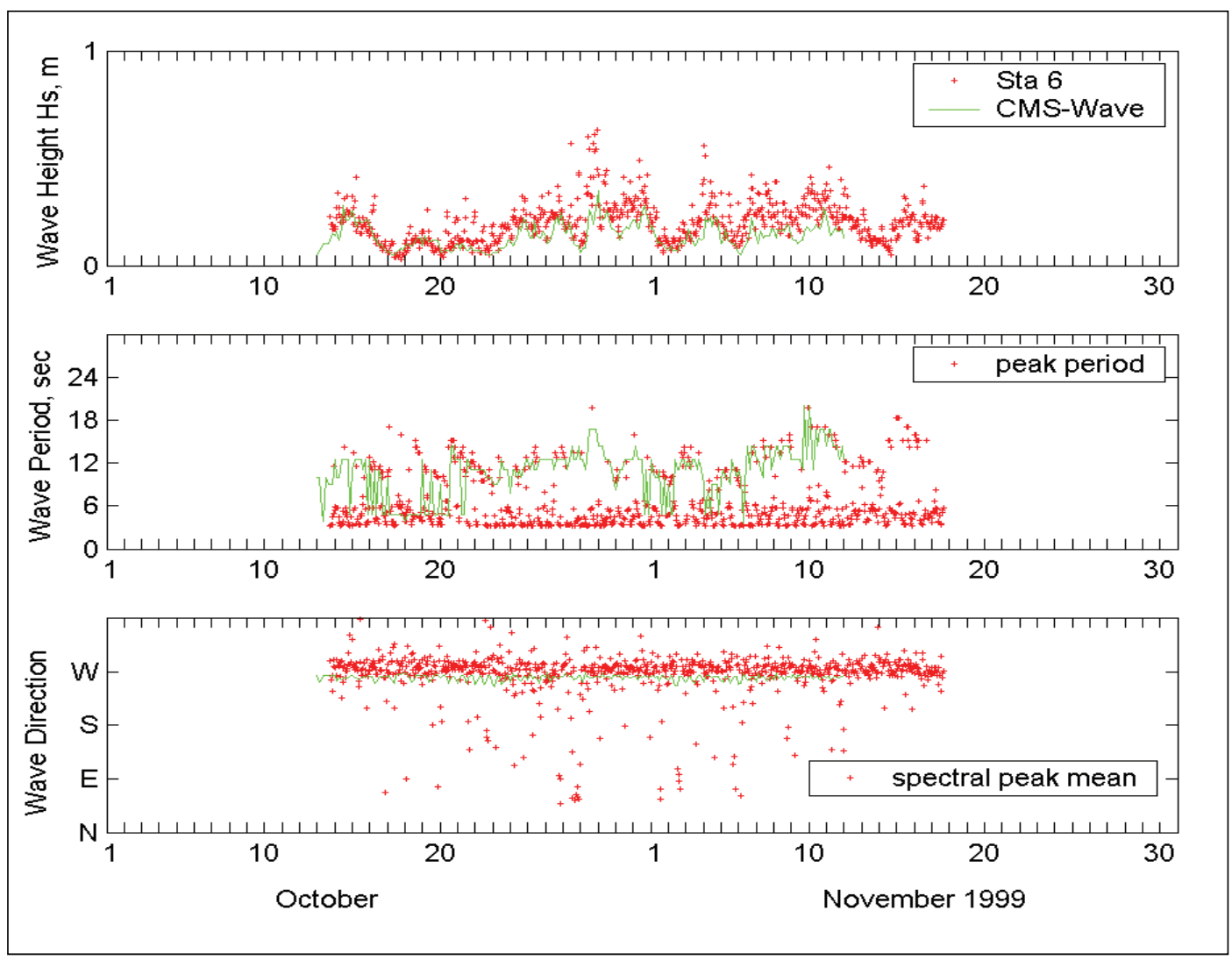

Figure 3-20. Measured and calculated waves at GH Sta 6.

\section{Model validation with 2003 data}

Model validation with the 2003-2004 data sets was made for a 20-day period of 10-30 December 2003 as the offshore waves observed in this period were much greater than J anuary and February 2004. Figure 3-21 shows the wind and wave time series data collected in December 2003 at Buoys 46029 and 46211. ADCIRC and CMS-Wave were validated similar to the 1999 simulation.

Figure 3-22 shows ADCIRC water levels and data at Stations at NOAA Tide Stations Toke Point, WA (9440910), Astoria, OR (9439040), and Southbeach, OR (9435380). Figure 3-23 shows ADCIRC water levels and data at Stations HMB 1 to 4. Overall, the model-data comparison in December 2003 was very good, with the model accurately representing the water surface elevation and capturing the tide range. 

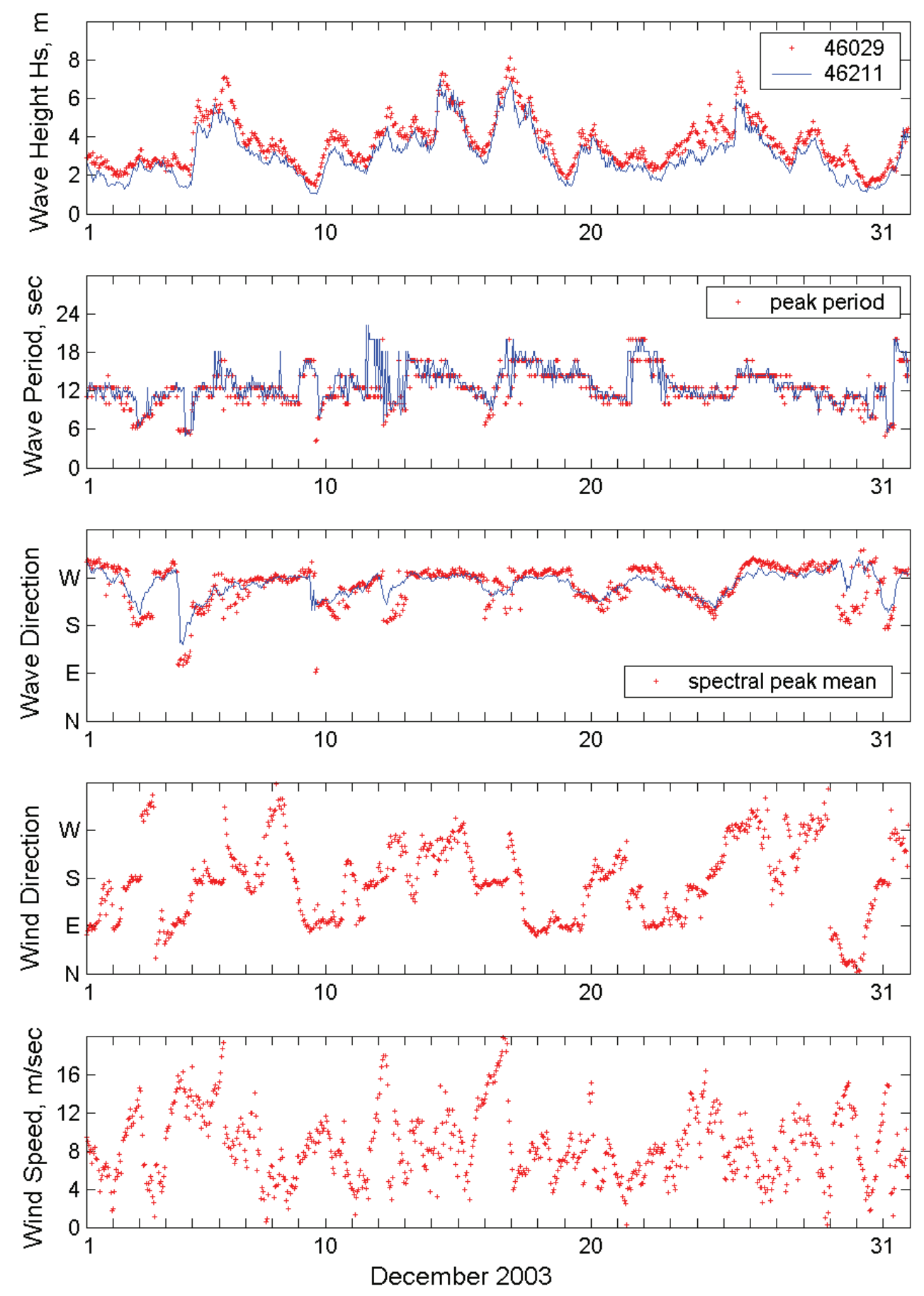

Figure 3-21. December 2003 wind and wave data at buoys 46029 and 46211. 


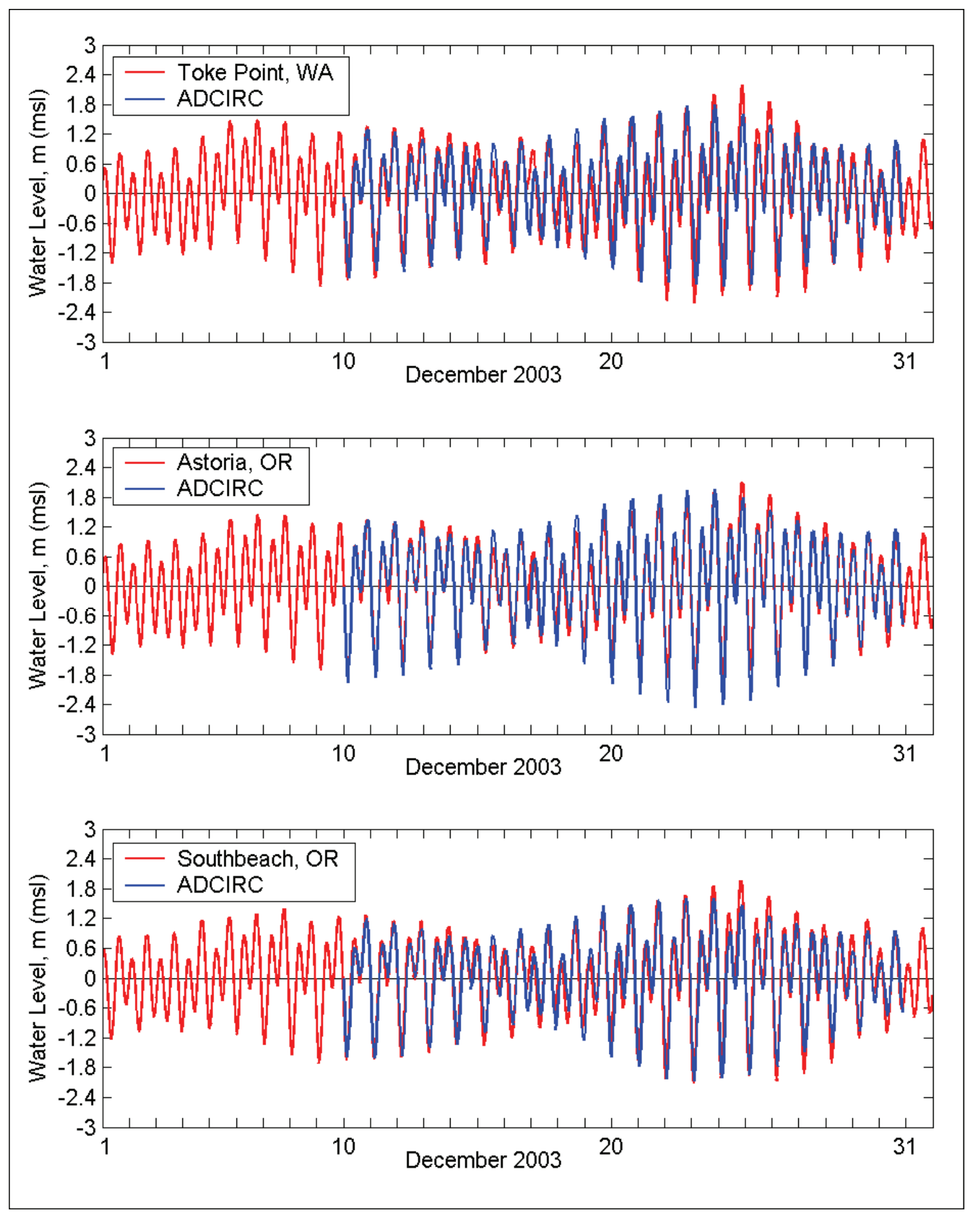

Figure 3-22. Measured and calculated water levels in December 2003 at Toke Point/WA, and Astoria and SouthBeach/OR. 


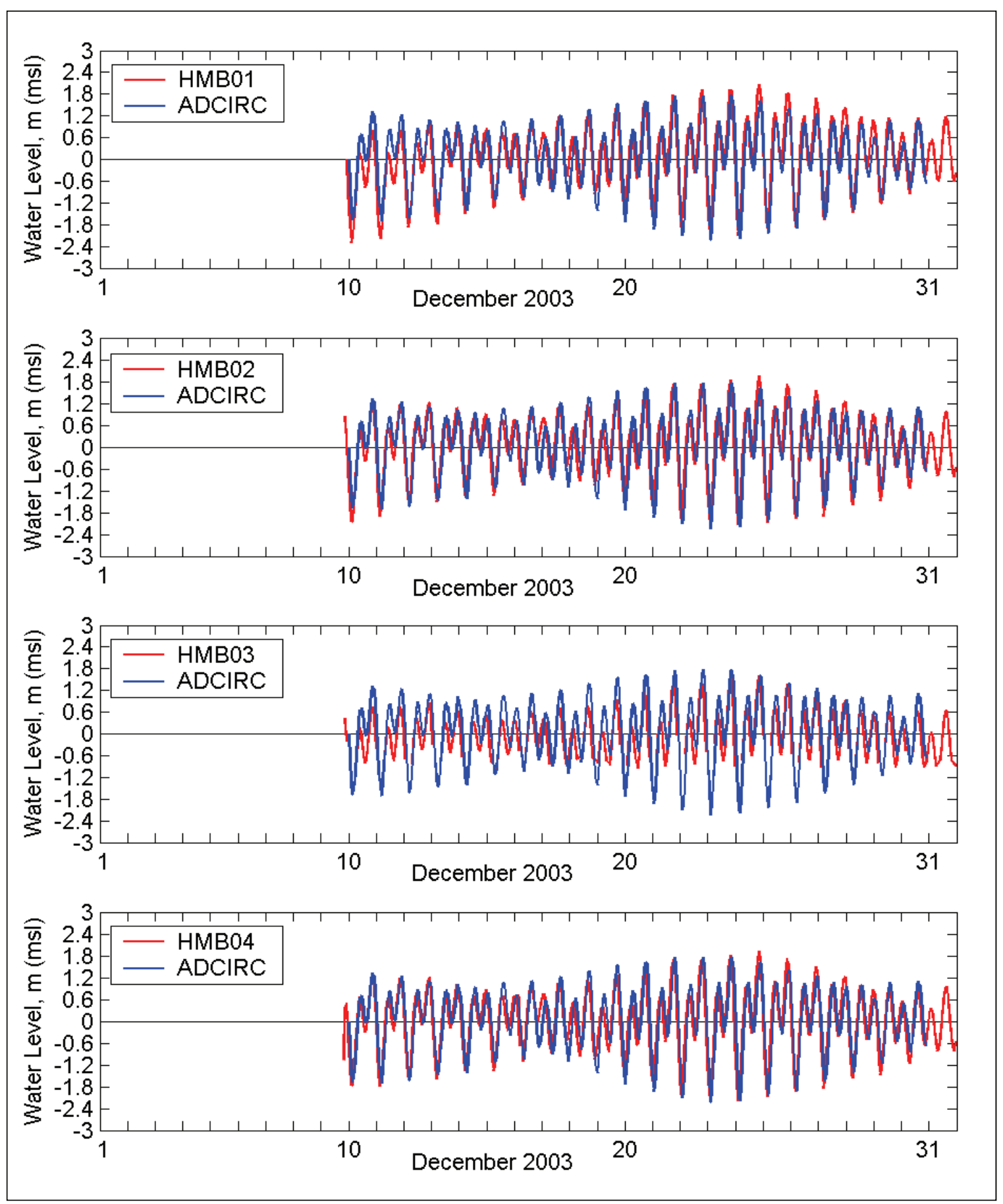

Figure 3-23. Measured and calculated water levels at HMB Stations 1 to 4.

Figures 3-24 and 3-25 show respectively calculated storm current fields in the Half Moon Bay area at 25 December 2003 for flood and ebb conditions. Figure 3-26 shows ADCIRC currents and data at HMB 1 to 4 . The velocity (current) estimate agreed better with data at HMB1, away from the HMB, than the other three stations. The reason for this difference is likely caused by the existence of local circulation cells developed in the HMB area. 


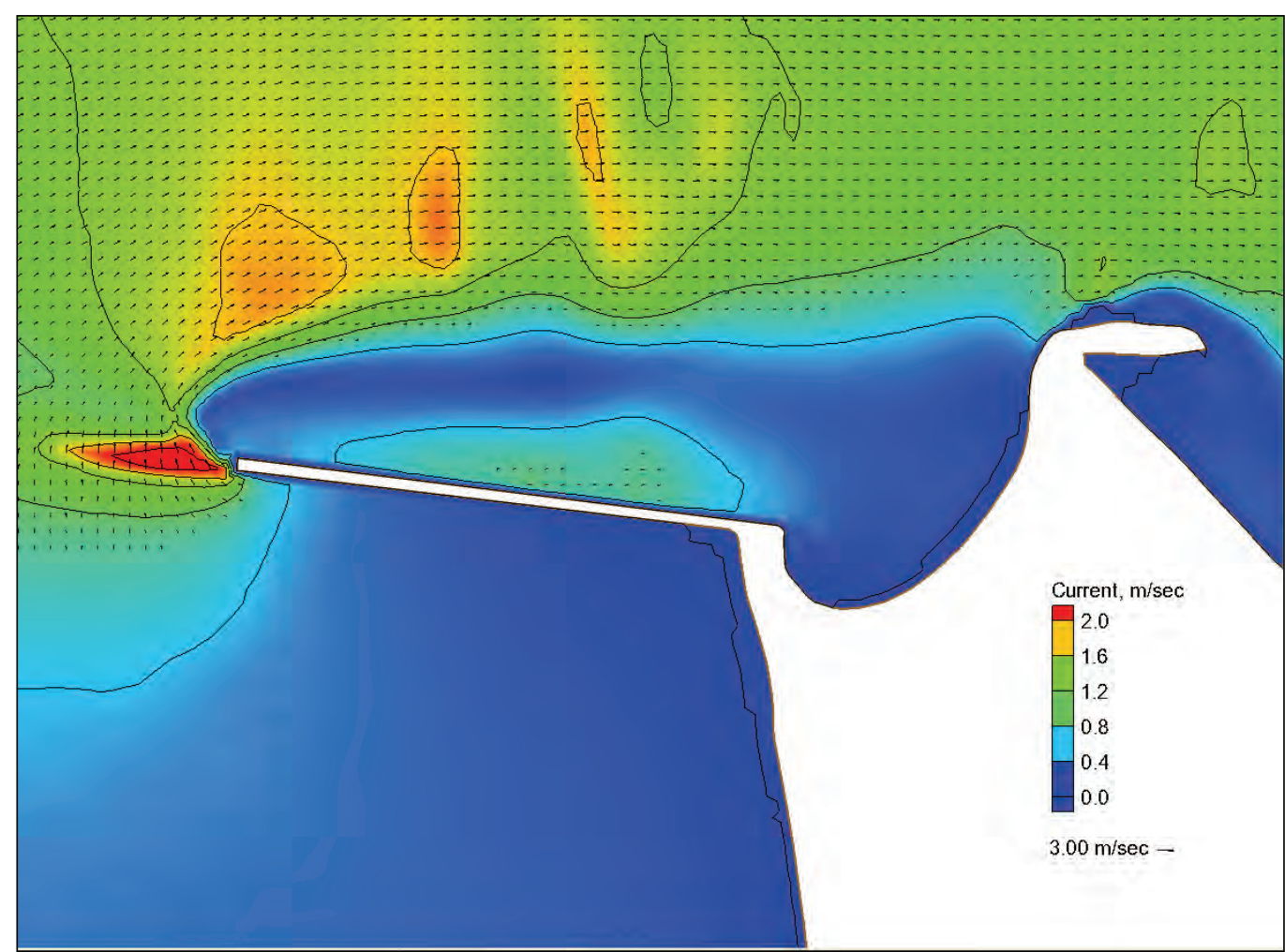

Figure 3-24. ADCIRC calculated maximum flood current field at HMB for the storm event of 25 December 2003.

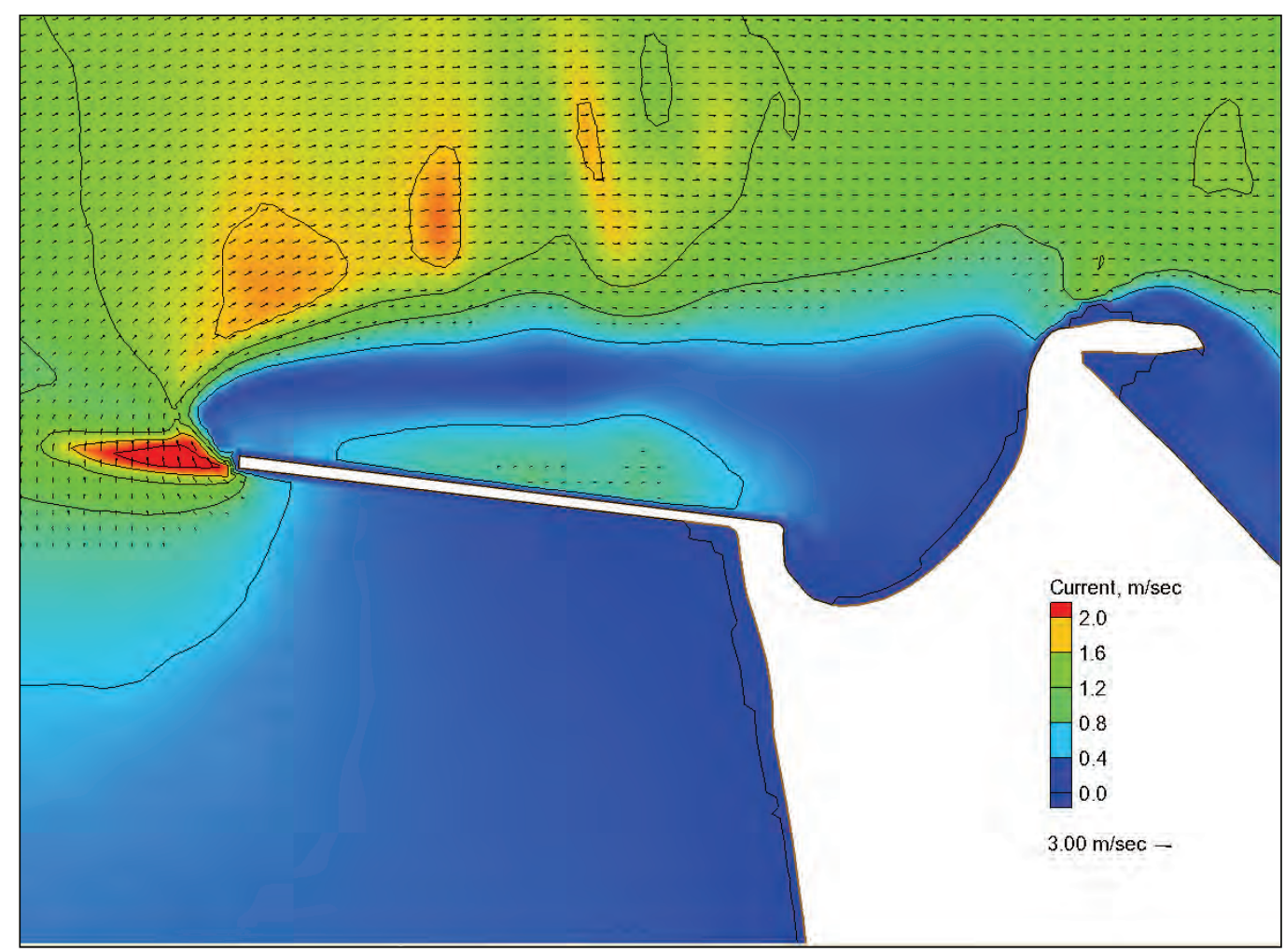

Figure 3-25. ADCIRC calculated maximum ebb current field at HMB for the storm event of 25 December 2003. 


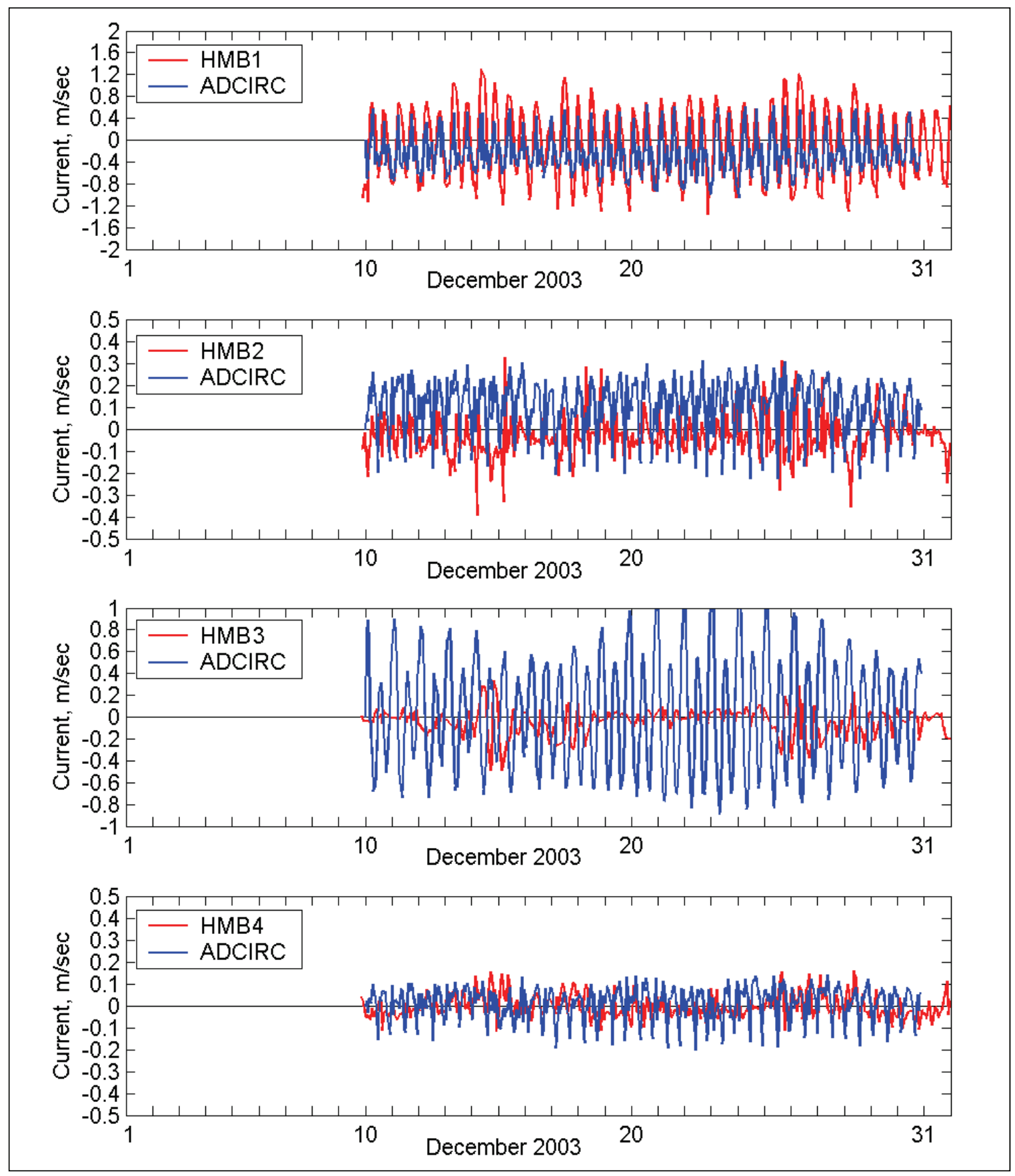

Figure 3-26. Measured and calculated currents at HMB Stations 1 to 4.

Figure 3-27 shows the calculated wave field corresponding to the peak storm event in 25 December 2003. Figures 3-28 to 3-31 show the calculated and measured waves at HMB 1 to 4 . These calculated wave results include simulations by CMS-Wave alone and CMS-Wave interacting with current (w-c). Results for wave-alone and w-c were overall similar, with slightly improved wave height estimate by $\mathrm{w}$-c inside the HMB area at Stations HMB3 and HMB4. 


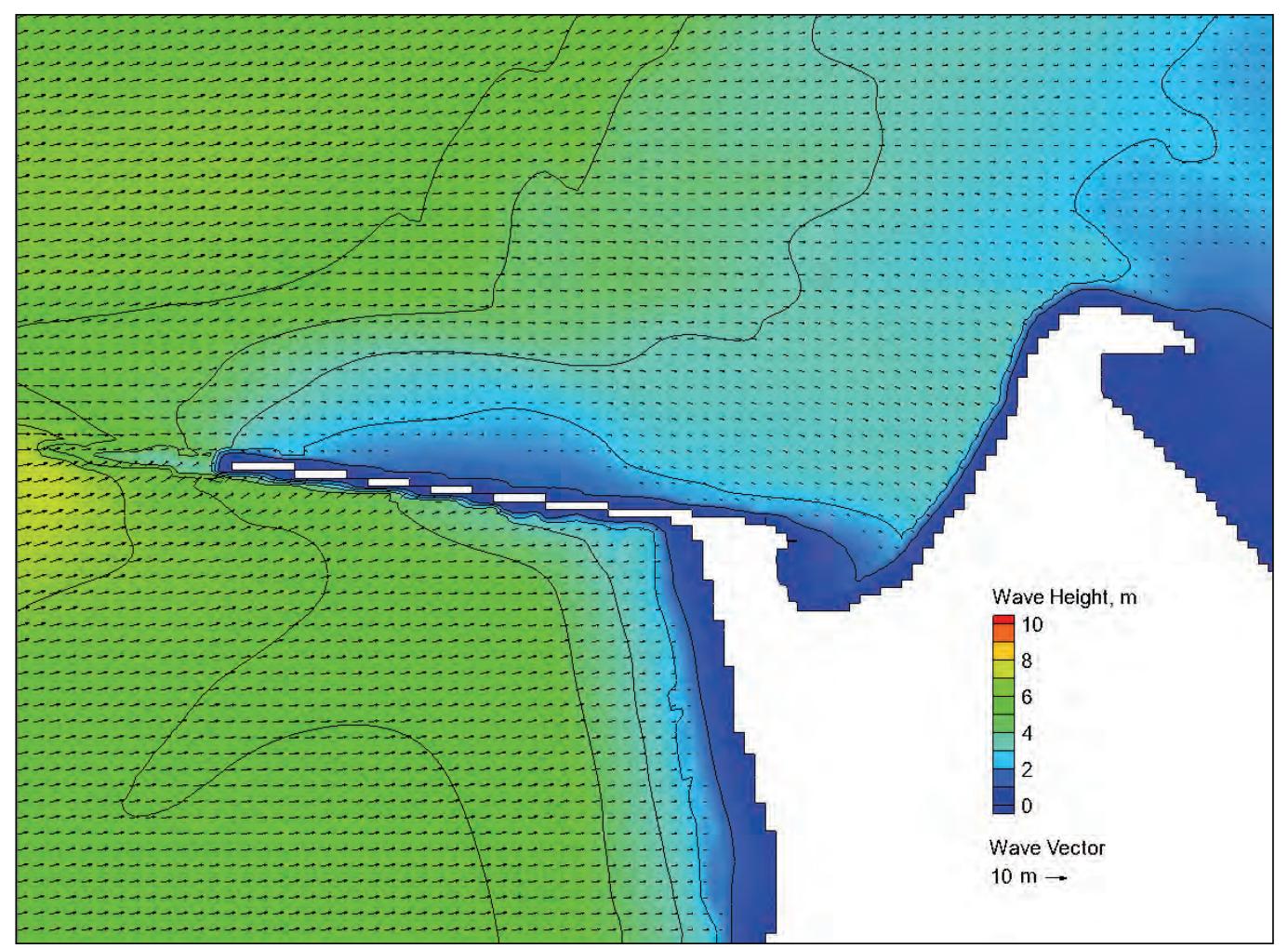

Figure 3-27. CMS-Wave calculated wave field at HMB for the peak storm event of 25 December 2003.
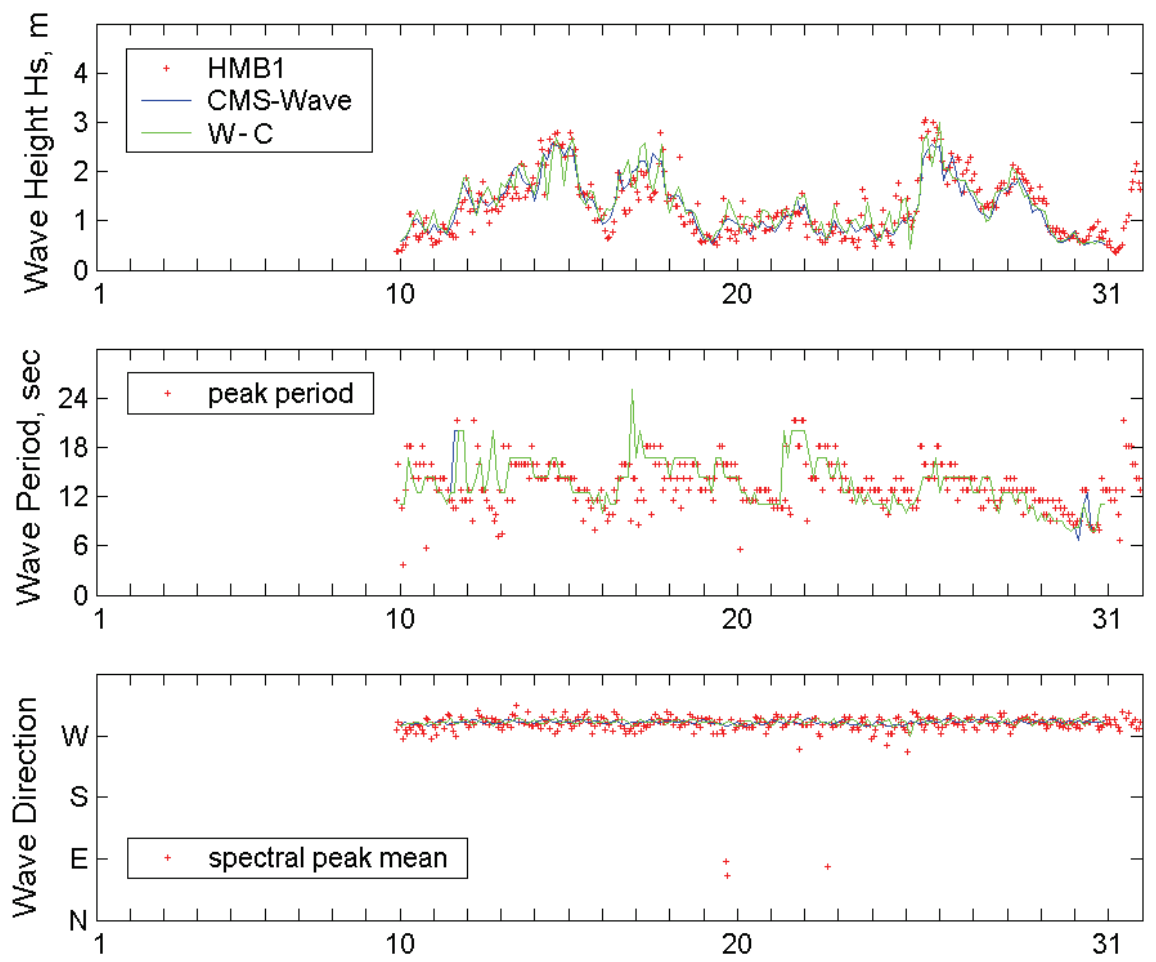

Figure 3-28. Measured and calculated waves at Station HMB 1. 

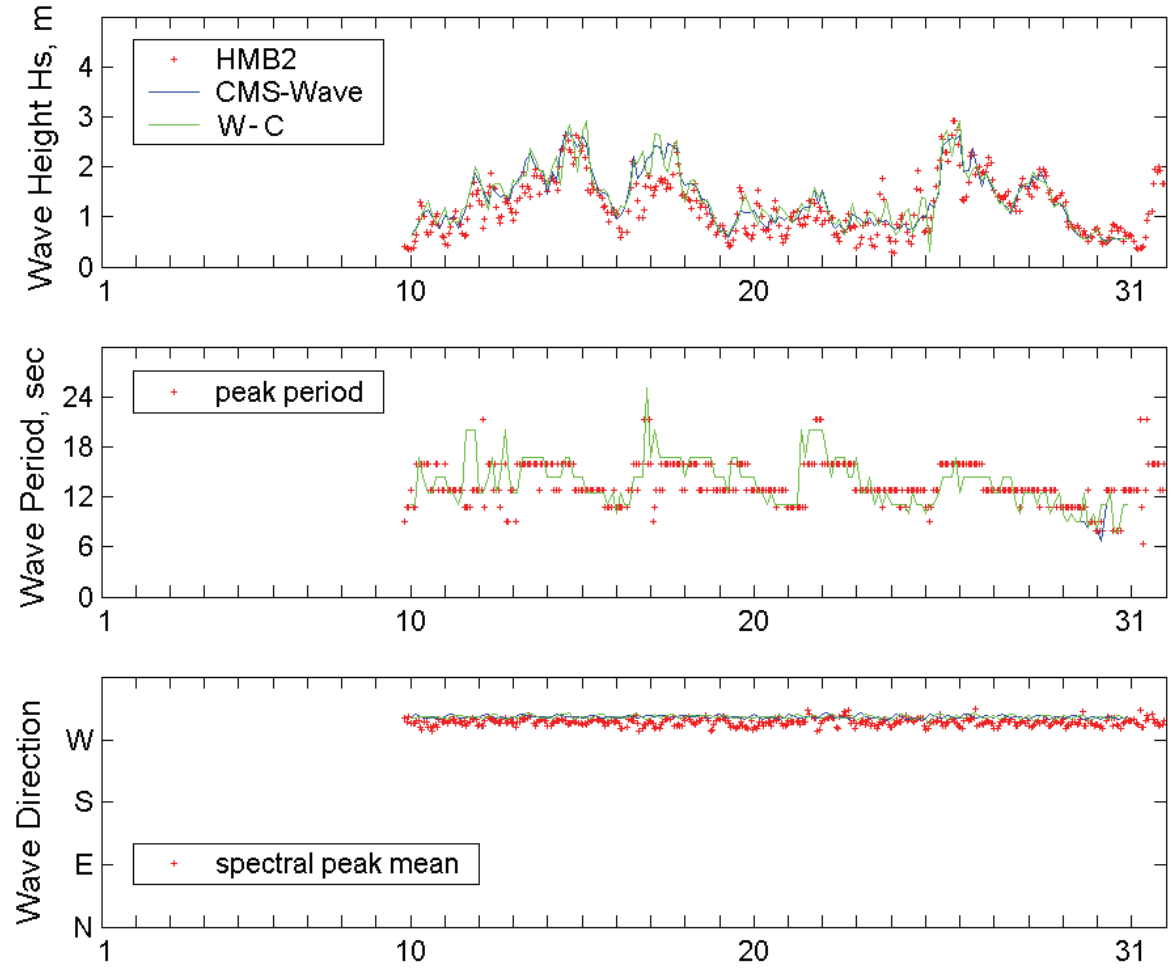

Figure 3-29. Measured and calculated waves at Station HMB 2.
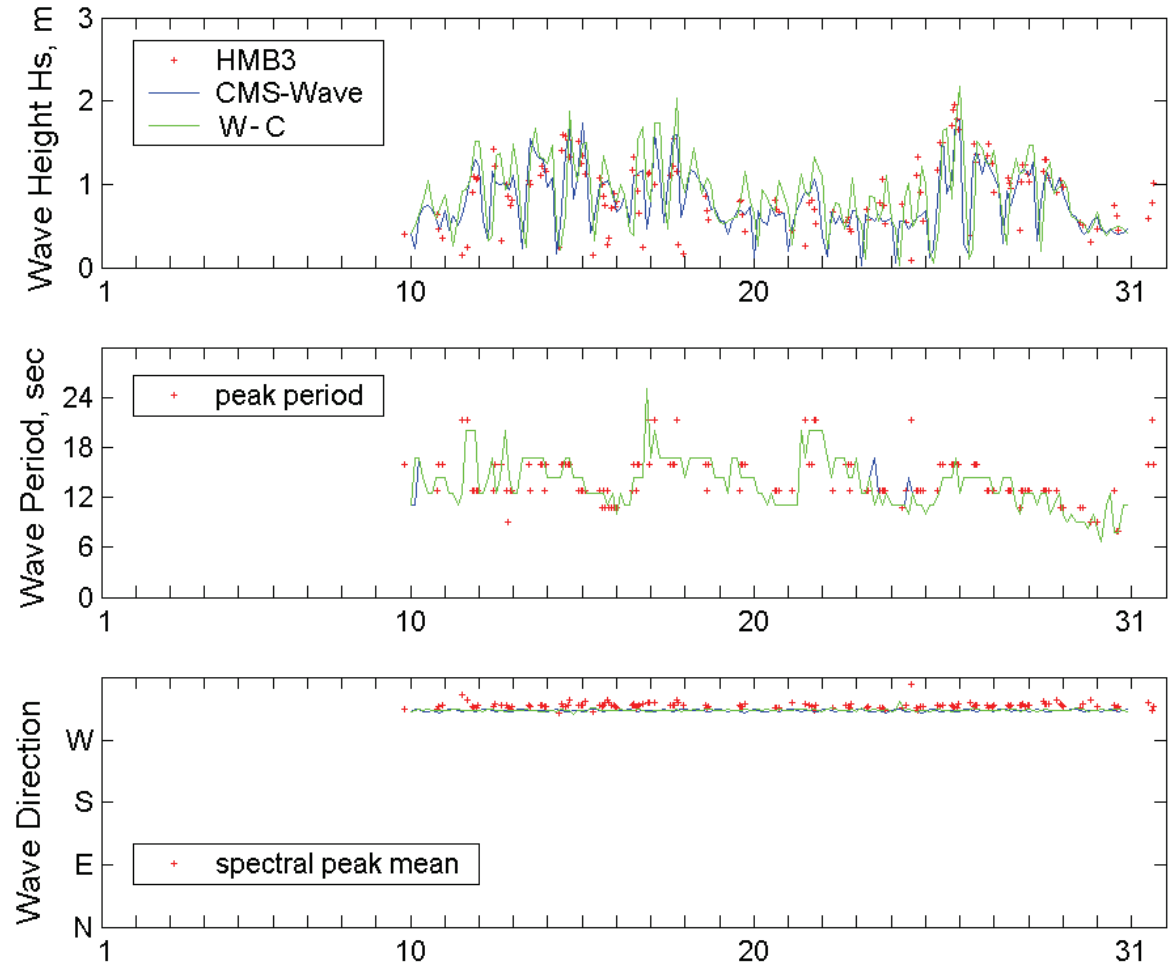

Figure 3-30. Measured and calculated waves at Station HMB 3. 

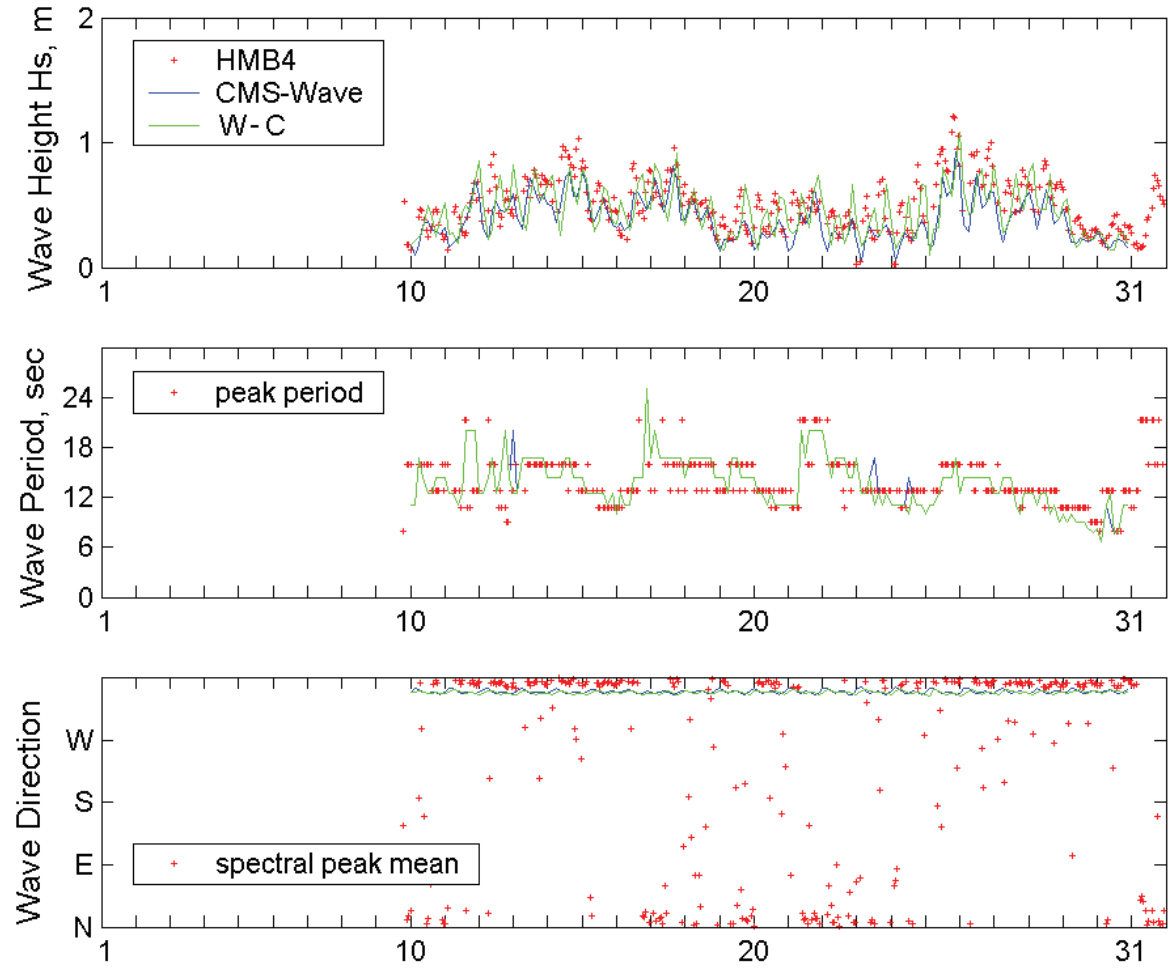

Figure 3-31. Measured and calculated waves at Station HMB 4. 


\section{Selection of Seasonal Storms}

\section{Introduction}

Large domain wave transformation and hydrodynamic models have been demonstrated to produce reasonable engineering estimates of the respective physical processes. However, the computational demands and associated cost of these models often precludes long-term simulations for many engineering and scientific studies. In such cases, a prudent and acceptable solution is to statistically characterize the environmental forcing to obtain the desired long-term response for engineering works. Statistically representative conditions developed on the basis of force-response relationships are best to represent the response of some engineered or natural system to environmental forcing that cannot be numerically simulated (e.g., computationally infeasible). It is indeed not possible in terms of resources and cost to numerically simulate all conditions in a 38-yr hindcast database that was available to this study. Since the ultimate goal in this study was to describe the sediment transport response of dredged material placement sites to the local forcing of waves and currents, a subset of representative conditions had to be simulated to determine short- and long-term sediment transport in the GH navigation channel system. This Chapter provides description of a statistical method used in this study for determining representative conditions for sediment transport modeling in the GH navigation channel and at dredged material placement sites. The simulation periods selected through this statistically based process define the simulation periods for hydrodynamic, wave transformation, and sediment transport models applied in this study.

\section{Method for selection of seasons}

Long-term records of wave climate and astronomical tidal forcing are available from simulated hindcasts and tidal constituents offshore. Offshore wave conditions were defined by the Global Reanalysis of Ocean Waves (GROW) hindcast (Oceanweather, 2007), a 38-year record spanning the years 1970-2007. The GROW hindcast has been extensively validated with approximately 1.2 million comparisons between hindcast and observations in the Northeast Pacific, with the following statistics on significant wave height (bias $(0.17 \mathrm{~m}), \mathrm{RMS}$ error $(0.81 \mathrm{~m})$, and correlation coefficient (0.88). Additional details of the GROW hindcast and data comparisons are 
available in Cox and Swail (2000) and Oceanweather (2007). Offshore tidal constituents were taken from the Le Provost database. Offshore tidal and wave conditions were transformed to local conditions at the dredged material placement sites with the numerical models ADCIRC and CMSWave.

The US Pacific Northwest coast is characterized by pronounced seasonal and inter-annual variability in storm conditions associated with El Nino Southern Oscillation (ENSO) climatic patterns (Ruggiero, et al., 2005). Consequently, the integration period for system response to environmental forcing was selected on a seasonal basis with seasons defined as the months J anuary - March, April - J une, J uly - September, and October December. The 38-year GROW hindcast defines the statistical period of analysis, and sediment mobility is selected as the parameter defining the relevant response of sediments at the dredged material placement sites to environmental forcing. The target return intervals of interest for dredging quantities are relatively short as compared to storm damage analyses of structures such as breakwaters, jetties, or levees. The target return intervals for this study were selected as $0.5,2$, and 5 years. However, extreme events are not negligible, and the extreme event from the 38-year record was also sought. The methods described in this section are adaptable to other sediment response parameters, integration periods, and record lengths for other sediment transport analyses and sites.

\section{General procedure}

To quantify sediment mobility at each of the dredged material placement sites, local wave and current conditions were required. These conditions were determined from the result of wave transformation and harmonic analysis of tidal conditions at locations selected within the dredged material placement sites. From the local wave and current conditions, a 38-year record of bottom shear stress and sediment mobility was determined at each selected location. Sediment mobility was integrated quarterly and ranked, resulting in a mobility score for each season and location in the analysis. Return intervals were computed from the ranked seasons, and return intervals approximately matching the target return intervals for all sites were selected as the representative simulation periods. Details of this general procedure are presented below. 


\section{Analysis points}

Six analysis points were selected within the three dredged material placement sites within the Grays Harbor entrance (Figure 4-1). These points were selected to obtain representative sampling for sediment transport potential within each of the sites. Environmental conditions and the resulting sediment transport response will be computed at each of these locations.

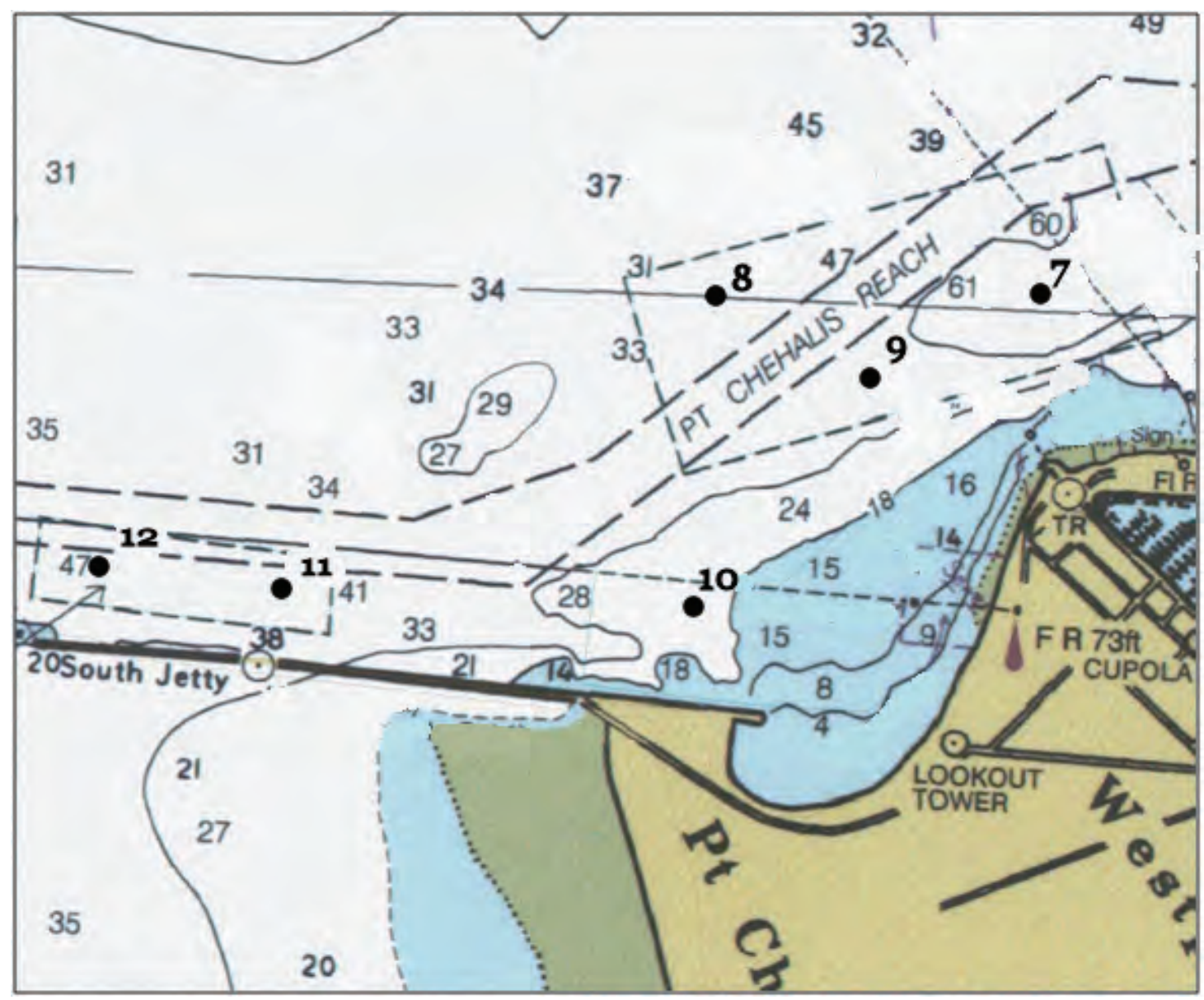

Figure 4-1. Six simulation points selected within the three dredged material placement sites near the Grays Harbor entrance. Analysis stations are indicated by filled black circles with bold numbering.

\section{Wave transformation}

To transfer offshore wave conditions to the local sites of interest, a matrix of wave transformation simulations was generated based on the offshore wave climatology. Wave transformation is dependent upon wave height, wave period, wave direction, and water depth. The offshore wave climate was binned into wave height, period, and direction bins. Wave height was 
binned in 2-m increments between 0-8 $\mathrm{m}$ and an additional bin for heights greater than $8 \mathrm{~m}$. Wave period was binned in 2-sec intervals between 6-24 sec. Wave direction was binned in 10-deg increments for waves traveling within \pm 30 deg from the jetty alignment and 20-deg increments outside this range. Water depth was binned from -2 to $+2 \mathrm{~m}$ MTL in 0.5- $\mathrm{m}$ increments. The resulting distribution of wave events in the 38-year offshore record (GROW Station 2041496) for each wave height, period, direction bin is provided in Figure 4-2. Each of the populated bins in the offshore matrix of Figure 4-2 was simulated at each of the water level bins, resulting in 2763 wave transformation simulations. Each wave simulation uses the central value of wave height, period, and direction from the defined bins.

The wave transformation simulations results in local wave height, period, and direction at each analysis point and wave condition/ water level. Results from the wave transformation simulations are stored in a wave transformation matrix for each point. Interpolations within the wave transformation matrix are used to determine local wave conditions from the offshore GROW hindcast.

\section{Harmonic analysis}

Harmonic analysis was performed on the water surface elevation, and horizontal velocity components resulting from a 45-day ADCIRC simulation. Harmonic analysis identifies the contribution of astronomical tide forcing at defined frequencies associated with solar and lunar tidal forcing. By determining these astronomical contributions to the hydrodynamics, tides and tidal currents may be reconstructed to produce a long record of hydrodynamic conditions without years of hydrodynamic model simulation. Drawbacks of this method are that hydrodynamic features such as shed eddies and meteorological forcing that do not occur at astronomical frequencies are not represented in the synthetic hydrodynamics.

Tides were well represented by the harmonic analysis, with $98-99 \%$ of modeled variation represented by the astronomical constituents. Representing currents with harmonic reconstruction was less accurate, but acceptable, with 96-99\% (principal axis) and 70-98\% (minor axis) modeled variation represented by astronomical constituents. For the purposes of event selection, the reconstructed hydrodynamics were considered sufficiently accurate. Given the relatively strong tidal currents 


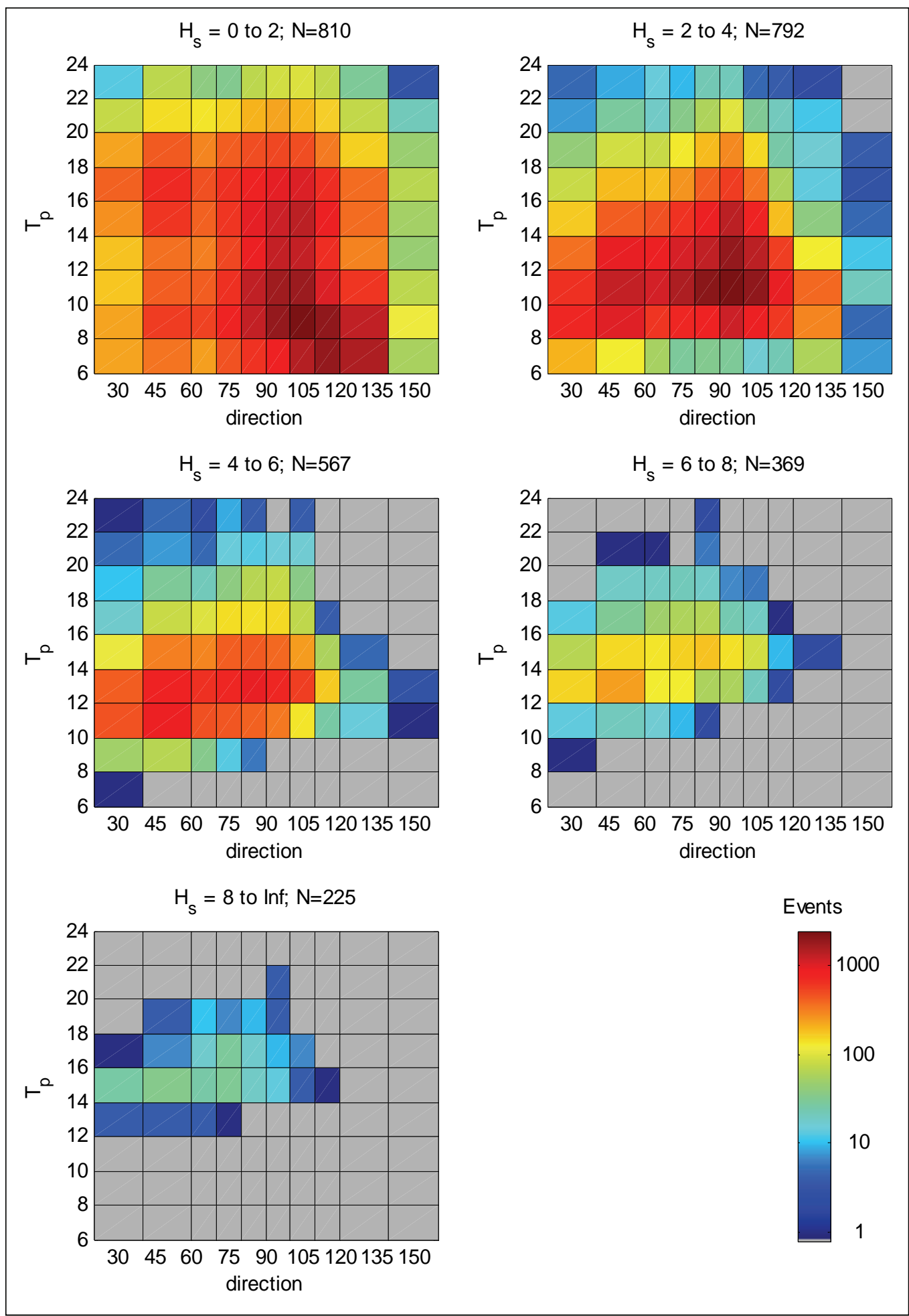

Figure 4-2. Binned wave climate for GROW hindcast station 2041496 for the period 19702007. Grey indicates no wave records. $N$ indicates number of populated bins (including water level bins). Total number of simulations is 2763 . Direction of wave travel (towards which or oceanographic sense) is indicated in degrees relative to true north $(0=$ north, $90=$ east). Wave periods are given in seconds and significant wave height in $\mathrm{m}$. 
at the study site, neglecting storm surge and associated currents was considered acceptable. For systems for which sediment transport is dominated by periods of wind-driven and/ or storm surge currents, the harmonic reconstruction of tides is inappropriate.

\section{Bed shear stress}

Combined wave-current bed shear stress was computed from the depthaveraged velocity components and local wave conditions for the 38-year GROW hindcast period. Soulsby (1997) provides a simple method for estimating combined wave-current shear stresses:

$$
\begin{aligned}
& \tau_{\mathrm{m}}=\tau_{\mathrm{c}}\left(1+1.2\left(\frac{\tau_{\mathrm{w}}}{\tau_{\mathrm{c}}+\tau_{\mathrm{w}}}\right)^{3.2}\right) \\
& \tau_{\mathrm{mx}}=\left(\left(\tau_{\mathrm{m}}+\tau_{\mathrm{w}} \cos \phi\right)^{2}+\left(\tau_{\mathrm{w}} \sin \phi\right)^{2}\right)^{1 / 2}
\end{aligned}
$$

where:

$$
\begin{aligned}
\tau_{\mathrm{m}} & =\text { average wave-current bed shear stress } \\
\tau_{\mathrm{c}} & =\text { current-only bed shear stress } \\
\tau_{\mathrm{w}} & =\text { wave-only bed shear stress } \\
\tau_{\mathrm{mx}} & =\text { peak wave-current bed shear stress } \\
\varphi & =\text { angle of waves relative to current }
\end{aligned}
$$

For Equation 4-1, current-only skin-friction shear stress is estimated by the von Karman-Prandtl logarithmic velocity profile. The wave-only skinfriction shear stress is estimated by Myrhaug (1989) method which is valid for smooth, transitional, and rough turbulent flows. For both wave- and current-only skin-friction shear stresses, the hydraulic roughness was determined assuming bed grain diameter of $0.25 \mathrm{~mm}$.

\section{Sediment mobility}

Sediment mobility is defined as the ratio of bed stress to critical stress.

$$
\begin{array}{cl}
\mathrm{M}=\frac{\tau_{\mathrm{mx}}}{\tau_{\mathrm{cr}}} & ; \tau_{\mathrm{mx}}>\tau_{\mathrm{cr}} \\
\mathrm{M}=0 \quad ; \tau_{\mathrm{mx}} \leq \tau_{\mathrm{cr}}
\end{array}
$$


where $\tau_{\text {cr }}$ is critical shear stress for sediment mobility. Critical shear stress for all calculation points was set to $0.2 \mathrm{~Pa}$, consistent with sandy sediment diameters of approximately $0.25 \mathrm{~mm}$, which is consistent with median grain sizes reported in USGS (2004) for nearshore surface samples collected north of the north jetty.

\section{Return intervals and seasonal selection}

Return intervals for each season in the 38-year record were determined by first, time-integrating sediment mobility over each quarter, then by ranking the results for each calculation point. Return interval for which sediment mobility is exceeded is determined by

$$
\mathrm{T}_{\mathrm{R}}=\mathrm{T}_{\mathrm{i}}\left(1-\frac{\mathrm{n}}{\mathrm{N}+1}\right)
$$

In Equation (4-3), $T_{R}$ is the return interval (years), $T_{i}$ sample interval (years, 0.25 for quarterly integration), $\mathrm{n}$ sediment mobility ranking by quarter, and $\mathrm{N}$ represents total samples.

Sediment mobility return periods for the 38-year GROW hindcast record for calculation points 8 and 12 are presented in Figure 4-3. Both locations exhibit higher sediment mobility during the more energetic autumn and winter seasons.

The sediment-mobility ranked seasons were compared for each calculation point and seasons nearly matching the target return periods at all points were selected for more detailed wave transformation and hydrodynamic simulation. The resulting quarterly simulations are 1993Q2 (0.5 year), 2006Q4 (2 year), and 1998Q4 (5 year).

\section{Storm selection}

In addition to the seasonal simulation periods, an extreme storm period was selected. The previously described methods for estimating sediment mobility were applied. The sediment mobility time series for each point was filtered with an averaging filter with window length of 8 days.

Storm conditions were identified as periods of elevated time-averaged sediment mobility. The start of a storm event was defined when timeaveraged mobility exceeded 15 percent of the record; the storm end was 

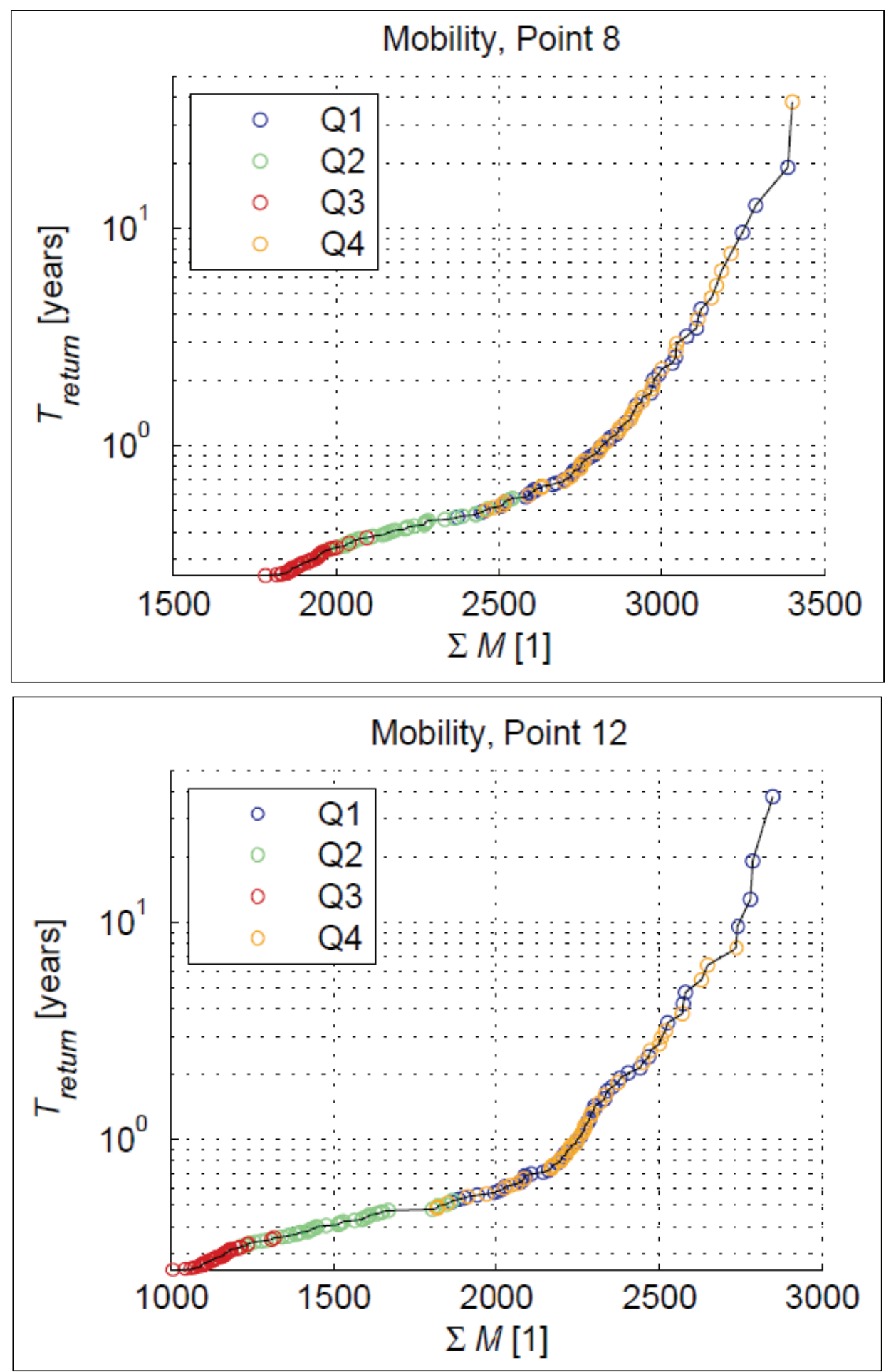

Figure 4-3. Sediment mobility return periods for 38-year GROW hindcast record at calculation points 8 and 12 . Results are presented by season, with Q1 representing winter (Jan-Mar) and Q4 representing autumn (Oct-Dec). 
defined when time-averaged mobility reduced below the 30 percent exceedance level. Storms were ranked at each calculation point by timeintegrated sediment mobility.

Sediment mobility for the most energetic storms was more variable across calculation points than the seasonally integrated evaluations. However, a suitably energetic period that was within the top 10 events at all calculation points was selected for the period $20 \mathrm{~J}$ anuary - 18 February 1990. This energetic period will be simulated by large scale models to represent an energetic storm period (extreme storm condition). The winter season of 1990 represents a 20-40 year return interval at the HMB and Point Chehalis placement sites and approximately 5-year return interval at the South J etty site.

\section{Concluding remarks}

A method for selecting representative environmental conditions producing statistically representative seasonal and extreme sediment transport responses was developed. Through this approach, meaningful evaluation of channel alignment and dredged material placement alternatives was possible with reduced computational expense. The hydrodynamic and wave transformation simulations performed through this analysis required simplified wave transformation and hydrodynamic estimates at the sites of interest which were justified for event selection. The seasonal and extreme event periods identified through this analysis were later simulated with greater rigor for final analysis. 


\section{Hydrodynamic and Wave Modeling Results}

Production runs were performed for the Existing and Realigned channel plans for three return periods: 0.5, 2 and 5 yrs. The description of return period selection process is given in Chapter 4 . The quarterly return periods in the production runs are shown in Table 5-1. Hydro and wave modeling results (wave parameters, water surface elevation and current estimates) in these production runs were developed for sediment transport modeling. Additional model simulations included a 4-week large storm period (16 J anuary to 15 February 1990) for the extreme wave condition. Results from production runs for the Existing and Realigned channel plans are analyzed and compared in this chapter.

Table 5-1. Simulation periods for production runs.

\begin{tabular}{|l|l|}
\hline Return Period (yr) & Year and Season (Quarter) \\
\hline 0.5 & 1993 Q2 (Apr-Jun) \\
\hline 2 & 2006 Q4 (Oct-Dec) \\
\hline 5 & 1998 Q4 (Oct-Dec) \\
\hline Extreme Event & 1990 (16 Jan- 15 Feb) \\
\hline
\end{tabular}

The purpose of production runs was to develop wave and current inputs for the sediment modeling. Because a large set of data had been developed from the production runs, both hydro and wave results are compared only at a few selected output stations in the entrance channels. The goal was to show the spatial variation of waves and currents along the Existing and Realigned channel configurations investigated for seasonal conditions of different return periods. The modeling results for the Realigned channel scenario are provided with the Existing channel filled and unfilled.

\section{Output stations}

To compare model results from the production runs, seven output stations were selected along the Existing and Realigned channels in the outer channel region. Figure 5-1 shows the locations of output stations. Sta 8, 11, 12, 13 and 14 are situated within the Existing channel whereas Sta 8, 9, 10, 13 and 14 are located along the Realigned channel. Sta 8, the most westward 
stations, as well as Sta 13 and 14, the two most eastward stations, are common to both Existing and Realigned channels. Table 5-2 presents the station coordinates $(\mathrm{x}, \mathrm{y}, \mathrm{z})$.

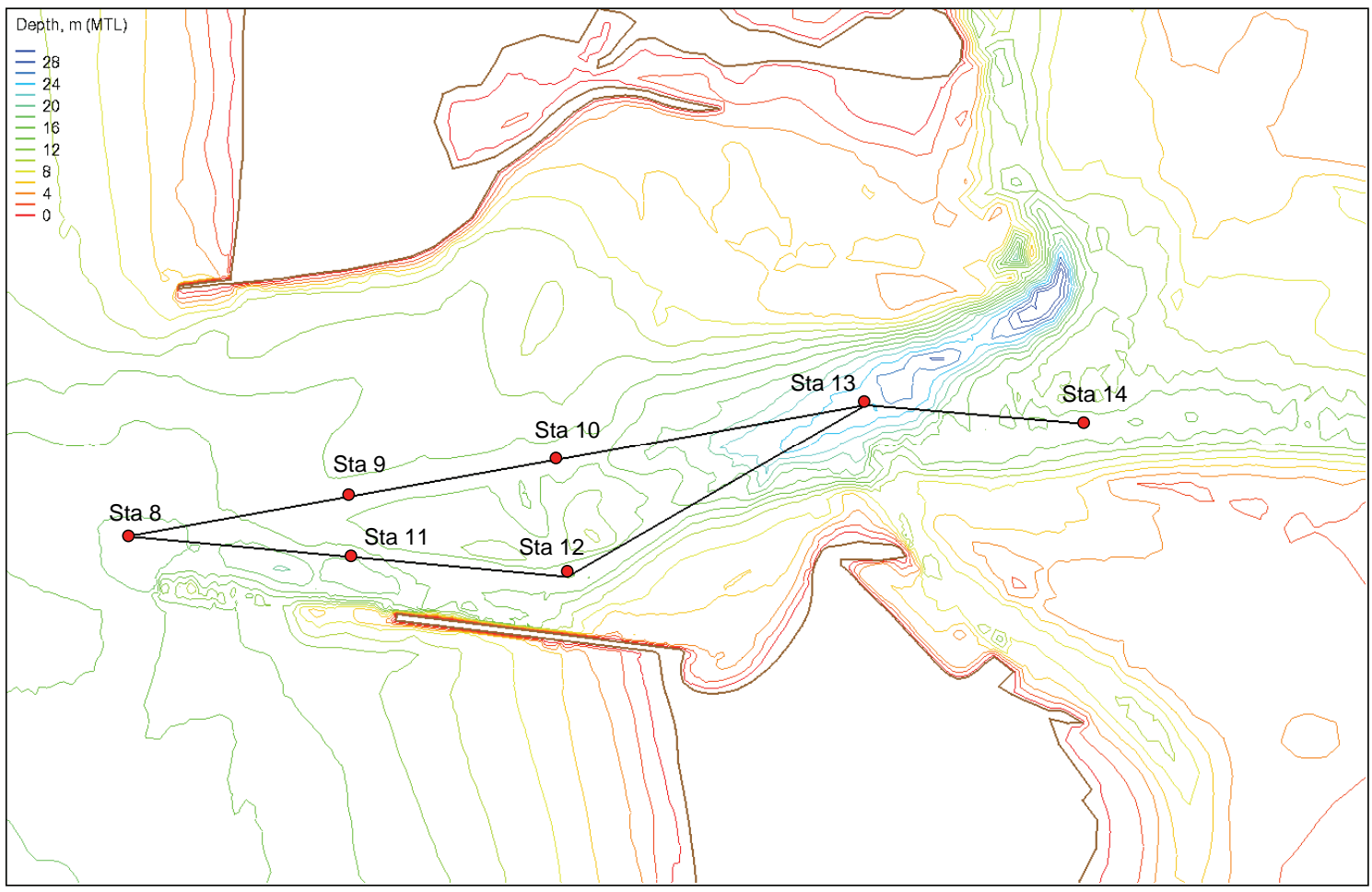

Figure 5-1. Output stations along Existing and Realigned channels.

Table 5-2. Station coordinates for display of results from production runs.

\begin{tabular}{|l|l|l|l|l|}
\hline $\begin{array}{l}\text { Sta } \\
\text { ID }\end{array}$ & $\begin{array}{l}\text { ADCIRC Grid } \\
\text { Node number }\end{array}$ & $\begin{array}{l}\mathrm{X} \\
(\mathrm{m})\end{array}$ & $\begin{array}{l}\mathrm{Y} \\
(\mathrm{m})\end{array}$ & $\begin{array}{l}\mathrm{Z} \\
(\mathrm{m})\end{array}$ \\
\hline 8 & 13378 & 219491.85 & 181908.27 & 18.8 \\
\hline 9 & 16283 & 221312.82 & 182237.04 & 15.1 \\
\hline 10 & 17956 & 222648.59 & 182432.67 & 15.9 \\
\hline 11 & 17392 & 221308.34 & 181733.93 & 16.4 \\
\hline 12 & 19426 & 222660.76 & 181598.05 & 13.9 \\
\hline 13 & 20027 & 224761.71 & 182848.56 & 24.9 \\
\hline 14 & 21480 & 226448.43 & 182689.57 & 15.0 \\
\hline
\end{tabular}

\section{Hydrodynamic model results}

The calculated flow modeling results are compared in the along-channel plots of average and maximum current speeds and also in pie charts showing percent occurrence of current speeds for the flood and ebb cycles 
of the simulation periods (quarters and extreme storm) for each channel alternative. The results are discussed in the next three sections for the Existing channel, Realigned channel (with the Existing channel unfilled) and Realigned channel (with the Existing filled), respectively.

\section{Existing channel}

Figures 5-2 and 5-3 show the average and maximum current speeds, respectively, along the Existing channel at Sta 8, 11, 12, 13 and 14. These average and maximum current speeds were calculated for flood and ebb cycles in three quarters for the return periods of 0.5, 2 and $5 \mathrm{yrs}$ and the extreme storm condition over a 4 -week period in 1990. There were some differences between flood and ebb current magnitudes along the Existing and Realigned channels. The flood current appears to be slightly stronger than ebb for the Existing channel for most of the simulated periods. The 1.7 knots largest average flood current occurred in the 5-yr return period (Q4/ 1998) at Sta 11, and was stronger than the ebb current (1.3 knots) at the same location. The largest maximum flood current speed reached nearly 4 knots at Sta 11 for return periods of 0.5-yr (Q2/ 1993) and 5-yr (Q4/ 1998). The corresponding maximum ebb current was slightly less than 3 knots at Sta 11 and 13. The average and maximum current speeds from the extreme storm period were overall weaker than those obtained with the quarterly return periods.

Figures 5-4 through 5-7 show the pie charts of the flood and ebb current speeds in the Existing channel for four simulated periods. Less than one percent occurrences were discarded from the pie charts. The left-side of pie charts correspond to the flood current speeds at Sta 8, 11, 12, 13 and 14, while the right-side pie charts are for the ebb current. These pie charts show the percentage of exceedance levels of the flood or ebb tidal current along the navigation channel scenarios over the entire simulation periods for each of the return period and extreme storm period. The percentages in pie charts clearly indicate that tidal currents are strong at Sta 11 and 13 in the Existing Channel. At Sta 11, there were more strong current occurrences in the flood cycle than ebb cycle. However, at Sta 13, stronger current occurred more often in the ebb cycle than the flood cycle, an indication that the tidal flow was more convergent in the Existing channel during the flood cycle than ebb cycle. 

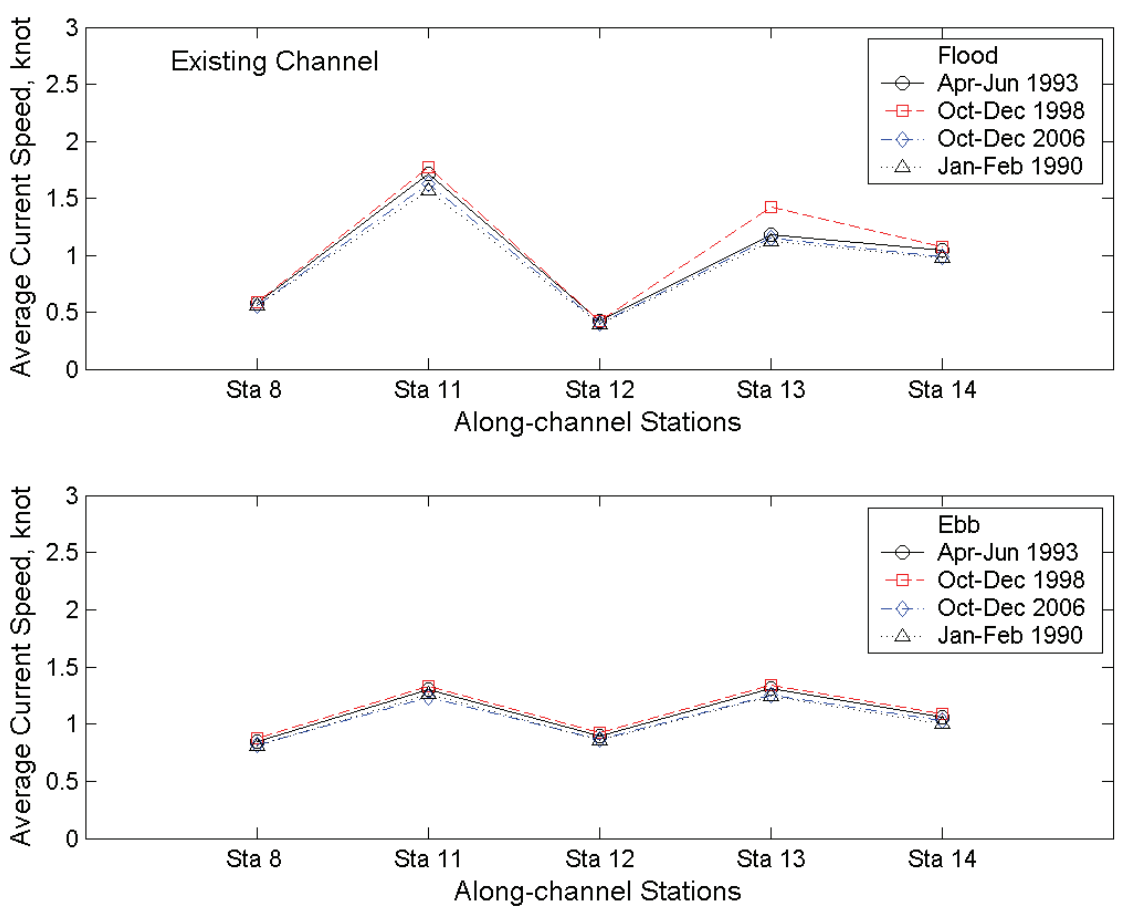

Figure 5-2. Spatial variation of average current speed at five stations along the Existing channel during the flood and ebb cycles.
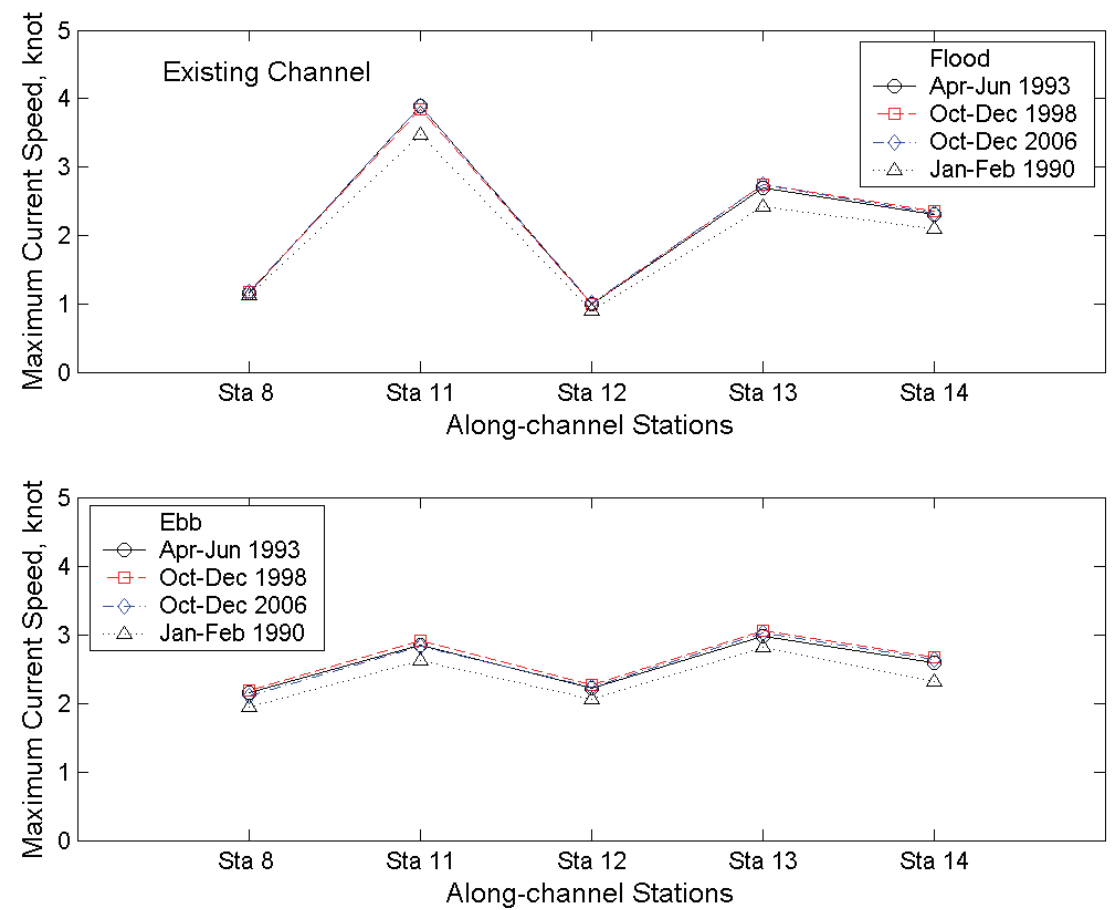

Figure 5-3. Spatial variation of maximum current at five stations along the Existing channel speed during the flood and ebb cycles. 

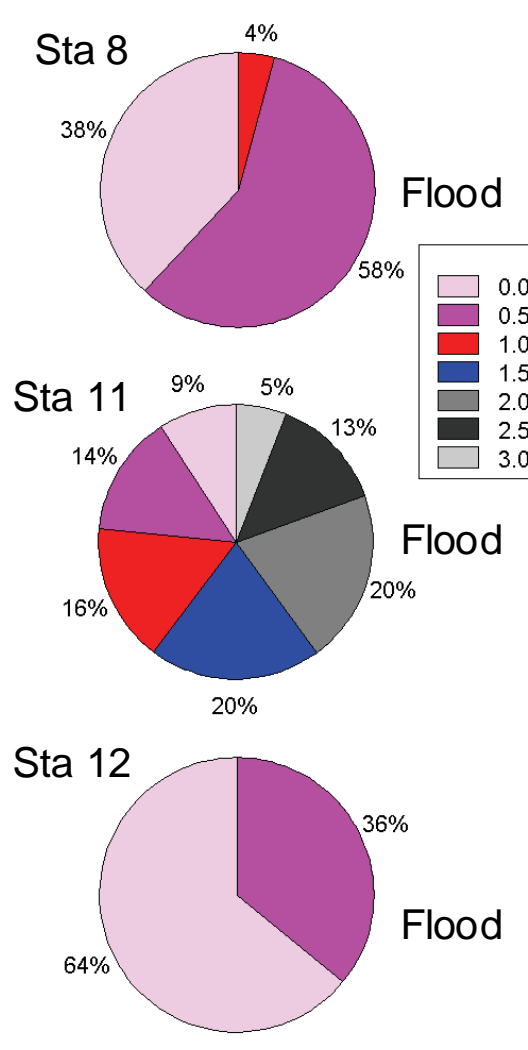

Sta 11
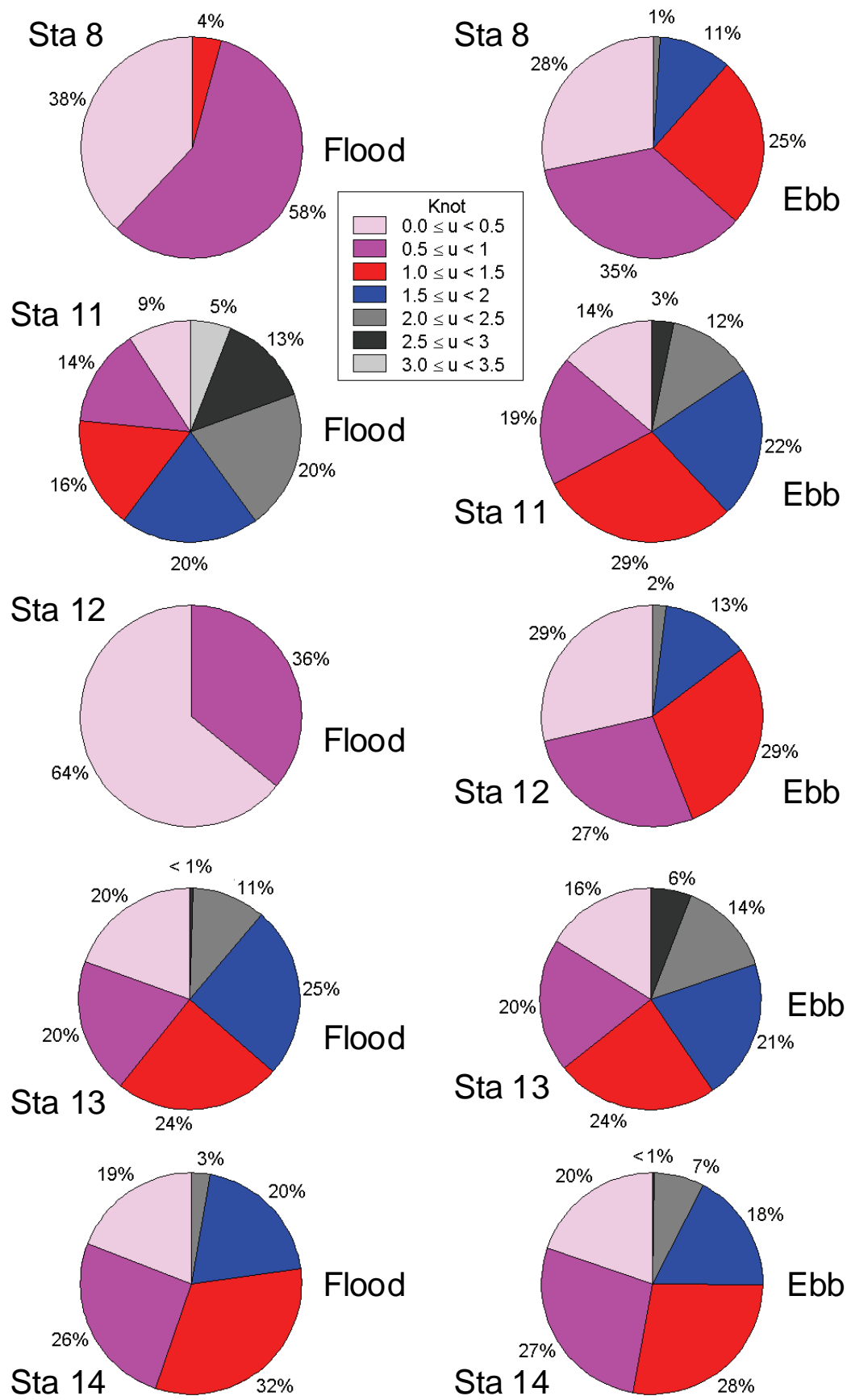

Figure 5-4. Percent occurrence of flood and ebb current at five stations along the Existing channel for 0.5-yr return period (Q2/1993). 


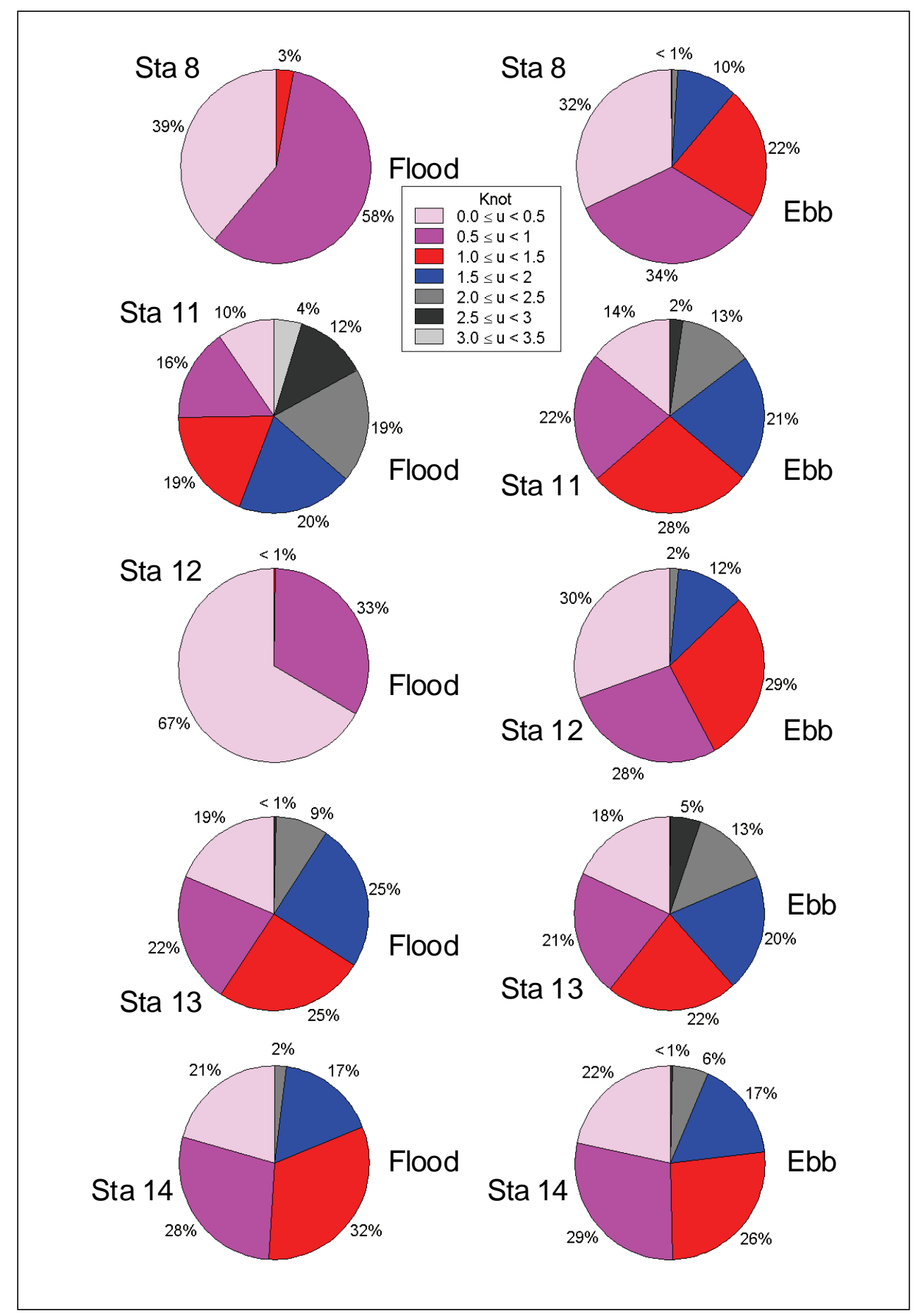

Figure 5-5. Percent occurrence of flood and ebb current at five stations along the Existing channel for 2-yr return period (Q4/2006). 


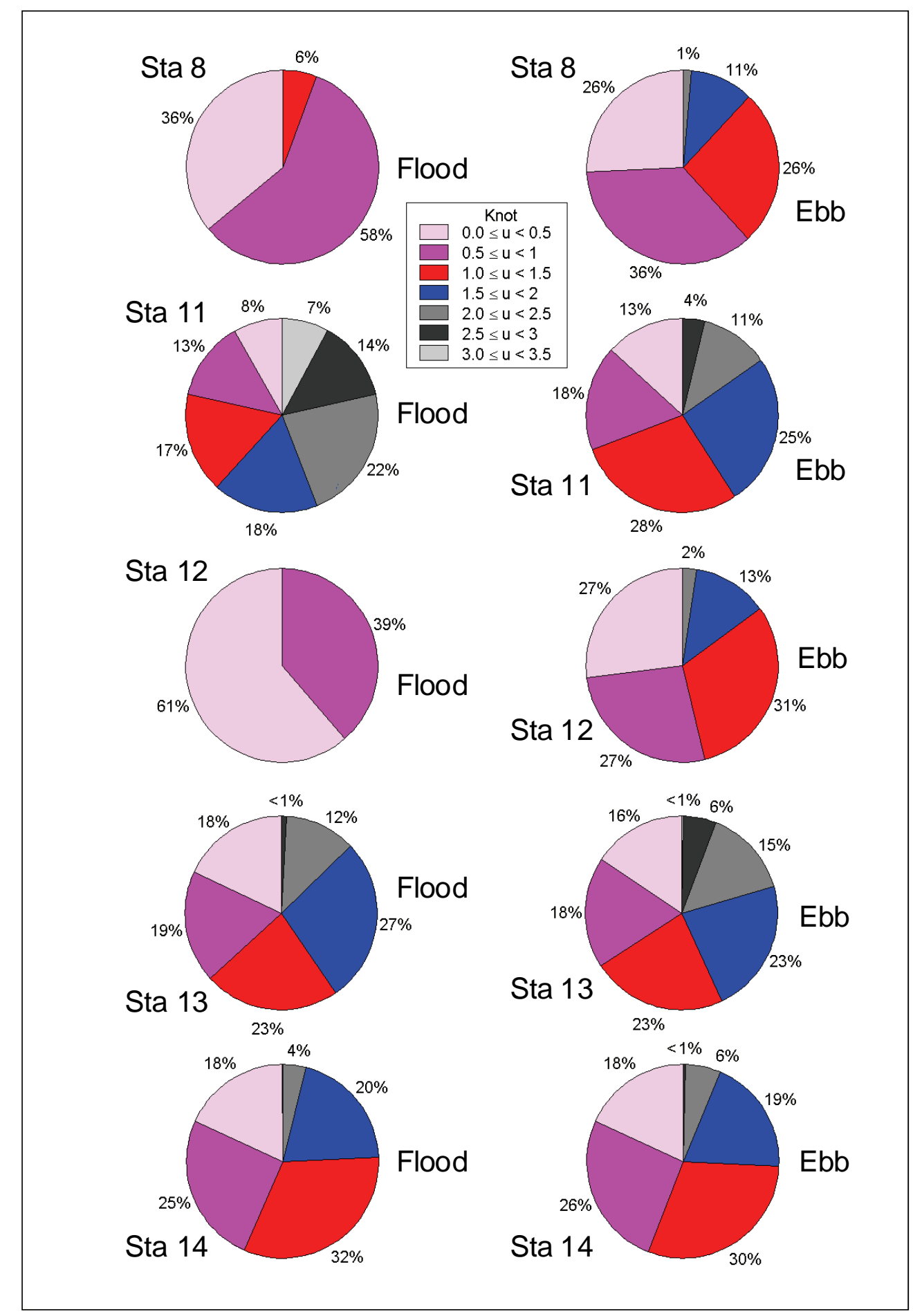

Figure 5-6. Percent occurrence of flood and ebb current at five stations along the Existing channel for 5-yr return period (Q4/1998). 


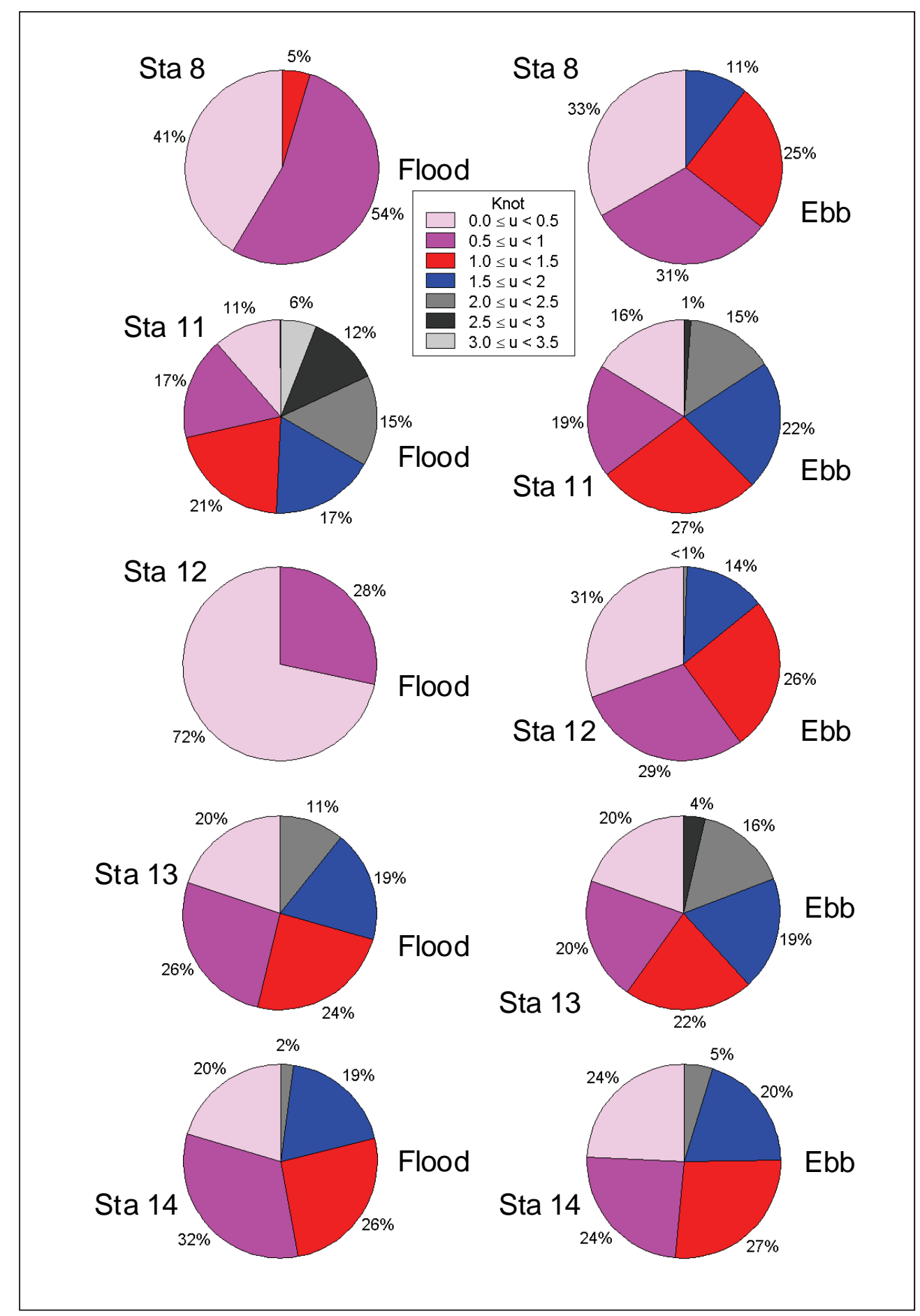

Figure 5-7. Percent occurrence of flood and ebb current at five stations along the Existing channel for the extreme storm period (Jan-Feb/1990). 


\section{Realigned channel (with Existing channel unfilled)}

Figures 5-8 and 5-13 show the spatial variation of current speeds along the Realigned channel (with the Existing channel unfilled) and the pie charts show percent occurrences at Sta 8, 9, 10, 13 and 14 for all simulated scenarios. Figures 5-8 and 5-9 are the along-channel plots of average and maximum current speeds, respectively, in the flood and ebb cycles. Along the Realigned channel (without the Existing channel filled), the magnitudes of the average flood and ebb current were similar, and there was less variation in current magnitude along the channel as compared to the Existing channel. For the Realigned channel, the largest average flood and ebb current were approximately 1.5 knots for all simulated conditions. The largest average flood current of 1.5 knots occurred for 5-yr return period (Q4/ 1998) at Sta 9, with an average ebb current of similar magnitude at Sta 10. The largest maximum flood current was 3.5 knots at Sta 9 for 5-yr return period (Q4/ 1998) and maximum ebb current was 3 knots at Sta 10 in the same return period. Along the Realigned channel, the average and maximum current speeds in the flood and ebb cycles for the extreme storm period were weaker than their counterparts for quarterly return periods (0.5-, 2- and 5-yr).
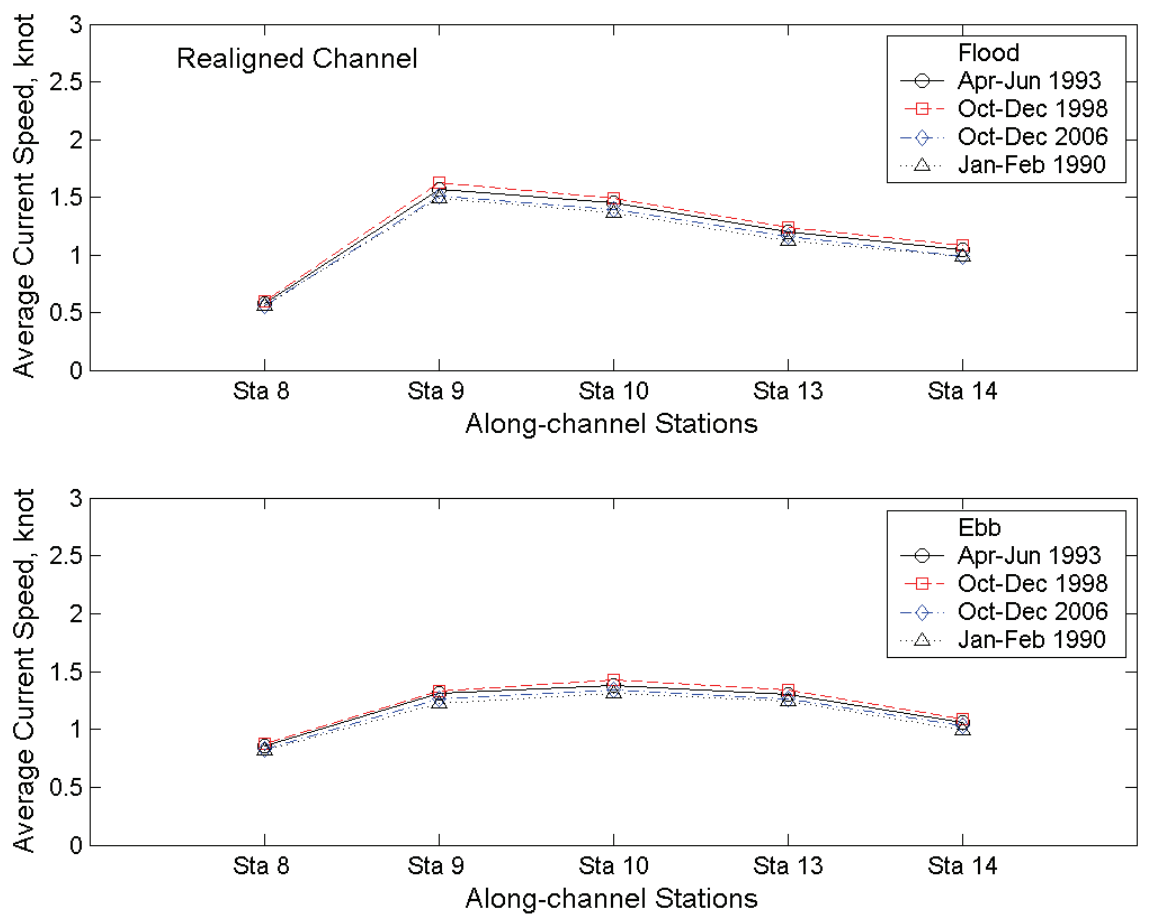

Figure 5-8. Spatial variation of average flood and ebb current speed at five stations along the Realigned channel with the Existing channel unfilled. 

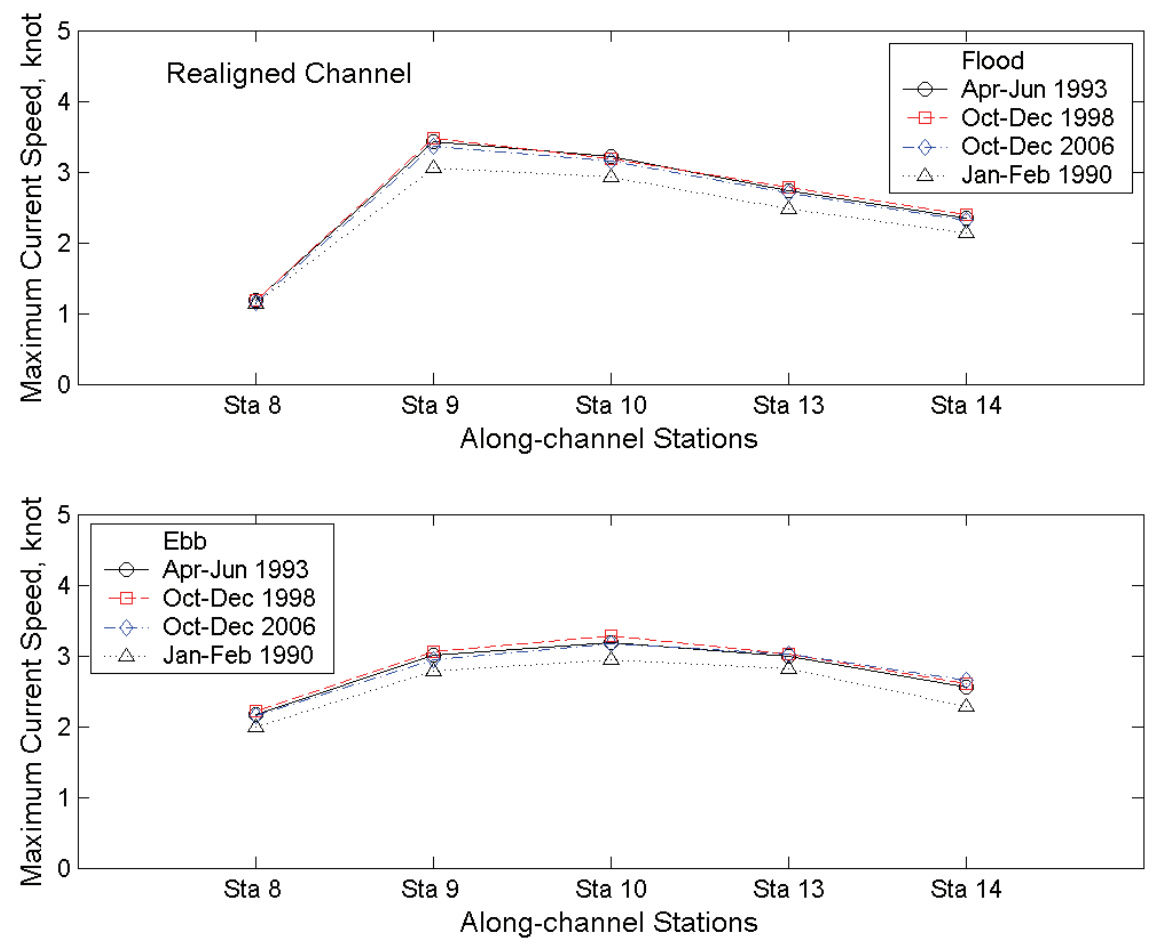

Figure 5-9. Spatial variation of maximum flood and ebb current speed at five stations along the Realigned channel with the Existing channel unfilled.

Figures 5-10 to 5-13 are the pie charts for flood and ebb current speeds in the Realigned channel (Sta 8, 9, 10, 13, and 14) for three simulated return periods and one extreme storm period. The percentages of less than 1 are not shown on these pie charts. The percent occurrences values given in these pie charts clearly indicate the presence of stronger flood and ebb currents at Sta 9, 10 and 13. The percentages were higher for strong currents at Sta 9 in the flood cycle than ebb cycle. This trend continued at Sta 10 where the strong flood and ebb current percentages were nearly equal. At Sta 13, the pie charts show a reversed pattern in that there were more strong currents in the ebb cycle than flood cycle. It is evident that there were stronger flood currents at Sta 10 than ebb currents at Sta 13 (i.e., greater percentage at Sta 10 than Sta 13).

\section{Realigned channel (with Existing channel filled)}

Figures 5-14 and 5-15 show the in-channel spatial variation of average and maximum current magnitude at Sta 8, 9, 10, 13 and 14 along the Realigned channel with the Existing channel filled. The magnitudes of average flood and ebb current were similar for the Realigned channel with the Existing 


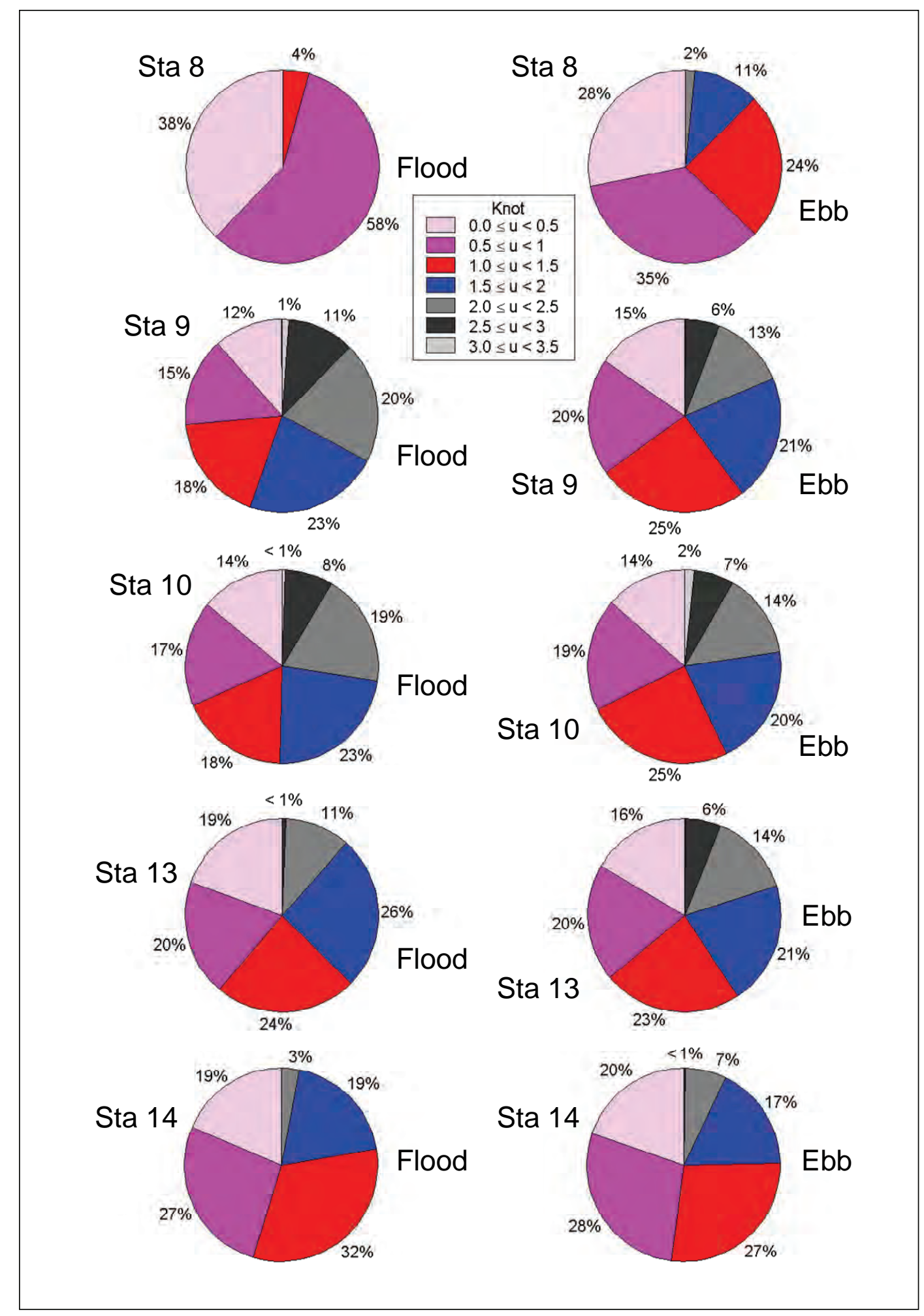

Figure 5-10. Percent occurrence of flood and ebb current at five stations along the Realigned channel for 0.5-yr return period (Q2/1993). 


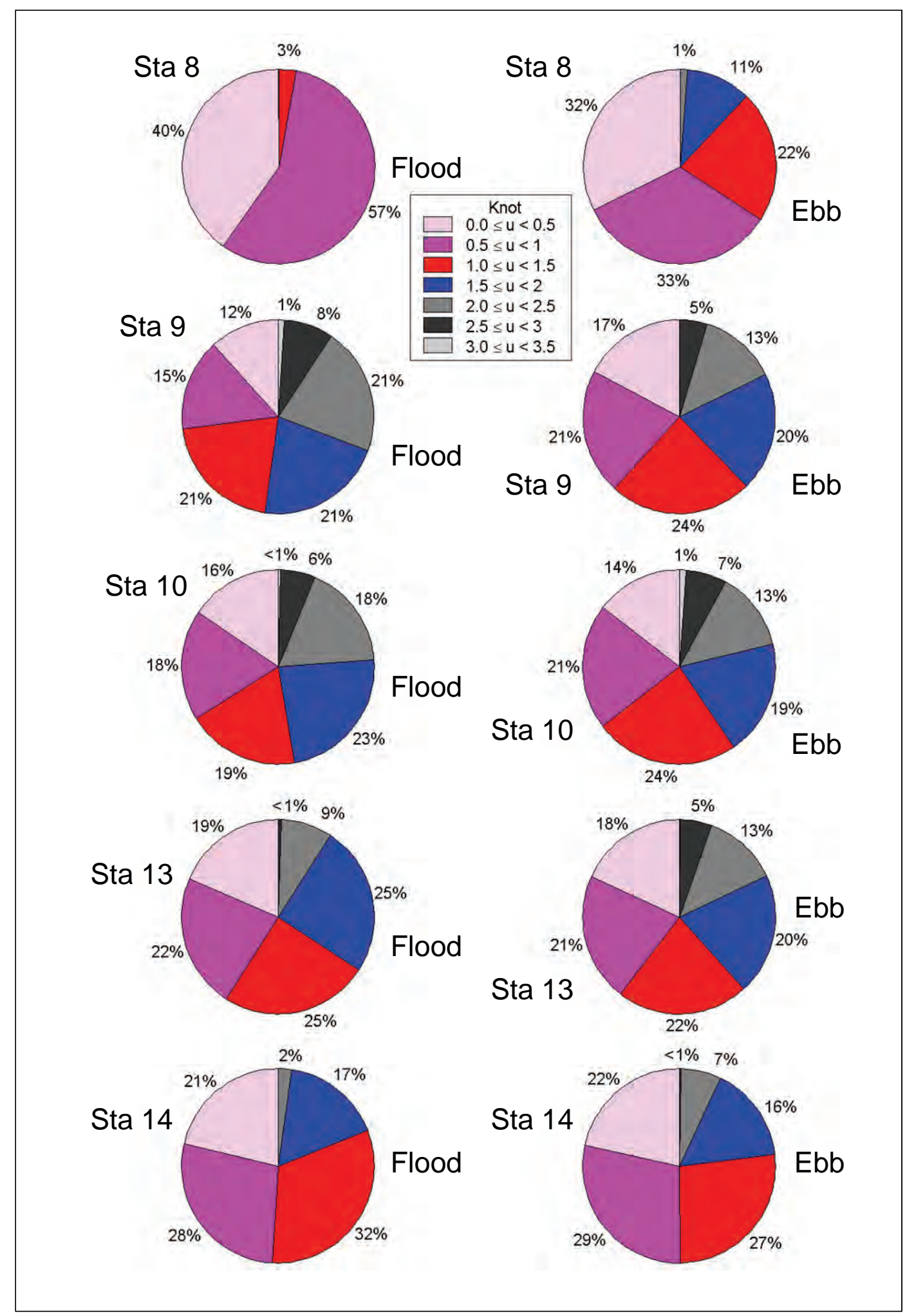

Figure 5-11. Percent occurrence of flood and ebb current at five stations along the Realigned channel for 2-yr return period (Q4/2006). 


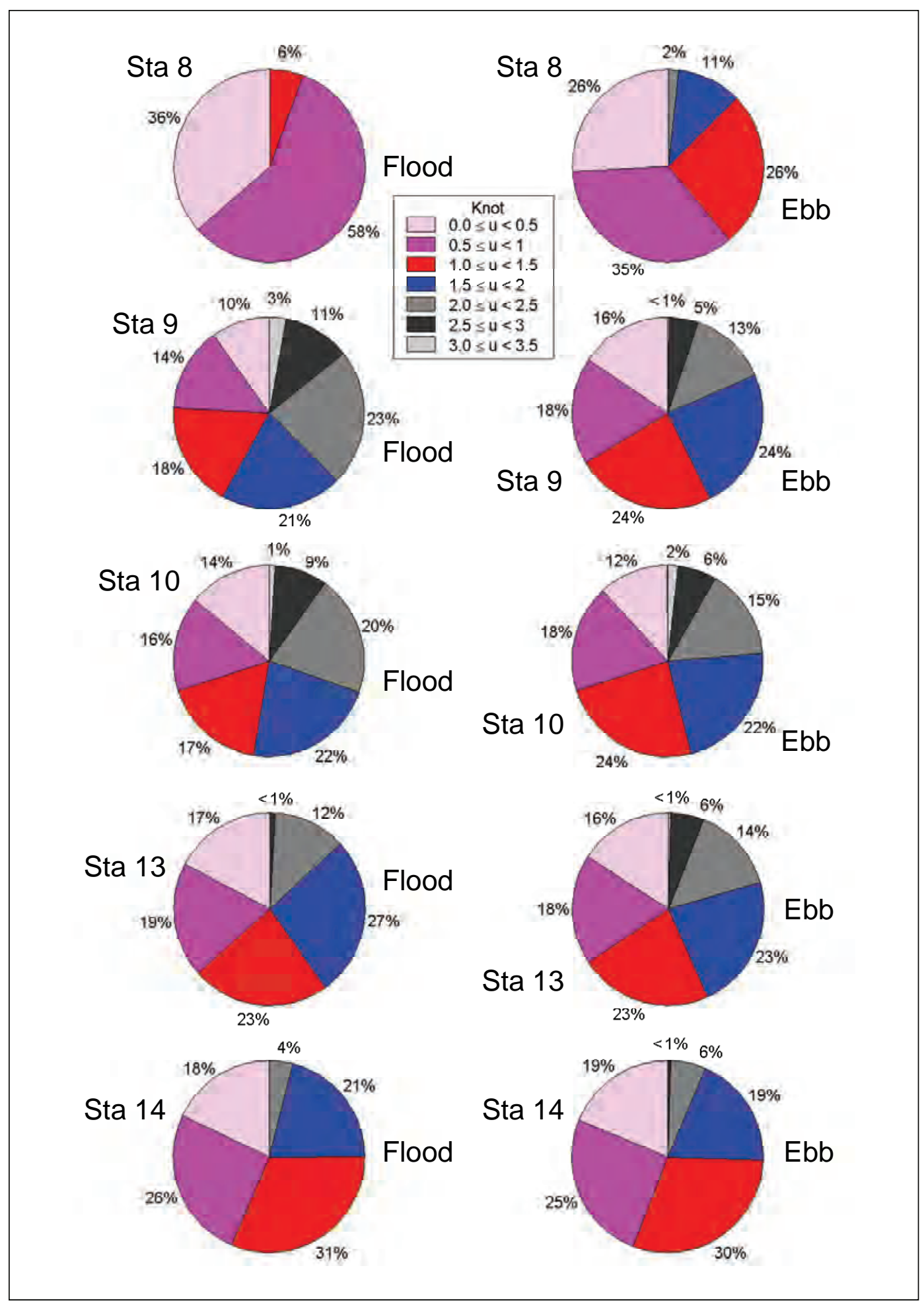

Figure 5-12. Percent occurrence of flood and ebb current at five stations along the Realigned channel for 5-yr return period (Q4/1998). 


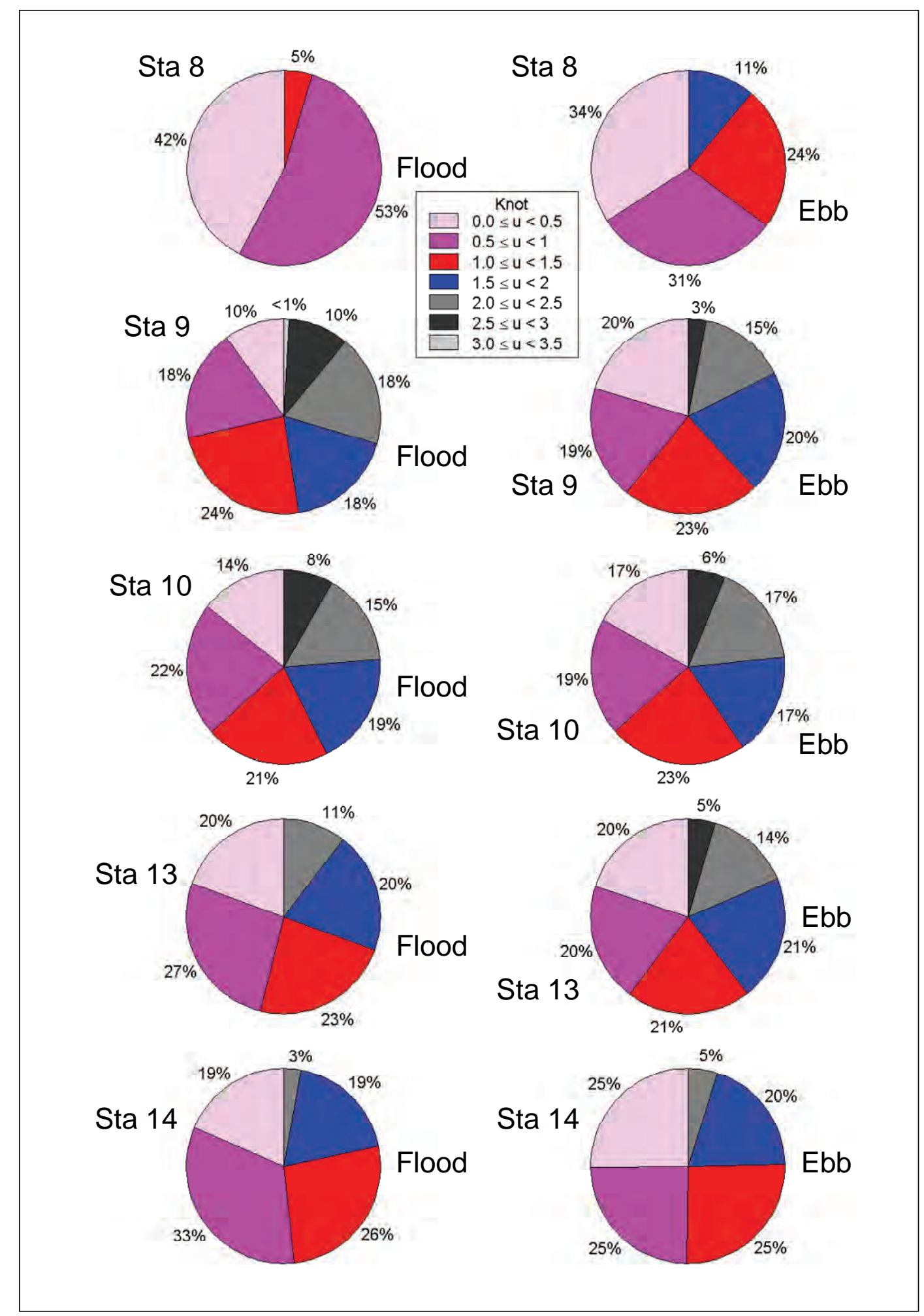

Figure 5-13. Percent occurrence of flood and ebb current at five stations along the Realigned channel for an extreme storm event (Jan-Feb/1990). 

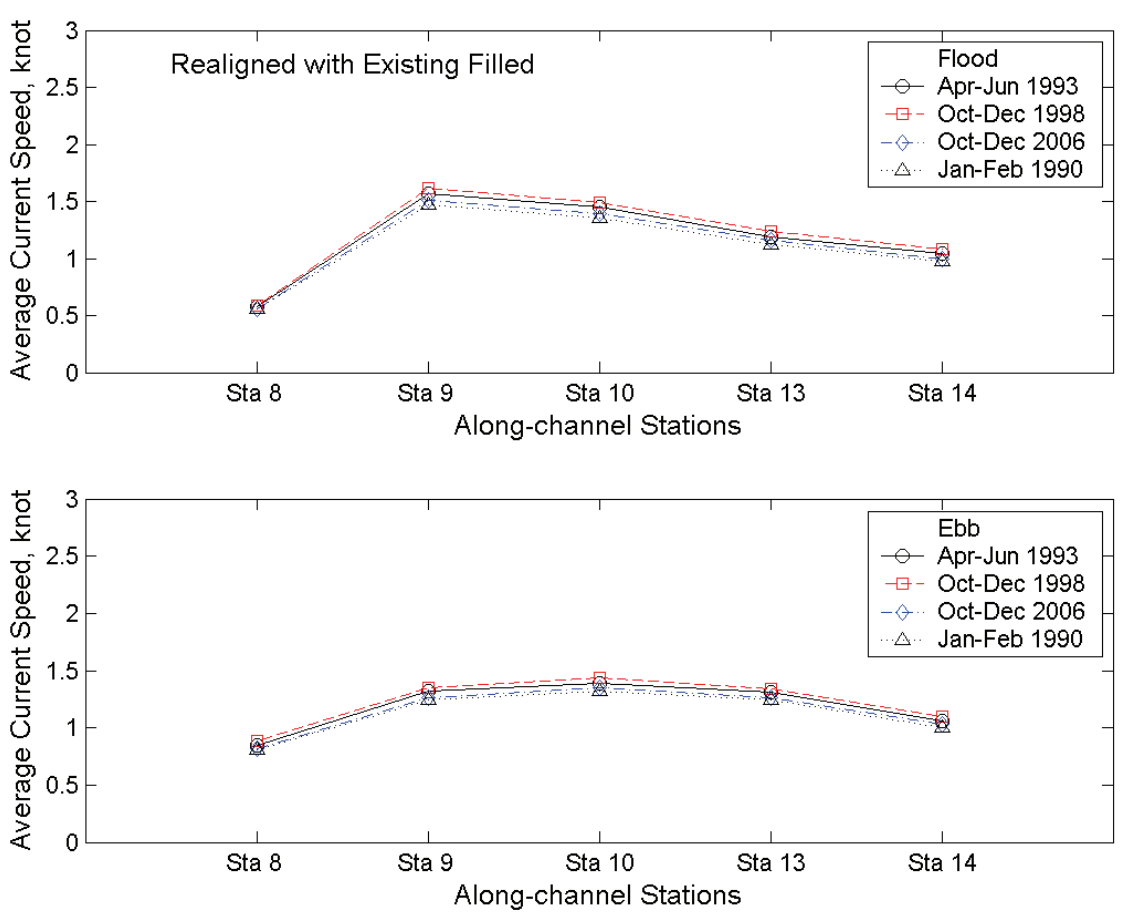

Figure 5-14. Spatial variation of average flood and ebb current speed at five stations along the Realigned channel with the Existing channel filled.
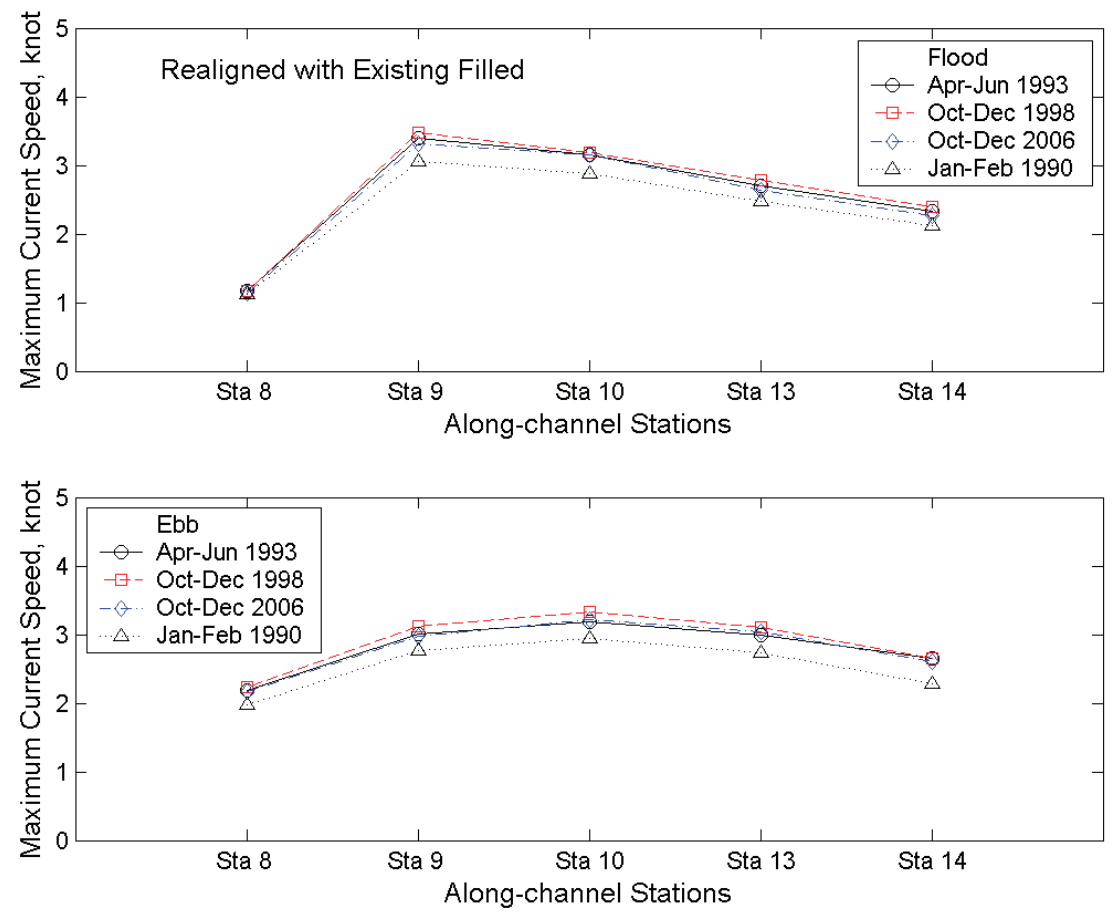

Figure 5-15. Spatial variation of maximum flood and ebb current speed at five stations along the Realigned channel with the Existing channel filled. 
channel filled, and nearly identical to values discussed in the previous section for the Realigned channel with the Existing channel unfilled. Overall, with or without the Existing channel filled, the Realigned channel (Sta 9 and 10) had comparatively weaker maximum current than the Existing channel (Sta 11 and 12).

In this case, the largest average flood and ebb current were approximately 1.5 knots for all simulated conditions. The largest average flood current of 1.5 knots occurred for 5-yr return period (Q4/ 1998) at Sta 9, with an average ebb current of similar value at this station. The largest maximum flood current was 3.5 knots at Sta 9 for 5-yr return period (Q4/ 1998). The corresponding maximum ebb current was 3.3 knots at Sta 10 for the same return period.

Figures 5-16 through 5-19 show the pie charts for the Realigned channel with the Existing channel filled for three return periods and one extreme storm period, respectively. The sum of percentages is 1 , except for cases where percent occurrences less than 1 are omitted. These pie charts show almost identical flood and ebb current speed distribution to the Realigned channel with the Existing channel unfilled. This indicates that the effect of the Existing channel filled was negligible to the Realigned channel.

\section{Wave model results}

This section presents the wave production results at seven output stations along the Existing and Realigned channels. The spatial variation of average and maximum significant wave height is shown first for three channel scenarios: Existing channel, Realigned channel with the Existing channel unfilled, and Realigned channel with the Existing channel filled. The calculated percent occurrence of significant wave height ranges is compared next in pie charts for the three channel scenarios.

\section{Spatial variation of wave height}

Figures 5-20 through 5-22 show the spatial variation of average and maximum significant wave height for the Existing channel and Realigned channel with and without the Existing Channel filled, respectively. Variations of the maximum and average significant wave height were provided at Sta 8, 11, 12, 13 and 14 for the Existing channel, and at Sta 8, 9, 10, 13 and 14 for the Realigned channel with and without the Existing channel filled. 


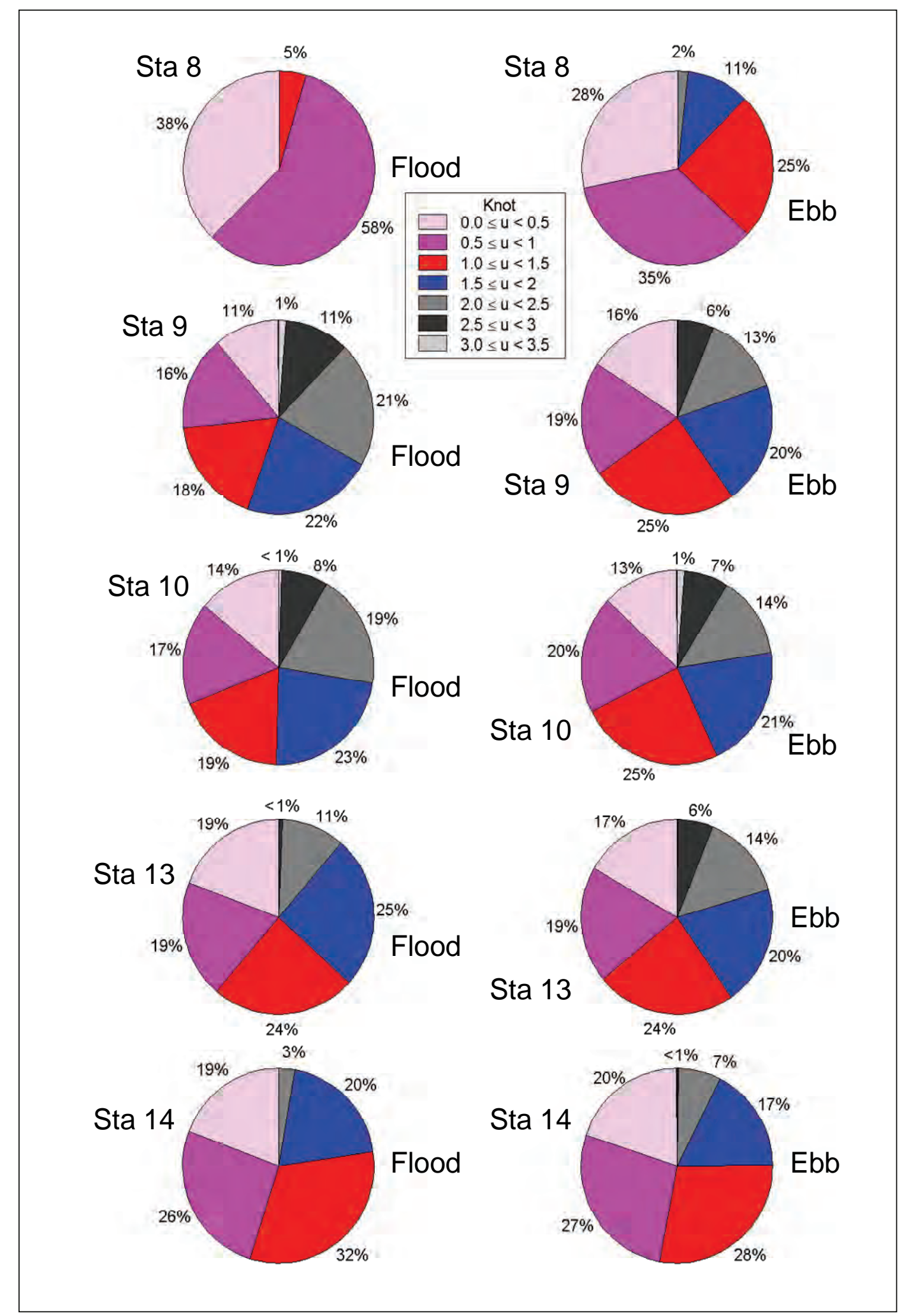

Figure 5-16. Percent occurrence of flood and ebb current at five stations along the Realigned channel (w/ Existing channel filled) for a 0.5-yr return period (Q2/1993). 


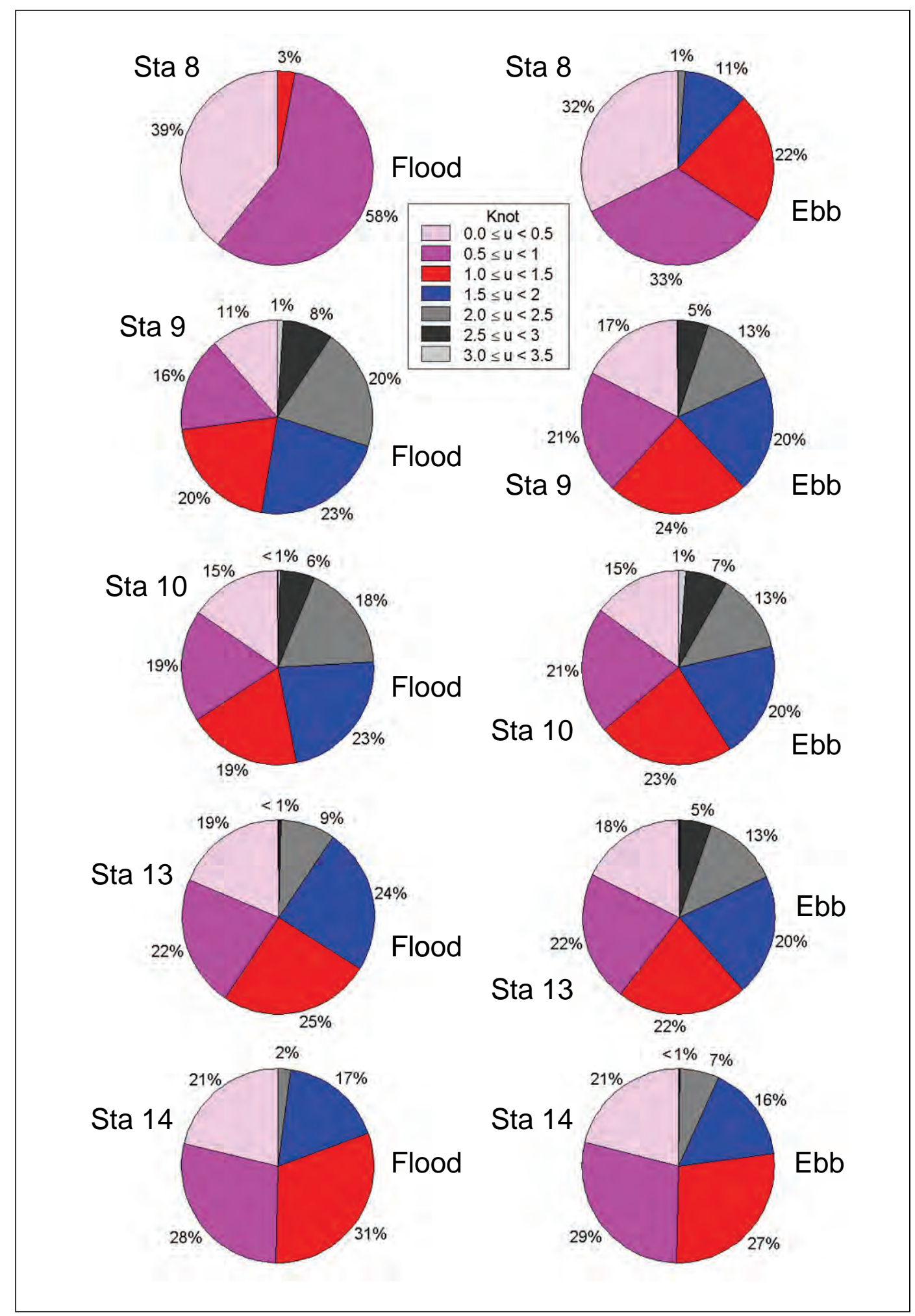

Figure 5-17. Percent occurrence of flood and ebb current at five stations along the Realigned channel (w/ Existing channel filled) for a 2-yr return period (Q4/2006). 


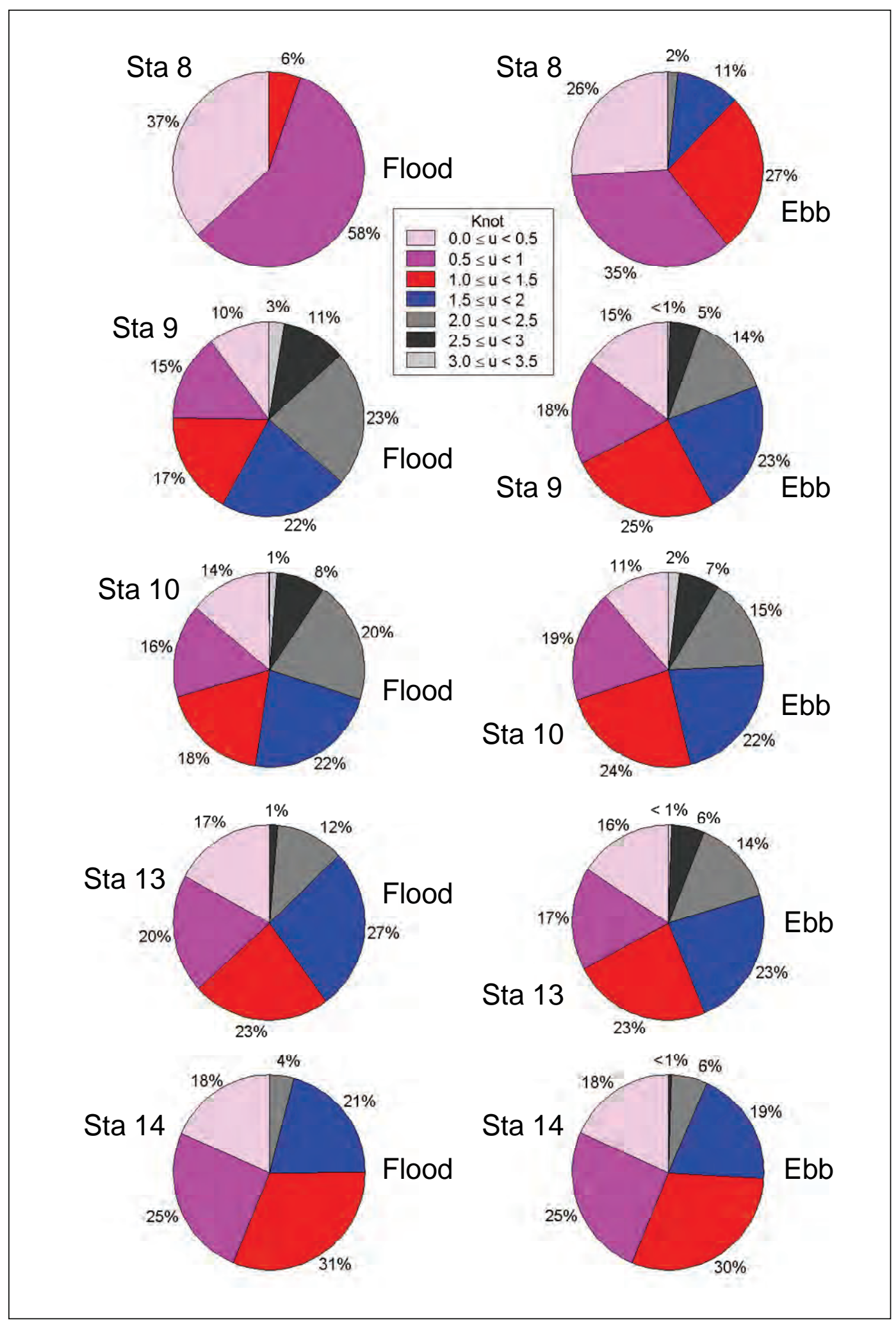

Figure 5-18. Percent occurrence of flood and ebb current at five stations along the Realigned channel (w/ Existing channel filled) for a 5-yr return period (Q4/1998). 


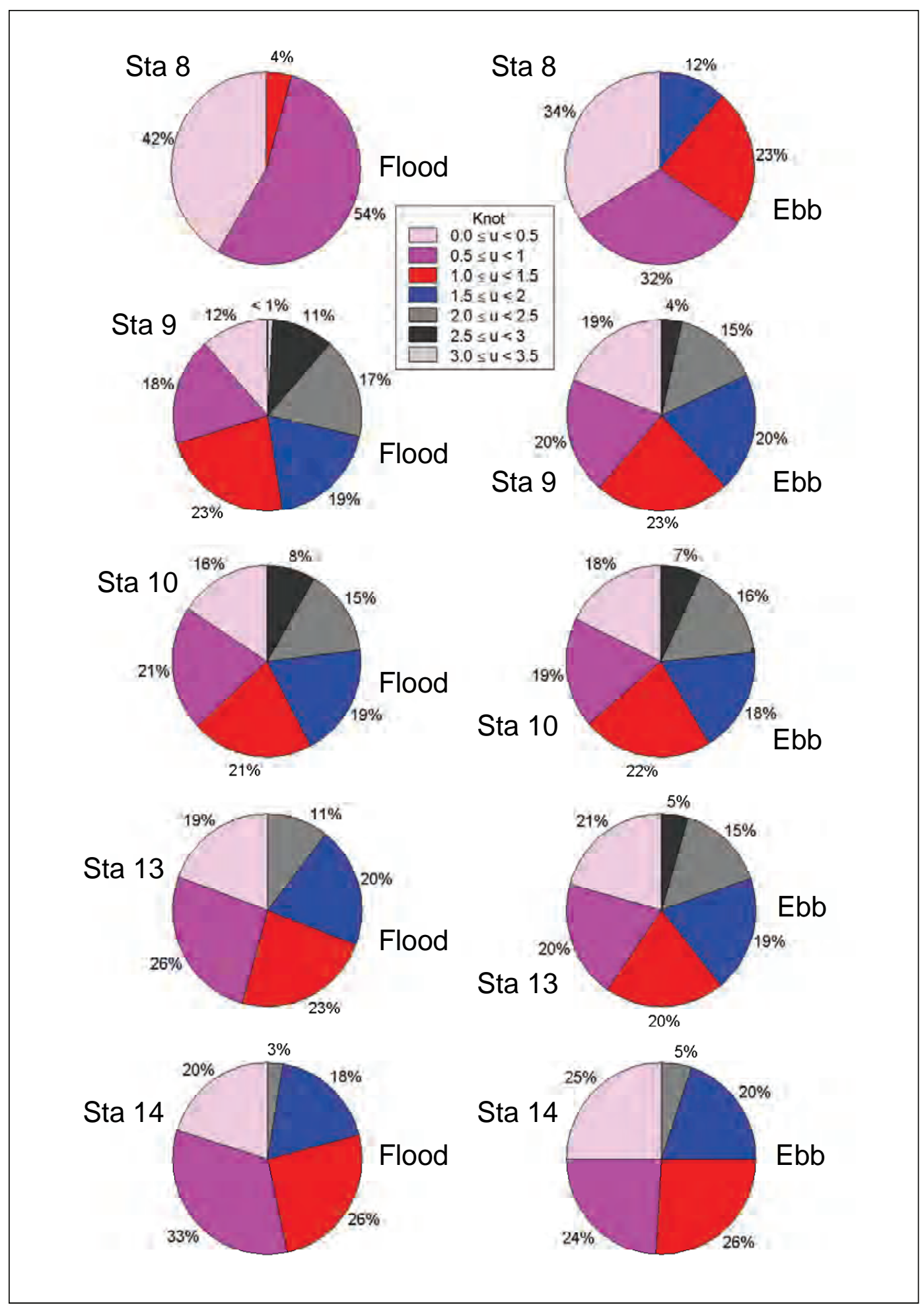

Figure 5-19. Percent occurrence of flood and ebb current at five stations along the Realigned channel (w/ Existing channel filled) for an extreme storm (Jan-Feb/1990). 

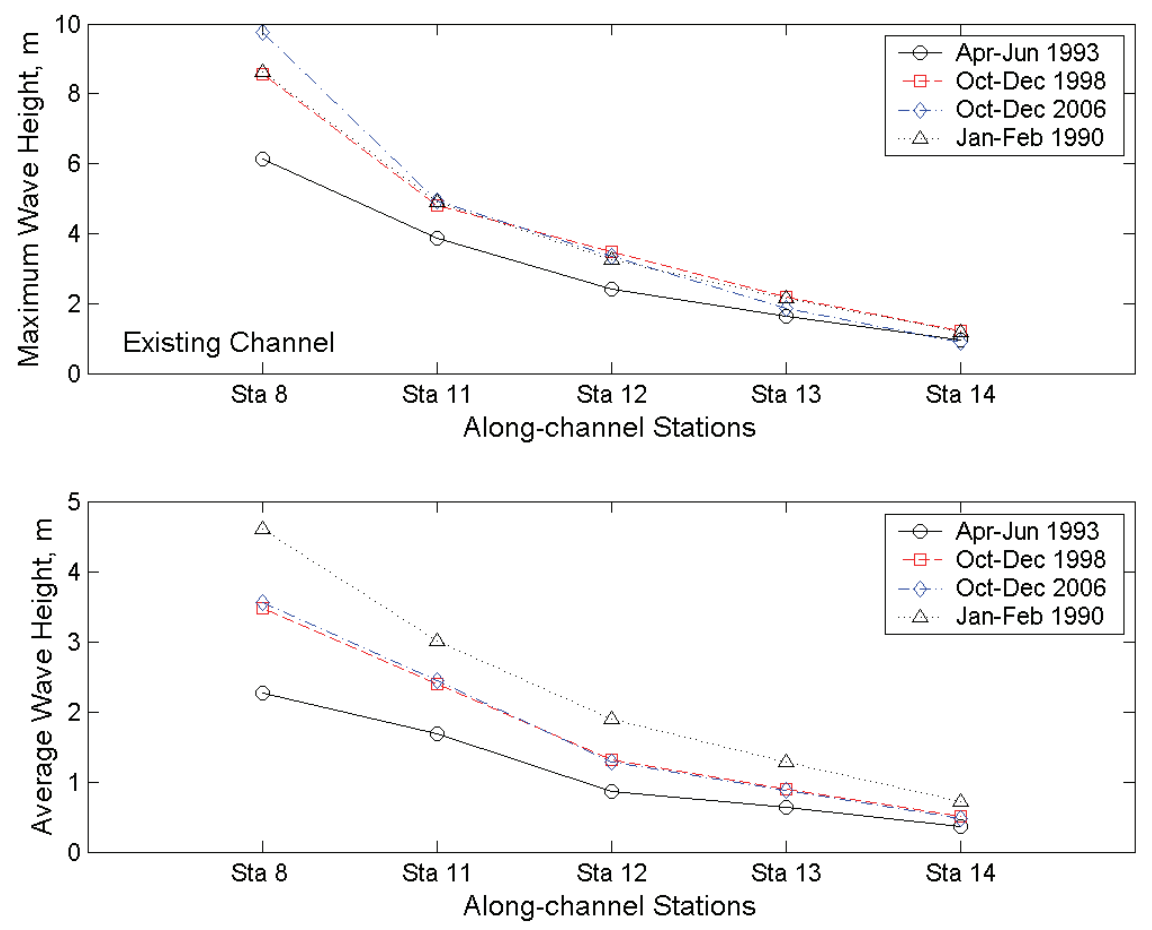

Figure 5-20. Maximum and average significant wave heights for the Existing channel.
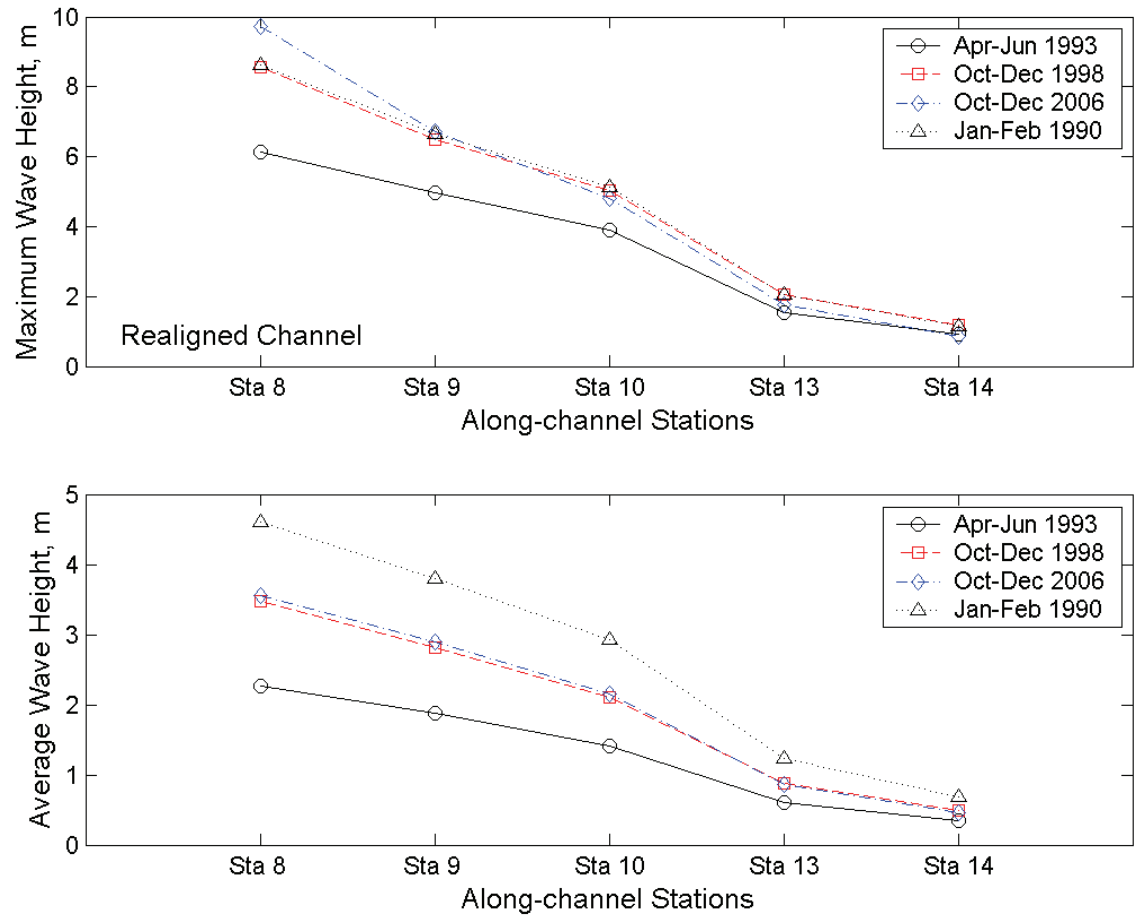

Figure 5-21. Maximum and average wave heights for the Realigned channel without the Existing channel filled. 

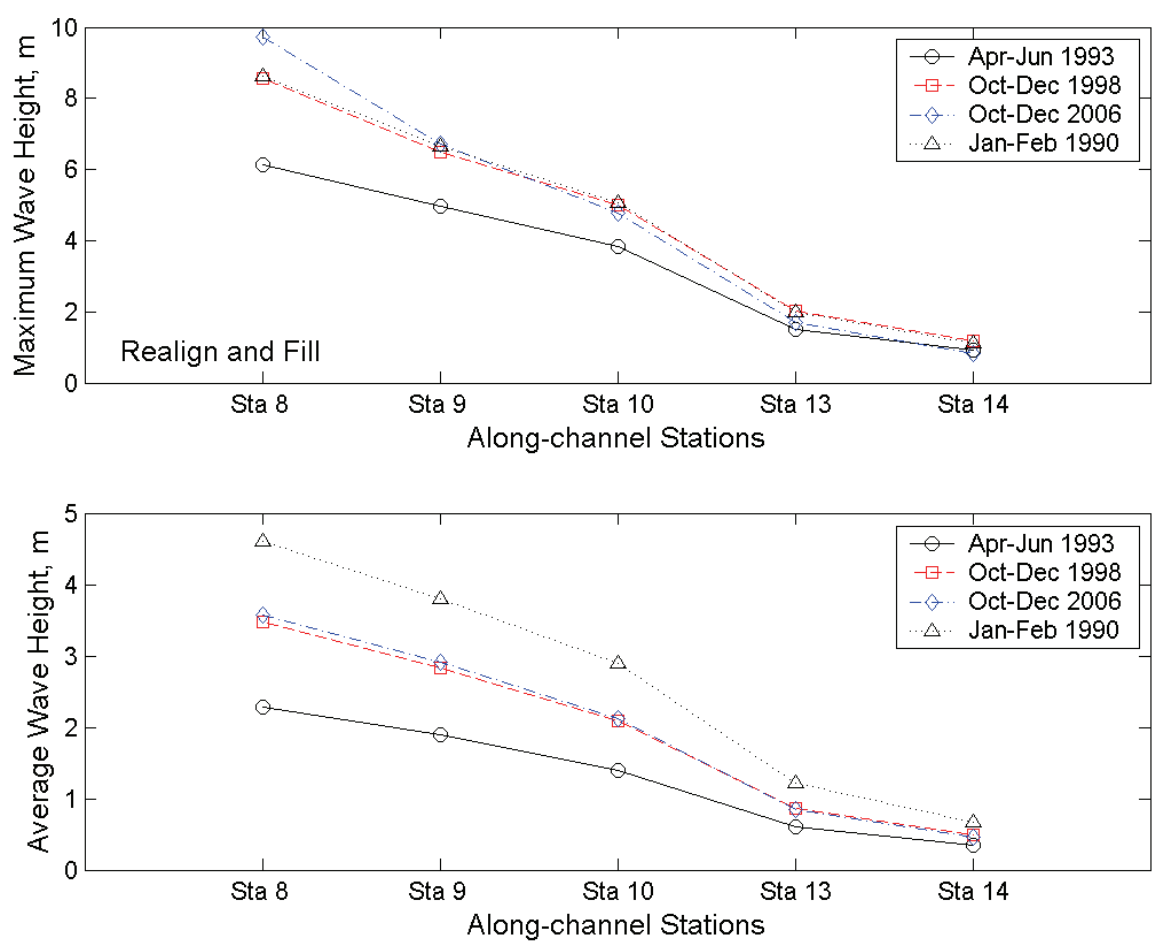

Figure 5-22. Maximum and average wave heights for the Realigned channel with the Existing channel filled.

For the Existing channel, the largest maximum significant wave height of roughly 10 m occurred at Sta 8 in Q4/ 2006 for the 2-yr return period. The significant wave height decreased quickly towand the bay to $1.5 \mathrm{~m}$ at Sta 14. The largest average significant wave height was $4.7 \mathrm{~m}$ at Sta 8 in the extreme storm period of J an-Feb 1990 and the smallest average wave height was 0.4 m at Sta 14 for Q2/ 1993.

For the Realigned channel (with the Existing Channel unfilled), the largest maximum significant wave height was roughly $10 \mathrm{~m}$ at Sta 8 in Q4/2006 for the 2-yr return period. The maximum significant wave height decreased approximately linearly towards the bay to $2 \mathrm{~m}$ at Sta 14. The largest average wave height was $4.7 \mathrm{~m}$ at Sta 8 in the Extreme storm period, and the smallest average wave height was $0.4 \mathrm{~m}$ at Sta 14 for Q2/ 1993 (0.5yr return period).

For the Realigned channel with the Existing channel filled, the largest maximum significant wave height was approximately $10 \mathrm{~m}$ at Sta 8 in Q4/ 2006 (2-yr return period). The trend in the spatial variation of 
maximum and average significant wave heights was similar to the Realigned channel with the Existing channel unfilled.

\section{Comparison of ave height ranges}

Figures 5-23 through 5-30 show the percent occurrence comparisons of the significant wave height ranges at Sta 8 to 14 for the Existing and Realigned channels with and without the Existing channel filled. Depending on data range, wave heights were divided into five or six bands as:

1. wave height range \#1: 0 to $2 \mathrm{~m}$

2. wave height range \#2: 2 to $4 \mathrm{~m}$

3. wave height range \#3: 4 to $6 \mathrm{~m}$

4. wave height range \#4: 6 to $8 \mathrm{~m}$

5. wave height range $\# 5$ : 8 to $10 \mathrm{~m}$

or

1. wave height range \#1: 0 to $1 \mathrm{~m}$

2. wave height range \#2: 1 to $2 \mathrm{~m}$

3. wave height range \#3: 2 to $3 \mathrm{~m}$

4. wave height range \#4: 3 to $4 \mathrm{~m}$

5. wave height range \#5: 4 to $5 \mathrm{~m}$

6. wave height range \#6: 5 to $6 \mathrm{~m}$

Each pie chart displays percent occurrences of the five or six wave height ranges for a given quarter associated with each return period and the extreme storm period. Percent occurrence of wave height ranges are compared at Sta 8, 9, 10, and at Sta 8, 11, 12 for Existing, Realigned and Realigned with the Existing channel filled scenarios. These are followed by comparison of pie charts at Sta 13 and 14.

Figure 5-23 shows the percent occurrences of wave height ranges at Sta 8, 9 and 10 for three channel scenarios in the J an-Feb 1990 Extreme storm period. The distribution of wave height at Sta 8 remained unchanged for three channel scenarios, and nearly half of waves were in the 4 to $6 \mathrm{~m}$ range. Wave heights at Sta 9 and 10 for the Existing channel were comparatively greater than those for two Realigned channel alternatives at these locations. There was essentially no difference between wave height percentages for two Realigned channel scenarios. A good portion of large significant wave heights between 6 and $10 \mathrm{~m}$ is at Sta 8 and 9. For the two Realigned channel 

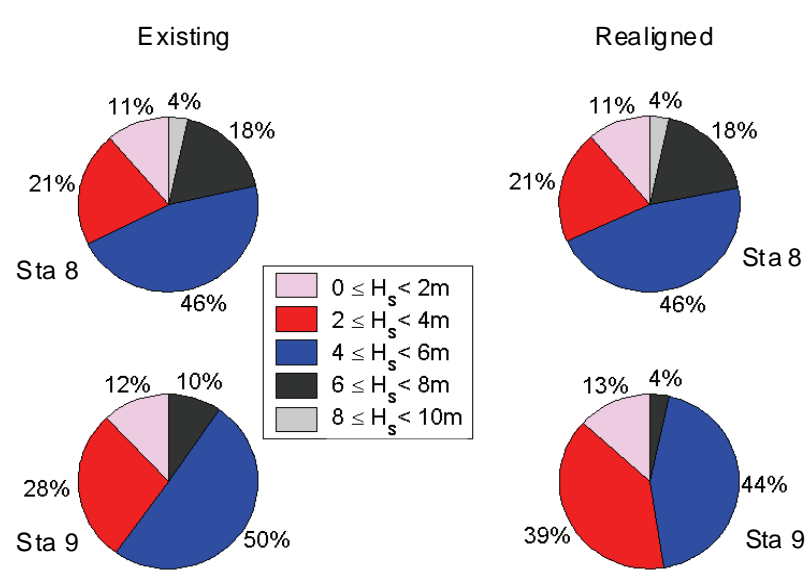

Realigned with

Existing Filled
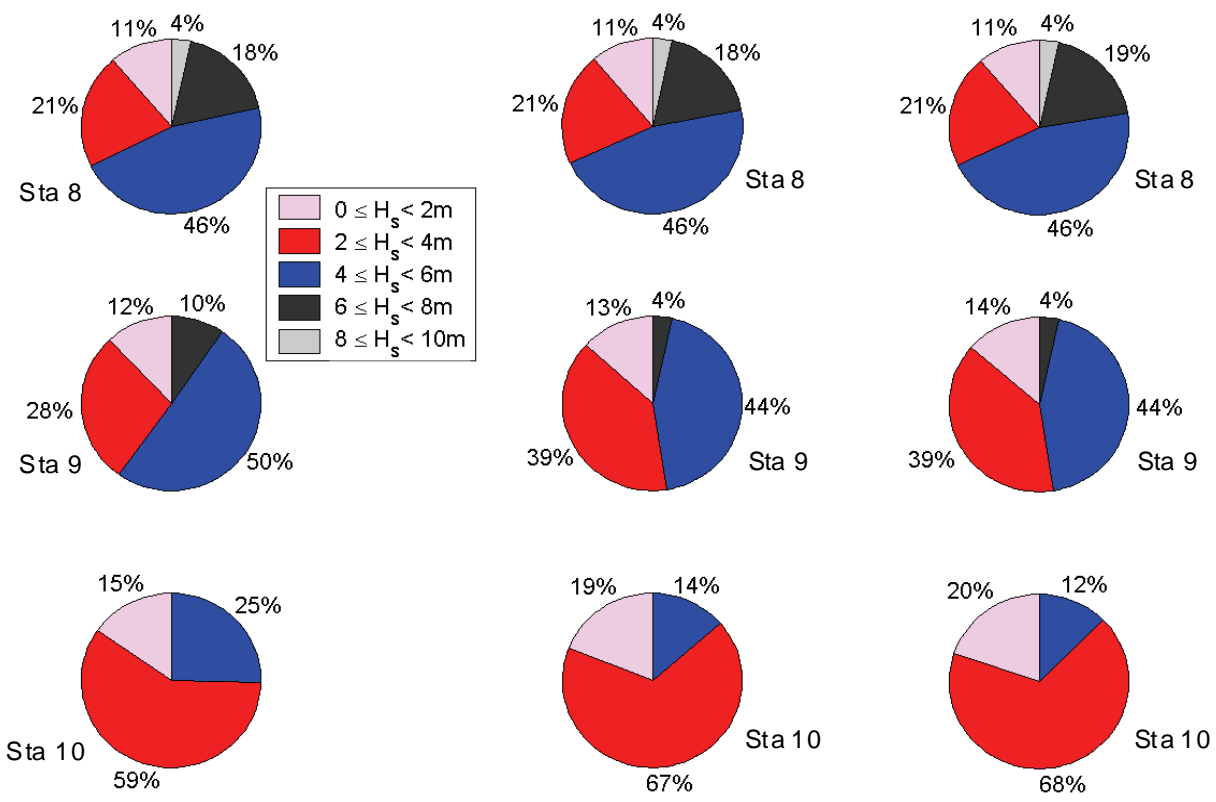

Figure 5-23. Percent occurrence comparison for three channels scenarios at Sta 8, 9 and 10 (Jan-Feb 1990, extreme storm period).

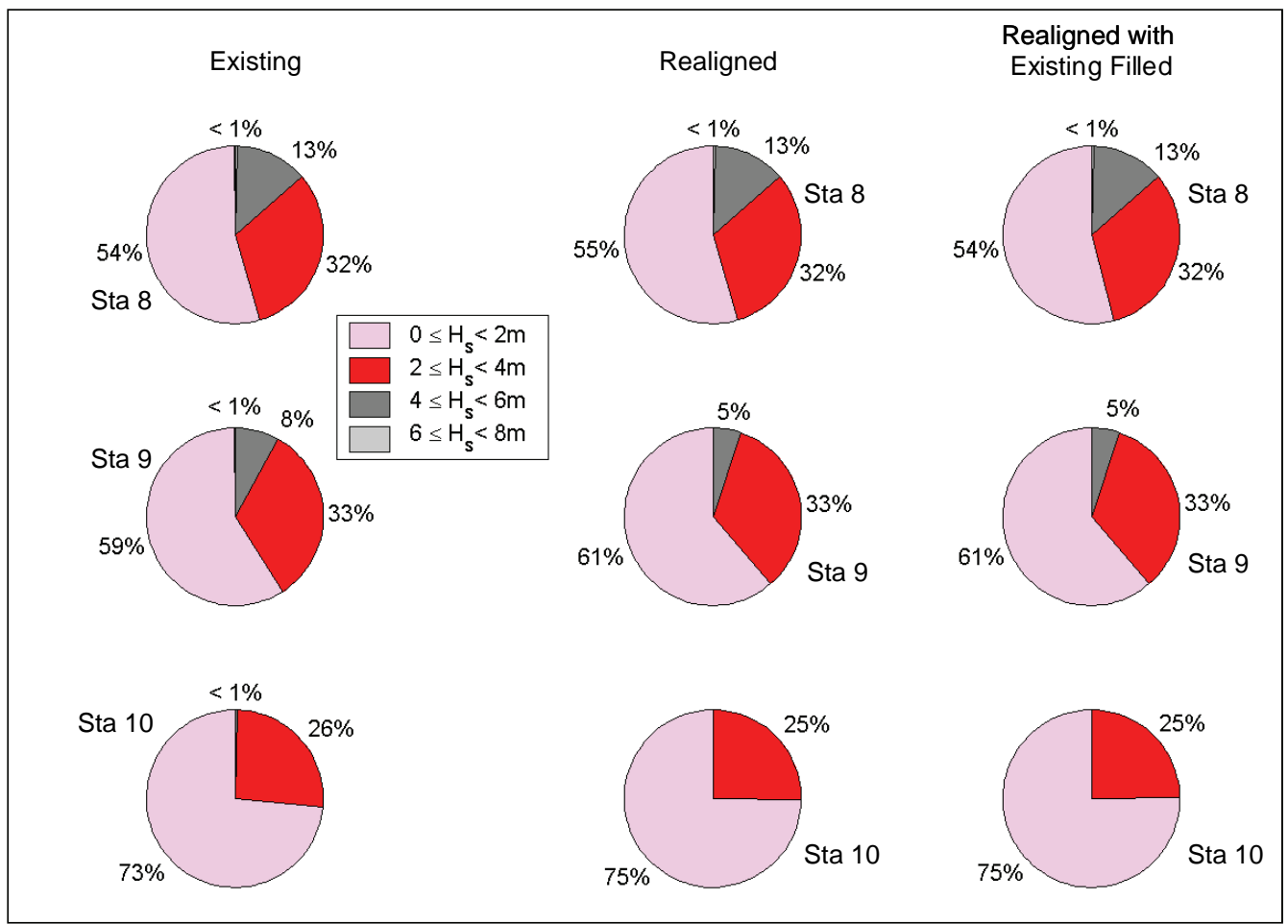

Figure 5-24. Percent occurrence comparison for three channels scenarios at Sta 8, 9 and 10 (Q2/1993, 0.5-yr return period). 


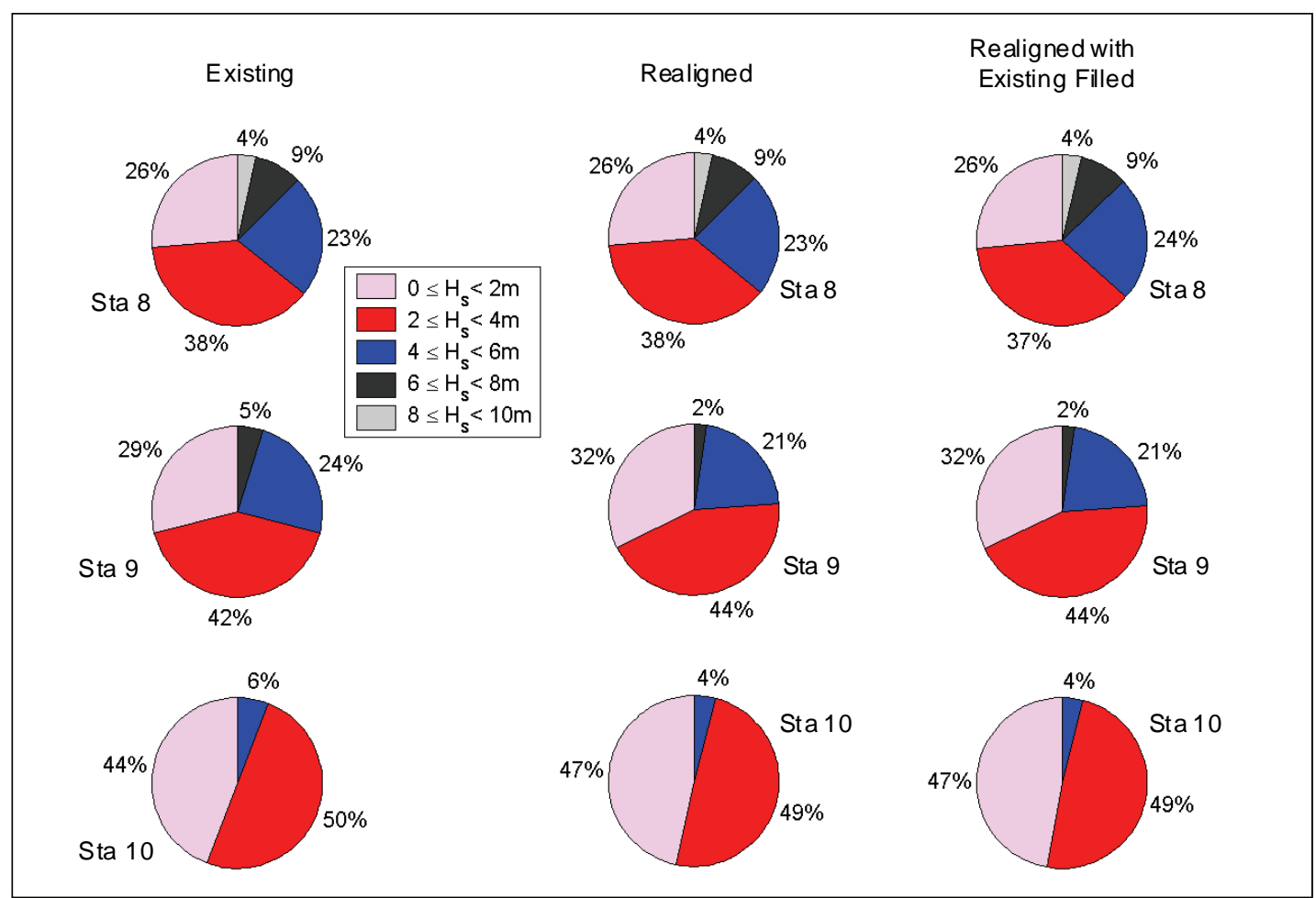

Figure 5-25. Percent occurrence comparison for three channels scenarios at Sta 8, 9 and 10 (Q4/2006, 2-yr return period).

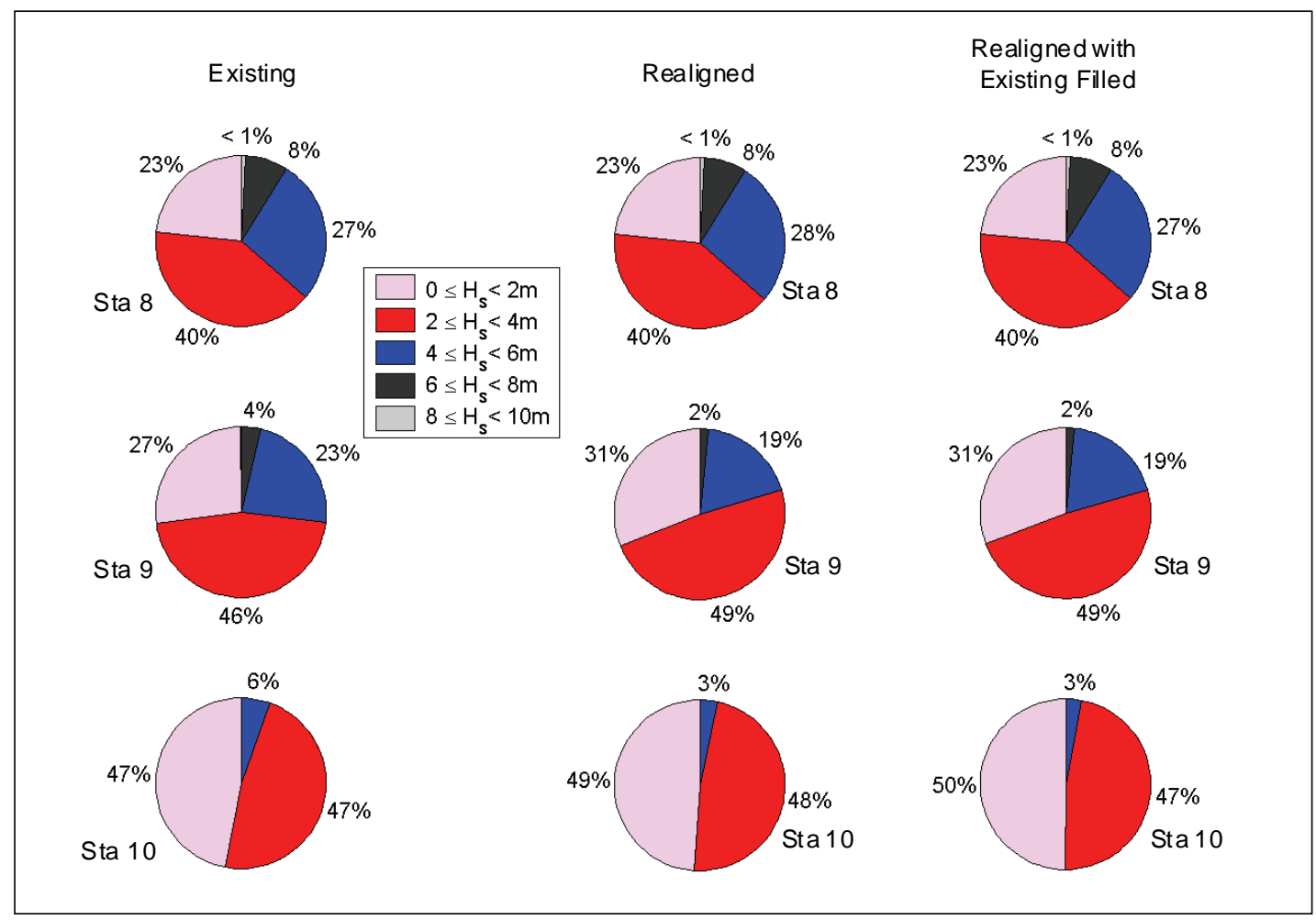

Figure 5-26. Percent occurrence comparison for three channels scenarios at Sta 8, 9 and 10 (Q4/1998, 5-yr return period). 


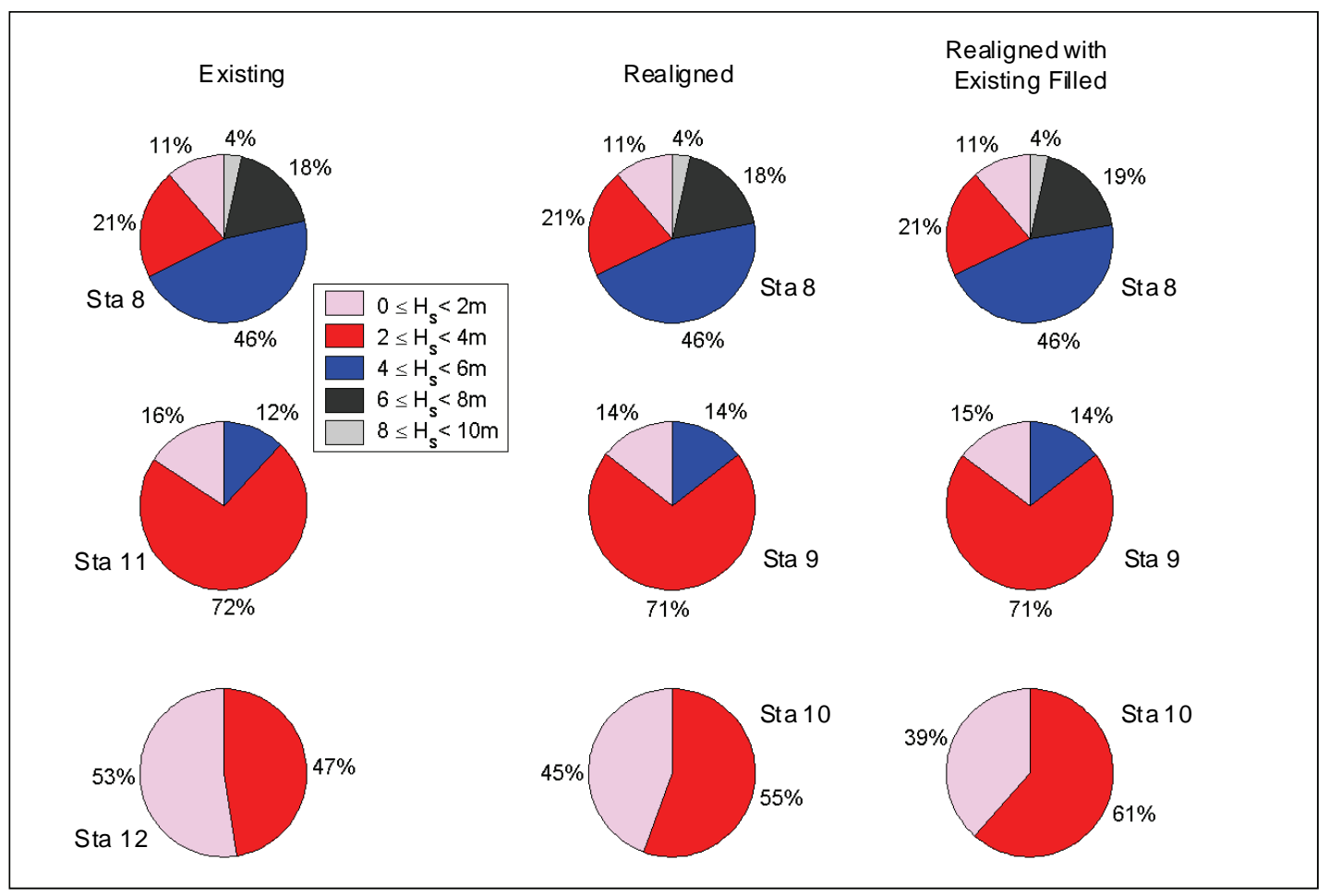

Figure 5-27. Percent occurrence comparison for three channels scenarios at Sta 8, 11 and 12 (Jan-Feb 1990, extreme storm period).

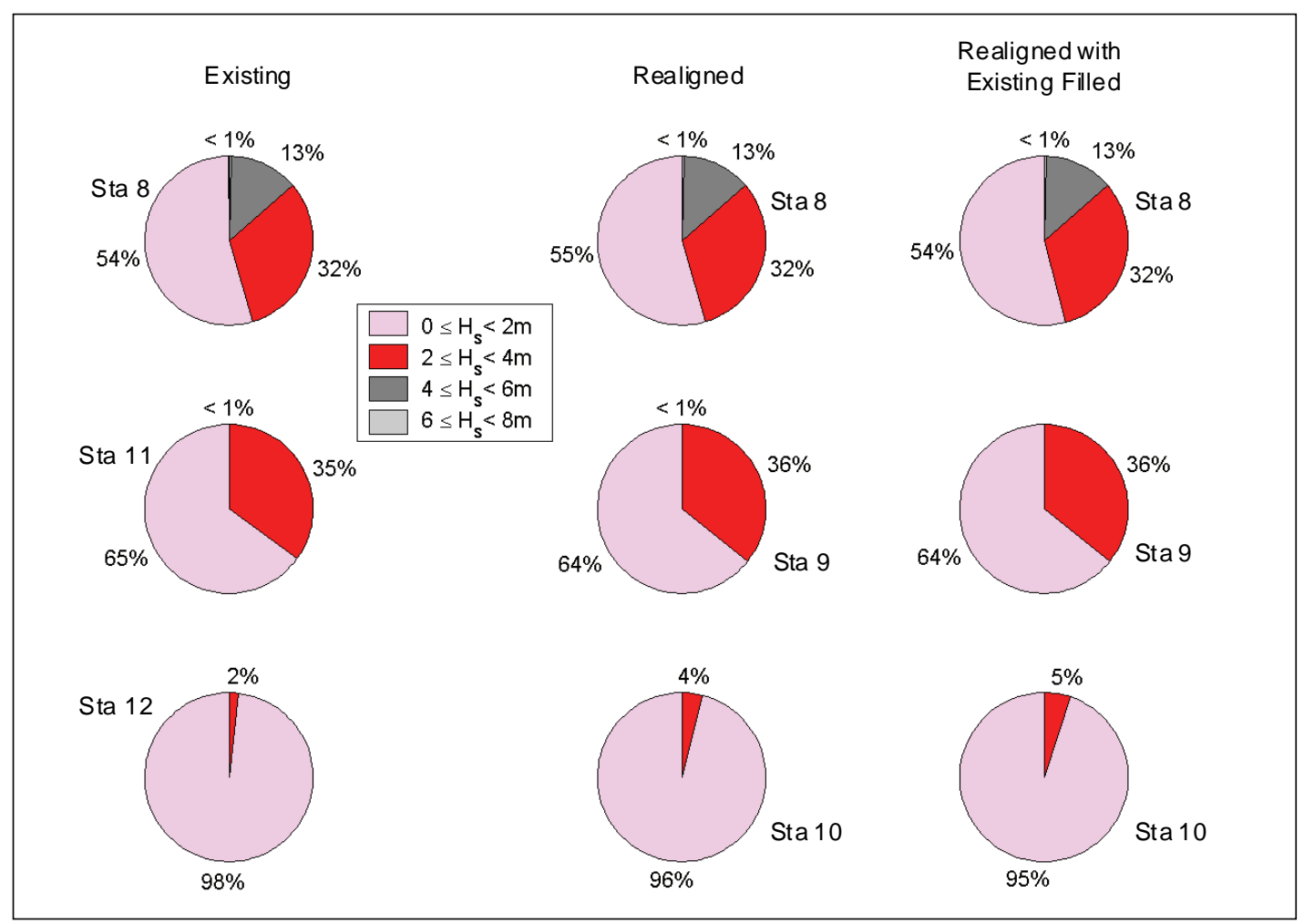

Figure 5-28. Percent occurrence comparison for three channels scenarios at Sta 8, 11 and 12 (Q2/1993, 0.5-yr return period). 


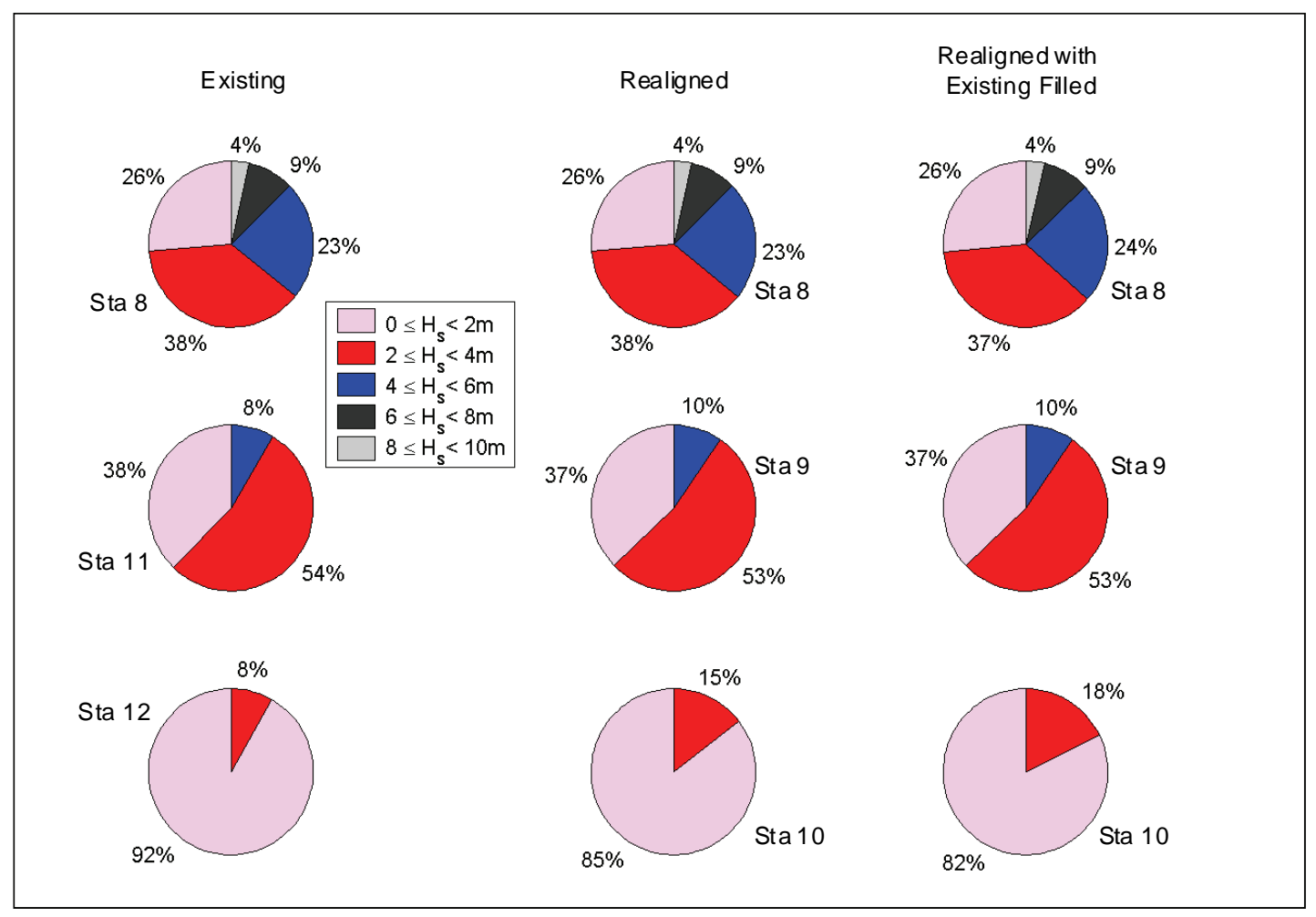

Figure 5-29. Percent occurrence comparison for three channels scenarios at Sta 8, 11 and 12 (Q4/2006, 2-yr return period).

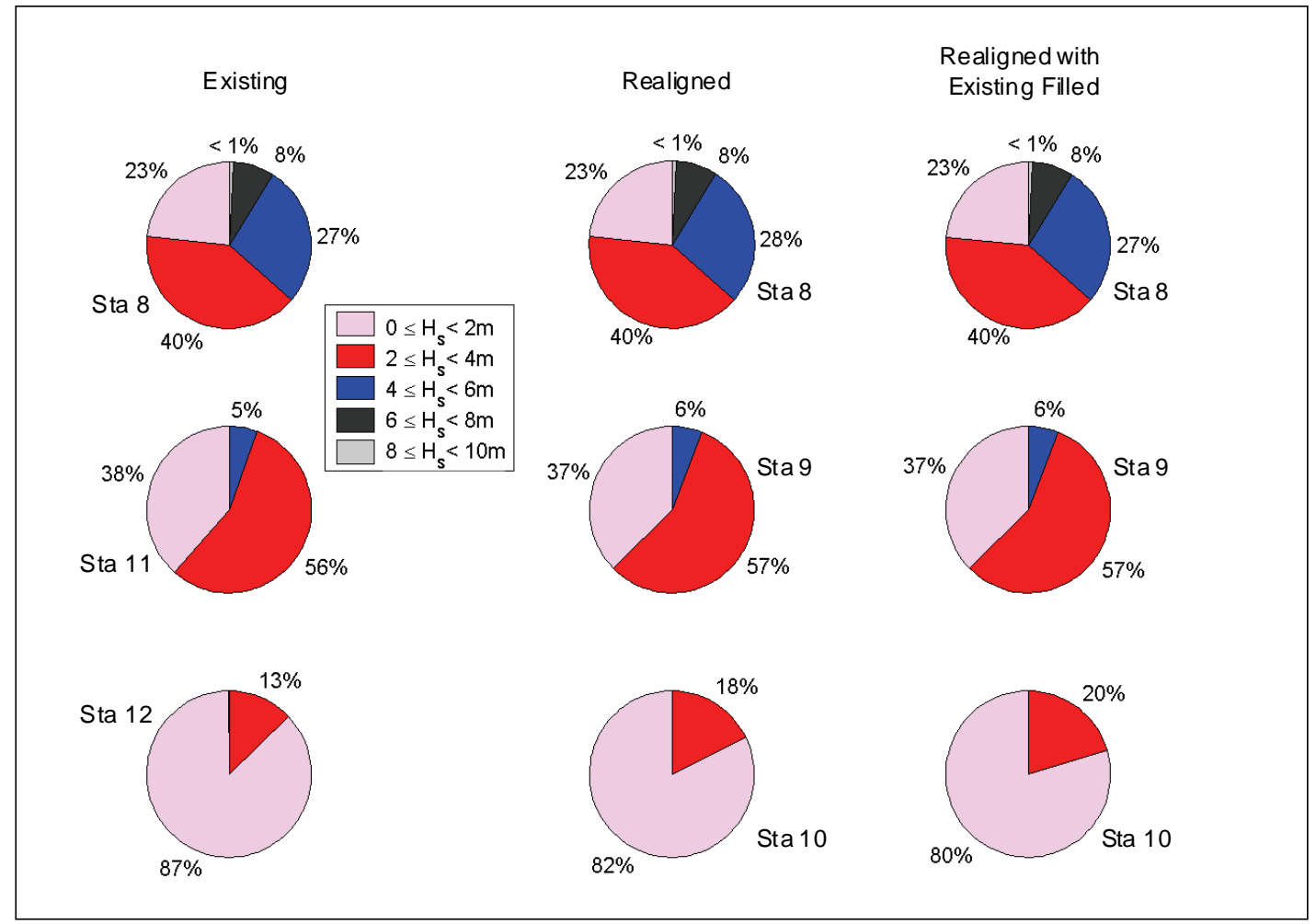

Figure 5-30. Percent occurrence comparison for three channels scenarios at Sta 8, 11 and 12 (Q4/1998, 5-yr return period). 
scenarios, the percentage of wave heights in the 4 to $6 \mathrm{~m}$ range at Sta 10 for the Existing channel reduced nearly by 50 percent. Wave heights remained below $6 \mathrm{~m}$ at Sta 9 and 10 which were further along the channels, and approximately 60 percent of wave heights were in the 2 to $4 \mathrm{~m}$ range.

Wave heights were consistently greater at Sta 8 than at Sta 9 and 10 for the 0.5-yr, 2-yr and 5-yr return periods and for all three channel scenarios. The distribution of wave height occurrence for Q2/ 1993 (0.5-yr return period) is shown in Figure 5-24, for Q4/ 2006 (2-yr return period) in Figure 5-25, and for Q4/ 1998 (5-yr return period) in Figure 5-26.

Figures 5-27 to 5-30 show the pie charts for Sta 8, 11 and 12 in three channel scenarios corresponding to the 1990 Extreme storm period, Q2/ 1993, Q4/ 2006, and Q4/ 1998, respectively. Approximately 50 percent of waves at Sta 8 were in the 4 to $6 \mathrm{~m}$ range for three channel scenarios. At Sta 11, about 70 percent of waves were in 2 to $4 \mathrm{~m}$ band. The percent of significant wave heights in the 2 to $4 \mathrm{~m}$ range at Sta 12 for the Existing channel was less than that for two Realigned channel alternatives. The percentage of wave height in 2 to $4 \mathrm{~m}$ for the Realigned channel with the Existing channel filled was 61 percent, and was greater than that for the Existing channel (47 percent) and Realigned with the Existing channel unfilled (55 percent).

Similar pie charts depict the results in Figures 5-31 through 5-34 for Sta 13 and 14, the two most eastward output stations common to the Existing and Realigned channel scenarios. Wave heights at these stations were comparatively less than waves predicted at stations in the outer sections. 


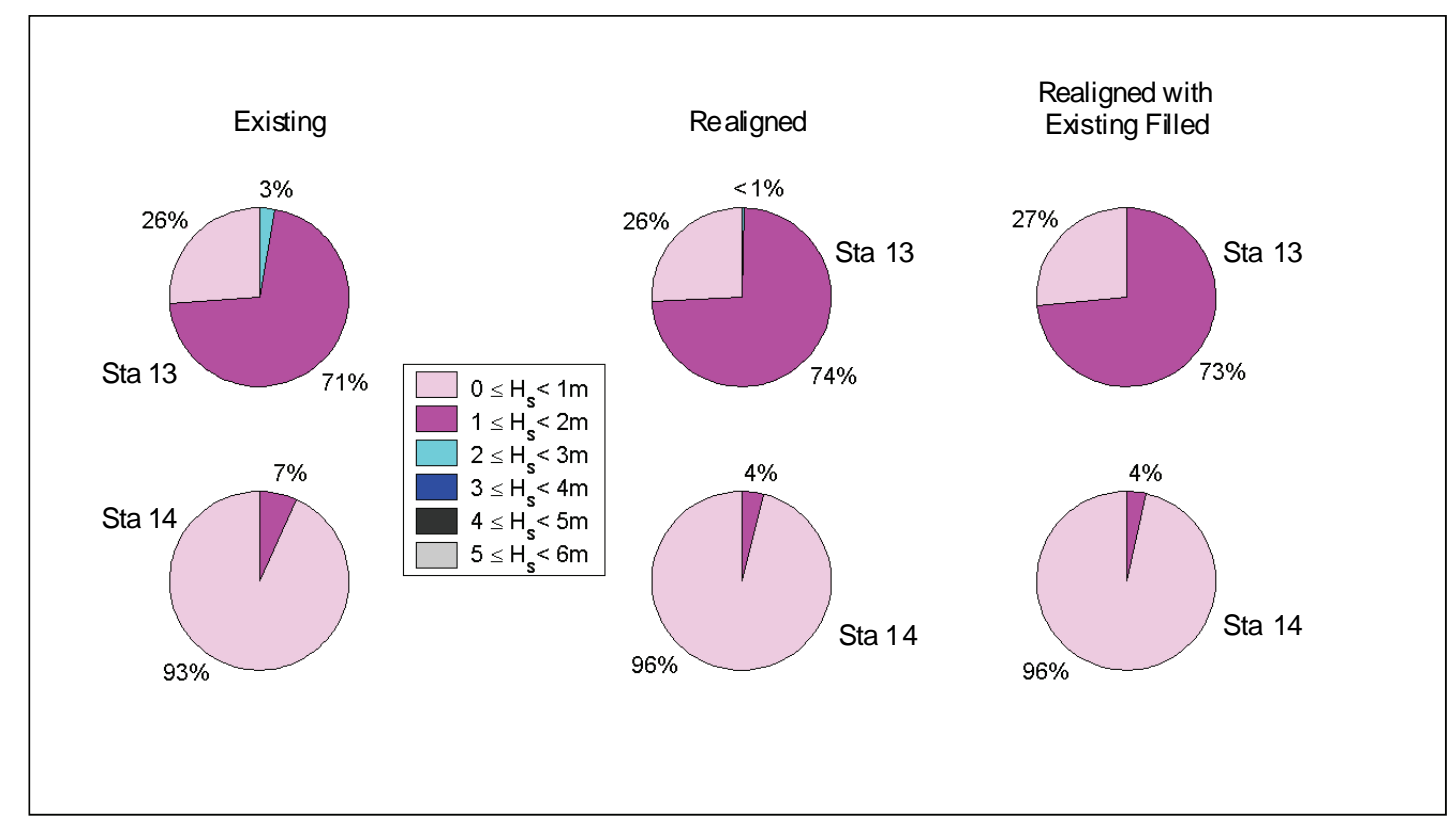

Figure 5-31. Percent occurrence comparison at Sta 13 and 14 for three channel scenarios (Jan-Feb 1990 extreme storm period).

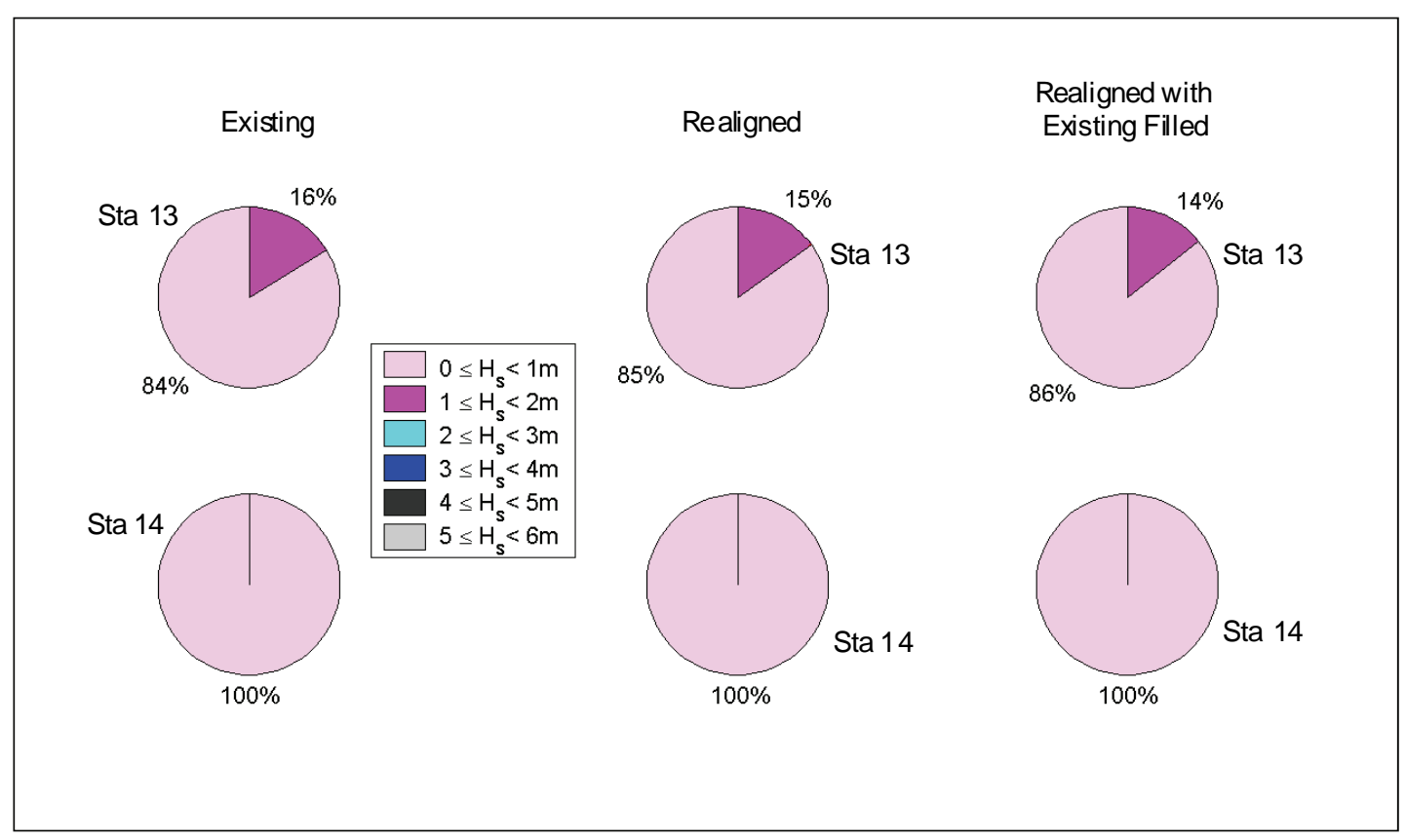

Figure 5-32. Percent occurrence comparison at Sta 13 and 14 for three channel scenarios (Q2/1993 of the 0.5-yr return period). 


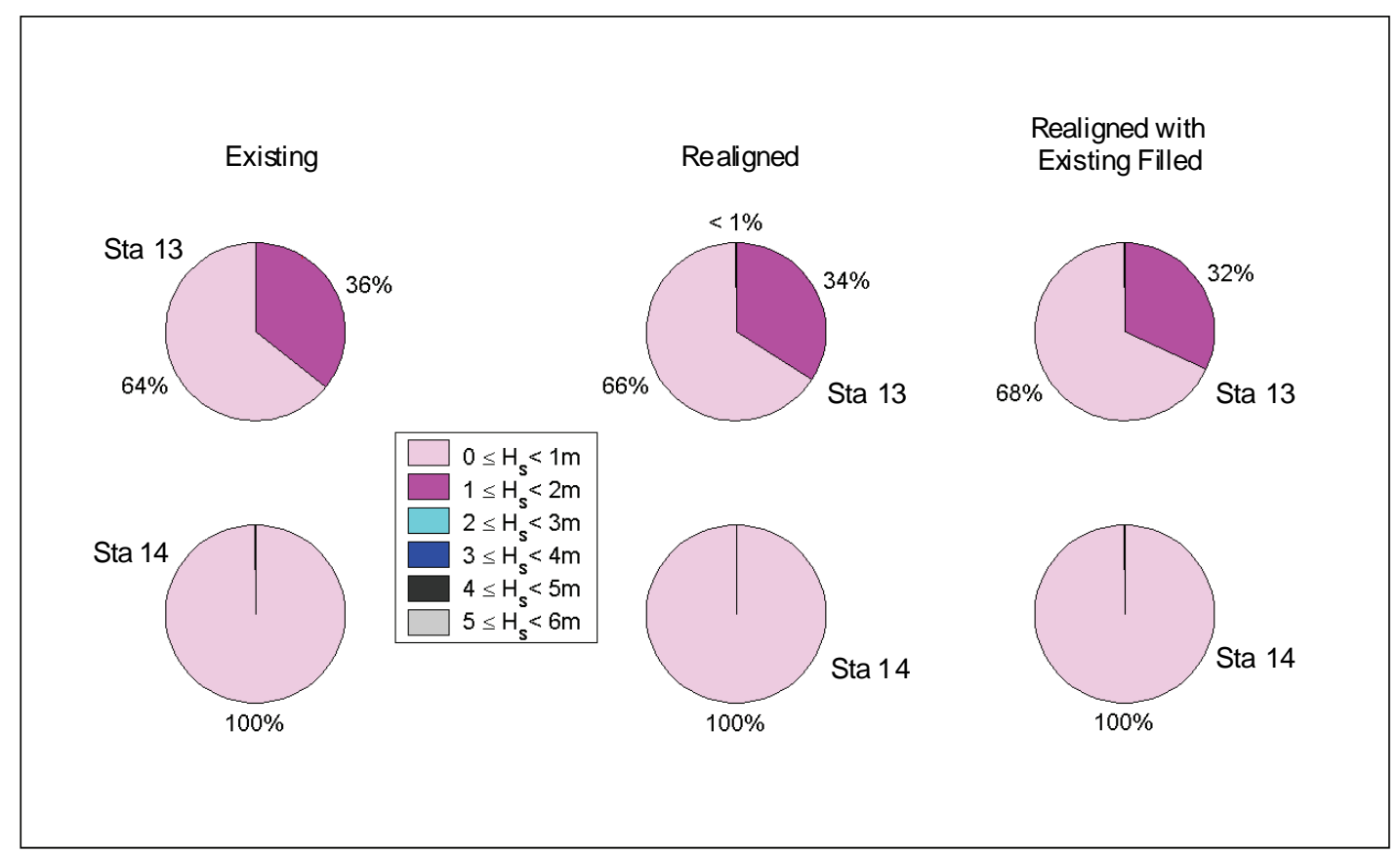

Figure 5-33. Percent occurrence comparison at Sta 13 and 14 for three channel scenarios (Q4/2006 of the 2-yr return period).

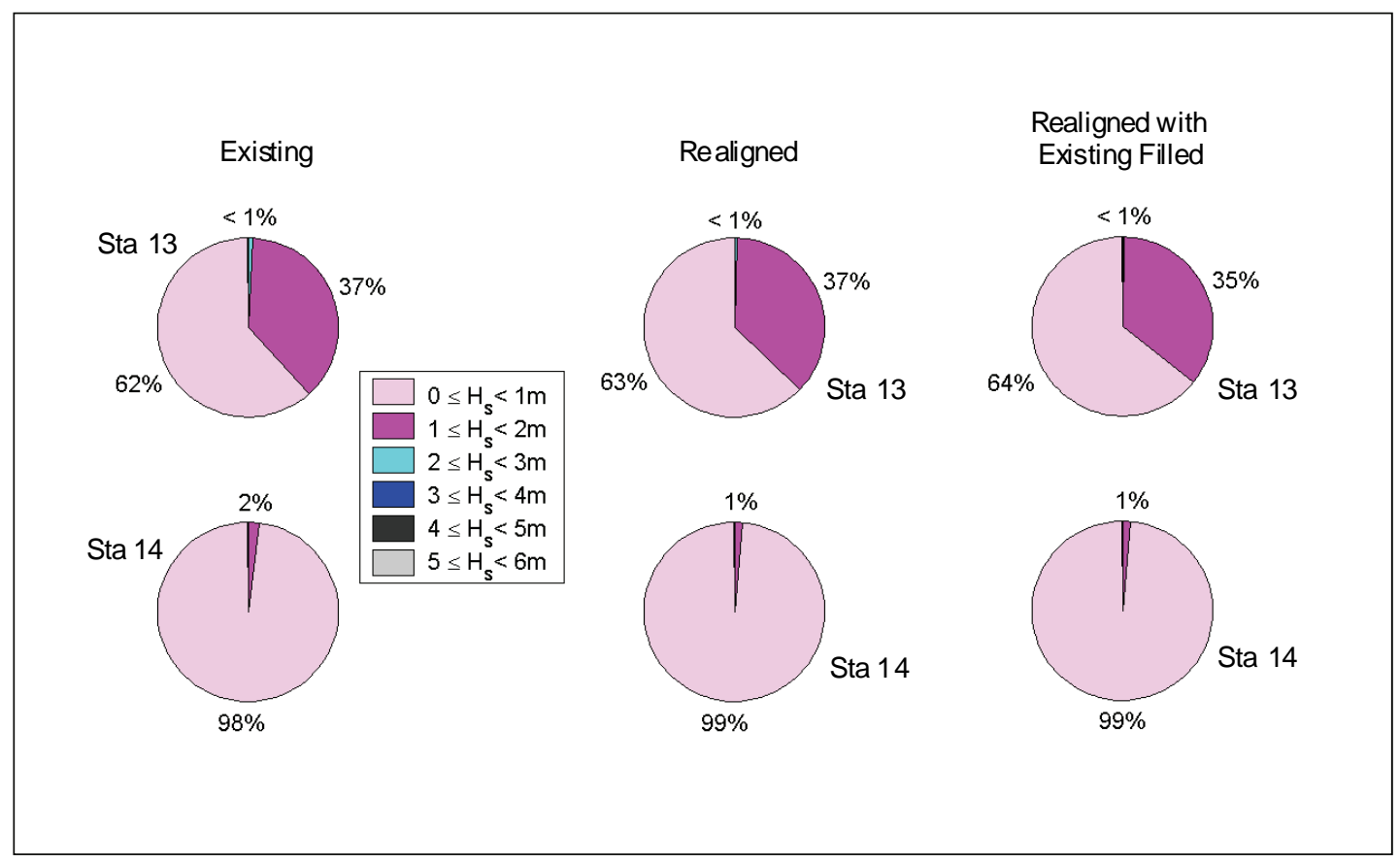

Figure 5-34. Percent occurrence comparison at Sta 13 and 14for three channel scenarios (Q4/1998 of the 5-yr return period). 


\section{Description of Sediment Transport Models}

\section{Introduction}

A primary focus of this study is to better understand sediment transport from three existing dredged material placement sites near the Grays Harbor Entrance and how channel realignment or modifications to dredged material management might influence channel sedimentation and/ or sediment dynamics within the region. To address these goals, three numerical sediment transport models were applied. MPFATE was applied to estimate post-placement dredged material configurations within placement sites. GTRAN was applied to estimate sand transport pathways from existing and potential dredged material placement sites within the Grays Harbor Entrance. SEDZLJ was applied to understand fate of mixed (sand and cohesive sediment) dredged material eroded and transported from existing dredged material placement sites.

This goal of this chapter is to describe the sediment transport processes included in the models applied in this study, as well as boundary and forcing conditions implemented for this application.

\section{MPFATE}

A goal of this study is to determine bed structure following dredged material placement at the Point Chehalis, South J etty, and Half Moon placement sites to define initial bed conditions for SEDZIJ simulations. The MPFATE model was configured and applied to dredged material placement at the Grays Harbor disposal sites. Currents at the site were characterized by ADCIRC (depth-averaged) hydrodynamic simulations. Dredged material placement was represented by convective descent and dynamic collapse processes. Dredged material characteristics and dredge vessel dimensions and operating parameters were developed from historical dredging records and sampling provided by NWS. Results of the simulations included postdredge bathymetry at each placement site as well as lift heights. This section describes the sediment processes during dredging, how MPFATE represents these processes, and boundary conditions and input for MPFATE simulations of Grays Harbor. 


\section{Sediment processes during dredged material placement operations}

Dredged material placement operations with bottom-release scows and hopper dredges involves transport of dredged material from the dredging site to the placement site, positioning of the vessel at the point of release, and release of the dredged material through the bottom of the scow or hopper. Frequency of placement at a DMP site is defined by the dredge production rate at the dredging site, capacity of the scow or hopper, and in the case of hopper dredges, the transit time between the dredging and placement sites.

Once released, the dredged material enters the water column as a dense fluid plume, descending through the water column through negative buoyancy. Point of impact of this dense, dredged-material plume on the bottom is governed by the velocity of the scow or hopper at time of release, the ambient currents, size and density anomaly of the plume, and water depth. Upon impact on the bottom, the dredged material vertical momentum is transferred to horizontal momentum and the plume spreads horizontally along the bottom until friction, viscosity, radial spreading, and sediment deposition arrest horizontal motion.

During release from the placement vessel, during descent, and collapse, a portion of the dredged material is mixed outside the dense plume and exists as lower-density clouds of suspended dredged sediments. Vertical transport of sediments in the lower-density clouds is balanced by settling velocity and vertical mixing of the suspended sediments. Deposition of these sediments onto the seabed is influenced by sediment settling velocity, ambient currents, horizontal turbulent mixing, and near-bed vertical turbulent mixing. Settling velocities of individual sediment particles is generally much slower than the descent rate of the density-driven plume. Therefore, lowdensity clouds of suspended sediment remain in the water column much longer and are transported much farther than the high-density plume. Individual sediment particles settle at widely varying rates, with sand and gravel particles settling much faster than silts and clays. This being the case, sediments deposited from lower concentration clouds become progressively finer with distance from the placement site.

Freshly deposited sediments from the placement operation are characterized by relatively high water content. With no additional sediment loading, freshly deposited sediments will expel pore water under the influence of its own weight, a process described as self-weight consolidation. With 
additional sediment loading, as in the case for additional dredged material placement, the internal stresses produced by the additional sediment load increases the expulsion of pore water from underlying sediments and further consolidation. The result of consolidation is increased density of the deposited sediment. So with increasing depth into the mound, bed density is expected to increase, volume occupied by the initial deposit of dredged material decreases, and total thickness of the mound decreases. Rate of pore water expulsion and consolidation vary with permeability of the sediment mixture, pore water pressures of surrounding sediments, thickness of the deposit, and time. Generally, sandy sediments expel pore water and consolidate at much faster rates than sediments with higher fractions of fine-grained sediments (silt and clay).

Mound development is the geomorphologic response of repeated placement of dredged materials within the DMP site as well as physical processes acting upon the recently deposited sediments. As dredged sediments accumulate in the DMP site, bathymetric relief in the site is modified. The sediment bed rises with each placement operation, and the developing signature of the dredged material mound is largely influenced by the pattern of release operations of the scow or hopper. If bottom deposition occurs persistently in one location, the mound may develop large local gradients in bed elevation. If local slopes become sufficiently steep, stresses in the deposited sediment exceed bed strength and a slope failure is initiated. The slope failure transports sediment down gradient and in the process adjusts the local bed to a more stable gradient. The process of slope adjustment through geotechnical failure is often described as avalanching. Other physical processes acting on the mound during placement operations include consolidation, erosion, and deposition. Erosion and deposition on the dredged material mound are influenced by both the placement operations and ambient waves and currents.

\section{Model description}

MPFATE is intended to represent the dominant physical processes describing DMP site morphology throughout a dredging cycle (timescales of weeks to years). Functions of the model include: description of the placement sequence, description of dredging equipment and sediment properties, physical processes during and immediately following placement (descent, collapse, passive transport), and physical processes at longer timescales following placement (consolidation, sediment transport, and avalanching). MPFATE model functions can be generally grouped into 
distinct components, each representing a defined process or group of processes influencing the ultimate morphology of a dredged material mound. Components of the model include: environmental conditions, dredged material description, definition of placement sequence, short-term physical processes, and long-term physical processes. MPFATE simulations generally proceed with the user defining dredged material characteristics, environmental conditions (waves, currents, water level), scow or hopper dimensions and characteristics, and dredged material placement operations (including vessel speed and location of placement for each load). MPFATE then develops the appropriate inputs for STFATE (J ohnson, 1990, J ohnson and Fong, 1995) for each hopper or scow load, including collection of appropriate environmental conditions (from hydrodynamic and wave models) and hopper/ scow release locations. Short-term processes of dredged material placement including convective descent, collapse, and passive dispersion are represented by STFATE. STFATE simulations are executed in sequence, with the resulting accumulation of dredged material from previous simulations used as initial bathymetry for subsequent simulations. The cycle of short-term processes (by STFATE) continues for the duration of dredged material placement, with intermediate and final conditions of the mound saved for evaluation by the user. More detailed descriptions of the sediment process and how the model simulates them are provided below.

\section{Environmental conditions}

Environmental conditions that influence morphology of the DMP sites include currents, waves, and water-column density structure. Improvements in the modeling of dredged material placement have been primarily made through improved resolution of hydrodynamics and water column density structure and improved methods for importing results from numerical hydrodynamic and wave transformation models into the simulation.

Improvements in representing hydrodynamics at DMP sites have been primarily achieved through upgrades to STFATE. In STFATE version 6.1, time-variance in currents at the placement site was incorporated (J ohnson and Smith, in publication). This feature allows time-varying velocities for either a point measurement (in which case the velocity field is distributed by forcing mass-conservation) or a full velocity field imported from an external numerical model. These enhancements allow a time-varying velocity description at the site which can vary in complexity from simple 
tidal harmonics, a time-series of velocity measurements, or velocity fields including wind-, tide-, and baroclinic- (density driven) forcing. ADCIRC currents generated by wind and tide were applied at the Grays Harbor.

Vertical density gradients primarily influence the descent rate of highdensity plumes and settling rate of individual particles. Both of these influences are associated with short-term dredged material placement processes. STFATE version 6.1 introduced improved resolution of the vertical density gradients in the water column, which in turn are available in MPFATE. The Grays Harbor simulations were performed with uniform water density of $1.025 \mathrm{~g} / \mathrm{cm}^{3}$.

\section{Boundary conditions and inputs}

MPFATE input includes several parameters including a description of the dredged material, vessel size, speed and bearing, hydrodynamic and environmental forcing, and dredged material placement sequence. Dredged material description defines important physical characteristics of the sediments handled by the dredging operation. Physical parameters required for short-term processes at the DMP sites include water content, clump fraction, sediment grain size distribution, sediment mineral density, sediment settling velocity, deposited void ratio, and critical bed shear stress for deposition. (The input parameters for simulations at each placement site are provided in Chapter 7.) The present version of MPFATE holds dredged material description constant for a single MPFATE simulation. Varying dredged material properties can be represented through a sequence of MPFATE simulations, each with a constant dredged material description. The approach taken for this study was to represent the dredged material in a mass-averaged sense, such that the material characteristics for each load of a particular vessel were represented as the composite characteristics of the dredged material to be placed within a disposal site. Often, the objectives of an MPFATE simulation is to determine the distribution of dredged material placement to achieve objectives such as maximum site capacity, avoidance of navigation hazards, minimization of erosion for nondispersive sites, or minimization of dredged material deposition outside the DMP site boundaries.

The morphological development at a DMP site is highly dependent upon the placement sequence and placement operations prescribed by the dredged material manager. Placement operations that influence DMP site morphology include: vessel velocity (including speed and direction) during 
placement, maneuvering of the placement vessel during release, distribution of placement locations, and ambient currents. Many of the parameters influencing placement operations are subject to the control of the dredged material manager through the dredging contract and can be controlled directly in the model through user input or estimated by internal algorithms in the model (based on the geometry of the site, characteristics of the specified dredging equipment, and typical placement operations).

\section{GTRAN}

\section{Model description}

To estimate sediment transport, predictive techniques are applied with available knowledge of the environmental conditions and sediment properties. The sediment transport model GTRAN applied currents calculated by ADCIRC and waves estimated by CMS-WAVE to predict transport magnitudes and pathways in the study area. GTRAN is a point model, which estimates potential transport and does not solve continuity of mass, i.e., it is a local transport model and it assumes unlimited sediment is available. GTRAN includes effects of waves and current on transport of non-cohesive sediment.

From input hydrodynamics and sediment bed conditions, GTRAN calculates sediment transport through a collection of sediment transport methods. A description of the GTRAN sediment transport methods, including sediment transport equations, follows in the next section. To calculate sediment transport, simplified assumptions and representations of the natural processes are applied. Making such approximations is standard practice in the field of numerical modeling and is not unique to sediment transport models. The following discussion of the approximations used for estimating transport rates is limited to general descriptions of the approximations applied.

\section{Transport methods}

This section describes the sediment transport methods incorporated into the sediment transport model. These descriptions aim to provide a general overview of the predictive techniques.

Algorithms that estimate sediment movement under specific wave and current conditions are referred to as transport methods. Presently, there 
are no sediment transport methods that are universally applicable to all environments and sediment types. For instance, a transport method developed for cobbles and boulders in an alpine stream is not likely to correctly represent sediment transport in an estuary or open-coast application. To correctly and reliably estimate sediment transport, the transport method must represent the first-order transport processes within the region of application. A general description and overview will be given for each transport method applied.

\section{Wikramanayake and Madsen transport method}

Under contract with the U.S. Army Corps of Engineers, Dredging Research Program (DRP), researchers at Massachusetts Institute of Technology developed non-cohesive sediment transport algorithms for combined wave-current environments. The algorithms include the effects of variation between current and wave directions. The methods are outlined in DRP reports (Madsen and Wikramanayake 1991; Wikramanayake and Madsen 1994a) and were specifically designed for nearshore transport in high-energy regions, although the initial validation and calibration were performed outside the surf zone. User input includes near-bottom orbital velocity, mean currents, bed slope, and grain size.

The method uses a time-invariant turbulent eddy viscosity model and a time-varying near-bottom concentration model to estimate suspended sediment transport fluxes. The method first calculates the bed roughness, using methods outlined by Wikramanayake and Madsen (1994b). Bed load and suspended sediment concentrations are then calculated using bottom shear stress. Estimates of vertical variation in suspended sediment concentration are based on a non-dimensional, time-varying, near-bottom reference concentration, $\mathrm{C}_{\mathrm{r}}(\mathrm{t})$. This concentration can be estimated as:

$$
\mathrm{C}_{\mathrm{r}}(\mathrm{t})=\frac{\mathrm{C}_{\mathrm{b}} \Upsilon_{\mathrm{o}}\left[\mid \Psi^{*}(\mathrm{t})-\Psi_{\mathrm{cr}} \|\right]}{\Psi_{\mathrm{cr}}}
$$

where:

$$
\begin{aligned}
\mathrm{C}_{b}= & \text { volume fraction of sediment in the bed } \\
\gamma_{0}= & \text { empirical resuspension coefficient } \\
\Psi^{*}(\mathrm{t})= & \text { the Shield's parameter based on instantaneous, skin-friction } \\
& \text { shear stress }
\end{aligned}
$$




$$
\Psi_{\text {cr }}=\text { the critical Shield's parameter }
$$

Laboratory experiments have demonstrated that $\gamma_{0}$ decreases with increasing Shield's parameter or wave skin friction shear stress. However, data were insufficient to develop empirical methods to relate the resuspension coefficient to Shield's parameter and constant values of $\gamma_{0}$ are applied for rippled and flat beds, respectively. The Shield's parameters are defined by:

$$
\begin{gathered}
\Psi^{*}(\mathrm{t})=\frac{\mathrm{u}_{*}(\mathrm{t})}{(\mathrm{s}-1) \mathrm{gd}_{50}} \\
\Psi_{\mathrm{cr}}=\alpha_{1} \tan (\varphi)
\end{gathered}
$$

where:

$$
\begin{aligned}
\mathrm{u} *(\mathrm{t}) & =\text { bed shear velocity } \\
\mathrm{s} & =\text { specific gravity of sediment } \\
\mathrm{g} & =\text { acceleration due to gravity } \\
\mathrm{d}_{50} & =\text { median grain diameter } \\
\alpha_{1} & =\text { coefficient dependent on the local Reynolds number } \\
\varphi & =\text { angle of repose of the sediment grains }
\end{aligned}
$$

The reference concentration is used to estimate vertically varying concentrations in the water column due to steady and oscillatory currents. The estimated suspended sediment concentration is coupled with the vertically varying velocities to estimate the total suspended sediment flux.

The Wikramanayake and Madsen model also includes a method for estimating the instantaneous bed-load flux based on the Meyer-Peter and Müller (1948) formula. This instantaneous bed-load flux, $\mathrm{Q}_{b}\left(\mathrm{~cm}^{3} / \mathrm{cm} \cdot \mathrm{s}\right)$, is estimated by:

$$
\overrightarrow{\mathrm{Q}}_{\mathrm{b}}(\mathrm{t})=\frac{\mathrm{d}_{50} \sqrt{(\mathrm{s}-1) \mathrm{gd}_{50}}}{2 \pi} \frac{8\left(\left|\Psi^{*}(\mathrm{t})\right|-\Psi_{\mathrm{cr}}\right)}{1+\tan \beta_{\mathrm{L}} \frac{\cos \left(\Phi_{\mathrm{t}}-\Phi_{\mathrm{sw}}\right)}{\tan \Phi_{\mathrm{f}}}} \frac{\vec{\tau}_{\mathrm{b}}^{\prime}(\mathrm{t})}{\vec{\tau}_{\mathrm{b}}^{\prime}(\mathrm{t}) \mid}
$$

where $\beta_{\mathrm{L}}=\mathrm{h} / 6 \delta$, h is the water depth, $\delta$ is the boundary layer length scale, $\Phi_{\mathrm{t}}$ is the angle between the current and the wave direction, $\Phi_{\mathrm{sw}}$ is the angle 
between the wave direction and bottom slope, and $\tau_{\mathrm{b}}{ }^{\prime}(\mathrm{t})$ is the instantaneous skin friction shear stress.

Wikramanayake and Madsen (1994a) performed several tests to compare their results to field measurements in wave/ current environments and found that the model accurately predicted the current-related and waverelated sediment fluxes and distributions in the water column. No verification was performed for the bed-load model estimates. Field verification of the transport method has been performed by CHL against data sets from the Columbia River mouth (Gailani et al. 2003) and in the surf zone at the Field Research Facility, Duck, North Carolina, with favorable comparisons to field data. The Wikramanayake and Madsen transport method is unsuitable for conditions in which sediment suspension and/ or waveinduced shear stresses are small, therefore other methods of approximating sediment transport were applied under bedload-dominated or current-dominated transport conditions.

Soulsby bedload transport method

Soulsby (1997) developed a formula for combined wave-current bedload by integrating the current-only bedload formula of Nielsen (1992) over a single sinusoidal wave cycle. The formula is expressed as follows:

$$
\begin{gathered}
\Phi_{\mathrm{x} 1}=12 \theta_{\mathrm{m}}^{1 / 2}\left(\theta_{\mathrm{m}}-\theta_{\mathrm{cr}}\right) \\
\Phi_{\mathrm{x} 2}=12(0.95+0.19 \cos 2 \varphi) \theta_{\mathrm{w}}^{1 / 2} \theta_{\mathrm{m}} \\
\Phi_{\mathrm{x}}=\text { maximum of } \Phi_{\mathrm{x} 1} \text { and } \Phi_{\mathrm{x} 2} \\
\mathrm{q}_{\mathrm{bx}}=\Phi_{\mathrm{x}}\left[\mathrm{g}(\mathrm{s}-1) \mathrm{d}_{50}^{3}\right]^{1 / 2}
\end{gathered}
$$

subject to $\Phi_{\mathrm{x}}=0$ if $\theta_{\mathrm{cr}} \geq \theta_{\max }$

where:

$\theta_{\mathrm{m}}=$ mean Shield's parameter over a wave cycle

$\theta_{\text {cr }}=$ critical Shield's parameter for initiation of motion

$\varphi=$ angle between current direction and direction of wave travel

$\theta_{\mathrm{w}}=$ amplitude of oscillatory component of $\theta$ due to waves 


$$
\begin{aligned}
\mathrm{q}_{\mathrm{bx}}= & \text { mean volumetric bedload transport rate per unit width } \\
\theta_{\max }= & \text { maximum Shield's parameter from combined wave-current } \\
& \text { stresses }
\end{aligned}
$$

Soulsby's combined wave-current bedload transport method was applied when sediment suspension was estimated to be near zero.

\section{Van Rijn current-dominated transport method}

The Van Rijn (1984) current-only total transport method was parameterized by Soulsby (1997) from Van Rijn's comprehensive theory of sediment transport in rivers. Although the method was developed for sediment transport in the riverine environment, the method may also be appropriately applied in the marine environment under conditions for which waves contribute little to the bottom shear stress. The simpler, parameterized formulae presented here approximate the full theory within \pm 25 percent and were developed for water depths between 1 and $20 \mathrm{~m}$, velocities between 0.5 and $5 \mathrm{~m} / \mathrm{s}$, d50 between 0.1 and $2 \mathrm{~mm}$, and for fresh water at $15 \mathrm{deg} C$. The resulting parameterized method estimates transport by the following simpler formulation:

$$
\begin{gathered}
\mathrm{q}_{\mathrm{t}}=\mathrm{q}_{\mathrm{b}}+\mathrm{q}_{\mathrm{s}} \\
\mathrm{q}_{\mathrm{b}}=0.005 \overline{\mathrm{U}} \mathrm{h}\left\{\frac{\overline{\mathrm{U}}-\overline{\mathrm{U}}_{\mathrm{cr}}}{\left[(\mathrm{s}-1) \mathrm{gd}_{50}\right]^{1 / 2}}\right\}^{2.4}\left(\frac{\mathrm{d}_{50}}{\mathrm{~h}}\right)^{1.2} \\
\mathrm{q}_{\mathrm{s}}=0.012 \overline{\mathrm{U}} \mathrm{h}\left\{\frac{\overline{\mathrm{U}}-\overline{\mathrm{U}}_{\mathrm{cr}}}{\left[(\mathrm{s}-1) \mathrm{gd}_{50}\right]^{1 / 2}}\right]^{2.4}\left(\frac{\mathrm{d}_{50}}{\mathrm{~h}}\right)\left(\mathrm{D}_{*}\right)^{-0.6}
\end{gathered}
$$

where:

$$
\begin{aligned}
& \bar{U}_{c r}=0.19\left(d_{50}\right)^{0.1} \log _{10}\left(\frac{4 h}{d_{90}}\right) \text { for } 0.1 \leq d_{50} \leq 0.5 \mathrm{~mm} \\
& \bar{U}_{c r}=8.50\left(d_{50}\right)^{0.6} \log _{10}\left(\frac{4 h}{d_{90}}\right) \text { for } 0.5 \leq d_{50} \leq 2.0 \mathrm{~mm}
\end{aligned}
$$




$$
\begin{aligned}
D_{*}=\left|\frac{g(s-1)}{v^{2}}\right|^{1 / 3} d_{50} \\
\mathrm{q}_{\mathrm{b}}=\text { bedload transport } \\
\mathrm{q}_{\mathrm{s}}=\text { suspended load transport } \\
\bar{U}=\text { depth-averaged current } \\
\mathrm{h}=\text { water depth } \\
\mathrm{d}_{90}=\text { sediment diameter for which } 90 \text { percent is finer by weight }
\end{aligned}
$$

\section{Boundary conditions and inputs}

GTRAN requires $\mathrm{X}, \mathrm{Y}$, and $\mathrm{Z}$ coordinates for each location where sediment transport is to be calculated. The computational domain of the model was defined by 418 discrete points variably spaced between 160 and $640 \mathrm{~m}$ throughout Grays Harbor. The number of points and spacing were selected so that there were sufficient points to define transport patterns within the Grays Harbor entrance and adjacent areas of interest with the primary emphasis on capturing the area of the re-aligned channel near the DMP sites (Figure 6-1).

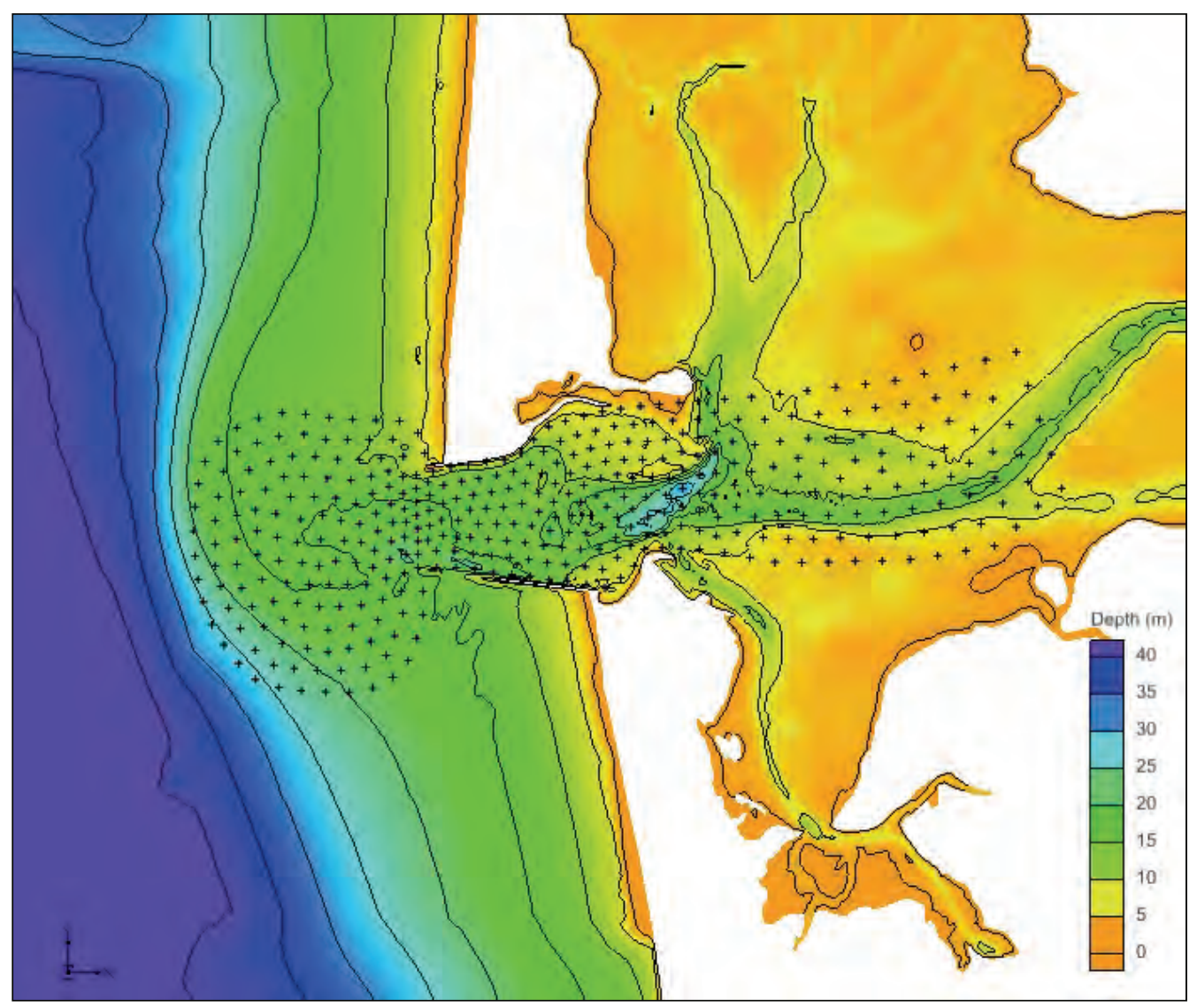

Figure 6-1. GTRAN calculation points 
GTRAN input includes bed grain size, bathymetry, and hydrodynamic / environmental conditions. Sediment size distributions were assumed uniform within the domain (Figure 6-2), with $d_{50}=0.26 \mathrm{~mm}, d_{90}=0.36 \mathrm{~mm}$ and $d_{10}=0.164 \mathrm{~mm}$. With the initial bed conditions specified, the model distributes environmental forcing conditions from ADCIRC large-domain circulation model and CMS-Wave model results to each of the computational points.

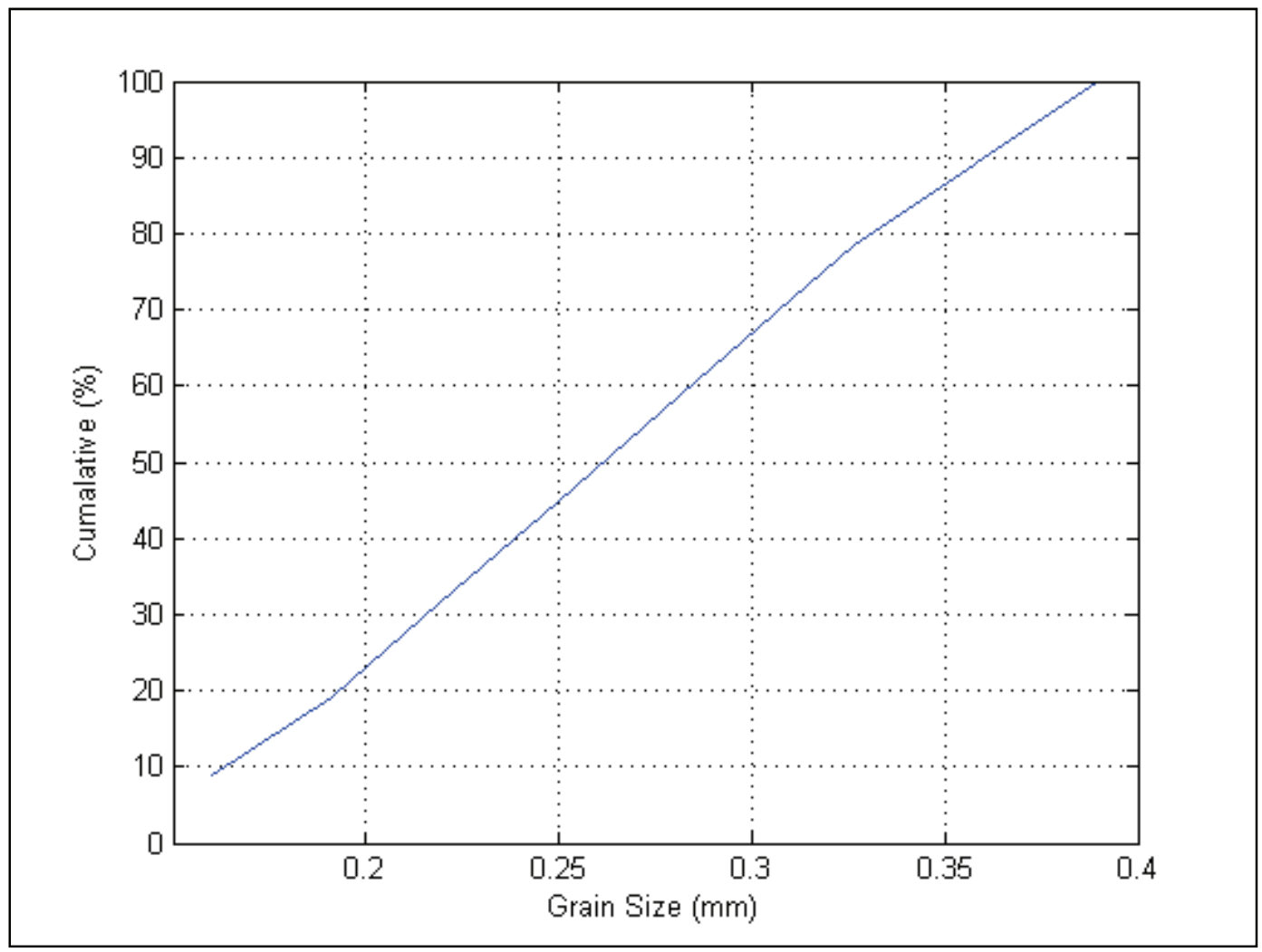

Figure 6-2. Input grain size distribution.

The temporal resolution of the current information is $1 \mathrm{hr}$. This resolution is adequate to define the temporal changes in hydrodynamics and waves for representing sediment transport. With local conditions determined, the model proceeds to estimate the current-related bottom shear stresses and to estimate the depth of the active sediment layer. The active sediment layer is defined as the depth of the sediment bed that is mobilized by sediment suspension and bed-load movement.

The transport method for each position and time step is selected on the estimated contributions of wave/ current bed stress and estimates of whether the bed stress is current dominated, or whether the transport regime is bedload dominated, or influenced by suspended sediment 
transport. Transport magnitude is computed by the appropriate transport regime discussed above and stored for each location and time interval.

\section{LTFATE}

\section{Model description}

The numerical modeling simulations for the sediment transport modeling component of this study were performed with the LTFATE model. The hydrodynamic model in LTFATE is the Environmental Fluid Dynamics Code (EFDC) surface water modeling system (Hamrick, 2007a, 2007b, and 2007c). EFDC is a public domain, three-dimensional finite difference model that contains dynamically linked hydrodynamic and sediment transport modules. EFDC can simulate barotropic and baroclinic flow in a water body due to astronomical tides, wind, density gradients, and river inflow. It solves the 3D, vertically hydrostatic, free surface, turbulence averaged equations of motion. EFDC is extremely versatile, and can be used for $1 \mathrm{D}, 2 \mathrm{D}$-laterally averaged (2DV), 2D-vertically averaged (2DH), or 3D simulations of rivers, lakes, reservoirs, estuaries, coastal seas, and wetlands.

For realistic representation of horizontal boundaries, the governing equations in EFDC are formulated such that the horizontal coordinates, $\mathrm{x}$ and $y$, are curvilinear. To provide uniform resolution in the vertical direction, the sigma (stretching) transformation is used. The equations of motion and transport solved in EFDC are turbulence-averaged, because prior to averaging, although they represent a closed set of instantaneous velocities and concentrations, they cannot be solved for turbulent flows. A statistical approach is applied, where the instantaneous values are decomposed into mean and fluctuating values to enable the solution. Additional terms that represent turbulence are introduced to the equations for the mean flow. Turbulent equations of motion are formulated to utilize the Boussinesq approximation for variable density. The Boussinesq approximation accounts for variations in density only in the gravity term. This assumption simplifies the governing equations significantly, but may introduce large errors when density gradients are large.

The resulting governing equations, presented in the next section, include parameterized, Reynolds-averaged stress and flux terms that account for the turbulent diffusion of momentum, heat and salt. The turbulence parameterization in EFDC is based on the Mellor and Yamada (1982) level 2.5 turbulence closure scheme as modified by Galperin et al. (1988) that 
relates turbulent correlation terms to the mean state variables. The EFDC model also solves several transport and transformation equations for different dissolved and suspended constituents, including suspended sediments, toxic contaminants, and water quality state variables. An overview of the governing equations is given in the following; detailed descriptions of the model formulation and numerical solution technique used in EFDC are provided by Hamrick (1992). Additional capabilities of EFDC include:

1. simulation of wetting and drying of flood plains, mud flats, and tidal marshes;

2. integrated, near-field mixing zone model;

3. simulation of hydraulic control structures such as dams and culverts; and

4. simulation of wave boundary layers and wave-induced mean currents.

The 3D, Reynolds-averaged equations of continuity (Equation 6-9), linear momentum (Equations 6-10 and 6-11), hydrostatic pressure (Equation 6-12), equation of state (Equation 6-13) and transport equations for salinity and temperature (Equations 6-14 and 6-15) written for curvilinear-orthogonal horizontal coordinates and a sigma vertical coordinate are given by Hamrick (1992) and repeated below:

$$
\begin{gathered}
\frac{\partial(\mathrm{m} \varepsilon)}{\partial \mathrm{t}}+\frac{\partial\left(\mathrm{m}_{\mathrm{y}} \mathrm{Hu}\right)}{\partial \mathrm{x}}+\frac{\partial\left(\mathrm{m}_{\mathrm{x}} \mathrm{Hv}\right)}{\partial \mathrm{y}}+\frac{\partial(\mathrm{mw})}{\partial \mathrm{z}}=0 \\
\frac{\partial(\mathrm{mHu})}{\partial \mathrm{t}}+\frac{\partial\left(\mathrm{m}_{\mathrm{y}} \mathrm{Huu}\right)}{\partial \mathrm{x}}+\frac{\partial\left(\mathrm{m}_{\mathrm{x}} \mathrm{Hvu}\right)}{\partial \mathrm{y}}+\frac{\partial(\mathrm{mwu})}{\partial \mathrm{z}}- \\
\left(\mathrm{mf}+\mathrm{v} \frac{\partial\left(\mathrm{m}_{\mathrm{y}}\right)}{\partial \mathrm{x}}-\mathrm{u} \frac{\partial \mathrm{m}_{\mathrm{x}}}{\partial \mathrm{y}}\right) \mathrm{Hv}=\mathrm{m}_{\mathrm{y}} \mathrm{H} \frac{\partial(\mathrm{g} \varepsilon+\mathrm{p})}{\partial \mathrm{x}}- \\
\mathrm{m}_{\mathrm{y}}\left(\frac{\partial \mathrm{H}}{\partial \mathrm{x}}-\mathrm{z} \frac{\partial \mathrm{H}}{\partial \mathrm{x}}\right) \frac{\partial \mathrm{p}}{\partial \mathrm{z}}+\frac{\partial\left(\mathrm{mH}^{-1} \mathrm{~A}_{\mathrm{v}} \frac{\partial \mathrm{u}}{\partial \mathrm{z}}\right)}{\partial \mathrm{z}}+\mathrm{Q}_{\mathrm{u}}
\end{gathered}
$$




$$
\begin{gathered}
\frac{\partial(\mathrm{mHv})}{\partial \mathrm{t}}+\frac{\partial\left(\mathrm{m}_{\mathrm{y}} \mathrm{Huv}\right)}{\partial \mathrm{x}}+\frac{\partial\left(\mathrm{m}_{\mathrm{x}} \mathrm{Hvv}\right)}{\partial \mathrm{y}}+\frac{\partial(\mathrm{mwv})}{\partial \mathrm{z}}+ \\
\left(\mathrm{mf}+\mathrm{v} \frac{\partial\left(\mathrm{m}_{\mathrm{y}}\right)}{\partial \mathrm{x}}+\mathrm{u} \frac{\partial \mathrm{m}_{\mathrm{x}}}{\partial \mathrm{y}}\right) \mathrm{Hu}=\mathrm{m}_{\mathrm{x}} \mathrm{H} \frac{\partial(\mathrm{g} \varepsilon+\mathrm{p})}{\partial \mathrm{y}}- \\
\mathrm{m}_{\mathrm{x}}\left(\frac{\partial \mathrm{H}}{\partial \mathrm{y}}-\mathrm{z} \frac{\partial \mathrm{H}}{\partial \mathrm{y}}\right) \frac{\partial \mathrm{p}}{\partial \mathrm{z}}+\frac{\partial\left(\mathrm{mH}^{-1} \mathrm{~A}_{\mathrm{v}} \frac{\partial \mathrm{v}}{\partial \mathrm{z}}\right)}{\partial \mathrm{z}}+\mathrm{Q}_{\mathrm{v}} \\
\frac{\partial \mathrm{p}}{\partial \mathrm{z}}=\frac{\mathrm{gH}\left(\rho-\rho_{\mathrm{o}}\right)}{\rho_{\mathrm{o}}}=\mathrm{gHb} \\
\frac{\partial(\mathrm{mHS})}{\partial \mathrm{t}}+\frac{\partial\left(\mathrm{m}_{\mathrm{y}} \mathrm{HuS}\right)}{\partial \mathrm{x}}+\frac{\partial\left(\mathrm{m}_{\mathrm{x}} \mathrm{HvS}\right)}{\partial \mathrm{y}}+\frac{\partial(\mathrm{mwS})}{\partial \mathrm{z}}=\frac{\partial\left(\frac{\mathrm{mA}_{\mathrm{b}}}{\mathrm{H}} \frac{\partial \mathrm{S}}{\partial \mathrm{z}}\right)}{\partial \mathrm{z}}+\mathrm{Q}_{\mathrm{s}} \\
\frac{\partial(\mathrm{mHT})}{\partial \mathrm{t}}+\frac{\partial\left(\mathrm{m}_{\mathrm{y}} \mathrm{HuT}\right)}{\partial \mathrm{x}}+\frac{\partial\left(\mathrm{m}_{\mathrm{x}} \mathrm{HvT}\right)}{\partial \mathrm{y}}+\frac{\partial(\mathrm{mwT})}{\partial \mathrm{z}}=\frac{\partial\left(\frac{\mathrm{mA}_{\mathrm{b}}}{\mathrm{H}} \frac{\partial \mathrm{T}}{\partial \mathrm{z}}\right)}{\partial \mathrm{z}}+\mathrm{Q}_{\mathrm{T}}
\end{gathered}
$$

where $\mathrm{u}$ and $\mathrm{v}$ are the mean horizontal velocity components in $(\mathrm{x}, \mathrm{y})$ coordinates; $m_{x}$ and $m_{y}$ are the square roots of the diagonal components of the metric tensor, and $m=m_{x} m_{y}$ is the J acobian or square root of the metric tensor determinant; $\mathrm{p}$ is the pressure in excess of the reference pressure, $\frac{\rho_{o} g H(1-z)}{\rho_{o}}$, where $\rho_{o}$ is the reference density; $\mathrm{f}$ is the Coriolis parameter for latitudinal variation; $A_{v}$ is the vertical turbulent viscosity; and $A_{b}$ is the vertical turbulent diffusivity. The buoyancy b in Equation 6-12 is the normalized deviation of density from the reference value. Equation 6-15 is the equation of state that calculates water density $(\rho)$ as functions of $\mathrm{p}$, salinity (S) and temperature (T).

The sigma (stretching) transformation and mapping of the vertical coordinate is given as 


$$
\mathrm{z}=\frac{\left(\mathrm{z}^{*}+\mathrm{h}\right)}{(\xi+\mathrm{h})}
$$

where $\mathrm{z}^{*}$ is the physical vertical coordinate, and $\mathrm{h}$ and $\xi$ are the depth below and the displacement about the undisturbed physical vertical coordinate origin, $\mathrm{z}^{*}=0$, respectively, and $H=h+\xi$ is the total depth.

The vertical velocity in $\mathrm{z}$ coordinates, $\mathrm{w}$, is related to the physical vertical velocity $\mathrm{w}^{*}$ by

$$
\mathrm{w}=\mathrm{w}^{*}-\mathrm{z}\left(\frac{\partial \xi}{\partial \mathrm{t}}+\frac{\mathrm{u}}{\mathrm{m}_{\mathrm{x}}} \frac{\partial \xi}{\partial \mathrm{x}}+\frac{\mathrm{v}}{\mathrm{m}_{\mathrm{y}}} \frac{\partial \xi}{\partial \mathrm{y}}\right)+(1-\mathrm{z})\left(\frac{\mathrm{u}}{\mathrm{m}_{\mathrm{x}}} \frac{\partial \mathrm{h}}{\partial \mathrm{x}}+\frac{\mathrm{v}}{\mathrm{m}_{\mathrm{y}}} \frac{\partial \mathrm{h}}{\partial \mathrm{y}}\right)
$$

The solutions of Equations 6-10, 6-11, 6-14 and 6-15 require the values for the vertical turbulent viscosity and diffusivity and the source and sink terms. The vertical eddy viscosity and diffusivity, $A_{v}$ and $A_{b}$, are parameterized according to the level 2.5 (second-order) turbulence closure model of Mellor and Yamada (1982), as modified by Galperin et al. (1988), in which the vertical eddy viscosities are calculated based on the turbulent kinetic energy and the turbulent macroscale equations. The Mellor and Yamada level 2.5 (MY2.5) turbulence closure model is derived by starting from the Reynolds stress and turbulent heat flux equations under the assumption of a nearly isotropic environment, where the Reynolds stress is generated due to the exchange of momentum in the turbulent mixing process. To make the turbulence equations closed, all empirical constants are obtained by assuming that turbulent heat production is primarily balanced by turbulent dissipation.

The vertical turbulent viscosity and diffusivity are related to the turbulent intensity, $q^{2}$, turbulent length scale, $l$ and a Richardson number $R_{q}$ as follows:

$$
\begin{gathered}
A_{v}=\Phi_{v} q l=0.4\left(1+36 R_{q}\right)^{-1}\left(1+6 R_{q}\right)^{-1}\left(1+8 R_{q}\right) q l \\
A_{b}=\Phi_{b} q l=0.5\left(1+36 R_{q}\right)^{-1} q l
\end{gathered}
$$

where $A_{v}$ and $A_{b}$ are stability functions that account for reduced and enhanced vertical mixing or transport in stable and unstable vertical, density-stratified environments, respectively, and the local Richardson number is given as 


$$
\mathrm{R}_{\mathrm{q}}=\frac{\mathrm{gH} \frac{\partial \mathrm{b}}{\partial \mathrm{z}}}{\mathrm{q}^{2}} \frac{\mathrm{l}^{2}}{\mathrm{H}^{2}}
$$

A critical Richardson number, $R_{q}=0.20$, was found at which turbulence and mixing cease to exist (Mellor and Yamada, 1982). Galperin et al. (1988) introduced a length scale limitation in the MY scheme by imposing an upper limit for the mixing length to account for the limitation of the vertical turbulent excursions in stably stratified flows. They also modified and introduced stability functions that account for reduced or enhanced vertical mixing for different stratification regimes.

The turbulence intensity $\left(\mathrm{q}^{2}\right)$ and the turbulence length scale (l) are computed using the following two transport equations:

$$
\begin{aligned}
& \frac{\partial\left(\mathrm{mHq}^{2}\right)}{\partial \mathrm{t}}+\frac{\partial\left(\mathrm{m}_{\mathrm{y}} \mathrm{Huq}^{2}\right)}{\partial \mathrm{x}}+\frac{\partial\left(\mathrm{m}_{\mathrm{x}} \mathrm{Hvq}^{2}\right)}{\partial \mathrm{y}}+\frac{\partial\left(\mathrm{mwq}^{2}\right)}{\partial \mathrm{z}}=\frac{\partial\left(\frac{\left.\mathrm{mA}_{\mathrm{q}} \frac{\partial \mathrm{q}^{2}}{\partial \mathrm{z}}\right)}{\mathrm{H}}\right)}{\partial \mathrm{z}}+\mathrm{Q}_{\mathrm{q}}(6-21) \\
& +2 \frac{\mathrm{mA} \mathrm{v}}{\mathrm{H}}\left(\left(\frac{\partial^{2} \mathrm{u}}{\partial \mathrm{z}^{2}}\right)+\left(\frac{\partial^{2} \mathrm{v}}{\partial \mathrm{z}^{2}}\right)\right)+2 \mathrm{mgA}_{\mathrm{b}} \frac{\partial \mathrm{b}}{\partial \mathrm{z}}-2 \mathrm{mH}\left(\frac{\mathrm{q}^{3}}{\left(\mathrm{~B}_{1} \mathrm{l}\right)}\right) \\
& \frac{\partial\left(\mathrm{mHq}^{2} \mathrm{l}\right)}{\partial \mathrm{t}}+\frac{\partial\left(\mathrm{m}_{\mathrm{y}} \mathrm{Huq}^{2} \mathrm{l}\right)}{\partial \mathrm{x}}+\frac{\partial\left(\mathrm{m}_{\mathrm{x}} \mathrm{Hvq}^{2} \mathrm{l}\right)}{\partial \mathrm{y}}+\frac{\partial\left(\mathrm{mwq}^{2} \mathrm{l}\right)}{\partial \mathrm{z}}= \\
& \frac{\partial\left(\frac{\mathrm{mA}}{\mathrm{q}} \frac{\partial \mathrm{q}^{2} \mathrm{l}}{\partial \mathrm{z}}\right)}{\partial \mathrm{z}}+\mathrm{Q}_{1}+2 \frac{\mathrm{mE}_{1} \mathrm{lA}}{\mathrm{H}}\left(\left(\frac{\partial^{2} \mathrm{u}}{\partial \mathrm{z}^{2}}\right)+\left(\frac{\partial^{2} \mathrm{v}}{\partial \mathrm{z}^{2}}\right)\right)+\mathrm{mgE}_{1} \mathrm{E}_{3} \mathrm{lA}_{\mathrm{b}} \frac{\partial \mathrm{b}}{\partial \mathrm{z}}(6-22) \\
& -\mathrm{H}\left(\frac{\mathrm{q}^{3}}{\left(\mathrm{~B}_{1}\right)}\right)\left(1+\mathrm{E}_{2}(\kappa \mathrm{L})^{-2} \mathrm{l}^{2}\right)
\end{aligned}
$$

The above two equations include a wall proximity function, $W=1+E_{2} l(\kappa L)^{-2}$, that assures a positive value of diffusion coefficient $\left.L^{-1}=(H)^{-1}\left(z^{-1}+(1-z)^{-1}\right)\right) . \mathrm{B}_{1}, \mathrm{E}_{1}, \mathrm{E}_{2}$, and $\mathrm{E}_{3}$ are empirical constants with values $0.4,16.6,1.8,1.33$, and 0.25 , respectively. All terms with Q's $\left(Q_{u}\right.$, $\mathrm{Q}_{\mathrm{v}}, \mathrm{Q}_{\mathrm{q}}, \mathrm{Q}_{\mathrm{l}}, \mathrm{Q}_{\mathrm{s}}, \mathrm{Q}_{\mathrm{T}}$ ) are sub-grid scale sink-source terms that are modeled as sub-grid scale horizontal diffusion. The vertical diffusivity, $A_{\mathrm{q}}$, is in general taken to be equal to the vertical turbulent viscosity, $A_{v}$ (Hamrick, 1992). 
The vertical boundary conditions for the solutions of the momentum equations are based on the specification of the kinematic shear stresses. At the bottom, the bed shear stresses are computed using the near bed velocity components $\left(u_{1}, v_{1}\right)$ as:

$$
\left(\tau_{\mathrm{bx}}, \tau_{\mathrm{by}}\right)=\mathrm{c}_{\mathrm{b}} \sqrt{\mathrm{u}_{1}^{2}+\mathrm{v}_{1}^{2}}\left(\mathrm{u}_{1}, \mathrm{v}_{1}\right)
$$

where the bottom drag coefficient $c_{b}=\left(\frac{\kappa}{\ln \left(\Delta_{1} / 2 z_{o}\right)}\right)^{2}$, where $\kappa$ is the von Karman constant, $\Delta_{1}$ is the dimensionless thickness of the bottom layer, $\mathrm{z}_{\mathrm{o}}$ $=\mathrm{z}_{0} * / \mathrm{H}$ is the dimensionless roughness height, and $\mathrm{z}_{0}{ }^{*}$ is roughness height in meters. At the surface layer, the shear stresses are computed using the $\mathrm{u}, \mathrm{v}$ components of the wind velocity $\left(u_{w}, v_{w}\right)$ above the water surface (usually measured at $10 \mathrm{~m}$ above the surface) and are given as:

$$
\left(\tau_{\mathrm{sx}}, \tau_{\mathrm{sy}}\right)=\mathrm{c}_{\mathrm{s}} \sqrt{\mathrm{u}_{\mathrm{w}}^{2}+\mathrm{v}_{\mathrm{w}}^{2}}\left(\mathrm{u}_{\mathrm{w}}, \mathrm{v}_{\mathrm{w}}\right)
$$

where $c_{s}=0.001 \frac{\rho_{a}}{\rho_{w}}\left(0.8+0.065 \sqrt{u_{w}{ }^{2}+v_{w}^{2}}\right)$ and $\rho_{a}$ and $\rho_{w}$ are the air and water densities, respectively. Zero flux vertical boundary conditions are used for the transport equations.

Numerically, EFDC is second-order accurate both in space and time. A staggered grid or C-grid provides the framework for the second-order accurate spatial finite differencing used to solve the equations of motion. Integration over time involves an internal-external mode splitting procedure separating the internal shear, or baroclinic mode, from the external free surface gravity wave, or barotropic mode. In the external mode, the model uses a semi-implicit scheme that allows the use of relatively large time steps. The internal equations are solved at the same time step as the external equations, and are implicit with respect to vertical diffusion. Details of the finite difference numerical schemes used in the EFDC model are given in Hamrick (1992), and will not be presented in this report.

The generic transport equation solved in EFDC for a dissolved (e.g., chemical contaminant) or suspended (e.g., sediment) constituent having a mass per unit volume concentration $\mathrm{C}$, is 


$$
\begin{aligned}
& \frac{\partial \mathrm{m}_{\mathrm{x}} \mathrm{m}_{\mathrm{y}} \mathrm{HC}}{\partial \mathrm{t}}+\frac{\partial \mathrm{m}_{\mathrm{y}} \mathrm{HuC}}{\partial_{\mathrm{x}}}+\frac{\partial \mathrm{m}_{\mathrm{x}} \mathrm{HvC}}{\partial \mathrm{y}}+\frac{\partial \mathrm{m}_{\mathrm{x}} \mathrm{m}_{\mathrm{y}} \mathrm{wC}}{\partial \mathrm{z}}-\frac{\partial \mathrm{m}_{\mathrm{x}} \mathrm{m}_{\mathrm{y}} \mathrm{w}_{\mathrm{sc}} \mathrm{C}}{\partial \mathrm{z}}= \\
& \frac{\partial}{\partial_{\mathrm{x}}}\left(\frac{\mathrm{m}_{\mathrm{y}}}{\mathrm{m}_{\mathrm{x}}} \mathrm{HK}_{\mathrm{H}} \frac{\partial \mathrm{C}}{\partial \mathrm{x}}\right)+\frac{\partial}{\partial_{\mathrm{y}}}\left(\frac{\mathrm{m}_{\mathrm{x}}}{\mathrm{m}_{\mathrm{y}}} \mathrm{HK}_{\mathrm{H}} \frac{\partial \mathrm{C}}{\partial \mathrm{y}}\right)+\frac{\partial}{\partial_{\mathrm{z}}}\left(\mathrm{m}_{\mathrm{x}} \mathrm{m}_{\mathrm{y}} \frac{\mathrm{K}_{\mathrm{v}}}{\mathrm{H}} \frac{\partial \mathrm{C}}{\partial \mathrm{z}}\right)+\mathrm{Q}_{\mathrm{c}}
\end{aligned}
$$

where $\mathrm{K}_{\mathrm{V}}$ and $\mathrm{K}_{\mathrm{H}}$ are the vertical and horizontal turbulent diffusion coefficients, respectively; $\mathrm{w}_{\mathrm{sc}}$ is a positive settling velocity when $\mathrm{C}$ represents the mass concentration of suspended sediment; and $\mathrm{Q}_{\mathrm{c}}$ represents external sources or sinks and reactive internal sources or sinks. For sediment, $C=S_{j}$, where $S_{j}$ represents the concentration of the $j$-th sediment class. The solution procedure is the same as that for the salinity and heat transport equations, which use a high-order upwind difference solution scheme for the advection terms (Hamrick, 1992). Although the advection scheme is designed to minimize numerical diffusion, a small amount of horizontal diffusion remains inherent in the numerical scheme. As such, the horizontal diffusion terms in Equation 6-25 are omitted by setting $\mathrm{K}_{\mathrm{H}}$ equal to zero.

The sediment transport model in LTFATE is the SEDZLJ sediment transport model (J ones and Lick, 2001). SEDZLJ is dynamically linked to EFDC in LTFATE. The SEDZLJ model was designed to directly use the results obtained using Sedflume. SEDZLJ is an advanced sediment bed model that represents the dynamic processes of erosion, bedload transport, bed sorting, armoring, consolidation of fine-grain sediment dominated sediment beds, settling of flocculated cohesive sediment, settling of individual noncohesive sediment particles, and deposition. An active layer formulation is used to describe sediment bed interactions during simultaneous erosion and deposition. The active layer facilitates coarsening during the bed armoring process.

Figure 6-3 shows the sediment mass balance achieved by SEDZLJ. In this figure, $\mathrm{U}=$ near bed flow velocity, $\delta_{\mathrm{bl}}=$ thickness of layer in which bedload occurs, $\mathrm{U}_{\mathrm{bl}}=$ average bedload transport velocity, $\mathrm{D}_{\mathrm{bl}}=$ sediment deposition rate for the sediment being transported as bedload, $\mathrm{E}_{\mathrm{bl}}=$ sediment erosion rate for the sediment being transported as bedload, $\mathrm{E}_{\text {sus }}=$ sediment erosion rate for the sediment that is eroded and entrained into suspension, and $\mathrm{D}_{\text {sus }}=$ sediment deposition rate for suspended sediment. Specific capabilities of SEDZIJ are listed below. 


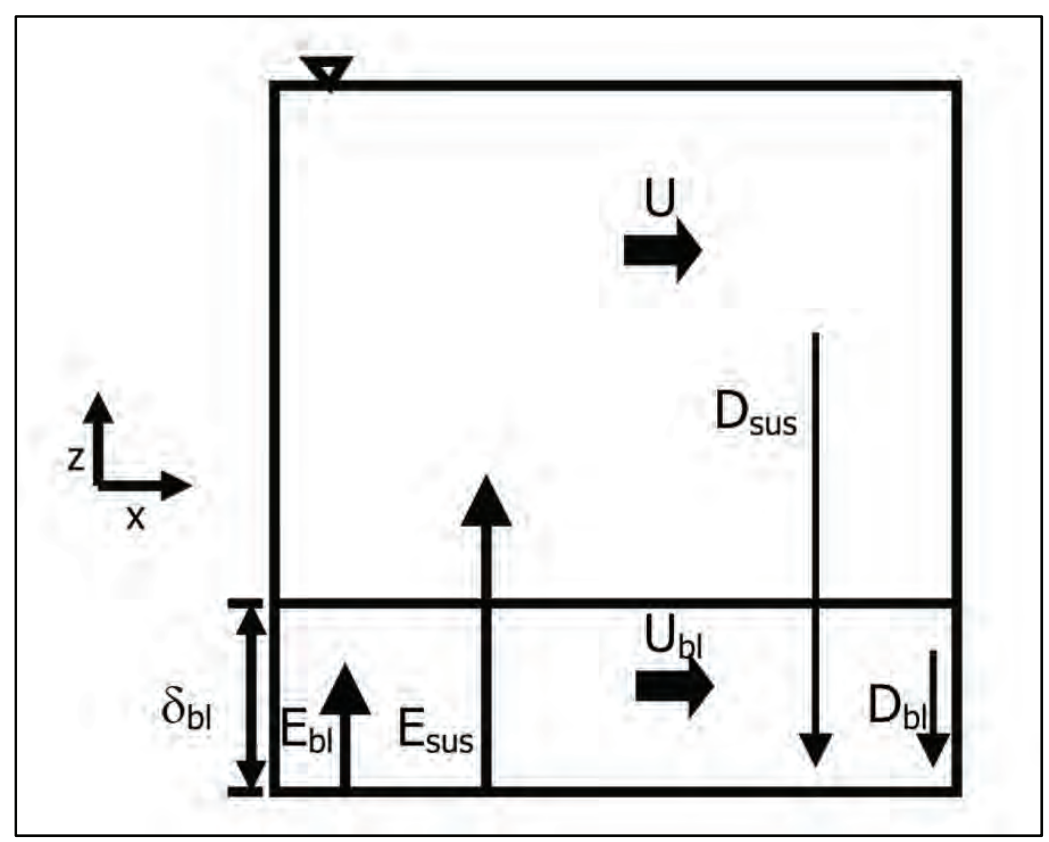

Figure 6-3. Sediment Mass Balance Achieved in SEDZU

- Whereas a hydrodynamic model is calibrated to account for the total bed shear stress, which is the sum of the form drag due to bed forms and other large-scale physical features (e.g., boulder size particles) and the skin friction (also called the surface friction), the correct component of the bed shear stress to use in predicting sediment resuspension and deposition is the skin friction. The skin friction is calculated in SEDZLJ as a function of the near-bed current velocity and the effective bed roughness. The latter is specified in SEDZLJ as a linear function of the mean particle diameter in the active layer.

Multiple size classes of both fine-grain (i.e., cohesive) and noncohesive sediments can be represented in the sediment bed. As stated previously, this capability is necessary in order to simulate coarsening and subsequent armoring of the surficial sediment bed surface during high flow events.

- To correctly represent the processes of erosion and deposition, the sediment bed in SEDZLJ can be divided into multiple layers, some of which are used to represent the existing sediment bed and others that are used to represent new bed layers that form due to deposition during model simulations. Figure 6-4 shows a schematic diagram of this multiple bed layer structure. The graph on the right hand side of this figure shows the variation in the measured gross erosion rate (in 
units of $\mathrm{cm} / \mathrm{s}$ ) with depth into the sediment bed as a function of the applied skin friction. SEDFLUME was used to measure these erosion rates.

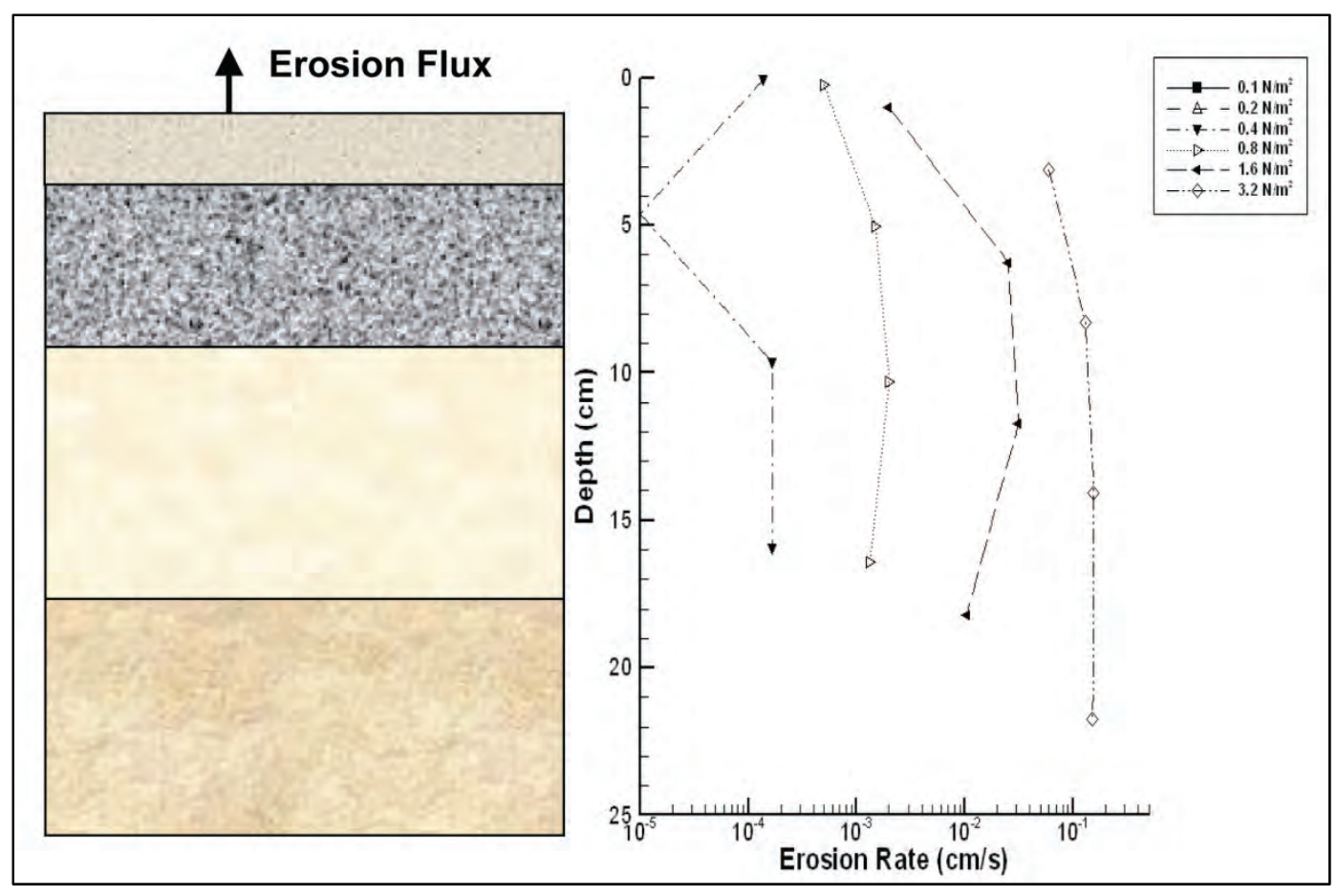

Figure 6-4. Multi-Bed Layer Model Used in SEDZU.

- Erosion from both cohesive and non-cohesive beds is affected by bed armoring, which is a process that limits the amount of bed erosion that occurs during a high-flow event. Bed armoring occurs in a bed that contains a range of particle sizes (e.g., clay, silt, sand). During a highflow event when erosion is occurring, finer particles (i.e., clay and silt, and fine sand) tend to be eroded at a faster rate than coarser particles (i.e., medium to coarse sand). The differences in erosion rates of the various sediment particle sizes creates a thin layer at the surface of the sediment bed, referred to as the active layer, that is depleted of finer particles and enriched with coarser particles. This depletionenrichment process can lead to bed armoring, where the active layer is primarily composed of coarse particles that have limited mobility. The multiple bed model in SEDZIJ accounts for the exchange of sediment through and the change in composition of this active layer. The thickness of the active layer is normally calculated as a time varying function of the mean sediment particle diameter in the active layer, the critical shear stress for resuspension corresponding to the mean particle diameter, and the bed shear stress. Figure 6-5 shows a 
schematic of the active layer at the top of the multi-bed layer model used in SEDZL $J$.

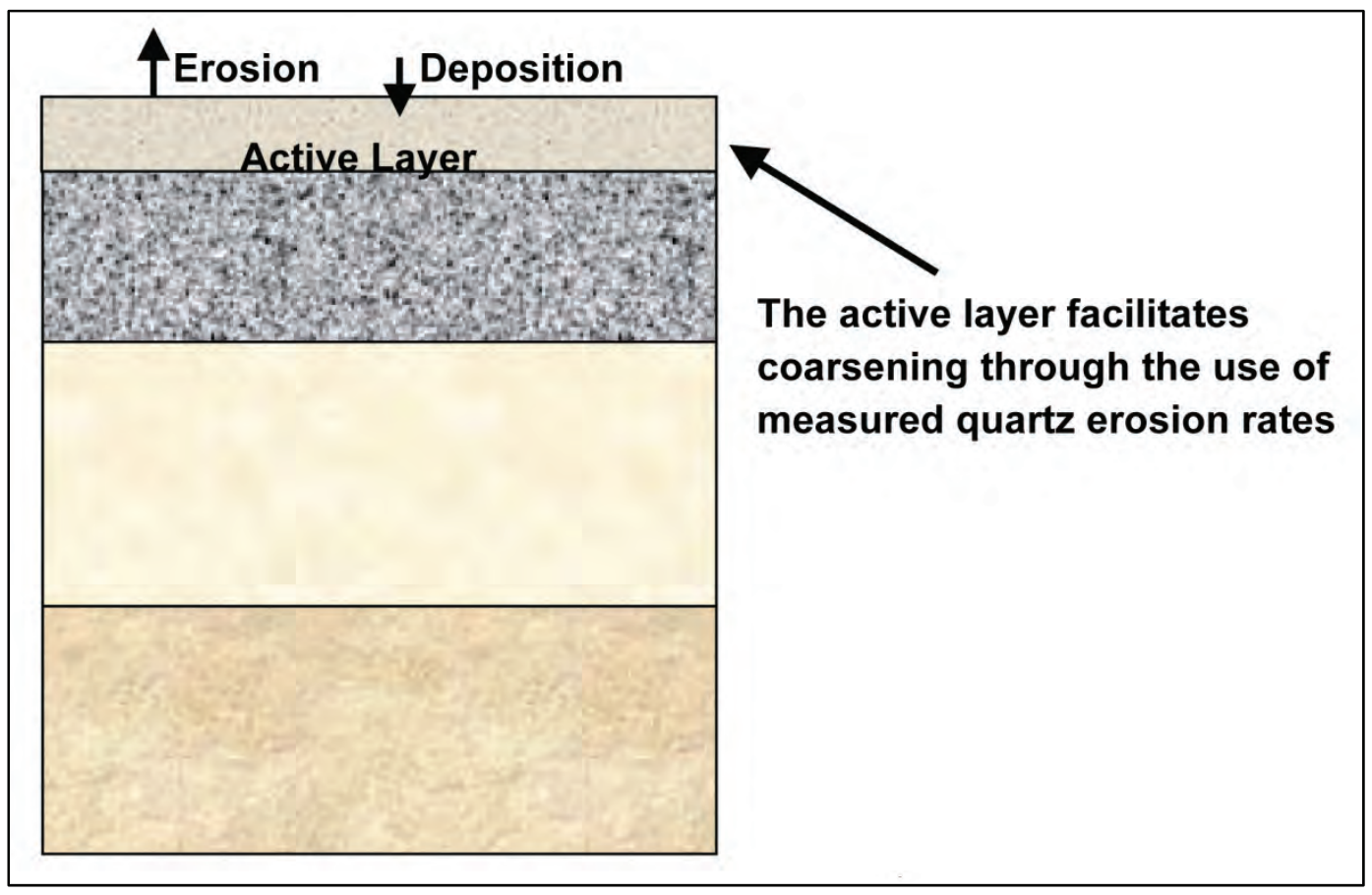

Figure 6-5. Schematic of Active Layer Used in SEDZL

- SEDZLJ was designed to use the results obtained with SEDFLUME, which is a straight, closed conduit rectangular cross-section flume in which detailed measurements of critical shear stress of erosion and erosion rate as a function of sediment depth are made using sediment cores dominated by cohesive sediment collected at the site to be modeled (McNeil et al., 1996). However, when SEDFLUME results are not available, it is possible to use a combination of literature values for these parameters as well as the results of SEDFLUME tests performed at other similar sites. In this case, a detailed sensitivity analysis should be performed to assist in quantifying the uncertainty that results from the use of these non-site specific erosion parameters.

- SEDZLJ can simulate overburden-induced consolidation of cohesive sediments. An algorithm that simulates the process of primary consolidation, which is caused by the expulsion of pore water from the sediment, of a fine-grained, i.e., cohesive, dominated sediment bed is included in SEDZLJ. The consolidation algorithm in SEDZIJ accounts for the following changes in two important bed parameters: 1) increase in bed bulk density with time due to the expulsion of pore water, and 2 ) increase in the bed shear strength (also referred to as the critical 
shear stress for resuspension) with time. The latter parameter is the minimum value of the bed shear stress at which measurable resuspension of cohesive sediment occurs. As such, the process of consolidation typically results in reduced erosion for a given excess bed shear stress (defined as the difference between the bed shear stress and bed shear strength) due to the increase in the bed shear strength. In addition, the increase in bulk density needs to be represented to accurately account for the mass of sediment (per unit bed area) that resuspends when the bed surface is subjected to a flow-induced excess bed shear stress.

- Models that represent primary consolidation range from empirical equations that approximate the increases in bed bulk density and critical shear stress for resuspension due to porewater expulsion (Sanford 2007) to finite difference models that solve the non-linear finite strain consolidation equation that governs primary consolidation in saturated porous media (e.g., Arega and Hayter, 2008). An empirical-based consolidation algorithm is included in SEDZLJ .

- SEDZLJ contains a morphologic algorithm that, when enabled by the model user, will adjust the bed elevation to account for erosion and deposition of sediment. 


\section{MPFATE and GTRAN Sediment Transport Model Results}

\section{MPFATE results}

The objective of MPFATE modeling is to provide initial bathymetric conditions for SEDZIJ simulations following dredged material placement at the Point Chehalis, South J etty, and Half Moon Bay placement sites. The hydrodynamic conditions and placement scheme of the 2008 and 2009 dredge placements were simulated.

Dredged material placement was accomplished with four vessels; the Liberty and Lummi Island scows, and the Essayons and Yaquina trailing suction hopper dredges. Dredged material within placement vessels is composed of sediment and water (contained within the sediment pore space and entrained during the dredging process). Hopper dredges entrain large volumes of water during dredging, and a common practice with hopper dredges is to allow overflow of water while dredging to increase the economic loading of sediment. During overflow, a portion of the dredged fine sediments also pass through the overflow weir. Hopper dredges generally disaggregate cohesive sediments; however, mechanically dredged sediments often include a fraction of dredged material in the form of intact bed material or clumps. The following sections describe each of the dredges used at Grays Harbor and the dredged material descriptions provided to MPFATE.

\section{Liberty and Lummi Island}

The Liberty and Lummi Island are scows used to transport mechanically dredged sediments. Liberty has a capacity of 4,000 cy and Lummi Island's capacity is 1,800 cy. Both vessels transported dredged material from Cow Point Reach from 16 J uly to 18 September 2008 and from 14 J anuary to 12 February 2009. Both vessels transported mechanically dredged material from the same location during the same time period, and their loads were treated as a single vessel in the MPFATE simulations, with a weighted average load derived from dredging records. The weighted average load was $2792 \mathrm{cy}$, of which 85 percent was estimated to be water. Clump fraction for these loads was estimated with an experience-based approach developed at ERDC based on plasticity and water content of the dredged material. The 
vessels dredged from the Inner Harbor, where the clump fraction was estimated to be 55 percent of the solids. Sand and fines fractions, determined from sediment samples collected at the site and analyzed at ERDC, were determined to be 30 and 70 percent, respectively, of the nonclumped solids. Therefore the total volume fractions of the dredged solids were 8.25 percent clumps, 2 percent sand, and 4.7 percent silts and clays (the remaining volume is water, including pore water and water entrained during dredging).

\section{Essayons}

The Essayons trailing suction hopper dredge has a capacity of 6,000 cy and operated at the site between 2 - 18 April 2009. The dredge has a pumping rate of $400 \mathrm{cy} / \mathrm{min}$ and pumped an average of $96 \mathrm{~min}$ at Grays Harbor. Essayons dredged from the outer harbor where the sediment was predominantly sand, 98 percent. The pumped sediment mixture was assumed to be 90 percent water and 10 percent solids (Bray et al., 1997). Based on the pumping rate, pumping time, and accounting for overflow, the average Essayons load contained 3,564 cy of solids, resulting in total dredged material volume fractions of 59 percent sand, less than one percent fines, and 40 percent water.

Yaquina

Yaquina has a capacity of 1,042 cy and operated from 29 April to 26 May 2009 at the Entrance Channel. Intake was 85 percent water, 15 percent solids, which consisted of 66.7 percent sand. Accounting for overflow, volume fractions for the average load consisted of 62 percent sand, 5 percent fines, and 33 percent water.

The MPFATE placement sequence at Grays Harbor was developed to reproduce the dredge placements conducted in 2008 and 2009 as indicated in dredging records. A bathymetric grid was developed from the ADCIRC model bathymetry with 82- by 82-ft spacing for each DMP site. Hydrodynamic forcing was provided from ADCIRC simulations for the placement locations and times obtained from the dredge track logs. Each vessel was assumed to place material at a speed ranging from 1 to 3 knots, with 10 degree variability in vessel bearing. Transport of the deposited dredged material was not simulated during the placement simulation. As a result, the mounds from the MPFATE simulations were more peaked than indicated by post-placement bathymetric surveys. 
MPFATE simulations were performed in chronological order of the dredge placements; Liberty and Lummi Island operated first, followed by Essayons, and concluded by Yaquina. The placement scheme simulated the actual placements performed with the vessels. Results are presented at each placement site in the following paragraphs.

\section{Point Chehalis}

All four vessels made placements at the Point Chehalis site; 175 by Liberty and Lummi Island, 72 by Essayons, and 155 by Yaquina. The resulting lift heights (deposited thickness) from the placements are shown in Figure 7-1.

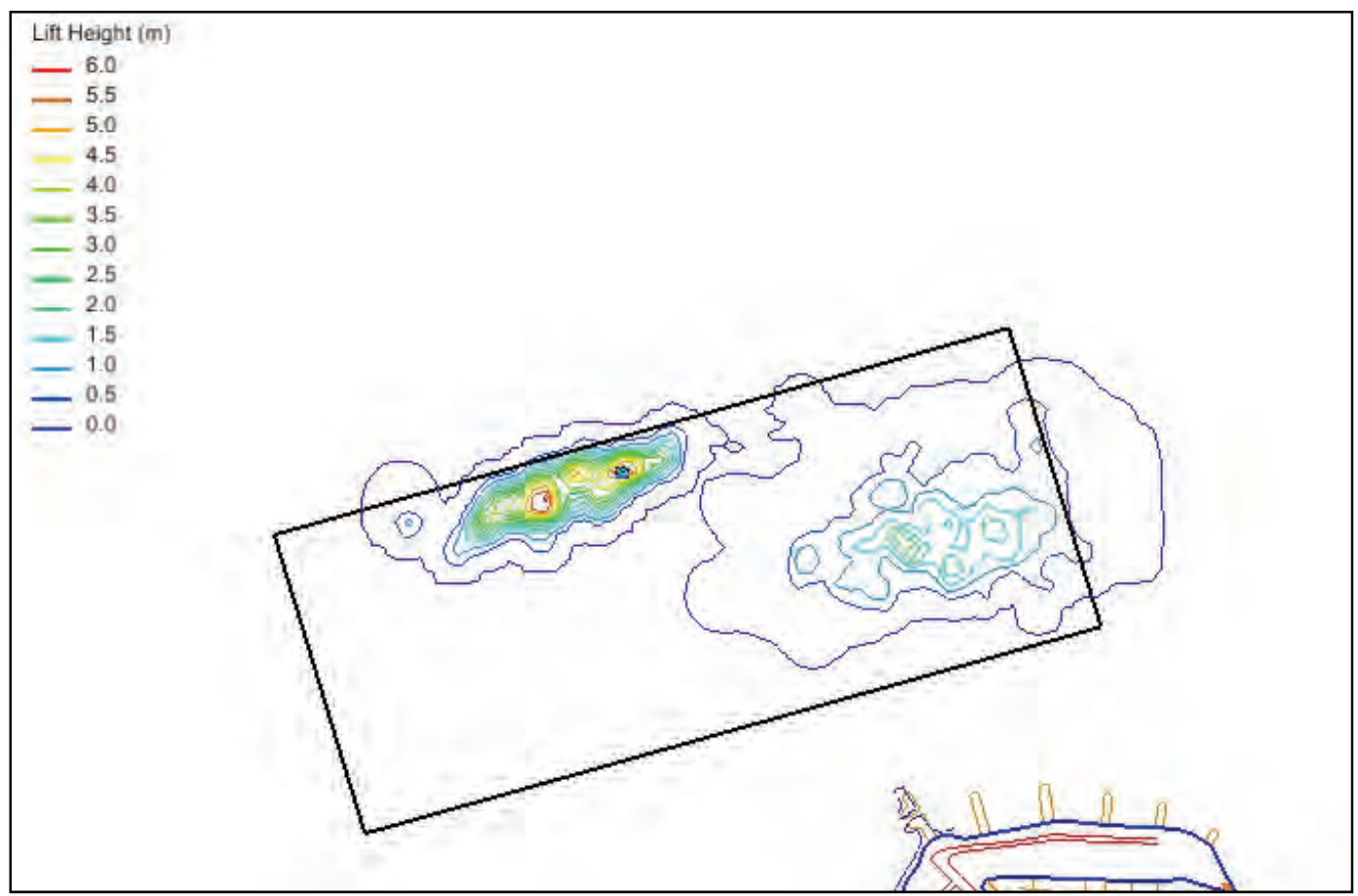

Figure 7-1. Lift heights at Point Chehalis placement site.

South Jetty

The Liberty and Lummi Island vessels made 183 placements at the South J etty site, followed by four additional placements by Essayons. Lift heights at the South J etty site are shown in Figure 7-2.

Half Moon Bay

Figure 7-3 shows the resulting lift heights from three placements by Liberty and Lummi Island and 63 by Yaquina. 


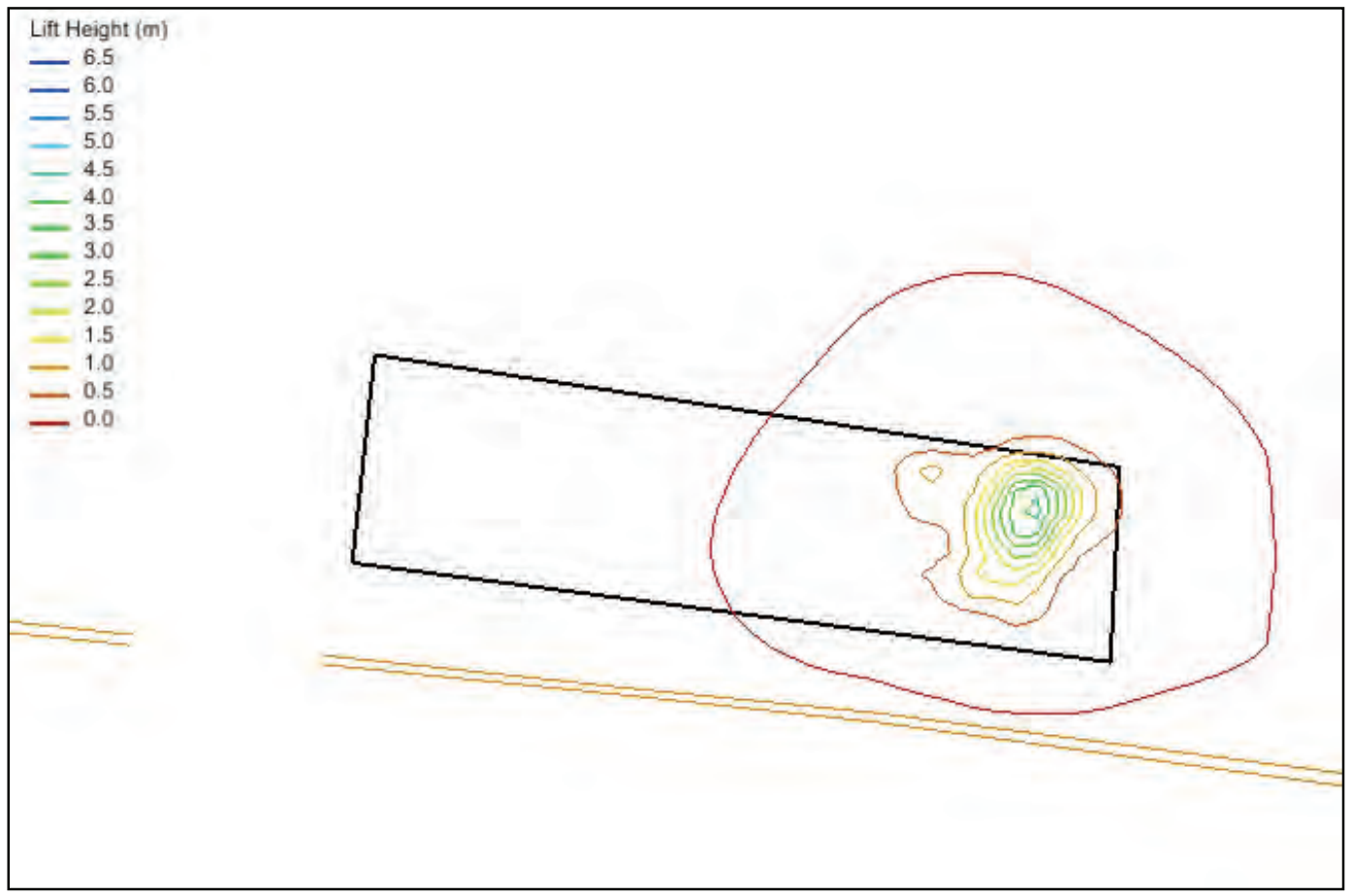

Figure 7-2. Lift heights at South Jetty placement site.

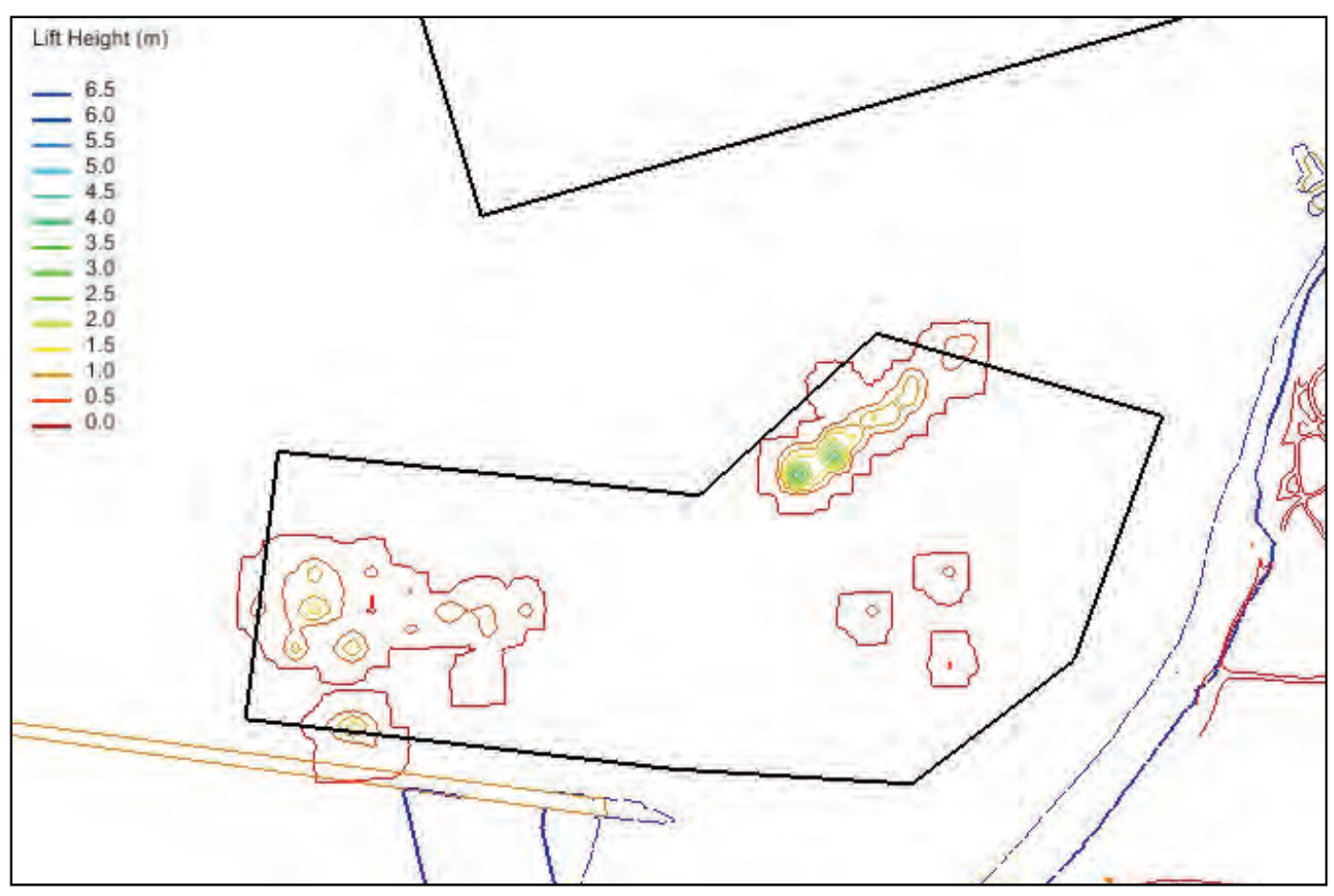

Figure 7-3. Lift heights at Half Moon Bay placement site. 


\section{GTRAN results}

The objective of GTRAN modeling is to identify sediment transport pathways at the three placement sites and to recommend alternatives to existing placement practices based on the estimated sediment transport pathways. Five simulations were performed; representing 6-month, 2-year, and 5-year return intervals; a high-energy period and a long-term (38 year) simulation. Event selection is described in Chapter 4. The 6-month return interval (represented by results from the second quarter of 1993), the 2-year return interval (represented by the fourth quarter of 2006), and the 5-year return interval (represented by the fourth quarter of 1998) were interpolated from ADCIRC and CMS-WAVE simulations. The high-energy period included a 31-day period in the first quarter of 1990, and the longterm event was simulated by results from the entire 1970 to 2007 GROW hindcast period. It should be noted that the four simulated periods (6-month, 2-year, 5-year, and high-energy) included astronomical (tides), transformed waves, and meteorological (surge) influence. The long-term event included only astronomical hydrodynamics and transformed waves.

GTRAN simulations were performed for existing and proposed channel realignment configurations. The same computational domain, sediment distribution, and hydrodynamics were performed for both channel alignment configurations.

Results from GTRAN in the study area are shown in rose plots. Each "wedge" in the rose represents cumulative transport for one of 20 directional bins at each point. Area of the colored wedge is scaled to transport potential. Therefore, the large wedges indicate high transport in a specific direction while small wedges indicate smaller amounts of transport. GTRAN is generally useful in evaluating relative transport and transport pathways and is not indicative of net transport because the model neglects sediment supply and morphology change. Wedge areas are used to demonstrate relative magnitude of transport at a point, transport pathways in a system, and to identify transport trends in active regions.

Rose plots presented in this report are of consistent scale within a given figure and are intended for comparisons within a given plot. Additionally, each wedge represents cumulative transport and the wedge size is dependent upon both time and intensity of transport. For the Grays Harbor simulations, the 6-month, 2-year, and 5-year return intervals had identical wedge scaling and were of similar duration. Scaling of the extreme event 
also was the same as the aforementioned return intervals, but was of shorter duration and the resulting wedges represent a smaller cumulative transport. Because of its long duration, the scale of the long-term event was reduced by a factor of 2.5 to present the results.

\section{Existing conditions}

GTRAN simulations were applied to Grays Harbor with the five hydrodynamic events for existing and realigned channels. The results are presented at each placement site.

\section{Point Chehalis}

GTRAN results at the Point Chehalis placement site are shown in Figure 7-4 for the five simulated hydrodynamic conditions. The results indicated that transport was generally bidirectional, indicating the alternating transport by tidal currents. Transport was ebb-dominant in the northern portion of the placement site, but weaker in the southeast corner where transport was more equally balanced.

It should be noted that although the figures indicate a large tidal influence, waves exerted an important influence in mobilizing sediment to be transported by tidally driven currents. Transport patterns were similar for each of the simulated periods; therefore, only the 5-year return interval will be presented in the subsequent text. Results of all hydrodynamic conditions are presented in Appendix A.

\section{South Jetty}

South J etty placement site results are similar for the 5-year return-interval (Figure 7-5) and other simulations (Figure A2). Transport within the South J etty site was ebb-dominant, especially near the jetty, for the simulated events. Additionally, transport magnitude increased with distance in the ebb direction, suggesting that the South J etty placement site was erosional. The long-term event showed generally equal bimodal transport within the placement site (Figure A2e). 


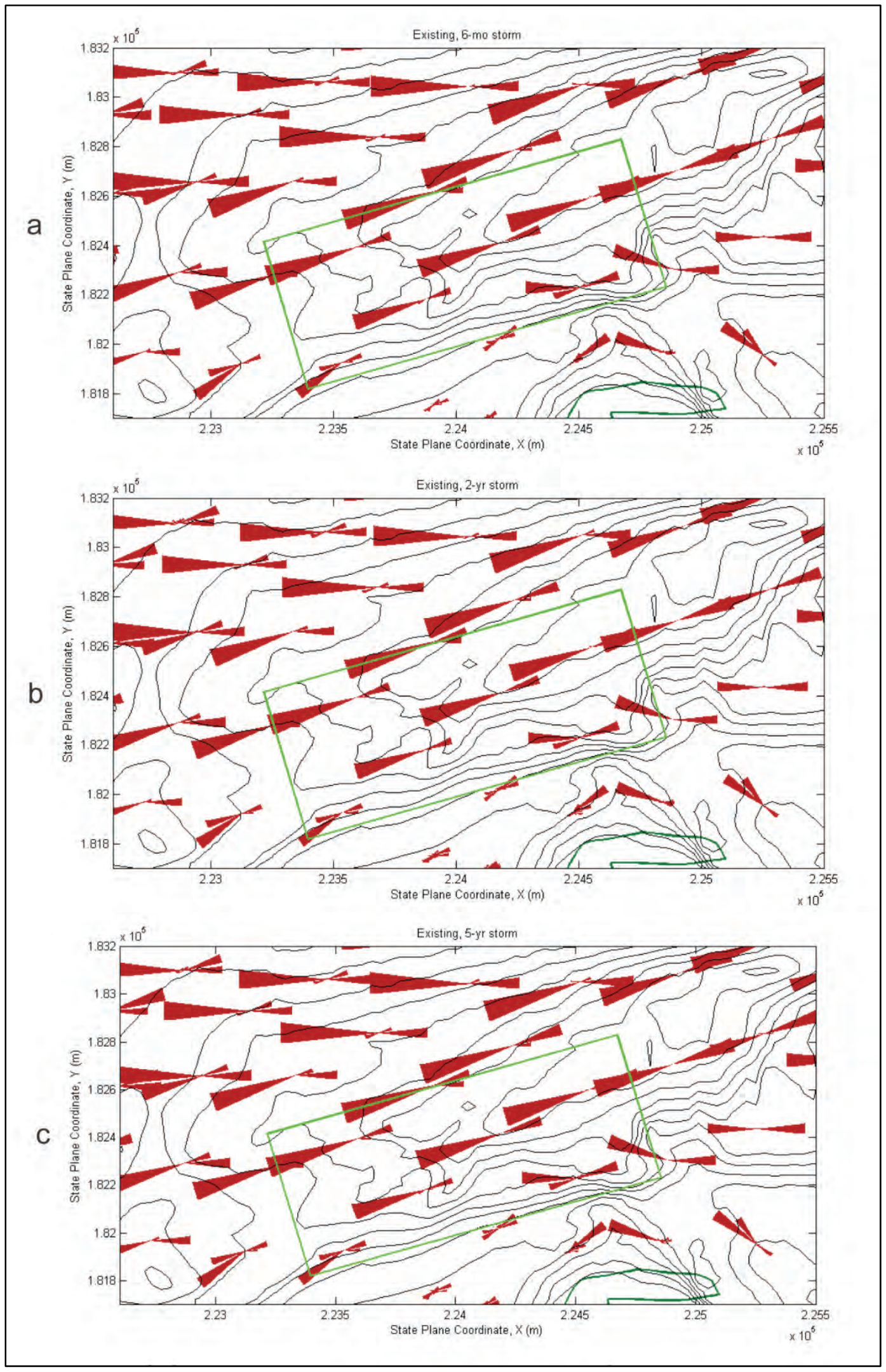

Figure 7-4. GTRAN results, existing conditions at Point Chehalis placement site. 

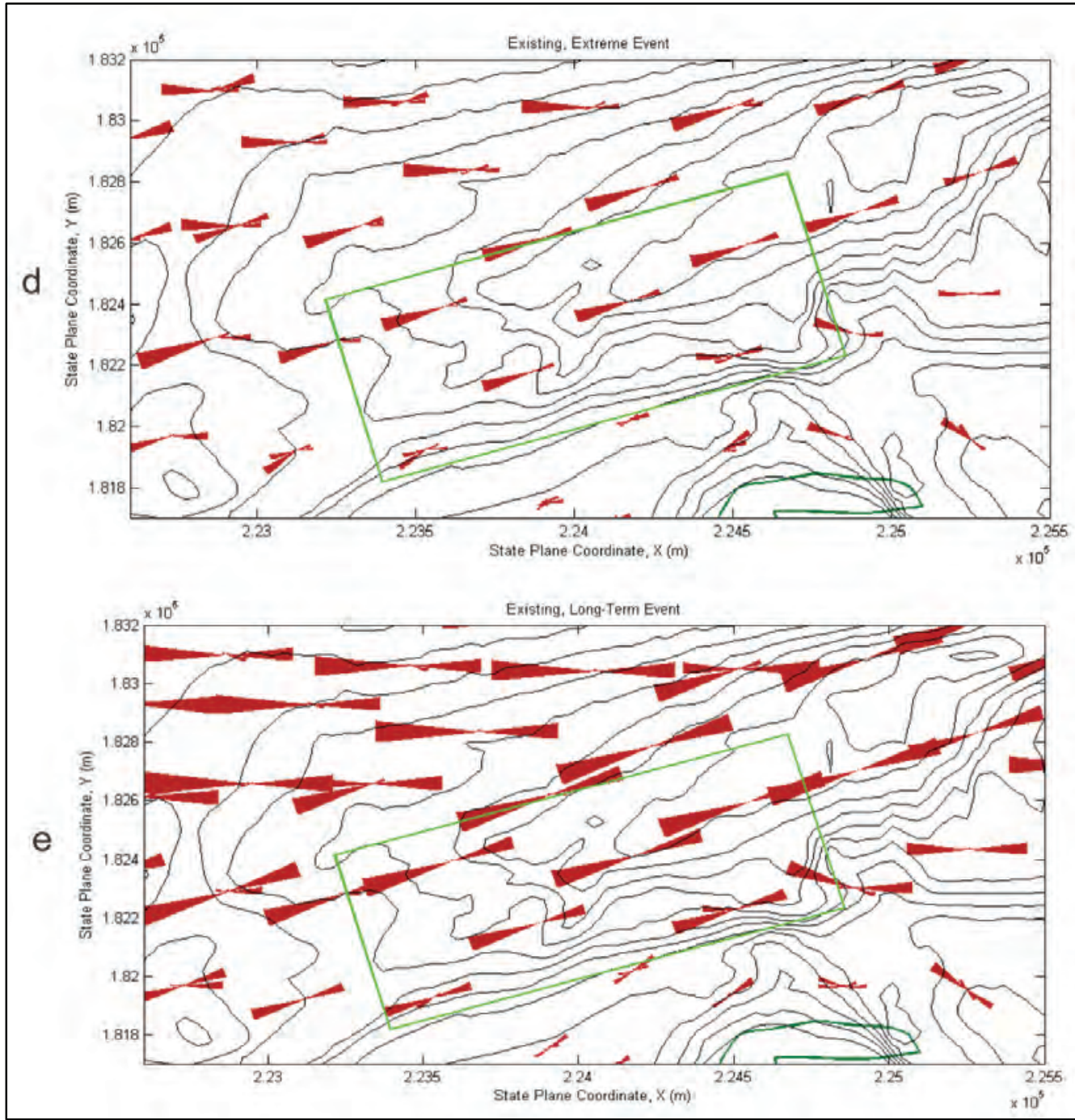

Figure 7-4 (cont.). GTRAN results, existing conditions at Point Chehalis placement site.

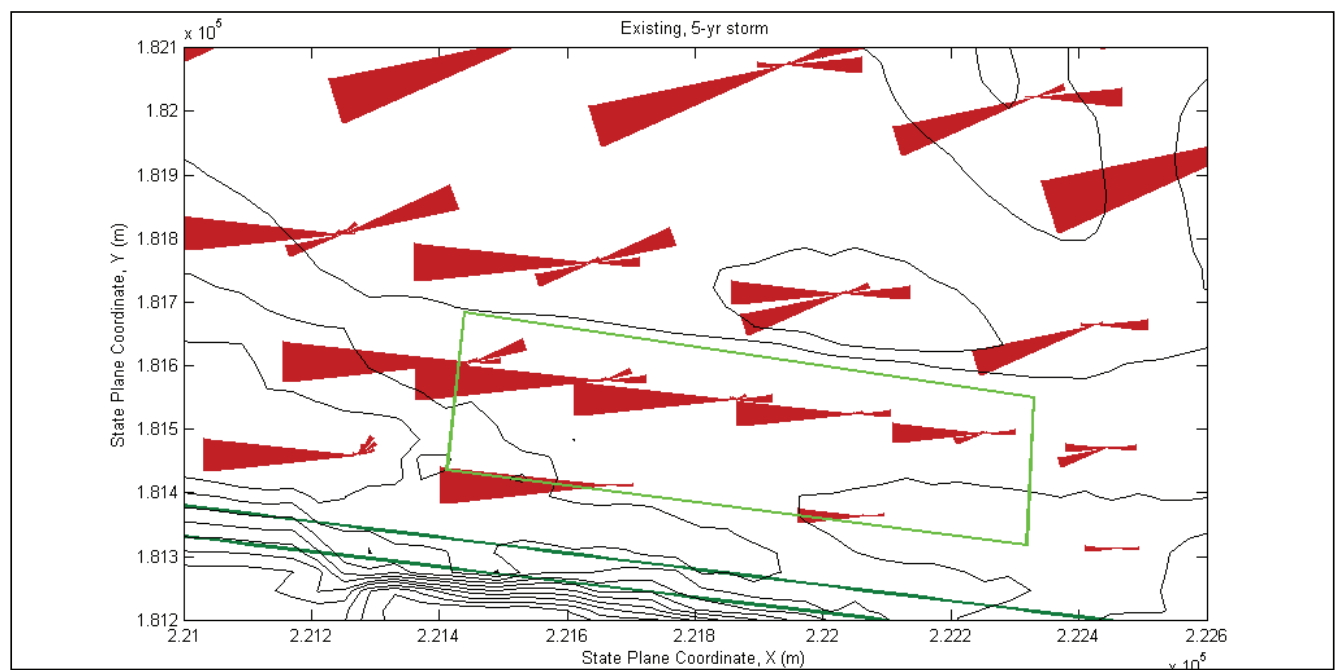

Figure 7-5. GTRAN results of 5-yr simulated event with existing conditions at South Jetty placement site. 


\section{Half Moon Bay}

Transport rates within the Half Moon Bay placement site (Figures 7-6 and A3) were much smaller compared to the other placement sites. Transport also was less bimodal, especially at the eastern extent of the site. The eastern portion of the site, an area influenced by an ebb-tidal eddy, was exposed to smaller tidal currents. The smaller tidal currents, stronger wave influence, and ebb-tidal eddy resulted in greater transport direction variability and flood dominance in the eastern portions of the site.

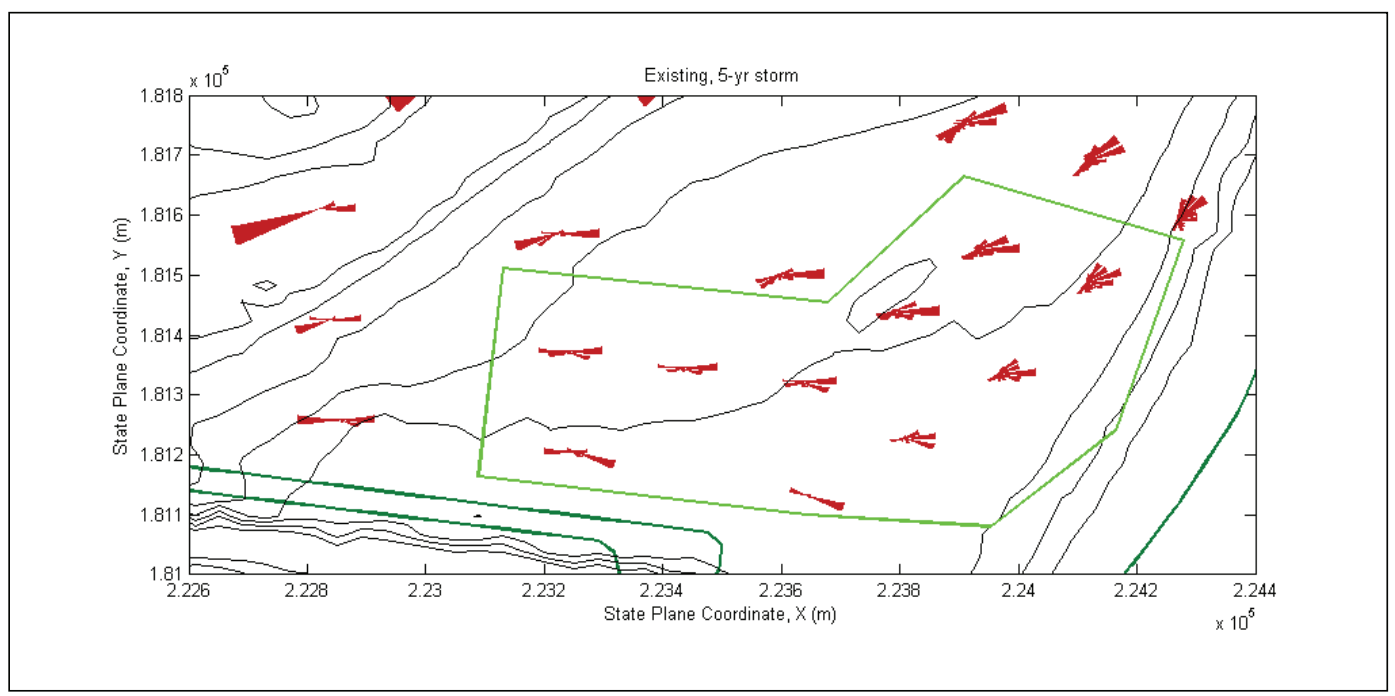

Figure 7-6. GTRAN results of 5-yr simulated event with existing conditions at Half Moon Bay placement site.

\section{Realigned channel condition}

Simulations were performed for the hydrodynamic events with the bathymetry altered to represent the realigned channel. In addition to increasing depth within the realigned channel, the existing channel depths were modified to represent infilling. The realigned channel results are presented by site in the following paragraphs.

\section{Point Chehalis}

GTRAN results at the Point Chehalis placement site with the realigned channel were very similar to results with the existing channel as shown in Figure 7-7 for the 5-year event, and also in Figure A4 for all storm events. Transport was generally bimodal, and transport magnitude was comparable to magnitudes with existing conditions. These results suggest that the 
realigned channel will have little effect on sand transport magnitudes and directions at this site.

\section{South Jetty}

Realigned channel GTRAN results at the South J etty placement site also were similar to results with existing conditions, shown in Figure 7-8, for the 5-year simulation. Like the existing channel condition, transport was predominately in the ebb-flow direction; however, transport magnitude was larger within the site. Results at the South J etty placement site for all storms showed similar patterns for the simulated events (Figure A5a-d). However, the long-term event showed more bimodal transport with magnitudes similar to or less than with the existing condition (Figure A5e). The larger transport gradients indicated that increased erosion would likely occur at this site.

\section{Half Moon Bay}

Transport magnitude and direction was essentially unchanged with the realigned channel at the Half Moon Bay placement site shown in Figure 7-9 for the 5-year storm and Figure A6 for all storms. Transport patterns were less bidirectional and weaker in magnitude than at the other two sites.

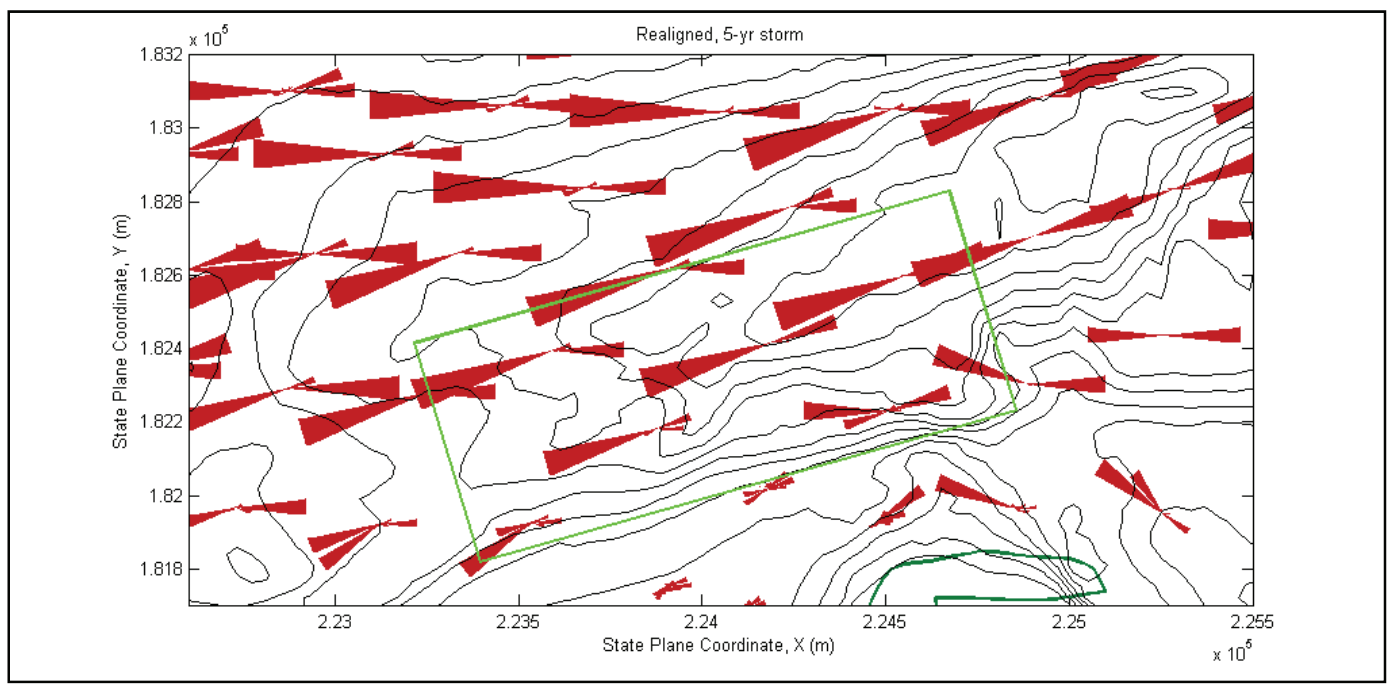

Figure 7-7 GTRAN results of 5-yr simulated event with realigned channel conditions at Point Chehalis placement site. 


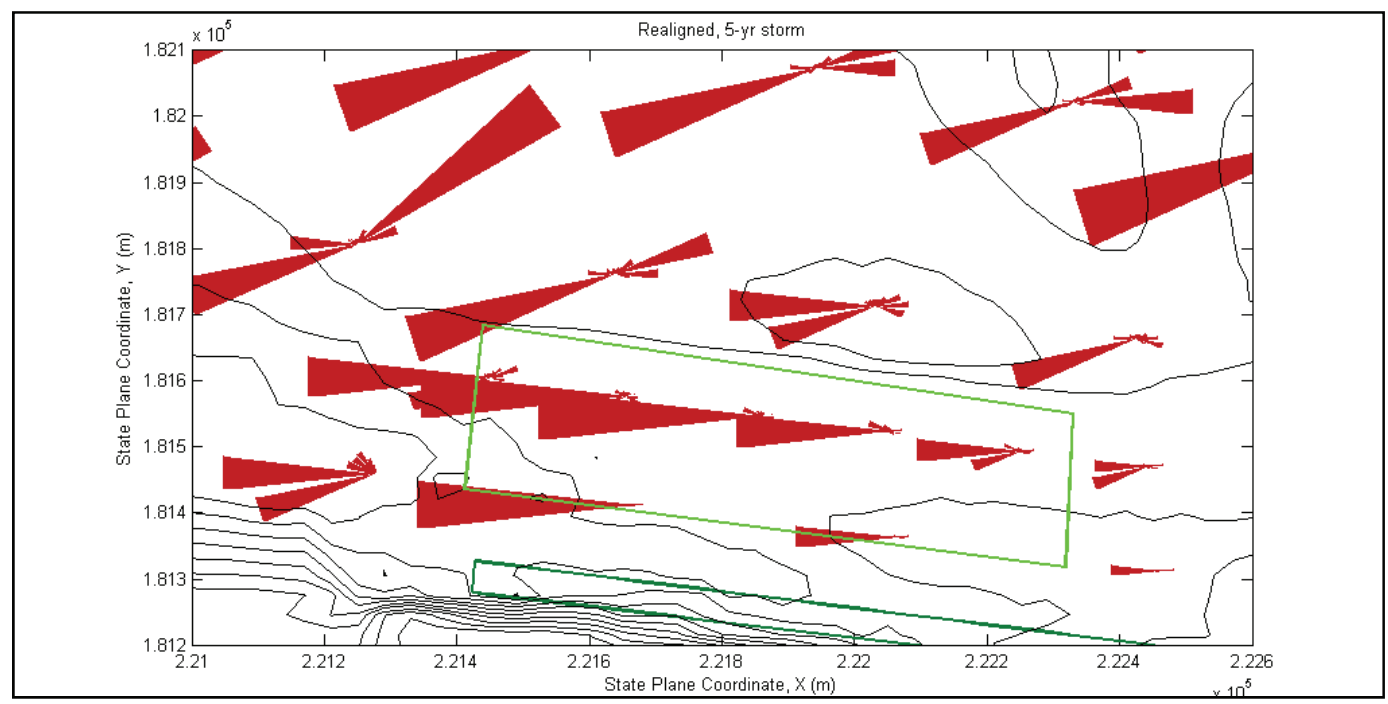

Figure 7-8. GTRAN results of 5-yr simulated event with realigned channel conditions at South Jetty placement site.

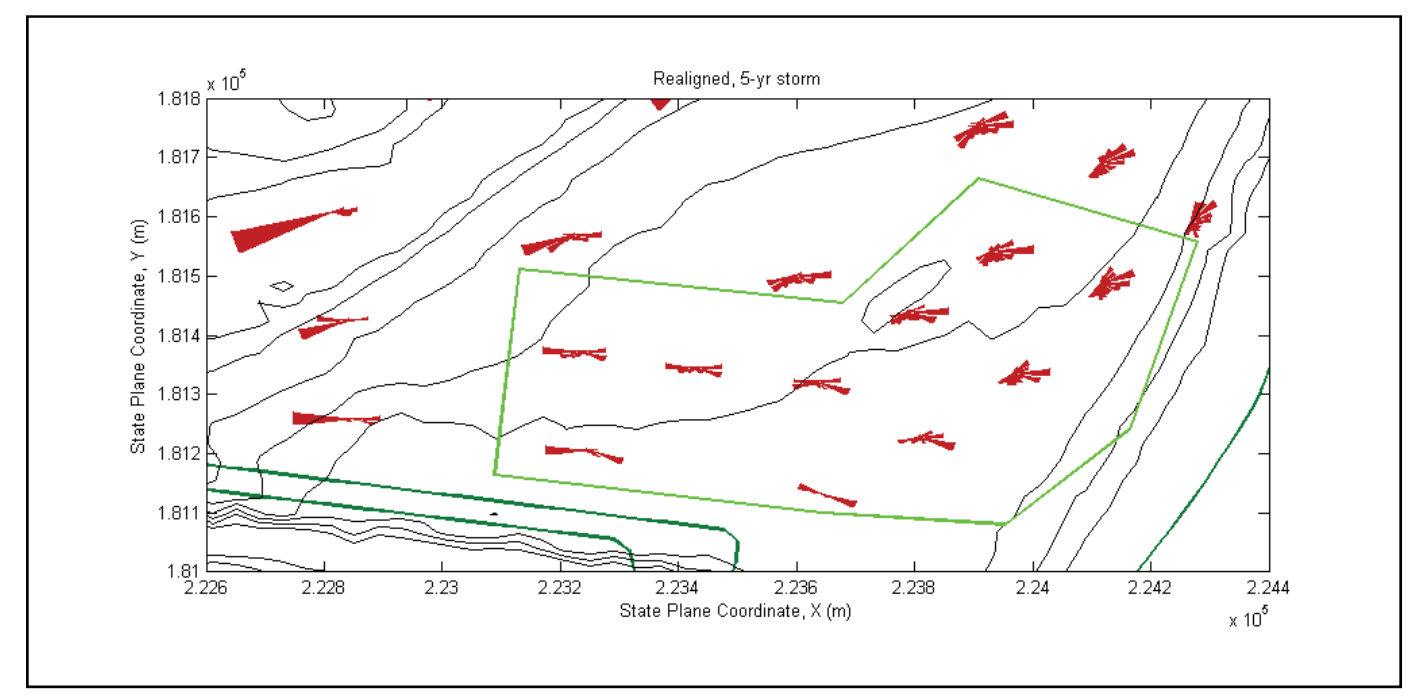

Figure 7-9. GTRAN results of 5-yr simulated event with realigned channel conditions at South Jetty placement site.

\section{Comparison of realigned channel with Existing conditions}

The ratio of cumulative total transport for the realigned channel to existing conditions was calculated for each GTRAN point within each of the placement sites. Figure 7-10 presents the realigned:existing ratios for the 5-yr return period, where values greater than unity indicate increased transport and values less than unity indicate a decrease in transport with the realigned channel. Transport within the Point Chehalis placement site was near unity at all points and implies that the realigned channel will have little effect on transport rate. An increase in transport was shown at the South J etty site at most of the calculation points with the realigned 
channel. The increased transport was attributed to shallower depths resulting from infilling of the existing channel at the South J etty site. The Half Moon Bay placement site showed slightly increased transport rates with the realigned channel configuration.

The range of the transport ratios for each simulation is given in Table 7-1. The results suggest that channel realignment did not appreciably change transport rates at the Point Chehalis site (less than 10 percent change with channel realignment). At the South J etty site, transport increased by up to a factor of two. As noted previously, the increased transport was associated with decreased depth at several locations within the South J etty as a result of artificially infilling the existing channel within the ADCIRC and CMSWave model bathymetries. The Half Moon Bay site transport generally increased on the order of 5 to 20 percent for most simulations, however the 2-year simulation period indicated up to 80 percent increase in transport, most likely an indication of sensitivity of this site to incident wave direction.

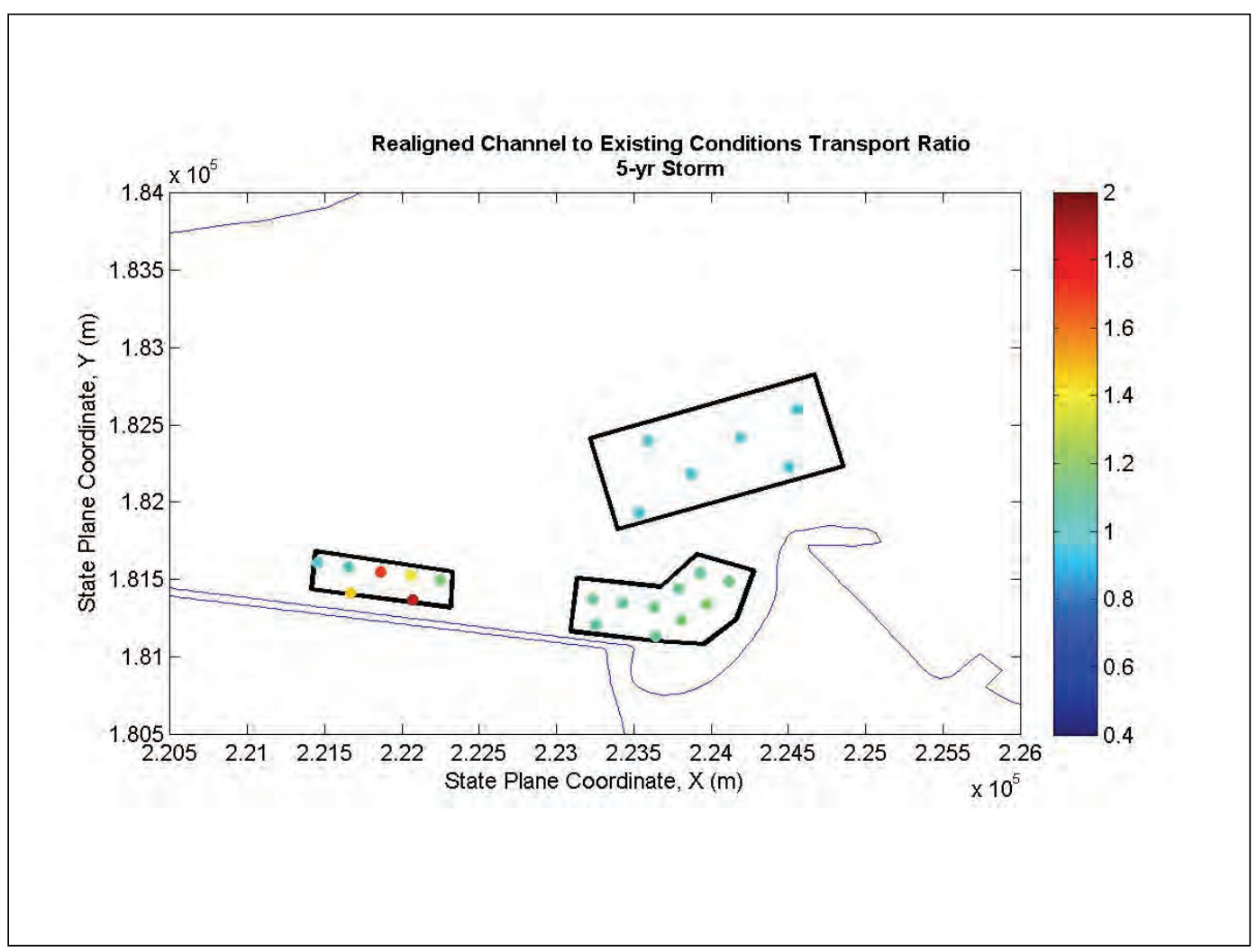

Figure 7-10. Transport ratio of realigned channel to existing conditions, 5-yr storm. 
Table 7-1: Ratio of transport with realigned channel to transport with existing channel.

\begin{tabular}{|l|l|l|l|l|l|l|l|l|l|l|}
\hline \multirow{2}{*}{$\begin{array}{l}\text { Disposal } \\
\text { Site }\end{array}$} & \multicolumn{9}{|c|}{6 month } & \multicolumn{2}{c|}{2 year } & \multicolumn{2}{c|}{5 year } & \multicolumn{2}{c|}{ Extreme } & \multicolumn{2}{c|}{ Long Term } \\
\cline { 2 - 11 } & Min & Max & Min & Max & Min & Max & Min & Max & Min & Max \\
\hline $\begin{array}{l}\text { Point } \\
\text { Chehalis }\end{array}$ & 0.97 & 1.08 & 0.96 & 1.07 & 0.97 & 1.10 & 0.93 & 1.04 & 0.77 & 1.18 \\
\hline $\begin{array}{l}\text { South } \\
\text { Jetty }\end{array}$ & 0.99 & 1.90 & 0.98 & 1.90 & 0.99 & 2.0 & 0.96 & 1.90 & 0.41 & 0.73 \\
\hline $\begin{array}{l}\text { Half } \\
\text { Moon } \\
\text { Bay }\end{array}$ & 1.04 & 1.16 & 1.09 & 1.80 & 1.07 & 1.16 & 1.07 & 1.19 & 1.20 & 1.47 \\
\hline
\end{tabular}

The sediment transport ratios presented in Figure 7-10 and Table 7-1 were generally similar for the 6-month, 2-year, 5-year, and extreme simulations. The long-term simulation, in contrast, yielded varying results. The longterm simulation at the Point Chehalis site indicated wider variability in total transport, with $+/$ - 20 percent change in transport. Long-term simulated transport at the Half Moon Bay site indicated transport increases of 20-50 percent. Long-term simulated transport at the South J etty site did not agree with the trends evident in the other simulated periods (with wind forcing). Evaluation of the hydrodynamic and wave forcing at the South J etty site indicated that inclusion of wind forcing was important at this site. With wind forcing, the simulated currents at the South J etty site were marginally stronger, but sufficiently so to exceed the critical shear stress much more frequently than for hydrodynamics without wind forcing. Additionally, the harmonic reconstruction of long-term tidal hydrodynamics eliminated eddies from the hydrodynamic solution. Given these observations, the results with wind forcing and simulated hydrodynamics (6-month, 2-year, 5-year, and extreme) are considered more reliable estimates of changes in sediment transport with channel realignment.

Rose plots were generated to compare directional differences in sand transport associated with channel realignment. The difference in transport at each binned direction is presented in the following section by placement site.

\section{Point Chehalis}

Comparison of the realigned channel from existing conditions with the 5-year event is shown for increased transport in Figure 7-11 and for decreased transport in Figure 7-12. Very little difference is evident and the 
increases and decreases indicated in the plots were most likely due to slight changes in current direction, i.e., transport shifts from east-northeast to a more easterly direction. Comparisons were similar with all the events for increased and decreased transport shown in Figures A7 and A8, respectively.

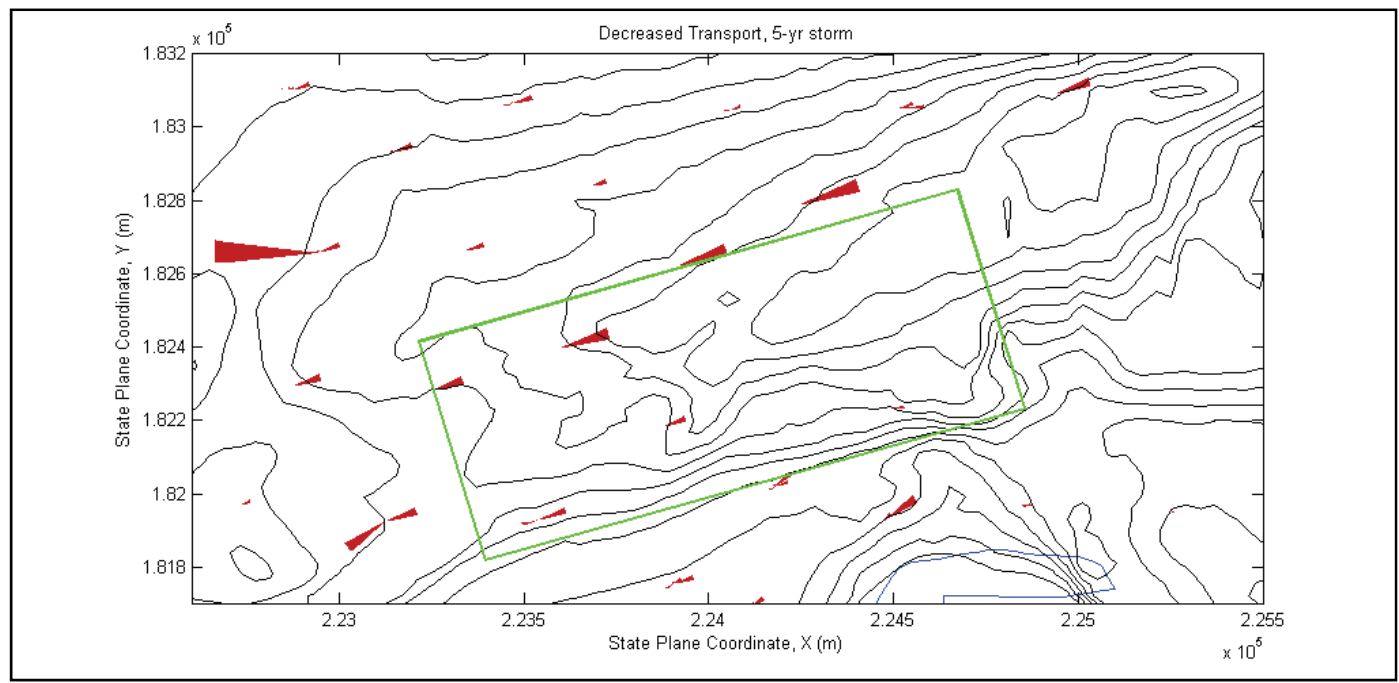

Figure 7-11. Increased transport with realigned channel at Point Chehalis placement site for $5-y r$ simulated event.

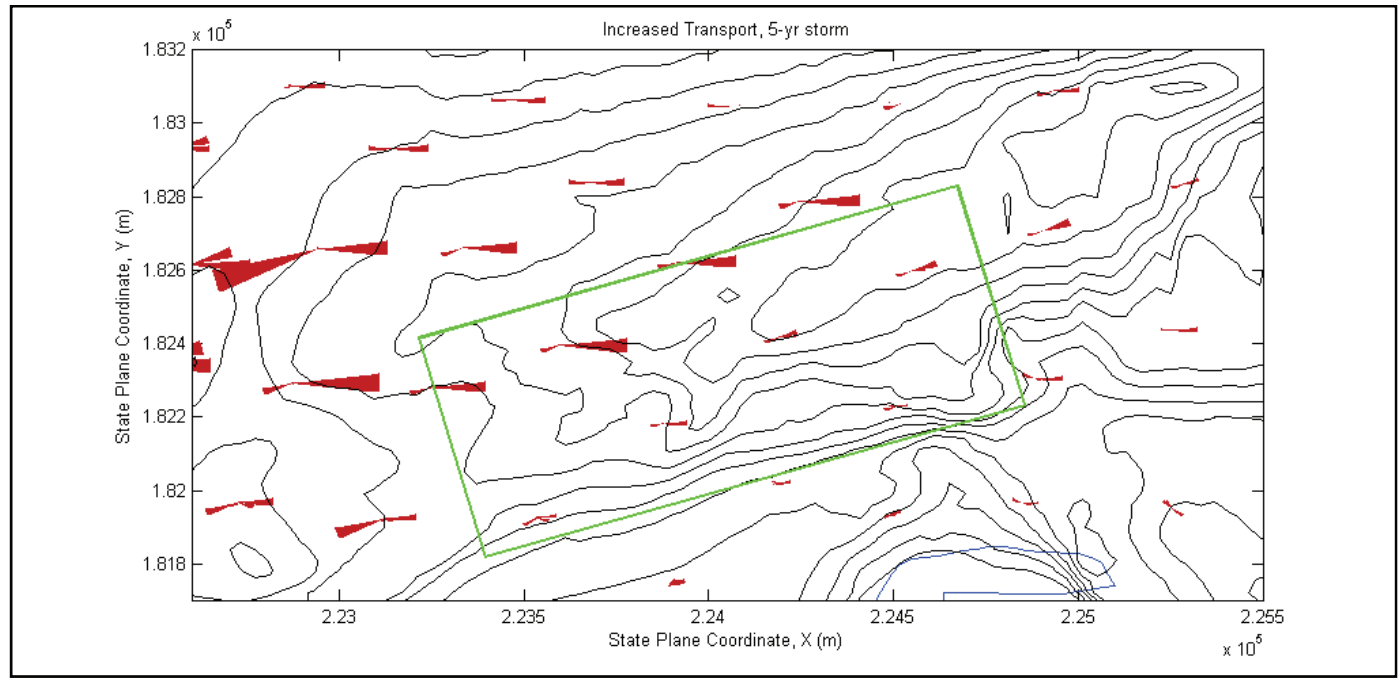

Figure 7-12. Decreased transport with realigned channel at Point Chehalis placement site for 5-yr simulated event.

South Jetty

Figure 7-13 shows increased transport with the 5-year simulated event in the ebb-flow direction with the realigned channel within the South J etty placement site. Decrease in transport due to realignment was small and 
mostly directed in the flood direction (Figure 7-14). Plots of increased and decreased transport at the South J etty site for all simulations are shown in Figures A9 and A10, respectively. Figures A9e and A10e illustrate that most of transport at the site decreased with the realigned channel for the long-term simulation, which was discussed previously.

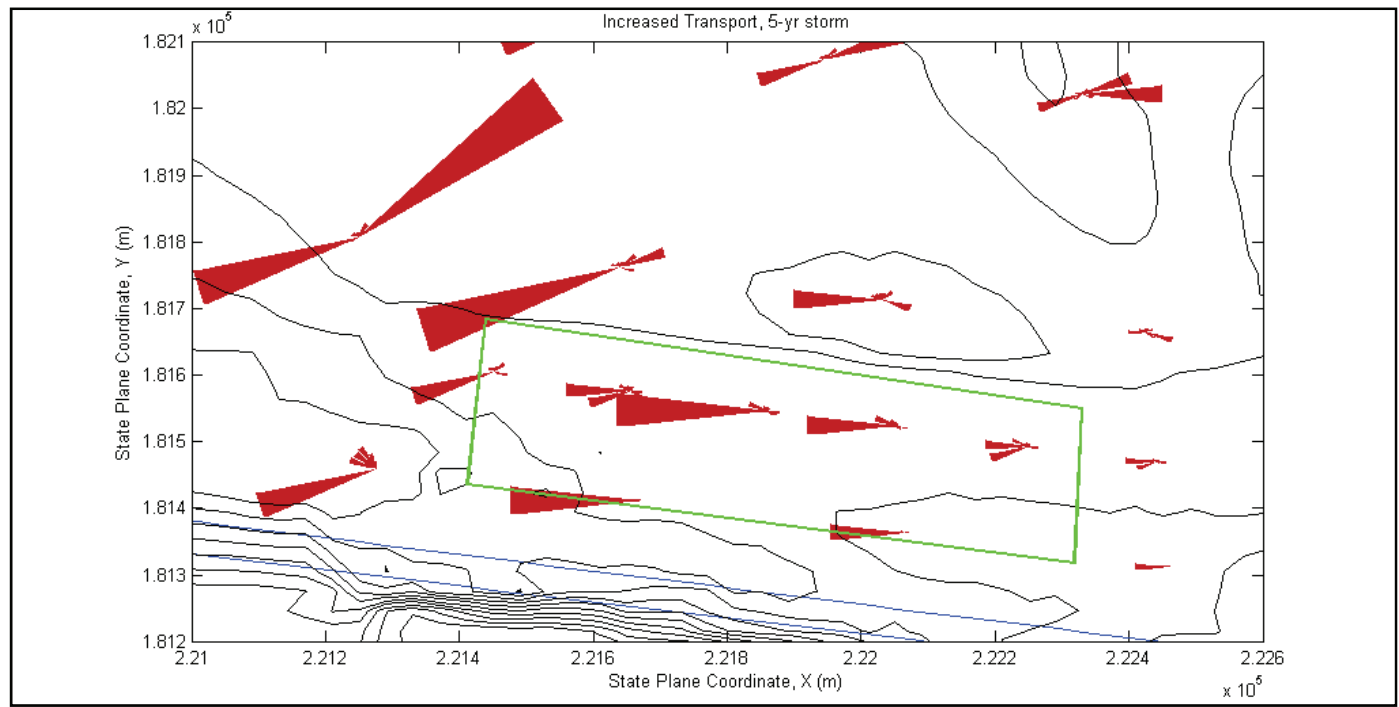

Figure 7-13. Increased transport with realigned channel at South Jetty placement site for 5-yr simulated event.

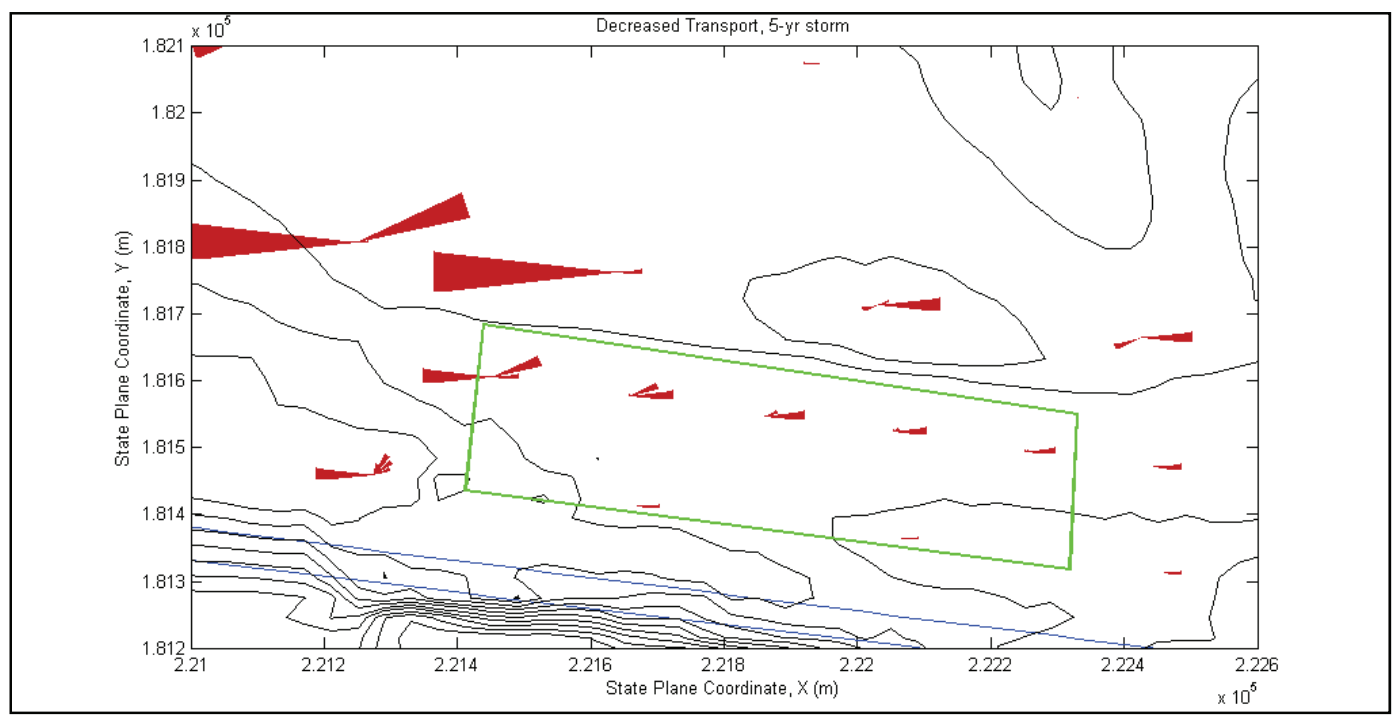

Figure 7-14. Decreased transport with realigned channel at South Jetty placement site for 5-yr simulated event.

Half Moon Bay

Differences in transport magnitude for the 5-year simulation at the Half Moon Bay placement site are shown in Figures 7-15 and 7-16, for increased 
and decreased transport magnitude respectively. Figure 7-15 shows that increased transport occurred in the western portion of the site and Figure 7-16 shows transport magnitude decreased in the flood direction. An overall increase in transport occurred with the realigned channel at the Half Moon Bay placement site; however, the differences in transport were generally small. Results for all storms are shown in Figures A11 and A12, for increased and decreased transport, respectively. Results for the longterm event differed from the other simulated events and showed increased transport towards the harbor (Figure A11e) and little decreased transport with the realigned channel (Figure A12e).

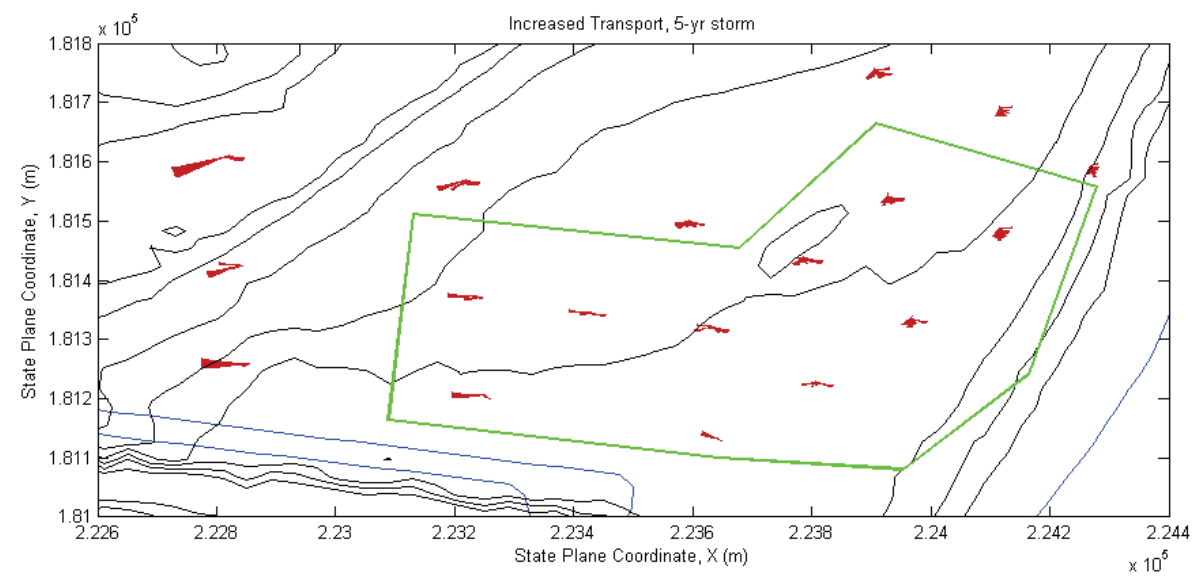

Figure 7-15 Increased transport with realigned channel at Half Moon Bay placement site for 5-yr simulated event.

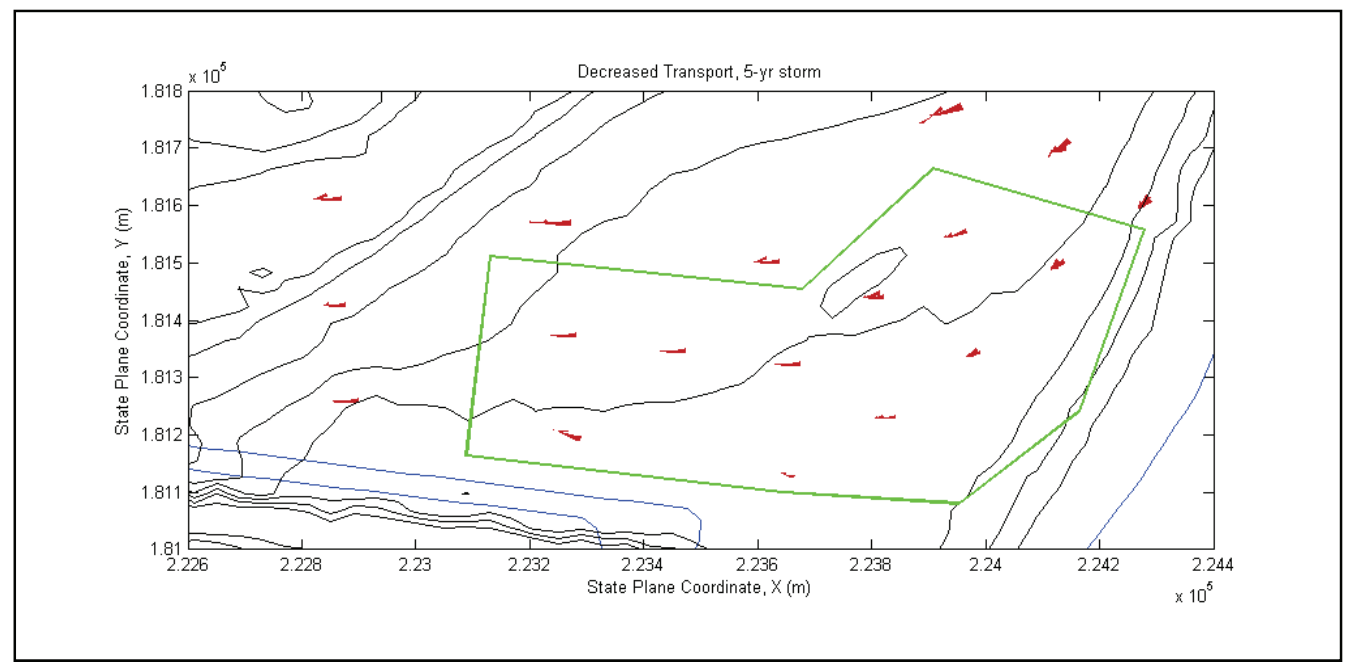

Figure 7-16. Decreased transport with realigned channel at Half Moon Bay placement site for 5 -yr simulated event. 


\section{Transport magnitude}

Transport rate at each calculation point was determined and plotted for the existing and realigned channel conditions. The transport rates in the vicinity of the placement sites for the 5-year simulated event are shown in Figures 7-17 and 7-18 for existing condition and realigned channel, respectively. Each point represents the average transport rate over the duration of the simulation for all directions of transport. The figures are near identical and indicate that transport rates will not change significantly with the realigned channel. Average transport rates for all the hydrodynamic events are given in Figures A13 (existing conditions) and A14 (realigned channel conditions).

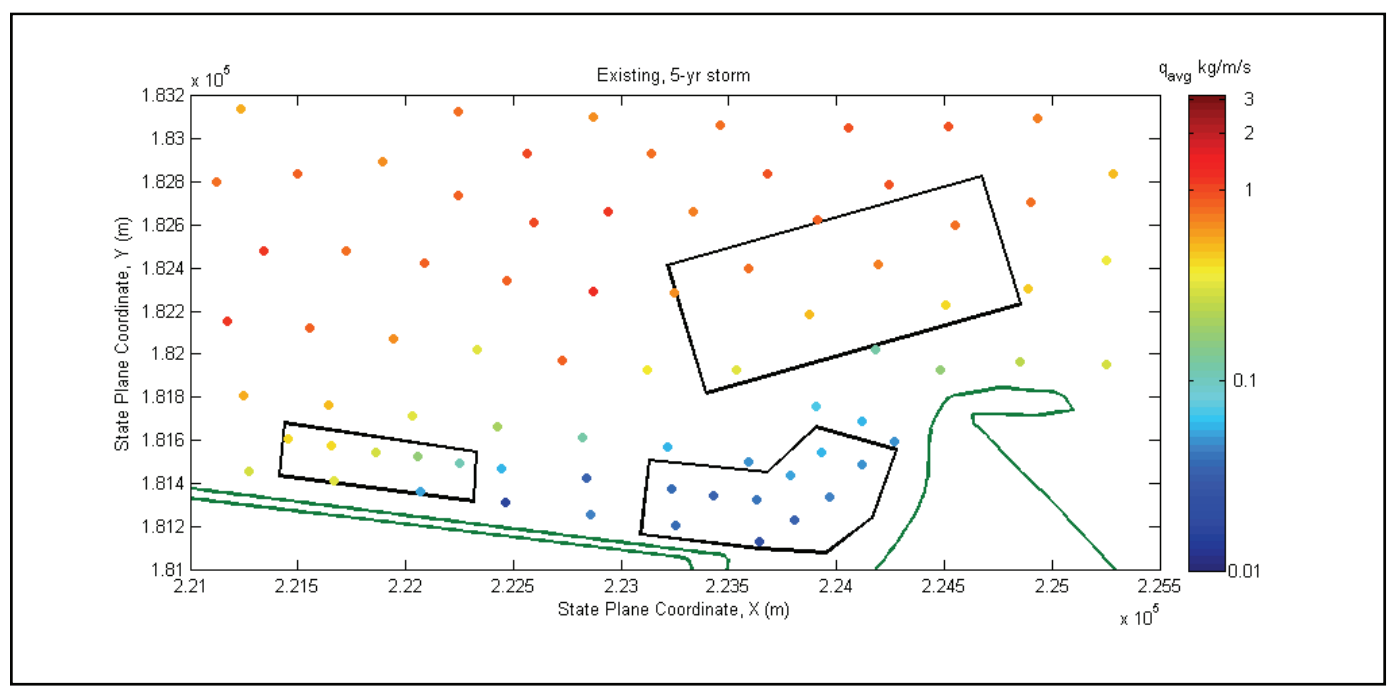

Figure 7-17. Average transport rate for 5-yr simulated event, existing conditions.

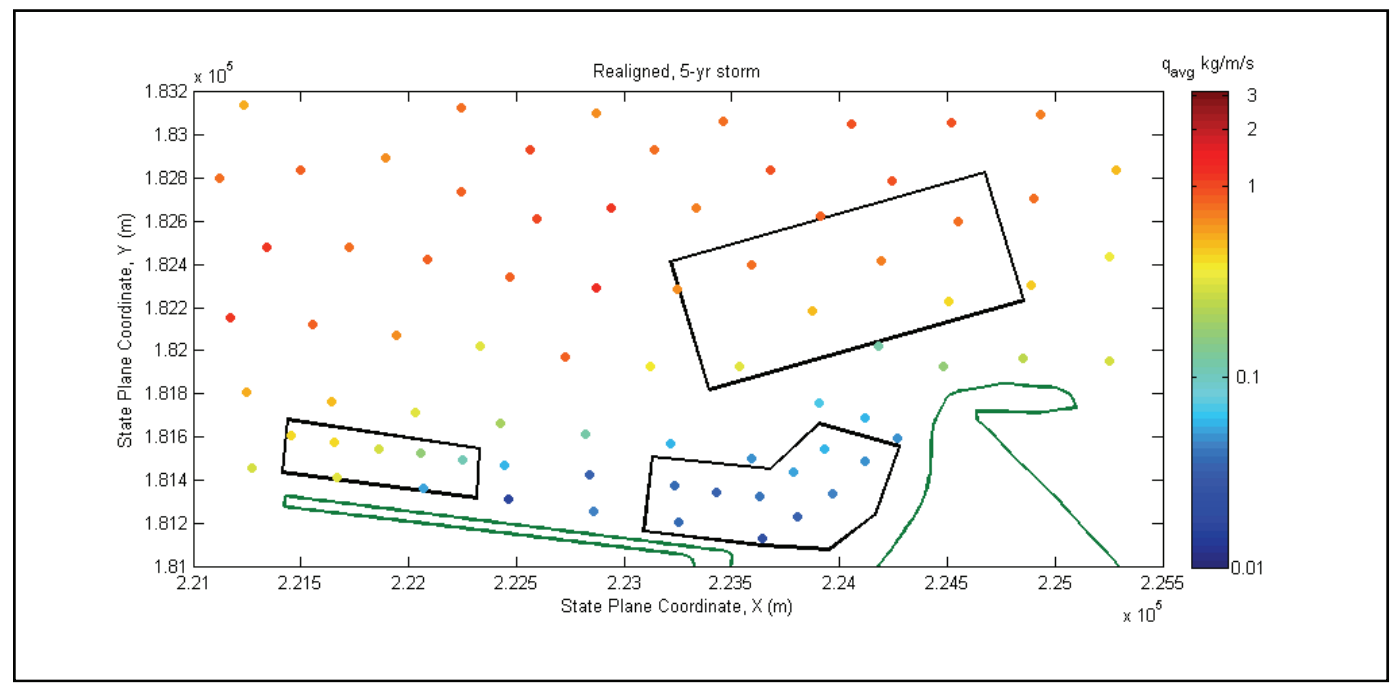

Figure 7-18. Average transport rate for 5-yr simulated event, realigned channel. 


\section{Transport streamlines}

Transport streamlines were plotted from GTRAN results to observe sediment pathways. Two groups of streamlines were plotted; one group included a line of grid points that originated in a line across the entrance west of the South J etty placement site (red streamlines), and the other included grid points originating in a line within the outer harbor immediately east of the Point Chehalis placement site (blue streamlines). Streamlines for the 5-year storm are plotted for the existing conditions in Figure 7-19 and for the realigned channel in Figure 7-20. Streamlines for all the hydrodynamic events are given in Figures A15 (existing conditions) and A16 (realigned channel conditions). Circulation cells were present north of the Point Chehalis placement site and near the end of the north jetty. The strength and extent of the recirculation pattern within the entrance did not change with the realigned channel. These results imply that sediment will accumulate within the cells, and that sediment placement north of the Point Chehalis site will feed the growth of shoals and lead to accumulation of sediment in the entrance. Based on this analysis, a more favorable site for transporting sediment outside the entrance would be north and west of the south jetty site, west of the circulation cell within the entrance. However, this location does not consider safety and logistical issues of placement. Additionally, east of the Point Chehalis site and within the channel, transport was directed in the flood direction.

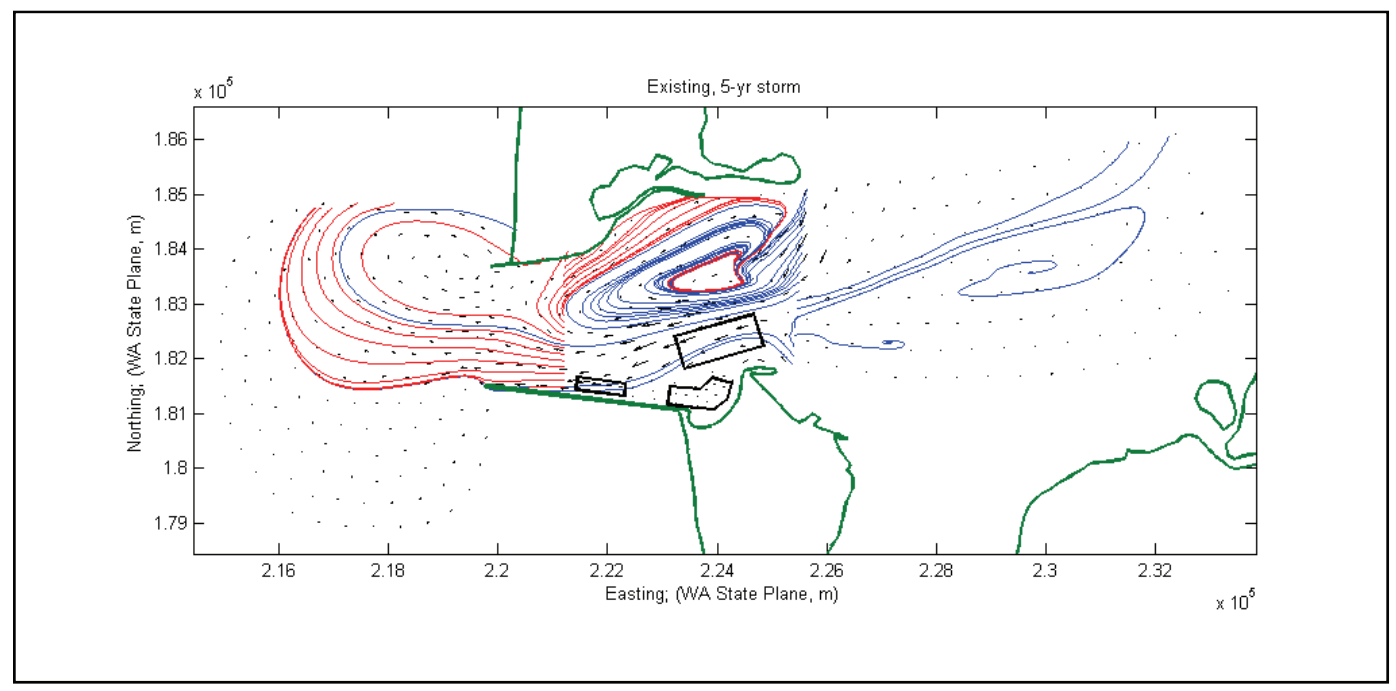

Figure 7-19. Transport streamlines for 5-yr simulated event, existing conditions. 


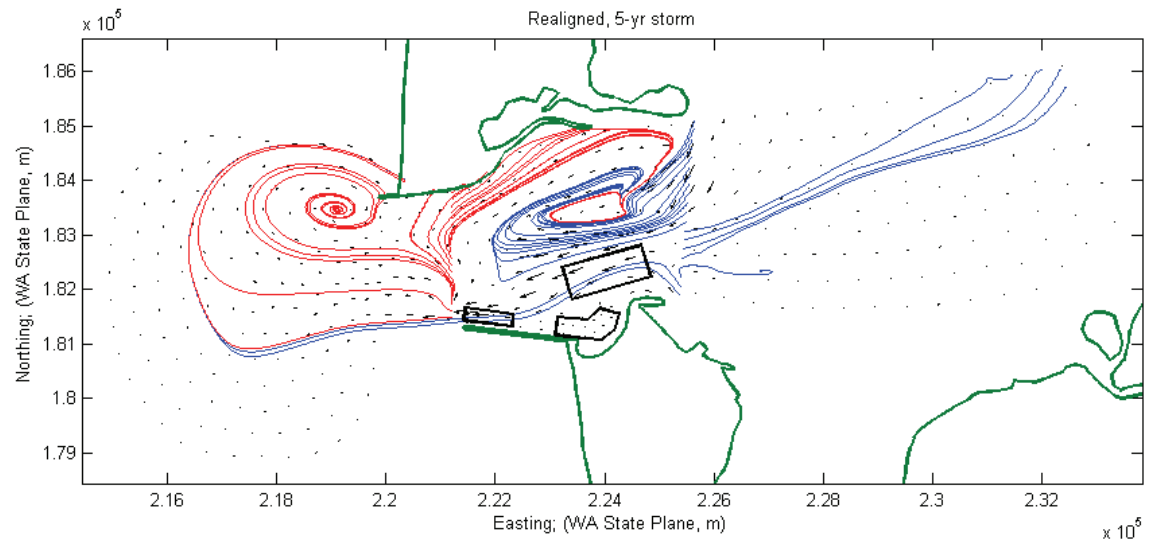

Figure 7-20. Transport streamlines for 5-yr simulated event, realigned channel.

\section{Summary}

Results from GTRAN indicated that transport at the placement sites was generally bimodal for both the existing and realigned channel. Transport at the Point Chehalis placement site was slightly ebb-dominant and transport at the South J etty placement site was strongly ebb-dominant. Less transport was calculated at the Half Moon Bay placement site, which showed a weak flood directed transport.

Transport magnitudes generally showed a slight increase in transport with the realigned channel, compared to magnitudes with the existing channel. Transport differences at the Point Chehalis placement site was small and differences with the realigned channel was likely due to a shift in current direction, i.e., transport shifts from east-northeast to a more easterly direction. The results showed that transport at the South J etty placement site increased in the ebb direction, which would lead to increased erosion. The increased transport appears to be a result of shallower depth at the site due to infilling of the existing channel. Transport at the Half Moon Bay placement site showed a flood-directed increase in transport.

Transport streamlines indicated circulation cells were present north of the Point Chehalis placement site and near the end of the north jetty. Based on plots of transport pathways, a more favorable location for dredge placement to transport sediment outside the entrance appears to be northwest of the South J etty site. However, this location has not been evaluated for practicality and safety. 


\section{Cohesive Sediment Physical Processes}

\section{Background}

As part of the numerical sediment transport studies, laboratory experiments were conducted with dredged material removed from Gray's Harbor Ship Channel to define cohesive sediment erosion and settling processes. The objective of these experiments was to parameterize cohesive sediment erosion processes associated with the dredged material. Resulting data were later applied within a numerical sediment transport model to represent behavior of cohesive sediments at the dredged material placement site.

\section{Erosion}

The dredged sediments of interest are classified as cohesive sediment. Noncohesive sediment (sand) erosion properties can be estimated as a function of grain size distribution. Cohesive sediment erosion rate is dominated by other factors. Cohesive sediments are generally a mixture of sand, silt, and clay sized particles. A general definition for cohesive sediment is material where the erosion rate cannot be estimated by standard sand transport methods. In these cases, cohesive forces are equivalent to or are greater than the gravitational forces that oppose sand transport. Cohesive sediment erosion characteristics are highly dependent upon factors such as particle size distribution, particle coating, fine sediment mineralogy, organic content, bulk density, gas content, pore-water chemistry, and biological activity. Erosion rate and critical shear stress for initiation of erosion can vary significantly with small changes in only one of these inter-dependent parameters. It has been well demonstrated that critical stress and erosion rates for cohesive sediment can vary over two orders of magnitude for sediments with only slightly differing properties. Therefore, the influence of cohesion on sediment processes is a significant factor in dredged material management. Qualitatively, it is understood which properties most significantly influence erosion. However, there are no quantitative methods available to base erosion rate on cohesive sediment properties. Therefore, due to the sensitivity and wide range of influencing parameters, erosion characteristics of cohesive sediments are determined by site-specific analysis of erosion with erosion flumes. 
Several flumes are available to parameterize site-specific cohesive sediment erosion algorithms. The majority of these devices operate over only a small range of shear stress ( $<2 \mathrm{~Pa}$ ) and only measure surface sediment erosion. Sedflume is an erosion device with capability to impose bed stresses in the range of 0.1 to $12 \mathrm{~Pa}$ and measures erosion rates from sediment cores taken from the field (for in-situ or stratified bed conditions) or prepared in the laboratory (for assessing disturbed sediments such as dredged material). Sedflume is designed to quantify erosion rates for surface and sub-surface sediments. These measurements permit description of the vertical variation in erosion rate within the bed. It should be noted that even if sediments are well mixed, cohesive sediment bed erosion will change with depth due to the influence of consolidation (density) on erosion rate. Erosion rate can vary by an order of magnitude between surficial sediments and sediment buried less than $30 \mathrm{~cm}$ below the surface. Conditions expected at the Grays Harbor ODMDS indicate that high shear stress will occur and deep erosion will be experienced. Therefore, Sedflume was used to quantify erosion rate and erosion rate variation with depth (density) for this study.

\section{Settling velocity of eroded aggregates}

Placement from hopper dredges or split-hull scows results in initial mounding of dredged material at the placement site. Following placement, pore water is expelled from the sediment, and the dredged material may erode from the site, depending upon ambient waves, currents, and sediment characteristics. Eroded dredged material may be released from the bed and suspended into the water column in a range of particulate states including single mineral grains, weakly aggregated flocs, or denser bed aggregates. Primary particles are composed of individual mineral grains of gravel, sand, silt, or small, tightly packed flocculi of clay mineral plates. Flocs released during erosion are generally recently deposited and unconsolidated sediments from the surficial sediment layer. Bed aggregates originate from fracturing and mass erosion of the consolidated sediment bed. Bed aggregates may range in size from silt- to pebble-sized particles. Additionally, bed aggregates settle much faster than the primary particles of which they are composed and lower density flocs.

The distribution of these aggregate states is dependent upon sediment composition, consolidation history, applied shear stress, and failure mechanisms of the bed during erosion. For cohesive and mixed sediment beds, the initial aggregate states resulting from erosion are not generally known and are determined from laboratory and field experiments. This 
section describes laboratory experiments conducted to determine initial aggregate states and settling velocities of these aggregates following erosion of dredged material.

Particle settling is governed by the balance of gravity, buoyancy, and drag forces. These forces are determined by fluid properties (density, viscosity) and particle properties (density, size, shape, permeability). A common description of particle settling velocity is provided by Stokes Law, which assumes small particle Reynolds number $\left(\operatorname{Re}_{p}=w_{s} d / v<<1\right)$ and impermeable, spherical particles.

$$
\mathrm{w}_{\mathrm{s}}=\frac{\left(\rho_{\mathrm{p}}-\rho_{\mathrm{w}}\right) \mathrm{gd}^{2}}{18 \mu}
$$

where, $\mathrm{w}_{\mathrm{s}}$ is settling velocity, $\mathrm{d}$ is particle diameter, $\mathrm{g}$ is gravitational acceleration, $\rho_{\mathrm{p}}$ is particle density, $\rho_{\mathrm{w}}$ is water density, $v$ is kinematic viscosity, and $\mu$ is dynamic viscosity. Many investigators (ten Brinke, 1994, Soulsby, 1997, and Winterwerp, 2002) recognize that large, fast-settling particles violate the laminar boundary assumption in Stokes' Law and have applied corrections (Schlichting and Gersten, 2000; Raudkivi, 1998) to extend Stokes Law to larger $\mathrm{Re}_{\mathrm{p}}$. The two most common approximations to spherical drag outside the laminar region are an empirically based relationship attributed to Schiller and Naumann (1933) by Raudkivi (1998):

$$
C_{D}=\frac{24}{\operatorname{Re}_{p}}\left(1+0.150 \operatorname{Re}_{p}^{0.687}\right)
$$

and Oseen (1927):

$$
C_{D}=\frac{24}{\operatorname{Re}_{p}}\left(1+\frac{3}{16} \operatorname{Re}_{p}\right)
$$

Equation 8-2 is applicable for Rep $<800$ and Equation 8-3 for $\mathrm{Re}_{\mathrm{p}} \leq 2$ (Graf, 1971; Raudkivi, 1998).

Winterwerp's (1998, 2002) implicit, fractal-based expression for settling velocity of flocs includes the Schiller-Naumann drag coefficient and is given by: 


$$
\mathrm{w}_{\mathrm{s}}=\frac{\theta \mathrm{g}}{18 \mu}\left(\rho_{0}-\rho_{\mathrm{w}}\right) \mathrm{d}_{0}^{3-\mathrm{n}_{\mathrm{f}}} \frac{\mathrm{D}_{\mathrm{f}}^{\mathrm{n}_{\mathrm{f}}-1}}{1+0.15 \mathrm{Re}_{\mathrm{p}}^{0.687}}
$$

where, $\theta$ is a particle shape factor ( 1 for spherical particles), $\rho_{0}$ is primary particle density, $\mathrm{d}_{0}$ is the primary particle diameter, $\mathrm{D}_{\mathrm{f}}$ is the floc diameter, $\mathrm{n}_{\mathrm{f}}$ is the fractal dimension, and $\mathrm{Re}_{\mathrm{p}}$ is the floc Reynolds number.

An empirically derived, explicit settling velocity expression that closely follows the Schiller-Naumann drag approximation is given by Soulsby (1997) :

$$
\mathrm{w}_{\mathrm{s}}=\frac{v}{\mathrm{~d}}\left[\left[10.36^{2}+1.049 \mathrm{D}_{*}^{3}\right]^{1 / 2}-10.36\right]
$$

where $D_{*}=\left[g\left(\rho_{p} / \rho_{w}-1\right) / v^{2}\right]^{1 / 3} d$

The empirical constants in Equation 8-5 were determined from settling experiments with sand. Equation 8-5 neglects the effect of shape and permeability on settling velocity, is valid for particle aspect ratios less than 2, and reduces to Stokes Law, Equation 8-1, for small Rep. At higher Rep, Soulsby's settling relationship shows close agreement with Stokes Law modified with the Schiller-Naumann drag coefficient (Equation 8-2); and therefore agrees closely with similar expressions such as Winterwerp $(1998,2002)$ that use the same drag approximation.

\section{Sediment samples}

This study included collection of sediment samples by NWS during dredging operations from five locations within the Cow Point Reach of Grays Harbor (Figure 8-1). Sediments were collected from the barge - after dredging, but before placement.

Any loss (winnowing) of channel dredged material that occurs during dredging operations is accounted for in these samples. However, there is a second loss mechanism for dredged material during placement Therefore, sediments collected from the barge may have higher fine content relative post- placement sediments at the ODMDS. Given the rather shallow water depth at the placement sites, loss during placement is expected to be small. 


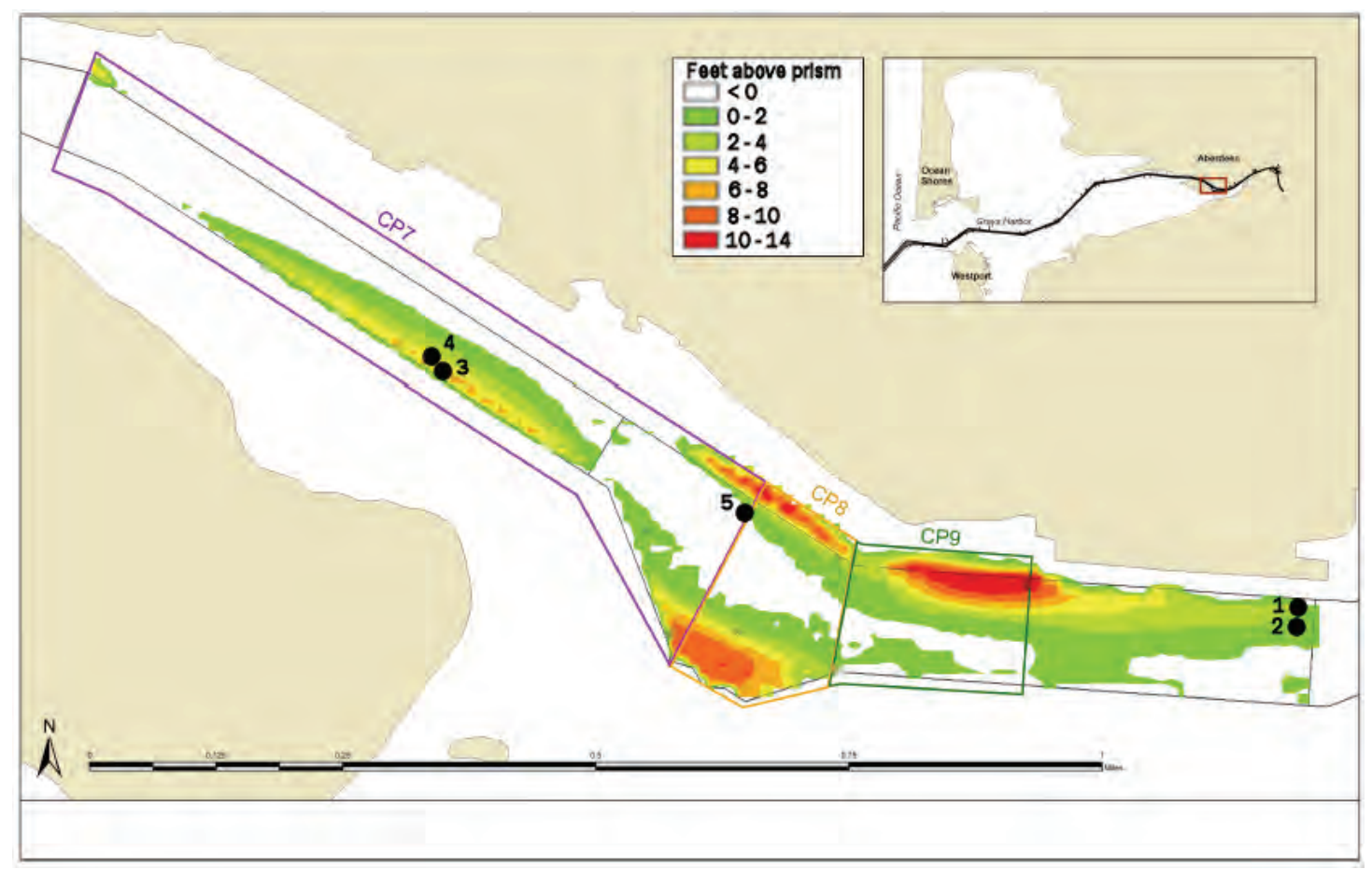

Figure 8-1. Cow Point Reach, Grays Harbor WA.

One 5-gallon bucket of dredged material was collected at each of the five dredging sites and shipped to ERDC. Once received at ERDC, samples were stored in a cooler to minimize change in characteristics of the organic material. Samples were not chilled during shipment.

The specific objective of this study is to parameterize erosion rates for dredged material from the Cow Point Reach. In actuallity, an offshore dredged material disposal site (ODMDS) will include multiple mounds with material of differing composition. As a first order estimate at parameterization, material from collection locations were slurried together to create a "representative" dredged material for the reach.

Specific loactions within Cow Point Reach where the five samples were collected are provided in Figure 8-1. One sample was collected from the barge during dredging at the north side of the turning basin $(\sim 1197+00)$. Two additional samples were collected at the south side of the channel west of the turning basin $(\sim 1180+00)$. The final two samples, were collected at the north side of the channel east of the turning basin $(\sim 1228+00)$. It should be noted that only four of the samples were used in this analysis. The turning basin dredged material included a large amount of debris (twigs and other vegetative material that had not decayed). Erosion rates for this type 
of material cannot be measured in Sedflume. Therefore, this sample was not included in the slurried "representative" dredged material.

A Malvern Mastersizer 2000 laser particle-sizer was used to measure the particle-size distributions in sediments from each collection site. Methods used by the Malvern will be described later in this chapter. Grain size distribution for each of the four samples considered acceptable for erosion experiments are shown in Figure 8-2. From this figure, it can be seen that three of the four sediment samples would be considered fine-grained (D50 of $<80 \mu \mathrm{m})$. CP- 2 is sandy, with a small percent of fines that compose of less than $10 \%$ of the sample. It should be noted that CP- 1 and CP- 2 were collected close to each other, but are of very different composition. This indicates that composition of material depositing in the channel varies significantly within a small distance.
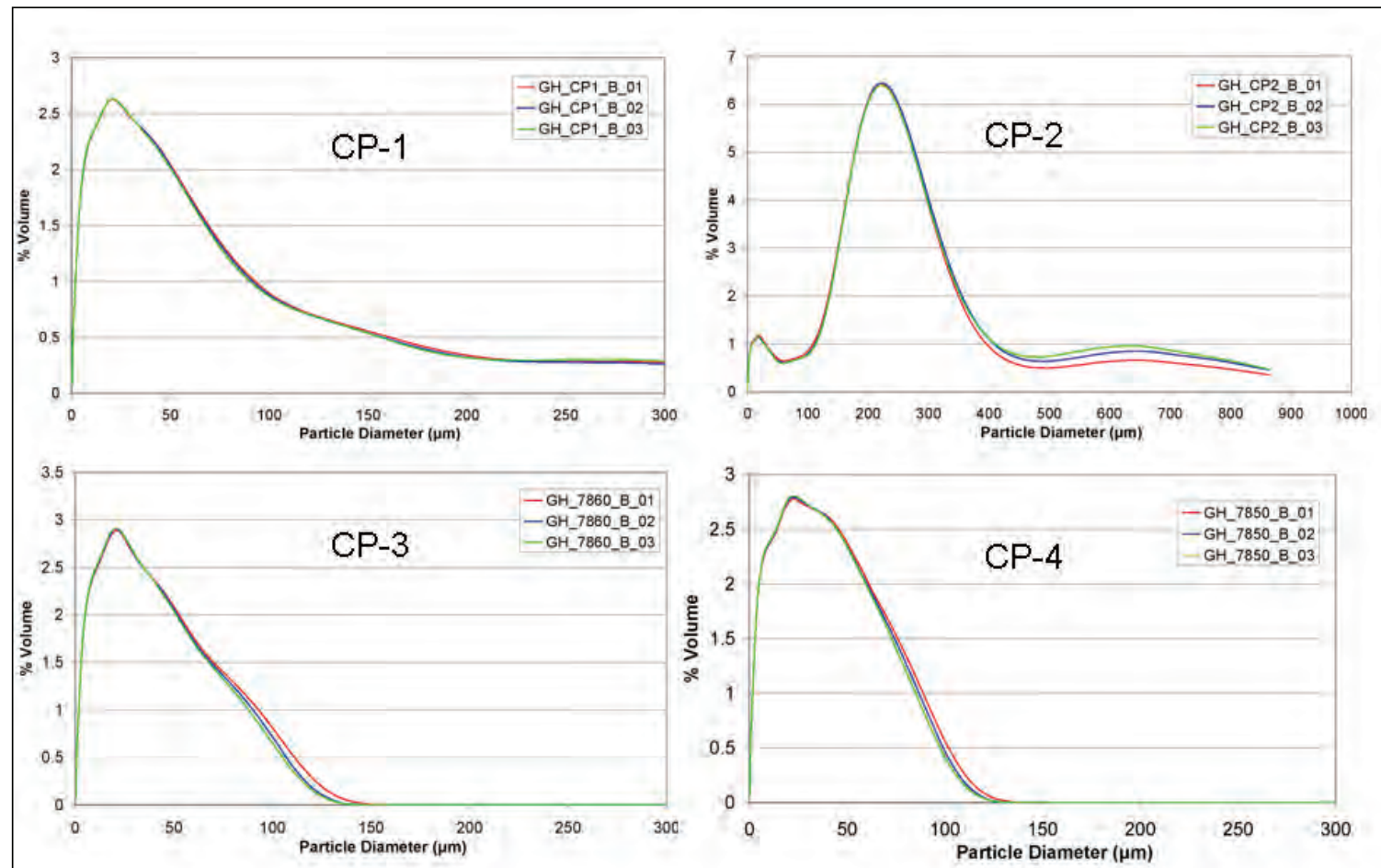

Figure 8-2. Grains size distribution measurements for samples CP-1 through CP-4.

\section{Methods}

This section describes the experimental and analysis methods performed as part of this study. Descriptions include Sedflume device and experimental procedures, physical sample collection and analysis, and analysis of erosion data. 


\section{Sedflume}

Sedflume is a field- or laboratory-deployable flume for quantifying cohesive sediment erosion. The USACE-developed Sedflume is a derivation of the flume developed by researchers at the University of California at Santa Barbara (McNeil et al. 1996). The flume includes an 80-cm-long inlet section (Figure 8-3) with cross-sectional area of $2 \times 10 \mathrm{~cm}$ for uniform, fully developed, smooth-turbulent flow. The inlet section is followed by a $15-\mathrm{cm}-$ long test section with a $10 \times 15 \mathrm{~cm}$ open bottom (the open bottom can accept cores with rectangular cross-section $(10 \times 15 \mathrm{~cm})$ or circular crosssection (10-cm diameter) ). Coring tubes and flume test section, inlet section, and exit sections are constructed of clear polycarbonate materials to permit observation of sediment-water interactions during the course of erosion experiments. The flume includes a port over the test section to provide access to the core surface for physical sampling. The flume accepts sediment cores up to 80-cm in length. An exit section for removal of water and eroded sediment follows the test section.

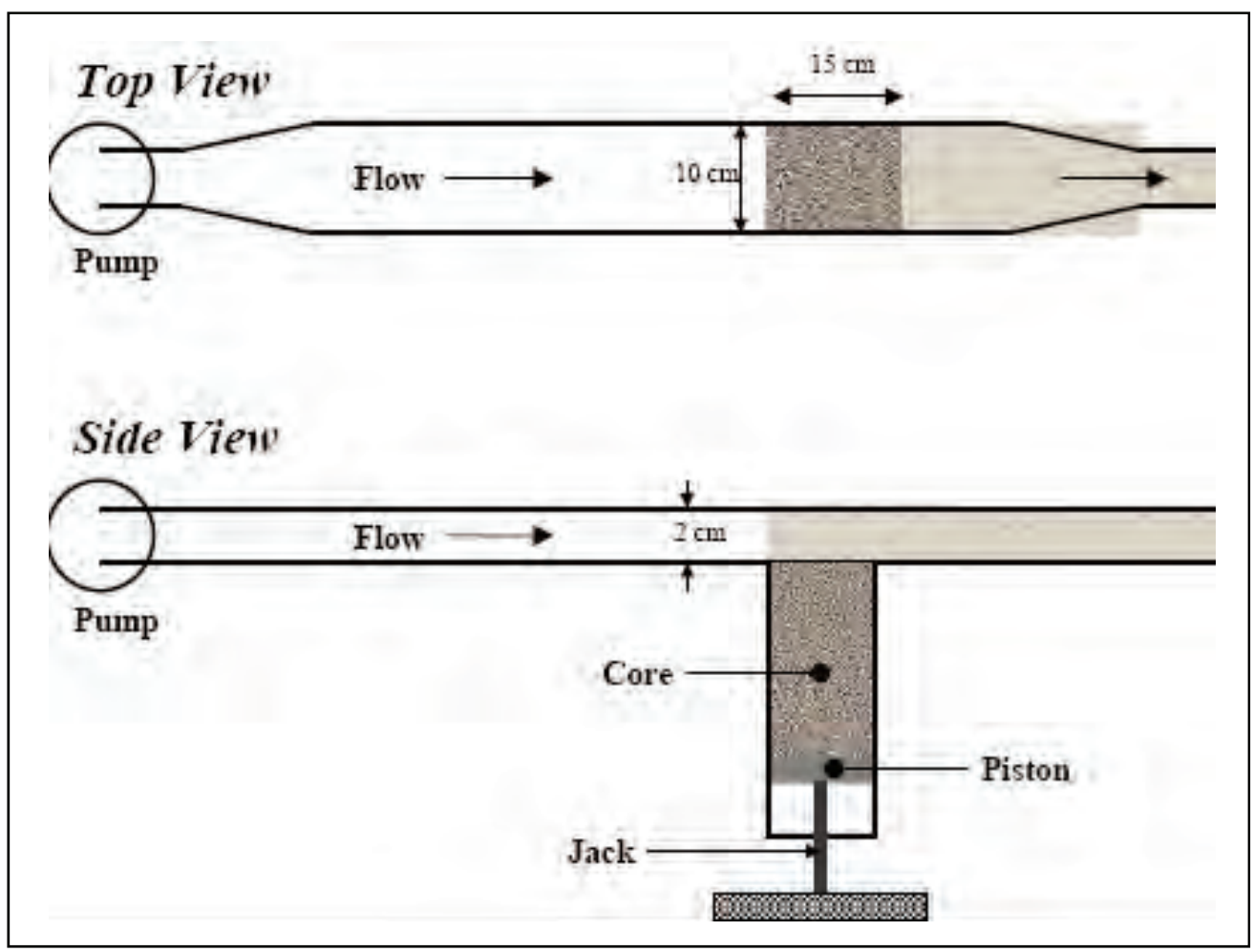

Figure 8-3. Schematic illustrating operating principles of Sedflume. Pictured are Sedflume channel, flow development region, testing section and sediment core. 


\section{Sample preparation and storage}

The work plan for these experiments designated that samples would be slurried together to create one sediment representative of dredged material designated for open water placement. One sediment sample, CP-5 (Figure 8-1), contained a significant amount of debris (mostly twigs and other vegetative material that had not decomposed). Sedflume is not capable of measuring erosion rate for this type of debris. Therefore, CP- 5 was not used in the Sedflume analysis

For laboratory-prepared cores, material from each of the four sediment samples was combined in equal amounts. This material was then slurried to near the gelling concentration of the sediment, and poured into $10-\mathrm{cm}$ diameter coring tubes with a bottom plunger in place. Slurrying is performed with site water, to maintain similar pore-water chemistry. The slurried cores are stored submerged in site water or laboratory-prepared water of similar salinity in a refrigerated environment. After prescribed periods of consolidation, the prepared cores are removed from the storage facility and prepared for erosion.

Plungers inserted into the bottom of the coring tube provide two functions: 1) to seal the bottom of the core to prevent pore-water drainage during storage and erosion experiments and 2) to provide a means of advancing the core surface within the flume during erosion experiments.

\section{Erosion experiments}

During experiment preparation, cores are measured and visual observations noted prior to the erosion experiment. Cores are inserted into the testing section of Sedflume and a screw jack is used to advance the plunger such that the core surface remains flush with the bottom wall of the flume. Flow is directed over the sample by diverting flow from a 1-hp pump, through a 5cm diameter stiff hose, into the flume. The flow through the flume produces shear stress on the surface of the core. (Numerical, experimental, and analytical analyses have been performed to relate flowrate to bottom shear stress.) Erosion of the surface sediment is initiated as the shear stress is increased beyond the critical stress for erosion, $\tau_{\mathrm{cr}}$. As sediment erodes from the core surface, the operator advances the screw jack to maintain the sediment surface flush with the bottom wall of the erosion flume. Figure 8-4 includes a photograph of the flume, a close-up photograph of the test section, and a table of flow rate/ shear stress relationships. 


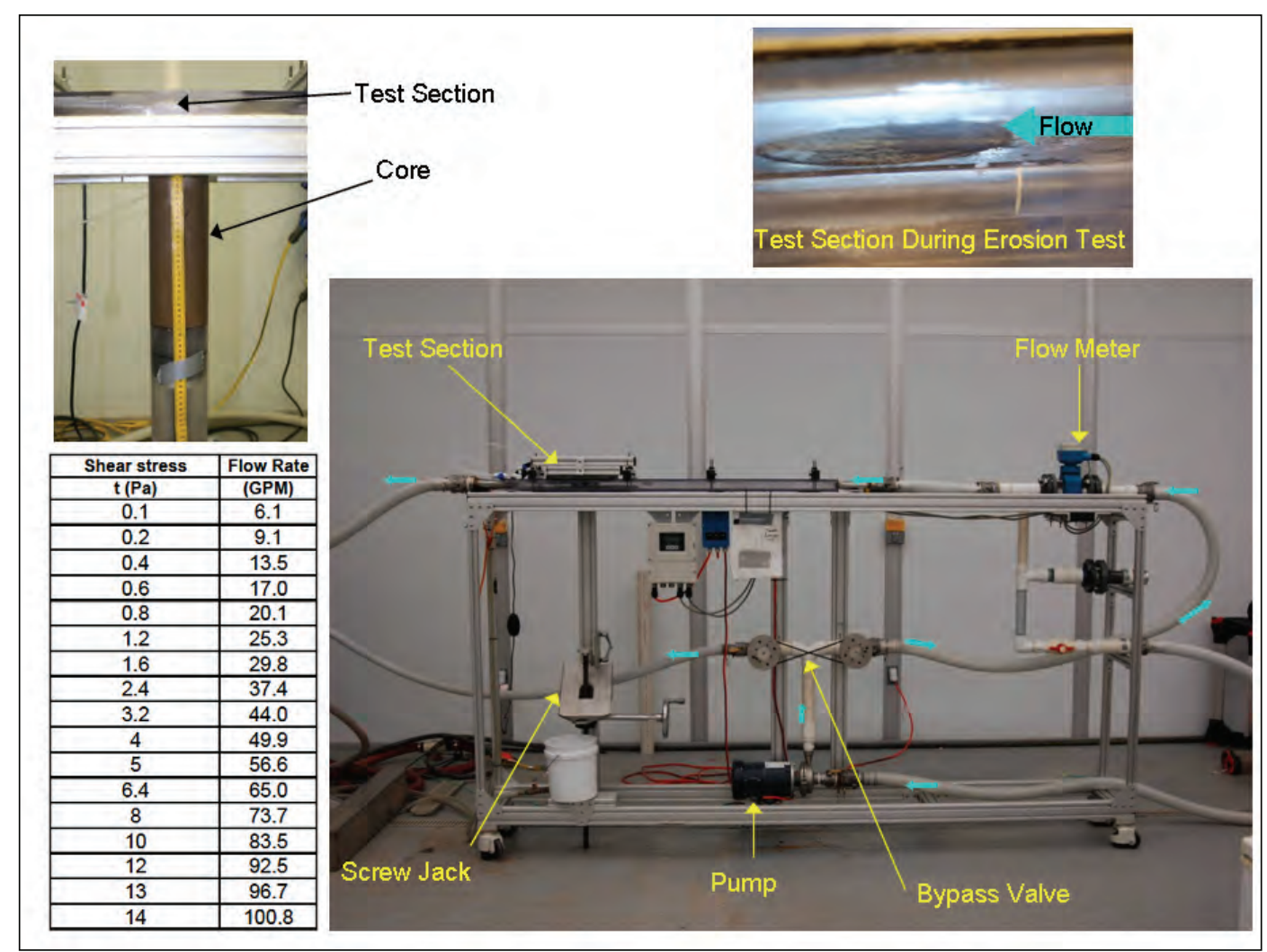

Figure 8-4. Sedflume erosion flume.

Erosion rate is determined from the displacement of the core surface over the elapsed time of the experiment. Generally, erosion experiments are performed in repeating sequences of increasing shear stress. Operator experience permits sequencing of erosion tests to allow greater vertical resolution of shear stress/ erosion rate data where required. The duration of each erosion experiment at a specified shear stress is dependent on the rate of erosion and generally is between 0.25 and 15 minutes. Shear stresses that induce no measurable erosion also are recorded. The decision on range of shear stress for each cycle is decided by the operator based on the previous erosion sequences and erosion behavior during the ongoing sequence. This method generally captures any reduction in erosion rate with depth below the initial sediment surface caused by increased consolidation.

\section{Measurements of sediment bulk properties}

Bulk sediment properties were measured at depth intervals within each core by suspending erosion experiments, draining the flume channel, opening the port over the test section, and extracting a sample from the sediment bed. Properties measured include bulk density and grain-size 
distribution. These properties strongly influence erosion; therefore, understanding their variation with depth is important in interpreting the erosion data. Samples were extracted from each sediment core during the erosion experiments at approximately 3- to 5-cm intervals, generally at the end of each shear stress cycle.

\section{Bulk density measurements}

To determine bulk sediment density of the sediments at a particular depth, the weights of the sediment analysis samples extracted after each shear stress cycle, including the aluminum dish containing the sample, were measured immediately after extraction from the core. Weight of the tray (tare weight) was measured and recorded prior to sample extraction. Wet weight of the sample was calculated by subtracting tare weight from the weight of the sample. The samples were then dried in the oven at approximately $180 \operatorname{deg} \mathrm{C}$ for at least 12 hours and weighed again. The dry weight of the sample was calculated as the tare weight subtracted from the weight after drying. The water content $\mathrm{w}$ is then given

$$
\mathrm{w}=\left(\frac{\mathrm{m}_{\mathrm{w}}-\mathrm{m}_{\mathrm{d}}}{\mathrm{m}_{\mathrm{d}}}\right)
$$

where $m_{w}$ and $m_{d}$ are the wet and dry weights, respectively. A volume of saturated sediment, $\mathrm{V}$, consists of both solid particles and water and can be written as

$$
\mathrm{V}=\mathrm{V}_{\mathrm{s}}+\mathrm{V}_{\mathrm{w}}
$$

where $V_{s}$ is the volume of solid particles and $V_{w}$ is the volume of water. If the sediment particles and water have density $\rho_{\mathrm{s}}$ and $\rho_{\mathrm{w}}$, respectively, the water content of the sediment can be written as

$$
\mathrm{w}=\frac{\rho_{\mathrm{w}} \mathrm{V}_{\mathrm{w}}}{\rho_{\mathrm{s}} \mathrm{V}_{\mathrm{s}}}
$$

A mass balance of the volume of sediment gives

$$
\rho V=\rho_{s} V_{s}+\rho_{w} V_{w}
$$

where $\rho$ is the bulk density of the sediment sample. 
Equations 8-6 through 8-9 are used to derive an explicit expression for the bulk density of the sediment sample, $\rho$, as a function of the water content, $\mathrm{w}$, and the densities of the sediment particles and water. This equation is

$$
\rho=\rho_{\mathrm{s}}+\frac{\mathrm{w} \rho_{\mathrm{s}}\left(\rho_{\mathrm{w}}-\rho_{\mathrm{s}}\right)}{\rho_{\mathrm{w}}+\mathrm{w} \rho_{\mathrm{s}}}
$$

For the purpose of these calculations, $\rho_{\mathrm{s}}=2.65 \mathrm{~g} \cdot \mathrm{cm}^{-3}$ and $\rho_{\mathrm{w}}$ is calculated for measured pore water salinity of 22.6 ppt at room temperature. Figure 8-5 shows density variation with depth for each consolidation period. It can be seen that the sediment density trend is inconsistent for the 2, 7, and 35 day cores. Possible causes include expulsion of gas entrained during pouring. It is evident; however, that sediment below $15 \mathrm{~cm}$ is more consolidated in the 135 day cores than in the shorter consolidation period cores. This behavior is typical of cohesive sediments, which may require significant time to fully consolidate. The 135 day core is considered the consolidated density profile for these sediments and is used in modeling. Density is approximately $1.4 \mathrm{~g} \cdot \mathrm{cm}^{-3}$ at

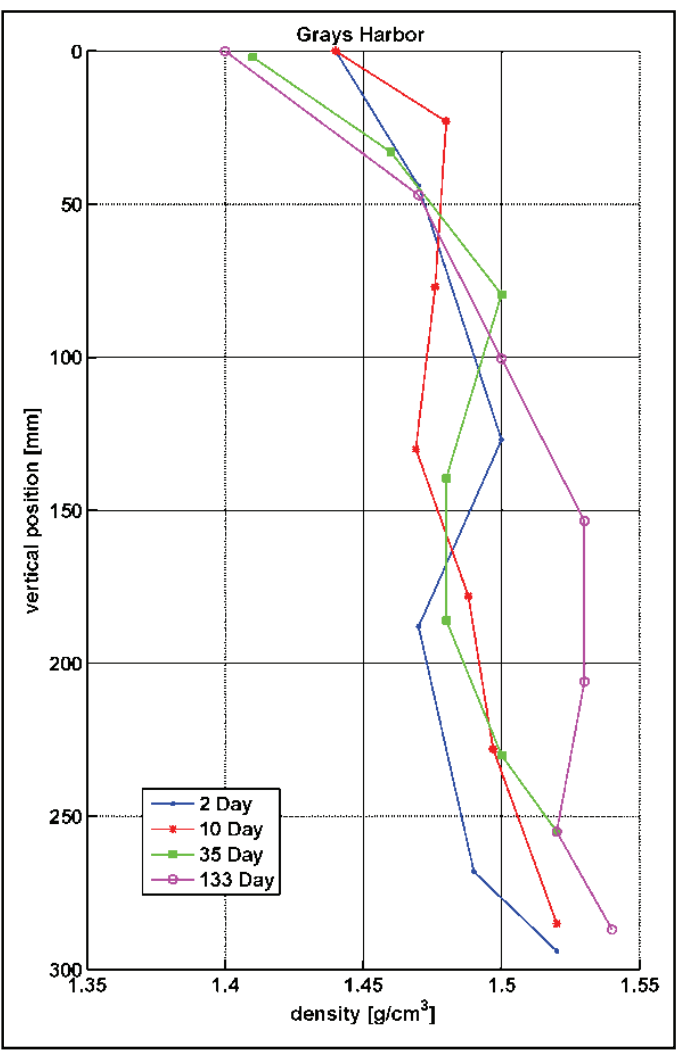

Figure 8-5. Density profiles for cores. the surface and steadily increases through the surface $15 \mathrm{~cm}$ of the core. Fully consolidated sediments are approximately $1.53-1.54 \mathrm{~g} \cdot \mathrm{cm}^{-3}$ below $15 \mathrm{~cm}$ sediment depth.

\section{Particle-size distribution}

A Malvern Mastersizer 2000 laser particle-sizer was used to measure the particle-size distributions in sub-samples collected from the cores. The Malvern measures particle size over the range 0.4 to $900 \mu \mathrm{m}$. Particle size distributions were measured by first removing and sieving particles larger than $850 \mu \mathrm{m}$. The passing portion of the sample was added to a small volume of water (about $150 \mathrm{~mL}$ ) and sonicated using a high-powered 
laboratory sonicator to disperse the sediment. The dispersed solution was placed in the particle sizer fluid module. The sample is pumped and recirculated through the optical module. The optical module includes a spatial filter assembly containing a laser diode and laser beam collimator. The diffraction detector assembly contains a custom photodetector array that is used for the measurement of light scattering by the suspended particles. The distribution of grain sizes and median grain sizes was obtained from these measurements and scaled according to the weight of sediment retained on the sieve. It should be noted that organic material was not oxidized before grain size analysis was performed; grain size results include organic material.

Representative composite grain size distribution for the sediment slurry used for Sedflume erosion tests is shown in Figure 8-6. A bimodal peak is visible, with one peak at approximately $20 \mu \mathrm{m}$ and a second peak at approximately $200 \mu \mathrm{m}$. The second peak is due to the inclusion of sandy sediments from sample CP-2 in the composite. Median particle size is approximately $22 \mu \mathrm{m}$. $90^{\text {th }}$ percentile particle size is approximately $200 \mu \mathrm{m}$ and $10^{\text {th }}$ percentile is $2 \mu \mathrm{m}$. This report refers to size fractions in terms of percent clay (percent passing $4 \mu \mathrm{m}$ ), percent fines (percent passing $62 \mu \mathrm{m}$ ), and percent sand (percentage coarser than $62 \mu \mathrm{m}$ ). The term "percent clay" is used for convenience to describe the percent passing $4 \mu \mathrm{m}$; it is not based on any mineralogical analysis.

\section{Multivariate erosion rate prediction}

Generally, with other sediment properties held constant, erosion rates increase exponentially with decrease in bulk density or increase in shear stress (J epsen et al. 1997a and 1997b; Roberts et al. 1998). For sediments of uniform composition, the data can be approximated by an equation of the form

$$
\begin{array}{cc}
\mathrm{E}=\mathrm{A} \tau^{\mathrm{n}} \rho^{\mathrm{m}} & \left(\tau>\tau_{\text {cr }}\right) \\
\mathrm{E}=0 & \left(\tau \leq \tau_{\text {cr }}\right)
\end{array}
$$

where $E$ is the erosion rate $\left(\mathrm{cm} \cdot \mathrm{s}^{-1}\right) ; \tau_{\text {cr }}$ is the critical shear stress for measurable sediment erosion; $\rho$ is the bulk density $\left(\mathrm{g} \cdot \mathrm{cm}^{-3}\right)$; and $\mathrm{n}, \mathrm{m}$, and A are site-specific (or sediment-specific) constants. Numerical algorithms are developed from Equation 8-11 to relate erosion rates to bulk sediment properties. The constants $\mathrm{A}, \mathrm{n}$ and $\mathrm{m}$ are determined from multivariate, 


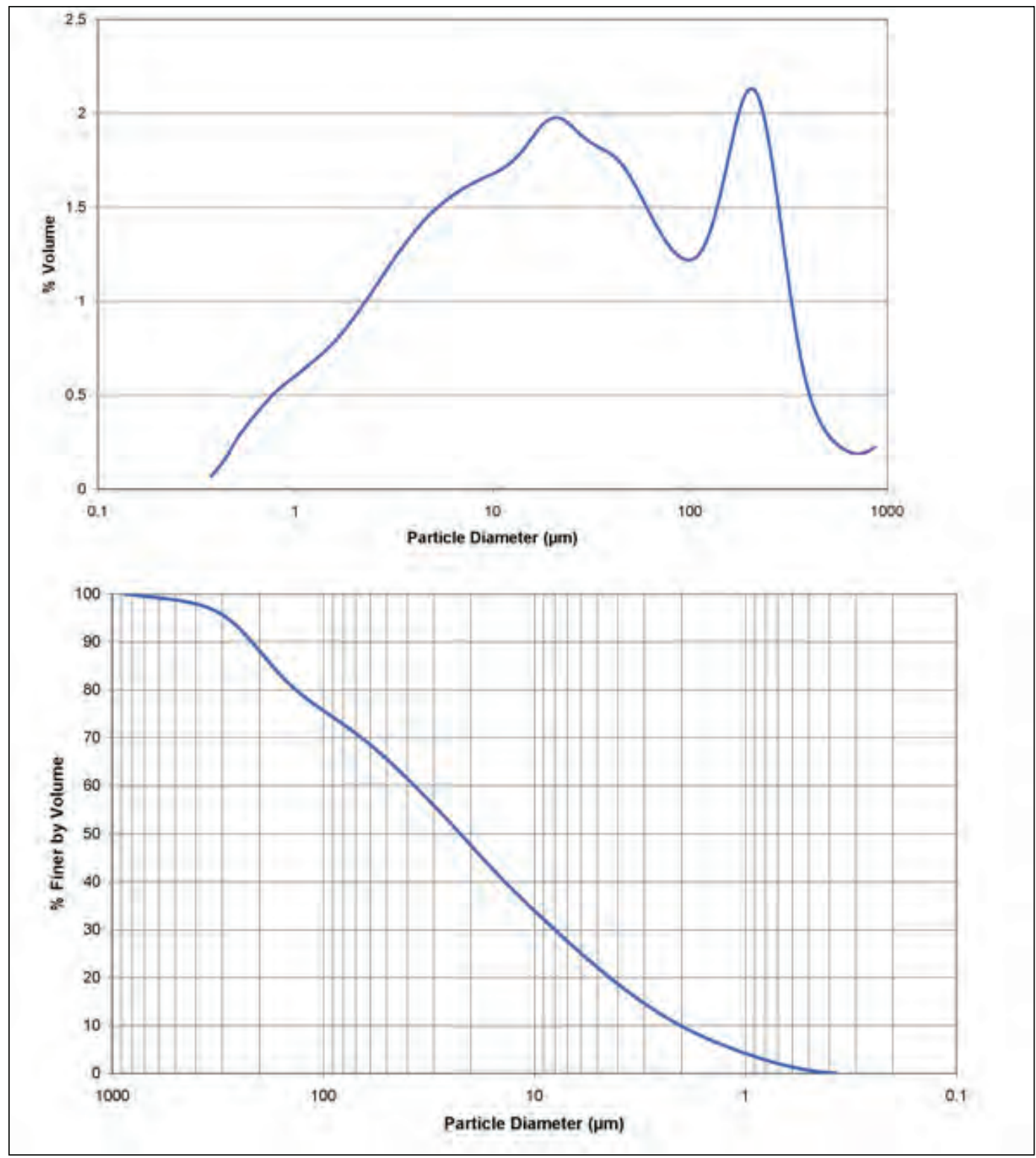

Figure 8-6. Size distributions (\% Volume and \% Finer) for slurried representative Grays Harbor dredged material.

non-linear, least squares regression on the erosion data. Additional details of data processing and analysis are presented in Results. Equation 8-11 has been demonstrated to successfully describe behavior of natural sediments (J epsen et al. 1997a and 1997b; J epsen et al. 1998).

\section{Critical shear stress for erosion}

Critical shear stress for erosion can be defined as the minimum shear stress for which sediment erosion is observed. Numerous critical stress definitions exist in the literature for cohesive and non-cohesive sediments. The lack of a 
unified definition of critical erosion stress is related to the wide range of hydrodynamic and sediment environments and the variety of sediment transport issues (e.g. bridge scour, geomorphological response, contaminant transport, and sedimentation) for which small erosion rates are important. For the purposes of this analysis, critical shear stress is defined as the shear stress at which a small, but measurable, rate of erosion occurs. In the present study, this rate of erosion was chosen to be $1 \times 10-4 \mathrm{~cm} \cdot \mathrm{s}-1$, representing approximately $1 \mathrm{~mm}$ of erosion in 3 hours. Since it would be difficult to measure all critical shear stresses at exactly1×10-4 cm.s-1, erosion rates were generally measured at and above the critical erosion rate. The data are then processed such that 8-11 is solved for critical shear stress:

$$
\mathrm{E}_{\mathrm{cr}}=\mathrm{A} \tau_{\mathrm{cr}}{ }^{\mathrm{n}} \rho^{\mathrm{m}}
$$

Rearranging terms, Equation 8- 12 becomes an equation to calculate $\tau_{\text {cr: }}$ :

$$
\tau_{\mathrm{cr}}=\left(\frac{\mathrm{E}_{\mathrm{cr}} \rho^{-\mathrm{m}}}{\mathrm{A}}\right)^{1 / \mathrm{n}}
$$

where $E_{c r}$, the critical erosion rate is defined here as $1 \times 10^{-4} \mathrm{~cm} \cdot \mathrm{s}^{-1}$ and the constants $\mathrm{A}, \mathrm{n}$, and $\mathrm{m}$ are determined from the erosion experiments.

\section{Settling velocity of eroded aggregates}

To estimate the aggregate states eroded from the dredged material bed and the settling velocity of these aggregates, the Particle Imaging Camera System (PICS) was coupled with Sedflume to measure size, settling velocity, and particulate density of the eroded dredged material. This section describes PICS and the experimental arrangement by which settling characteristics of eroded particles were characterized.

Particle Imaging Camera System (PICS)

The Particle Imaging Camera System (PICS) was developed to measure insitu particle size and settling velocity. PICS is conceptually similar to other video devices for in-situ particle settling measurements such as INSSEV (Fennessy et al. 1994), VIS (van Leussen and Cornelisse 1993), Sternberg et al. (1996), Mikkelsen et al. (2004), and Sanford et al. (2005). The PICS sample collection, optical and lighting design, and image acquisition were designed to produce high-quality, in-situ image sequences within dredge 
plumes. PICS, (Figure 8-7B), consists of a 1-m long, 5-cm inner diameter settling column with a mega-pixel digital video camera and strobed LED lighting. The settling column is equipped with two pneumatically controlled ball valves at the column ends which permit sample capture and a third pneumatic actuator for rotating the column from horizontal to vertical orientation for image acquisition. For the erosion experiments, the PICS settling column was plumbed to the Sedflume effluent and the settling column remained in the vertical position.

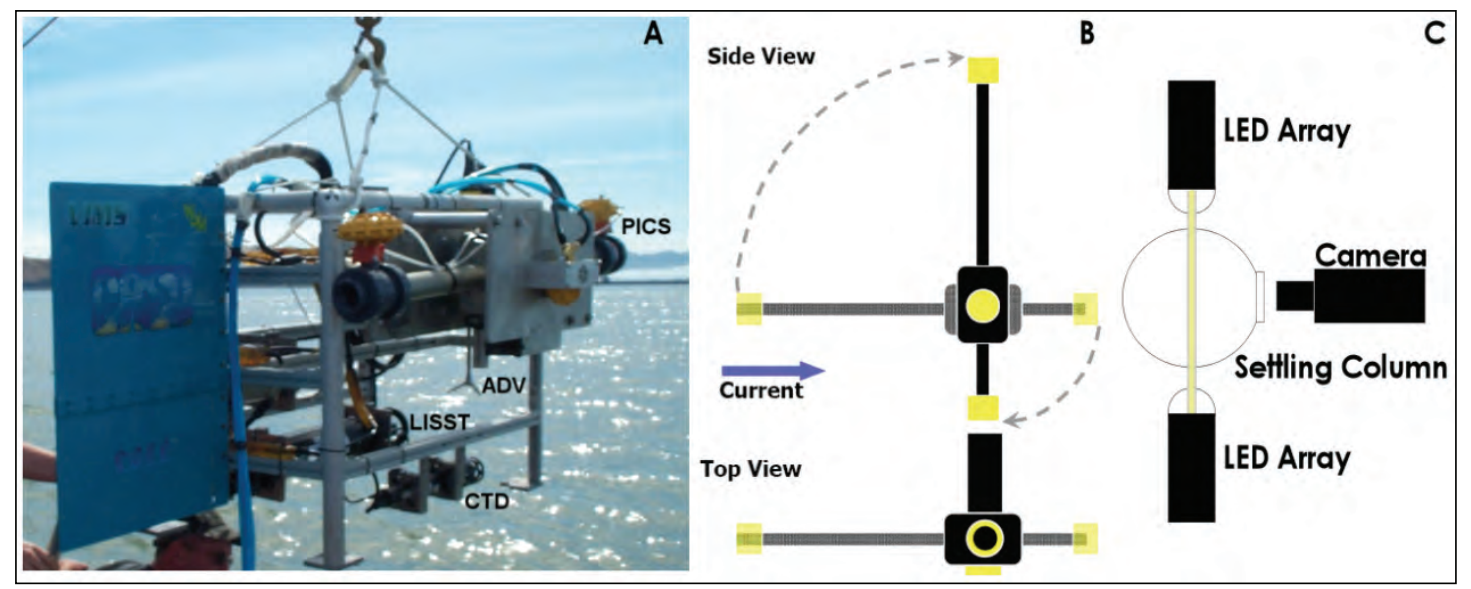

Figure 8-7. A) Instrumentation frame indicating positioning of PICS, ADV, LISST, and CTD,

B) Schematic of settling column indicating sample collection and image acquisition positions (in laboratory setting, column remains vertical with Sedflume effluent passing through settling column). C) Schematic of camera, settling column cross section, and LED lighting.

A monochrome Prosilica CF1380 digital video camera collects noninterlaced video with $1380 \times 1024$ pixel resolution at up to 20 fps with 10 bit resolution. Camera controls and image transfer are transmitted over $1 \mathrm{~GB}$ ethernet cable over distances up to $50 \mathrm{~m}$. The camera focuses on a $13.8 \times 10.2 \mathrm{~mm}$ region in the center of the settling column (Figure 8-7C) with a 1-mm depth of focus through a 25-mm Pentax c-mount lens with extension tubes used for macro-magnification. Illumination of the field is achieved by two opposing LED light arrays collimated through cylindrical lenses to produce a light sheet orthogonal to the camera lens. The LED light arrays are strobed for $30 \mu$ s with a strobe controller synchronized with camera exposure. Images are logged in AVI format through Matlabbased image acquisition and control software.

Data collection with the Sedflume-PICS arrangement proceeds by observing erosion at a given core depth and applied surface shear stress, capturing a sample of the eroded material by closing the ball valves at the ends of the settling column, permitting turbulence within the column to 
dissipate ( $\sim 15$ to $30 \mathrm{sec}$ ), and collecting $30 \mathrm{sec}$ of particulate settling video. Upon completion of video logging, the valves are opened and the process described above is repeated.

For particle tracking purposes, particles must appear in images as $3 \times 3$ or greater regions of pixels. Consequently, the PICS configuration described above is capable of imaging particles between 30 and approximately $1000 \mu \mathrm{m}$ in diameter. (The upper size limit results from the depth of focus.) The strobe duration and length of settling column above the imaging plane permit resolution of settling velocities between $0-15 \mathrm{~mm} \mathrm{~s}^{-1}$. At high particle concentrations, light scattering and attenuation result in images that are of poor quality or obscured to a degree that prohibits image analysis. The threshold at which scattering and attenuation produce problems in image analysis varies with particle size and degree of flocculation, ranging from 50-400 $\mathrm{mg} \mathrm{L}^{-1}$, depending upon the degree of aggregation within the sample.

\section{Coupling of PICS and Sedflume}

For estimating size and settling velocity of eroded sediments, PICS is coupled with Sedflume. In this configuration, the PICS column remains in the vertical position (Figure 8-7B) and the Sedflume effluent hose is coupled to the PICS column such that flow passes downward through PICS. During sample capture, the ball valves at each end of the settling column are closed, capturing a sample of the eroded material in suspension. A bypass hose is included in the laboratory setup, such that the Sedflume experiment can proceed after closure of the PICS valves. At the conclusion of image acquisition, the PICS valves are reopened and ready for the next sample.

\section{Image Analysis}

Automated image processing routines were developed to enhance digital imagery, identify and track particles between successive image frames, and determine particle characteristics such as size and settling velocity. Raw grayscale images collected with PICS are first adjusted for background illumination. This procedure determines the minimum illumination level for each pixel across all frames and subtracts this value from all frames to remove effects of non-uniform illumination and variable background intensity of the Charge-Coupled Device (CCD) elements. Grayscale images are then converted to binary with a thresholding procedure, followed by dilation and erosion. The binary images are then evaluated with a Particle 
Tracking Velocimetry (PTV) method, in which cross-correlation and Kalman filtering methods are applied to match particles between adjacent frames in the image sequence. Additionally, false pairing of particles was reduced by constraining changes in particle size and shape between frames. Performance of the automated particle tracking routine was verified through comparisons of the automated results to manual tracking results, and visual inspection of the automated particle track sequences.

Image analysis of the binary images permits the determination of particle characteristics such as projected area, centroid position, short and long axis length, and eccentricity. Prior to and following each experiment, a calibration grid is photographed with PICS for the purpose of transforming pixel space to length space in the imaged plane and verifying that optical settings remain constant during the experiment. Additional derived properties of interest such as settling velocity, particle diameter, and effective particle density are computed from observed characteristics.

A primary objective of the image analysis described above is to estimate particulate settling velocities relative to the ambient fluid. Although measures are taken to ensure that the fluid within the settling column is still, fluid motion within the column is introduced by lingering turbulence and volume flux of settling particles. To correct measured particle displacements relative to fluid motions, small particles ranging in size from (5-20 $\mu \mathrm{m})$ are tracked with an automated Particle Image Velocimetry (PIV) technique as a proxy for local fluid velocity. These particles are assumed to have sufficiently small settling velocities to serve as proxy for fluid velocity, similar to the procedure described by van Leussen (1994). For the PIV analysis, the image frame is subdivided into a $10 \times 8$ grid of interrogation regions. Fluid velocities are estimated from small particle motions within each of these interrogation regions, resulting in a velocity field with approximately $1.3-\mathrm{mm}$ spatial resolution and $0.1 \mathrm{~s}$ temporal resolution.

The settling velocity of each PTV-tracked particle is then determined as:

$$
\mathrm{w}_{\mathrm{s}}=\frac{\Delta \mathrm{z}}{\Delta \mathrm{t}}-\mathrm{w}_{\mathrm{f}}
$$

where, $\Delta \mathrm{z}$ is vertical displacement of the particle centroid, $\Delta \mathrm{t}$ is the elapsed time over which the particle was tracked, and $\mathrm{w}_{\mathrm{f}}$ is the estimated fluid velocity. 
Several measures of particle dimensions are available from image analysis: $\mathrm{min} /$ max dimension, projected area, and diameter. Equivalent spherical diameter (esd) is computed as the spherical diameter producing the same projected area as the observed particle, esd $=(4 \mathrm{~A} / \pi)^{1 / 2}$, where $\mathrm{A}$ is the projected area of the particle. Particle density is estimated by rearranging Equation 8-5:

$$
\rho_{\mathrm{p}}=\rho_{\mathrm{w}}+\frac{\rho_{\mathrm{w}} v^{2}}{\mathrm{gK}_{2} \mathrm{~d}^{3}}\left[\left(\frac{\mathrm{w}_{\mathrm{s}} \mathrm{d}}{v}+\mathrm{K}_{1}\right)^{2}-\mathrm{K}_{1}{ }^{2}\right]
$$

where $K_{1}=10.36$ and $K_{2}=1.049$.

Particle classes were discriminated based on estimated density. Flocs are associated with density between $1010-1200 \mathrm{~kg} \mathrm{~m}^{-3}$ (excess density: 0-180 $\mathrm{kg} \mathrm{m}^{-3}$ ), bed aggregates: $1200-1800 \mathrm{~kg} \mathrm{~m}^{-3}$ (excess density: $180-780 \mathrm{~kg} \mathrm{~m}^{-3}$ ), primary particles: $1800-3000 \mathrm{~kg} \mathrm{~m}^{-3}$ (excess density: $780-2000 \mathrm{~kg} \mathrm{~m}^{-3}$ ). Density range for flocs was determined from published data (Krone, 1963; Krank et al. 1993; van Leussen, 1994). The density range for bed aggregates extends from the upper limit of flocs to $1800 \mathrm{~kg}$ $\mathrm{m}^{-3}$ (an upper limit based on saturated bulk density of densely consolidated cohesive and mixed sediment beds and supported by published data: Torfs et al., 2001; Winterwerp and van Kesteren, 2004). Density range for primary particles was set from the upper limit of bed aggregates to the maximum expected mineral density. The primary particle class defined here is not synonymous with primary particles defined in Equation 8-4.

\section{Erosion and Settling Experiment}

PICS settling experiments were conducted on 07 December 2009 with a sediment core compositing Cow Point Reach samples collected from sampling locations CP-1, CP-2, CP-3, and CP-4. The core was prepared on 02 J uly 2009 and permitted to consolidate for 158 days. Settling experiments were conducted for sediments eroded from 0.25 to $3.0 \mathrm{~cm}$ below the sediment-water interface at shear stresses ranging from 2.4 to $6.0 \mathrm{~Pa}$. 


\section{Results and discussion}

This section presents results and discussion of the erosion experiments, bulk sediment properties analysis, generation of erosion rate algorithms, and settling velocities of eroded aggregates.

\section{Core preparation}

Five sediment cores were prepared at $200 \mathrm{~g} / \mathrm{L}$ dry solids from the sediment composite including equal parts sediment from samples collected on the dredge at sites CP-1, CP-2, CP-3, and CP-4. Cores were allowed to consolidate for 2, 10, 35, 120 and 133 days before erosion experiments were performed. The 133 day core is considered a replicate of the 120 day core since density profile was almost identical. The 120 and 133 day cores were labeled as $120 \mathrm{~A}$ and $120 \mathrm{~B}$ respectively during analysis. Initial plans were to allow for a maximum consolidation period of 60 days, but observations from the shorter consolidation periods suggested that a longer period of consolidation would be warranted. Therefore, the 60 day samples were permitted to consolidate for 120 days. Each of the five cores was eroded as described in the processes section of this chapter. Data were then combined for analysis. The objective is to quantify erosion rate as a function of applied shear stress and density. These data, coupled with density profiles will permit parameterization of dredged material mound erosion in numerical modeling.

\section{Erosion data and analyses}

Erosion data resulting from the three cores were quality checked and then compiled into a single data set. Bed density for each erosion measurement was interpolated from the profiles presented in Figure 8-4. Erosion characteristics of the sandy sediments that accumulated at the bottom of the core have distinctly different erosion behavior than the predominantly fine sediments above and were excluded from this analysis.

The resulting erosion dataset is presented in Figure 8-8, demonstrating the relationship between erosion rate, bed density, and applied shear stress. A non-linear, multivariate, least squares fit was applied to Equation 8-11, resulting in the curves at the given shear stress values, estimates of the equation parameters: $\mathrm{A}=301, \mathrm{n}=2.5$, and $\mathrm{m}=33.7$, and erosion equation 


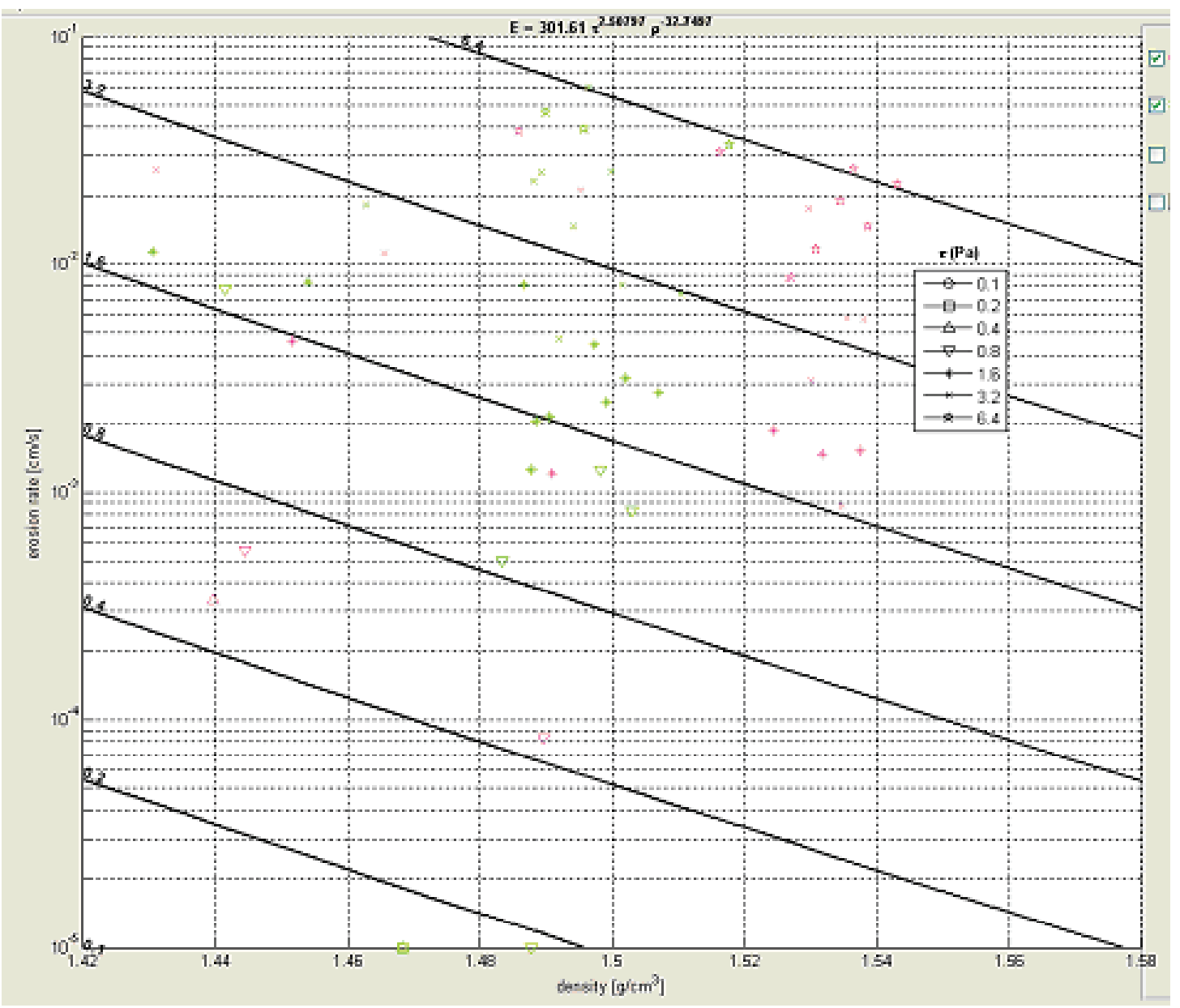

Figure 8-8. Multivariate optimization of erosion function to Sedflume data for All core data. Points represent measured erosion rates at varying shear stress; lines represent optimized function values for each value of shear stress.

$$
\begin{array}{cc}
\mathrm{E}=301 \tau^{2.5} \rho^{-33.7} & \left(\tau>\tau_{\mathrm{cr}}\right) \\
\mathrm{E}=0 & \left(\tau \leq \tau_{\mathrm{cr}}\right)
\end{array}
$$

For sediments that are highly cohesive, erosion rate increases rapidly with increasing density. The strength and frequency of electro-chemical bonds between particles increase with increasing density. Therefore, the large negative value of $\mathrm{m}$ for this parameterization indicates that the sediment is highly cohesive. The value of $n$ generally ranges from 1.5-3.0 for most cohesive sediments. The value of $\mathrm{n}$ determined for the Grays Harbor dredged material during these experiments falls within this range.

Non-cohesive sediments generally erode at a constant rate. Cohesive sediments may be stable for some time period followed by episodic erosion as cohesive bonds begin to fail. Erosion of non-cohesive sediments is 
characterized by movement of individual grains. Cohesive sediment erosion often includes intermittent separation of large aggregates. Therefore, measured erosion rates for cohesive sediment have much more variability than for non-cohesive sediments. This is not necessarily an artifact of Sedflume, but rather it is representative of cohesive sediment behavior. Therefore, when analyzing Sedflume erosion data, some individual data points do not fit the trend. These data points are sometimes removed from the analysis so that the analysis remains more consistent with the majority of data. Bulk property data (density, organic content, grain size) often also indicate that these sediments are not representative of the trend. Even for well mixed laboratory samples, such as in these experiments, there will be inconsistent data points. User judgment, based on experience, is a critical factor in selecting these non-representative points. Non-representative data points are removed from the least-square analysis used to develop the Grays Harbor dredged material parameterization shown in Equation 8-16.

In general, it is appropriate to minimize operator judgment from laboratory and field measurement methods. However, this is not possible for cohesive sediments. The subsequent data analysis and selection of data points used in analysis provides the model developer with a powerful tool for parameterization. The developer is able to select data sets for baseline and conservative assumptions. Conservative (i.e., more erodible) assumptions were selected for an alternative Grays Harbor dredged material parameterization. In this parameterization, some outlying data points that included high erosion and were excluded from the base line least square fit shown in Equation 8-16 were re-incorporated into the data set. The A, $n$, and $m$ values for this parameterization are 1790, 2.4, and 36.5 , respectively. It should be noted that including these higher erosion rates in the analysis affects the overall results of Equation 8-16 by less than 10 percent. This small difference indicates that there are sufficient data which follow the general trend such that inclusion of outlying points does not greatly influence the final results.

\section{Critical shear}

As stated previously, critical erosion is defined as $\mathrm{E}=1 \times 10^{-5} \mathrm{~cm} \cdot \mathrm{s}^{-1}$. Applying the erosion parameters determined above to Equation 8-11, critical shear stress is determined for a range of bed density, $\rho$, and presented in Figure 8-9. Erosion of the surface nephloid (fluff) layer is not measured in Sedflume. Surface layer sediment density is approximately $1.4 \mathrm{~g}^{\cdot \mathrm{cm}^{-3}}$ is typical. Figure 8-9 shows that the critical shear stress will be approximately 


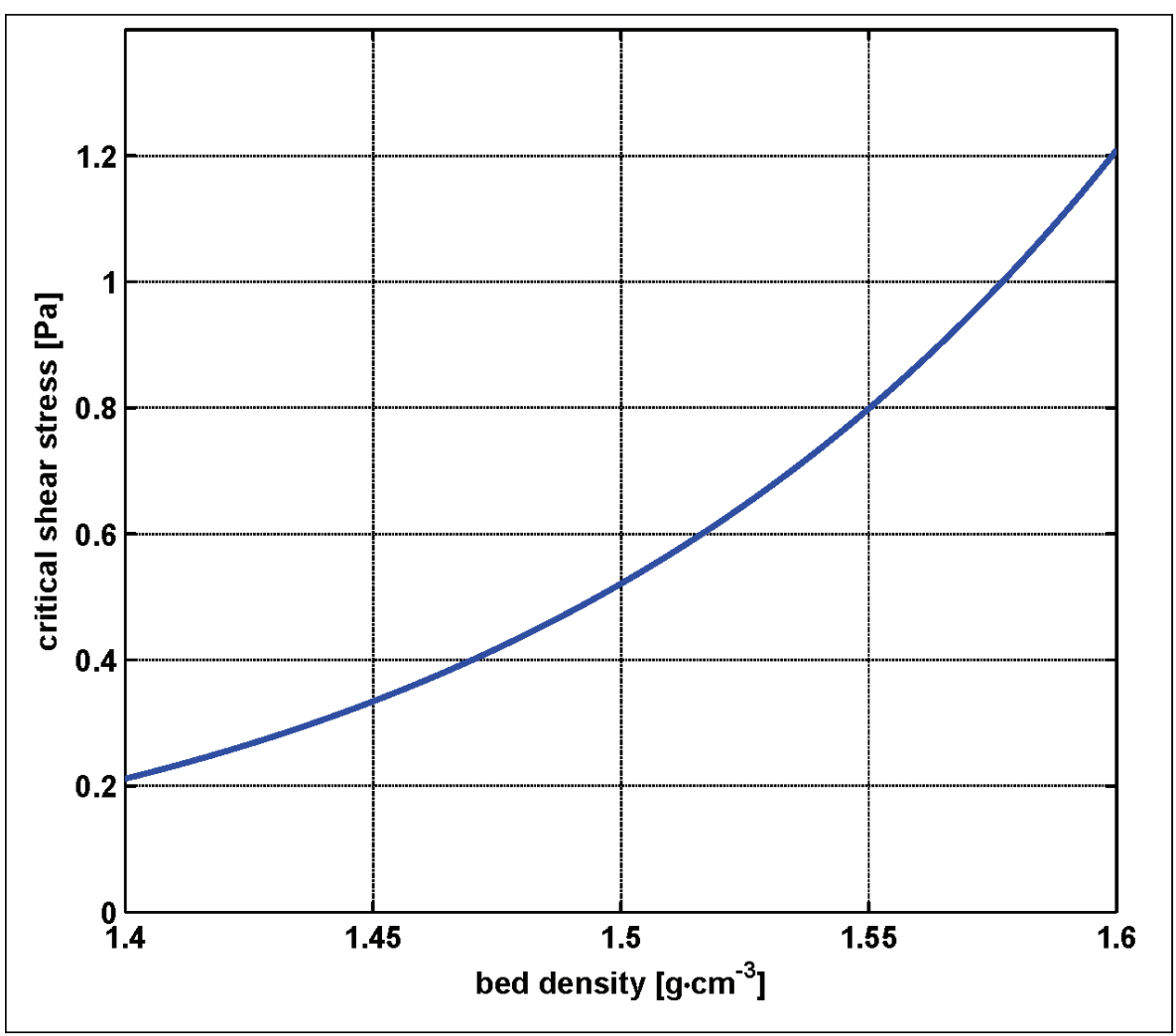

Figure 8-9. Estimated critical shear stress from base line erosion data.

0.2 Pa for these surface sediments. Density increases within the top $15 \mathrm{~cm}$ of sediment to approximately $1.55 \mathrm{~g} \cdot \mathrm{cm}^{-3}$. Critical shear stress for these sediments will be approximately $0.8 \mathrm{~Pa}$. It is plausible, and even likely, that the ODMDS mounds will consolidate to densities greater than the laboratory samples. At 1.6 Pa, the critical shear stress will be $1.2 \mathrm{~Pa}$ and will increase rapidly at greater density. Critical shear stress on the order of 3-4 Pa is not unusual for deeply buried cohesive sediments. The large, negative values of $m$ derived from the erosion experiments indicate that the Grays Harbor dredged sediments are highly cohesive. Therefore, the steep slope in Figure 8-9 for $\rho>1.5 \mathrm{~g} \cdot \mathrm{cm}^{-3}$ is expected.

\section{Settling velocity}

Video from 15 settling experiments was analyzed with the image processing and particle tracking software. Each of the video analyses results in particle size, settling velocity, and density estimates for each particle. An example of the resulting data from a single video sequence is provided in Figure 8-10 (GH06b). In this video, 459 particles were tracked by PTV, and the massweighted distribution of particle classes is 76 percent bed aggregates, 14 percent primary particles, and 10 percent flocs. 


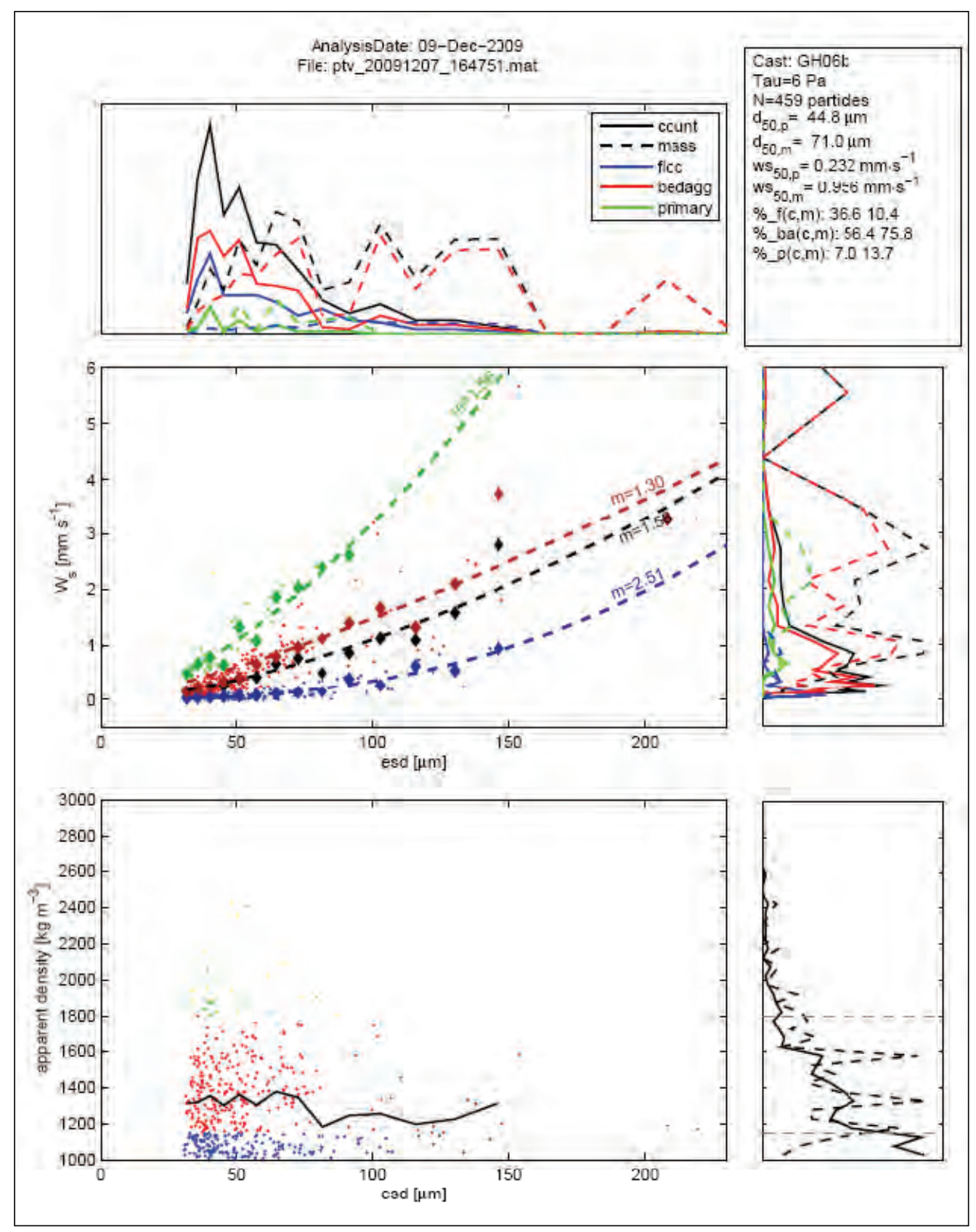

Figure 8-10. A) Mass and count distributions of particle size (esd = equivalent spherical diameter), B) size and settling velocity for each tracked particle, C) size and estimated particle density, D) distributions of particle settling velocity, E) distributions of particle density.

The mass fractions and median settling velocities for all 15 settling experiments are presented in Figure 8-11. Figure 8-11B presents the mass fraction by particle class for each erosion experiment. In each erosion experiment, the mass of bed aggregates is clearly dominant and quite constant, ranging between 68 and 87 percent of the total suspended mass. Primary particles and flocs contributed nearly equally to the suspended 

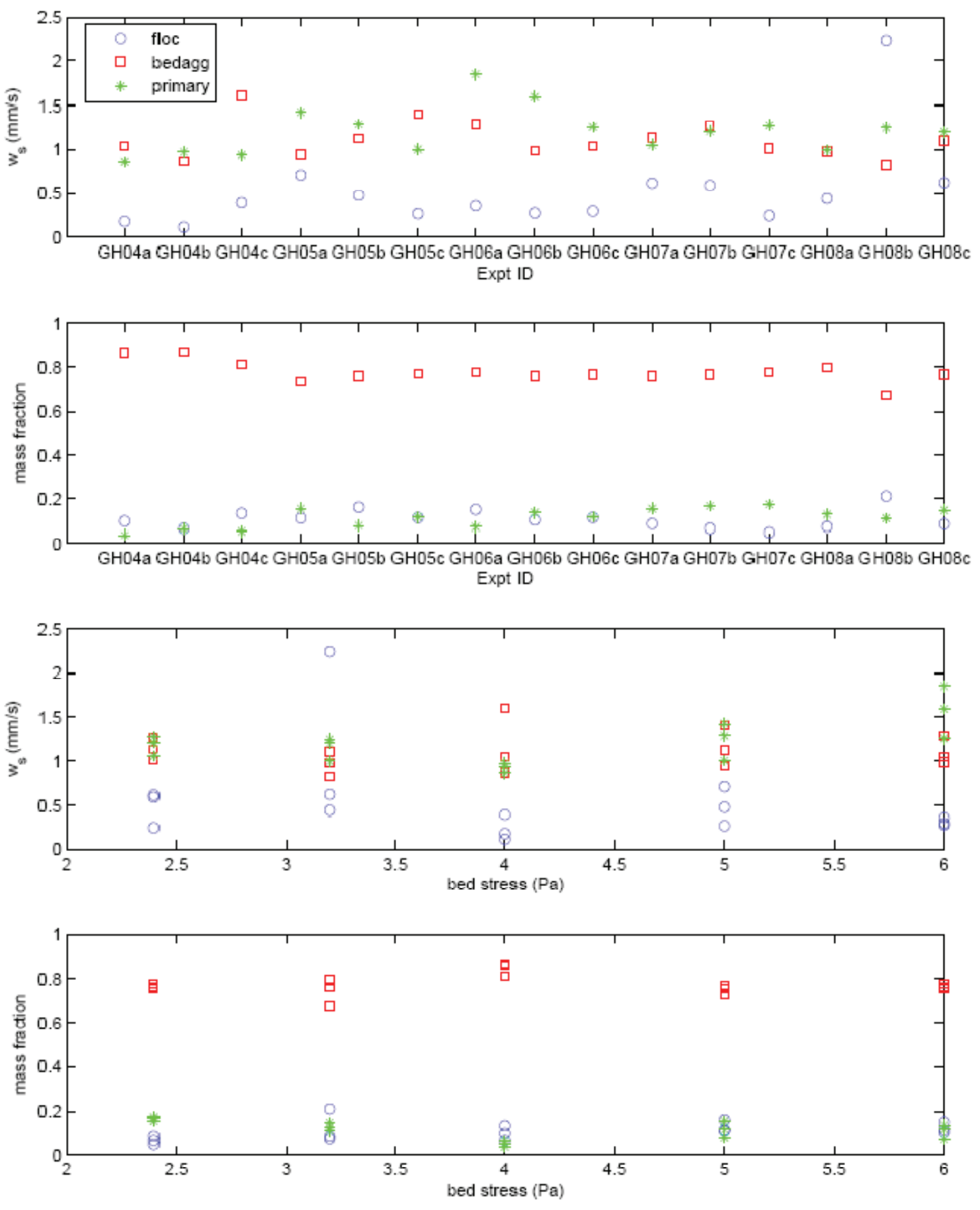

Figure 8-11. A) Median settling velocity by particle class for all settling experiments, B) mass fraction by particle class for all settling experiments, $C$ ) settling velocity versus shear stress for all particle classes, D) mass fraction versus shear stress for all particle classes.

mass, representing on average 11 percent and 10 percent, respectively. It should be noted that the time required to permit turbulence damping in the settling column may exclude a portion of the faster settling particles 
(predominantly sand) settling at velocities on the order of $15-20 \mathrm{~mm} / \mathrm{s}$ or faster.

The median settling velocity of bed aggregates was found to be relatively constant across all experiments (Figure 8-11A), ranging between 0.8 to $1.6 \mathrm{~mm} / \mathrm{s}$ with a mean of $1.1 \mathrm{~mm} / \mathrm{s}$. Median settling velocities of primary particles were slightly higher in magnitude, ranging between 0.9 to $1.8 \mathrm{~mm} / \mathrm{s}$, with a mean of $1.2 \mathrm{~mm} / \mathrm{s}$. Floc settling velocities were notably slower, ranging between 0.1 to $0.7 \mathrm{~mm} / \mathrm{s}$, with mean of $0.35 \mathrm{~mm} / \mathrm{s}$ (excluding the outlier in $\mathrm{GH} 08 \mathrm{~b}$, which was influenced by a very large particle, which appeared to be a fragment of organic woody debris). Particle class fractions and settling velocities were evaluated for any significant trends associated with applied bed stress during the erosion experiments (Fig 8-11 C-D). Neither particle states nor settling velocity were found to be related to applied bed stress for these experiments.

\section{Summary and conclusions}

Five dredged sediment samples were collected from Cow Point Reach in Grays Harbor to quantify cohesive sediment erosion, consolidation, and settling characteristics. One sample could not be used in the analysis because of a large amount of debris within the sample. Three of the four remaining were of similar geotechnical characteristics dominated by fine sediment (median particle size of approximately $22 \mu \mathrm{m}$ ). The fourth sample was predominately fine-medium sand with a median particle size of approximately $200 \mu \mathrm{m}$. The four samples were composited into a single "representative" dredged sediment sample for Cow Point Reach. Sediment cores were prepared from the sample at an initial sediment concentration of $200 \mathrm{~g} / \mathrm{L}$. The cores were allowed to consolidate for periods of 2, 8, 23, and 142 days and then eroded with Sedflume to determine erosion rates as a function of shear stress and density. Density range for the consoldiated sediments ranged from approximately $1.4-1.6 \mathrm{~g} \cdot \mathrm{cm}^{-3}$.

Sedflume erosion data were analyzed for consistency. Appropriate data were processed using a multivariate optimization routine to develop parameterized erosion equations that were a function of shear stress and density. Sedflume data analysis indicated that the Grays Harbor dredged material is highly cohesive. Therefore erosion rate and critical shear stress for initiation for erosion are highly sensitive to sediment bulk density and bulk denisty of eroding sediments must be included in any sediment transport modeling. 
Aggregate states and settling velocities were characterized for consolidated, mixed-sediment dredged material obtained from the Cow Point Reach. The experiments were conducted by coupling the Particle Image Camera System (PICS) with Sedflume. Settling velocity and aggregate states were found to be near-constant and uncorrelated to applied shear stress. For modeling purposes, the eroded sediments from a consolidated dredged material mound composed of Cow Point Reach sediments can be treated as a suspension of 80 percent bed aggregates, 10 percent flocs, and 10 percent primary particles. Floc settling velocities were estimated to be $0.35 \mathrm{~mm} / \mathrm{s}$, and the settling velocity of bed aggregates is estimated at $1.1 \mathrm{~mm} / \mathrm{s}$. 


\section{Sediment Transport Modeling Using SEDZLJ}

\section{Introduction}

A goal of the study was to simulate the post-placement transport of dredged material from the Point Chehalis, South J etty, and Half Moon placement sites. The MPFATE-simulated sediment bed structures, following placement at these disposal sites, were used as the initial bed conditions in SEDZLJ . As described in Chapter 6, the latter is the sediment bed model in LTFATE. The objective of this modeling was to identify sediment transport pathways at the three placement sites and to recommend alternatives to existing placement practices based on the estimated sediment transport pathways. Four simulations were performed; representing 6-month, 2-year, and 5-year return intervals; and a high-storm event. Event selection is described in Chapter 4. The 6-month return interval (represented by results from the second quarter of 1993), the 2-year return interval (represented by the fourth quarter of 2006), and the 5-year return interval (represented by the fourth quarter of 1998) were simulated using LTFATE. As described herein, riverine flows and adjusted ADCIRC simulated water surface elevations were used as the boundary conditions for EFDC, the hydrodynamic and transport model in LTFATE, for these four simulations. Interpolated CMSWAVE results for these four simulated events were used during the sediment transport simulations to calculate the current- and wave-induced bed shear stresses in every active, i.e., wet, grid cell in the LTFATE model domain. It should be noted that the four simulated periods (6-month, 2year, 5-year, and extreme) included ADCIRC simulated meteorological and astronomical (tides) forcings.

LTFATE simulations were run for the Grays Harbor modeling domain for the four selected events for both the existing and realigned channel configurations. The same computational domain, sediment distribution, and hydrodynamic boundary conditions were used for both channel alignment configurations. The results presented and discussed later in this chapter are the following: 1) mass and volume of sediment that is eroded from each of the three placement sites; and 2) the mass of sediment that erodes from each placement site and subsequently deposits in one of the following five reaches of the navigation channel: bar channel, entrance 
channel, Pt Chehalis channel, south channel, and cross-over channel. The following section describes the application of LTFATE to Grays Harbor, including model setup, calibration and the results from the simulated events.

\section{Hydrodynamic modeling}

\section{Model setup}

A curvilinear-orthogonal grid with 5,406 horizontal grid cells was used to represent the same model domain as that used for CMS-Wave. The model domain and model bathymetry are shown in Figure 9.1. Notice that the model domain extends approximately $15 \mathrm{~km}$ up the Chehalis River to the location of Tide \#5 station (see Figure 3-2). The bathymetry data used in constructing this grid were provided by the NWS and National Geophysical Data Center, Coastal Relief Bathymetry Database.

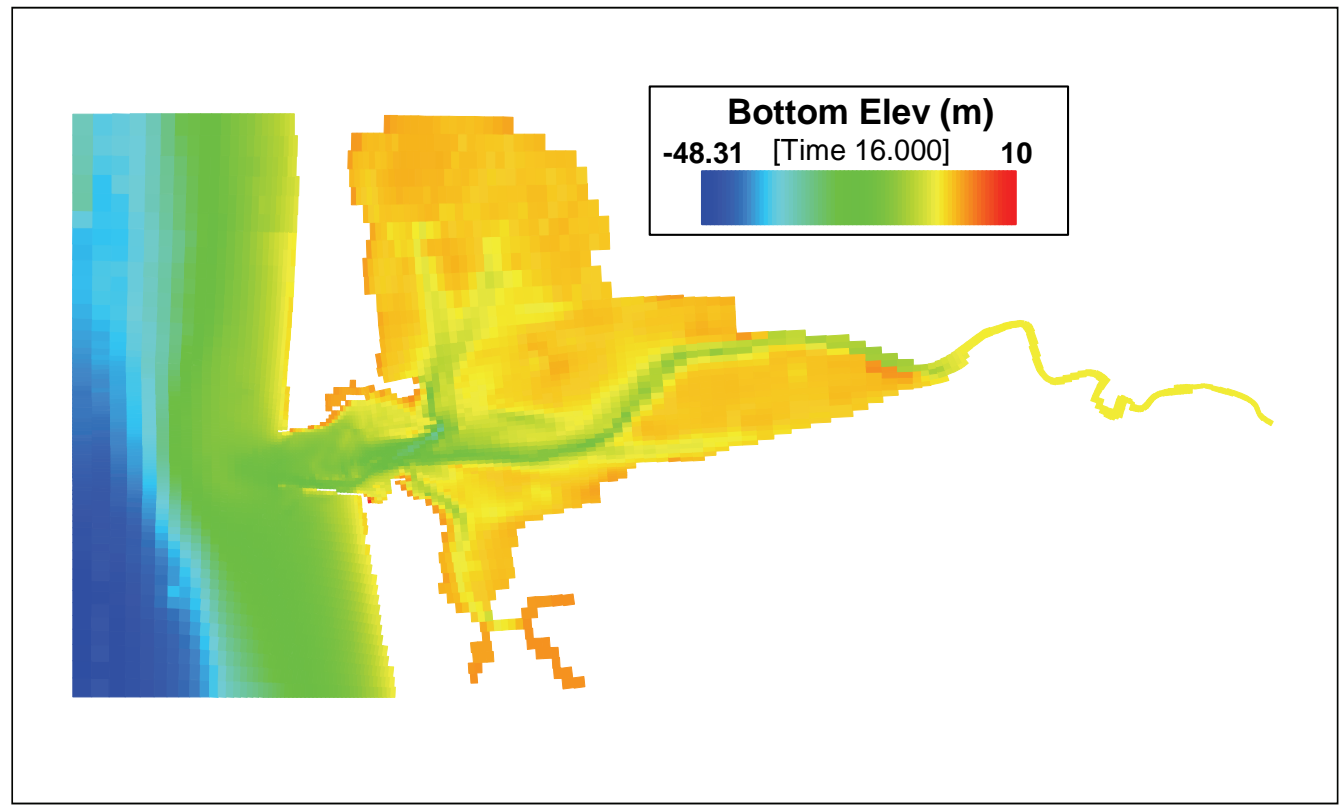

Figure 9-1. LTFATE Model Domain for Grays Harbor.

As described previously, astronomical tides are the dominant forcing mechanism within Grays Harbor, with riverine flows in the Chehalis River and the Humptulips River secondary in importance. As stated previously, EFDC was driven by ADCIRC simulated tides around the ocean open water boundaries seen in Figure 9.1. Because of the relatively small modeling domain (as quantified by the time it takes for the tidal wave to propagate the full length of the water body being modeled that was relatively short), it was not necessary to use the radiation-separation boundary condition 
option in EFDC. Instead, clamped boundary conditions were constructed using the ADCIRC interpolated water surface elevation time series for each grid cell composing the three ocean boundaries.

The river inflows from the Chehalis and Humptulips Rivers are also simulated in the model (see Figures 9-2 and 9-3). The Chehalis River flow record was constructed using the USGS gage 12031000 on the Chehalis River at Porter, WA. This was the closest gage to Grays Harbor that had a continuous period of record from J anuary 1, 1990 to the present.

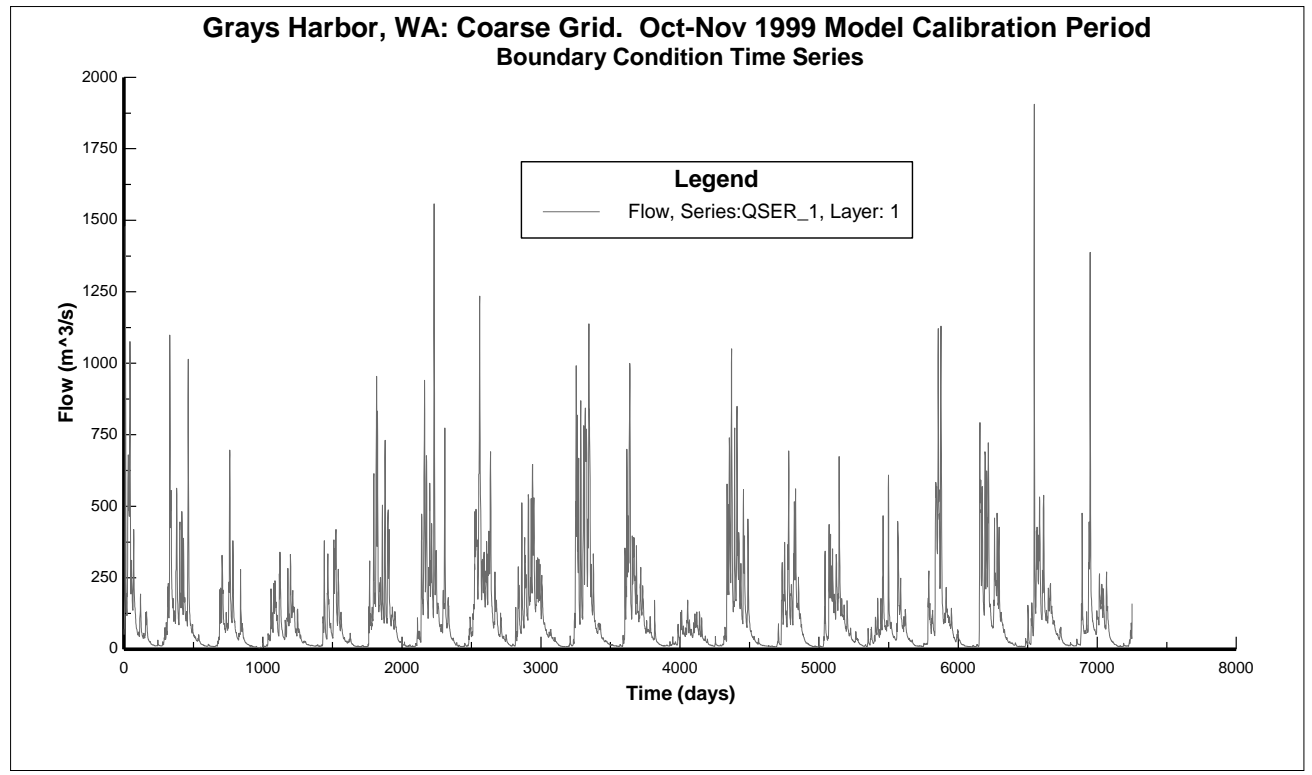

Figure 9-2. Chehalis River Discharge Time Series. Day 0 corresponds to 01 Jan 1990.

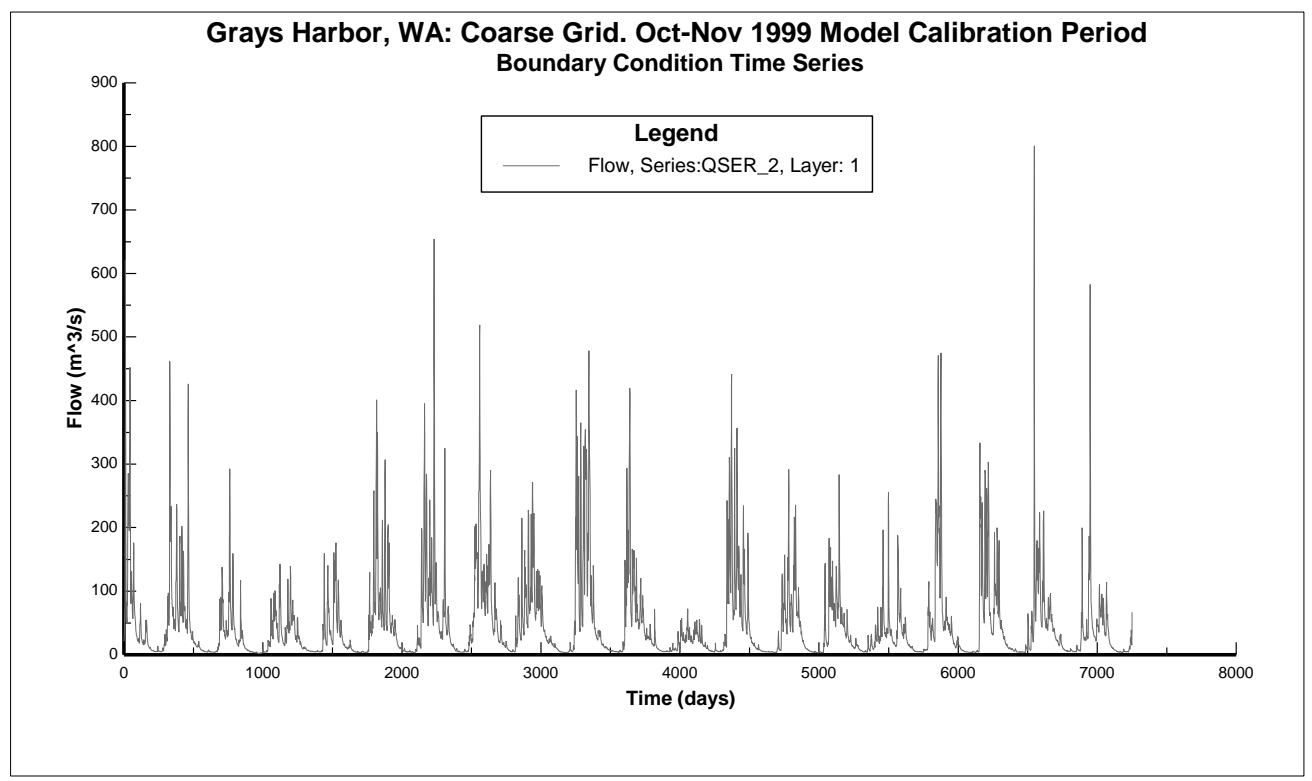

Figure 9-3. Humptulips River Discharge Time Series. Day 0 corresponds to 01 Jan 1990. 
The flow recond at Porter was pro-rated to that at the USGS gage 12035100 at Montesano, WA using the ratio of the drainage basin areas at these two gages. A similar procedure was used to construct the discharge time series for the Humptulips River. The Chehalis River flow record was applied at the upstream most grid cell in the short reach of the Chehalis River included in the model domain. The Humptulips River flow record was applied at a cell at the northeastern corner of North Bay in Grays Harbor. Other physical processes represented by the model include bottom friction and Coriolis acceleration. Winds were neglected in the present application.

With the meso-tidal conditions in Grays Harbor, the water column is not completely vertically well-mixed for most of the tidal cycle, though measurements by Landerman et al. (2004) showed that the maximum difference between surface and bottom salinities at several nearshore stations was approximately 3 psu. No measurements of vertical salinity profiles inside the harbor were found. With such a relatively small salinity gradient, baroclinic flow in Grays Harbor would be minimal. As such, the EFDC model was run in the depth-averaged mode. However, to represent the longitudinal salinity profile that was apparent from the salinity measurements by Hericks and Simpson (2000) at the five tidal stations shown in Figure 3-2, the salinity transport module in EFDC was used. A salinity of 31 psu was assumed at the three ocean boundaries of the model domain, and salinities of 0 psu were used for the river inflows in the Chehalis and the Humptulips Rivers.

\section{Model calibration}

The selected model calibration time period (14 October to 12 November 1999) was simulated using LTFATE for the purposes of adjusting the effective bottom friction coefficient used in EFDC to achieve an acceptable agreement with measured tides and current velocities. The tides measured at tide stations 1 - 5 (see Figure 3-2) and currents measured at stations 2 - 6 (see Figure 3-1) during the 1999 data collection program were compared to LTFATE simulated tides and currents at the grid cells where the measurements were made. It was found that the LTFATE simulated tides and currents at these cells were less than the measured tidal ranges and maximum current speeds. The ADCIRC simulated water surface elevation time series used for the ocean tidal boundaries had to be increased by 10 percent (i.e., each ADCIRC simulated water surface elevation was multiplied by 1.1) to achieve satisfactory agreement with the measured tides and currents. 
Figures 9-4 through 9-8 show comparisons between the measured tides and LTFATE simulated tides for the calibration period. While not acceptable at all phases of the spring-neap cycle, and particularly poor during neap tides for unknown reasons, the overall agreement between tidal ranges and phases is acceptable considering a larger scale coastal sea model (ADCIRC), as opposed to measured tides, was used to drive tidal propagation in Grays Harbor with EFDC. The more significant differences seen in Figure 9-8 are attributable to the use of a discharge boundary condition at this location and the unknown bathymetry in the Chehalis River between this boundary and the upper end of Grays Harbor.

Figures 9-9 through 9-12 show comparisons between the measured currents and LTFATE simulated currents for the calibration period. The comparison at current station \#1 is not included because measurements were only obtained for less than the first half of the calibration period. The worst agreement was obtained at current station \#3 (see Figure 9-10). Differences of this magnitude are usually caused by differences in bathymetry between that at the site of the measurement and that in the model grid. While not acceptable at all phases of the spring-neap cycle, the overall agreement between measured and simulated current speeds is acceptable. It is particularly important that the simulated current speeds agree as closely as possible when simulating sediment transport, since erosion rates are approximately proportional to the current speed to the fourth power. The Sedflume results reported in the previous chapter showed that the erosion rate of deposited fine-grain sediment varies to the fifth power of the current speed since the exponent on the relationship between erosion rate and bed shear stress was 2.5.

\section{Model validation}

The selected model validation time period (21 days in December 2003) was simulated using LTFATE for the purposes of checking the calibrated hydrodynamic model. The bottom friction coefficient was not adjusted for this simulation. The tides measured at tide stations 1 - 5 (see Figure 3-2) and currents measured at stations 2 - 6 (see Figure 3-1) during the 2003 data collection program were compared to LTFATE simulated tides and currents at the grid cells where the measurements were made. 


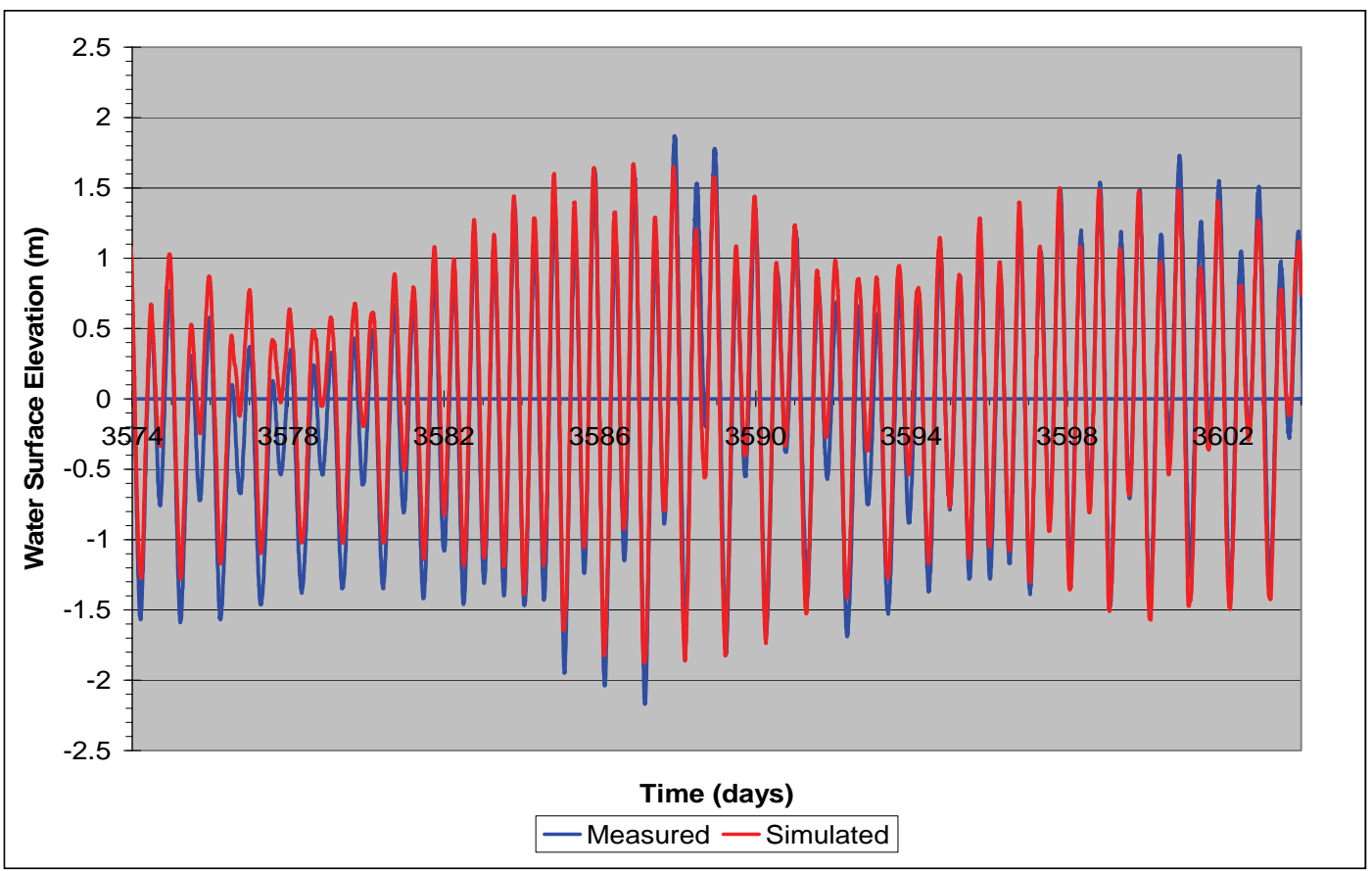

Figure 9-4. Comparison of measured and simulated tides at Tide Station \#1 during calibration period. Day 0 corresponds to 01 Jan 1990.

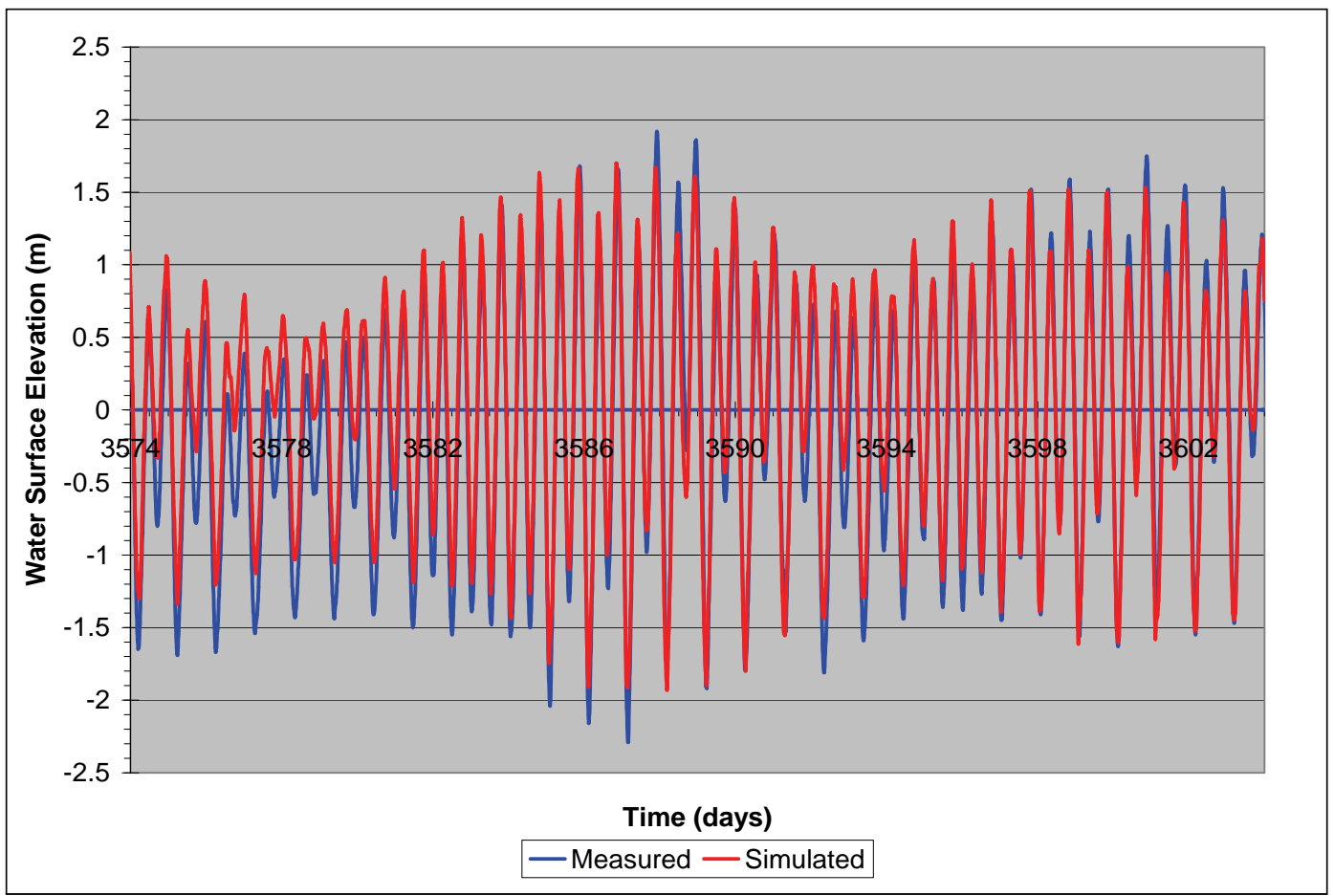

Figure 9-5. Comparison of measured and simulated tides at Tide Station \#2 during calibration period. Day 0 corresponds to 01 Jan 1990. 


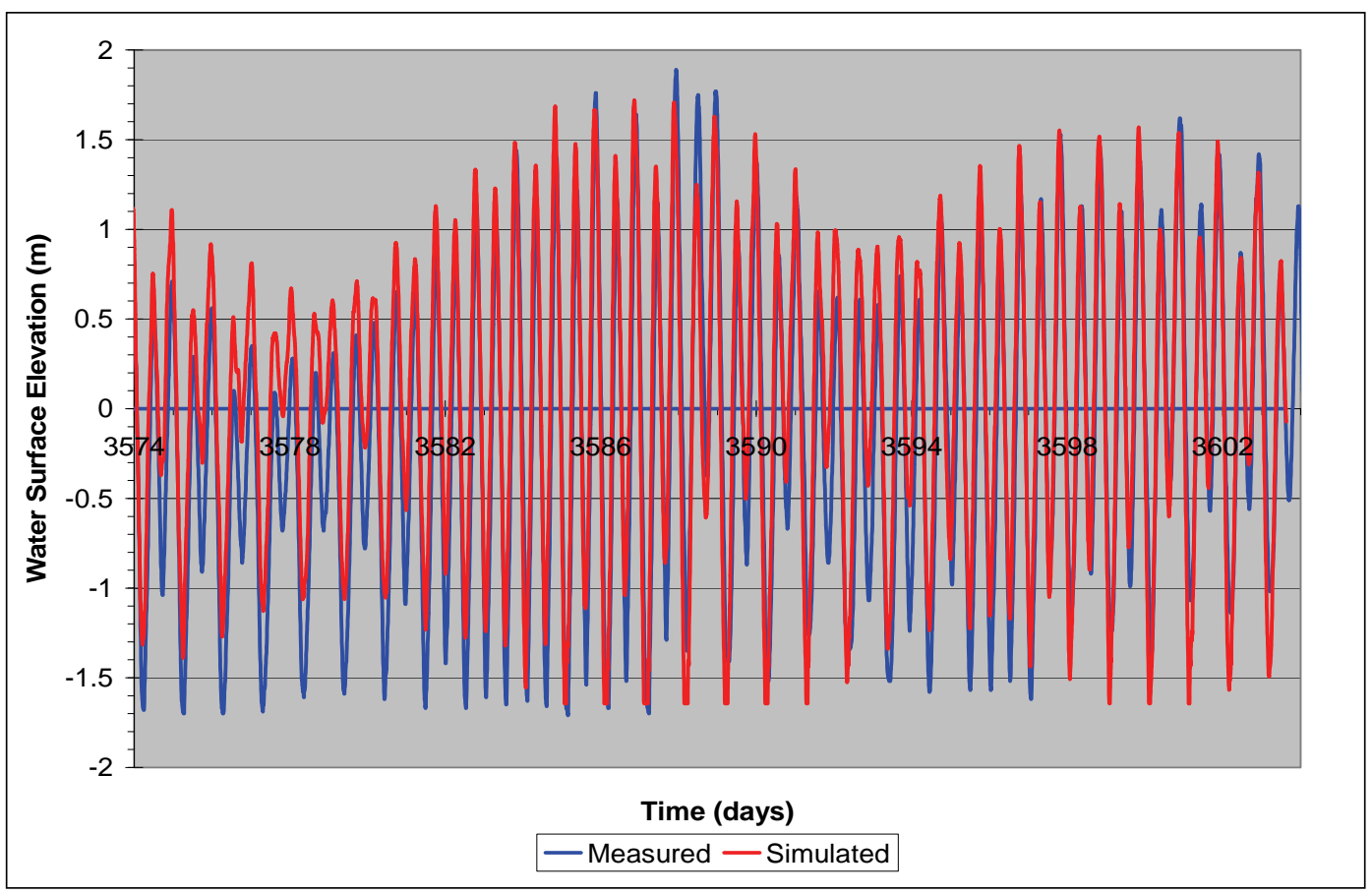

Figure 9-6. Comparison of measured and simulated tides at Tide Station \#3 during calibration period. Day 0 corresponds to 01 Jan 1990.

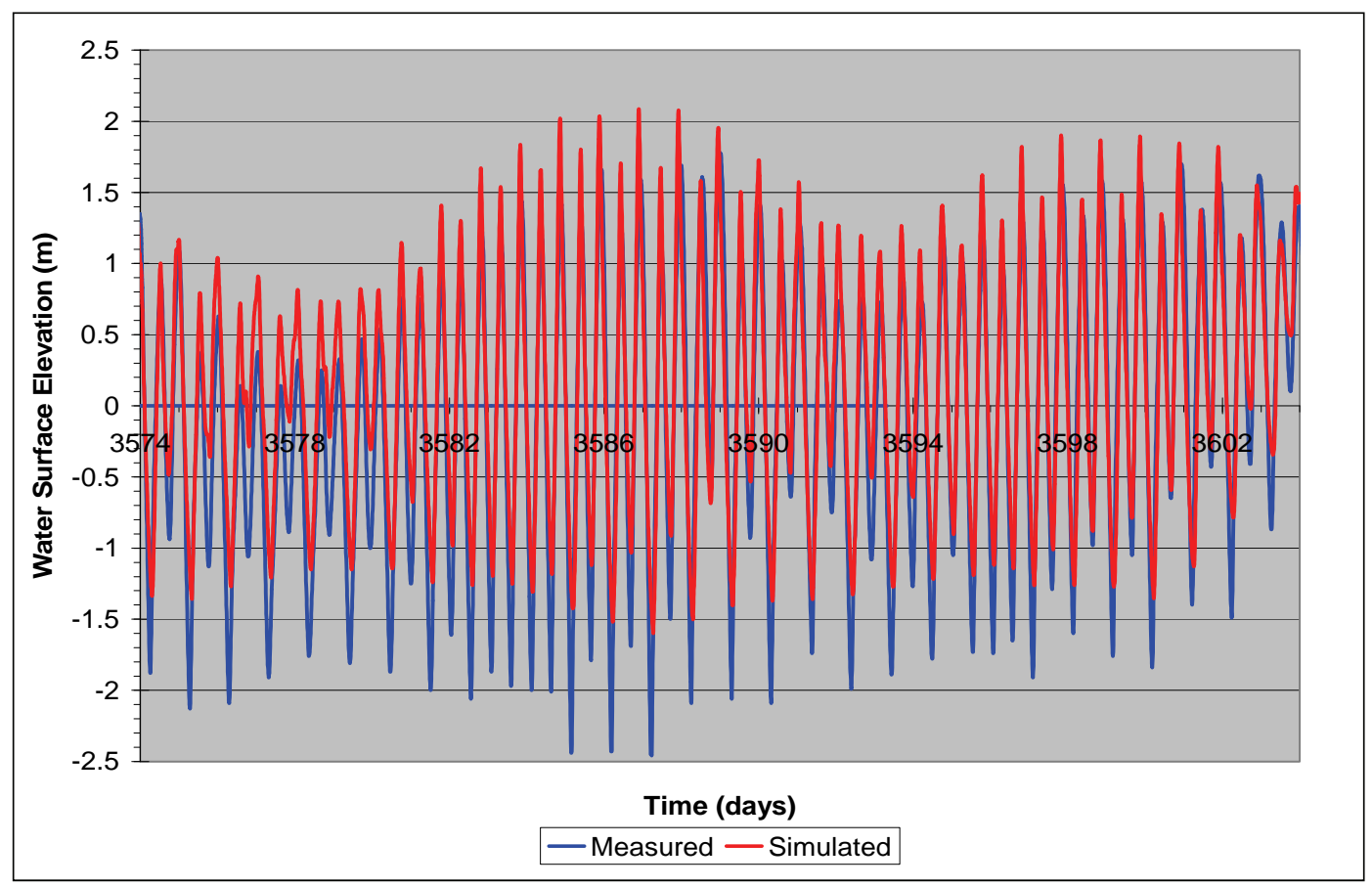

Figure 9-7. Comparison of measured and simulated tides at Tide Station \#4 during calibration period. Day 0 corresponds to 01 Jan 1990. 


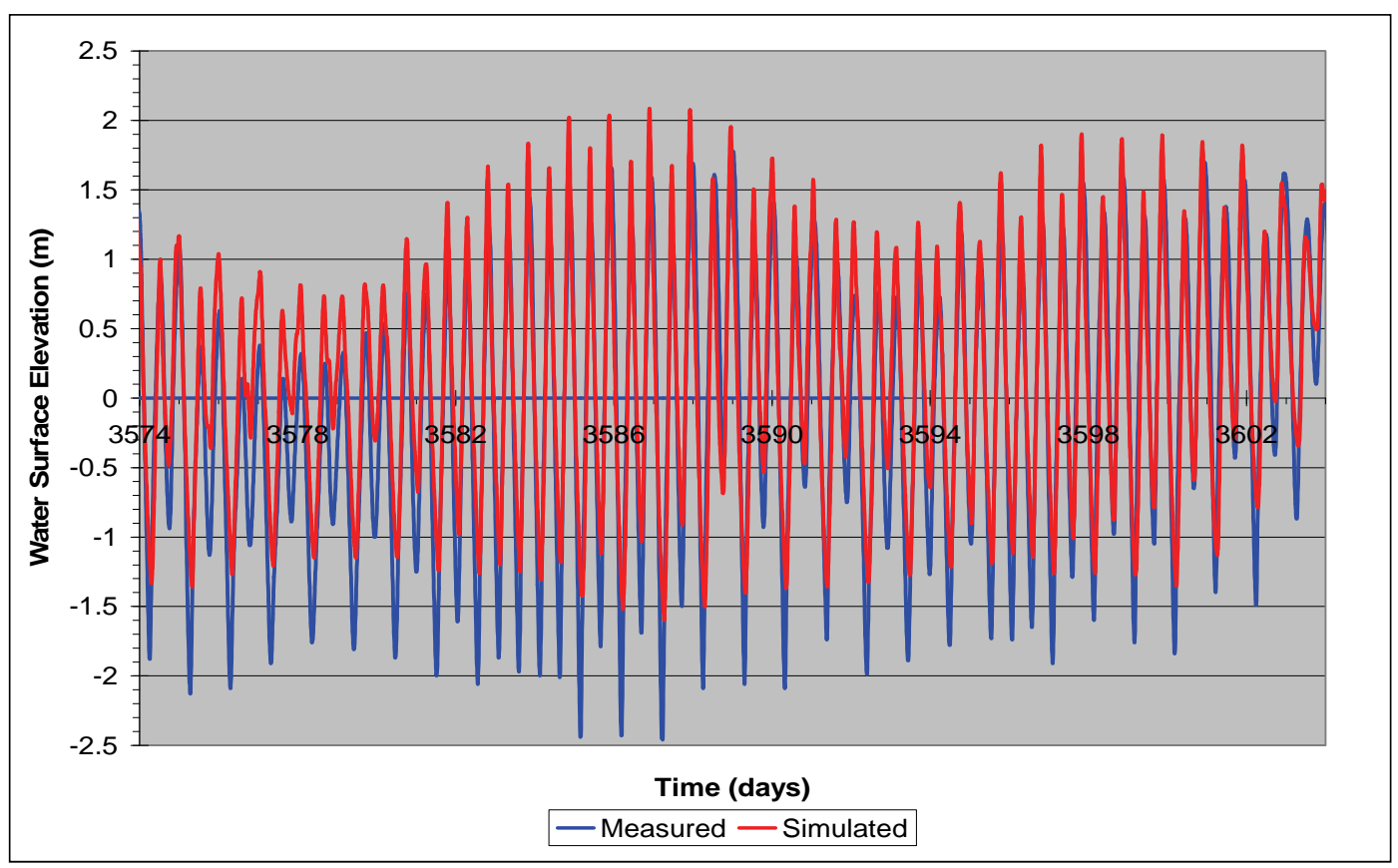

Figure 9-8. Comparison of measured and simulated tides at Tide Station \#5 during calibration period. Day 0 corresponds to 01 Jan 1990.

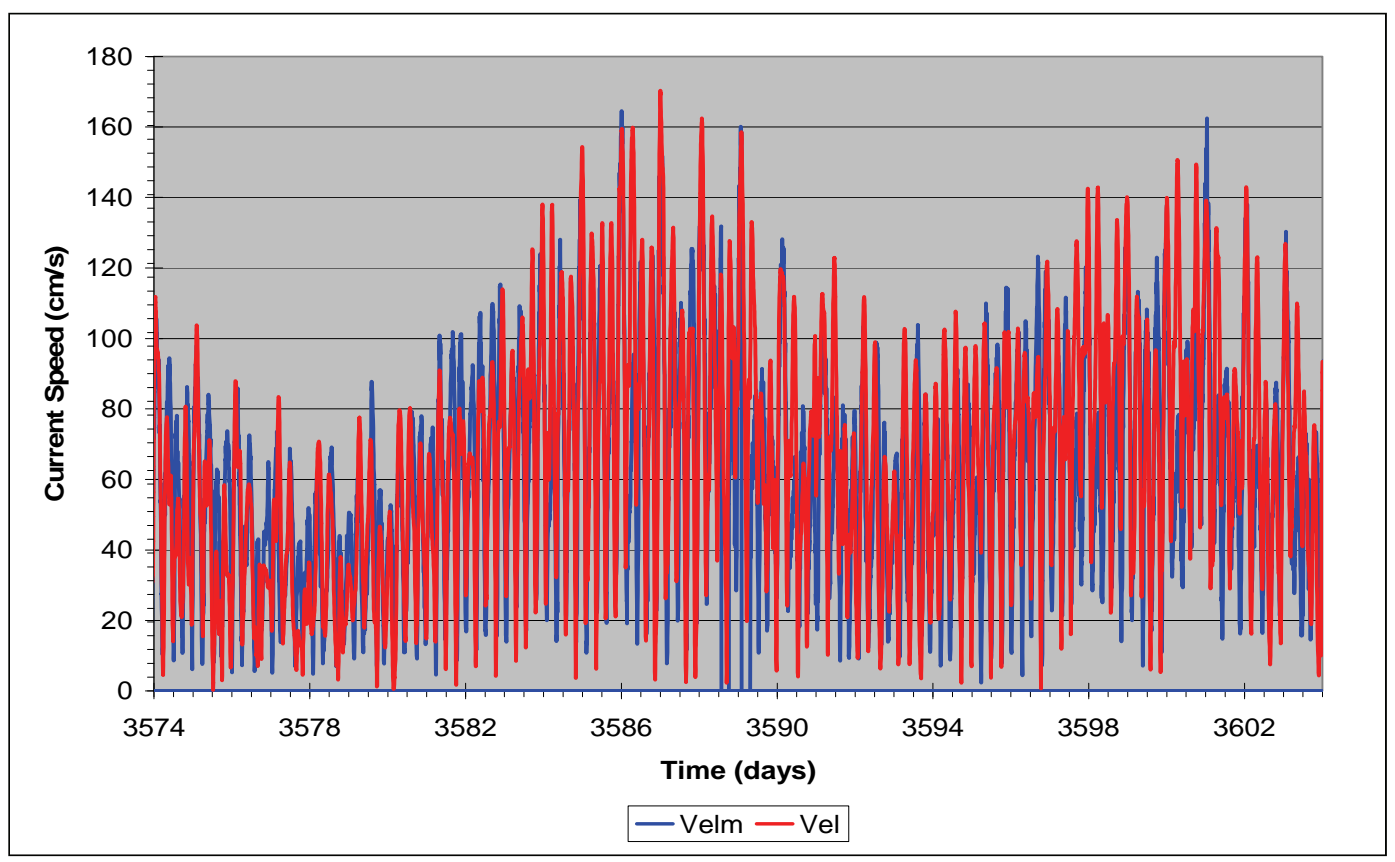

Figure 9-9. Comparison of measured and simulated currents at Current Station \#2 during calibration period. Day 0 corresponds to 01 Jan 1990. 


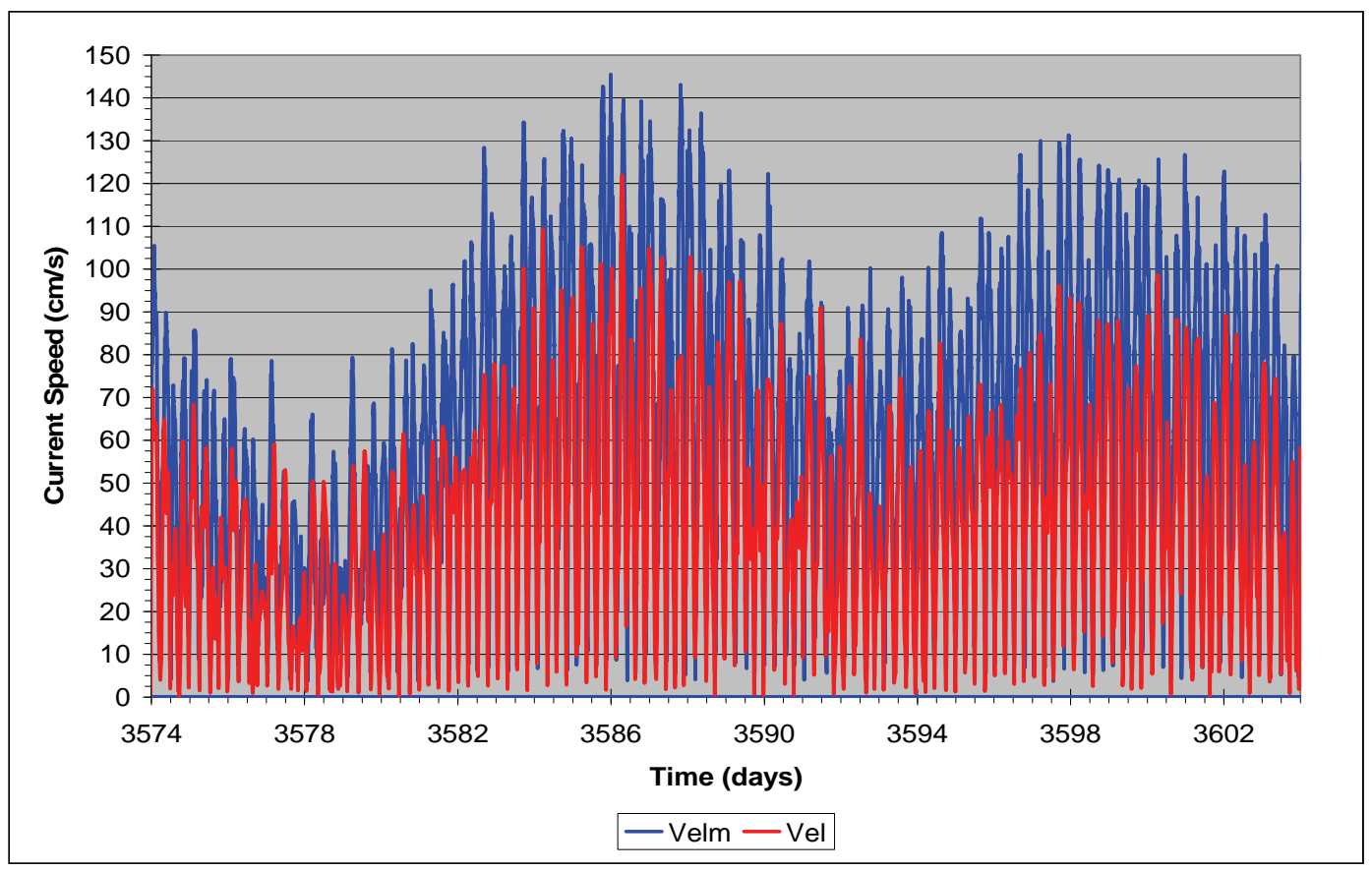

Figure 9-10. Comparison of measured and simulated currents at Current Station \#3 during calibration period. Day 0 corresponds to 01 Jan 1990.

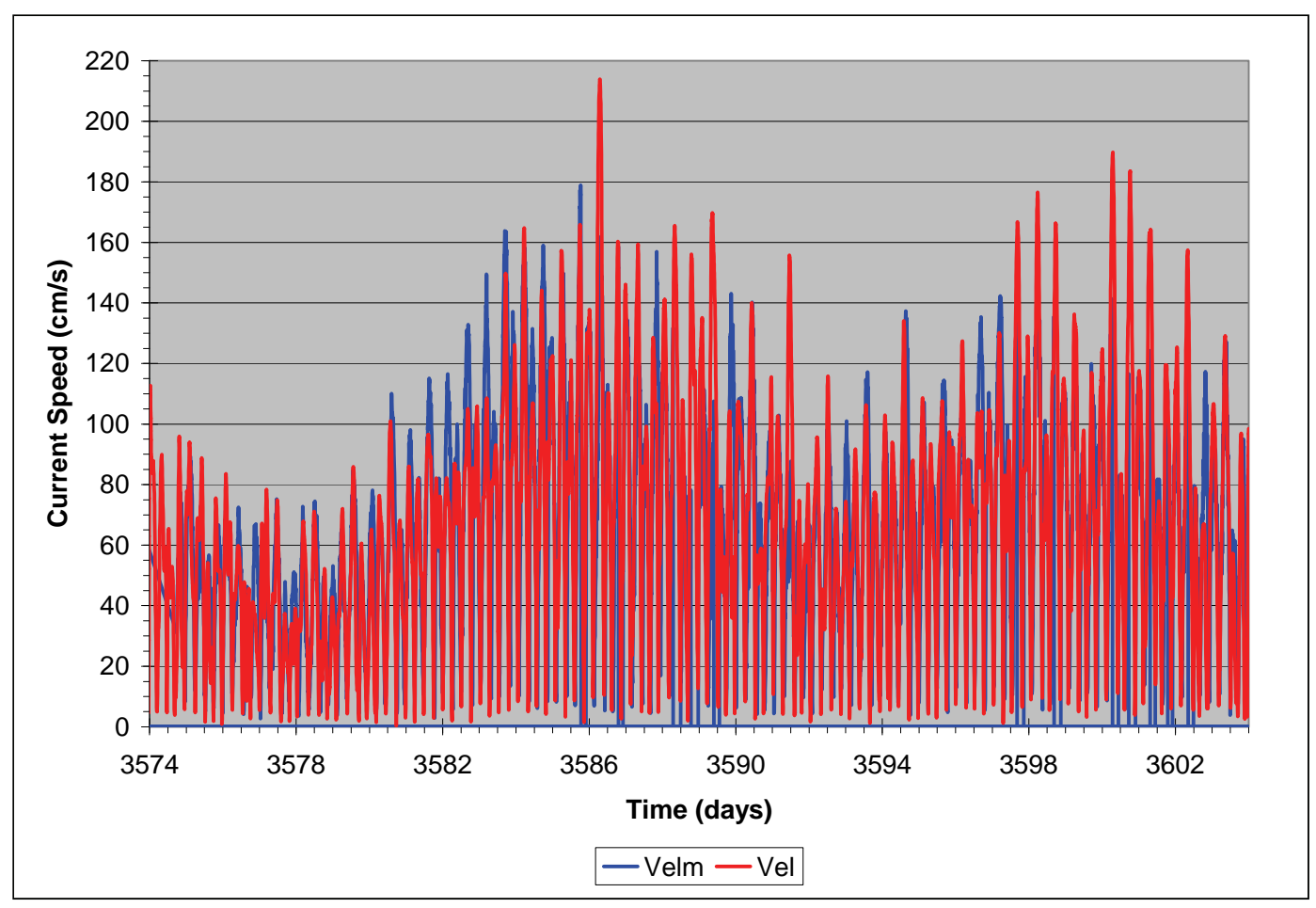

Figure 9-11. Comparison of measured and simulated currents at Current Station \#4 during calibration period. Day 0 corresponds to 01 Jan 1990. 


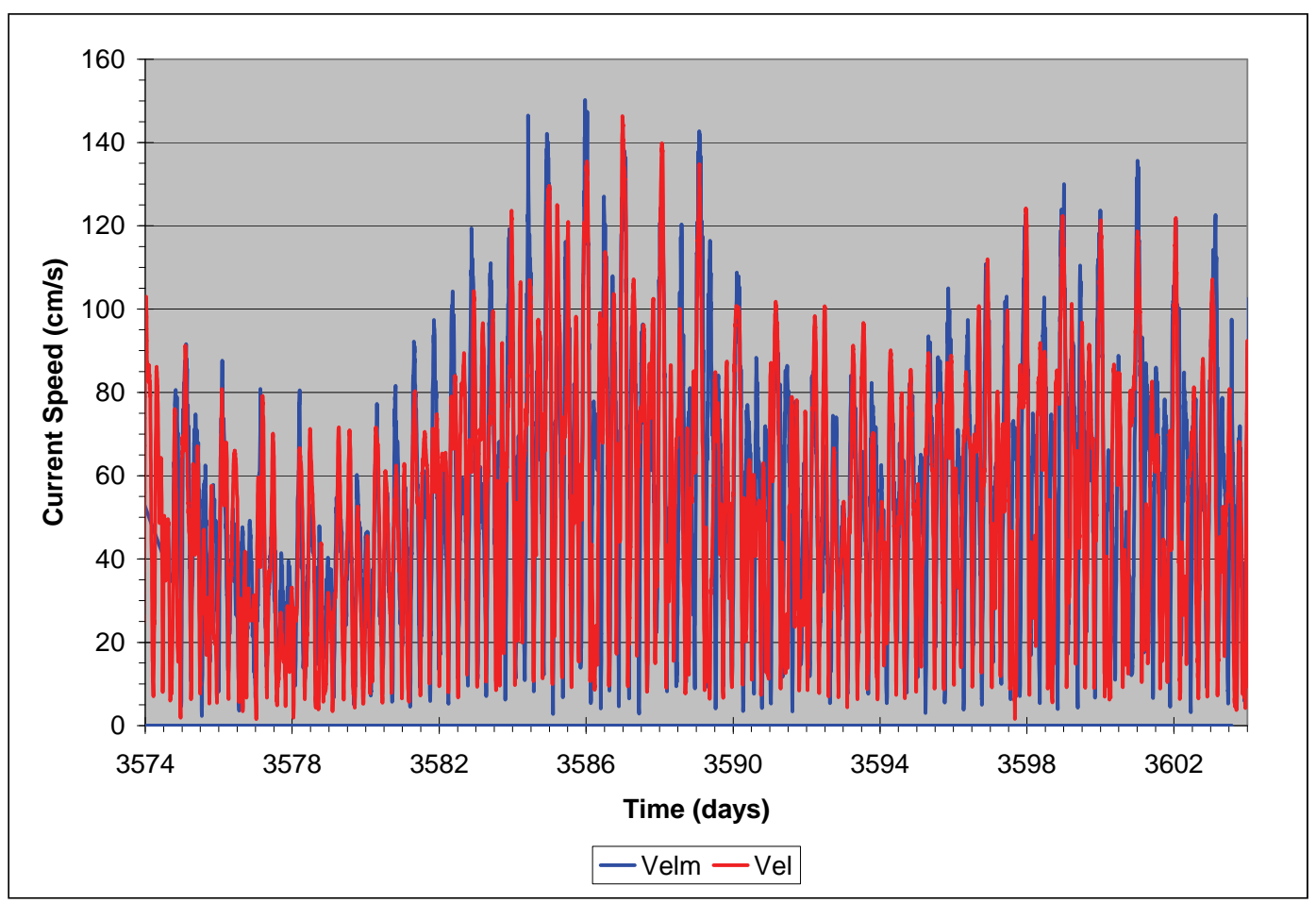

Figure 9-12. Comparison of measured and simulated currents at Current Station \#5 during calibration period. Day 0 corresponds to 01 Jan 1990.

Figures 9-13 through 9-17 show comparisons between the measured tides and LTFATE simulated tides, and Figures 9-18 through 9-21 show comparisons between the measured and simulated currents for the validation period. The comparison of the tides show a similar degree of agreement with that achieved during model calibration. Once again, there was good agreement between the measured and simulated tidal phases, whereas the agreement between the measured and simulated tidal ranges, while not acceptable at all portions of the spring-neap cycle, the overall agreement is acceptable.

As seen in Figures 9-18 - 9-21, there was less agreement between the measured and simulated currents during model validation than during model calibration, in particular at current stations 2 and 4 . However, this is not an unexpected occurrence when performing model validation.

Differences in bathymetry between that incorporated into the model grid and that at the site where the ADCPs were installed are most likely the cause for the observed differences in current speeds at these two stations. 


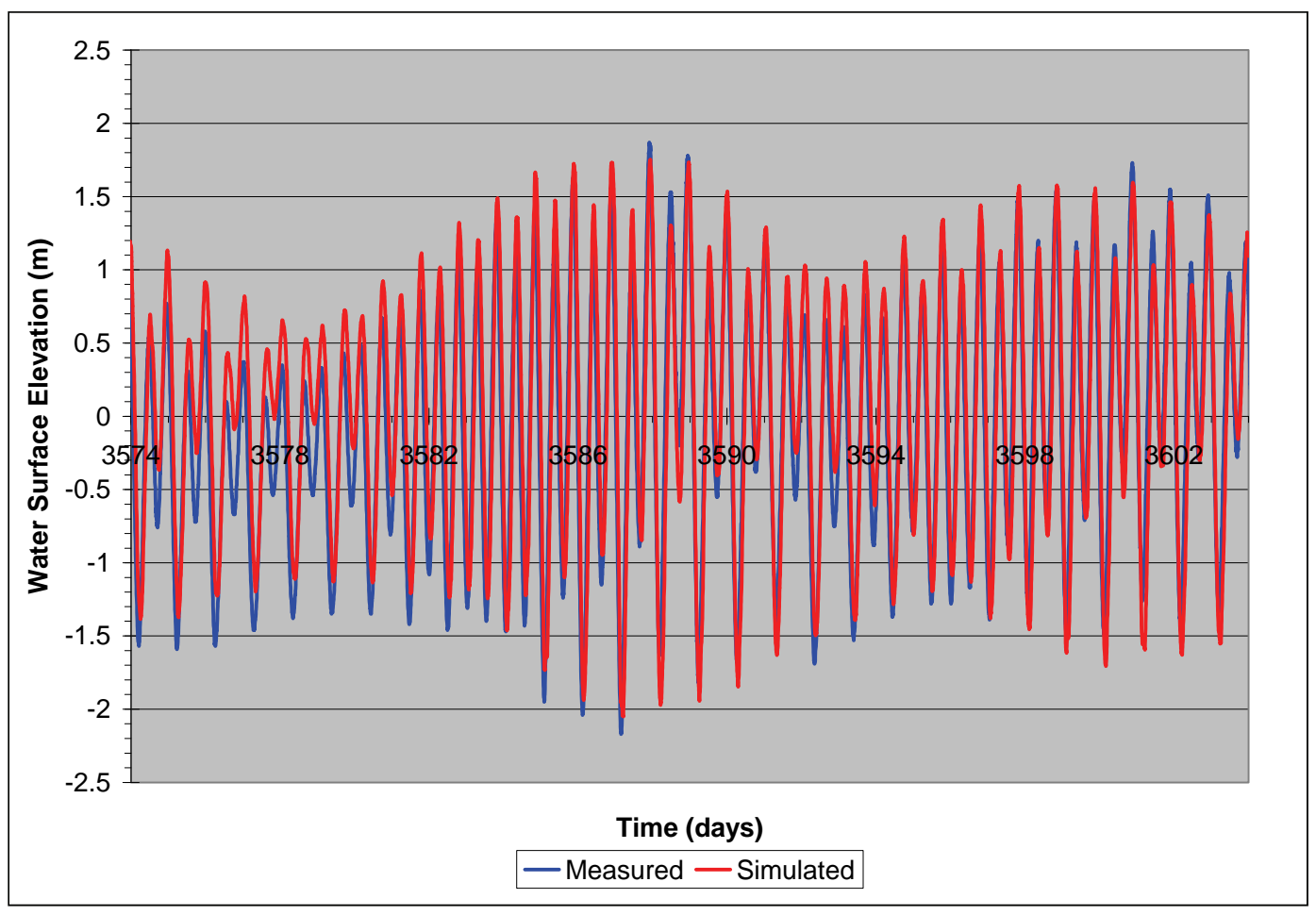

Figure 9-13. Comparison of measured and simulated tides at Tide Station \#1 during validation period. Day 0 corresponds to 01 Jan 1990.

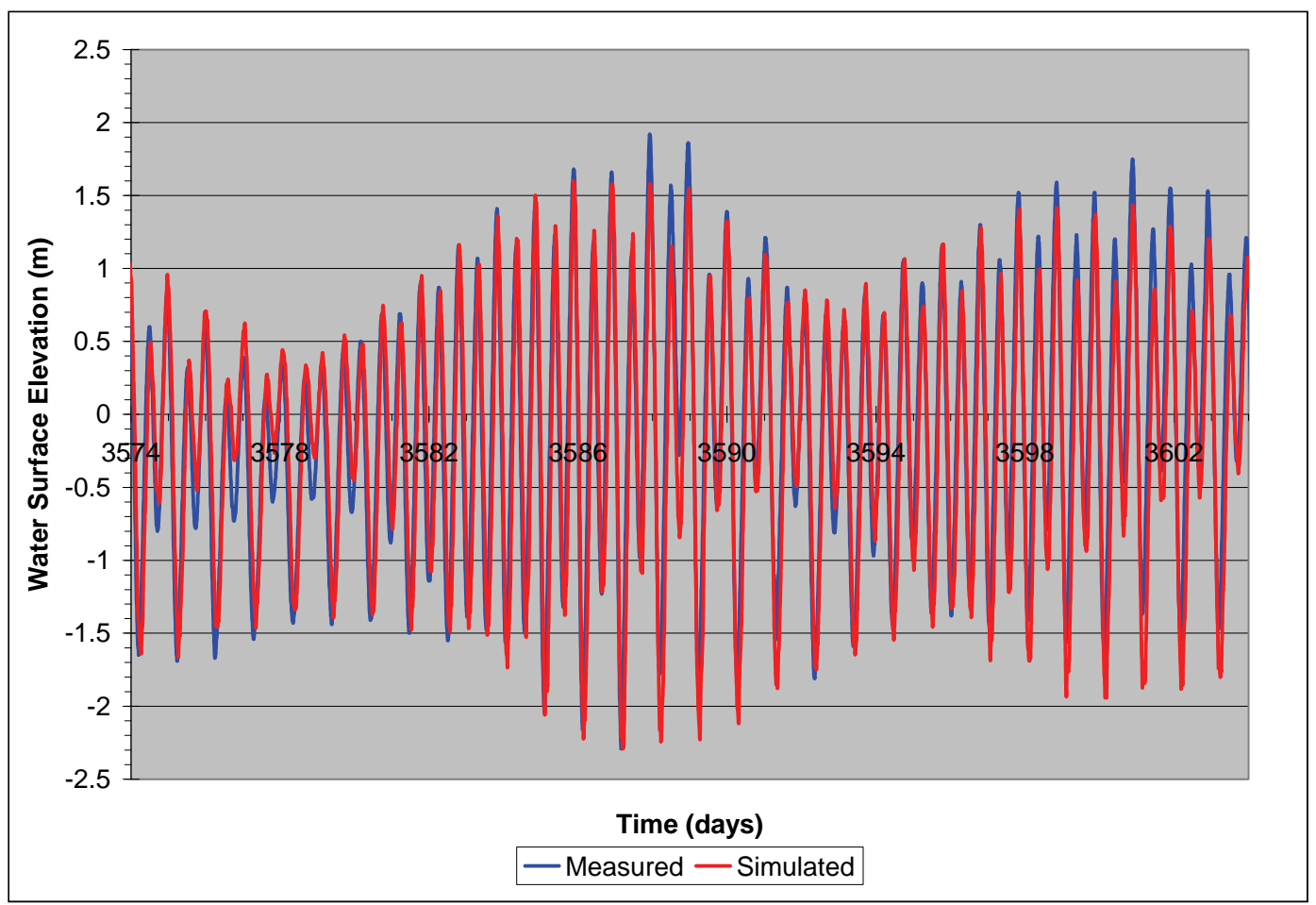

Figure 9-14. Comparison of measured and simulated tides at Tide Station \#2 during validation period. Day 0 corresponds to 01 Jan 1990. 


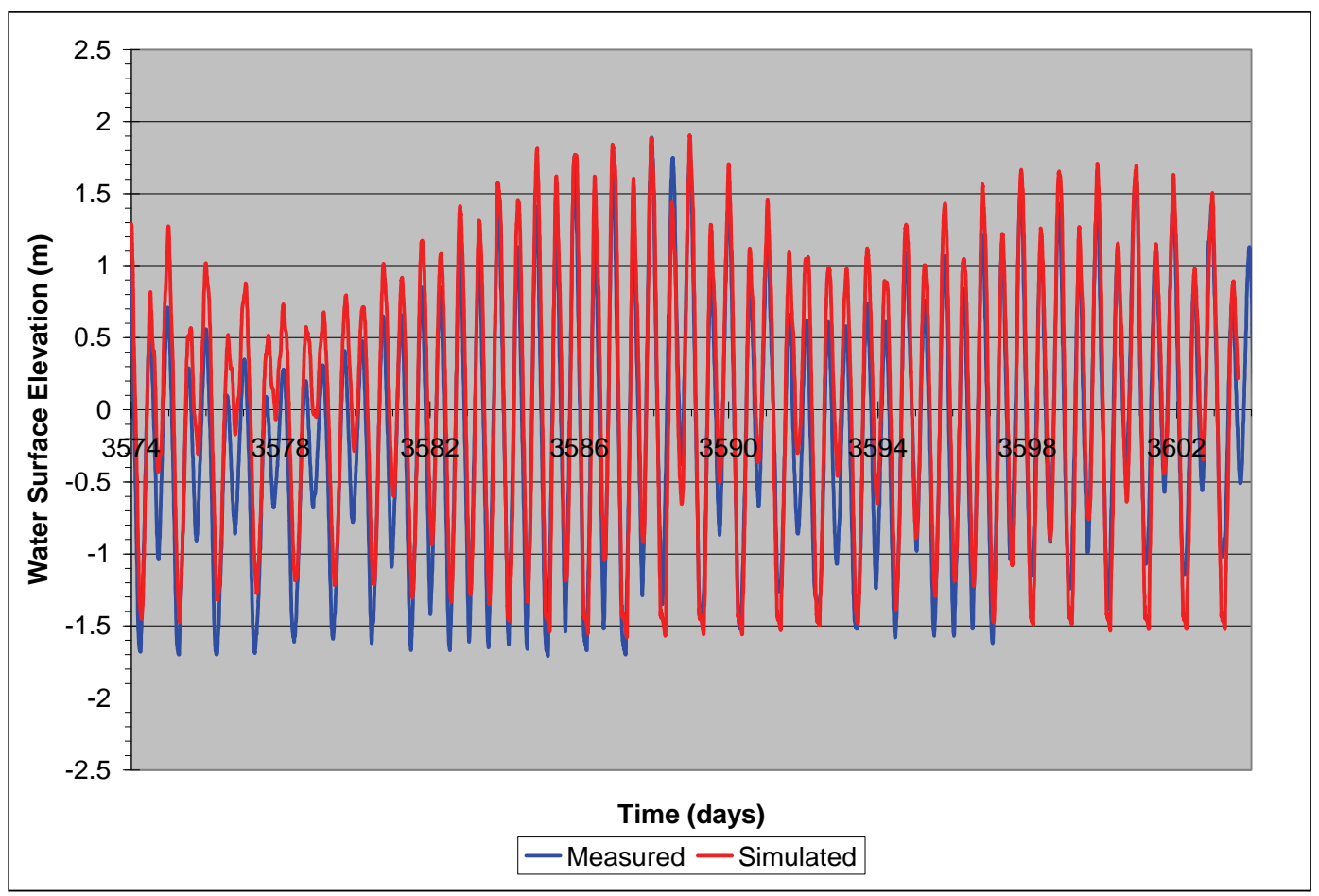

Figure 9-15. Comparison of measured and simulated tides at Tide Station \#3 during validation period. Day 0 corresponds to 01 Jan 1990.

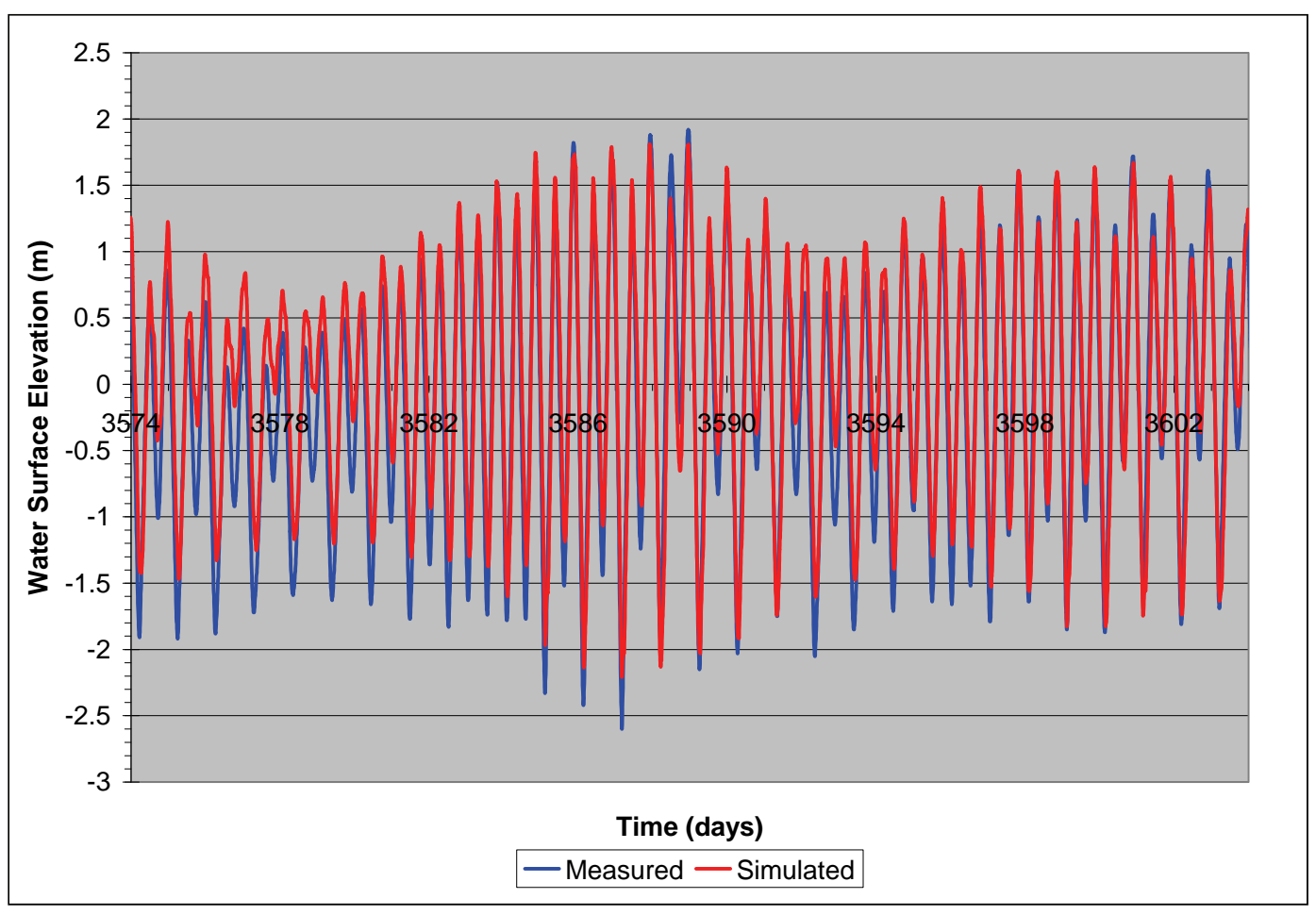

Figure 9-16. Comparison of measured and simulated tides at Tide Station \#4 during validation period. Day 0 corresponds to 01 Jan 1990. 


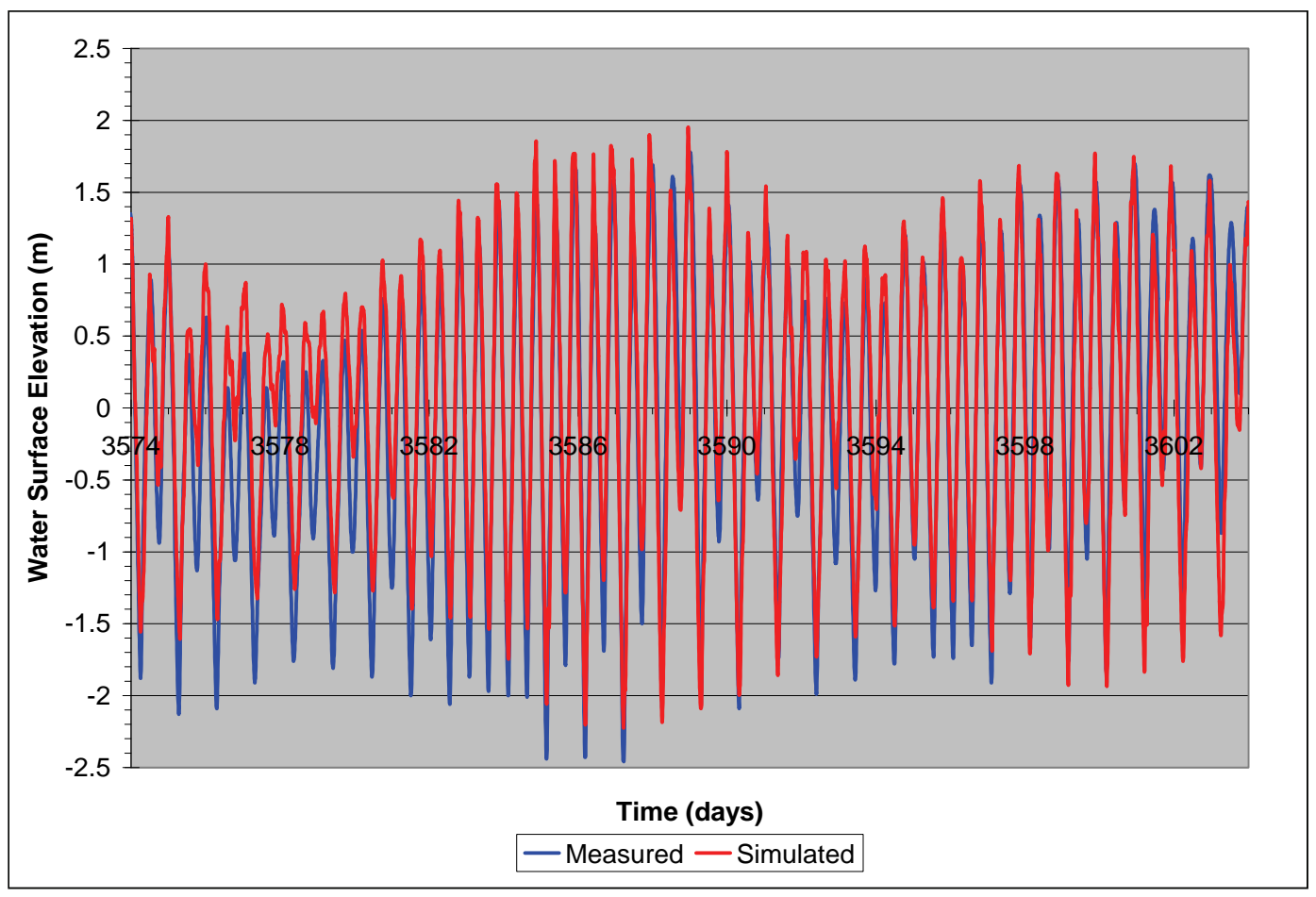

Figure 9-17. Comparison of measured and simulated tides at Tide Station \#5 during validation period. Day 0 corresponds to 01 Jan 1990.

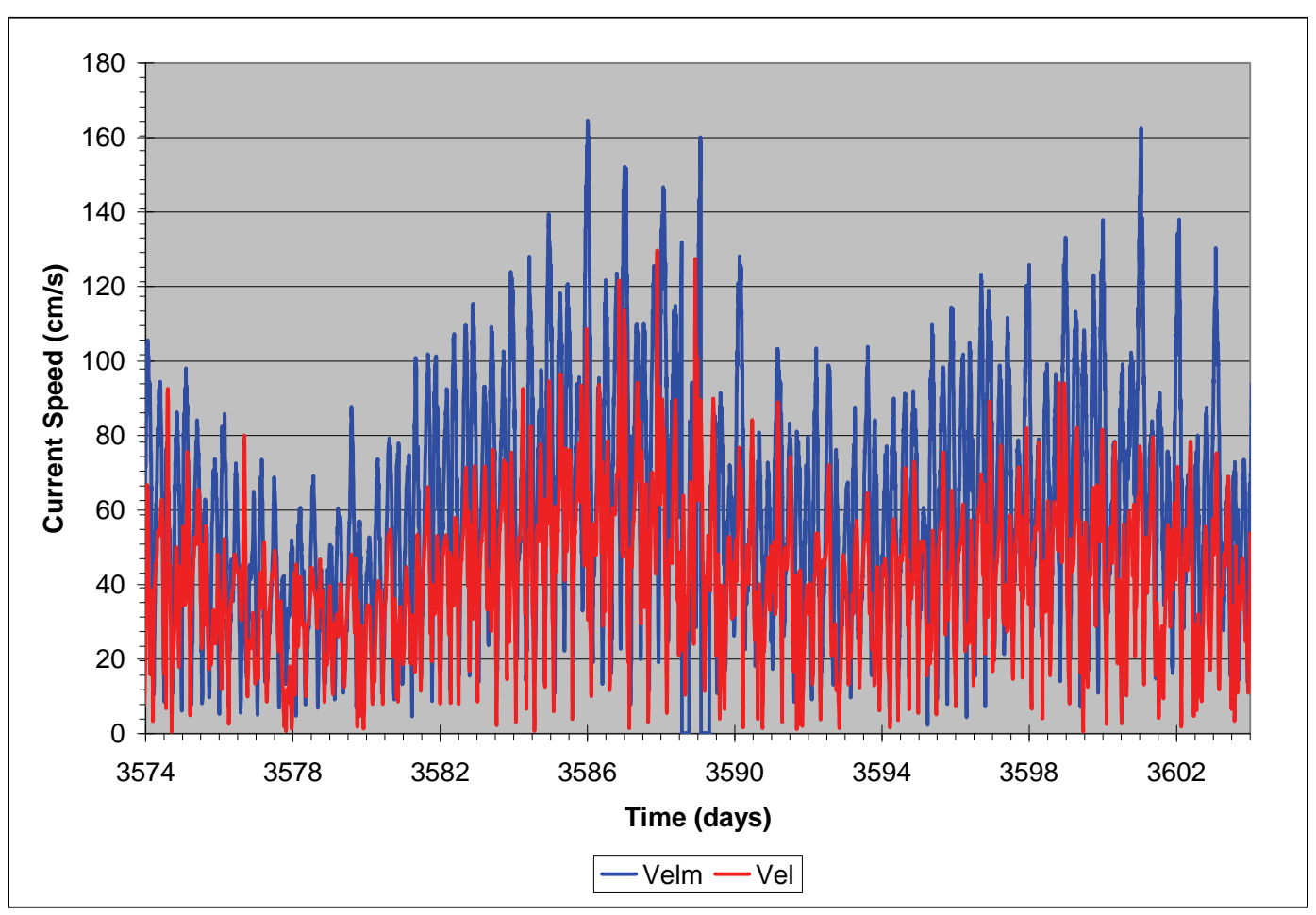

Figure 9-18. Comparison of measured and simulated currents at Current Station \#2 during validation period. Day 0 corresponds to 01 Jan 1990. 


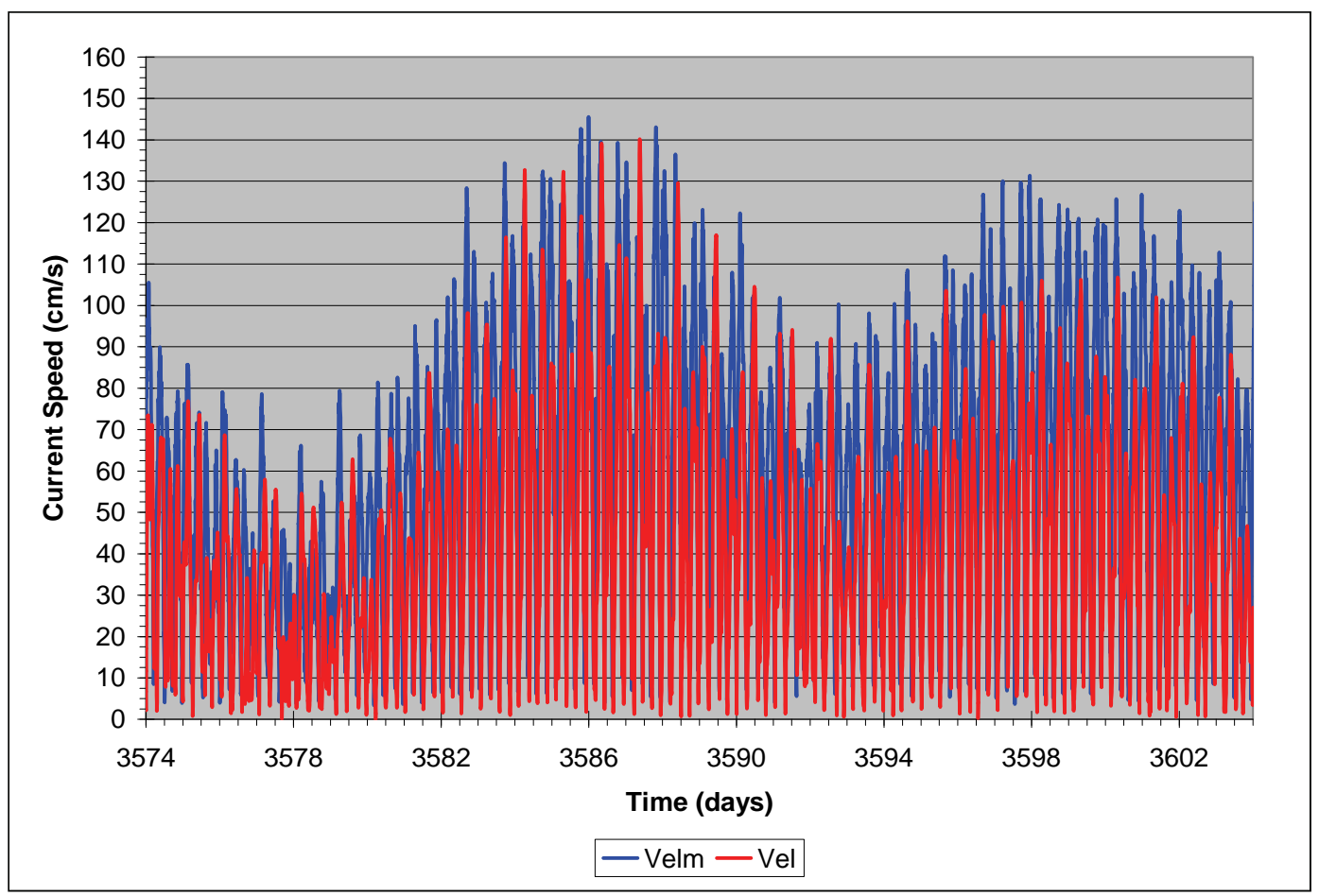

Figure 9-19. Comparison of measured and simulated currents at Current Station \#3 during validation period. Day 0 corresponds to 01 Jan 1990.

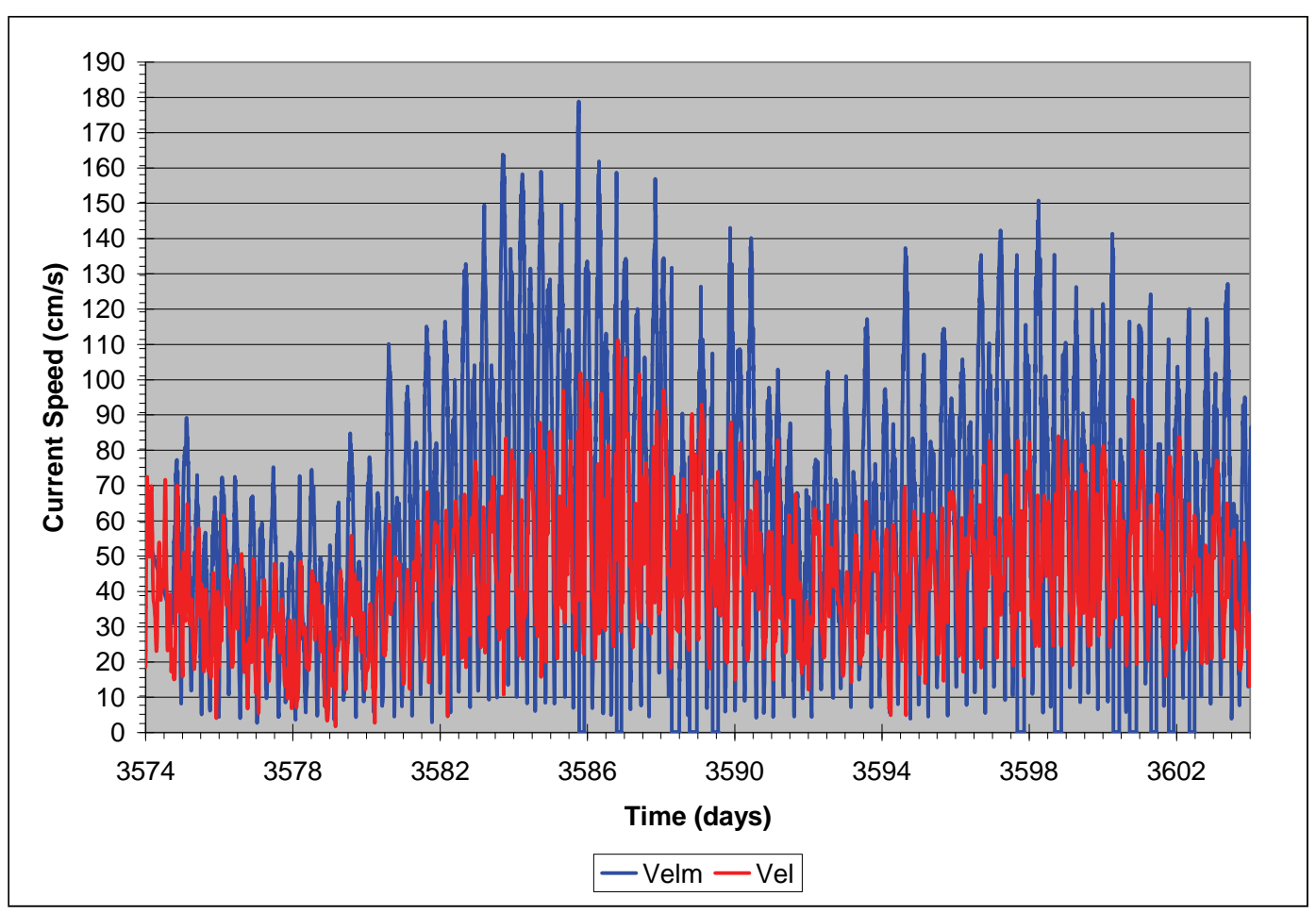

Figure 9-20. Comparison of measured and simulated currents at Current Station \#4 during validation period. Day 0 corresponds to 01 Jan 1990. 


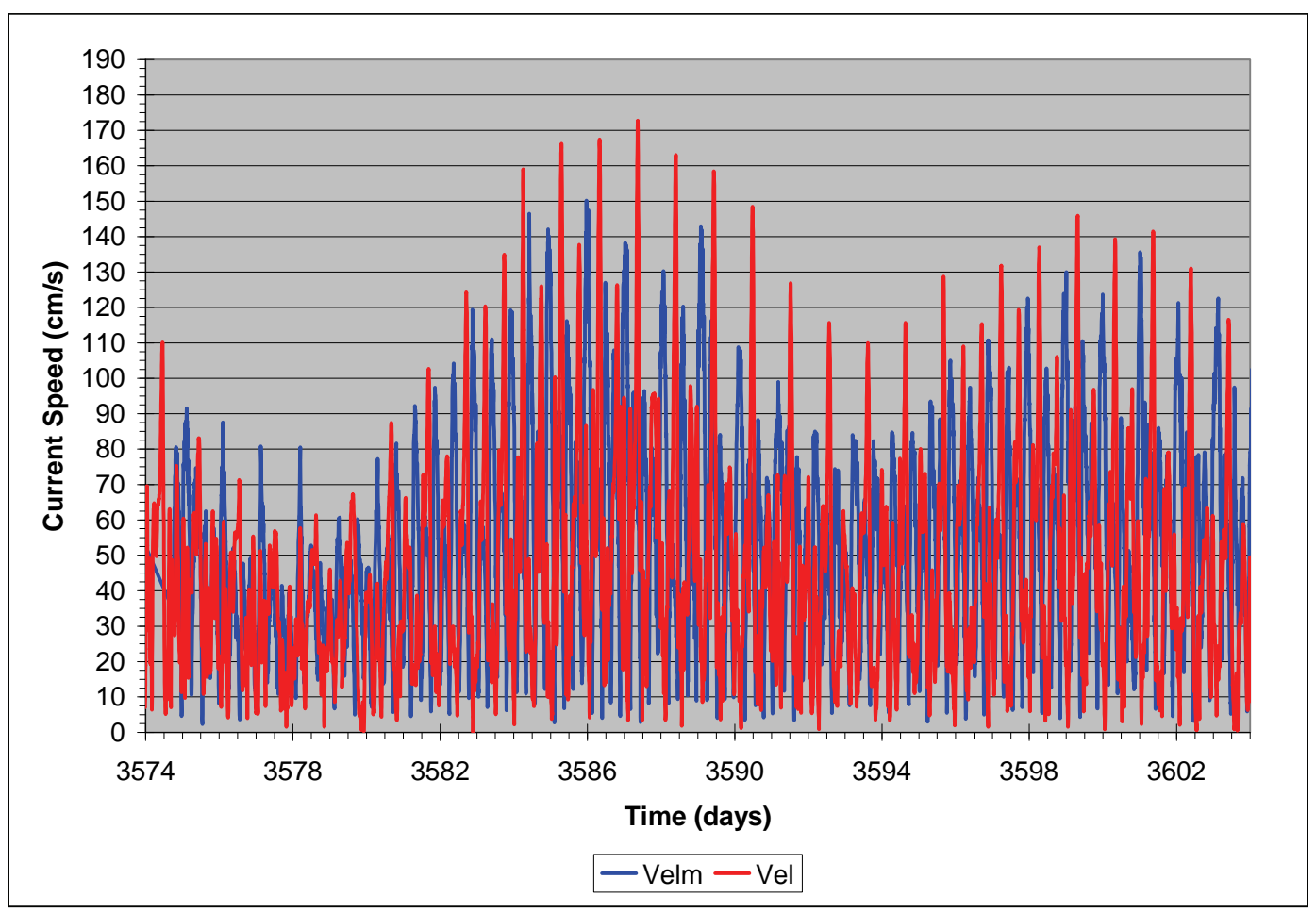

Figure 9-21. Comparison of measured and simulated currents at Current Station \#5 during validation period. Day 0 corresponds to 01 Jan 1990

\section{Sediment transport modeling}

\section{Model setup}

The SEDZIJ model was setup to simulate sediment transport in Grays Harbor using the following information:

- Mean settling velocities for flocs of $0.35 \mathrm{~mm} / \mathrm{s}$, and mean settling velocities of bed aggregates of $1.1 \mathrm{~mm} / \mathrm{s}$.

- Size distributions (\% Volume and \% Finer) for slurried Grays Harbor dredged material seen in Figure 8-6.

- Sedflume determined erosion rate versus bed shear stress given by Equation 8-16 and the critical shear stress for erosion versus bed density relationship given by Equation 8-9 and shown in Figure 8-9 for the representative dredged sediment sample for Cow Point Reach.

- The MPFATE simulated mound configurations at the three placement sites shown in Figures 7-1 through 7-3.

- The regions inside Grays Harbor where marine, river, and mixed marine and river sediments have deposited as reported by Scheidegger and Phipps (1976). Refer to Figure 3-9 in Kraus et al. (2003) for an adaptation of what appears in Scheidegger and Phipps (1976). 
- Grain size distributions at multiple locations inside and at the mouth of Grays Harbor, the lower Chehalis River, and offshore locations reported by SAIC (2007) and SAIC (2009). These distributions were used to determine the initial composition of the marine, river, mixed marine and river sediments that were used in cold starts of the SEDZLJ model.

Based on an analysis of all these data, it was decided that six sediment grain sizes were needed to adequately represent the wide range of sediment from clay to gravel. The diameters of the six sediment size classes used are 10, 22, 222 (fine sand), 375 (medium sand), 750 (coarse sand), and 4,000 $\mu \mathrm{m}$ (fine to very fine gravel). It was assumed that the specific gravity of all six size classes was 2.65. The $10 \mu \mathrm{m}$ size class was used to represent the flocs whose settling speeds were measured in the PICs experiment, whereas the $22 \mu \mathrm{m}$ size class was used to represent the bed aggregates eroded in the Sedflume experiments using the representative Grays Harbor dredged material. These two cohesive size classes are used to represent the erosion, transport and settling of the fine-grain sediment deposited at the three placement sites. They are not treated as individual sediment particles with the specified diameters. In fact, the specified diameters for these two cohesive size classes are not used in SEDZLJ. The gravel size sediment was needed to represent the range of noncohesive sediment found by SAIC (2009) in the lower Chehalis River.

Based on the size distributions (\%Volume and \% Finer) for the slurried Grays Harbor dredged material, three sediment size classes (22, 222 and $375 \mu \mathrm{m}$ ) were used to represent the placement material in the mounds at the three placement sites. To be able to determine the fate of the sediment eroded from each placement site, nine additional sediment size classes were used - three each for each placement site. So a total of 15 sediment size classes were used in the SEDZLJ modeling. Using such a large number of size classes greatly increased the computer run times for all eight model runs but was necessary to achieve one of the project objectives of determining how much of the sediment eroded from each of the placement sites deposited in the navigation channel for both the existing and proposed realigned channel configurations.

Using the available grain size distribution data, eight different sediment compositions were used to represent the various sediment types with spatially varying composition in the Grays Harbor model domain. One of 
the specify sediment compositions is assigned to each grid cell. The eight sediment compositions are the following: offshore, marine, mixed marine and river, river, Chehalis River, the Half Moon Bay placement site, the South J etty placement site, and the Point Chehalis placement site. The grain size distributions for these eight sediment types are shown in Table 9-1. Each number in this table represents the percentage of each of the 15 sediment size classes in each sediment type. The grain size distributions for the three placement sites were determined from the grain size distributions of the composited sediment cores that were tested using Sedflume.

Table 9-1. Sediment Composition of the Eight Sedflume Cores.

\begin{tabular}{|l|l|l|l|l|l|l|l|l|l|l|l|l|l|l|l|}
\hline & \multicolumn{9}{|c|}{ Sediment Diameter $(\mu \mathrm{m})$} \\
\cline { 2 - 13 } & 10 & 22 & 222 & 375 & 750 & 4000 & 22 & 222 & 375 & 22 & 222 & 375 & 22 & 222 & 375 \\
\hline $\begin{array}{l}\text { Redflume Corine } \\
\text { Sediments }\end{array}$ & 13 & 57 & 24 & 5 & 1 & & & & & & & & & & \\
\hline $\begin{array}{l}\text { Mixed Riverine } \\
\text { and Marine } \\
\text { Sediments }\end{array}$ & 6 & 28 & 62 & 3 & 1 & & & & & & & & & & \\
\hline $\begin{array}{l}\text { Marine } \\
\text { Sediments }\end{array}$ & 1 & 1 & 80 & 15 & 2 & 1 & & & & & & & & & \\
\hline Pt. Chehalis & & & & & & & 66 & 29 & 5 & & & & & & \\
\hline South Jetty & & & & & & & & & & 66 & 29 & 5 & & & \\
\hline Half Moon Bay & & & & & & & & & & & & & 66 & 29 & 5 \\
\hline $\begin{array}{l}\text { Offshore } \\
\text { Sediments }\end{array}$ & 1 & 1 & 95 & 2 & 1 & & & & & & & & & & \\
\hline $\begin{array}{l}\text { Chehalis River } \\
\text { Sediments }\end{array}$ & & 53 & 7 & 1 & 22 & 17 & & & & & & & & & \\
\hline
\end{tabular}

Seven bed layers were used for each Sedflume core. The first (top) layer is the active layer through which depositing and eroding sediment passes. The second layer is the layer in which new sediment deposits are placed. This layer is subdivided into a user-specified number of sublayers that are used to represent consolidating fine-grain dominated sediment. The third through seventh bed layer are used to represent the existing sediment bed in each grid cell at the start of the model simulation. The grain size distribution in each bed layer in each Sedflume core was assumed to be the same, but the critical shear stress and bed density was increased for the lower layers for the cores in which cohesive sediment (i.e., clay and silt size sediment) made up at least 20 percent by mass of the sediment. 
A different procedure was used for the Sedflume cores that represented the Point Chehalis, South J etty and Half Moon Bay placement sites. Bed layers 3 through 5 were used to represent the placement material at these sites, whereas bed layers 6 and 7 were composed of marine sediments. As seen in the referenced figure in Kraus et al. (2003), marine sediments occupied the entire inlet mouth and outer bay regions of Grays Harbor.

The thicknesses of layers 3 through 5 in the grid cells that represented the three placement sites were calculated using the MPFATE calculated mound thickness in those cells shown in Figures 7-1 through 7-3. For example, if the mound thickness in a given LTFATE grid cell was $3.0 \mathrm{~m}$, the thickness of each of the three layers, i.e., layers 3 through 5, was set as $1.0 \mathrm{~m}$. Using multiple bed layers to represent the mounds at the three placement sites allows the affect of overburden-induced primary consolidation of the deposited dredged material, as quantified by the Sedflume analysis of the composite core that was formed using sediment collected at sites CP-1, CP2 , CP-3, and CP-4, to be explicitly incorporated into the sediment transport modeling through the use of increasing bed densities and critical shear stresses for erosion in layers 4 and 5.

Because LTFATE was run in a depth-averaged mode, a Rouse profile was assumed for the vertical suspended sediment concentration profiles for all four noncohesive sediment size classes. This is a normal assumption that is made in modeling the transport of noncohesive sediments and represents the fact that the highest suspended sediment concentration occurs immediately above the bed. This nearbed concentration used in defining the Rouse profile was calculated for each noncohesive sediment size class in each grid cell at each timestep as a function of the settling velocity for that sediment size class, and the time-variable depth-averaged suspended sediment concentration, flow depth, and shear velocity. The deposition rate for each noncohesive sediment size class was calculated as the product of the nearbed concentration, the settling velocity, and the probability of deposition for noncohesive sediment.

No measurements of suspended sediment concentrations (SSC) or total suspended solids (TSS) have been made at the USGS gages in the Chehalis and Humptulips Rivers that were used in developing a discharge time series for these two rivers. As such, it was assumed that these rivers transported a constant $100 \mathrm{mg} / \mathrm{L}$ concentration of the two cohesive sediment size classes and the finest noncohesive sediment size class. 


\section{Model comparison}

The model calibration time period (14 October to 12 November 1999) was simulated using LTFATE for the purpose of comparing the suspended sediment concentrations measured by the two optical back scatter (OBS) meters at stations 1- 7 (see Figure 3-1) during the 1999 data collection program performed by Landerman et al. (2004) to the LTFATE simulated suspended sediment concentrations. Figures 9-22 through 9-28 show comparisons between the measured SSC and LTFATE simulated SSC at stations 1-7, respectively. The following six important points should be considered when reviewing the results presented in these figures:

1. The comparisons are not that good primarily due to the lack of detailed grain size distribution data over the spatial extent of the modeling domain (see Figure 9-1). This data limitation results in more uncertainty in the model results.

2. OBS response is sensitive to suspended particle size (Conner and deVisser, 1994). While the OBS from this study were calibrated to bed sediments collected near the deployment site, this doesn't guarantee that this is the size distribution in suspension. In general, a size distribution finer than the calibration material will result in an exaggerated (or overestimate) in OBS response. Given that the bed material is likely to be coarser than that in suspension, OBS calibration to bed material is likely to overestimate suspended sediment concentrations.

3. Some of the measured SSC values (determined from regression equations given by Landerman et al. 2004) showed that the higher OBS meter located $0.9 \mathrm{~m}$ above the bottom - measured a significantly higher SSC than thelower meter - located 0.3 m above the bottom (see Figures 9-24 through 9-28). These unexpected results were handled by ignoring the record from the higher OBS meter when those SSC values were higher than the SSC values from the lower meter.

4. Some of the SSC values reported by Landerman et al. (2004) were greater than $10 \mathrm{~g} / \mathrm{L}$, and some were even higher than $20 \mathrm{~g} / \mathrm{L}$ (see Figures 9-24, 927 and 9-28). Based on the measured current speeds at stations 1-7it is unlikely that the actual SSC values were this high as the flow would be non-Newtonian at this concentration. It is believed that these high conœentrations are the result of extrapolation of the reported regression equations. If this is true, then the extrapolated values are outside the range of SSC values that were used in development of the regression equations and are not accurate. 


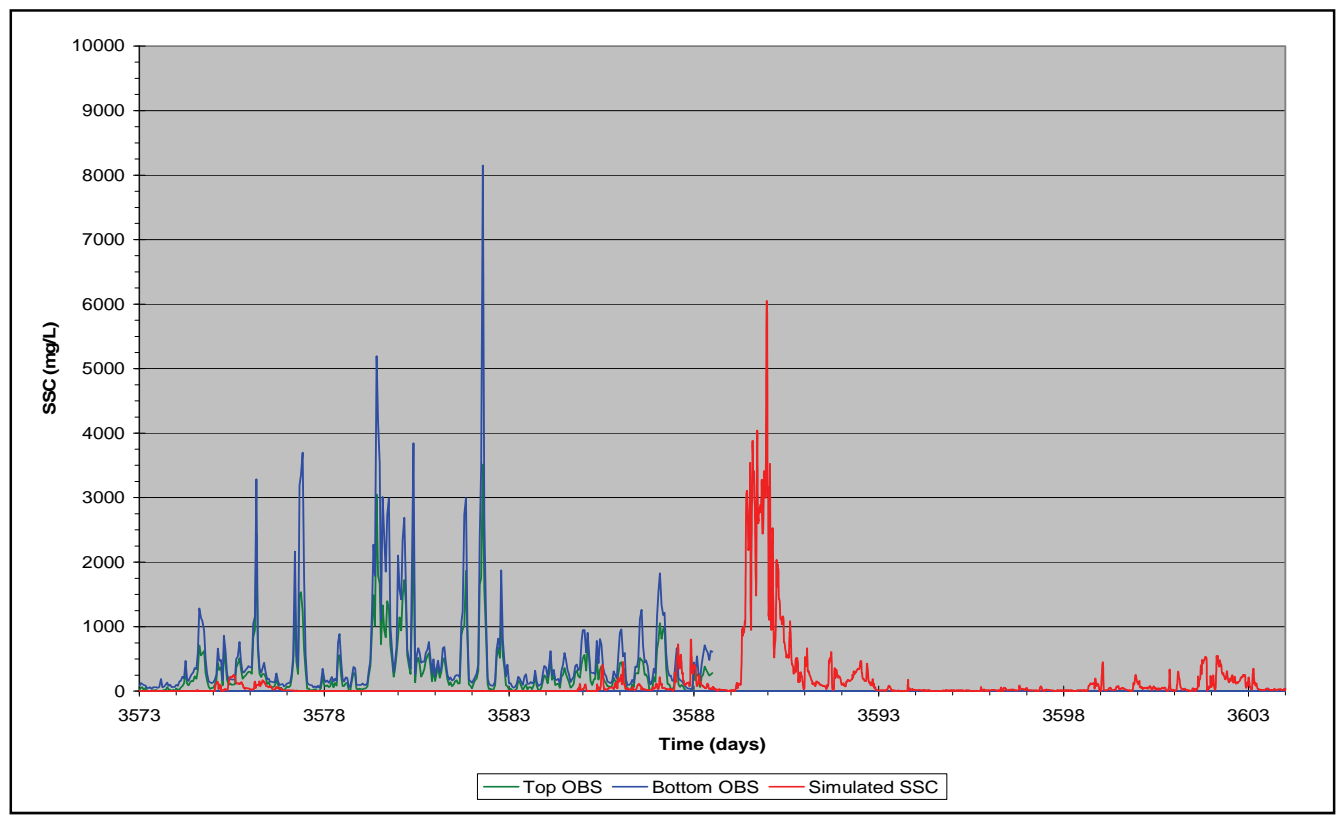

Figure 9-22. Comparison of measured and simulated SSC at Current Station \#1 during the calibration period. Day 0 corresponds to 01 Jan 1990.

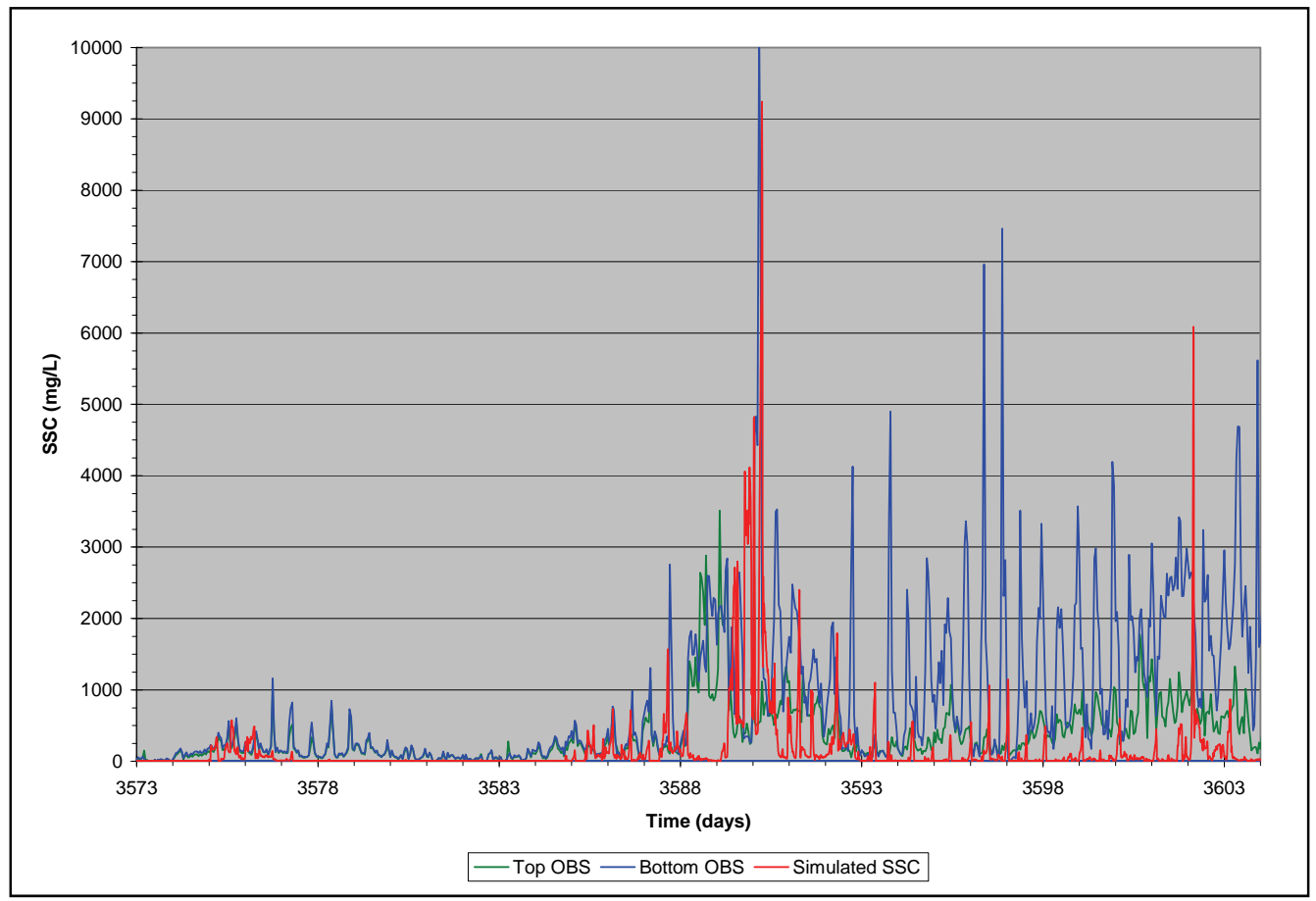

Figure 9-23. Comparison of measured and simulated SSC at Current Station \#2 during the calibration period. Day 0 corresponds to 01 Jan 1990. 


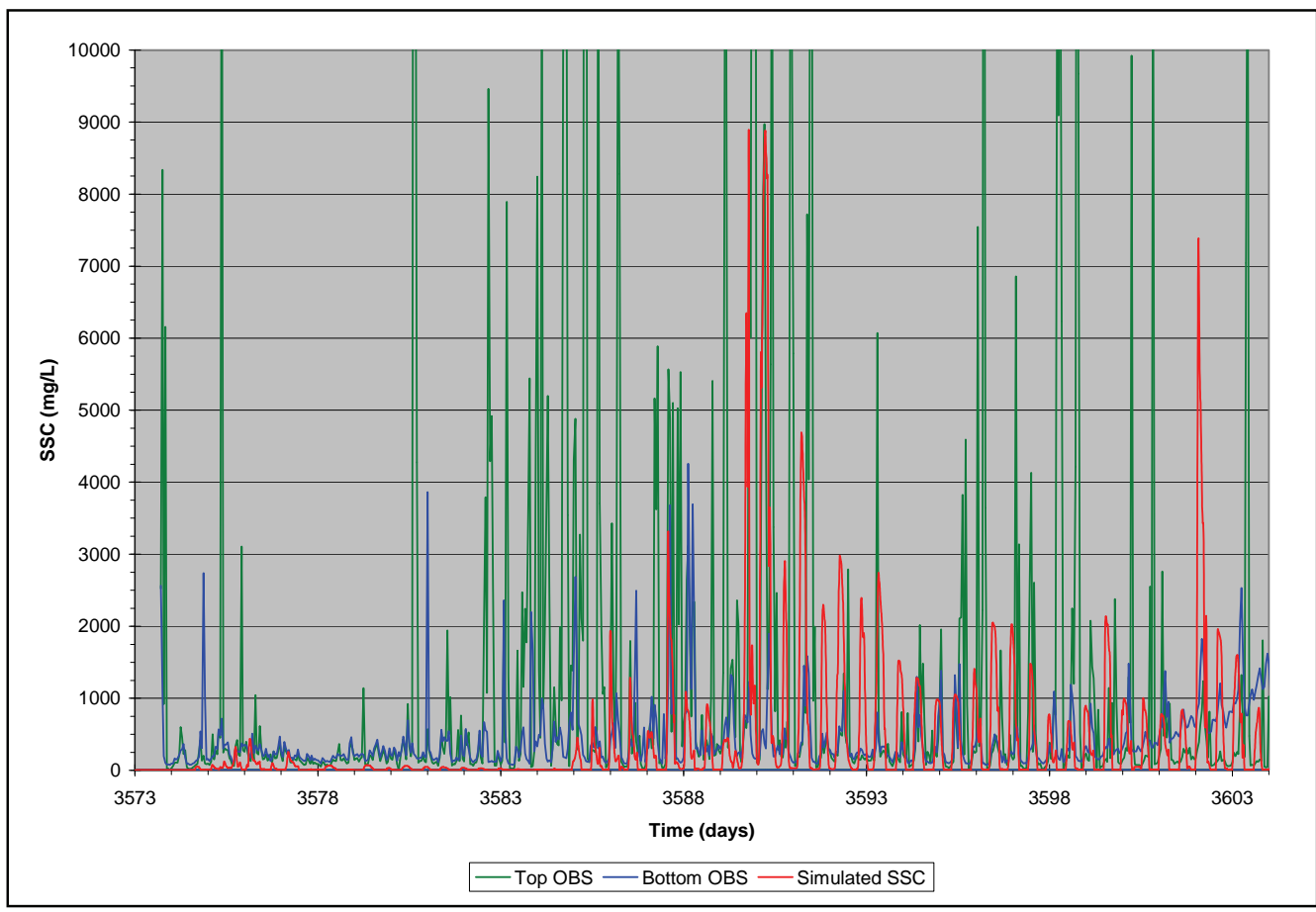

Figure 9-24. Comparison of measured and simulated SSC at Current Station \#3 during the calibration period. Day 0 corresponds to 01 Jan 1990.

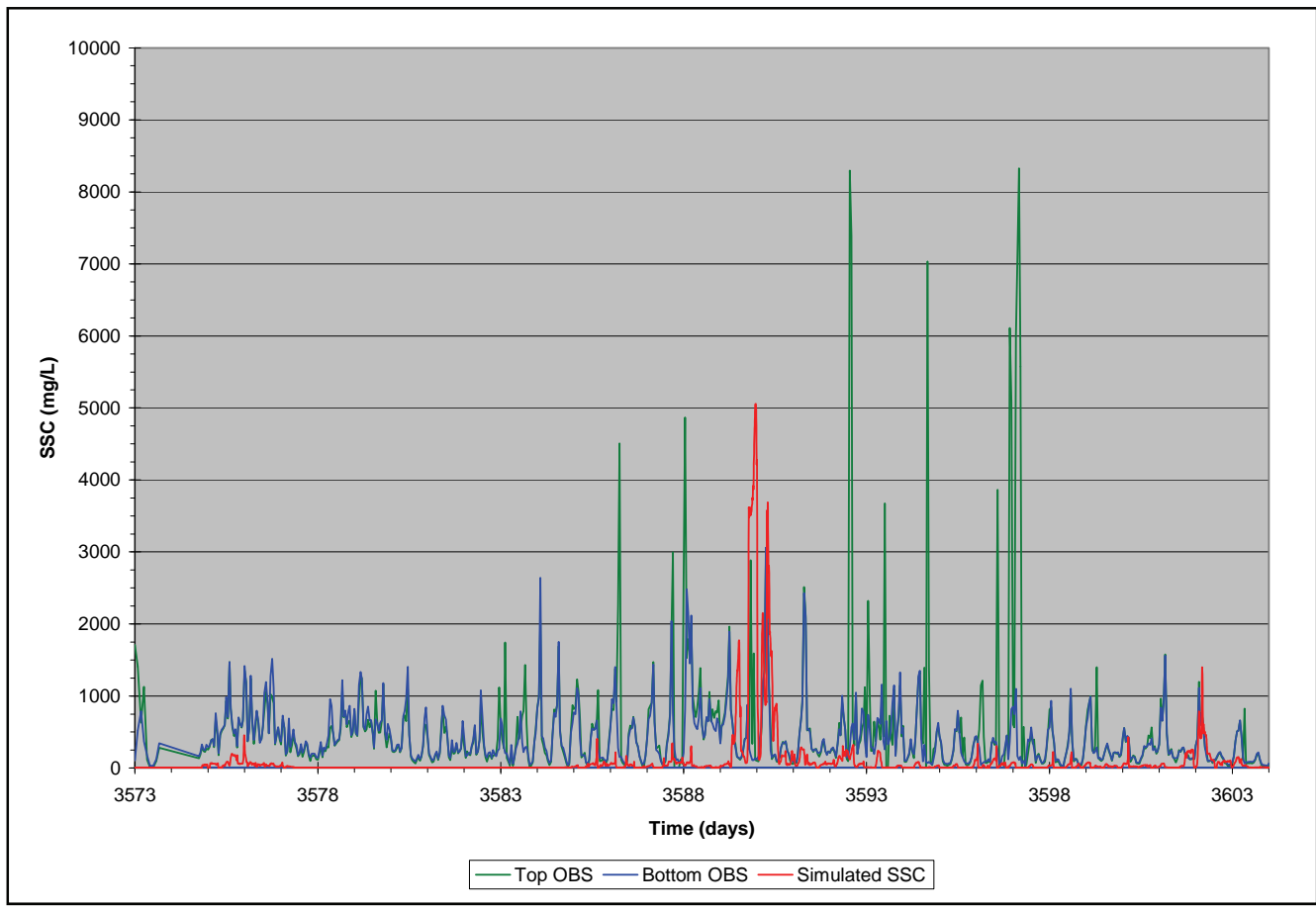

Figure 9-25. Comparison of measured and simulated SSC at Current Station \#4 during the calibration period. Day 0 corresponds to 01 Jan 1990. 


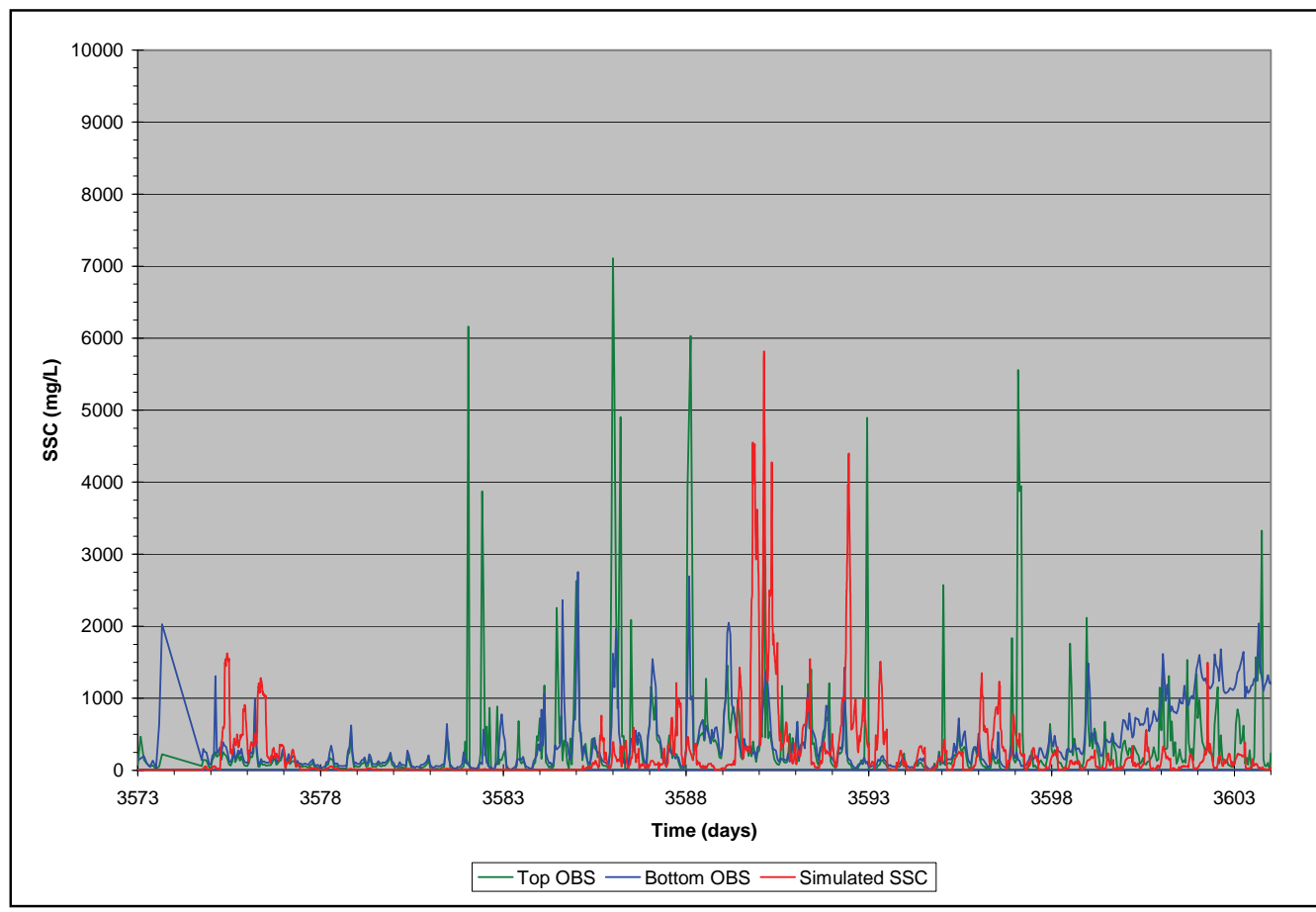

Figure 9-26. Comparison of measured and simulated SSC at Current Station \#5 during the calibration period. Day 0 corresponds to 01 Jan 1990.

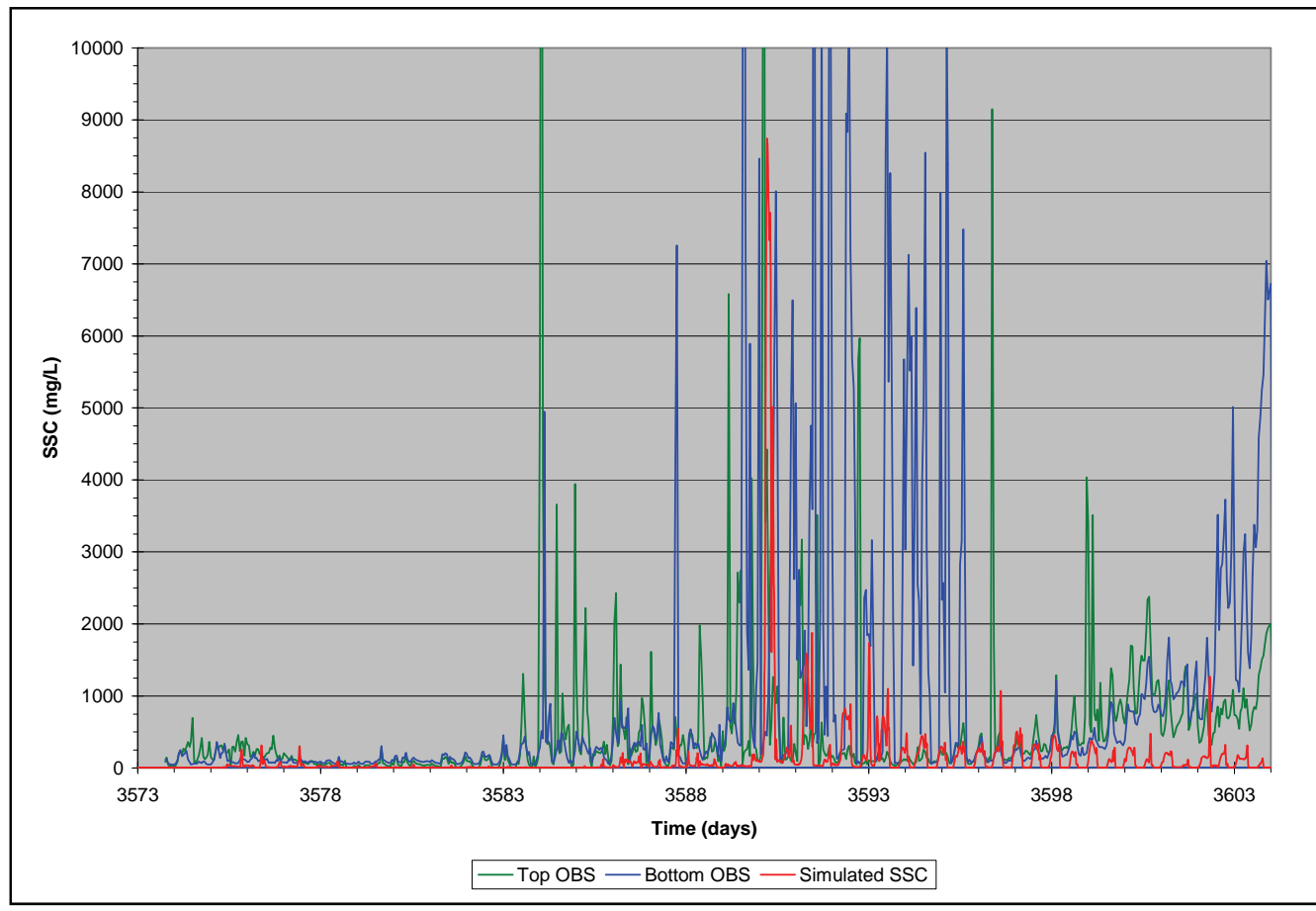

Figure 9-27. Comparison of measured and simulated SSC at Current Station \#6 during the calibration period. Day 0 corresponds to 01 Jan 1990. 


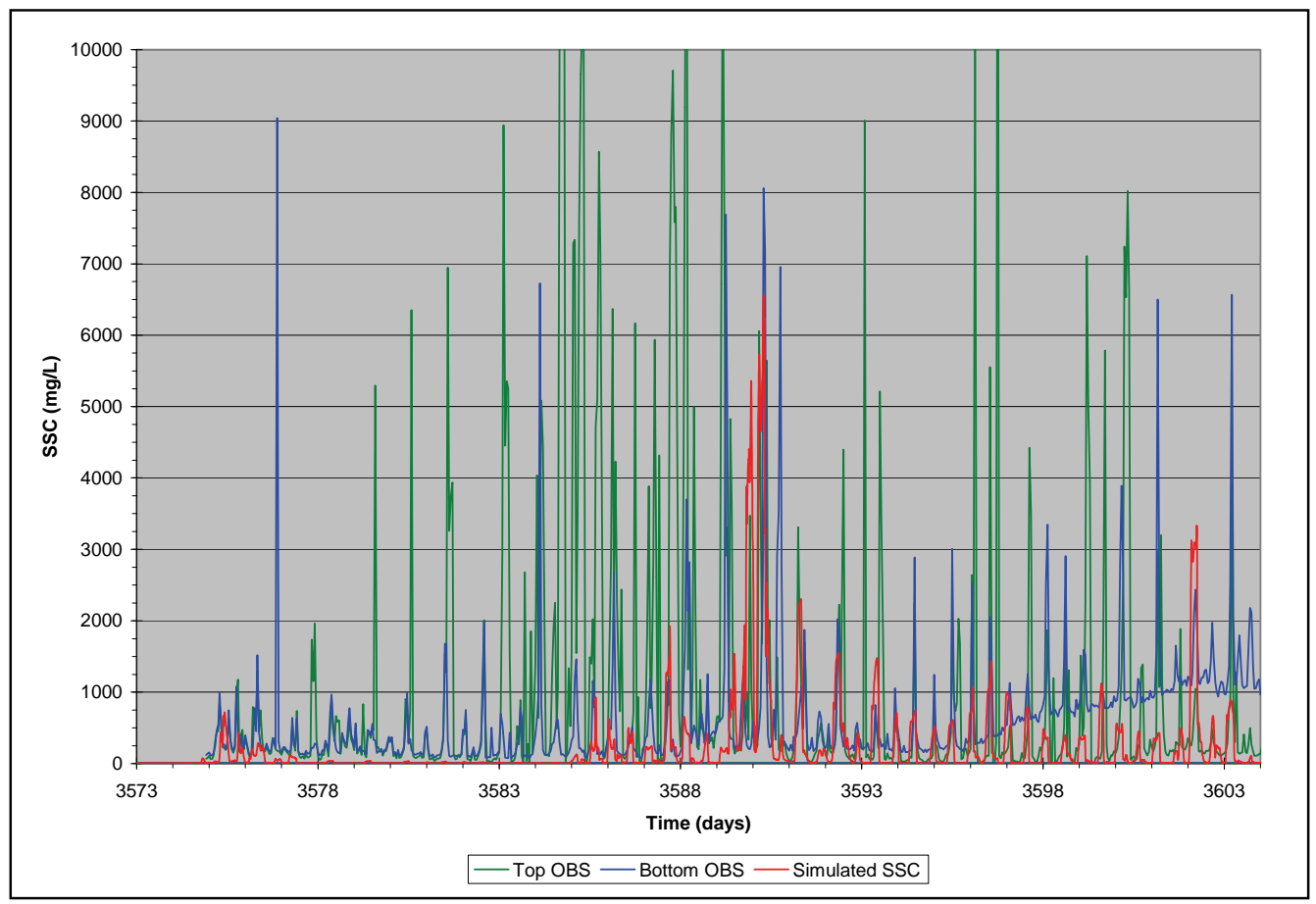

Figure 9-28. Comparison of measured and simulated SSC at Current Station \#7 during the calibration period. Day 0 corresponds to 01 Jan 1990.

5. No calibration of the sediment transport model was performed because of insufficient data to perform such a calibration. In addition to the lack of detailed grain size distribution data mentioned above, measurement of the SSC profile over the entire water column over several tidal cycles would be needed at multiple locations in the model domain, specifically in proximity to the three dredged material placement sites, to perform a model calibration.

6. The model simulation shown in Figures 9-22 through 9-28 was the result of a hot start model run. Hot start in this context means the following: a) A spun-up salinity field was used to specify the depth-averaged salinity in every grid cell. b) The initial sediment distribution in every grid cell was a spun-up sediment bed that consisted of the sediment bed particle size distribution in every grid cell at the end of a cold start model run over the calibration period. The cold start model run began with the sediment distribution described in the last bullet in the Model Setup section. c) The hydrodynamic model was spun-up for one day before the sediment transport simulation was initiated. The use of a spun-up sediment bed resulted in much less sediment being moved as bedload and in suspension during the hot start model run because the sediment bed in most of the grid cells was at least partially armored at the end of cold start model run. Nevertheless, it is more realistic to use a spun-up bed when there is as 
significant a data gap in the grain size distribution as there is at Grays Harbor because the simulated physics of sediment transport during the cold start model run will result in a more realistic sediment distribution to use for sediment bed initial conditions for the hot-started model run described in this section as well as the eight model production runs described in the next section.

As such, the purpose of performing these comparisons was only to compare the magnitude of the peaks in the measured and simulated SSC as well as the times at which the SSC noticeably increased. Comments on all these figures are given below.

1. Notice that in Figure 9-22 the data only covers the first half of the model simulation during which there is essentially no agreement between model results and the measured data at this offshore station. The total lack of agreement is somewhat surprising, but not completely unexpected due to the data gap mentioned above as well as possible differences in bottom elevations at the location where the measurements were made and the bottom elevation in the grid cell where the instrument tripod was placed. Considering it is the furthest offshore station, less significance is placed on this comparison than that at the other six measurement locations.

2. Some agreement in timing of simulated and measured SSC increases is seen at Station \#2 (Figure 9-23), but as noted in Figure 9-22, less sediment was transported in suspension than measured. The relatively close agreement between the timing and magnitude of the SSC peak at day 3590 is noteworthy. The event on day 3590 is obviously the most energetic during the model calibration period, so the observed agreement during this event demonstrates at least in part that LTFATE, even with the data gap and lack of model calibration, is capable of approximately representing sediment transport during relatively high energy events (as was simulated in the four chosen periods described in Chapter 4) in Grays Harbor.

3. The comparison at Station \#3 as seen in Figure 9-24 is somewhat similar to that for Station \#2. However, the extremely high SSC calculated for the top OBS during many of the events when there are increases in sediment transport, makes this comparison more problematic. For the reason mentioned above, it is recommended that the comparison be made between the SSC calculated for the bottom OBS and the simulated SSC. SSC peaks at both the bottom OBS and during the model simulation are seen to occur at approximately the same time about half of the time, especially after day 3585. 
4. Other than during the event at day 3590 and a smaller event at day 3602 , there is no observed agreement seen in Figure 9-25 between the calculated SSC for the bottom OBS and the model simulated SSC seen at Station \#4.

5. More agreement in the occurrences of SSC peaks is seen in Figure 9-26 at Station \#5 than that at Station \#4. The cause of the more-or-less monotonic increase in the SSC measured at the bottom OBSfrom day 3598 to 3603 at this station as well as at Stations \#6 and \#7 is unknown.

6. Limited agreement is seen in Figure 9-27 between the measured and simulated SSC is seen to occur during days 3590, 3593 and 3602 at Station \#6.

7. Overall more agreement is seen in Figure 9-28 to occur between the measured and simulated SSC at Station \#7 than that at Station \#6.

\section{Model results}

The LTFATE model was used to simulate the four hydrodynamic events using the existing navigation channel as well as the realigned navigation channel. LTFATE was run in the morphologic mode, which means that simulated changes in the bed elevation due to erosion or deposition in each grid cell was used to update the flow field during the next time step. The output from each of these eight simulations was processed to determine the percentage of the initial total mass of dredged placement sediment that erodes (see Table 9-2). Results from the model simulations were postprocessed to calculate the percentage of sediment that eroded from the three placement sites and deposited in one of the following four reaches of the Grays Harbor navigation channel: Entrance channel, Pt. Chehalis reach, South reach, and Crossover reach. These navigation channel reaches are shown in Figure 1 in Hericks and Simpson (2000) and in Figure 9-29, which is a reproduction of NOAA Chart 18502-11-1996 that was downloaded from the Office of Coast Survey Historical Map \& Chart Project web site (http://historicalcharts.noaa.gov/historicals/historical_zoom.asp).

Because the grid cells are not perfectly aligned with all of the navigation reaches, the deposited sediment masses used to calculate the percentages shown in the following set of figures are not exact, as the sum of the area of the cells that were used to calculate the results for each channel reach are not exactly equal to the projected horizontal area of each reach. Nevertheless, the results given in these figures are reasonable estimations of the percentage of eroded sediment from the placement sites that deposit in the specified navigation channel reaches. 
Table 9-2. Percentage of Dredged Placement Sediment that Eroded from Placement Sites.

\begin{tabular}{|l|l|l|}
\hline \multirow{2}{*}{$\begin{array}{l}\text { Placement Site } \\
\text { Event }\end{array}$} & Existing Conditions & Realigned Channel \\
\cline { 2 - 3 } & \% Eroded Mass & \% Eroded Mass \\
\hline Pt Chehalis & 6 & \\
\hline 1993-Q2 & 18 & 2 \\
\hline 2006-Q4 & 53 & 7 \\
\hline 1998-Q4 & 13 & 7 \\
\hline South Jetty & & 4 \\
\hline 1993-Q2 & 94 & \\
\hline $2006-Q 4$ & 100 & 90 \\
\hline 1998-Q4 & 100 & 100 \\
\hline 1990-Extreme & 97 & 100 \\
\hline Half Moon Bay & & 97 \\
\hline 1993-Q2 & 80 & \\
\hline 2006-Q4 & 97 & 60 \\
\hline 1998-Q4 & 100 & 97 \\
\hline 1990-Extreme & 95 & 97 \\
\hline & & 95 \\
\hline
\end{tabular}

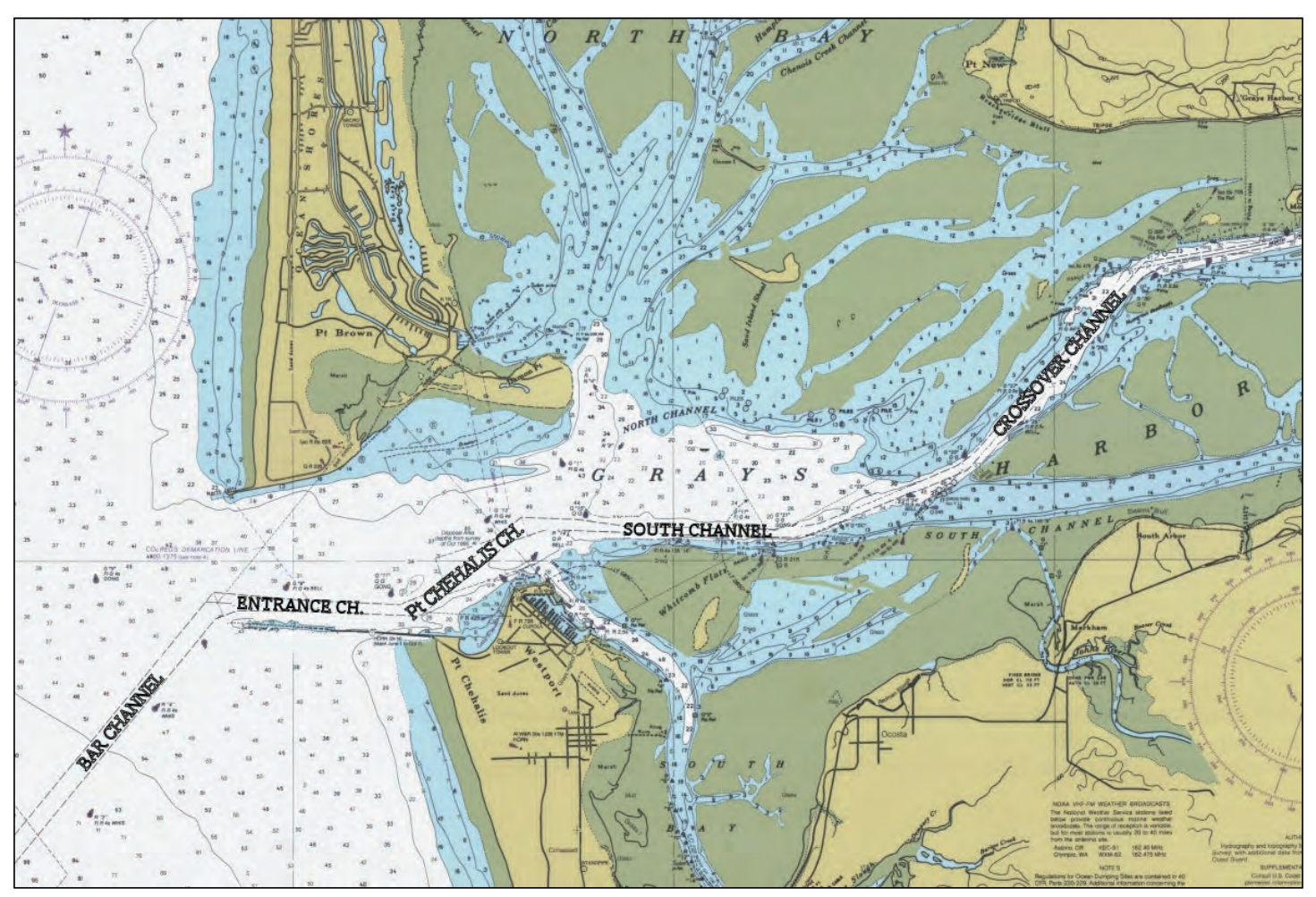

Figure 9-29. Nautical Chart 18502-11-1996 of Grays Harbor (NOAA, 1996). 
Figures 9-30 and 9-31 show bar graphs of simulation results for the Pt Chehalis placement site for both the existing condition (Figure 9-30) and the realigned condition (Figure 9-31) for the 0.5 year event (1993 second quarter) in the top panel, for the 2 year event (2006 fourth quarter) in the second panel, for the 5 year event (1998 fourth quarter) in the third panel, and for the extreme event (J an-Feb 1990) in the bottom panel, respectively. The ordinate shows the ratio (percentage) of sediment mass of each of the three sediment size classes that eroded from this placement site that subsequently deposited in the navigation channel reach specified along the abscissa to the total sediment mass that eroded from the placement site. The total bar to the right of the $375 \mu \mathrm{m}$ bar represents the sum of the three percentages for each channel reach. The fifth column (Total) represents the sum of eroded material deposited in the four channel reaches.

Figures 9-32 and 9-33 and Figures 9-34 and 9-35 present the same results for the South J etty and Half Moon Bay placement sites, respectively. Note that the scale of the ordinate in Figures 9-30 and 9-31 is different than that in Figures 9-32 through 9-35.

\section{Discussion}

\section{Eroded dredged placed sediment}

Mass eroded from Pt Chehalis placement site (Table 9-2) is relatively sensitive to offshore wave conditions for the existing condition. The percentage of eroded mass increases with the return interval for the three quarterly simulations, representing 0.5-, 2-, and 5-year return intervals. Approximately double the amount of erosion occurred during the 24-day extreme event (1990) as occurred during the most frequent quarterly event. As seen in Table 9-2, very little dredged placed sediment eroded from the Pt Chehalis placement site for the realigned channel configuration.

The results shown in Table 9-2 for the South J etty placement site indicate that the vast majority of the placed sediment was eroded during the simulated events for both the existing and realigned channel configurations. For the Half Moon Bay placement site, the results also show that the vast majority of the placed sediment was eroded during the three largest events, whereas 20 percent less sediment was eroded with the realigned channel configuration than with the existing channel configuration. 


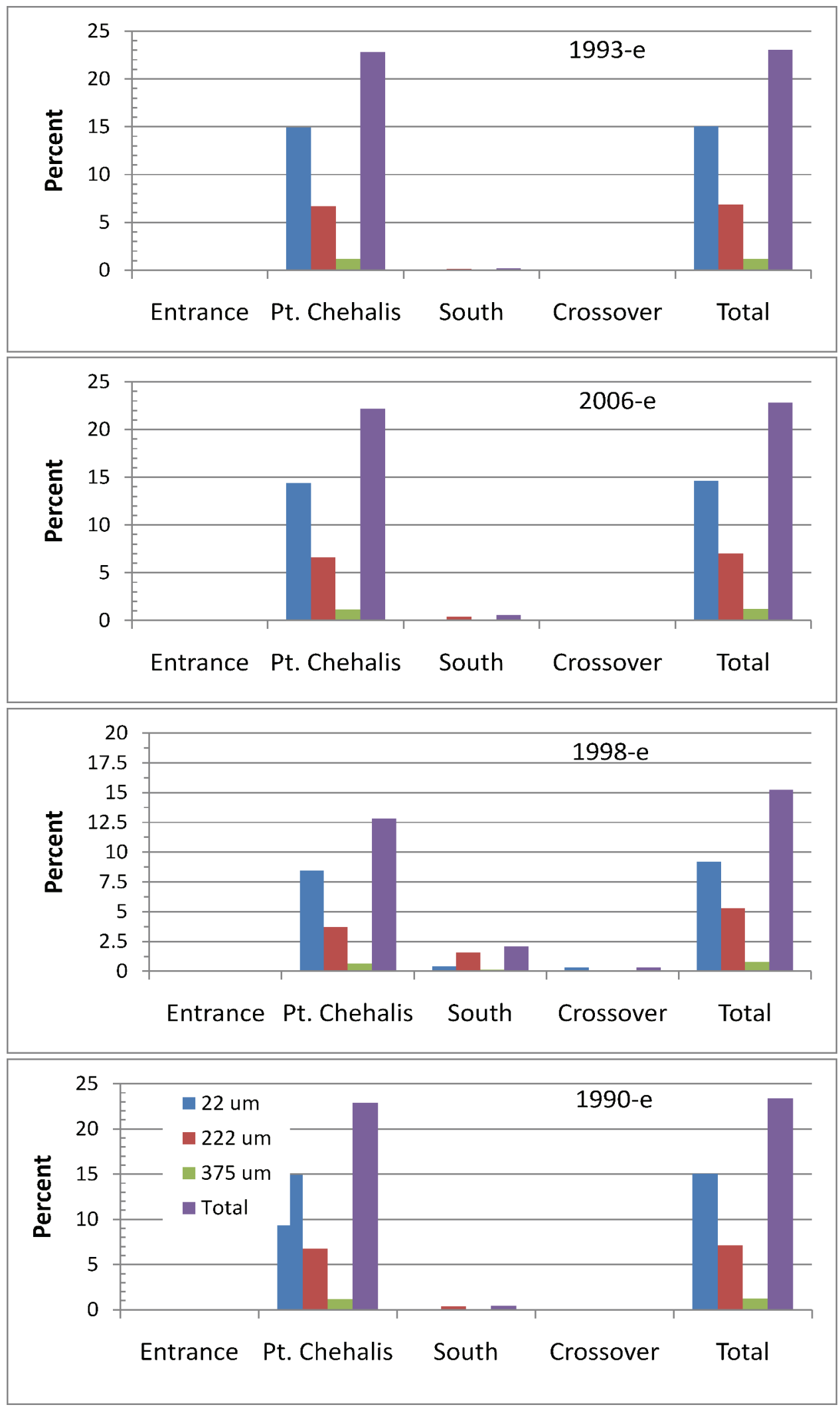

Figure 9-30. Percentage of sediment eroded from Pt Chehalis placement site with existing conditions that deposits in selected channel reaches for: a) 1993 event, b) 2006 event, c) 1998 event, and d) 1990 event. 


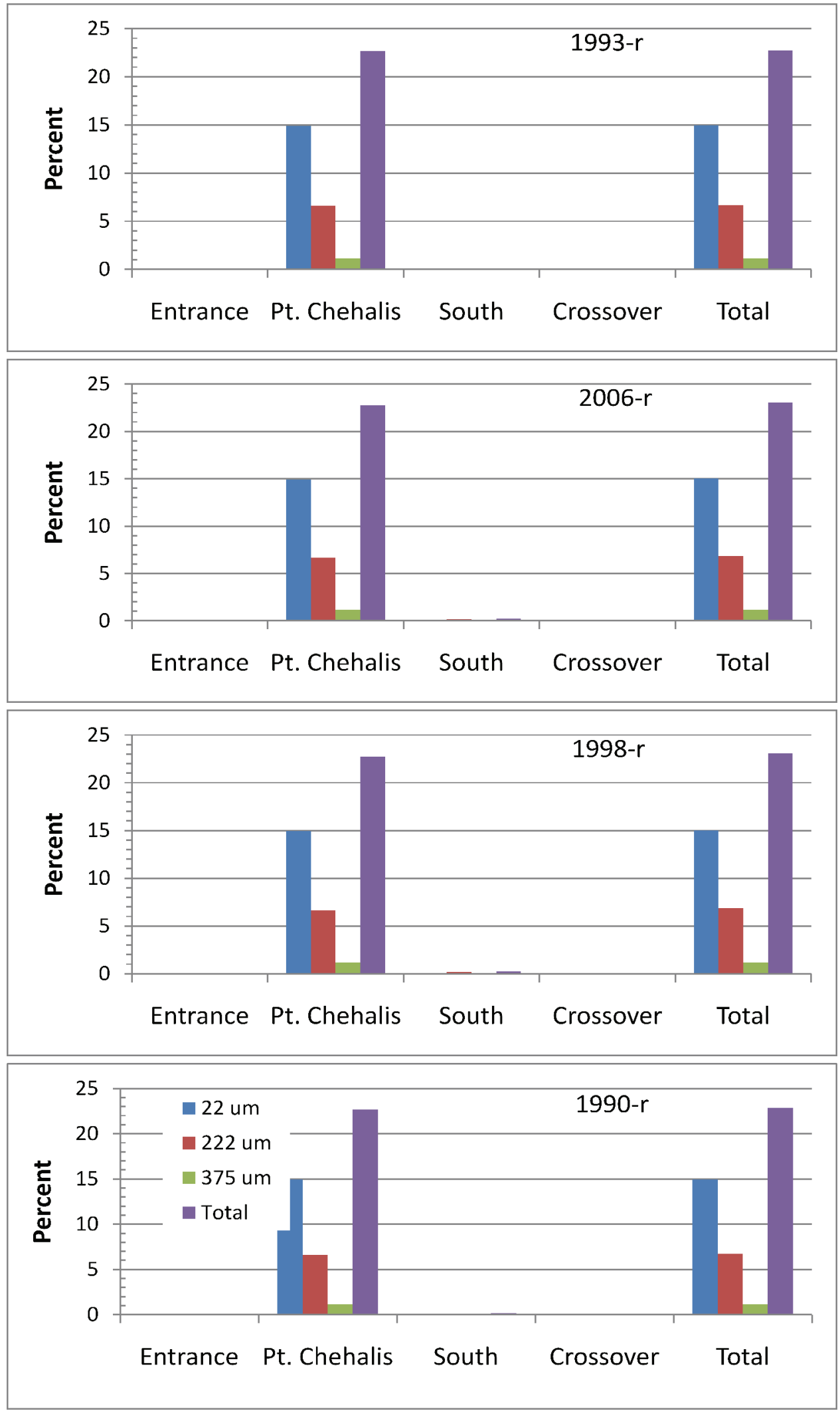

Figure 9-31. Percentage of sediment eroded from Pt Chehalis placement site with realigned channel that deposits in selected channel reaches for: a) 1993 event, b) 2006 event, c) 1998 event, and d) 1990 event. 


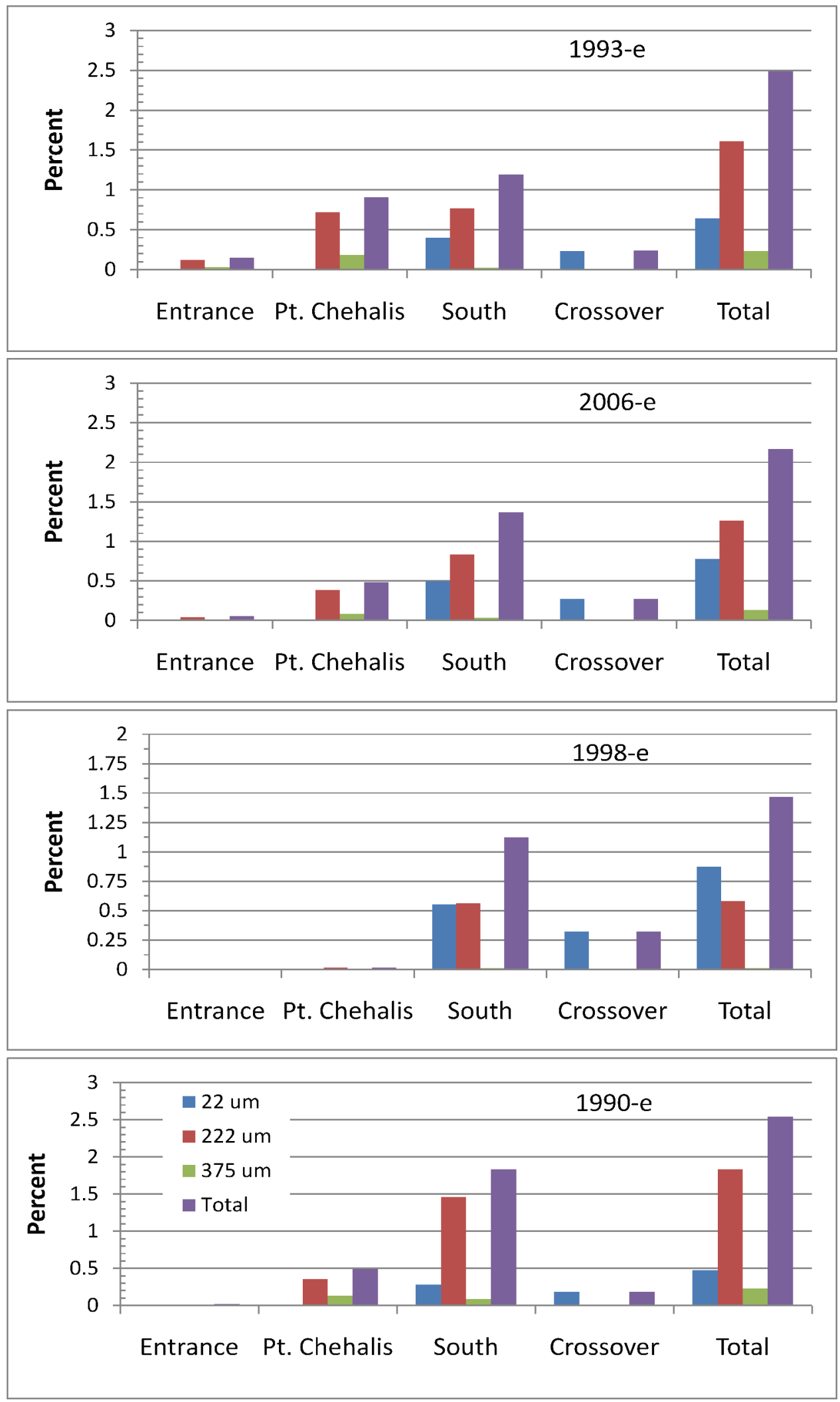

Figure 9-32. Percentage of sediment eroded from South Jetty placement site with existing conditions that deposits in selected channel reaches for: a) 1993 event, b) 2006 event, c) 1998 event, and d) 1990 event. 

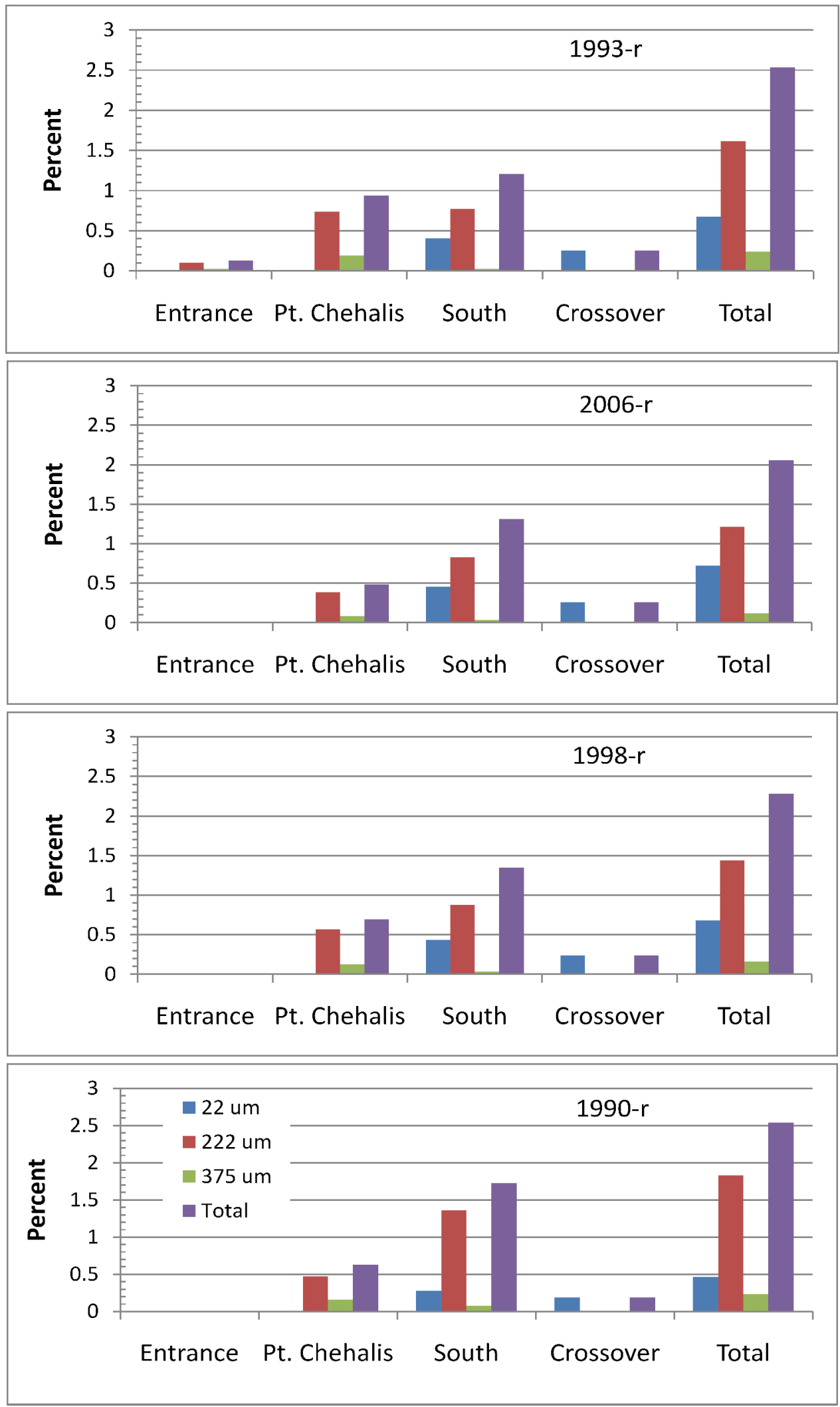

Figure 9-33. Percentage of sediment eroded from South Jetty placement site with realigned channel that deposits in selected channel reaches for: a) 1993 event,

b) 2006 event, c) 1998 event, and d) 1990 event. 


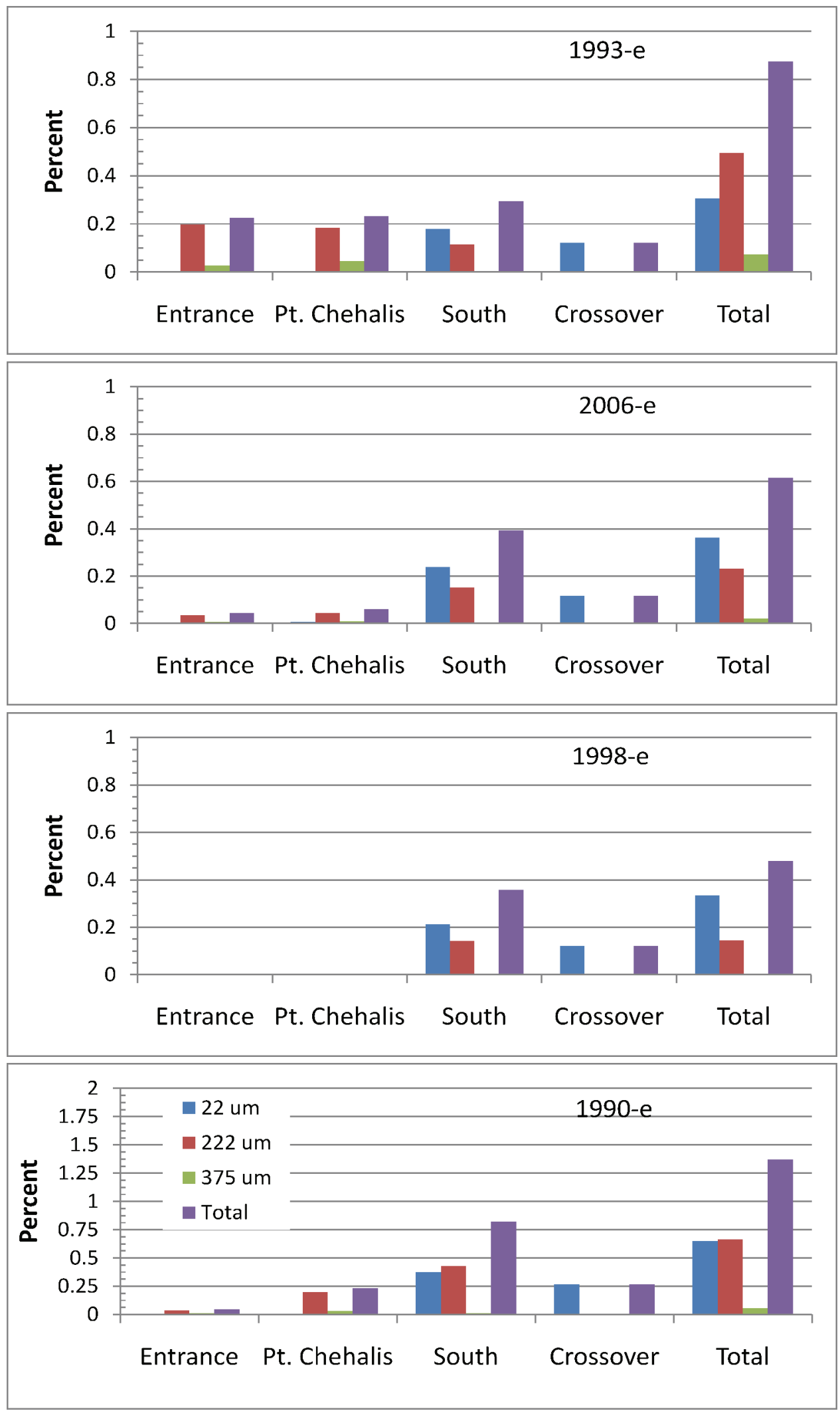

Figure 9-34. Percentage of sediment eroded from Half Moon Bay placement site with existing conditions that deposits in selected channel reaches for: a) 1993 event, b) 2006 event, c) 1998 event, and d) 1990 event. 


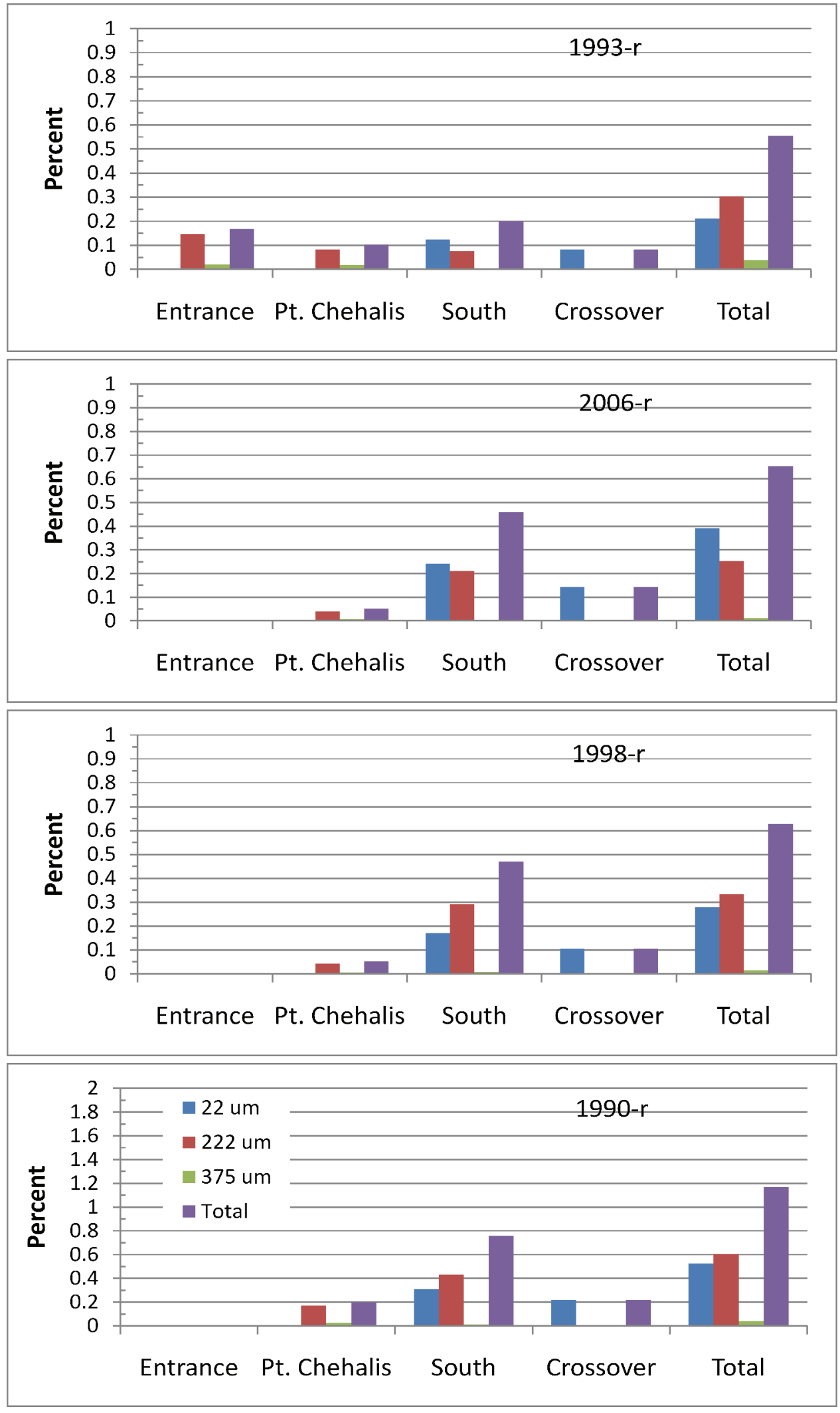

Figure 9-35. Percentage of sediment eroded from Half Moon Bay placement site with realigned channel that deposits in selected channel reaches for: a) 1993 event, b) 2006 event, c) 1998 event, and d) 1990 event. 
Residence time of dredged place sediment

Residence times for the placed sediment at each of the placement sites for all four modeled events were calculated. Specifically, the time it took for 25 percent and 50 percent of the initial dredged placement sediment to erode was calculated. The results are shown in Tables 9-3 and 9-4. Numbers in parentheses indicate that less than 25 percent and/ or 50 percent of the placed sediment eroded during those model simulations, with the numbers inside the parentheses representing the percent of the initial sediment that eroded. For example, it is seen in Table 9-3 that less than 7 percent of the placed sediment at the Pt Chehalis placement site eroded during the four simulated events for the realigned channel configuration. As seen in these tables, more than 25 percent of the dredged placed sediment eroded from this site only during the 1998-Q4 simulated event during which 53 percent of the sediment eroded.

Table 9-3. Times for $25 \%$ of the Dredged Placement Sediment to Erode from Placement Sites

\begin{tabular}{|l|l|l|}
\hline \multirow{2}{*}{$\begin{array}{l}\text { Placement Site } \\
\text { Event }\end{array}$} & Existing Conditions & Realigned Channel \\
\cline { 2 - 3 } Pt Chehalis & & Time (days) \\
\hline $1993-Q 2$ & $(6 \%)$ & $(2 \%)$ \\
\hline $2006-Q 4$ & $(18 \%)$ & $(7 \%)$ \\
\hline $1998-Q 4$ & 51.3 & $(7 \%)$ \\
\hline $1990-E x t r e m e$ & $(13 \%)$ & $(4 \%)$ \\
\hline South Jetty & & \\
\hline $1993-Q 2$ & 9.1 & 10.3 \\
\hline $2006-Q 4$ & 15.5 & 22.7 \\
\hline 1998-Q4 & 2.0 & 17.2 \\
\hline $1990-E x t r e m e$ & 9.8 & 9.8 \\
\hline Half Moon Bay & & \\
\hline 1993-Q2 & 2.7 & 14.8 \\
\hline $2006-Q 4$ & 15.1 & 20.0 \\
\hline $1998-Q 4$ & 1.6 & 19.2 \\
\hline $1990-E x t r e m e$ & 4.1 & 5.1 \\
\hline & & \\
\hline
\end{tabular}


Table 9-4. Times for $50 \%$ of the Dredged Placement Sediment to Erode from Placement Sites

\begin{tabular}{|l|l|l|}
\hline \multirow{2}{*}{$\begin{array}{l}\text { Placement Site } \\
\text { Event }\end{array}$} & Existing Conditions & Realigned Channel \\
\cline { 2 - 3 } & Time (days) & Time (days) \\
\hline Pt Chehalis & & \\
\hline $2006-Q 4$ & $(6 \%)$ & $(2 \%)$ \\
\hline $1998-Q 4$ & $(18 \%)$ & $(7 \%)$ \\
\hline 1990-Extreme & 64.1 & $(7 \%)$ \\
\hline South Jetty & $(13 \%)$ & $(4 \%)$ \\
\hline $1993-Q 2$ & & \\
\hline $2006-Q 4$ & 17.1 & 18.1 \\
\hline 1998-Q4 & 24.1 & 24.4 \\
\hline 1990-Extreme & 2.4 & 28.1 \\
\hline Half Moon Bay & 11.4 & 11.5 \\
\hline 1993-Q2 & 17.6 & \\
\hline $2006-Q 4$ & 23.2 & 35.9 \\
\hline 1998-Q4 & 2.2 & 24.3 \\
\hline 1990-Extreme & 6.1 & 47.7 \\
\hline & & 8.4 \\
\hline
\end{tabular}

These two tables show that for the South J etty placement site both the 25 percent and 50 percent residence times for the realigned channel configuration was slightly (for the 1993-Q2 event) to a lot greater (for the 1998-Q4 event) than those for the existing channel configuration. The residence times for the 1990-Q1 event were the same for the two channel configurations. For the Half Moon Bay placement site, the residence times were consistently greater for the realigned channel configuration than for the existing channel configuration, with the differences for the 50 percent eroded residence times being minimum for the 2006-Q4 event and maximum for the 1998-Q2 event.

\section{Deposition in navigation channels}

As seen in Table 9-2, there are significant differences in the mass of sediment that erodes from the mounds at the Pt Chehalis placement site for the two most extreme events, the 1998-Q4 and 1990-Q1 events. As seen in Figures 9-30 and 9-31, there are no significant differences in the fate of the eroded sediment between the existing conditions and realigned channel simulations. Of the mass eroded from the Pt Chehalis placement site, from 
approximately 15 to 23 percent deposits within the navigation channel during the simulation period. As seen specifically in the figures, Pt Chehalis reach receives the vast majority of the sediment that erodes from this site and ultimately deposits in the navigation channel.

Mass eroded from the South J etty site does not vary significantly with offshore wave conditions (Table 9-2). Eroded fractions for the existing and realigned channel configurations are essentially identical. Figures 9-32 and 9-33 show that the largest fractions of dredged material eroded from the South J etty Site deposit at the Pt Chehalis and South Channel reaches, although the total amount deposited is very low (2-3 percent). Insignificant fractions deposited in the Entrance and Crossover reaches. Since the percentage of eroded sediment was essentially the same for the simulated events, the results seen in Figures 9-32 and 9-33 indicate that the vast majority of the sediment that eroded during the simulations for both channel configurations deposited elsewhere, i.e., not in these four navigation channel reaches.

Like the South J etty site, the Half Moon Bay site is mostly insensitive to incident wave climate (Table 9-2). The milder 1993-Q2 period eroded 80 and 60 percent of the dredged material for the existing and realigned configurations, respectively, while the more energetic 2006-Q4, 1998-Q4, and 1990-Q1 periods eroded between 95 to 100 percent of the dredged material. As seen in Figures 9-34 and 9-35, differences between existing and realigned channel configurations are insignificant at the Half Moon Bay site. The cited figures show that approximately the same percentage of sediment that eroded from the Half Moon Bay site during the 1993-Q2 simulation deposited in the Entrance Channel, Pt Chehalis Channel and South Channel reaches, while insignificant fractions deposited in the Entrance and Crossover reaches for the three more energetic simulation events. These figures show that very little (less than 1.5 percent) of the sediment that erodes from the Half Moon Bay site deposits in any of these four navigation channel reaches.

Uncertainties should be considered in the interpretation of the model results. Two primary uncertainties are associated with the specification of native sediment composition within the modeling domain and specification of dredged material erosion and settling characteristics determined from laboratory experimentation instead of direct field experiments. These uncertainties could be reduced in future studies by obtaining additional 
sediment bed grain size distributions within Grays Harbor, and conducting cohesive sediment erosion and settling experiments on material collected directly from the dredged material placement sites. 


\section{Conclusions}

\section{Hydrodynamics}

The study results showed that hydrodynamics in and around the navigation channel were weakly affected by short-term bathymetric changes caused by dredging operations or natural sedimentation processes occurring in the GH entrance and back-bay area considered in the present study. This modeling results with 1999 to 2008 bathymetry data showed no significant change in the calculated kinematics (water surface elevation and velocities) in the vicinity of navigation channel. There was a comparatively larger difference in the velocity magnitudes between 1999 and 2003 field measured data and modeling during strong storm seasons. The term "strong" is defined here as a short lived event with flows and winds speeds of comparatively larger magnitudes than those occurring at other times. During storm events, the calculated increasing transport depends on characteristics of sediments, wave conditions and flow speed and direction.

For the Existing channel, the calculated maximum and average current speeds are respectively 4 and 1.5 knots along the channel for three return periods (0.5, 2 and 5-yr). Flood and ebb currents have similar magnitude and pattern of variation along the channel. In the channel section between north and south jetties, the current first increases and then decreases in a non uniform fashion. For the Realigned channel (with Existing channel unfilled), maximum and average current speeds are not as strong as those for the Existing channel ( 3.5 and 1.3 knots versus 4 and $1.5 \mathrm{knots}$ ). In this case, current speed initially increases similar to the Existing channel case, but the subsequent decrease in current magnitude is nearly linear and much weaker. There are no large spatial variations in current as seen in the Existing channel. The magnitude of flood current is slightly stronger than ebb current. There is essentially no difference in current magnitude between the Realigned channel with the Existing channel either unfilled or filled alternatives.

As far as waves along the channel are concerned, the largest maximum significant wave height obtained was $10 \mathrm{~m}$ for the 2-yr return period in the channel reach between two jetties. The wave height varies from $0.4 \mathrm{~m}$ to $10 \mathrm{~m}$ for all simulations conducted for three return periods and one extreme storm month period. Wave height decreases rapidly in a nonlinear fashion 
for the Existing channel. In contrast, the largest maximum wave height value for the Realigned channel with or without the Existing channel filled is about $10 \mathrm{~m}$, but in this case, wave height decreases more uniformly as compared to the Existing channel case. The largest average wave height is less than $5 \mathrm{~m}$ and minimum average wave height is $0.4 \mathrm{~m}$ for the Realigned channel, same as for the Existing channel. Uniform transitions in wave height/ current are more advantageous to navigation. These impact navigation by reducing gradients that move in/ out sediments from channel. Limiting cross-current has also a favorable impact on navigation and channel maintenance.

\section{Sand transport pathways}

Sand transport at the dredged material placement sites near the GH entrance is influenced by both waves and currents (Chapters 6 and 7). Wave-current interactions act to increase bed stress and sediment mobility. The effects of waves diminish with deeper water depth and decreased wave height. Consequently, shallower areas near the entrance are more strongly influenced by waves than deeper areas within GH. While waves act to enhance the bottom stress and mobilizing forces on bed sediments, currents dictate the rate and direction of transport.

GTRAN-estimated sediment transport pathways (Chapter 7) indicate a general pattern of flood-dominated transport on the northern half of the GH entrance and ebb-dominated sediment transport on the southern half of the entrance. Transport at the dredged material placement sites is generally bimodal for both the existing and realigned channel. Transport at the Point Chehalis placement site is slightly ebb-dominant and transport at the South J etty placement site is strongly ebb-dominant. Less transport was calculated at the Half Moon Bay placement site, which showed a weak flood directed transport.

Transport magnitudes generally showed a slight increase in transport with the realigned channel compared to magnitudes with the existing channel. Transport differences at the Point Chehalis placement site was small and differences with the realigned channel is likely due to a shift in current direction, i.e., transport shifts from east-northeast to a more easterly direction. The results showed that transport at the South J etty placement site increased in the ebb direction, which would lead to increased erosion. The increased transport appears to be a result of shallower depth at the 
site due to infilling of the existing channel. Transport at the Half Moon Bay placement site showed a slight flood-directed increase in transport.

Transport streamlines indicate circulation cells are present north of the Point Chehalis placement site and near the end of the north jetty. Based on plots of transport pathways, a more favorable location for dredge placement to transport sediment outside the entrance appears to be northwest of the South J etty site. However, this location has not been evaluated for practicality and safety.

\section{Cohesive and mixed sediment processes}

Sedflume data analysis (Chapter 8) indicated that the dredged material from Cow Point Reach is highly cohesive. Therefore erosion rate and critical shear stress for initiation for erosion are highly sensitive to sediment bulk density, and bulk denisty of eroding sediments must be included in any sediment transport modeling. Eroded aggregates were characterized through settling velocity experiments (Chapter 8). Settling velocity and aggregate states were found to be near-constant and uncorrelated to applied shear stress. For modeling purposes, the eroded cohesive sediments can be treated as a suspension of 80 percent bed aggregates, 10 percent flocs, and 10 percent primary particles. Floc settling velocities were estimated to be $0.35 \mathrm{~mm} / \mathrm{s}$, and the settling velocity of bed aggregates is estimated at $1.1 \mathrm{~mm} / \mathrm{s}$.

\section{Cohesive and mixed sediment transport}

The LTFATE modeling of Grays Harbor sediment transport at the three existing placement sites showed the following general results (specific details are provided in Chapter 9).

- During the simulation periods, 6 to 53 percent of the placed mass eroded from the Pt Chehalis site with the existing channel configuration, whereas less than 7 percent of the placed sediment eroded with the realigned channel. At the South J etty Site, 90 to 100 percent of the placed sediment eroded for both channel configurations. For the Half Moon Bay site, 80 to 100 percent eroded with the existing channel, whereas 60 to 97 percent eroded with the realigned channel. Significant variation in the eroded sediment mass with offshore wave conditions only occurred at the Pt Chehalis site for the existing channel configuration, and at the Half Moon Bay site for the realigned channel. 
- Residence times for the placed sediment at each of the placement sites for all four modeled events were calculated. Specifically, the time it took for 25 percent and 50 percent of the initial dredged placement sediment to erode was calculated. At the Pt Chehalis placement site, less than 7 percent of the placed sediment eroded during the four simulated events for the realigned channel configuration. More than 25 percent of the dredged placed sediment eroded from this site only during the 1998-Q4 simulated event during which 53 percent of the sediment eroded. For the South J etty placement site both the 25 percent and 50 percent residence times for the realigned channel configuration was slightly (for the 1993-Q2 event) to a lot greater (for the 1998-Q4 event) than those for the existing channel configuration, whereas the residence times for the 1990-Q1 event were the same for the two channel configurations. For the Half Moon Bay placement site, the residence times were consistently greater for the realigned channel configuration than for the existing channel configuration, with the differences for the 50 percent eroded residence times being minimum for the 2006-Q4 event and maximum for the 1998-Q2 event.

- There are no significant differences in the fate of the eroded sediment between the existing conditions and realigned channel simulations. Of the mass eroded from the Pt Chehalis placement site, approximately 20 percent deposits within the navigation channel during the simulation period, with the Pt Chehalis reach receiving the vast majority of the sediment that erodes from this site. Mass eroded from the South J etty site does not vary significantly with offshore wave conditions. Eroded fractions for the existing and realigned channel configurations are essentially identical. The largest fractions of dredged material eroded from the South J etty Site deposit at the Pt Chehalis and South Channel reaches, although the total amount deposited is very low (2-3 percent). Insignificant fractions deposited in the Entrance and Crossover reaches. Since the percentage of eroded sediment was essentially the same for the simulated events, the vast majority of the sediment that eroded during the simulations for both channel configurations deposited elsewhere, i.e., not in these four navigation channel reaches. Like the South J etty site, the Half Moon Bay site is mostly insensitive to incident wave climate. The milder 1993-Q2 period eroded 80 and 60 percent of the dredged material for the existing and realigned configurations, respectively, while the more energetic 2006-Q4, 1998Q4, and 1990-Q1 periods eroded between 95 to 100 percent of the dredged material. Differences between existing and realigned channel 
configurations are insignificant at the Half Moon Bay site. Approximately the same percentage of sediment that eroded from this site during the 1993-Q2 simulation deposited in the Entrance Channel, Pt Chehalis Channel and South Channel reaches, while insignificant fractions deposited in the Entrance and Crossover reaches for the three more energetic simulation events. Very little (less than 1.5 percent) of the sediment that erodes from the Half Moon Bay site deposits in any of these four navigation channel reaches.

- Erosion rates of dredged material and subsequent fate of this material within the federal navigation channel were not significantly changed between the existing and realigned channel configurations.

It should be recognized that dredged material deposited outside the navigation channel during these 3-month simulations may be subsequently resuspended and deposited in the channel. A longer term simulation would have to be performed to confirm this possibility and quantify the amount of additional deposition, if any that occurs. One finding from these limited number of model simulations is that the realigned navigation channel does not appear to significantly alter the quantity of sediment eroded from the three dredged material sites or the mid-term (months) fate of the eroded material. Other recommendations based on the present study are:

- Reduce the large uncertainty in the initial grain size distribution throughout the modeling domain by executing a spatially stratified surface grab sample program throughout the model domain and analyzing these samples for grain size distributions.

- Perform a Sedflume study of the sediment in the mounds at the three disposal sites.

- Quantify the flux and grain size distribution of the suspended sediment load transported by the two main rivers that flow into the harbor over a Spring, mean and neap tidal cycle.

- These actions would greatly help to reduce the uncertainty in the model results. The data gathered from these three tasks are essential for additional numerical modeling of sediment transport using LTFATE to accurately predict the resuspension rates of the mounded sediment at the disposal sites and the fate of the resuspended sediment during the four simulated events. 


\section{References}

Arden, H. T. 2003. South jetty breach fill at Grays Harbor Washington: Doing the right thing with dredged material. Shore \& Beach, 71(1)3-5.

Arega, F., and E. J . Hayter. 2008. Coupled Consolidation and Contaminant Transport Model for Simulating Migration of Contaminants through Sediment and a Cap. J ournal of Applied Mathematical Modelling. (32)2413- 2428.

Bray, R. N., A. D. Bates, and J . M. Land. 1997. Dredging: A Handbook for Engineers. Arnold. London.

Demirbilek, Z., and V. Panchang. 1998. CGWAVE: A coastal surface-water wave model of the mild-slope equation. Coastal and Hydraulics Laboratory Technical Report CHL-98-26. Vicksburg, MS: U.S. Army Engineer Waterways Experiment Station.

Demirbilek, Z., L. Lin, and A. Zundel. 2007. WABED model in the SMS: Part 2. Graphical interface. Coastal and Hydraulics Laboratory Engineering Technical Note ERDC/CHL CHETN-I-74. Vicksburg, MS: U.S. Army Engineer Research and Development Center.

Demirbilek, Z., L. Lin, and O. G. Nwogu. 2008. Wave modeling for jetty rehabilitation at the Mouth of the Columbia River, Washington/ Oregon, USA. ERDC/ CHL TR08-3. Vicksburg, MS: U.S. Army Engineer Research and Development Center.

Fennessy, M. J ., K. R. Dyer, and D. A. Huntley. 1994. INSSEV: An instrument to measure the size and settling velocity of flocs in situ. Mar. Geol. (117)107-117.

Gailani, J . Z., S. J . Smith, and N. C. Kraus. 2003. Monitoring dredged material disposal at the mouth of the Columbia River, Washington/Oregon, USA. ERDC/CHL TR03-5. Vicksburg, MS: U.S. Army Engineer Research and Development Center.

Galperin, B., L. H. Kantha, S. Hassid, and A. Rosati. 1988. A quasi-equilibrium turbulent energy model for geophysical flows. J. Atmos. Sci., (45)55-62.

Graf, W. H. 1971. Hydraulics of Sediment Transport. New York: McGraw-Hill.

Hamrick, J . M. 2007a. The Environmental Fluid Dynamics Code User Manual: USEPA Version 1.01. Fairfax, VA: Tetra Tech, Inc.

Hamrick, J . M. 2007. The Environmental Fluid Dynamics Code Theory and Computation. Volume 1: Hydrodynamics and Mass Transport. Fairfax, VA: Tetra Tech, Inc.

Hamrick, J . M. 2007c. The Environmental Fluid Dynamics CodeTheory and Computation. Volume 2: Sediment and Contaminant Transport and Fate. Fairfax, VA: Tetra Tech, Inc.

Hericks, D. B., and D. P. Simpson. 2000. Grays Harbor Estuary Physical Dynamics Study, Final Data Report: September 11, 1999-November 17, 1999. Edmonds, WA: Pacific International Engineering. 
J epsen, R., J . Roberts, and W. Lick. 1997a. Effects of bulk density on sediment erosion rates. Water, Air, and Soil Pollution, 99, 21-31.

J ohnson, B. H., and M. T. Fong. 1995. Development and Verification of Numerical Models for Predicting the Initial Fate of Dredged Material Disposed in Open Water, Report 2: Theoretical Developments and Verification Results. Technical Report DRP-93-1. Vicksburg, MS: U.S. Engineer Waterways Experiment Station.

J ohnson, B. H. 1990. User's guide for models of dredged material disposal in open water. Technical Report D-90-5. Vicksburg, MS: U.S. Army Engineer Waterways Experiment Station.

J ohnson, B. H., and S. J . Smith. 200x. Enhancements to the STFATE Numerical Model. DOER Technical Notes Collection (ERDC TN-DOER-xxx). Vicksburg, MS: U.S. Army Engineer Research and Development Center. http://el.erdc.usace.army.mil/dots/doer/technote.html

J ones, C. A., and W. Lick. 2001. SEDZLJ : A Sediment Transport Model. Final Report. Santa Barbara, CA: University of California.

Krank, K., E. Petticrew, T. G. Milligan, and I. G. Droppo. 1993. In situ particle size distributions resulting from flocculation of suspended sediment. In: Nearshore and Estuarine Cohesive Sediment Transport, ed. Mehta, A. J . 60-74. American Geophysical Union.

Kraus, N. C., and H. T. Arden. 2003. North J etty Performance and Entrance Navigation Channel Maintenance, Grays Harbor, Washington. ERDC/ CHL TR-03-12. Vicksburg, MS: U.S. Army Engineer Research and Development Center.

Krone, R. B. 1963. A study of rheological properties of estuarial sediments. Technical Bulletin No. 7, Committee on Tidal Hydraulics, Vicksburg, MS: U.S. Army Engineer Waterways Experiment Station.

Landerman, L.A., C. R. Sherwood, G. Gelfenbaum, J . Lacy, P. Ruggiero, D. Wilson, T. Chisholm, and K. Kurrus. 2004. Grays Harbor Sediment Transport Experiment Spring 2001—Data Report. Data Series 98, U.S. Geological Survey, Reston, VA.

Le Provost, C., M. L. Genco, F. Lyard, P. Vincent, and P. Canceill. 1994. Spectroscopy of the world tides from a hydrodynamic-finite element model. J ournal of Geophysical Research, 99(Cl2), 777-797.

Lick, W. L. 1982. The transport of contaminants in the Great Lakes. Annual Review of Earth and Planetary Science, 10, 327-353.

Lin, L., and Z. Demirbilek. 2005. Evaluation of two numerical wave models with inlet physical model. J ournal of Waterway, Port, Coastal, and Ocean Engineering, 131(4):149-161, ASCE.

Lin, L., H. Mase, F. Yamada, and Z. Demirbilek. 2006. Wave-action balance equation diffraction (WABED) model: Tests of wave diffraction and reflection at inlets. ERDC/CHL CHETN-III-73. Vicksburg, MS: U.S. Army Engineer Research and Development Center. 
Lin, L., Z. Demirbilek, H. Mase, J . Zheng, and F. Yamada. 2008. CMS-Wave: A Nearshore Spectral Wave Processes Model for Coastal Inlets and Navigation Projects. ERDC/ CHL TR-08-13. Vicksburg, MS: U.S. Army Engineer Research and Center.

Luettich, R. L., J . J . Westerink, and N. W. Scheffner. 1992. ADCIRC: An advanced threedimensional circulation model for shelves, coasts, and estuaries, Report l: Theory and methodology of ADCIRC-2DDl and ADCIRC_3DL. Technical Report DRP92-6, Vicksburg, MS: U.S. Army Engineer Waterways Experiment Station.

Madsen, O. S., and P. N. Wikramanayake. 1991. Simple models for turbulent wavecurrent bottom boundary layer flow. Contract Report DRP-91-1. Vicksburg, MS: U.S. Army Engineer Waterways Experiment Station.

Mase, H. 1989. Random wave runup height on gentle slope. J ournal of Waterway, Port, Coastal, and Ocean Engineering, 85(3):123-152, ASCE.

Mase, H. 2001. Multidirectional random wave transformation model based on energy balance equation. Coastal Engineering J ournal, 43(4):317-337J SCE.

Mase, H., and T. Kitano. 2000. Spectrum-based prediction model for random wave transformation over arbitrary bottom topography. Coastal Engineering J ournal, 42(1):111-151, J SCE.

Mase, H., and Y. Iwagaki. 1984. Runup of random waves on gentle slopes. Proceeding 19th International Conference on Coastal Engineering, ASCE, 593-609.

Mase, H., H. Amamori, and T. Takayama. 2005a. Wave prediction model in wave-current coexisting field. Proceedings 12th Canadian Coastal Conference (CD-ROM).

Mase, H., K. Oki, T. S. Hedges, and H. J . Li. 2005b. Extended energy-balance-equation wave model for multidirectional random wave transformation. Ocean Engineering, 32(8-9):961-985.

McNeil, J ., C. Taylor, and W. Lick. 1996. Measurements of erosion of undisturbed bottom sediments with depth. J. Hydr. Engr., 122(6), 316-324.

Mellor, G. L., and T. Yamada. 1982. Development of a turbulence closure model for geophysical fluid problems. Rev. Geophys. Space Phys., 20, 851-875.

Meyer-Peter, E., and R. Müller. 1948. Formulas for bed-load transport. Second International Association of Hydraulic Engineering and Research (IAHR) Congress, Stockholm, Sweden. Delft, Netherlands: IAHR.

Mikkelsen, O. A., T. G. Milligan, P. S. Hill, and D. Moffatt. 2004. INSSECT-an instrumented platform for investigating floc properties close to the seabed. Limnol. OCeanogr. Methods 2, 226-236.

Myrhaug, D. 1989. A rational approach to wave friction coefficients for rough, smooth, and transitional turbulent flow. Coastal Engineering, 13: 11-21.

Nielsen, P. 1992. Coastal Bottom Boundary Layers and Sediment Transport. World Scientific Publishing, Singapore, Advanced Series on Ocean Engineering, vol. 4. 
Nwogu, O., and Z. Demirbilek. 2001. BOUSS-2D: A Boussinesq wave model for coastal regions and harbors. ERDC/CHL TR-01-25. Vicksburg, MS: U.S. Army Engineer Research and Development Center.

Oceanweather. 2007. Global reanalysis of ocean waves (GROW), Project Description. Oceanweather Letter Report, dated 2 October 2007. Oceanweather Inc., Cos Cob, CT, USA.

Osborne P. D., and M. H. Davies. 2004. South jetty sediment processes study, Grays Harbor, Washington: Processes along Half Moon Bay. Pacific International Engineering (PIE), Technical Report, Edmonds, WA.

Osborne, P. D., D. B. Hericks, and N. C. Kraus. 2002. Deployment of oceanographic instruments in high-energy environments and near structures. ERDC/ CHL CHETN IV-46. Vicksburg, MS: U.S. Army Engineer Research and Development Center.

Osborne, P. D., T. V. Wamsley, and H. T. Arden. 2003. South jetty sediment processes study, Grays Harbor, Washington: Evaluation of engineering structures and maintenance measures. ERDC/ CHL TR-03-4. Vicksburg, MS: U.S. Army Engineer Research and Development Center.

Partheniades, E. 1965. Erosion and deposition of cohesive soils. J ournal of the Hydraulic Division, 91(HY1) 105-139.

Raudkivi, A. J . 1998. Loose Boundary Hydraulics, fourth ed., Taylor \& Francis, London.

SAIC. 2007. Grays Harbor Navigational Channel Maintenance Dredging, Grays Harbor, WA. FY06-07 Dredged Material Characterization Data Report-FINAL, Bothell, Washington.

SAIC. 2009. Dredged Material Characterization for Grays Harbor Navigational Channel Maintenance Dredging Grays Harbor, WA. FY08- 09 Dredged Material Characterization Data Report Final, Bothell, Washington.

Sanford, L. P. 2008. Modeling a dynamically varying mixed sediment bed with erosion, deposition, bioturbation, consolidation, and armoring. Computers \& Geosciences, 34(10): 1263-1283.

Sanford, L. P., P. J . Dickhudt, L. Rubiano-Gomez, M. Yates, S. E. Suttles, C. T. Friedrichs, D. D. Fugate, and H. Romine. 2005. Variability of suspended particle concentrations, sizes, and settling velocities in the Chesapeake Bay turbidity maximum. In: Flocculation in Natural and Engineered Environmental Systems, ed. Droppo, I. G., Leppard, G. G., Liss, S. N., and Milligan, T. G. Boca Raton, FL: CRC Press.

Scheidegger, K. F., and J. B. Phipps. 1976. Dispersal Patterns of Sands in Grays Harbor Estuary, Washington. J ournal of Sedimentary Petrology, 46(1), 163-166.

Schiller, L. and A. Naumann. 1933. Über die grundlegenden Berechnungen bei der Schwerkraftaufbereitung, Z. VDI, vol. 77.

Schlichting, H. and K. Gersten. 2000. Boundary-Layer Theory. Springer, Berlin. 
Soulsby, R. L., and R. J. S. W. Whitehouse. 1997. Threshold of sediment motion in coastal environments. Proceedings Pacific Coasts and Ports '97, Christchurch, 149 -154.

Soulsby, R. L. 1997. Dynamics of Marine Sands. Thomas Telford. London.

Soulsby, R. L. 1997. Dynamics of Marine Sands. Thomas Telford, London

Ten Brinke, W. B. M. 1994. Settling velocities of mud aggregates in the Oosterschelde tidal basin (The Netherlands), determined by a submersible video system. Estuar. Coast. Shelf S. 39, 549-564.

Torfs, H., J . Jiang, and A. J . Mehta. 2001. Assessment of the erodibility of fine/ coarse sediment mixtures. In: Coastal and Estuarine Fine Sediment Processes, ed. W. H. McAnally and A. J . Mehta, 109-124. Elsevier.

Van Leussen, W. 1994. Estuarine Macroflocs and Their Role in Fine-Grained Sediment Transport, Ministry of Transport, Pubic Works and Water Management. Den Haag.

Van Leussen, W. V., and J . M. Cornelisse. 1993. The determination of the sizes and settling velocities of estuarine flocs by underwater video system. Neth. J . Sea Res. 31(3), 231-241.

Van Rijn, L. C. 1984. Sediment Transport: part I: bedload transport; part ii: suspended load transport: part iii: bed forms and alluvial roughness. J ournal of Hydraulic Engineering 110(10): 1431-1456; 110(11): 1613-1641, 110(12): 1733-1754.

Washington Department of Ecology. 1977. Maintenance dredging and the environment of Grays Harbor Washington summary report. Prepared for U.S. Army Engineer District, Seattle, Contract No. DACW67-74-C-0086, 102 p.

Wikramanayake, P. N., and O. S. Madsen. 1994a. Calculation of suspended sediment transport by combined wave-current flows. Contract Report DRP-94-7. Vicksburg, MS: U.S. Army Engineer Waterway Experiment Station.

Wikramanayake, P. N., and O. S. Madsen. 1994b. Calculation of movable bed friction factors. Contract Report DRP-94-5. Vicksburg, MS: U.S. Army Engineer Waterway Experiment Station.

Winterwerp, J . C. 2002. On the flocculation and settling velocity of estuarine mud. Cont. Shelf Res. 22, 1339-1360.

Winterwerp, J . C. 1998. A simple model for turbulence induced flocculation of cohesive sediment. IAHR J. Hydraul. Res. 36 (3), 309-326.

Winterwerp, J . C., and W. G. M. van Kesteren. 2004. Introduction to the Physics of Cohesive Sediment in the Marine Environment, Developments in Sedimentology series, volume 56, Elsevier. Amsterdam.

Zundel, A. 2006. Surface-water modeling system reference manual - Version 9.2. Brigham Young University Environmental Modeling Research Laboratory, Provo, UT. 


\section{Appendix A: Results from GTRAN Simulations}

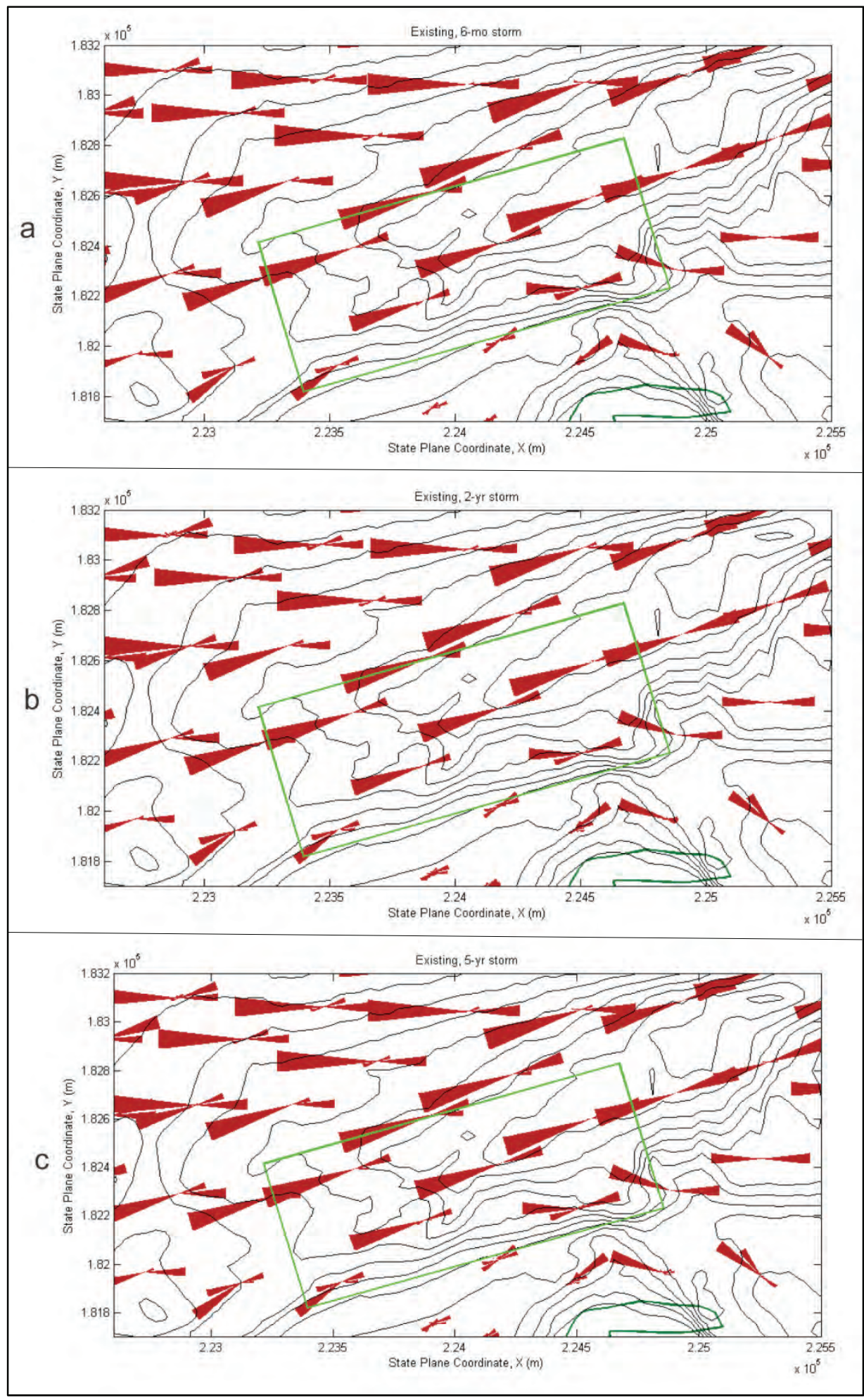

Figure A1. GTRAN results for the Existing Channel at Point Chehalis placement site. 

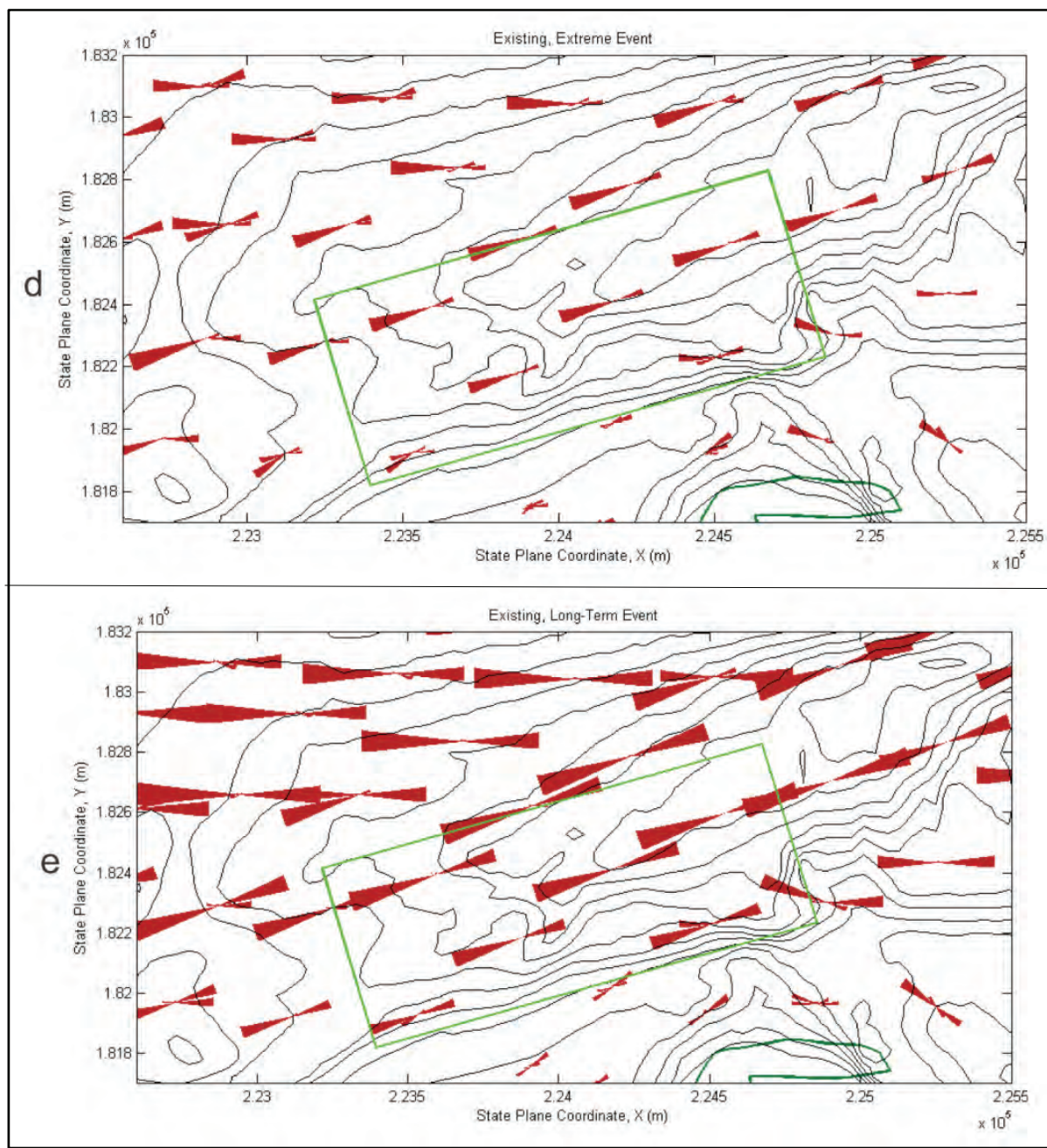

Figure A1 (cont.). GTRAN results for the Existing Channel at Point Chehalis placement site. 

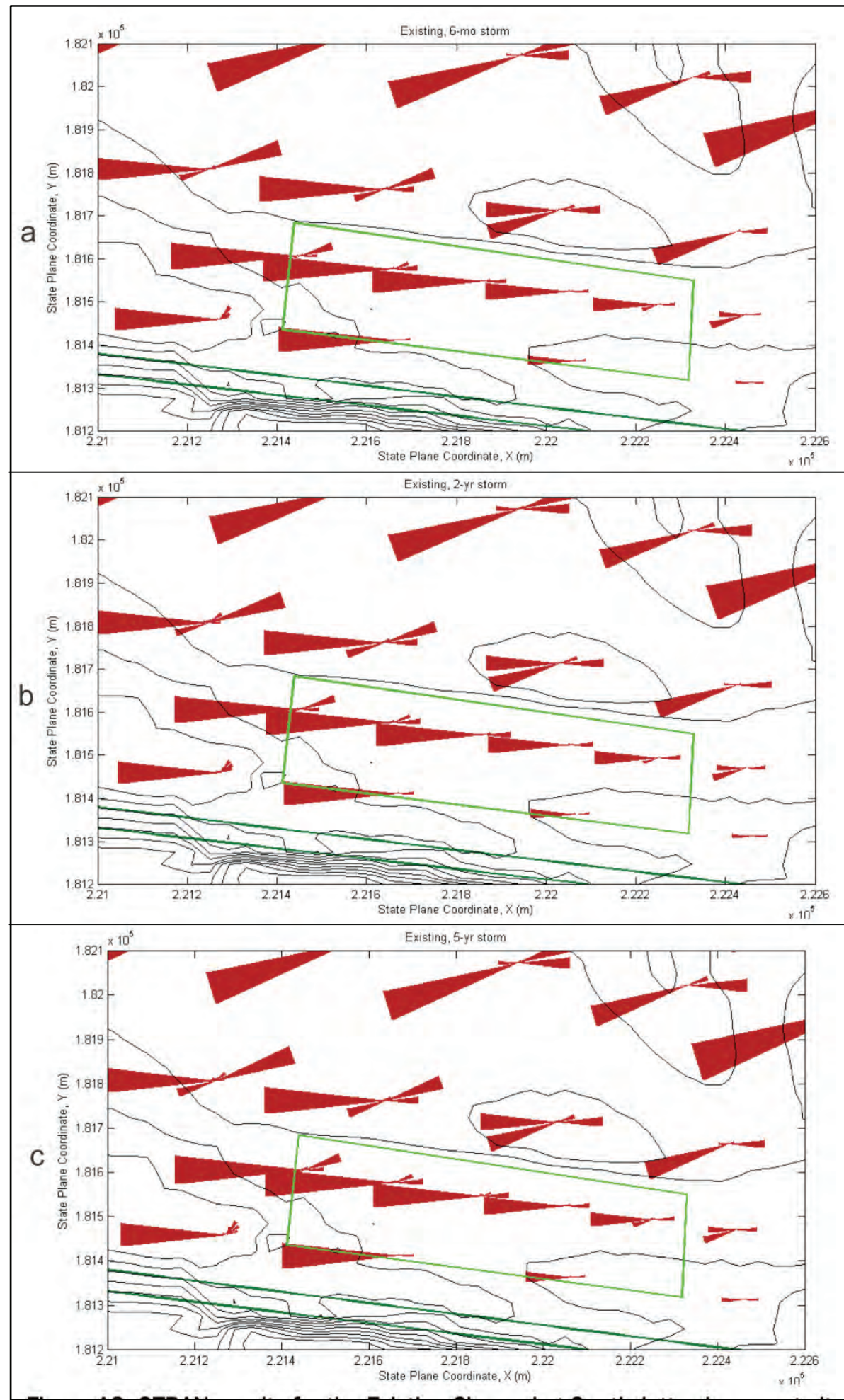

Figure A2. GTRAN results for the Existing Channel at South Jetty placement site. 

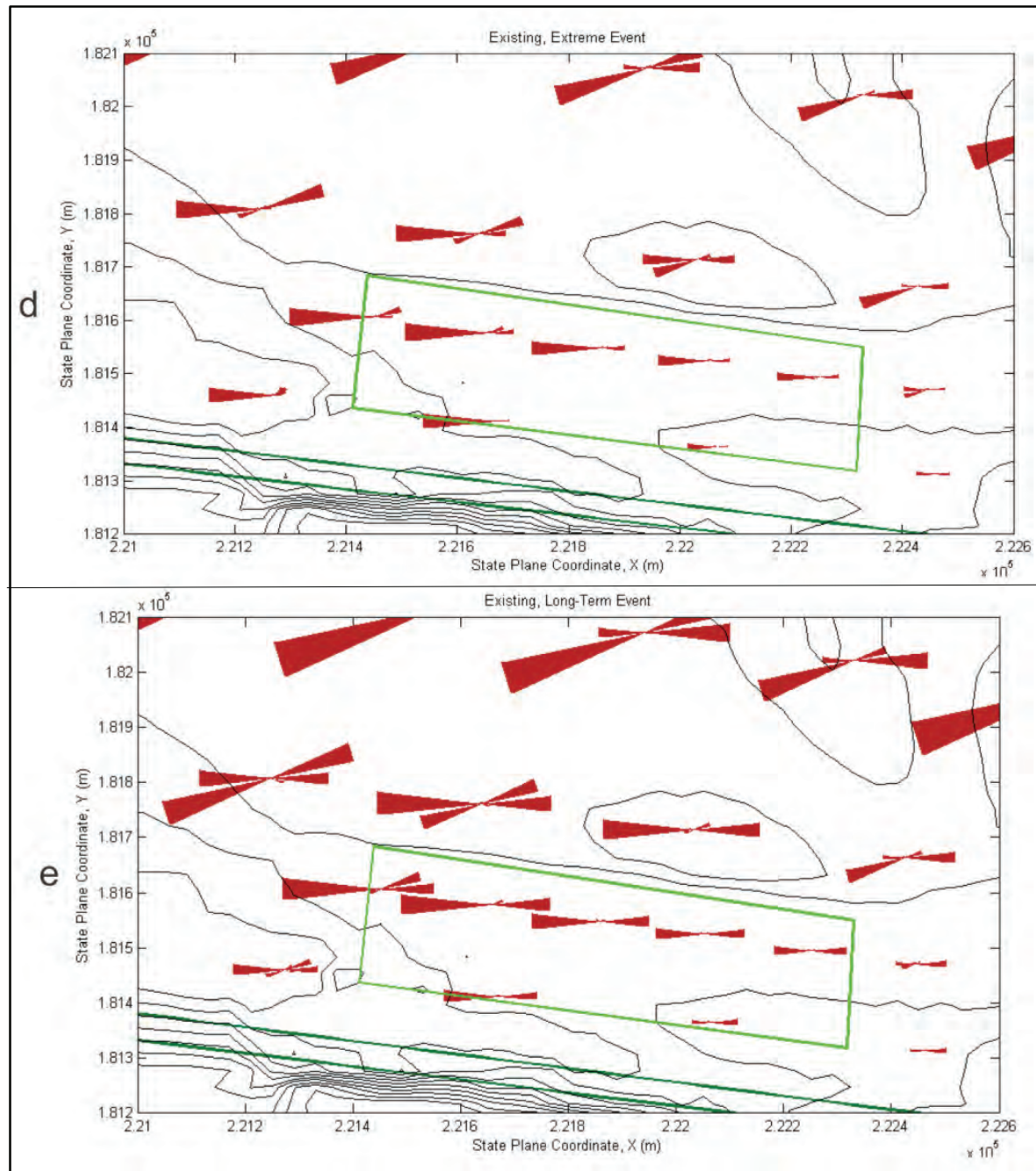

Figure A2 (cont.). GTRAN results for the Existing Channel at South Jetty placement site. 


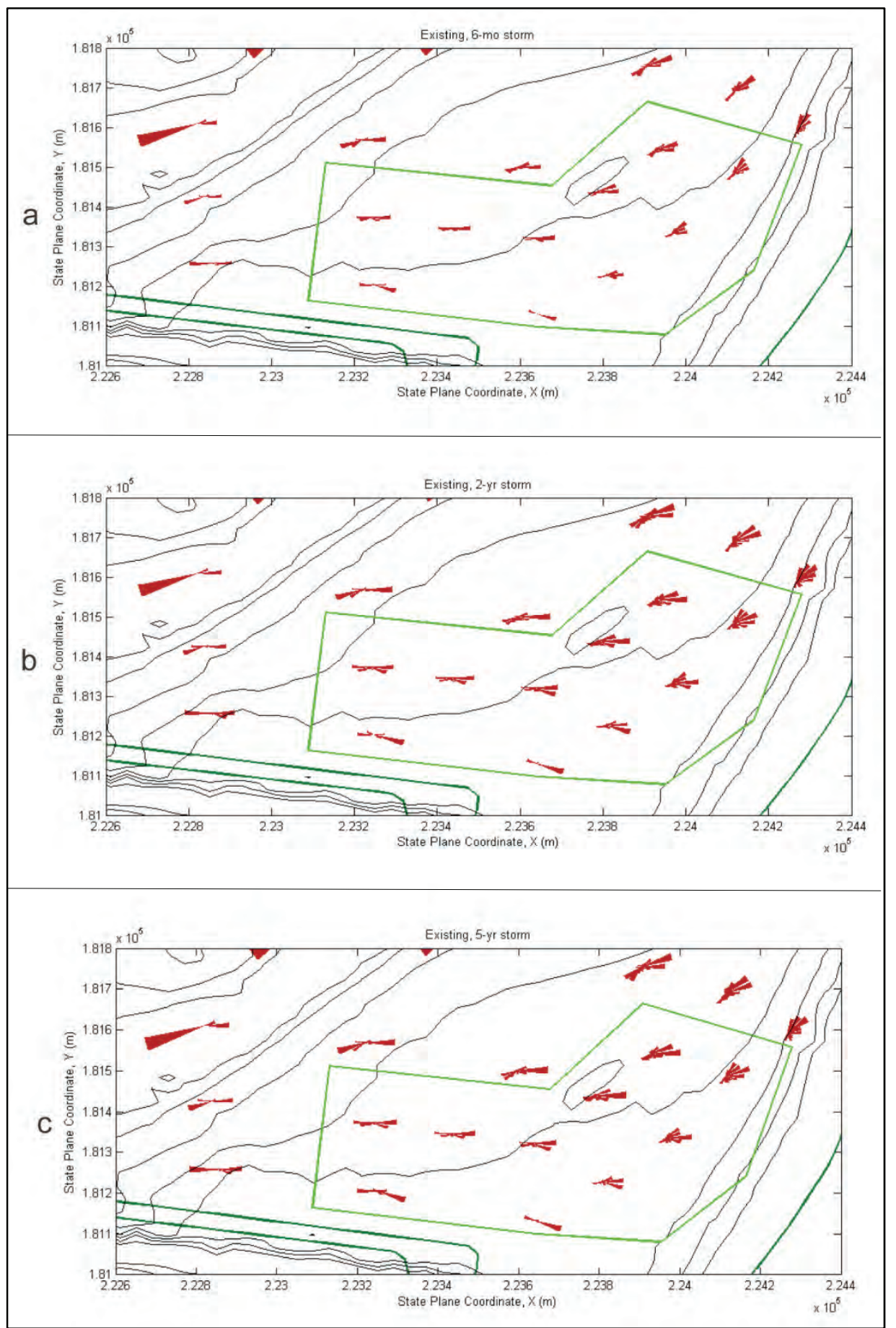

Figure A3. GTRAN results for the Existing Channel at Half Moon placement site. 


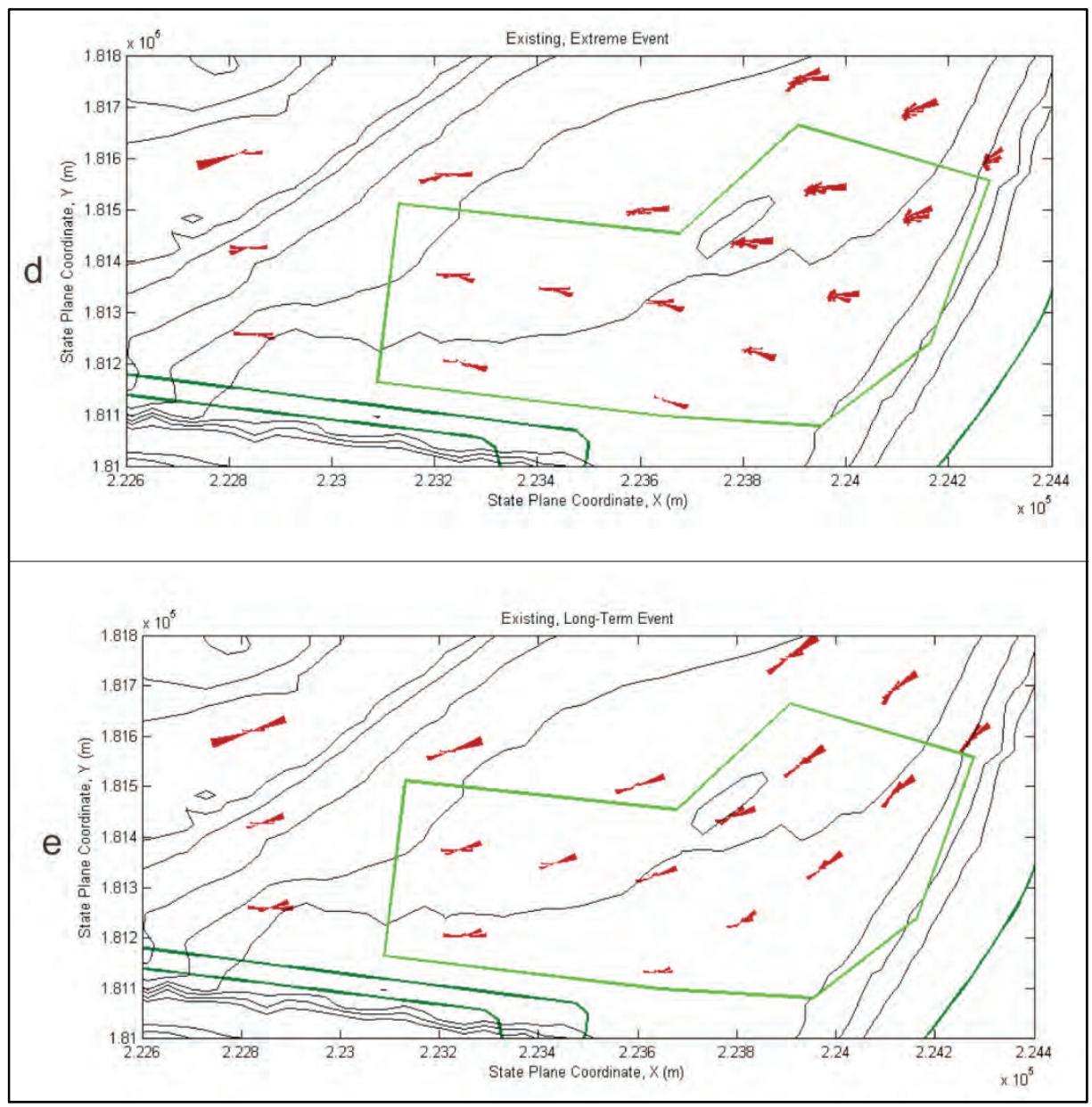

Figure A3 (cont.). GTRAN results for the Existing Channel at Half Moon placement site. 


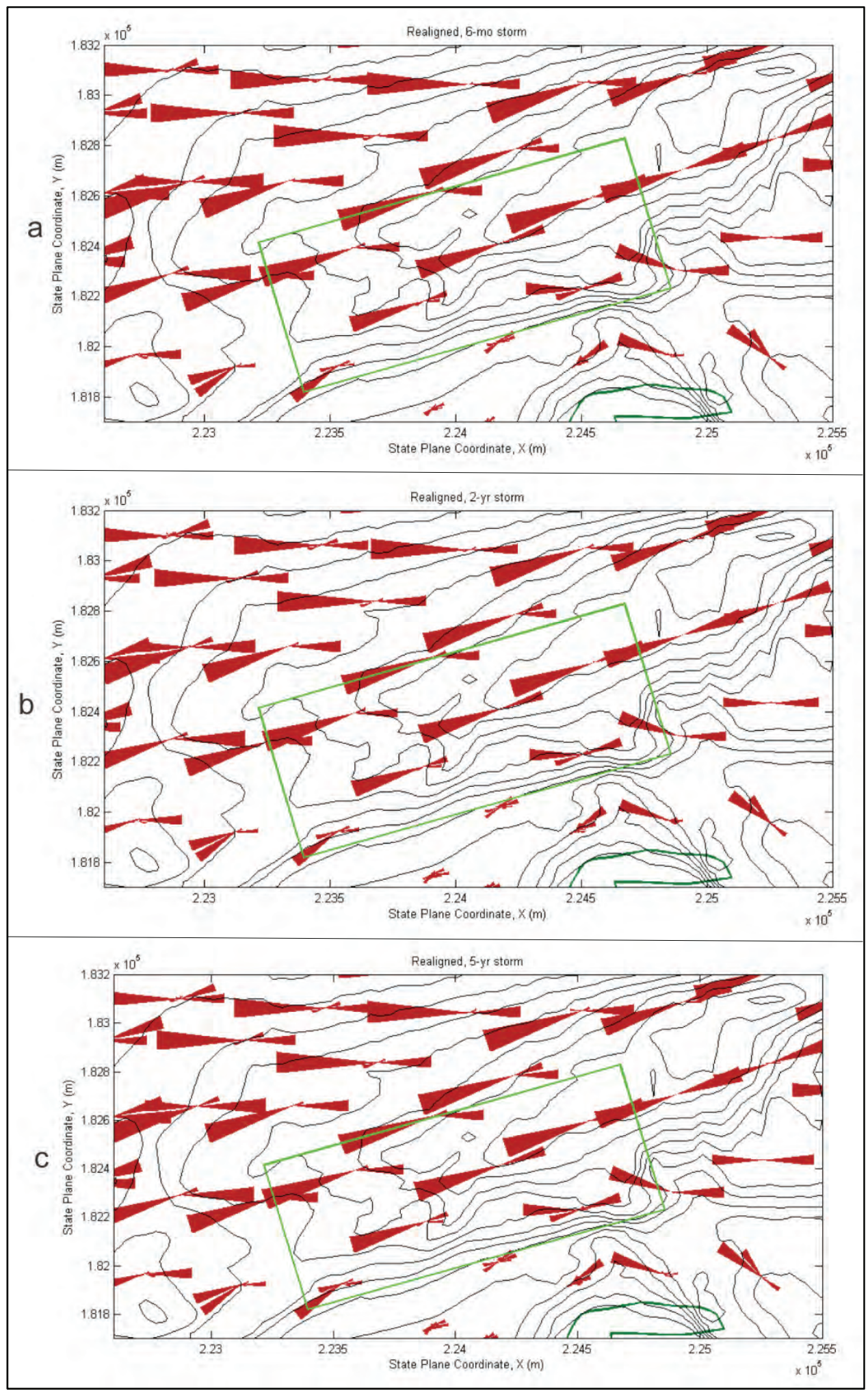

Figure A4. GTRAN results for the Realigned Channel at Point Chehalis placement site. 


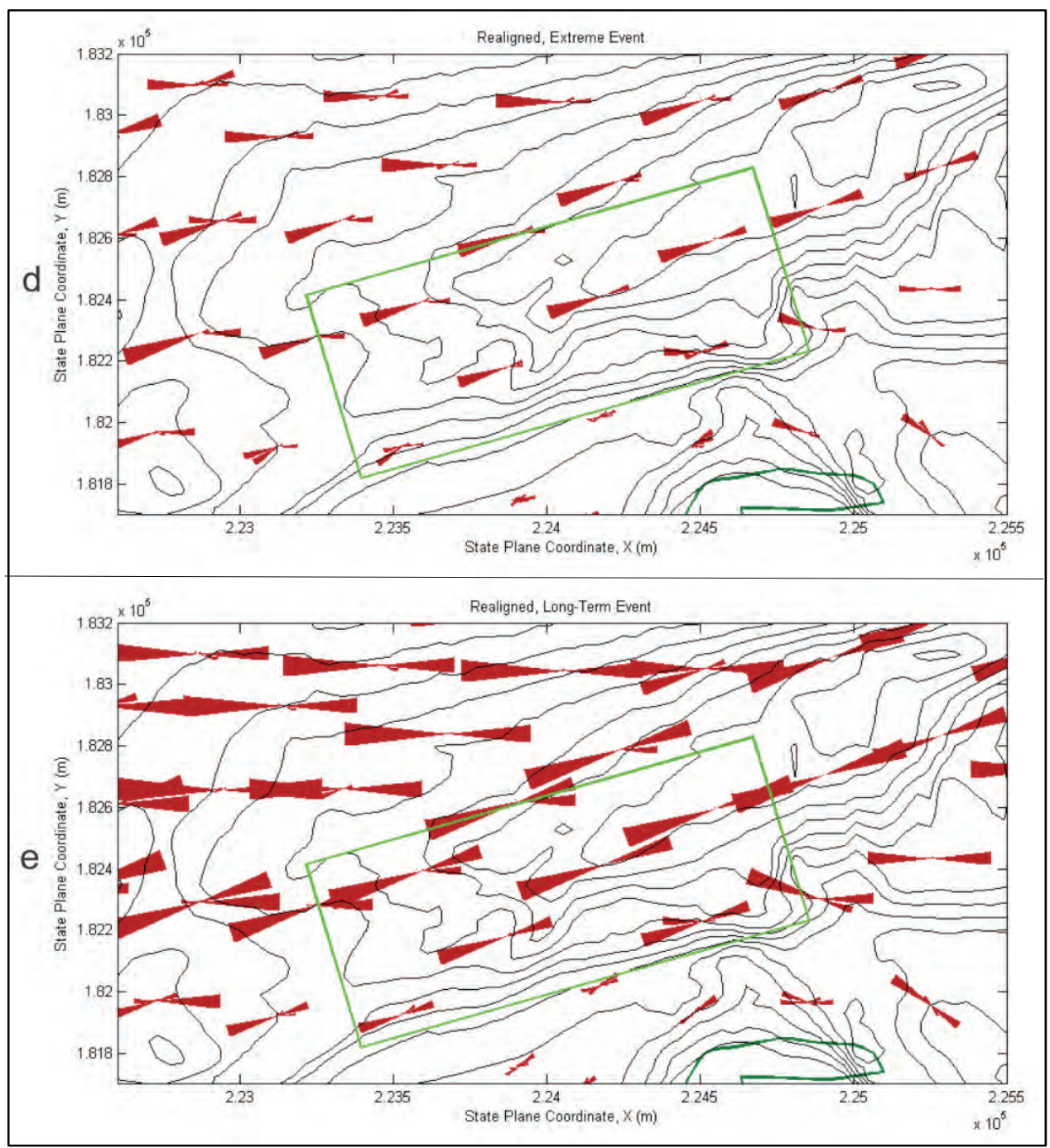

Figure A4 (cont.). GTRAN results for the Realigned Channel at Point Chehalis placement site. 

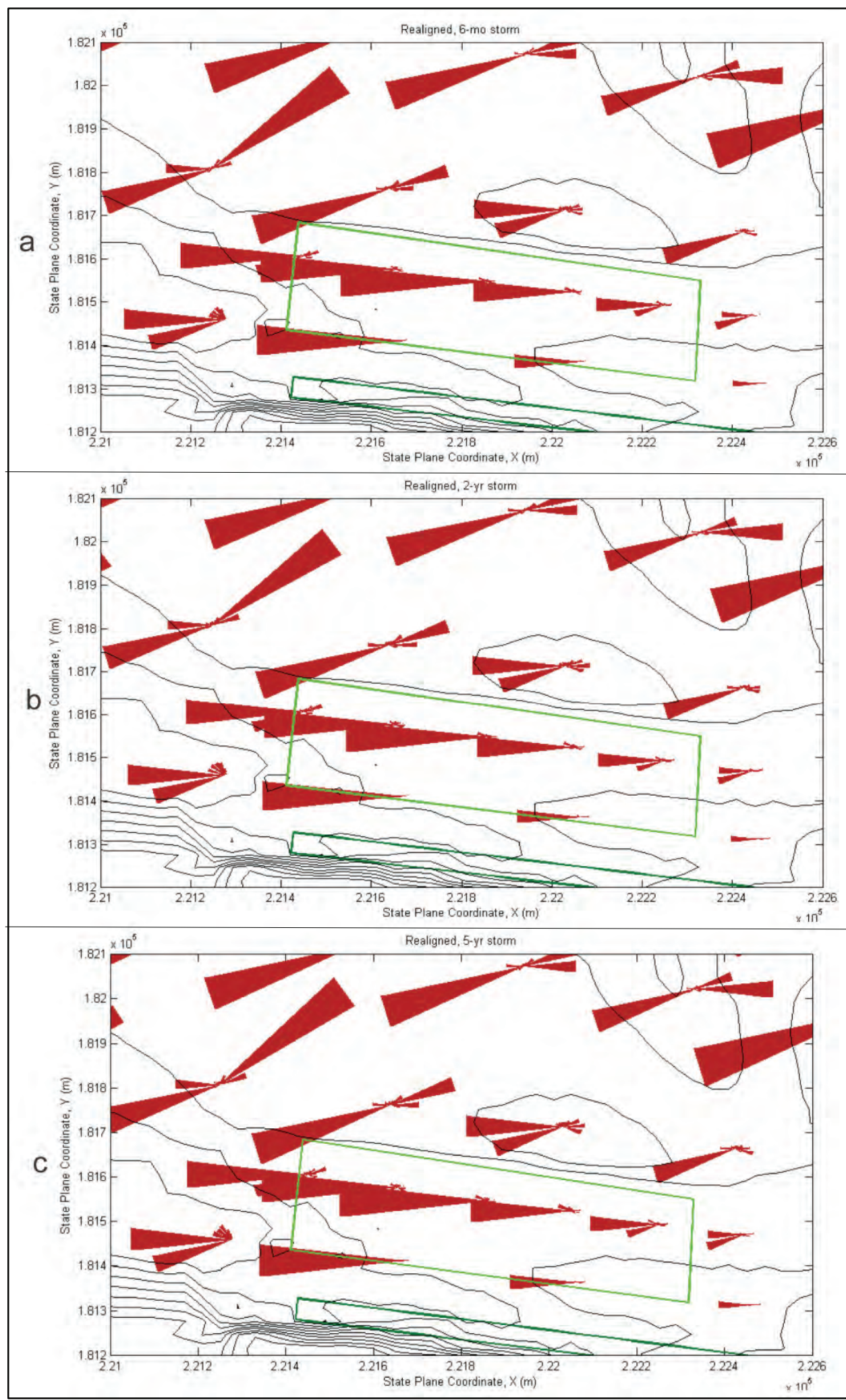

Figure A5. GTRAN results for the Realigned Channel at South Jetty placement site. 


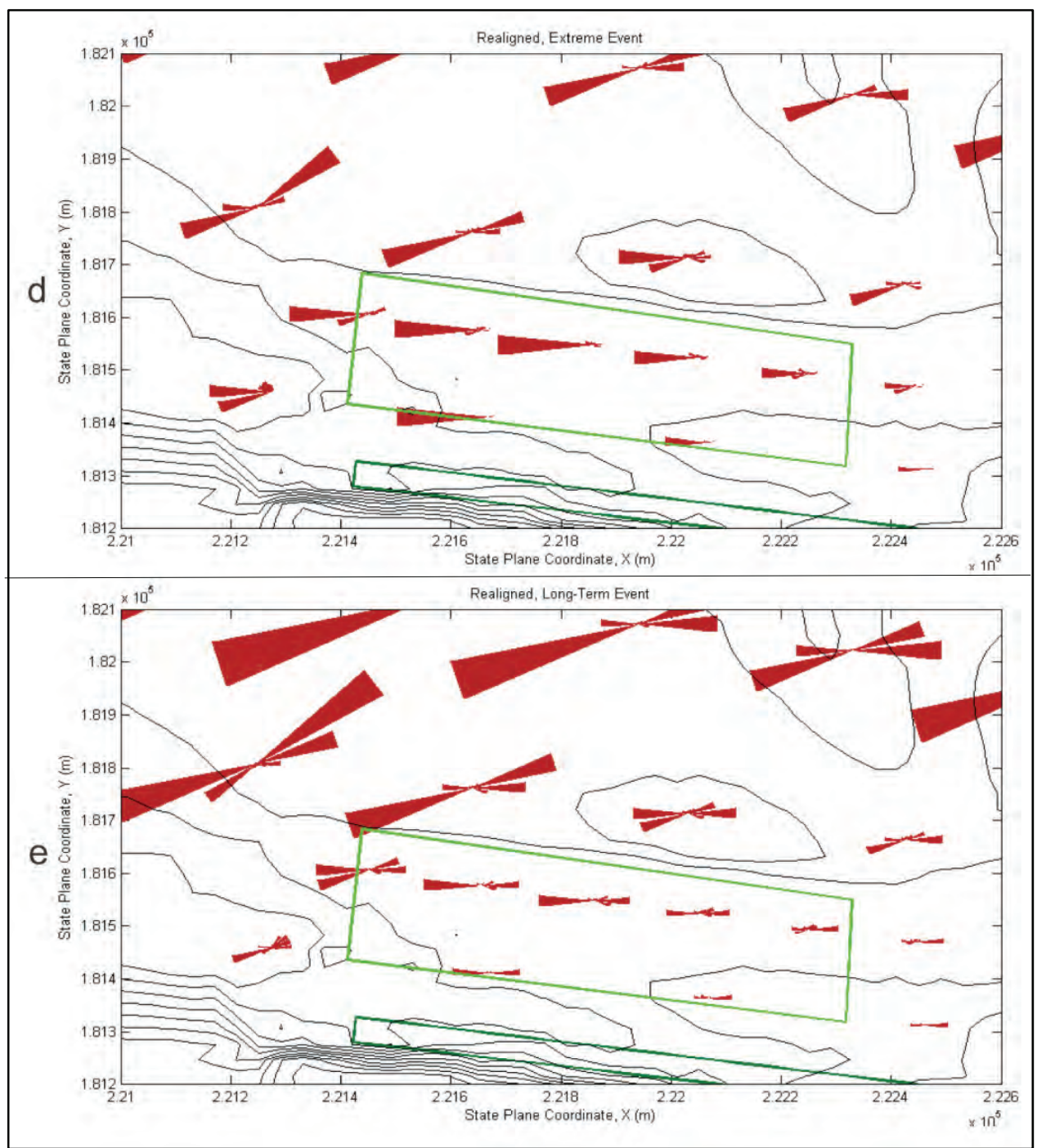

Figure A5 (cont.). GTRAN results for the Realigned Channel at South Jetty placement site. 


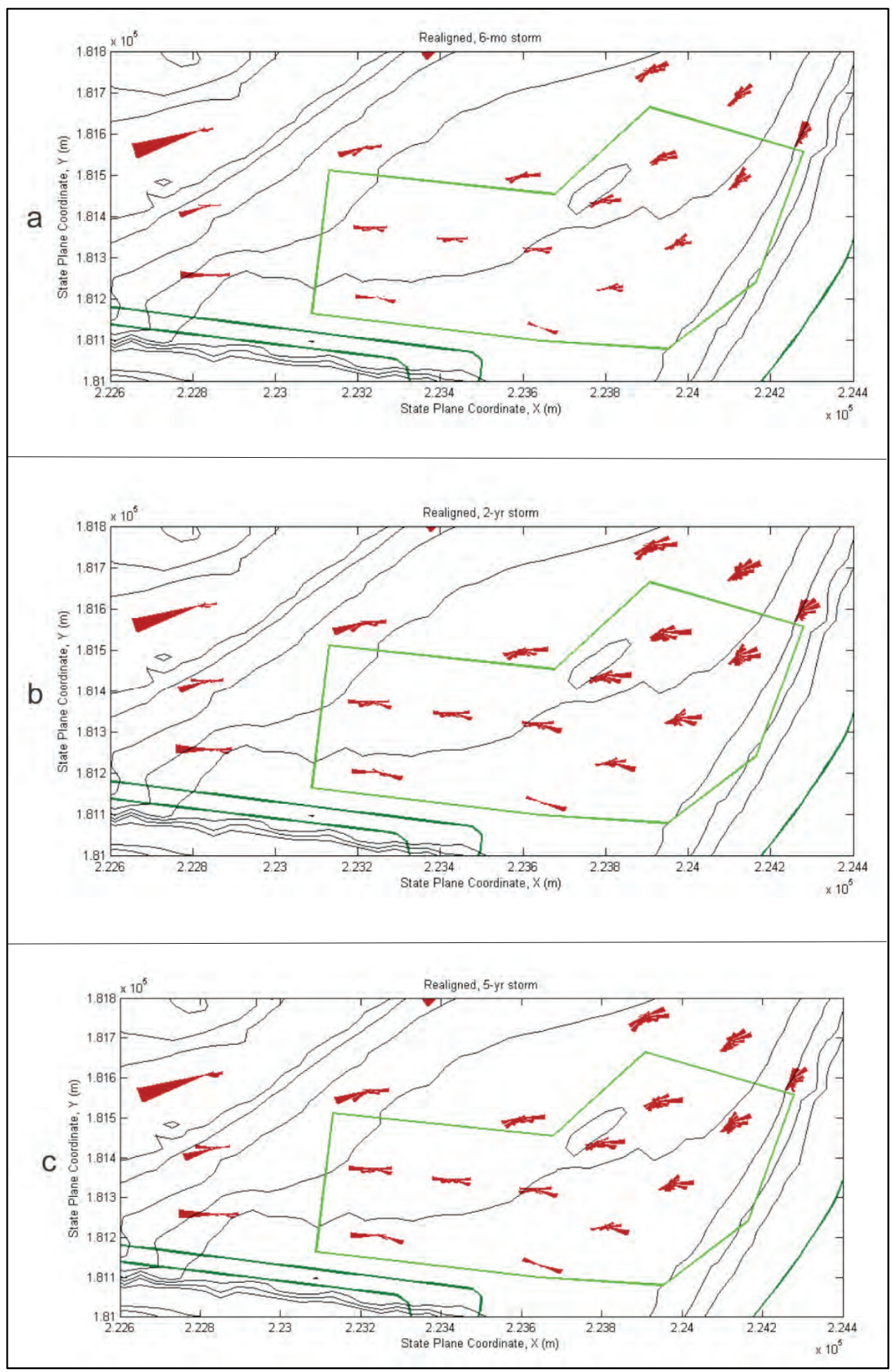

Figure A6. GTRAN results for the Realigned Channel at Half Moon placement site. 


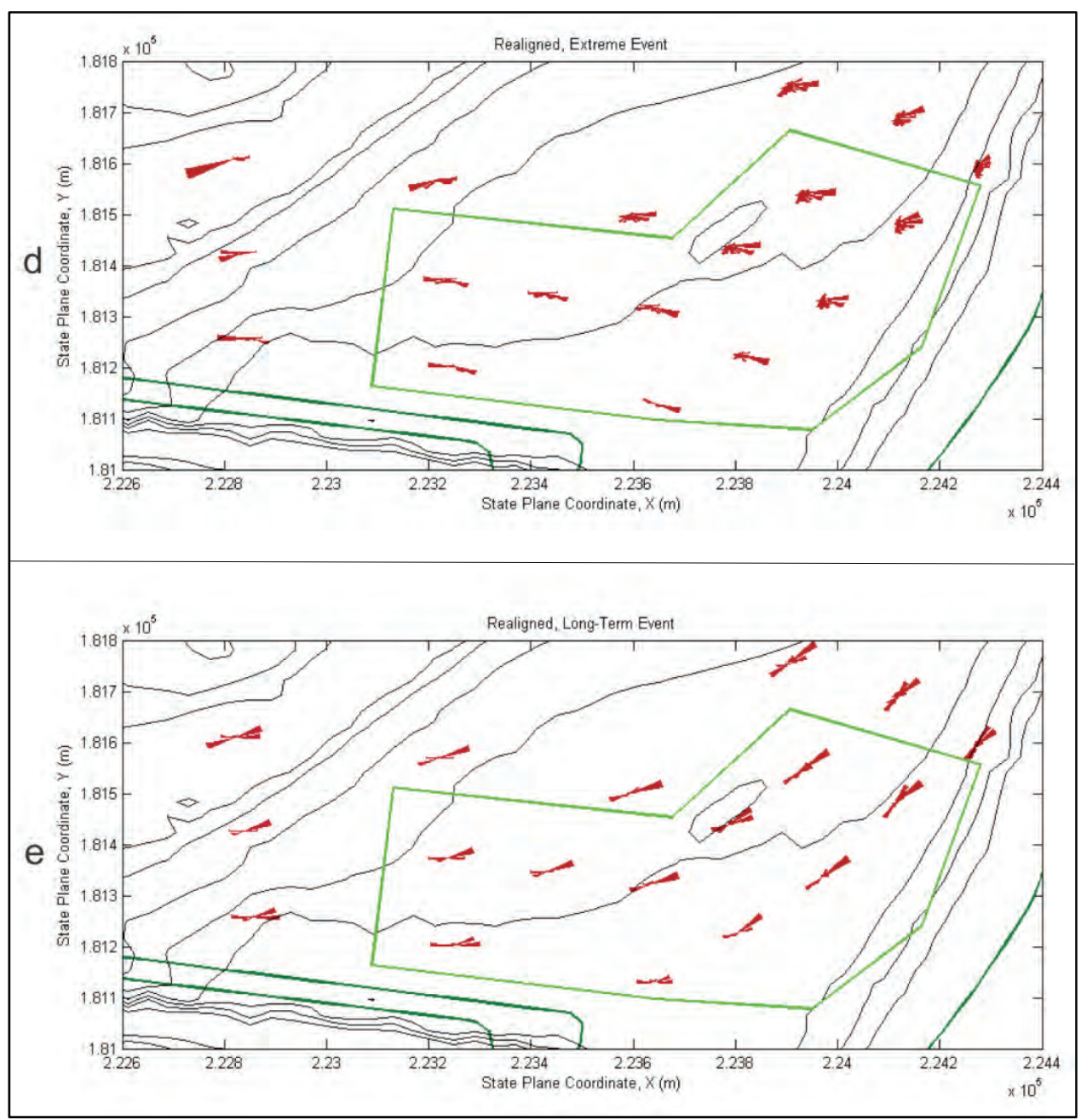

Figure A6 (cont.). GTRAN results for the Realigned Channel at Half Moon placement site. 


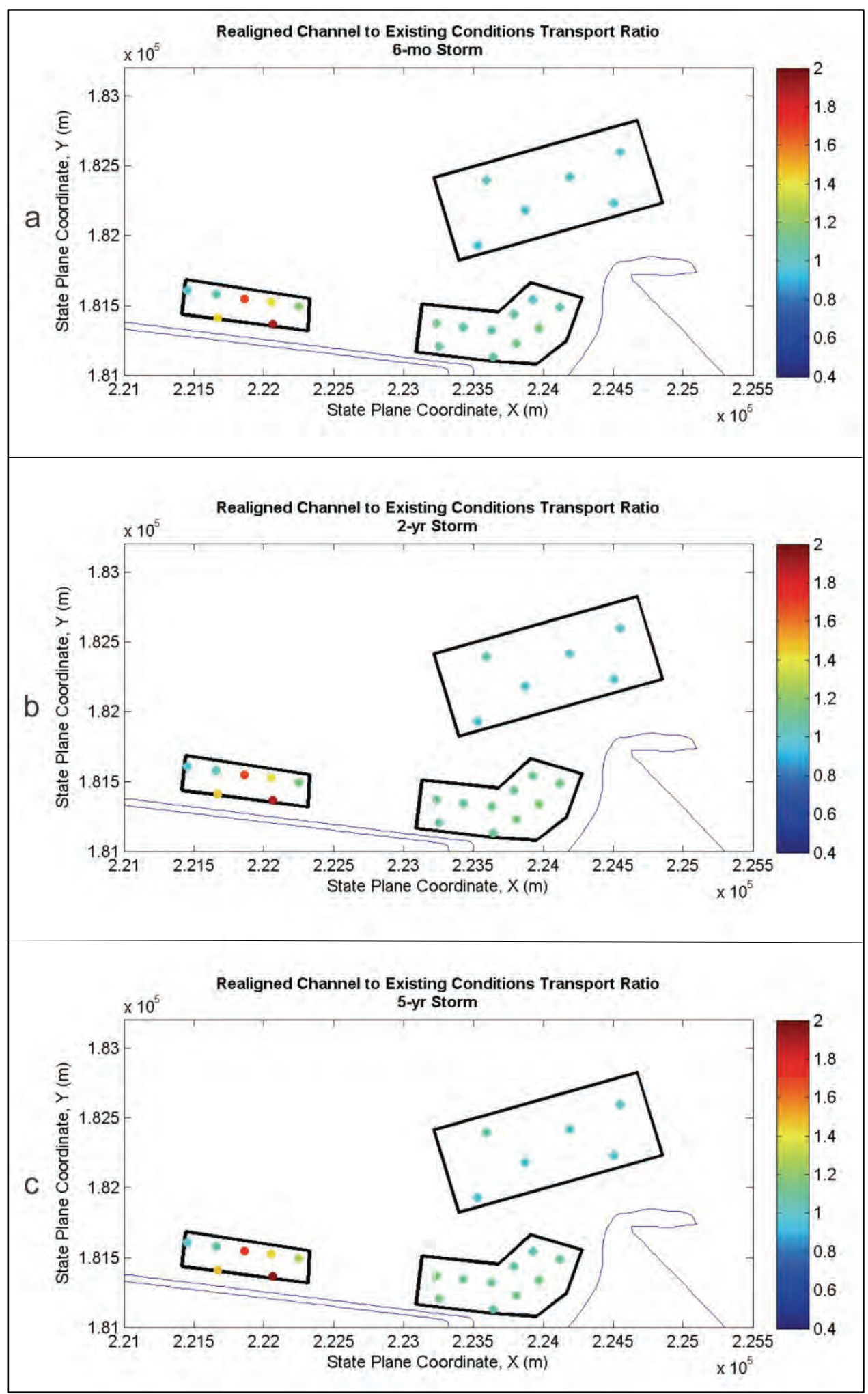

Figure A7. Ratio of transport of Realigned Channel to Existing Channel. 


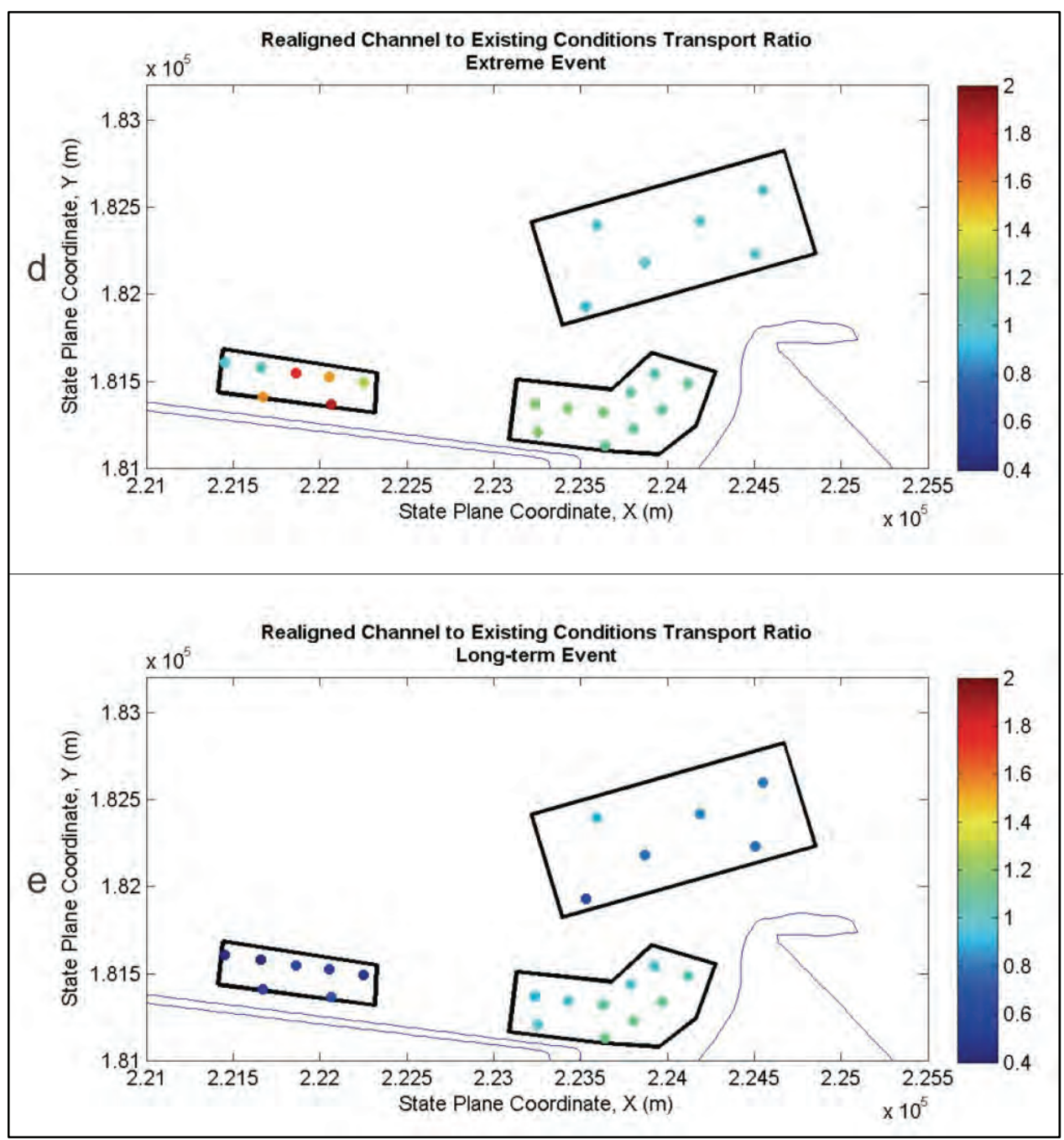

Figure A7 (cont.). Ratio of transport of Realigned Channel to Existing Channel. 


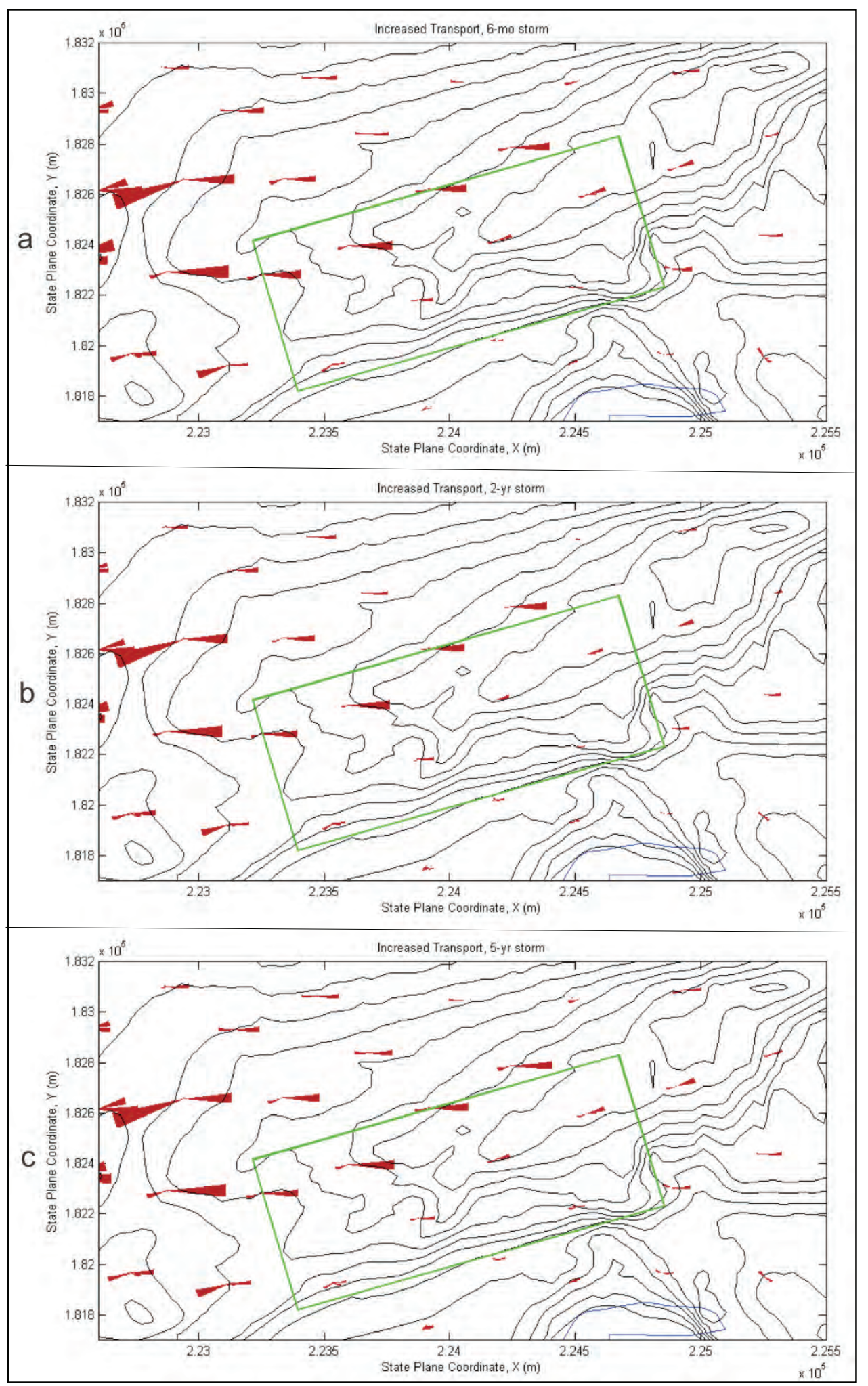

Figure A8. Areas of increased transport at Point Chehalis placement site with Realigned Channel. 


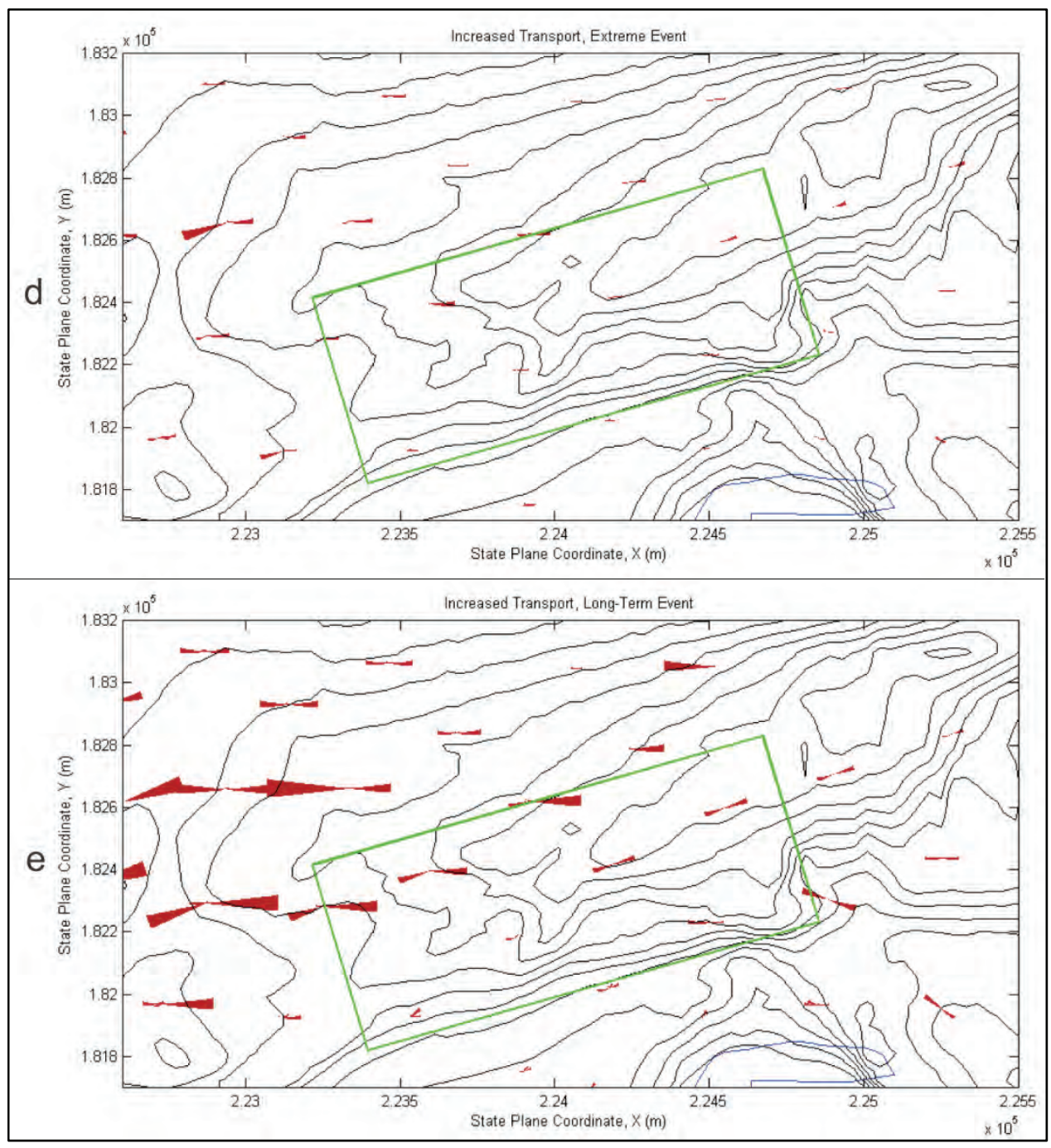

Figure A8 (cont.). Areas of increased transport at Point Chehalis placement site with Realigned Channel. 


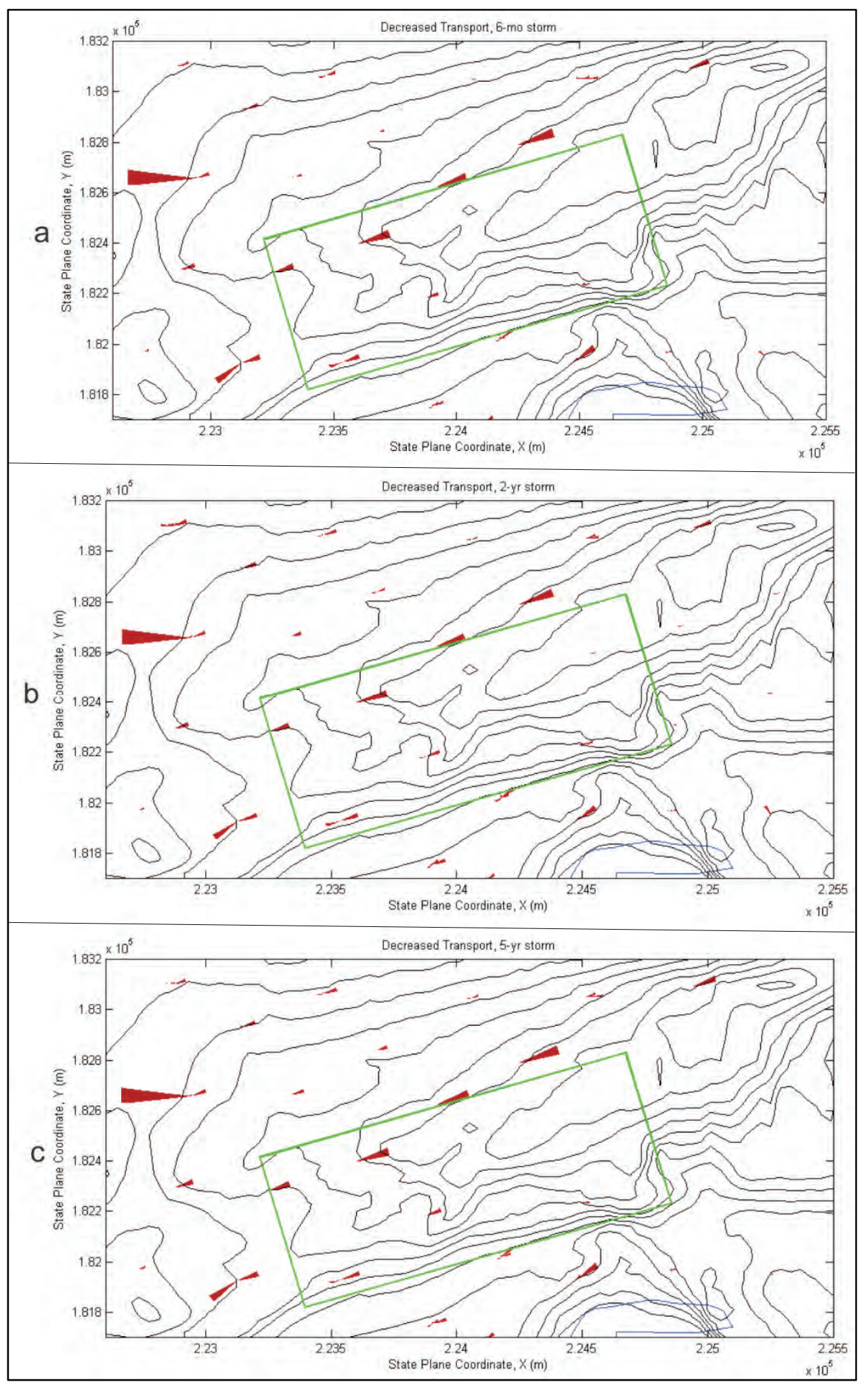

Figure A9. Areas of decreased transport at Point Chehalis placement site with Realigned Channel. 


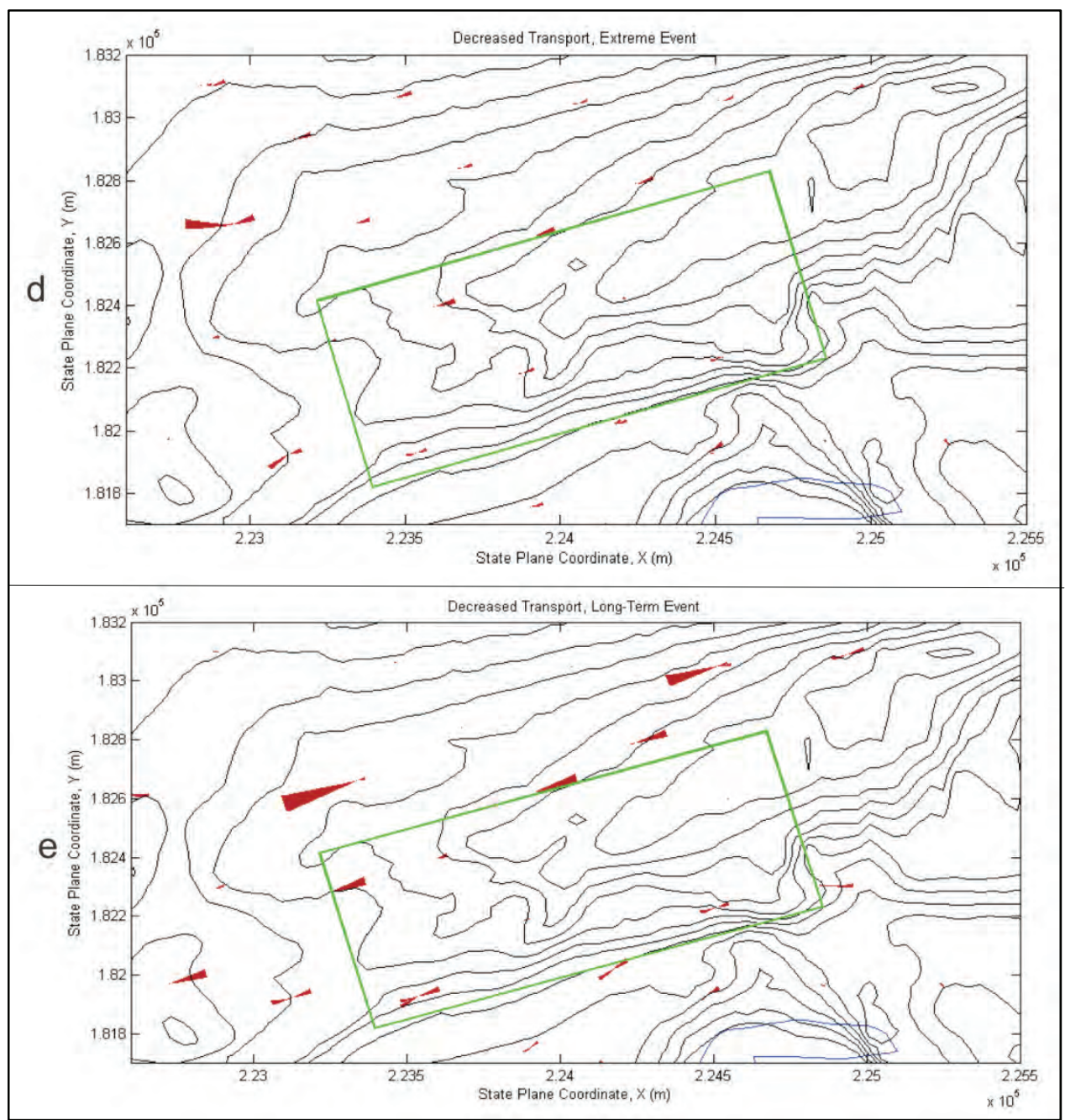

Figure A9 (cont.). Areas of decreased transport at Point Chehalis placement site with Realigned Channel. 
ERDC/CHL TR-10-13

226

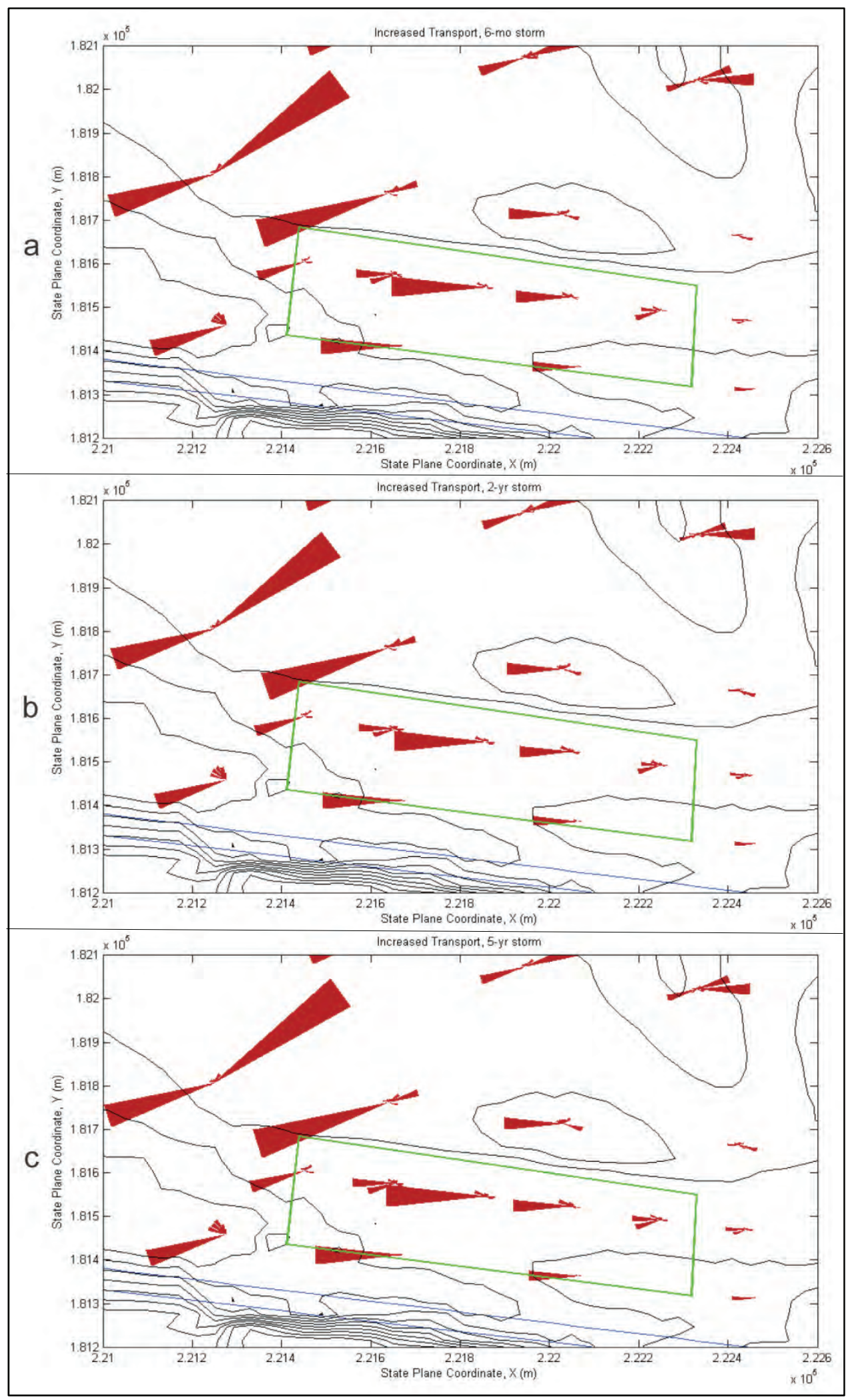

Figure A10. Areas of increased transport at South Jetty placement site with Realigned Channel. 


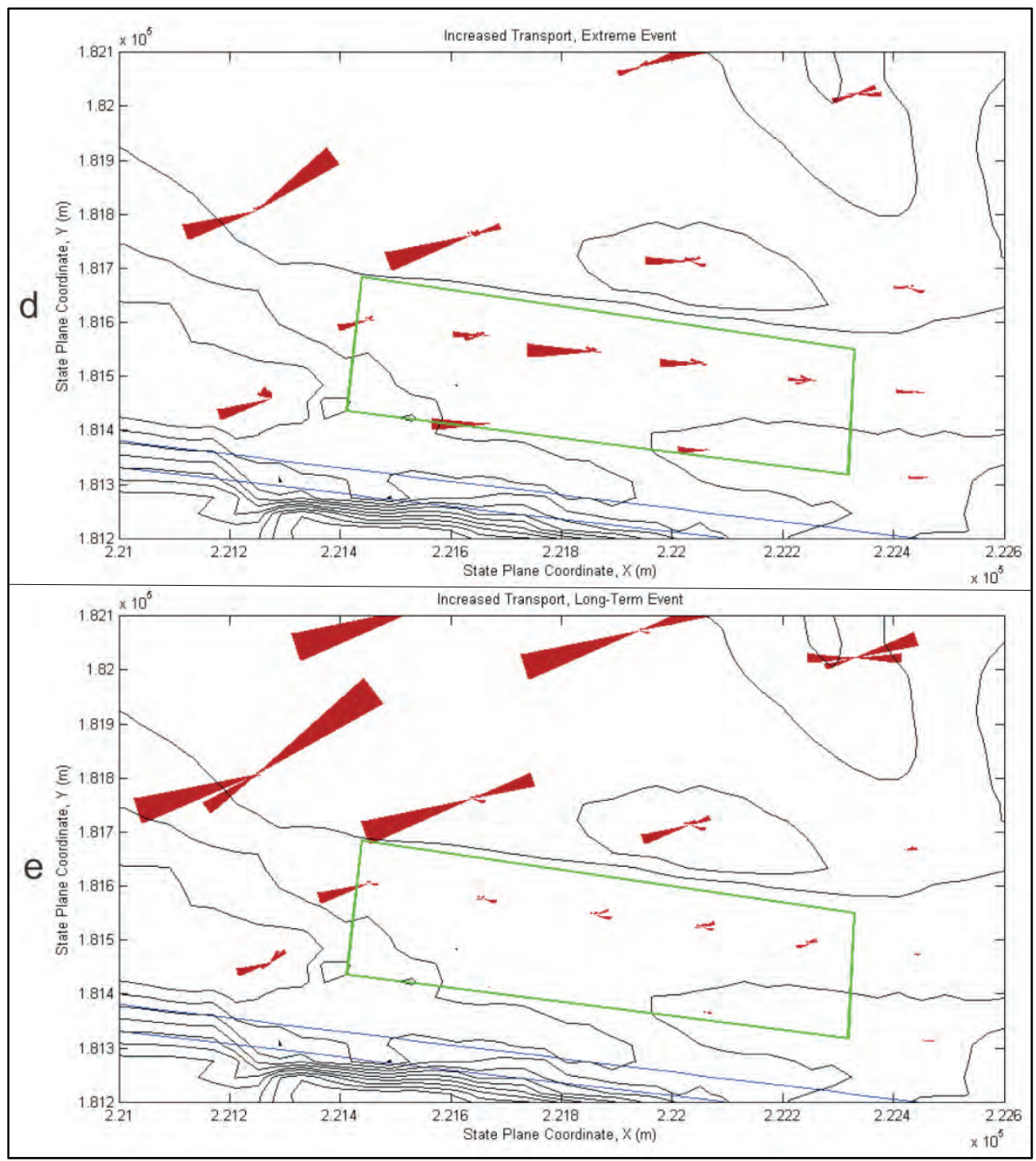

Figure A10 (cont.). Areas of increased transport at South Jetty placement site with Realigned Channel. 


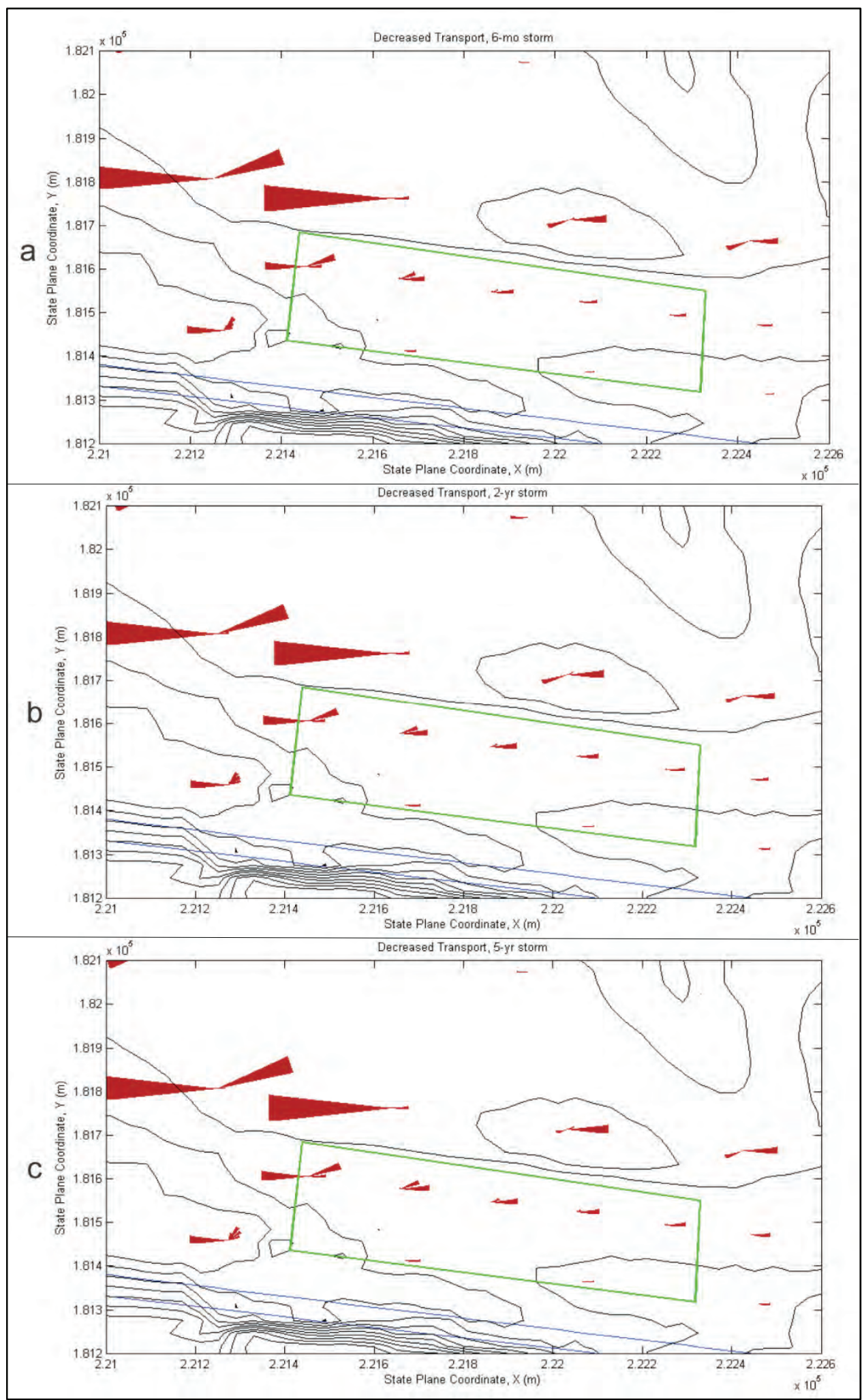

Figure A11. Areas of decreased transport at South Jetty placement site with Realigned Channel. 


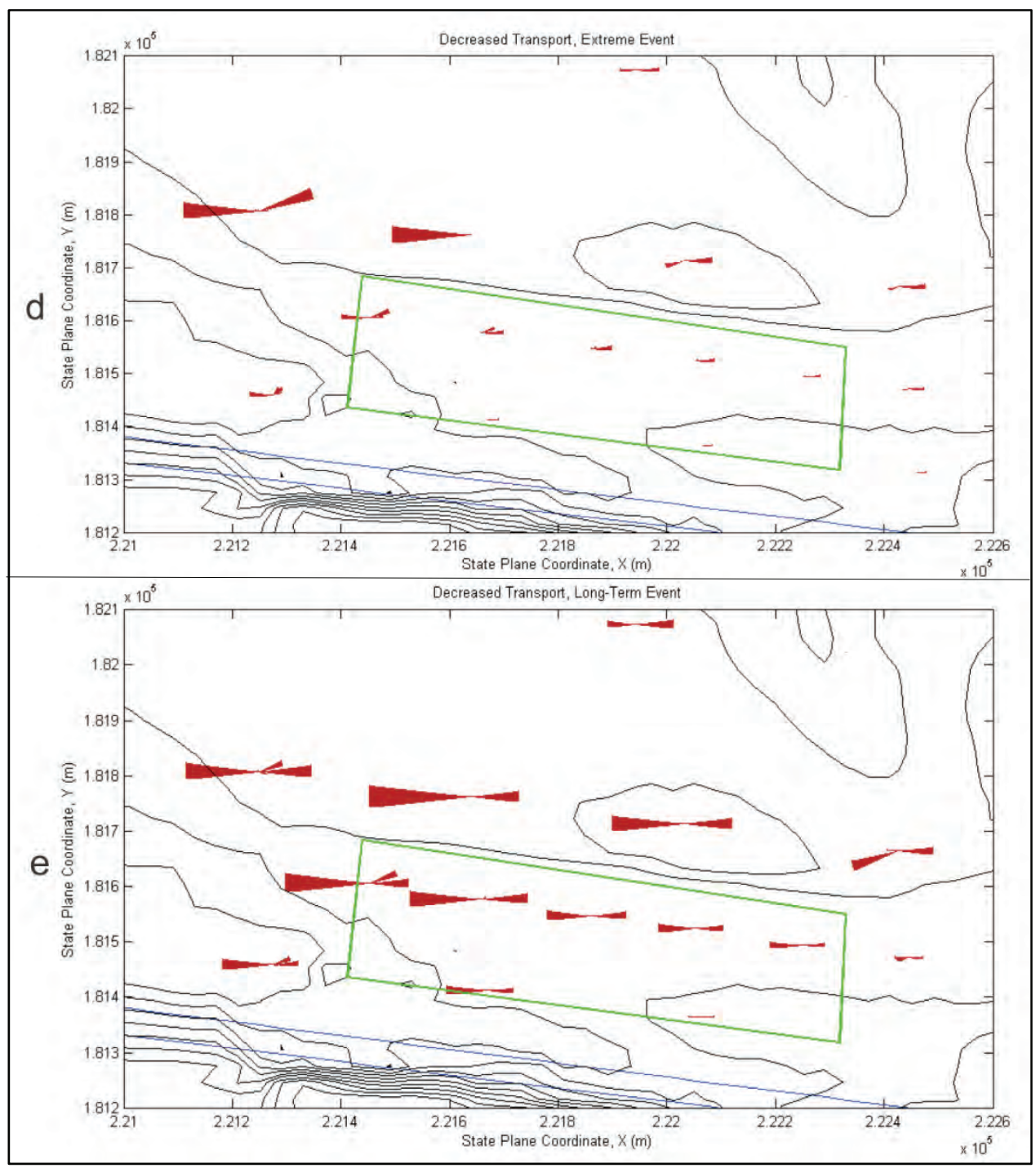

Figure A11 (cont.). Areas of decreased transport at South Jetty placement site with Realigned Channel. 


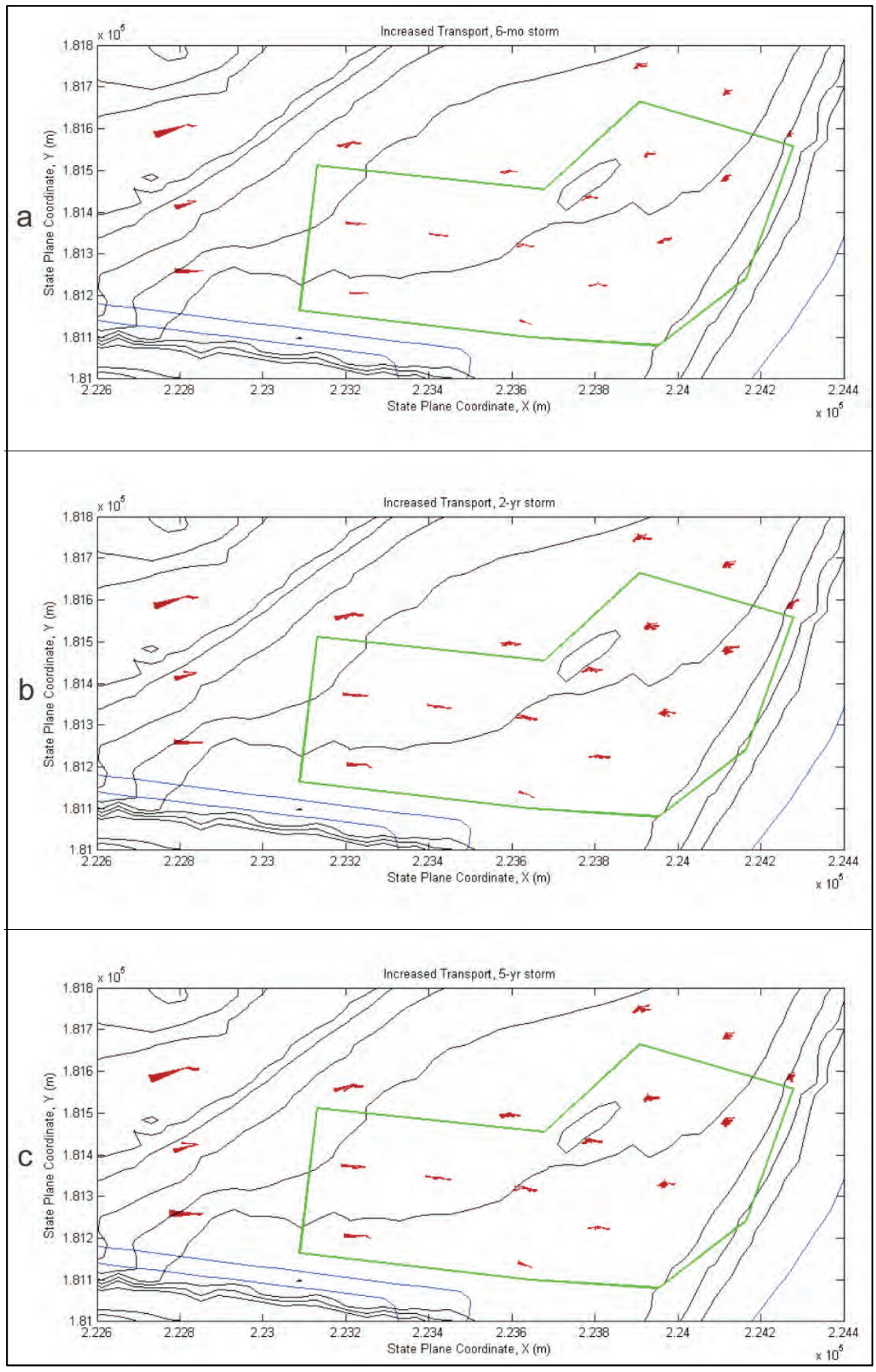

Figure A12. Areas of increased transport at Half Moon placement site with Realigned Channel . 


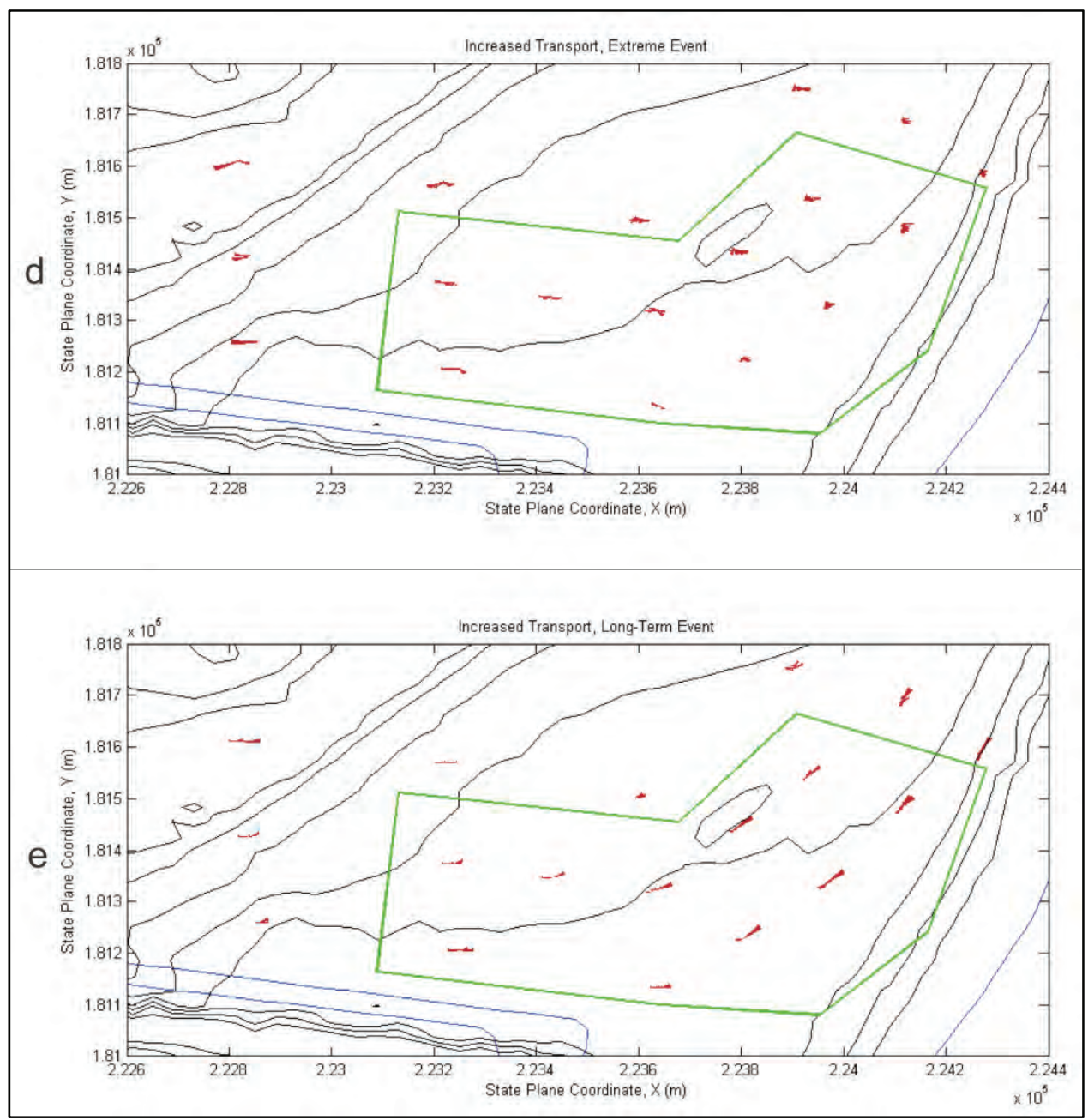

Figure A12 (cont.). Areas of increased transport at Half Moon placement site with Realigned Channel. 


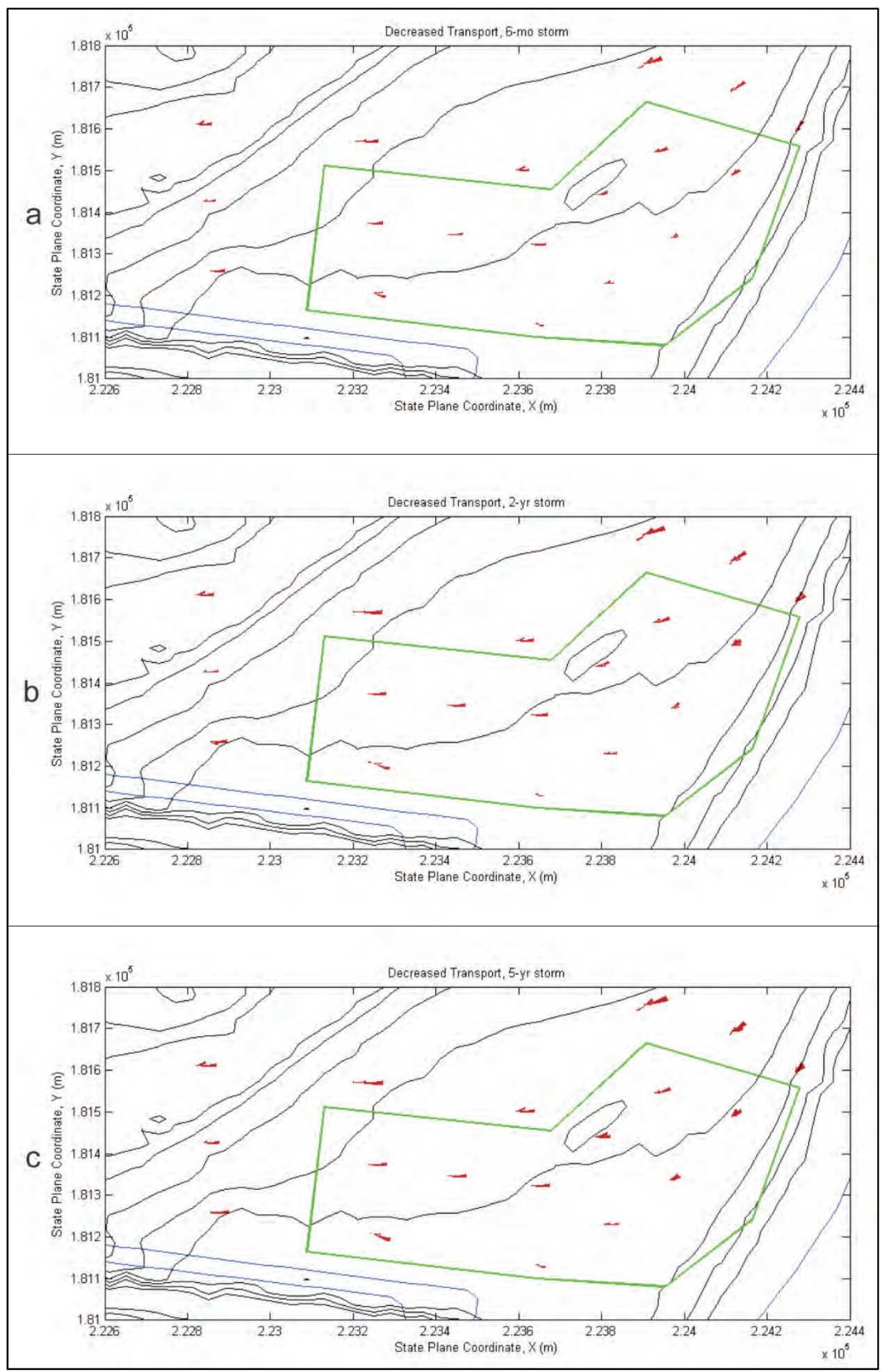

Figure A13. Areas of decreased transport at Half Moon placement site with Realigned Channel. 


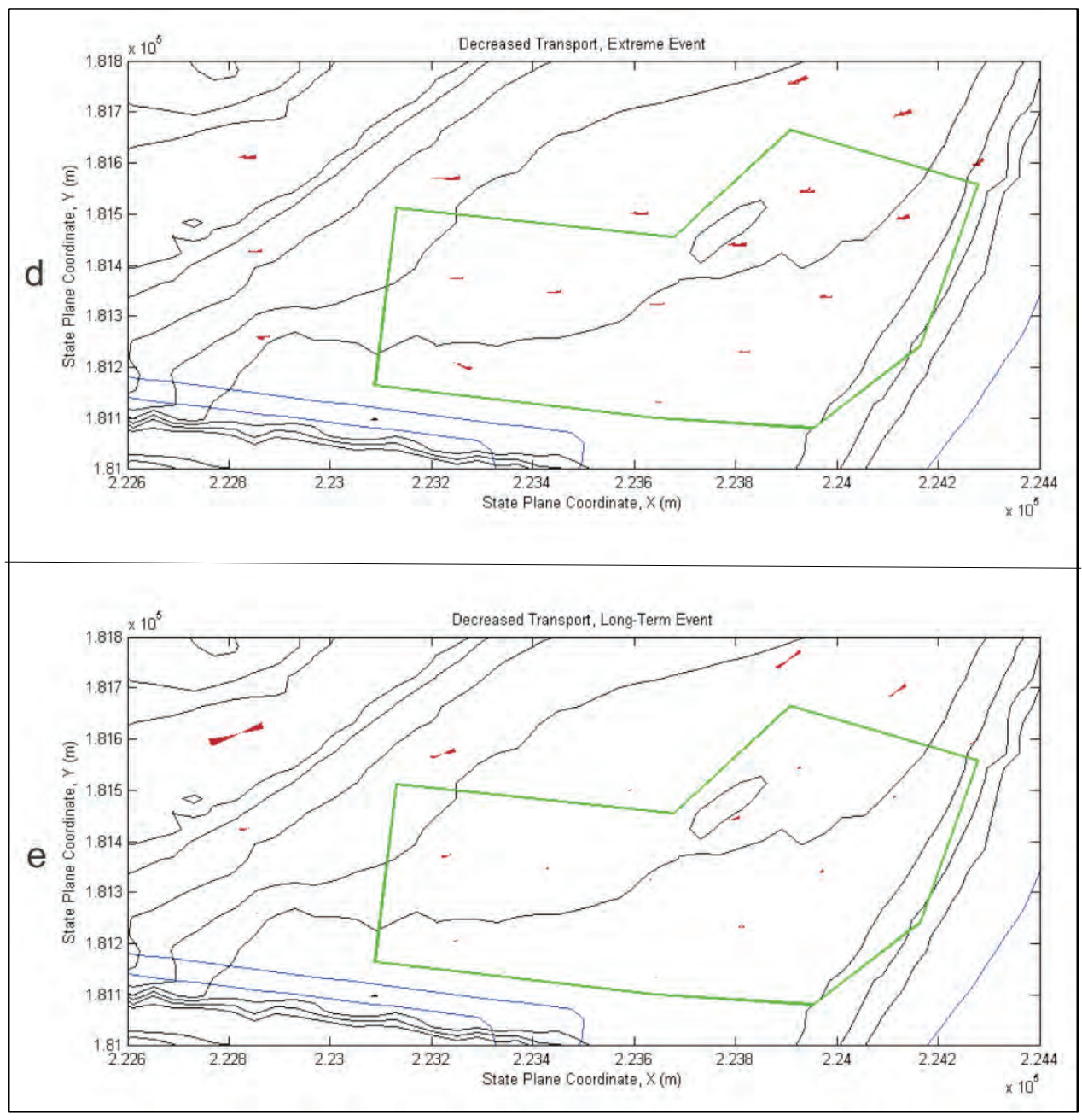

Figure A13 (cont.). Areas of decreased transport at Half Moon placement site with Realigned Channel. 


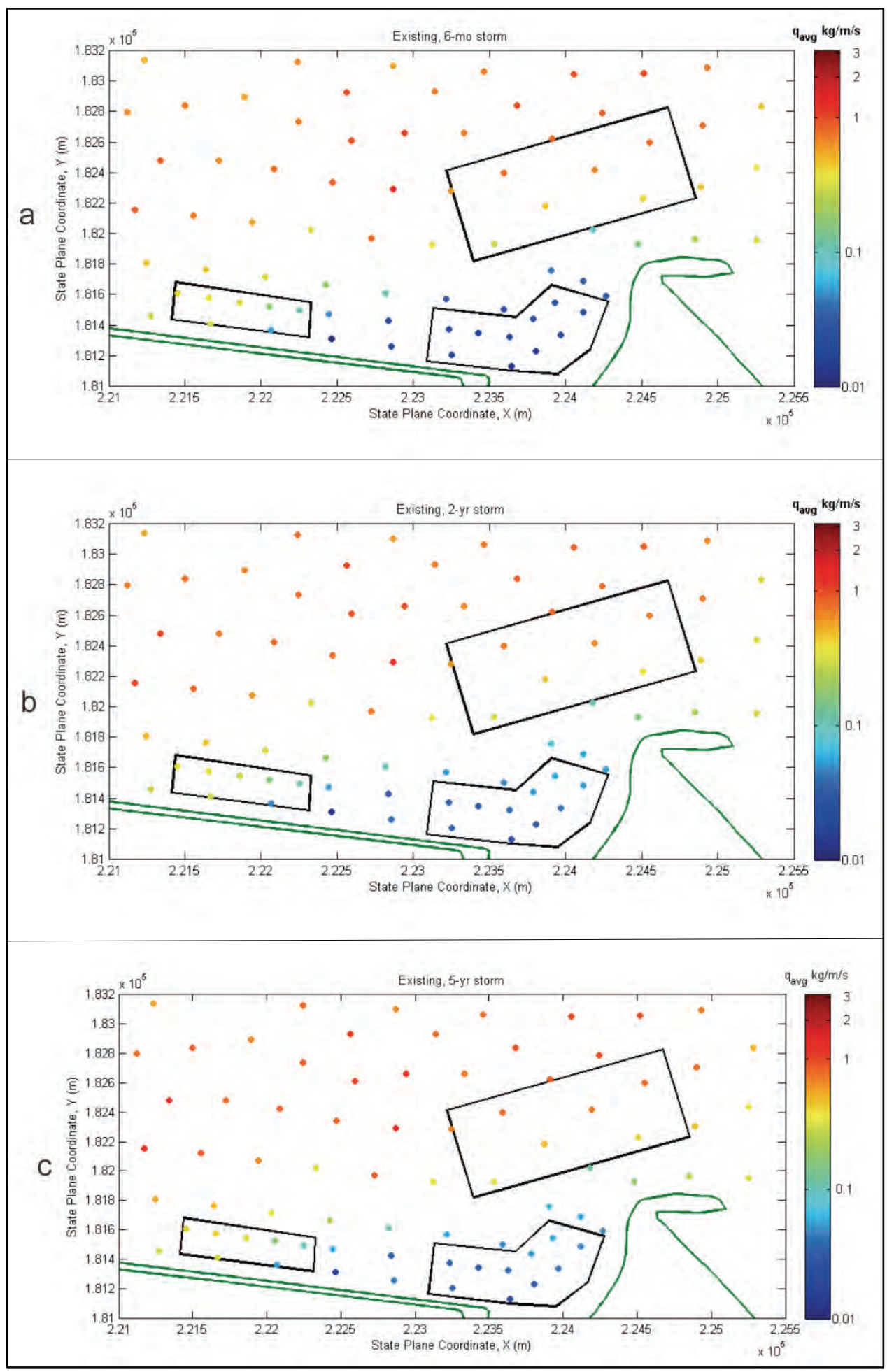

Figure A14. Average transport rate for the Existing Channel. 


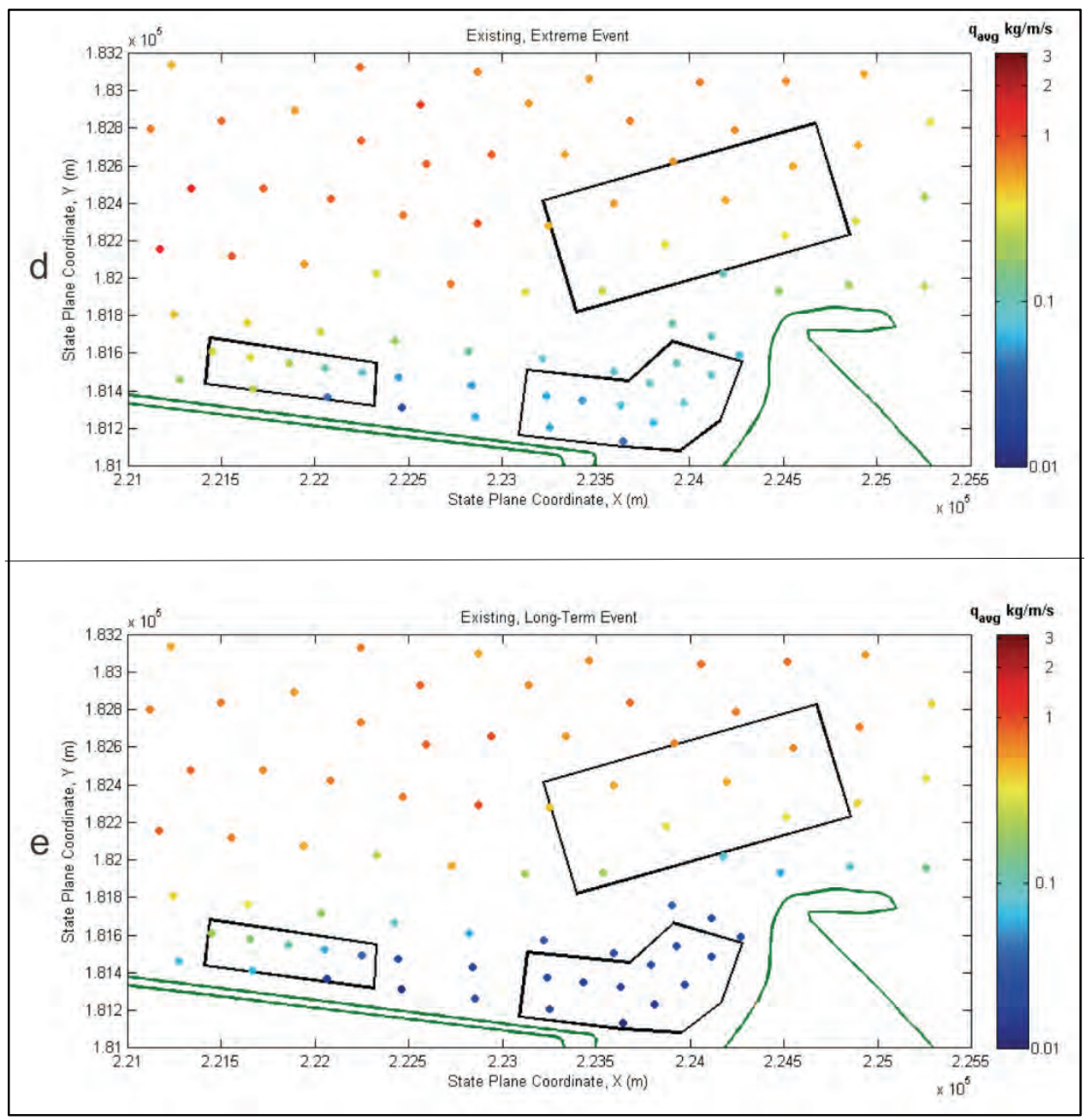

Figure A14 (cont.). Average transport rate for the Existing Channel. 


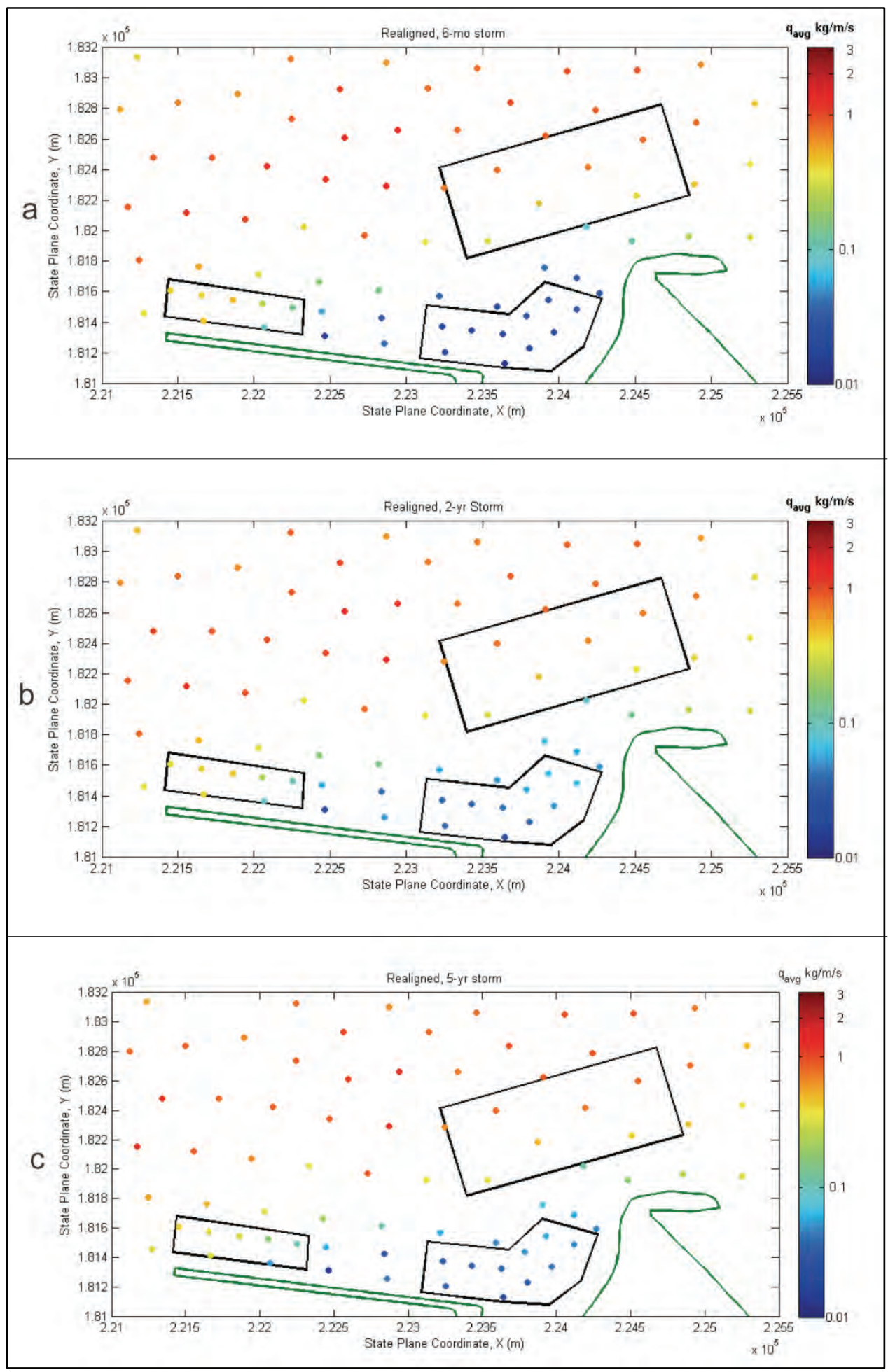

Figure A15. Average transport rate for the Realigned Channel. 


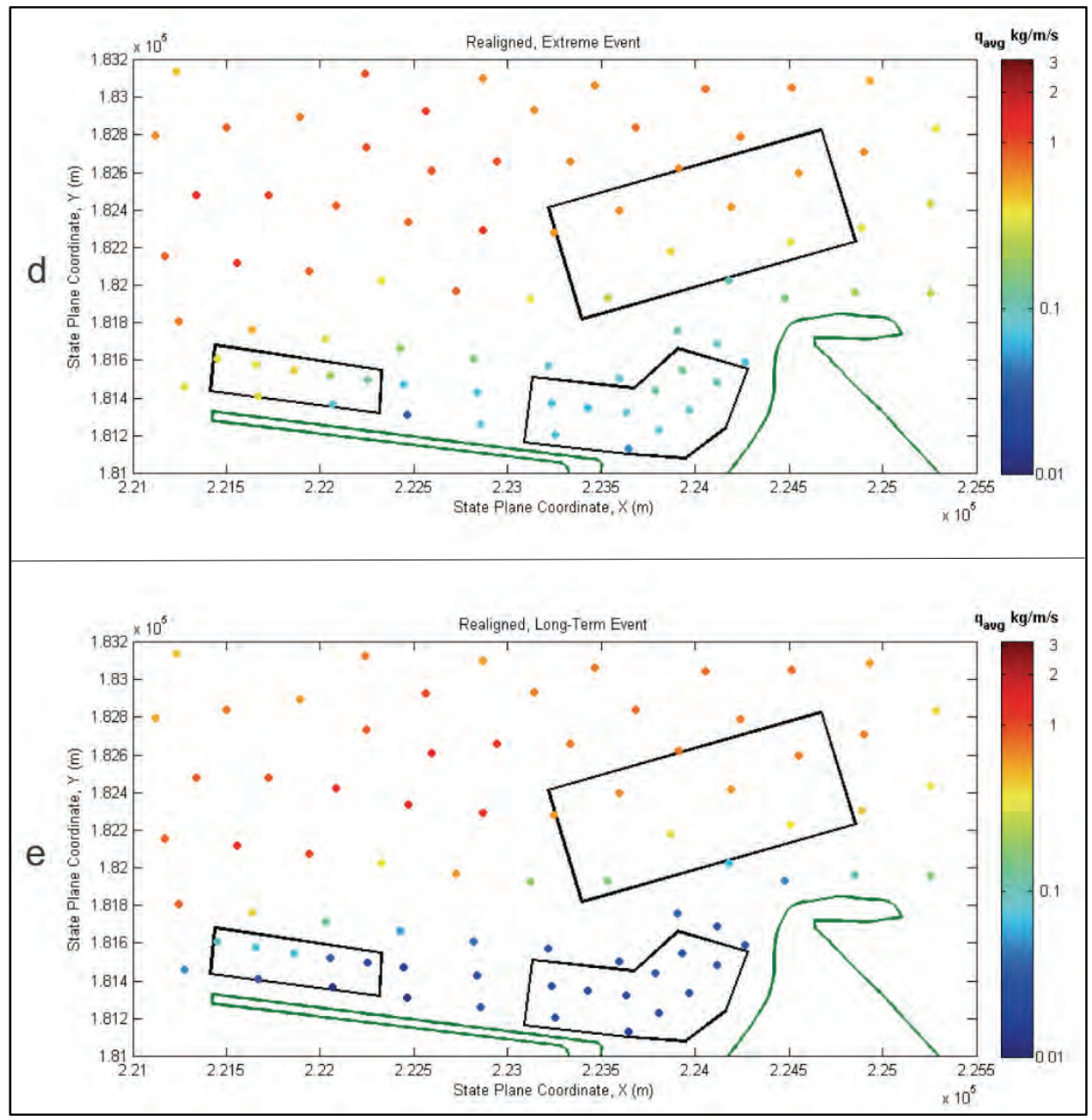

Figure A15 (cont.). Average transport rate for the Realigned Channel. 


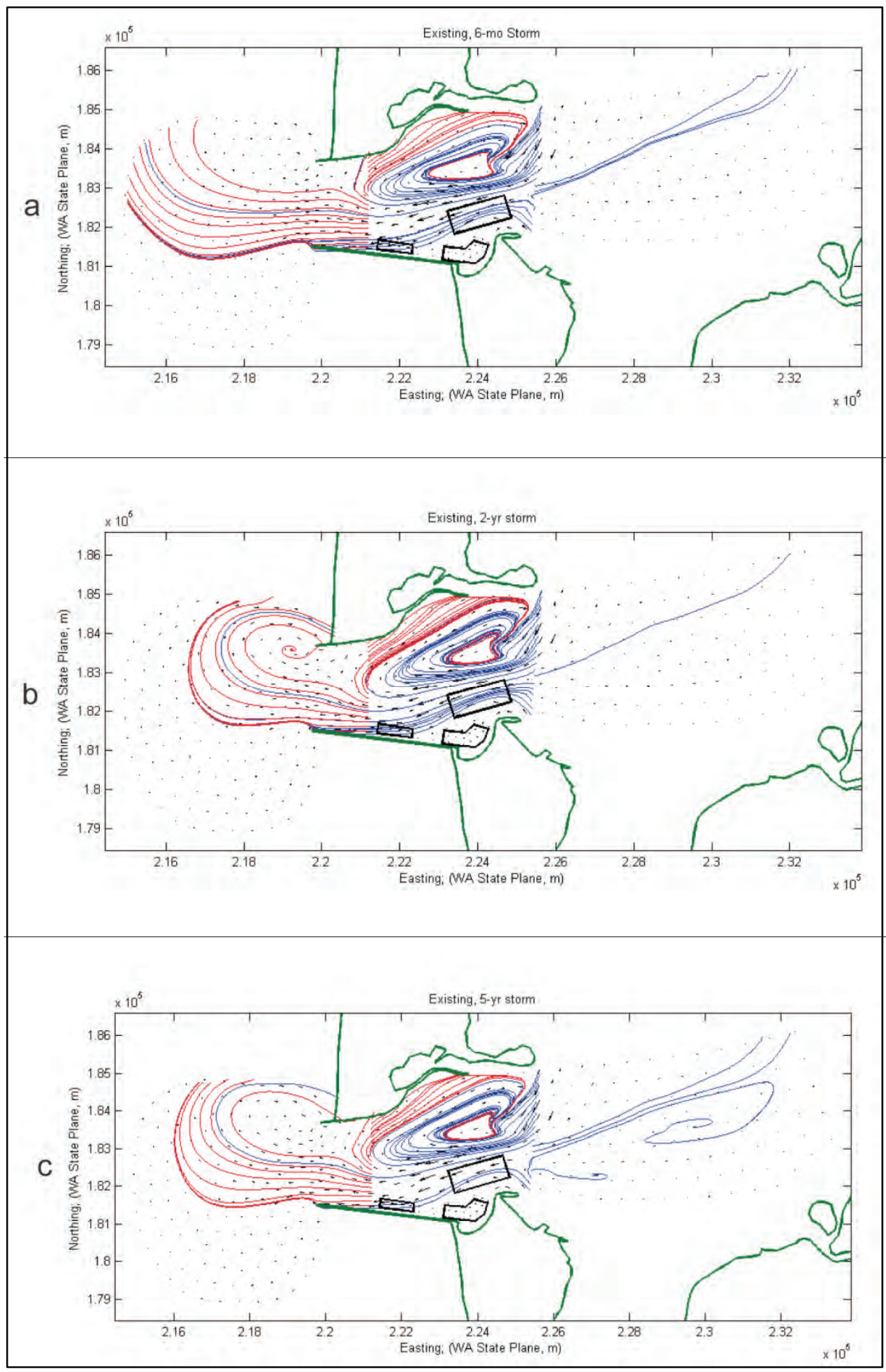

Figure A16. Transport streamlines for the Existing Channel. 


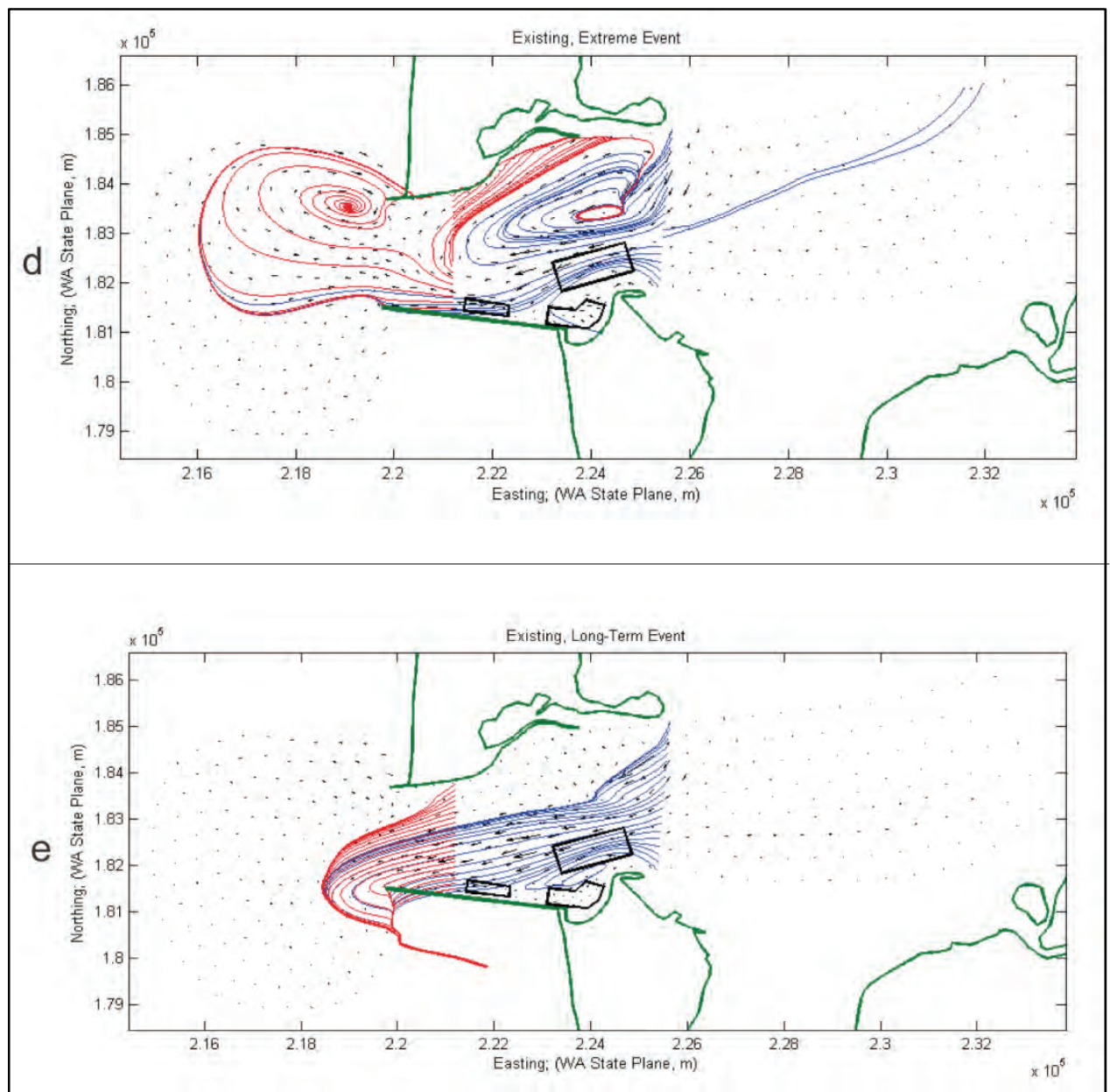

Figure A16 (cont.). Transport streamlines for the Existing Channel. 


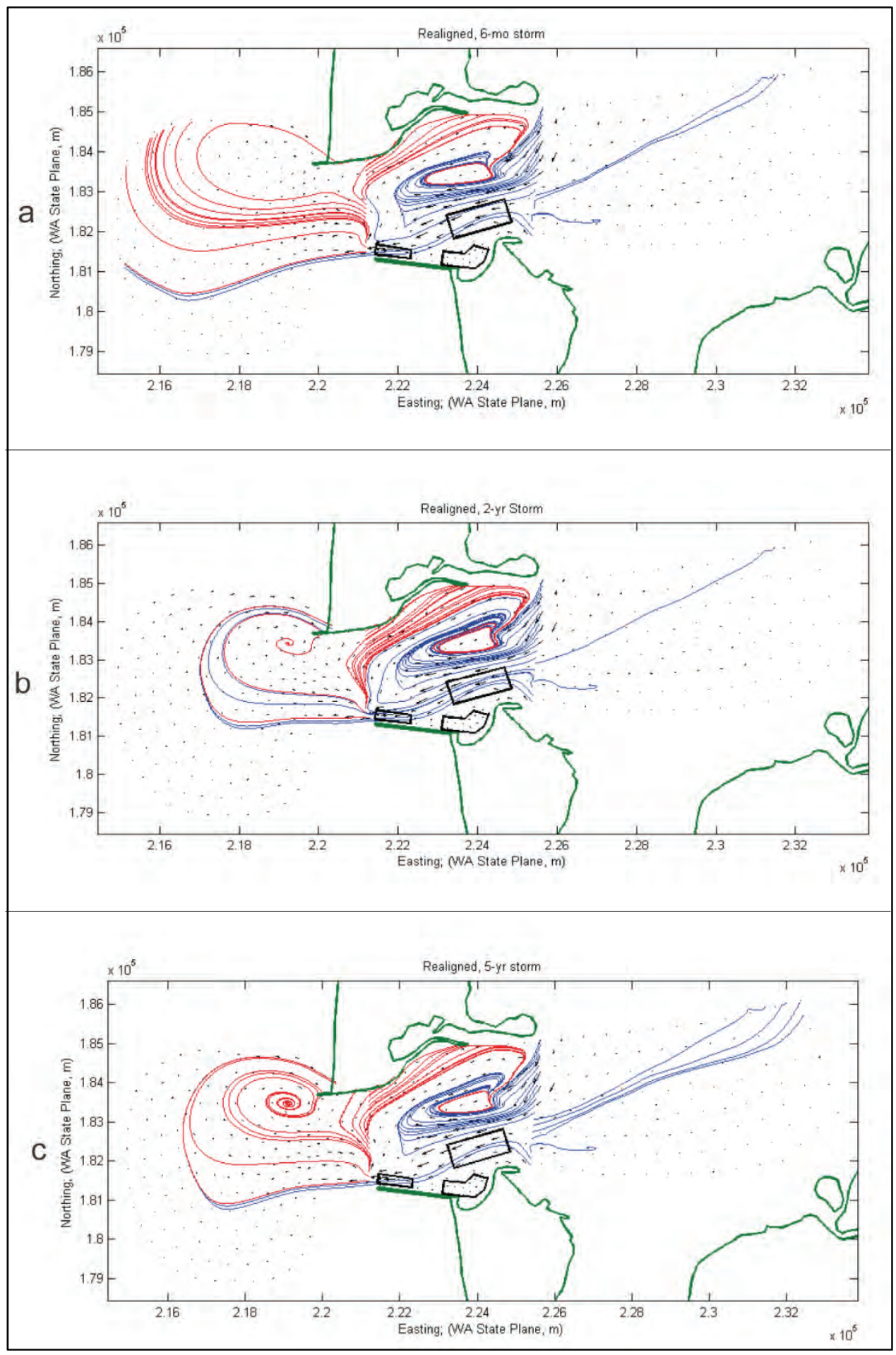

Figure A17. Transport streamlines for the Realigned Channel. 


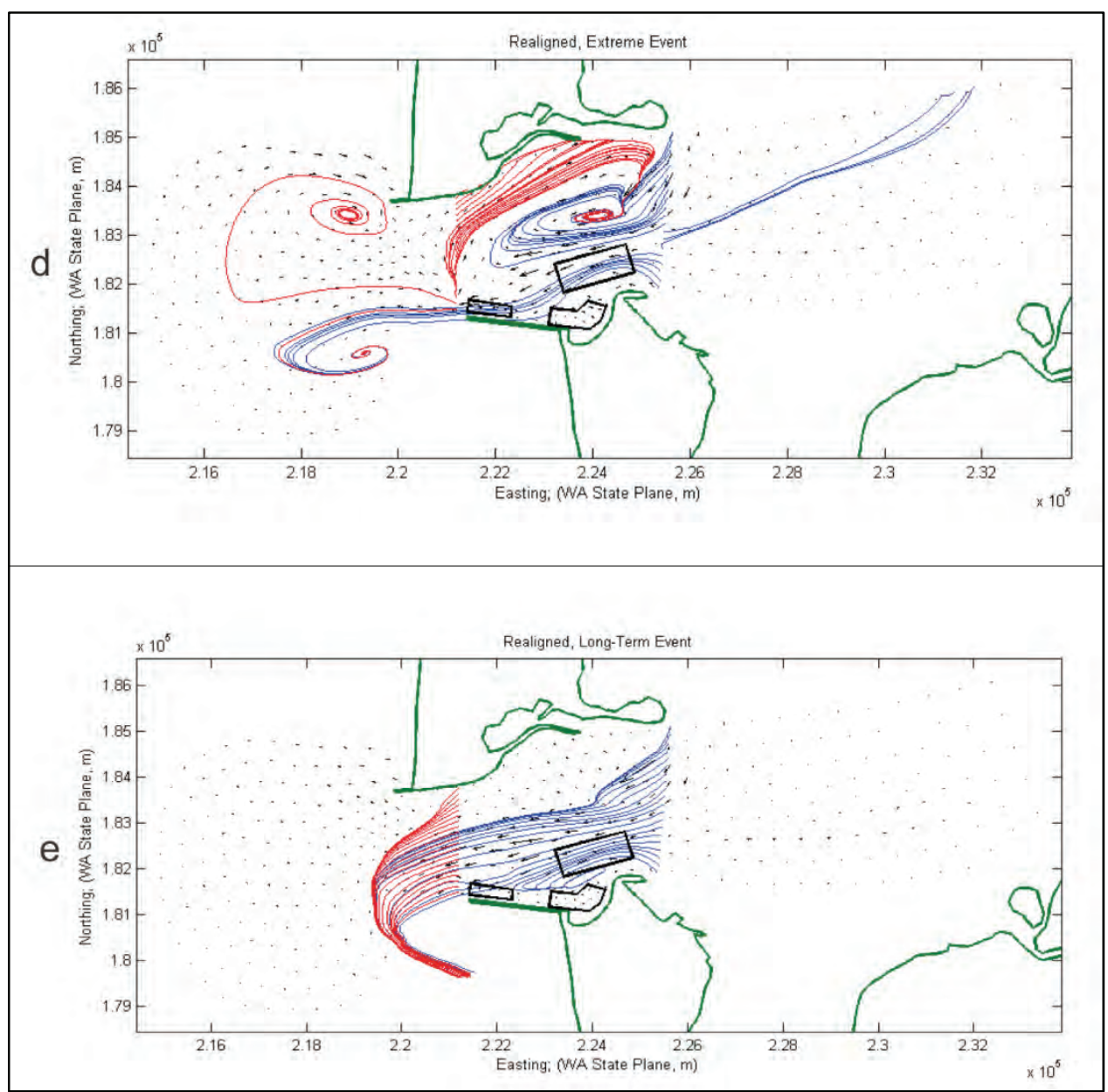

Figure A17 (cont.). Transport streamlines for the Realigned Channel . 


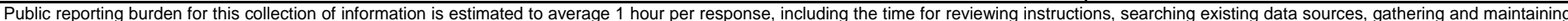

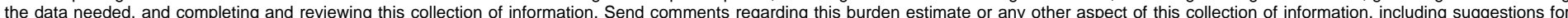

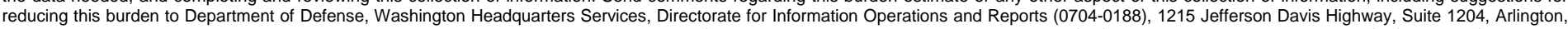

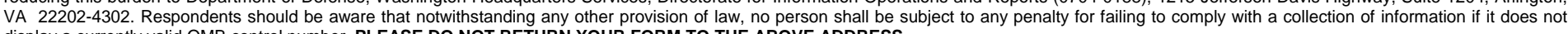
display a currently valid OMB control number. PLEASE DO NOT RETURN YOUR FORM TO THE ABOVE ADDRESS.
1. REPORT DATE (DD-MM-YYYY)
2. REPORT TYPE
December 2010
Final report
DATES COVERED (From - To)

\section{TITLE AND SUBTITLE}

Waves, Hydrodynamics and Sediment Transport Modeling at Grays Harbor, WA

5a. CONTRACT NUMBER

5b. GRANT NUMBER

5c. PROGRAM ELEMENT NUMBER

\section{AUTHOR(S)}

Zeki Demirbilek, Lihwa Lin, Jarrell Smith, Earl Hayter, Ernest Smith, Joseph Gailani, Gregory Norwood, and David Michalsen

\section{5d. PROJECT NUMBER}

5e. TASK NUMBER

5f. WORK UNIT NUMBER

8. PERFORMING ORGANIZATION REPORT NUMBER

ERDC/CHL TR-10-13

U.S. Army Engineer Research and Development Center

Coastal and Hydraulics Laboratory

3909 Halls Ferry Road

Vicksburg, MS 39180-6199

9. SPONSORING I MONITORING AGENCY NAME(S) AND ADDRESS(ES)

U.S. Army Corps of Engineers, Seattle District

P.O. Box 3755

Seattle, WA 98124-3755

4735 East Marginal Way South

Seattle, WA 98134-2385

\section{DISTRIBUTION / AVAILABILITY STATEMENT}

Approved for public release; distribution is unlimited

\section{SUPPLEMENTARY NOTES}

\section{ABSTRACT}

This numerical modeling study was performed for the purpose of addressing short-term and mid-term dredge material management issues for the Federal Navigation Project at Grays Harbor, Washington. Seattle District (NWS) is also currently evaluating Grays Harbor navigation channel realignment in the Point Chehalis/Entrance reach. Historic trends in survey data indicate this area is naturally scouring a new thalweg. The realigned channel would take advantage of this new thalweg developing just north of the present channel, and relocating the channel is hypothesized to reduce annual dredging quantities. The impact of dredged material placement sites on channel maintenance is also examined. The three dredged disposal sites of interest considered in the present study are the Point Chehalis Disposal Site (PCDS), South Jetty Disposal Site (SJDS), and Half Moon Bay Beneficial Use Site (HMBBUS). Currently, the inner harbor sediments (silts/clays) are placed exclusively at the PCDS and SJDS, and the outer channel sediments (>95\% marine sand) are placed at the three sites. The NWS is considering the realignment of the Point Chehalis/Entrance reach of GH navigation channel in an attempt to establish optimal locations for the PCDS and SJDS.

(Continued)

\begin{tabular}{ll} 
15. SUBJECT TERMS & Dredge disposal sites \\
Channel realignment & Dredging \\
Channel sedimentation & Grays Harbor \\
& Hydrodynamics \\
\hline
\end{tabular}

16. SECURITY CLASSIFICATION OF:

\begin{tabular}{|l|l|}
\hline a. REPORT & b. ABSTRACT \\
UNCLASSIFIED & UNCLASSIFIED
\end{tabular}

c. THIS PAGE

UNCLASSIFIED
17. LIMITATION OF ABSTRACT
Numerical modeling
Return period
Sediment transport
Waves

\begin{tabular}{c|l}
$\begin{array}{c}\text { 18. NUMBER } \\
\text { OF PAGES }\end{array}$ & $\begin{array}{l}\text { 19a. NAME OF RESPONSIBLE } \\
\text { PERSON }\end{array}$ \\
\cline { 2 - 2 } 265 & $\begin{array}{l}\text { 19b. TELEPHONE NUMBER (include } \\
\text { area code) }\end{array}$ \\
\hline
\end{tabular}


The key issues of interest to the NWS investigated in this study were: a) changes in waves and hydrodynamics at GH navigation channel over time scales of 0.5 to 5 years, b) consequences of channel realignment on waves, hydrodynamics and sedimentation of GH navigation channel, c) sediment transport pathways in the lower GH and at three dredge material placement (DMP) sites, and d) channel infilling estimates from frequently occurring, low energy storms and less frequent, but more energetic storms. These issues were examined for two channel alternatives: "Existing” channel configuration at GH/HMB complex, and "Realigned" channel configuration. The Realigned channel was modeled with and without the Existing channel filled.

Wave and hydrodynamic modeling results for the Existing and Realigned channels were used in the sediment modeling for the associated short- and long-term sediment transport at GH/HMB complex. Waves and hydrodynamics were modeled using CMS-Wave and ADCIRC models, which were validated with 1999 and 2003 field data sets collected by USACE at GH that included wave, water level and velocity measurements. The bathymetry data for these years were provided by the NWS. The tidal and wind forcings of model boundary conditions were developed using a 38-yr deepwater data set to investigate channel sedimentation and sediment transport patterns in the Grays Harbor's outer channel region from the entrance to Point Chehalis. Sediment transport modeling was performed using GTRAN, MPFATE, LTFATE and SEDZLJ models. Detailed description of wave, hydrodynamic and sediment transport modeling are provided in this report. 